Gerson Alves Pereira Junior Hermila Tavares Vilar Guedes

(Organizadores)

\section{Simulação em saúde \\ para ensino e avaliação: conceitos e práticas}

ENSINO

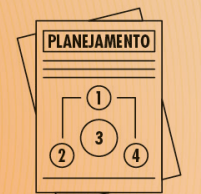

8 $\sqrt{3}$

DESENVOLVIMENTO

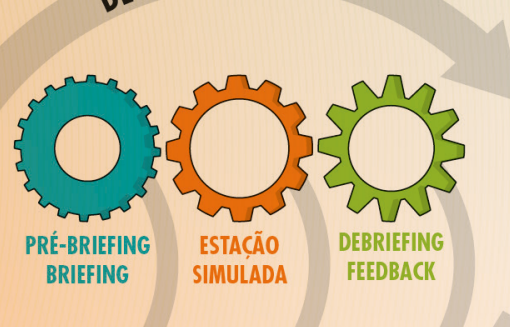

EACIIITADORES E ESTUDANISS

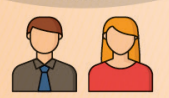

AYALICACACO

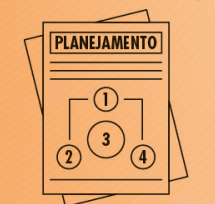

易量是
FIDELIDADE

COMPLEXIDADE

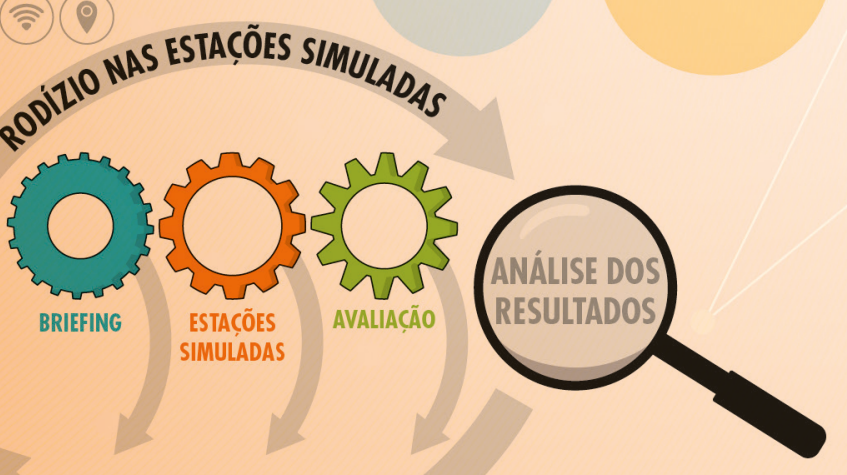

AVALIADORES ESTUDANTES
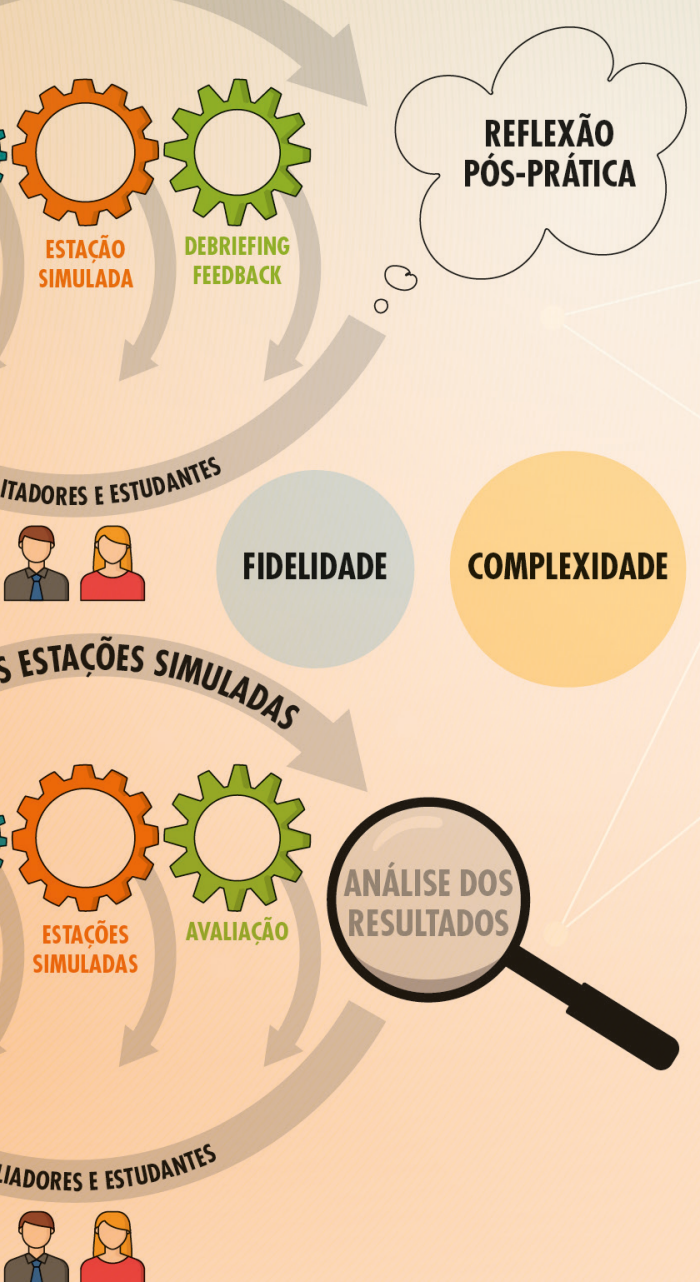

Em 2013, a Secretaria de Gestão do Trabalho e Educação na Saúde (SGTES) do Ministério da Saúde do Brasil formalizou um intercâmbio de políticas e práticas sobre demografia médica, avaliação de competências dos profissionais da saúde e centros de simulação realística com a Conselheria de Igualdade, Saúde e Políticas Sociais da Junta de Andaluzia, Espanha. Após as mudanças decorrentes da publicação da Lei 12.871/2013 (Programa Mais Médicos para o Brasil), colocou-se em pauta a ordenação da formação de profissionais de saúde pelo SUS, postulando-se nessa parceria, entre outras ações, a transferência de tecnologia para construção de centros de simulação realística em saúde no Brasil. A partir deste primeiro acordo e de oficinas de formação e desenvolvimento, a Ebserh foi incorporada à proposta e realizou-se com os professores de Andaluzia uma oficina na Universidade Federal de São Carlos, UFSCar, na perspectiva de mobilizar centros de formação em simulação realística no SUS, voltados para educação permanente de profissionais de saúde e também para formação de estudantes e residentes. Este foi o primeiro movimento que, após anos, resultou na presente carta-acordo que possibilitou à ABEM, em parceria com a OPAS, SGTES, Ebserh, realizar o Projeto "Desenvolvimento da Rede de centros de Simulação Clínica: elaboração de curso para capacitação de multiplicadores".

Este livro - Simulação em saúde para ensino e avaliação: conceitos e práticas - foi escrito por estudiosos e pesquisadores e reflete a experiência de elaboração e desenvolvimento de um curso para capacitação de multiplicadores oferecido em 18 Centros de Simulação, distribuídos nas diferentes regiões do País, do qual participaram mais de 300 profissionais de saúde. Com a presente publicação, esperamos poder contribuir para educação em saúde no século XXI.

Eliana Goldfarb Cyrino e Nildo Alves Batista 
Gerson Alves Pereira Junior

Hermila Tavares Vilar Guedes

(Organizadores)

\section{Simulação em saúde para ensino e avaliação: conceitos e práticas}

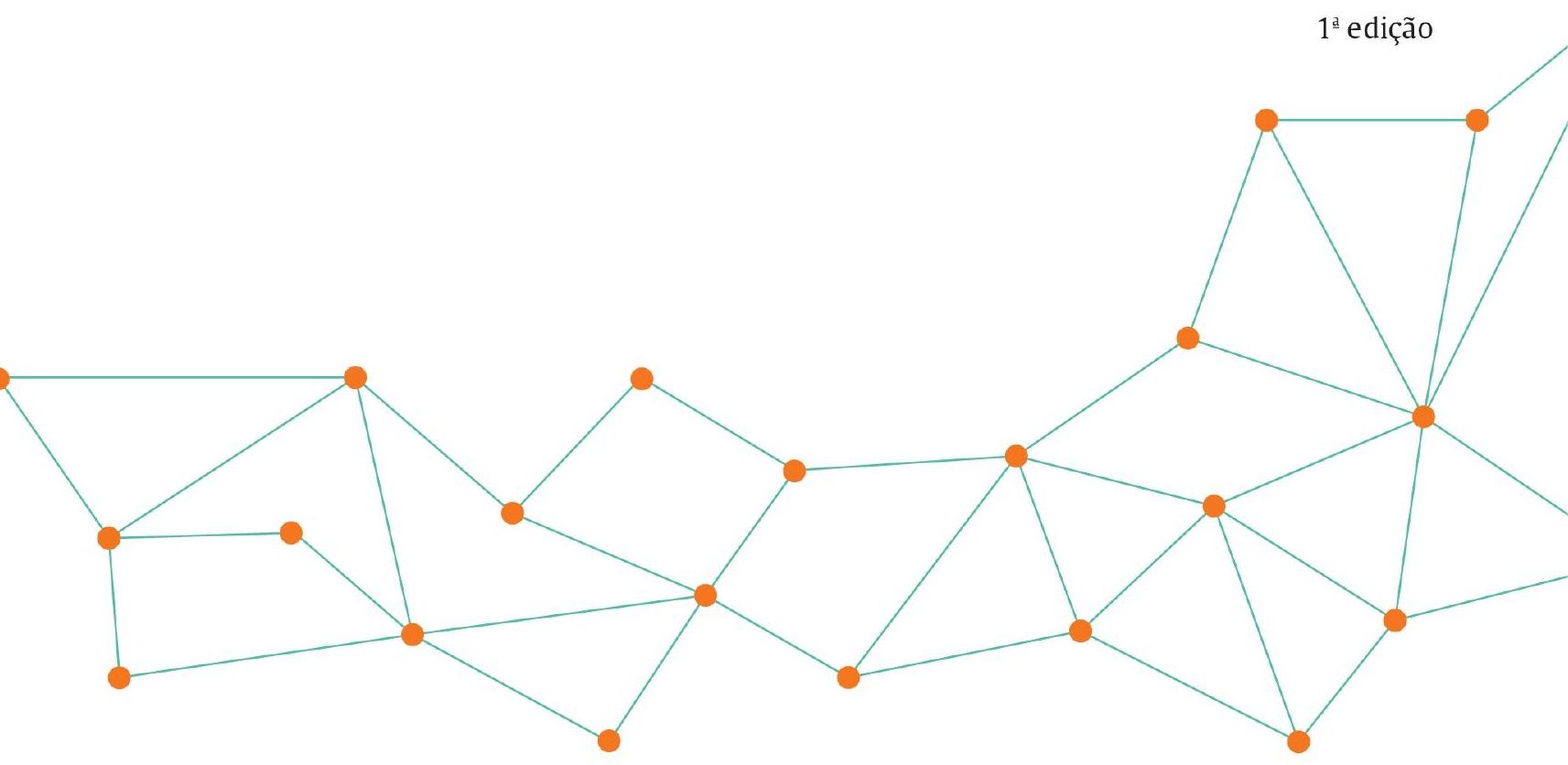

editora cubo

São Carlos 
Todos os direitos desta edição reservados à Associação Brasileira de Educação Médica, Organização Pan-Americana da Saúde/Organização Mundial da Saúde e Empresa Brasileira de Serviços Hospitalares.

Venda proibida. Distribuição gratuita.

Esta publicação contou com o apoio da SGTES/MS, OPAS/OMS, ABEM e EBSERH.

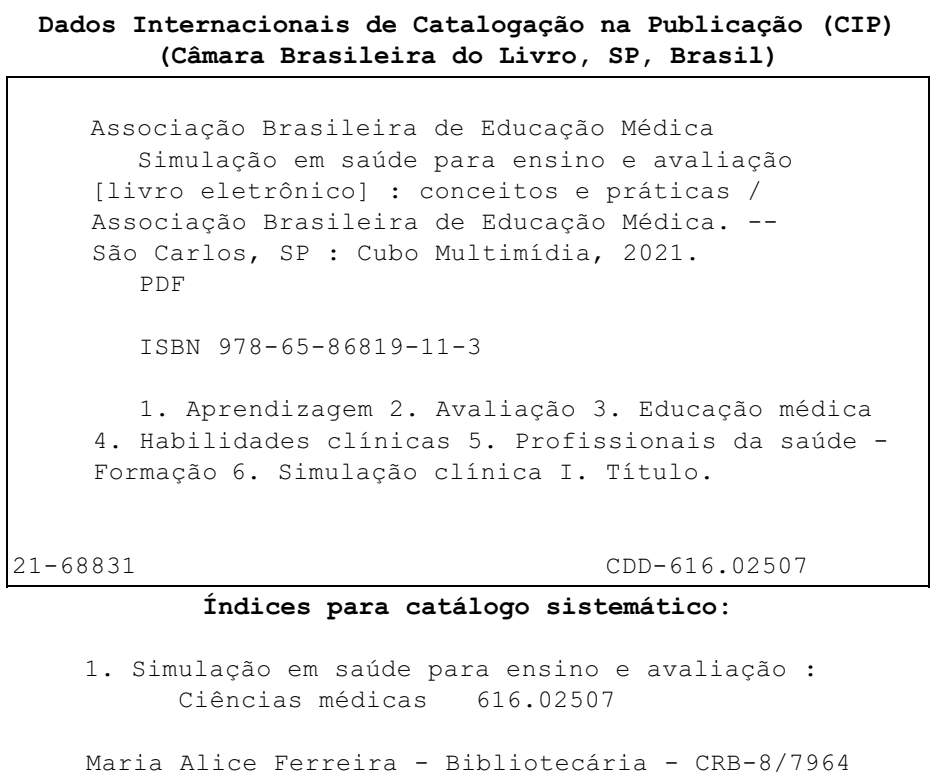

https://doi.org/10.4322/978-65-86819-11-3

Direitos autorais, 2021,

da Associação Brasileira de Educação Médica (ABEM);

Organização Pan-Americana da Saúde/Organização Mundial da Saúde (OPAS/OMS) e Empresa Brasileira de Serviços Hospitalares (EBSERH)

\author{
Associação Brasileira de Educação Médica (ABEM) \\ SCN - QD 02 - BL D - Torre A - Salas 1021 e 1023 \\ Asa Norte - Brasília | DF | CEP: 70712-903 \\ Telefones: (61) 3024-9978 / 3024-8013
}




\section{Conselho Diretor}

Diretor Presidente

Diretor Vice-presidente

Diretora Tesoureira

Diretora de Inovação

Diretor Secretário

Diretor Discente

Diretor Médico Residente
Prof. Nildo Alves Batista

Prof. Sandro Schreiber de Oliveira

Profa. Denise Herdy Afonso

Profa Eliana Goldfarb Cyrino

Prof. Eduardo Arquimino Postal

Acad. Carlos Eduardo Merss

Prof. André Ferreira de Abreu Júnior

\section{Coordenadores Regionais}

Centro Oeste

Minas Gerais

Nordeste I

Nordeste II

Norte

$R J / E S$

São Paulo

Sul I

Sul II
Profa Ana Maria de Oliveira

Prof Gustavo Antonio Raimondi

Prof Jorge Carvalho Guedes

Profa Daniela Chiesa

Profa Maira Tiyomi Sacata Tongu Nazima

Prof Paulo Roberto Alves de Pinho

Prof Aristides Palhares

Prof Leandro Tuzzin

Profa Lara Cristina Leite Guimaraes Machado

\section{Coordenadores Residentes - Gestão 2020 - 2021}

Guilherme Antoniacomi Pereira - São Paulo

João Lucas Cruz Castanho - RJ/ES

\section{Coordenadores Discentes - Gestão 2020 -2021}

Caio Alexandre Mendes Moreira - Centro Oeste

Júlia de Matos Rodrigues de Souza - Minas Gerais

Lía Sousa Rocha- Norte

\section{Equipe Administrativa}

Rozane Landskron Gonçalves

Cristiane Cavalcanti Pinto Ruiz

Érika Maria Lima Bandeira

Dyanara Lays Rohte Sbruzzi

Amara Rodrigues Mune 
Assessoria Técnica editorial do livro

Eliana Goldfarb Cyrino

Nildo Alves Batista

Acompanhamento técnico OPAS/OMS

Monica Diniz Durães 
Agradecemos aos nossos parceiros na realização e desenvolvimento do presente projeto que possibilitou a construção deste livro, a EBSERH, OPAS E SGTES. 


\section{Conselho Editorial}

Luiz Ernesto Almeida Troncon

Oscarina da Silva Ezequiel

Ruy Guilherme Silveira de Souza

Valéria Vernaschi Lima 


\section{Sumário}

9 Prefácio

Prof. Dr. Nildo Alves Batista

11 Apresentação

Mayra Isabel Correia Pinheiro

13 Apresentação

Mónica Padilla

15 Apresentação

Oswaldo de Jesus Ferreira

\section{Apresentação do Livro 1}

Prof. Gerson Alves Pereira Júnior

\section{Capítulo 1}

As Diretrizes Curriculares Nacionais (DCNs) e a evolução do conceito de competências para marcos de competências e "Entrustable Professional Activities" (EPAs): um entendimento necessário para adequações da formação médica

Gerson Alves Pereira Júnior

\section{Capítulo 2}

A simulação como enfoque para a segurança do paciente Rosana Alves, Gustavo Alves Saldanha

\section{Capítulo 3}

Conhecimentos básicos para estruturação do treinamento de habilidades e da elaboração das estações simuladas

Sara Fiterman Lima, Aurean D'Eça Junior, Richardson Augusto Rosendo da Silva, Gerson Alves Pereira Júnior

\section{Capítulo 4}

Princípios Instrucionais na Simulação: Uso das Diretrizes de Desenho Instrucional na Simulação

Brena Melo

\section{Capítulo 5}

Uso de pacientes simulados no ensino e avaliação em saúde

Emerson de Barros Rossini, Gerson Alves Pereira Júnior

\section{Capítulo 6}

A confecção da Moulage em diferentes cenários simulados

Mateus Henrique Goncalves Meska, Elaine Cristina Negri 


\section{Capítulo 7}

Confecção e uso de simuladores de baixo custo: experiências da Medicina e

Enfermagem

Roxana Knobel, Raphael Raniere de Oliveira Costa

\section{Capítulo 8}

A colaboração como fundamento para o trabalho interprofissional em saúde Marcelo Viana da Costa

\section{Capítulo 9}

A utilização da simulação na educação interprofissional

Sara Fiterman Lima, Cristiano Gil Regis, Marcelo Viana da Costa, Gerson Alves Pereira Júnior

\section{Capítulo 10}

A utilização da simulação na Gestão do Fator Humano e Riscos Assistenciais na área da saúde (Crew Resource Management)

Gerson Alves Pereira Júnior, Alexandre Slullitel, Haggeas da Silveira Fernandes

\section{Capítulo 11}

Estruturação do ensino, treinamento e avaliação de habilidades

Fernanda Berchelli Girão Miranda

\section{Capítulo 12}

Avaliação na educação em saúde com o uso da simulação

Gerson Alves Pereira Júnior

\section{Capítulo 13}

Avaliação com o uso de Checklists e Escalas de Avaliação Global

Renato Soleiman Franco, Camila Ament Giuliani dos Santos Franco

\section{Capítulo 14}

O uso de Feedback e Debriefing na Simulação

Renato Soleiman Franco, Camila Ament Giuliani dos Santos Franco

\section{Capítulo 15}

Cenários de Avaliação de Habilidades Não Técnicas (HNT)

Camila Ament Giuliani dos Santos Franco, Renato Soleiman Franco

\section{Capítulo 16}

O uso de instrumentos para a avaliação do ensino, da aprendizagem e de outros atributos nos laboratórios simulados

Fernanda Berchelli Girão Miranda

\section{Capítulo 17}

Redesenho dos espaços físicos de acordo com o uso das metodologias ativas de aprendizagem e a convergência tecnológica: orientações na montagem dos Centros de Simulação

Gerson Alves Pereira Júnior, Hugo Silva Ferreira, Luciane Reginato Dobrowski,

Claudio Soares de Santana 


\section{Prefácio}

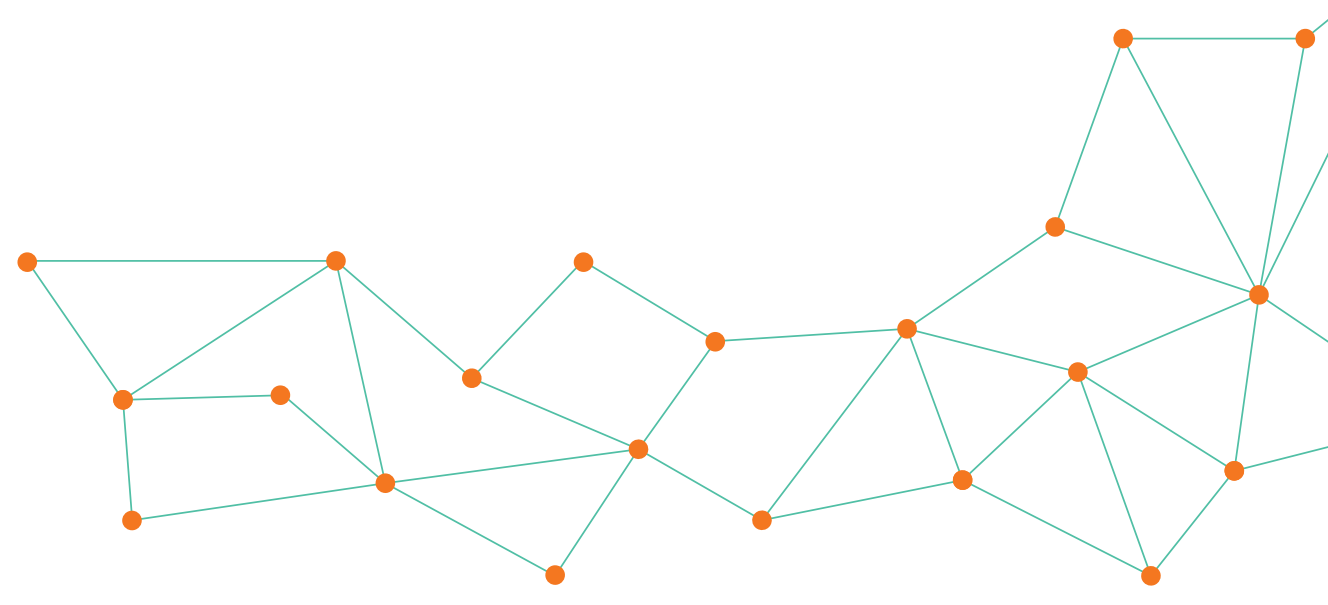

É com muita alegria que, em nome do Conselho Diretor da Associação Brasileira de Educação Médica (ABEM), participo do lançamento deste livro, um dos produtos do projeto "Desenvolvimento da Rede de Centros de Simulação Clínica: Elaboração de curso para capacitação de multiplicadores”, desenvolvido pela ABEM, em parceria com a Organização Panamericana de Saúde (OPAS), a Secretaria de Gestão do Trabalho e da Educação em Saúde (SGTES) e a Empresa Brasileira de Serviços Hospitalares (EBSERH).

Esta livro - Simulação em saúde para ensino e avaliação: conceitos e práticas - foi escrito por quase duas dezenas de estudiosos e pesquisadores sobre Simulação e reflete uma experiência única e bastante consolidada de elaboração e desenvolvimento de um curso para capacitação de multiplicadores oferecido em 18 Centros de Simulação, distribuídos nas diferentes regiões do País, do qual participaram mais de 300 profissionais de saúde.
Aborda as diferentes dimensões da Simulação, entendida como uma metodologia ativa e participativa de ensino, cada vez mais utilizada na formação em saúde, tanto na graduação como na pós-graduação, em cenários práticos controlados e protegidos.

O livro inicia explorando a relação entre Diretrizes Curriculares Nacionais, Competências, Marcos de Competências e Entrustable Professional Acivities (EPAs) para desenvolvimento de Matrizes Curriculares, aspectos relevantes na discussão da Educação Médica contemporânea.

Conhecimentos básicos para estruturação do treinamento de habilidades, princípios instrucionais na Simulação, uso de pacientes simulados, confecção de moldagens e uso de simuladores artesanais e de baixo custo, vão indicando ruptura com uma "ideia (exclusiva) de simulações com ambientes informatizados/robotizados e com simuladores hiper-realistas (que) tornam o uso dessa estratégia inalcançável para a maioria dos campos de 
ensino", e que "a simulação e o uso de ambientes simulados podem ser utilizados mesmo com recursos limitados".

A avaliação é também discutida, enfatizando desde os cenários para habilidades não técnicas, como comunicação, liderança, trabalho em equipe, gerenciamento de tarefas, tomada de decisão, dentre outras, até a avaliação de habilidades, com destaque para a importância do Feedback e do Debriefing, bem como o uso de Checklists e Escalas de Avaliação Global.

A Simulação como estratégia de preparo de uma prática profissional comprometida com a SEGURANÇA do paciente é também enfatizada, uma vez que "oportuniza aos estudantes de medi- cina vivenciar situações de erros e acertos, relatar e discutir sistematicamente estes erros e os quase acidentes, reconhecer condições inseguras, investigar, repetir procedimentos até o acerto e melhorar estes sistemas com uma compreensão completa da falibilidade humana".

Entendemos que a comunidade da Educação Médica Brasileira recebe, sem dúvida, uma grande obra! Sua leitura reveste-se de uma efetiva oportunidade de aprofundar a compreensão de pressupostos, teorias e práticas sobre Simulação, com seus avanços e desafios na (re)construção de processos formativos que tenham significado e representem possibilidades efetivas de transformação das práticas profissionais.

Prof. Dr. Nildo Alves Batista Diretor-Presidente da ABEM 


\section{Apresentação}

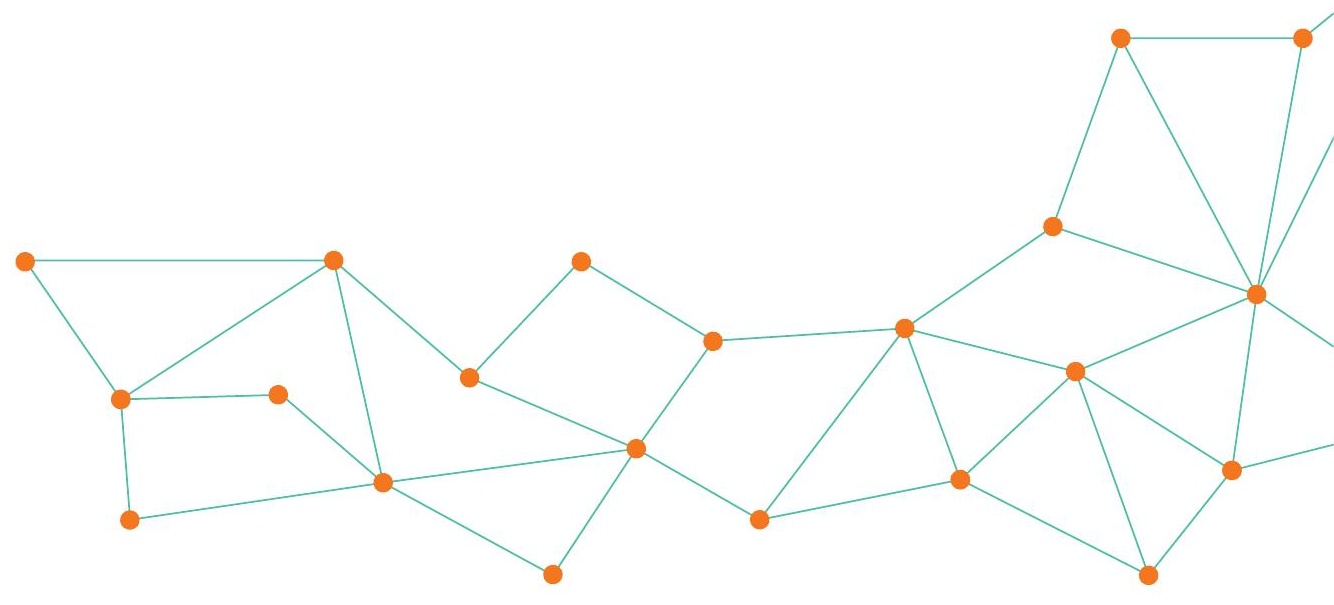

É para mim motivo de honra e privilégio escrever o prefácio do livro que será utilizado no Projeto "Desenvolvimento da Rede de Centros de Simulação Clínica: elaboração de curso de capacitação de multiplicadores".

A simulação clínica é um processo dinâmico que envolve a criação de uma situação hipotética que incorpora uma representação autêntica da realidade, facilitando a participação ativa do aluno e integrando o aprendizado prático e teórico com oportunidades para a repetição, feedback, avaliação e reflexão, sem o risco de causar dano ao paciente.

As evidências mostram que as tecnologias de simulação clínica são estratégias capazes de articular práticas de ensino e pesquisa, necessárias na qualificação dos profissionais da saúde, nos diversos níveis de atenção à saúde da população.

Há uma recomendação da Organização Mundial da Saúde (OMS) para a utilização dessa estratégia durante a formação em saúde. Aprender e praticar técnicas e/ou procedimentos em pacientes em situação de vulnerabilidade pode assim ser substituída por um modelo de treinamento mais ético, com minimização de erros em saúde, que possam comprometer a segurança do paciente.

O curso de capacitação de multiplicadores é assim uma excelente contribuição para o conhecimento e formação em simulação realística no país, já reconhecida como instrumento importante no processo de ensino-aprendizagem na saúde, essencial para o aperfeiçoamento de profissionais dessa área e para a oferta de melhor assistência aos pacientes. Os temas tratados nesse curso, tais como o uso de instrumentos para a avaliação do ensino nos laboratórios simulados, a utilização da simulação na capacitação da gestão de recursos em crise na área da saúde, a colaboração como fundamento para ao trabalho interprofissional em saúde, entre tantos outros, compõem assim um conjunto de ofertas que indiscutivelmente marcam um avanço na educação em saúde no Brasil.

Mayra Isabel Correia Pinheiro Secretária da Gestão do Trabalho e da Educação na Saúde/ SGTES/MS 


\section{Apresentação}

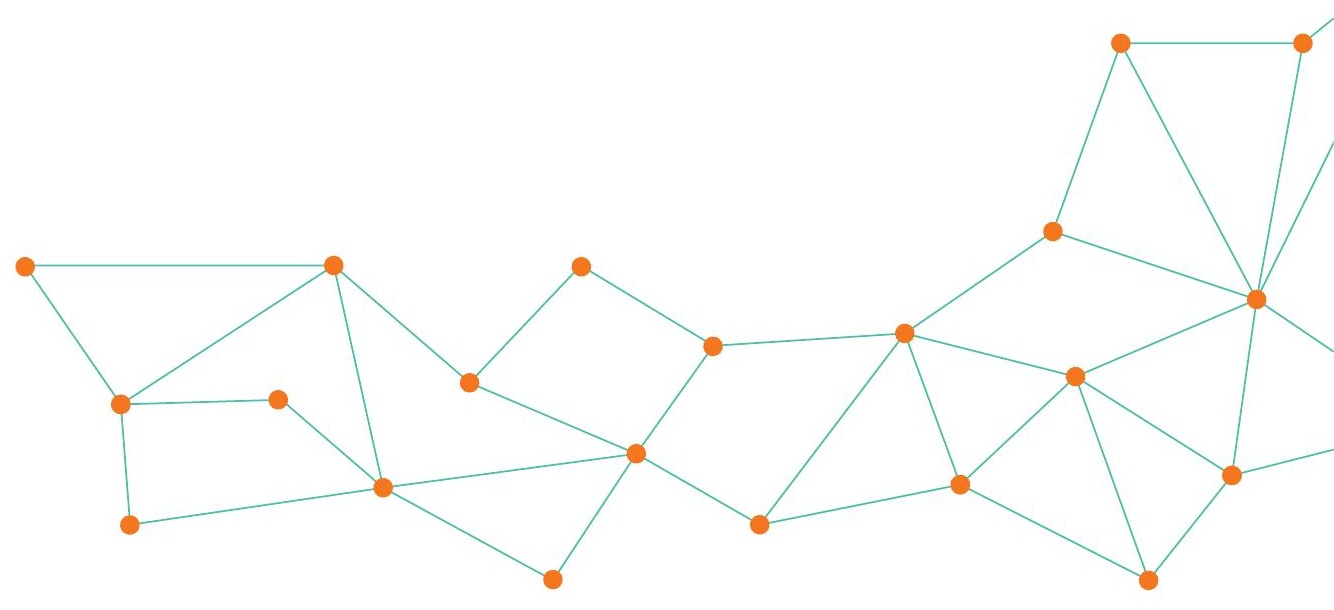

$\mathrm{N}$ os últimos vinte anos, a aplicação de metodologias de simulação, como ferramenta de ensino-aprendizagem, foi desenvolvida como uma das principais alternativas para trabalhar competências educacionais (conhecimentos e habilidades) em um ambiente controlado, seguro e que permite ser adaptado às necessidades de cada momento.

Os modelos de simulação realística, cada vez mais semelhantes à realidade, têm sido adaptados a diferentes campos, onde os cenários de simulação causam impacto e permitem mais aquisição de competências, com agilidade de transferência destas em relação à situação treinada.

A simulação como estratégia de ensino-aprendizagem é de grande importância nos processos formativos, pois cada vez mais é necessário garantir a segurança do paciente para não ser considerado um objeto de aprendizado. O uso das simulações realísticas sempre terá como princípio garantir a segurança e a prevenção de erros críticos, pois os modelos de simulação baseiam-se na capacidade de controlar variáveis que possam influenciar a aquisição e colocar em prática competências definidas, bem como garantir um ambiente seguro, tanto para os profissionais como para os usuários.

No campo da saúde, a aplicação dos modelos de aprendizagem por simulação permite trabalhar competências profissionais em ambientes realistas, diminuindo, de forma significativa, o tempo necessário para a aquisição de habilidades ao permitir a repetição de ações de treinamento de forma ilimitada, utilizando ambientes com diferentes níveis de dificuldade, do mais simples ao mais complexo.

No movimento da mudança das Diretrizes Curriculares Nacionais (DCNs) do Curso de Graduação em Medicina, em 2014, o Ministério da Saúde e a Organização Pan-Americana da Saúde (OPAS) estabeleceram parceria com a Escuela Andaluza de Salud Publica (Easp), que, entre outras ações, dedicou um componente específico para 
trabalhar a área de aprendizagem por meio de simulação, um componente importante a ser estimulado e desenvolvido no país.

Naquele momento, coube às autoridades sanitárias e educacionais do país promover e difundir essa metodologia nos processos de aprendizagem, por meio da articulação e da integração entre ensino e serviço. A parceria com a Empresa Brasileira de Serviços Hospitalares (EBSERH) foi de suma importância, visto que se estava iniciando a estruturação dos centros de simulação em seus hospitais. A articulação com as Faculdades de Medicina, por meio da Associação Brasileira de Educação Médica (Abem), possibilitou identificar profissionais que estavam se especializando nessa área.

Seguindo a experiência de criação do Complexo Multifuncional Avançado de Simulação, Inovação e Tecnologia (CMAT) de Granada, na Andaluzia, a assessoria da Easp abrangeu diversos aspectos no processo de tomada de decisão para estruturar e desenvolver centros de aprendizagem por simulação realística. A criação de cenários adequados que permitem reproduzir situações que os profissionais enfrentam e momentos em que devem integrar seus conhecimentos e suas competências técnicas e relacionais para trabalhar em equipe fez esse componente ampliar seu escopo, possibilitando que profissionais dos serviços de saúde fossem contemplados na formação ofertada. Esta assessoria apresentou ao final: a) Guia de orientação para implantação e manutenção de centros de simulação no Sistema Único de Saúde; b) Guia de desenvolvimento do programa de formação de profissionais de saúde com o uso da simulação realística em saúde.

A produção do livro Simulação em saúde para ensino e avaliação: conceitos e práticas, produto do Projeto Desenvolvimento da Rede de Centros de Simulação Clínica: Elaboração de Curso para Capacitação de multiplicadores, apresenta avanços nessa área. A pandemia ocasionada pela Covid-19 tem permitido identificar a importância de manter esses cenários de prática como centros de treinamento permanentes para desenvolver competências críticas no sistema e, neste sentido, reforça ainda mais parcerias como esta que devem ser impulsionadas no país, para proporcionar estruturas que visam à qualificação de todos os trabalhadores da saúde. para a Saúde Opas/Organização Mundial da Saúde 


\section{Apresentação}

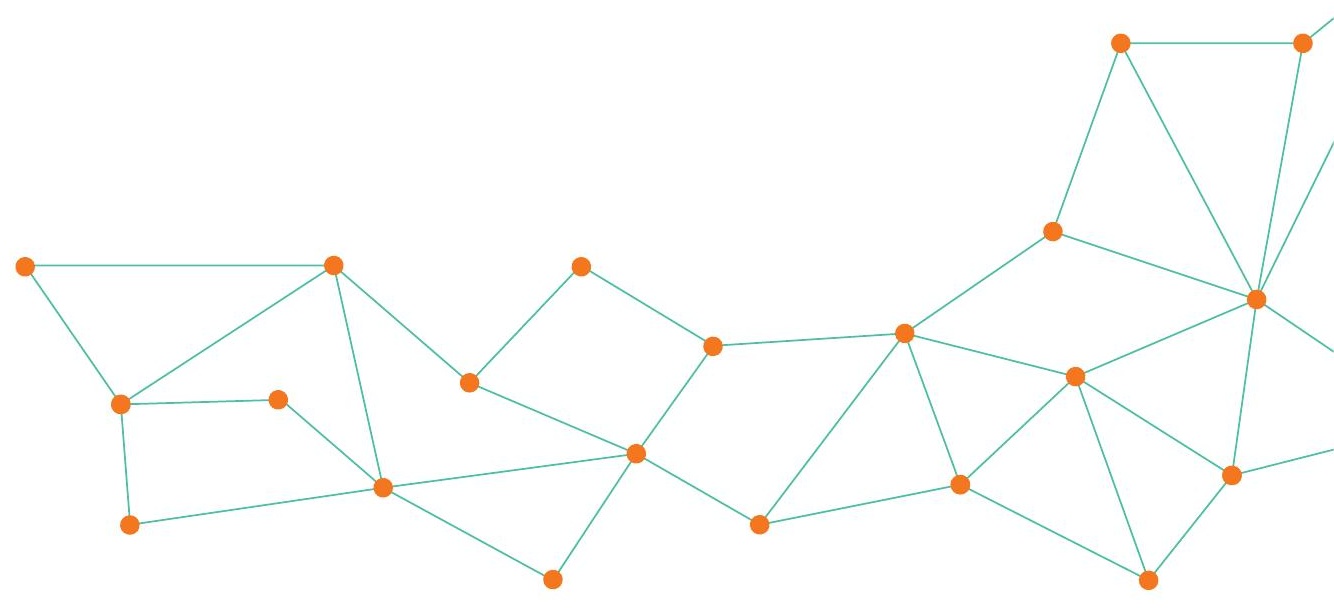

A parceria ABEM-Ebserh-Ministério da Saúde/OPAS viabilizou a realização do projeto "Desenvolvimento da Rede de Centros de Simulação Clínica: Elaboração de Curso para Capacitação de Multiplicadores”, que teve como objetivo desenvolver e capacitar multiplicadores em simulação clínica, no intuito de qualificar a atuação em ensino, pesquisa e extensão dos centros de treinamento referenciais por meio de simulação.

A Empresa Brasileira de Serviços Hospitalares, Ebserh, empresa pública vinculada ao Ministério da Educação (MEC), criada pela Lei n ${ }^{\circ} 12.550$, de 15 de dezembro de 2011 , tem por finalidade a prestação de serviços gratuitos de assistência médico-hospitalar, ambulatorial e de apoio diagnóstico e terapêutico à comunidade, em média e alta complexidade, assim como a prestação de serviços de apoio ao ensino, à pesquisa e à extensão, ao ensino-aprendizagem e à formação de pessoas no campo da saúde pública às instituições públi- cas federais de ensino ou instituições congêneres, observada, nos termos do art. 207 da Constituição Federal, a autonomia universitária.

A Ebserh caracteriza-se como uma rede que integra 40 unidades hospitalares vinculadas a 37 instituições federais de ensino superior (IFES), das cinco regiões do País. Tem como propósito "Ensinar para transformar o cuidar" e a missão de fornecer campo de prática de excelência para inovação em saúde por meio do ensino e pesquisa, praticando assistência de qualidade e uma gestão sustentável e transparente.

Atualmente, a Rede Ebserh conta com 18 polos estruturados que trabalham com centros de simulação ligados a hospitais e/ou a IFES. As demais unidades hospitalares da Rede utilizam práticas de simulação clínica, tais como simulação cênica, robótica, de baixa, média e alta complexidades, como estratégias de ensino-aprendizagem aplicadas aos cenários de práticas dos discentes e capacitação de 
seus profissionais. Não por acaso, a Rede reuniu as condições necessárias para essa diferenciada ação de capacitação, cujos resultados ainda incluem a valiosa publicação desta obra.

A evolução científica e as discussões éticas sobre modelos de ensino-aprendizagem trouxeram grandes restrições ao ensino em ciências da saúde, uma vez que por muitos anos tal formação foi baseada em modelos animais. Como consequência, apesar das diversas restrições impostas por controles éticos, o ensino prático realizado diretamente no paciente ainda é o principal modelo utilizado, o que traz questões tanto para a formação do profissional quanto para a qualificação do cuidado prestado.

$\mathrm{O}$ uso de simuladores para aprendizado tem sido aplicado há muitos anos em diversas áreas do conhecimento. Notadamente, na área de aviação repercutiu de forma direta na diminuição do número de erros e aumento da segurança. Contudo, seu uso como recurso de ensino-aprendizagem na área da saúde é relativamente recente.

O planejamento do ensino baseado em competências e habilidades trouxe um grande incentivo à prática da simulação como meio de desenvolvimento do processo de ensino-aprendizagem com várias vantagens relacionadas a aspectos éticos, reprodutibilidade, segurança, eficiência, efetividade, custo e receptividade por parte dos aprendizes. Nesse sentido, desde 2016 a Ebserh tem fomentado, tanto a criação de laboratórios de habilidades e simulação quanto a formação de pessoal com com- petências e habilidades para a gestão de centros de simulação e organização de atividades para formação e capacitação.

O livro Simulação em saúde para ensino e avaliação: conceitos e práticas é mais uma iniciativa para qualificação de recursos humanos que colabora para que o ensino baseado em simulação seja uma realidade e uma prática corriqueira nos hospitais universitários federais.

A perspectiva pedagógica trazida nos capítulos converge para atender à necessidade crescente de profissionais envolvidos na compreensão da relação entre as diretrizes estabelecidas para a formação e a implementação de práticas interdisciplinares colaborativas, base para aquisição de novos conhecimentos com vistas a uma atuação interpessoal e técnica integradas, além do domínio da metodologia baseada em simulação em saúde.

Sem dúvida, o presente livro será referência para a comunidade acadêmica, profissionais de saúde, estudantes, preceptores e docentes, do ensino técnico à pós-graduação, nos diversos hospitais universitários e nas diferentes unidades da rede de ensino e saúde do País. Isso porque representa um convite à reflexão, ao debate e à atenção aos desafios para o futuro das atividades de simulação clínica na formação e na capacitação dos profissionais para melhorar a qualidade da assistência e garantir mais segurança para os pacientes. A Ebserh orgulha-se de ter participado de tão importante parceria! 


\section{Apresentação do Livro 1}

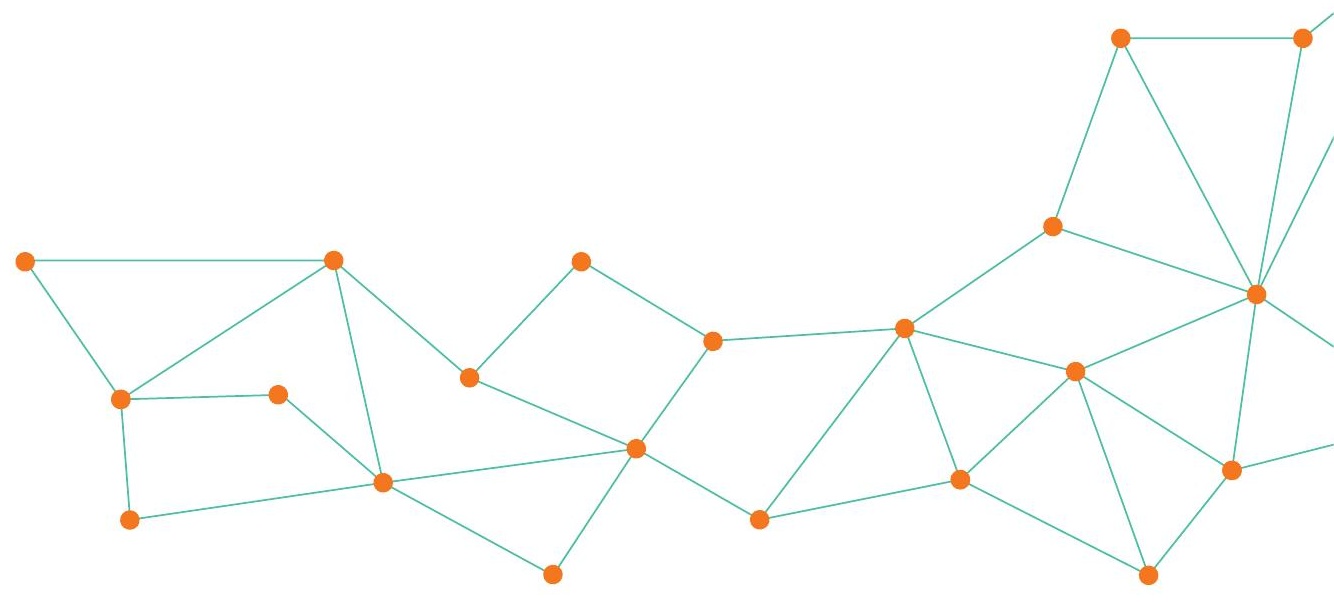

$\mathrm{N}$ o Brasil, a simulação clínica começou com atividades pontuais que tiveram seu início na década de 1990, principalmente com cursos de suporte avançado de vida, como ATLS e ACLS. Nessa década e no início da seguinte, muitos acreditavam que a Aprendizagem Baseada em Problemas seria a única metodologia ativa que deveria ser aplicada e que resolveria todas as questões de ensino dos cursos de medicina. Isso perdurou por muito tempo, a ponto de se criar a alcunha pejorativa de "Cursos PBL".

Nessa época, não havia a inserção regular de atividades de simulação nas matrizes curriculares, limitando-se apenas ao treinamento de habilidades, mais adotado pelos cursos de enfermagem do que de medicina.

Dessa forma, o uso da simulação clínica como ensino manteve-se no país em atividades isoladas realizadas por poucos docentes pioneiros. Cabe destacar que esteve presente de forma mais estrutu- rada no curso de medicina da Universidade Estadual de Londrina (UEL), que teve seu Laboratório de Habilidades e Simulação montado e coordenado pelo Prof. Samuel Silva da Silva (cardiologista e hemodinamicista), juntamente com a Dra. Zuleika Thompson (pediatra) e o Dr. Kazuhiro Ito (patologista). Devemos reconhecimento a esses pioneiros e também muita gratidão aos professores Marcio José de Almeida e João Campos, que receberam dezenas de professores visitantes na UEL com generosidade e compartilhamento total de informações e experiências. Foi o que aconteceu comigo em 2003, quando passei uma semana em Londrina/PR para conhecer e vivenciar todas as atividades dos estudantes da UEL.

Da mesma maneira, a utilização da simulação clínica para atividades de avaliação do tipo OSCE ocorriam em alguns cursos de medicina públicos e privados, porém apenas de forma esparsa, com grande esforço pessoal de professores que preci- 
savam convencer seus gestores acadêmicos, vencer imensas barreiras logísticas e conseguir a adesão do corpo docente para serem avaliadores, além de precisarem suplantar a desconfiança e o medo do corpo discente em ser avaliado por novas metodologias. A partir de 2004, aplicamos o OSCE semestral para todas as turmas do novo currículo com uso de metodologias ativas na Universidade de Ribeirão Preto (UNAERP).

Em documento publicado em 2009, a Organização Mundial da Saúde (OMS) definiu o conceito de Segurança do Paciente como a redução dos riscos de danos desnecessários associados à assistência em saúde até um mínimo aceitável. Com isso, a tradicional abordagem do ensino de medicina do tipo "veja e faça" para aprender e experimentar, expondo os pacientes ao atendimento de profissionais de saúde inexperientes, e mesmo internos de medicina, não mais se sustentava do ponto de vista ético.

Essa escalada íngreme da curva de aprendizagem não é mais aceitável, pois a prática de tentativa e erro com pacientes reais torna-se cada vez mais questionável. A simulação, nesse contexto, emerge como instrumento que auxilia a formação de profissionais de saúde no treino de habilidades e de cenários simulados, antecipando a prática clínica sem expor o paciente a erros evitáveis pela falta de conhecimento adequado e segurança na realização dos procedimentos.

Na carreira docente na Universidade de São Paulo (USP) desde 2012, venho trabalhando com blended learning e sala de aula invertida para atividades simuladas na medicina de emergência traumática e não traumática. Meu projeto aprovado para o Programa de Desenvolvimento Docente para Educadores das Profissões da Saúde do Instituto Regional FAIMER Brasil para os anos de 2013 e 2014 foi sobre a "Avaliação do processo de implantação da estratégia sequencial do ensino de urgência e emergência na graduação médica”. Este projeto FAIMER coincidiu com um dos quatro projetos da Carta-Acordo com a Organização Pan-Americana da Saúde (OPAS) em comemoração aos 50 anos da Associação Brasileira de Educação Médica (ABEM) e 10 anos das Diretrizes Curriculares Nacionais de 2001. Como resultado de ambos, foram publicadas as recomendações ABEM para o ensino de urgência e emergência na graduação médica em 2013, atualizada em 2015.

Nessa mesma época, foi lançado o edital do PET/ Redes de urgência (2013-2015), e tive um projeto aprovado sobre o "Estudo das estratégias de inte- gração da rede de urgência e emergência visando a integralidade da atenção à saúde", a partir do qual vários projetos de iniciação científica e mestrado foram realizados. Um dos projetos foi sobre a realização de simulação interprofissional no Campus USP de Ribeirão Preto, que envolveu estudantes de medicina, enfermagem, fisioterapia, farmácia e psicologia, além das ciências matemáticas e da computação do Campus USP de São Carlos, inclusive promovendo um Simpósio Internacional de Simulação Clínica Interprofissional em maio de 2017.

No período de 21 a 25 de novembro de 2014, foi realizada a $1^{\text {a }}$ Oficina de Formação em Competências e Simulação, na Universidade Federal de São Carlos (UFSCar/SP), com a equipe do instituto IAVANTE da Andaluzia, cujo objetivo era definir um modelo de formação baseado em simulação, valorizando a melhora dos indicadores-chaves dos processos assistenciais para, ao mesmo tempo, atender às necessidades de formação de profissionais dos diferentes estados do Brasil. No entanto, apesar da realização dessa e de outras três oficinas, o projeto não foi adiante.

Outra oportunidade de aprofundamento dos conhecimentos em simulação como avaliação tem sido a participação de docentes de cursos de medicina de todo o Brasil nas aplicações da prova prática da $2^{\text {a }}$ fase do Exame de Revalidação de Diplomas de Médicos formados no Exterior (REVALIDA), principalmente nas edições a partir de 2015, quando a prova simulada passou a ser realizada, de forma simultânea, em muitas cidades das diversas regiões do País, dada a quantidade cada vez maior de candidatos inscritos.

No Congresso Brasileiro de Educação Médica (COBEM) de 2015, no Rio de Janeiro/RJ, houve a programação prática de habilidades e simulação para os estudantes e uma programação teórica voltada aos docentes. Notou-se que não havia um programa de simulação na ABEM. Apresentamos uma moção que foi aprovada na plenária deste congresso para a criação e reconhecimento de um grupo de trabalho para um diagnóstico situacional sobre a utilização da simulação nas escolas médicas e capacitação docente.

A Diretoria ABEM, em março de 2016, solicitou a entrega de um programa de simulação que foi elaborado com base em quatro componentes: 1) Diagnóstico situacional da presença do laboratório de habilidades e simulação (LHS), área física, acervo, uso nas programações curriculares para ensino e avaliação, e identificação e contato dos professores responsáveis, 2) Capacitação docente com 
parte online e parte presencial, 3) Plano de seguimento institucional, que iria depender das necessidades identificadas e 4) Produção de material didático acerca dos conceitos e princípios práticos da simulação clínica. Esse programa, apesar de entregue à diretoria da época, nunca foi discutido nem desenvolvido.

Nos COBEM seguintes, o programa de simulação evoluiu para a demonstração de uma grande quantidade de cenários simulados em Brasília/DF (2016), e posteriormente para a realização das Olimpíadas de Simulação em Porto Alegre/RS (2017) e Vitória/ES (2018). Na competição de 2019 em Belém/PA, que assim como no ano anterior foi planejada e operacionalizada por professores das escolas médicas das Regionais do congresso, houve três salas simultâneas com utilização de manequins de alta complexidade (Empresa LAERDAL), casos clínicos da Body Interact (Empresa CIVIAM) e a simulação cênica, permitindo maior interação entre as equipes participantes e a discussão dos casos clínicos com a plateia.

Essas Olimpíadas de Simulação do último COBEM presencial em Belém/2019 foram, mais uma vez, um enorme sucesso de participação dos estudantes e do público, que assistiu às disputas entre as equipes. Na entrega dos prêmios às três equipes primeiras colocadas durante a plenária de encerramento do congresso, os depoimentos dos estudantes (que podem ser vistos no link: https:// www.youtube.com/watch?v=sVERheV2HwQ) mostraram que a competição entre as escolas era encarada pelos discentes de maneira bastante saudável, e o aprendizado com a experiência foi valorizado pelos participantes.

No final da gestão da Diretoria ABEM em 2018, foi aprovada uma parceria entre a ABEM, a Rede Ebserh de Hospitais Universitários Federais e a OPAS para o desenvolvimento do projeto de simulação entregue em 2016, porém limitando-se apenas à capacitação de multiplicadores. No início da gestão da Diretoria ABEM de 2019, reorganizei o projeto para essa parceria com a Ebserh, cujo curso começou em 31 de outubro de 2019. Devido à pandemia da covid-19, o curso teve que ser prorrogado com a finalização da parte online em setembro de 2020. A parte presencial, com a realização das provas práticas utilizando estações simuladas (tipo OSCE), para conclusão do curso nos 18 polos Ebserh, também foi adiada. Com a persistência da situação epidemiológica, para finalizar o curso foi realizado o OSCE online para estudantes do internato médico dos cursos de medicina das universi- dades federais ligadas aos hospitais da rede Ebserh que participaram do curso de simulação.

O curso de formação de multiplicadores da rede Ebserh teve duração de 180 horas, com o formato de ensino à distância (EaD), e o conteúdo foi distribuído em cinco módulos: 1) metodologias de ensino com simulação; 2) avaliação focada na simulação; 3) módulos específicos nas oito áreas de atuação (pediatria, clínica médica, cirurgia, medicina de família e comunidade, saúde mental, ginecologia e obstetrícia, medicina de emergência e saúde coletiva) com produção de dezenas de estações práticas simuladas; 4) gestão de centro de simulação; e 5) aplicação presencial das estações práticas em cada polo. Porém, devido à situação epidemiológica do país, ao invés da aplicação presencial da avaliação prática, foi realizado o OSCE online.

O curso começou com uma revisão dos cursistas sobre os projetos pedagógicos dos cursos em que estão inseridos, à luz das novas Diretrizes Curriculares Nacionais e da evolução do conceito de competências para marcos de competências e Entrustable Professional Activities (EPAs). Em cada atividade dentro dos módulos, os cursistas participavam de fóruns de debates sobre os temas e tiravam dúvidas, compartilhando experiências. No Módulo 3, os cursistas foram divididos nas 8 áreas de atuação (pediatria, clínica médica, cirurgia geral, ginecologia/obstetrícia, medicina de família e comunidade, saúde mental, medicina de emergência e saúde coletiva), com a tarefa inicial de elaborar o mapeamento da Rede de Atenção à Saúde dentro das linhas de cuidados de sua região e as características epidemiológicas regionais de morbi-mortalidade. Nessa atividade destacaram os pontos positivos e as fraquezas das linhas de cuidado. Em seguida, as matrizes de conteúdo construídas pelos tutores foram complementadas com sugestões dos cursistas. Os tutores também elaboraram os marcos de competência com base no projeto Milestones (Marcos de Competências), adaptado para nosso meio e divididos em seis níveis (os níveis iniciais são o pré-internato e o final do internato), além das Entrustable Professional Activities (EPAs). Após essa etapa, discutiram a educação e o trabalho em equipe multiprofissional. A partir dessa base de conhecimentos, os cursistas sugeriram casos clínicos prevalentes e relevantes de suas experiências clínicas para a construção das estações simuladas completas, utilizando o modelo do Revalida.

Foram convidados dois tutores médicos e um da enfermagem com experiência em simulação clínica 
para cada área, que são os autores dos capítulos. A plataforma digital disponibilizou os materiais didáticos (textos e vídeos) elaborados pelos tutores.

Os capítulos deste livro foram os materiais didáticos elaborados pelos autores para o $1^{\circ}$ curso de capacitação de multiplicadores em simulação clínica da rede Ebserh, que contou com a participação de 18 polos (Belo Horizonte/MG, Uberaba/MG, Juiz de Fora/MG, Rio de Janeiro/RJ, São Carlos/SP, Brasília/DF, Goiânia/GO, Cuiabá/MT, Campo Grande/MS, Manaus/AM, Fortaleza/CE, Natal/RN, Recife/PE, Aracaju/SE, Teresina/PI, Maceió/AL, Curitiba/PR e Rio Grande-Pelotas/RS), numa parceria entre a Organização Pan-Americana de Saúde (OPAS), Empresa Brasileira de Serviços Hospitalares (Ebserh) e o Programa de Simulação Clínica da Associação Brasileira de Educação Médica (ABEM).

Foram capacitados 321 profissionais de saúde (docentes e preceptores), 160 médicos e 161 profissionais de outras áreas da saúde (enfermagem, fisioterapia, farmácia, psicologia e outros), distribuídos nas 8 áreas de atuação nos 18 polos Ebserh.

Durante todos os módulos do curso, os conceitos apresentados e discutidos foram aplicados e os cursistas com experiência clínica, após essa assimilação de conhecimentos, foram capazes de elaborar mais de cinco centenas de estações simuladas de bastante qualidade nas oito áreas de atuação propostas no curso.

Este curso foi a primeira iniciativa de capacitação de multiplicadores em simulação clínica em maior escala realizada no país para instituições públicas federais de ensino na saúde, ligadas à Ebserh.

Dois desdobramentos do curso, propostos dentro do Programa de Simulação Clínica da ABEM, já foram encaminhados e aprovados pela Diretoria em agosto de 2020, porém ainda não desenvolvidos. O primeiro será a oferta do curso para as escolas médicas associadas que tenham interesse na sua realização, e o outro desdobramento será a montagem dos Núcleos de Simulação das Regionais da ABEM, compostos por dois docentes. O objetivo é desenvolver essa metodologia de aprendizagem em diversos distritos geográficos de atuação e interagir com as escolas médicas e seus membros. Além disso, pretende-se criar uma rede colaborativa diante da diversidade de contextos e situações existentes quanto à presença de laboratórios de habilidades e simulação, e a utilização da simulação clínica nas matrizes curriculares dos cursos de medicina.

Esses Núcleos terão as seguintes funções: 1) mapear as atividades de simulação clínica como atividade de ensino e/ou avaliação de cada escola da Regional e os principais responsáveis, 2) mapear as provas de residência que envolvam a realização de provas práticas, 3 ) fomentar o desenvolvimento de capacitação docente em simulação, 4) organizar eventos que envolvam a simulação clínica na Regional, e 5) participar do desenvolvimento e operacionalização de projetos regionais e nacionais que envolvam a simulação. Essa proposta contempla os objetivos do Projeto de Simulação Clínica encaminhado à Diretoria da ABEM em março de 2016.

Os Núcleos de Simulação das Regionais devem estar vinculados a um Núcleo Central de Simulação, atrelado à Diretoria da ABEM, que coordene o programa de simulação da entidade, assim como ocorre para o programa do Teste de Progresso.

Essa organização será um grande passo para o desenvolvimento da simulação no país, permitindo a criação de uma rede colaborativa de centros e professores. Espera-se que, no futuro, seja o suporte para a organização e realização de uma prova prática nacional para nossos formandos e para uma etapa regional classificatória para as Olimpíadas de Simulação do COBEM.

Ainda como desdobramento deste curso de capacitação em simulação com a rede Ebserh, este livro com seus 17 capítulos tornou-se a Disciplina de PósGraduação de 90 horas (4 créditos) na Universidade de São Paulo (HRB 4095) de "Simulação Clínica: Conceitos e Aplicação na Formação e Capacitação de Profissionais", oferecida no primeiro semestre de 2021, tendo os autores como professores externos. Essa disciplina online teve mais de 150 alunos inscritos, sendo a maioria professores universitários de instituições públicas e privadas de todo o país.

Para encerrar, gostaria de agradecer ao apoio sempre presente e justo da Profa. Hermila Guedes (Universidade Estadual da Bahia), que foi a diretora da ABEM responsável pelo acompanhamento de quase todo o curso, sem a qual não venceríamos os inúmeros obstáculos no caminho de sua realização.

Prof. Gerson Alves Pereira Júnior 
As Diretrizes Curriculares Nacionais (DCNs) e a evolução do conceito de competências para marcos de competências e "Entrustable Professional Activities" (EPAs): um entendimento necessário para adequações da formação médica 


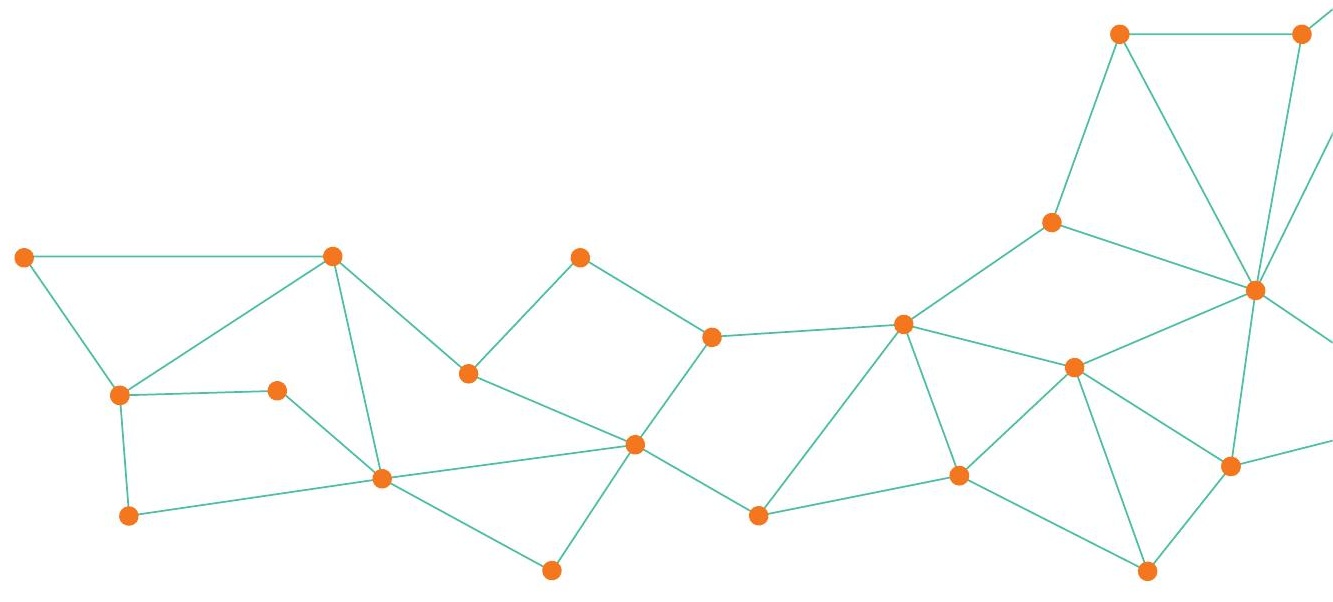

Nos últimos anos, o ensino superior brasileiro tem experimentado mudanças significativas, mais especificamente nas carreiras da saúde. São notórias as complexidades e as exigências que envolvem a formação desses profissionais. As transformações mundiais decorrentes das inovações tecnológicas, científicas e econômicas, aliadas a um mercado progressivamente instável e flexível, têm estabelecido novas regras de convivência social e práticas profissionais. Dessa maneira, há a necessidade de atualização contínua na área da educação, pois a simplificação e a fragmentação do saber estão dando lugar a novos modelos de formação e gestão da força de trabalho (CAMELO; ANGERAMI, 2013; PÜSCHEL et al., 2017).

Ainda hoje, muitos cursos da área da saúde têm seu currículo organizado em disciplinas. Nessa estrutura tradicional, o estudante, inicialmente, tem contato com a teoria e, depois, com as situações práticas. Essa configuração parte do pressuposto de que os estudantes aplicarão o que lhes foi ensinado automaticamente e de forma adequada, partindo do abstrato para o concreto (MAKUCH; ZAGONEL, 2017). Na prática, esse modelo de formação resulta em um distanciamento evidente entre o perfil dos profissionais que estão se inserindo no mercado de trabalho e as reais necessidades de saúde dos usuários (SPORTSMAN, 2010; FRENK et al., 2010). Por isso, muitas escolas médicas já avançaram para outros modelos, ainda que parcialmente, buscando uma maior interdisciplinaridade e aplicação precoce dos conhecimentos.

Assim, é necessário um processo formativo que expresse compromissos éticos e políticos com o exercício da cidadania e com a qualidade de vida da população, rompendo com o modelo de ensino 
voltado apenas para a transmissão e absorção passiva do conhecimento. $O$ processo de aprendizagem deve ser direcionado para aprender a pensar, saber comunicar-se e pesquisar, desenvolvendo no estudante o raciocínio lógico, sínteses e elaborações teóricas (FERNANDES; REBOUÇAS, 2013).

O estudo de Barasuol e Poli (2014) demonstra uma problemática muito comum ao revelar que acadêmicos das áreas da saúde, incluindo aqueles que concluíram mais da metade da carga horária total da graduação, não dominam o conhecimento suficiente sobre suas funções profissionais no seu campo de trabalho, o que compromete o desempenho acadêmico e a prática profissional. Os autores atribuem esse problema à centralização do aprendizado em conhecimentos técnicos, distanciando os estudantes das competências exigidas ao enfermeiro no mercado de trabalho. $\mathrm{O}$ artigo conclui afirmando a necessidade de abordagem das competências desde o início do curso, pois isso amplia a visão dos estudantes sobre o cotidiano e as necessidades do trabalho.

\section{CONCEITO DE COMPETÊNCIAS}

Existem diversas interpretações e definições acerca do conceito de competência nos campos da administração e da educação. Porém, falta um modelo consensual para aplicação das competências no contexto do ensino e da avaliação dos profissionais em saúde, tanto daqueles em formação quanto dos já formados. Desta maneira, esses conhecimentos não são transportados em ganhos reais para estudantes e formadores.

O conceito de competência foi construído a partir da história, cultura e desenvolvimento da sociedade e foi descrito pela primeira vez de maneira estruturada em 1973 por David McClelland. Esse autor evidenciou a compreensão da ação humana direcionada para os resultados. A partir de então, competência passou a ser entendida como um conjunto de conhecimentos, habilidades e atitudes que explicam um alto desempenho, presumindo que os melhores desempenhos estão fundamentados na inteligência e personalidade das pessoas (BONFIM, 2012; FURUKAWA; CUNHA, 2010).

A competência não é uma avaliação estática, e sim um processo contínuo que envolve habilidades técnicas, raciocínio clínico, capacidade de resolver problemas, tomadas de decisões, comportamento psicológico e social para se adaptar aos novos ambientes e condições (SPORTSMAN, 2010).
Competência é uma palavra do senso comum, utilizada para indicar que o indivíduo é qualificado para realizar alguma atividade. É “um saber agir responsável e reconhecido que implica mobilizar, integrar, transferir conhecimentos, recursos, habilidades, que agreguem valor econômico à organização e valor social ao indivíduo" (FLEURY; FLEURY, 2001, p. 188; FURUKAWA; CUNHA, 2010).

O conceito de competência tem como alicerce três dimensões distintas: conhecimentos, habilidades e atitudes. A essas três dimensões também se aliam atributos que envolvem os aspectos cognitivos, técnicos, sociais e afetivos para o sucesso de uma atividade laboral (RUTHES; CUNHA, 2016).

Na educação, há três importantes enfoques conceituais sobre competência: o primeiro associa competência a atributos pessoais; o segundo vincula competência aos resultados de tarefas realizadas; e o terceiro propõe a noção de competência dialógica, originada na associação das características pessoais para a realização de ações em contextos específicos, visando atingir determinados resultados (LIMA, 2005).

Na área da saúde, o modelo de Miller (1990) inclui diferentes níveis de capacitação, que sustentam a competência profissional e podem determinar sua evolução, e é representado por uma pirâmide, em cuja base estão os conhecimentos necessários para o desempenho eficaz do profissional; no segundo nível, está a capacidade dele em utilizar os seus conhecimentos; no terceiro nível, como ele demonstra suas habilidades em determinada situação; e no pico da pirâmide, a ação dele em situações clínicas reais (MILLER, 1990). Atualmente, diversos estudos têm discutido o acréscimo de mais um nível de avaliação na pirâmide de Miller (1990), um nível de desenvolvimento acima do "fazer", que é o nível "ser", no qual a identidade profissional, os valores, os comportamentos, as ações e as aspirações profissionais passam a ser considerados (CRUESS et al., 2015; CRUESS; CRUESS; STEINERT, 2016; AL-ERAKY; MAREI, 2016). A Figura 1 mostra a pirâmide de Miller atualizada.

Sabe-se que a competência não é algo que se observa diretamente, mas pode ser inferida pelo desempenho e pela articulação de tarefas e capacidades, que dão a noção de competência profissional com base em padrões ou critérios definidos. As Diretrizes Curriculares Nacionais (DCNs) de 2014 preconizam que competência "é compreendida como a capacidade de mobilizar conhecimentos, habilidades e atitudes, com utilização dos recursos disponíveis; é também a capacidade de ter 


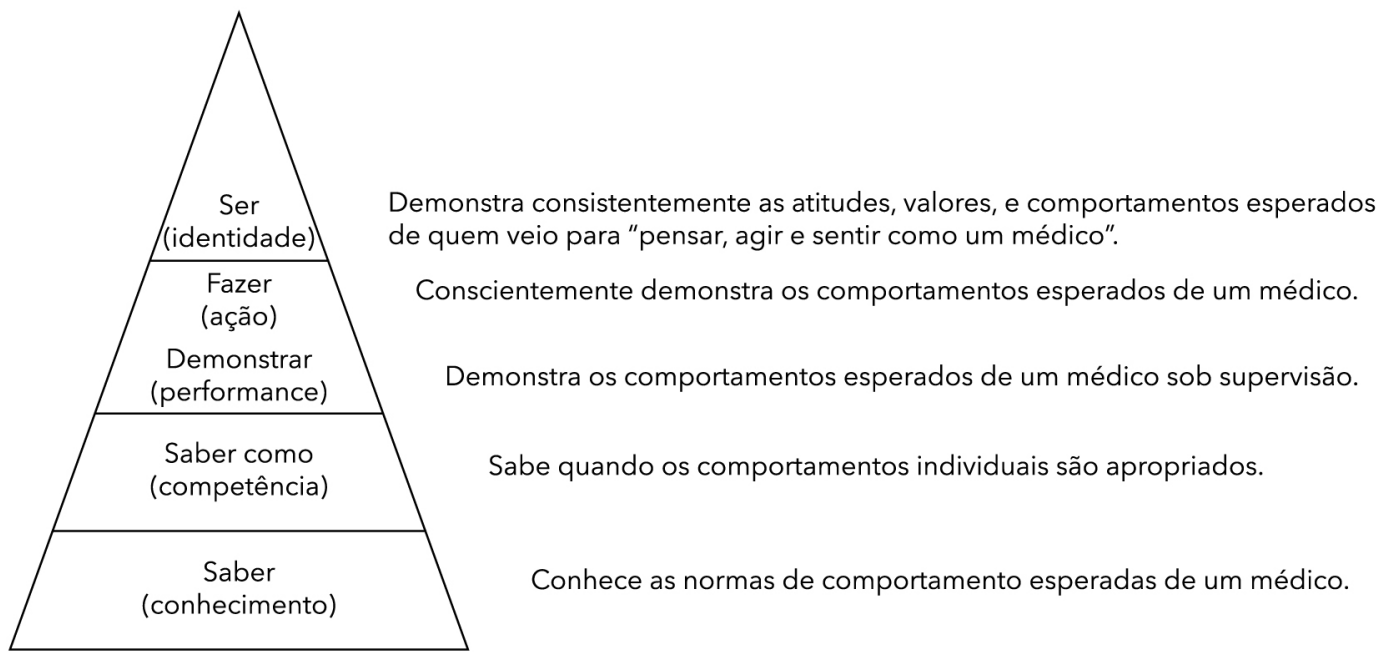

Figura 1. A versão corrigida da pirâmide de Miller, com a adição de "ser" e um esboço do que deve ser avaliado em cada nível. Fonte: adaptada de Cruess, Cruess e Steinert (2016).

iniciativas e ações que traduzam desempenhos capazes de solucionar, com pertinência, oportunidade e sucesso, os desafios que se apresentem à prática profissional em diferentes contextos do trabalho em saúde, traduzindo a excelência da prática médica" (BRASIL, 2014).

\section{A INCLUSÃO DAS COMPETÊNCIAS NAS \\ DIRETRIZES CURRICULARES NACIONAIS PARA OS CURSOS DA ÁREA DA SAÚDE E A NECESSIDADE DE REORIENTAÇÃO CURRICULAR}

Para atender às necessidades do mercado de trabalho, as instituições de ensino devem determinar as competências necessárias ao profissional da área, priorizando as mais críticas e importantes para garantir a formação de estudantes, os quais, ao final do processo de formação, devem estar seguros e preparados para a prática clínica profissional (SPORTSMAN, 2010; FRENK et al., 2010).

Há a exigência de formar um profissional competente, crítico e reflexivo, que seja capaz de corresponder às constantes mudanças sociais e ao desenvolvimento da cidadania. Para oferecer profissionais com esse perfil ao mercado de trabalho, os órgãos reguladores do ensino na área da saúde têm proposto a revisão das DCNs e a coerência delas com os projetos pedagógicos dos cursos (BERNARDINO; FELLI; PERES, 2010; SPORTSMAN, 2010).
No contexto das diretrizes do Plano Nacional de Educação (PNE), do Ministério da Educação (MEC), expresso na Lei $n^{\circ} 10.172 / 2001$, o Conselho Nacional de Educação (CNE) aprovou em 2001 as Diretrizes Curriculares para o Curso de Medicina. Esse foi um marco na regulamentação do ensino em saúde, especialmente médico, no Brasil, pois abrange todas as escolas de Medicina do país. As diretrizes de 2001 foram o parâmetro para a educação médica até junho de 2014, quando o MEC lançou as novas Diretrizes Curriculares Nacionais do Curso de Graduação em Medicina, que se tornaram os parâmetros a serem observados na organização, desenvolvimento e avaliação dos cursos de Medicina de todo o país (BRASIL, 2014; GONTIJO et al., 2013).

Para Makuch e Zagonel (2017), a reformulação do modelo pedagógico vigente é indispensável e apenas acontecerá por meio da implementação de um currículo que possibilite o desenvolvimento de competências. No entanto, embora as diretrizes curriculares atuais indiquem esse objetivo, ainda existem muitas limitações nas discussões sobre o modelo curricular orientado por competência profissional (PEREZ; TOURINHO; CARVALHO JÚNIOR, 2016; MAKUCH; ZAGONEL, 2017).

A discussão sobre as necessidades de mudanças e de novas adequações no ensino superior acontece há tempos, visto que o processo de formação dos profissionais da área da saúde apresenta lacunas no ensino ou na aprendizagem. Assim, os estudantes estão recebendo uma formação com o foco na me- 
canização do fazer clínico, técnico e assistencial, enquanto as demais competências têm sido abordadas de maneira menos objetiva e, por muitas vezes, fragmentadas. Além disso, verifica-se a descontextualização entre teoria e prática (BARASUOL; POLI, 2014).

Considera-se que o movimento das DCNs dos cursos da área da saúde enfoca a reestruturação dos programas curriculares universitários, com a intenção de atender às exigências do perfil profissional, as quais são determinadas pelas competências e habilidades que devem ser seguidas por todas as instituições formadoras no território brasileiro (MAKUCH; ZAGONEL, 2017).

Assim, as DCNs estabelecem formal e organizadamente os princípios, os fundamentos e as finalidades da formação em Medicina. Em consonância com orientações tão bem estipuladas, o momento atual exige das escolas médicas a formação de um profissional com visão holística, ciente da sua relevância social e capacitado ética, técnica e cientificamente.

A função de uma matriz de competências é expressar os consensos coletivos acerca do que é imprescindível e as inter-relações entre os conteúdos essenciais que nenhum estudante deverá deixar de saber ao se formar (ARAÚJO, 2007). Para tanto, as DCNs preconizam que a formação médica deve se basear em competências, e o ensino por competências implica desenvolver no estudante a capacidade de mobilizar conhecimentos, habilidades e atitudes para lidar com situações, problemas e dilemas da vida real, e sua certificação expressa legitimação social de pessoas que passam a ser reconhecidas como capazes de atuar na carreira médica.

As DCNs visam, basicamente, à flexibilização curricular ao pretender uma sólida formação de acordo com o conhecimento desenvolvido em cada área, permitindo ao estudante contextualizar as mudanças na área da saúde e seus desdobramentos no mundo do trabalho, estimulando o perfil profissional generalista que promova o cuidado integral, técnico, científico, humanista, crítico e reflexivo, preparado para atuar nos diferentes níveis de atenção à saúde (MAKUCH; ZAGONEL, 2017).

Muito se discute sobre as propostas e os desafios encontrados na implementação das novas DCNs, as quais fundamentalmente abordam as mudanças do ensino centrado no professor para o ensino e a aprendizagem enfocados no estudante, como sujeito ativo do seu processo de formação, além de buscar romper com a fragmentação do modelo disciplinar para a construção de um modelo integrado, cujo eixo de formação passa a ser a prática, o trabalho e o cuidado. As discussões visam a uma articulação conjunta entre a teoria e a prática, modificando o modelo atual, no qual a teoria é apresentada de maneira desconectada e antecede a prática. O desafio mais difícil é romper as barreiras institucionais que favorecem a rigidez curricular, o que é fundamental para permitir a construção de modelos pedagógicos criativos e inovadores.

Para o avanço dessas questões, é necessário acabar com a rigidez curricular que dificulta a incorporação de atividades ou módulos complementares, que proporcionam estratégias de aproveitamento de conhecimentos adquiridos pelo estudante, por meio de estudos e práticas independentes. É preciso extinguir o uso, quase que exclusivo, da avaliação somativa em prol da avaliação formativa, à medida que haja maior experiência dos professores e maior amadurecimento dos estudantes. Porém, a simples adoção da avaliação formativa substituindo a somativa, sem a experiência e o amadurecimento necessários, pode ser catastrófica. A avaliação deve ser centrada na prática, deixando de ser pontual, punitiva e discriminatória para respeitar a individualidade do estudante, articulando pesquisa, ensino e extensão, desenvolvendo habilidades e produzindo conhecimentos próprios e inovadores mediante sua inserção em realidades concretas (FERNANDES; REBOUÇAS, 2013).

Cada vez mais as competências profissionais devem ser consideradas como aspectos essenciais no desenvolvimento dos projetos pedagógicos e das matrizes curriculares dos cursos da área da saúde, norteando o processo de formação. Assim, o modelo de currículo fundamentado em competências é privilegiado para alavancar as transformações e necessidades que vêm ocorrendo no mundo do trabalho, preparando o profissional para melhor atender a população e aos serviços dos diferentes níveis de atenção à saúde (PEREZ; TOURINHO; CARVALHO JÚNIOR, 2016).

Desse modo, a instituição das DCNs vem provocando mudanças na estruturação curricular de diversos cursos e nos projetos das instituições de ensino em saúde no cenário nacional. E sabe-se que a definição e a articulação entre conhecimentos, habilidades e atitudes requeridas do egresso são imprescindíveis para o futuro exercício profissional do médico.

As DCNs de 2001 preconizam que a formação do médico tem por objetivo dotar o profissional dos conhecimentos requeridos para o exercício das seguintes competências e habilidades gerais: (I) atenção à saúde, (II) tomada de decisões, (III) comunicação, 
(IV) liderança, (V) administração e gerenciamento, e (VI) educação permanente. Com base nessas competências, a formação do médico deverá contemplar o sistema de saúde vigente no país, a atenção integral da saúde e o trabalho em equipe (BRASIL, 2001a; PEREIRA; LAGES, 2013).

Por outro lado, as DCNs de 2014 trazem as competências e habilidades preconizadas para o egresso do curso de Medicina de maneira diferente em alguns aspectos, de modo que a formação do graduado em Medicina deve se desdobrar nas seguintes áreas: (I) atenção à saúde, (II) gestão em saúde e (III) educação em saúde (BRASIL, 2014). O Quadro 1 elenca as competências definidas como necessárias ao egresso do curso de Medicina (FRANCO; CUBAS; FRANCO, 2014).
Existem diferentes formas de organização curricular embasadas no desenvolvimento de competências (ARAÚJO, 2007). Como mencionado, esse tipo de ensino objetiva ir além do simples repasse de conhecimento teórico. Nele, o estudante deve ser inserido em contextos práticos que possibilitem o exercício da mobilização de conhecimentos em situações complexas (PEREZ; TOURINHO; CARVALHO JÚNIOR, 2016).

As discussões sugerem o uso de estratégias e metodologias ativas de ensino e aprendizagem com a finalidade de estimular e desenvolver atitudes e competências ativas nos estudantes. Isso contribui para que o aprendizado integre conteúdos teóricos e práticos, com enfoque formativo de modo a estimular o estudante a buscar construir o conheci-

Quadro 1. Descrição das competências propostas pelas DCNS de 2014. Fonte: Franco, Cubas e Franco (2014, p. 223-224).

\begin{tabular}{|c|c|}
\hline Competência & Descrição da competência \\
\hline 1 & Atenção à saúde. \\
\hline 2 & Tomada de decisões. \\
\hline 3 & Comunicação. \\
\hline 4 & Liderança. \\
\hline 5 & Administração e gerenciamento. \\
\hline 6 & Educação permanente. \\
\hline I & $\begin{array}{l}\text { Promover estilos de vida saudáveis, conciliando as necessidades tanto dos seus } \\
\text { clientes/pacientes quanto de sua comunidade, atuando como agente de transformação } \\
\text { social. }\end{array}$ \\
\hline II & $\begin{array}{l}\text { Atuar nos diferentes níveis de atendimento à saúde, com ênfase nos atendimentos } \\
\text { primário e secundário. }\end{array}$ \\
\hline III & $\begin{array}{l}\text { Comunicar-se adequadamente com os colegas de trabalho, os pacientes e seus } \\
\text { familiares. }\end{array}$ \\
\hline IV & $\begin{array}{l}\text { Informar e educar seus pacientes, familiares e comunidade em relação à promoção da } \\
\text { saúde, prevenção, tratamento e reabilitação das doenças, usando técnicas apropriadas } \\
\text { de comunicação. }\end{array}$ \\
\hline $\mathrm{V}$ & $\begin{array}{l}\text { Realizar com proficiência a anamnese e a consequente construção da história clínica, } \\
\text { bem como dominar a arte e a técnica do exame físico. }\end{array}$ \\
\hline VI & $\begin{array}{l}\text { Dominar os conhecimentos científicos básicos da natureza biopsicossocioambiental } \\
\text { subjacentes à prática médica e ter raciocínio crítico na interpretação dos dados, na } \\
\text { identificação da natureza dos problemas da prática médica e na sua resolução. }\end{array}$ \\
\hline VII & $\begin{array}{l}\text { Diagnosticar e tratar corretamente as principais doenças do ser humano em todas as } \\
\text { fases do ciclo biológico, tendo como critérios a prevalência e o potencial mórbido das } \\
\text { doenças, bem como a eficácia da ação médica. }\end{array}$ \\
\hline VIII & $\begin{array}{l}\text { Reconhecer suas limitações e encaminhar, adequadamente, pacientes portadores de } \\
\text { problemas que fujam ao alcance da sua formação geral. }\end{array}$ \\
\hline
\end{tabular}


Quadro 1. Continuação...

\begin{tabular}{|c|c|}
\hline Competência & Descrição da competência \\
\hline IX & $\begin{array}{l}\text { Otimizar o uso dos recursos propedêuticos, valorizando o método clínico em todos seus } \\
\text { aspectos. }\end{array}$ \\
\hline $\mathrm{X}$ & $\begin{array}{l}\text { Exercer a medicina utilizando procedimentos diagnósticos e terapêuticos com base em } \\
\text { evidências científicas. }\end{array}$ \\
\hline XI & $\begin{array}{l}\text { Utilizar adequadamente recursos semiológicos e terapêuticos, validados } \\
\text { cientificamente, contemporâneos, hierarquizados para atenção integral à saúde, no } \\
\text { primeiro, segundo e terceiro níveis de atenção. }\end{array}$ \\
\hline XII & $\begin{array}{l}\text { Reconhecer a saúde como direito e atuar de forma a garantir a integralidade da } \\
\text { assistência, entendida como conjunto articulado e contínuo de açôes e serviços } \\
\text { preventivos e curativos, individuais e coletivos, exigidos para cada caso em todos os } \\
\text { níveis de complexidade do sistema. }\end{array}$ \\
\hline XIII & $\begin{array}{l}\text { Atuar na proteção e na promoção da saúde e na prevenção de doenças, bem como no } \\
\text { tratamento e reabilitação dos problemas de saúde e acompanhamento do processo de } \\
\text { morte. }\end{array}$ \\
\hline XIV & $\begin{array}{l}\text { Realizar procedimentos clínicos e cirúrgicos indispensáveis para o atendimento } \\
\text { ambulatorial e para o atendimento inicial das urgências e emergências em todas as } \\
\text { fases do ciclo biológico. }\end{array}$ \\
\hline $\mathrm{XV}$ & $\begin{array}{l}\text { Conhecer os princípios da metodologia científica, possibilitando a leitura crítica de } \\
\text { artigos técnico-científicos e a participação na produção de conhecimentos. }\end{array}$ \\
\hline XVI & Lidar criticamente com a dinâmica do mercado de trabalho e com as políticas de saúde. \\
\hline XVII & $\begin{array}{l}\text { Atuar no sistema hierarquizado de saúde, obedecendo aos princípios técnicos e éticos } \\
\text { de referência e contrarreferência. }\end{array}$ \\
\hline XVIII & $\begin{array}{l}\text { Cuidar da própria saúde física e mental e buscar seu bem-estar como cidadão e como } \\
\text { médico. }\end{array}$ \\
\hline XIX & $\begin{array}{l}\text { Considerar a relação custo-benefício nas decisões médicas, levando em conta as reais } \\
\text { necessidades da população. }\end{array}$ \\
\hline $\mathrm{XX}$ & $\begin{array}{l}\text { Ter visão do papel social do médico e disposição para atuar em atividades de política e } \\
\text { de planejamento em saúde. }\end{array}$ \\
\hline XXI & Atuar em equipe multiprofissional. \\
\hline XXII & Manter-se atualizado com a legislação pertinente à saúde. \\
\hline
\end{tabular}

mento, em vez de meramente recebê-lo (SOUZA; SILVA; SILVA, 2018).

Trata-se de uma concepção educacional a favor do processo de ensino e aprendizagem, que pode ser utilizada em experiências reais ou simuladas, integrando teoria e prática para a resolução de problemas. Permite que o estudante possa desenvolver competências ainda inexploradas, contrariamente ao enfoque apenas no conteúdo teórico. Isto contribui de forma significativa para a formação de profissionais mais qualificados, fomentando competências técnicas, éticas e políticas para o enfren- tamento dos problemas de saúde nos quais estejam inseridos (SOUZA; SILVA; SILVA, 2018).

Com o uso dos métodos ativos de ensino e aprendizagem, estão sendo buscadas mudanças de paradigmas da relação clássica de poder vertical entre docente-discente para uma relação mais horizontal, em que todos aprendem e contribuem com seus valores, experiências e conhecimentos. No entanto, é essencial que o currículo proposto apresente objetivos de aprendizagem e estratégias de ensino bem definidos, com métodos de avaliação confiáveis e válidos para o desenvolvimento das compe- 
tências (BOLLELA; MACHADO, 2010; FONSECA; OLIVEIRA, 2013; FERNANDES et al., 2012; SOUZA, 2012; PINILLA-ROA, 2013).

As estratégias pedagógicas são essenciais para promover a construção integradora do conhecimento, a observação reflexiva e a maior aproximação possível do ambiente real. Porém, na maioria dos cursos da área da saúde, ainda há uma escassez da aplicação de metodologias ativas de aprendizagem e poucas oportunidades de vivência prática dos futuros profissionais, que ainda são formados por currículos com base em estratégias tradicionais de ensino (MARTINS, 2017). Muitas vezes, há o uso quase que exclusivo da aprendizagem baseada em problemas como sinônimo do uso de metodologias ativas, o que tornou até jocosa a expressão que classifica os "cursos PBL".

Em todas as áreas de ensino dos profissionais de saúde, é preciso ocorrer modificações do aprendizado clínico e diversificação dos cenários de aprendizagem. Os métodos para a avaliação de competências precisam se adaptar à nova realidade, e isso inclui o uso de técnicas que facilitem o processo de avaliação do estudante durante o desenvolvimento de suas funções (AMARAL; DOMINGUES; ZEFERINO, 2012).

Dessa forma, pode-se concluir que a educação baseada em competências é definida por uma capacidade tangível de atuar no local de trabalho como resultado da educação. É uma abordagem que visa preparar futuros médicos para a prática orientada para formar habilidades de resultados e organizada em torno de competências derivadas de uma análise das necessidades sociais e dos pacientes. Ao valorizar as competências, o método destaca o treinamento com base no tempo e promete maior responsabilidade, flexibilidade e centralização no estudante (FRANK et al., 2010).

A educação baseada em competências tem sido adotada por escolas médicas com o objetivo de orientar a formação a partir da aplicação do conhecimento e do desenvolvimento de habilidades e atitudes. Esse método pressupõe uma avaliação formativa, em que se avalie o desempenho do estudante em relação às competências previamente estabelecidas (CARRACCIO et al., 2002; GRUPPEN; MANGRULKAR; KOLARS, 2012; SANTOS, 2011). Embora a competência tenha sido sempre o objetivo implícito das mais tradicionais estruturas educacionais, a Competency-Based Education (CBE) torna isso mais explícito, estabelecendo desempenhos observáveis e mensuráveis que os estudantes devem atingir para serem considerados com- petentes. A aquisição de competências, integrando conhecimentos, habilidades e atitudes em prol do trabalho na prática, deve ser confirmada em um ambiente de trabalho.

A organização do currículo no local de trabalho (workplace curriculum) é um conjunto ordenado de experiências em um ambiente do mundo real que promove a aquisição de competências necessárias para atuar como profissional. Os recursos que caracterizam um currículo no local de trabalho incluem: (i) uma trajetória de participação de baixa a alta responsabilidade; (ii) acesso a conhecimentos que não seriam aprendidos apenas pela descoberta; (iii) orientação direta de outras pessoas e especialistas mais experientes; e (iv) orientação indireta fornecida pelo ambiente físico e social (BILLETT, 2001, 2014).

\section{O CONCEITO DE MARCOS DE COMPETÊNCIA}

Existem inúmeros desafios na formação em saúde nas instituições de ensino das diferentes categorias profissionais, no sentido de promover o desenvolvimento do aprendiz com a responsabilidade de oferecê-lo à sociedade como um profissional qualificado que atenda não somente às expectativas do sistema de saúde, mas, principalmente, que corresponda positivamente às reais necessidades da população.

Apesar das dificuldades para superar a educação tradicional e incorporar metodologias de ensino e aprendizagem baseadas em competências, tais necessidades têm seus principais progressos descritos no ensino de Medicina de língua inglesa (GRUPPEN; MANGRULKAR; KOLARS, 2012; FERNANDES et al., 2012; BOLLELA; CASTRO 2014; LEUNG; TREVENA; WATERS, 2016; KLAMEM et al., 2016). Surgiram estudos sobre o desenvolvimento de marcos de competências, como as publicações do CanMEDS Framework (FRANK; DANOFF, 2007; VAN DER LEE et al., 2013), Milestones (KORTE et al., 2013; TEHERANI; CHEN, 2014; TEN CATE et al., 2015), Tomorrows Doctors, do Reino Unido, e Scottish Doctor, da Escócia (VAN LOON, 2014).

Os marcos de competências são descrições dos conhecimentos, habilidades e atitudes para cada uma das competências esperadas durante a formação do estudante. São organizados de forma a evidenciar os resultados de desenvolvimento progressivo dos estudantes com base em competências, que vão desde a sua inserção na universi- 
dade até a pós-graduação (WANCATA et al., 2016; LAMBA et al., 2016). Dessa forma, fornecem uma visão geral e de progressão para avaliar o desenvolvimento do graduando em Medicina e do médico-residente em dimensões-chave dos elementos da competência em uma especialidade ou subespecialidade e, posteriormente, a recertificação do médico especialista (WANCATA et al., 2016; LAMBA et al., 2016).

De maneira narrativa, descrevem as competências que devem ser demonstradas repetidamente durante as programações curriculares em ambientes clínicos com diferentes níveis de complexidade (KRUPAT; PELLETIER, 2016). Isso permite a possibilidade de feedback formativo para estímulo a mudanças nos comportamentos observados, além de possibilitar uma maior precisão na aplicação de escalas avaliativas (BEESON et al., 2013; LOMIS et al., 2017; PAGE et al., 2017). Esse modelo expandiu-se nas variadas especialidades médicas (SWING et al., 2013), como Cirurgia Geral (LYLE et al., 2016; DROLET et al., 2017), Pediatria (HICKS et al., 2010; BARTLETT et al., 2015) e Urologia (SMITH et al., 2017), com destaque para a Medicina de Emergência (BEESON et al., 2014; PECK et al., 2014; BEESON et al., 2015; KETTERER et al., 2017), cujos avanços no cuidado multiprofissional ocorrem em todo o mundo.

Com cada especialidade médica desenvolvendo metas voltadas para sua área de atuação, houve a necessidade de desenvolver nomenclatura comum a todas (LYLE, 2016). Um conjunto de marcos de competência consiste na definição de todas as etapas de desenvolvimento em todos os níveis para uma subcompetência em particular (WANCATA et al., 2016; DROLET et al., 2017).

Os marcos de competências representam habilidades explícitas ou comportamentos que ocorrem durante o processo de tornar o médico capaz de desenvolver suas atividades profissionais de modo confiável, definidas para cada especialidade (WANCATA et al., 2016). Esses marcos aumentam a compreensão acerca das competências quando apresentadas de uma forma geral e estanque por:

1) descrever competências mais específicas do que o modelo atual;

2) identificar o núcleo específico da especialidade sobre conhecimentos, habilidades, atitudes e crenças;

3) descrever as subcompetências como progressões dos conhecimentos, habilidades, atitudes que devem ser demonstrados desde a graduação (nível 1), residência médica (níveis 2 a 4) até a prática profissional (nível 5) (Figura 2 e Tabela 2).

O marco de competência corresponde ao comportamento observável dentro de cinco níveis de proficiência, desde o nível 1 de entrada (graduando da escola médica), ao nível 5, a ser alcançado após anos de prática clínica (Tabela 2). O nível 4 é o comportamento esperado para o médico-residente para a certificação inicial (WANCATA et al., 2016).

Assim, a decisão de se desenvolverem marcos para descrever as expectativas progressivas para aprendizagem e desempenho é consistente com modelos mais atuais de desenvolvimento. Tais modelos enfatizam a natureza progressiva da aquisição de conhecimentos, proporcionando a base conceitual para marcos de competência (LOMIS et al., 2017).

A formação generalista é a base de atuação do futuro egresso e tem como objetivo o fortalecimento do SUS e, em especial, da Atenção Primária à Saúde e das urgências. Nesse contexto, o profissional desenvolverá atividades com usuários de todos os ciclos de vida. Além disso, é a base também para futuras especializações nas linhas de atenção e cuidados, cujas prevalências de morbimortalidades sejam estatisticamente significativas para a organização em rede dos serviços e do trabalho.

Para atingir essa formação desejada, é necessária a construção de autonomia e de práticas que se ancorem na integralidade. Somente em um cenário educacional em transformação é possível construir uma prática médica também transformadora, a despeito de todos os desafios (FREITAS et al., 2018).

A expectativa é de que os marcos de competência sejam indicadores de qualidade dos programas de aprendizado nos vários momentos da formação e da prática médica. Dessa forma, na avaliação individual dos aprendizes, pode-se monitorar o progresso por meio desses marcos e determinar se houve progresso, estagnação ou regressão como uma indicação da necessidade específica de correções (PAGE et al., 2017).

Por outro lado, os marcos das competências avaliadas também serão utilizados para determinar se existem lacunas nos programas curriculares ou da residência médica que precisam ser adequadas. Isso também poderá ser usado para garantir segurança aos pacientes, à sociedade, aos prestadores de serviços e aos formuladores de políticas de atenção à saúde (BEESON et al., 2013a).

Muito embora esteja ocorrendo essa evolução na educação médica, na formação em enfermagem é um tema ainda a ser explorado, pois ainda permanece a visão de que o conteúdo ensinado de- 


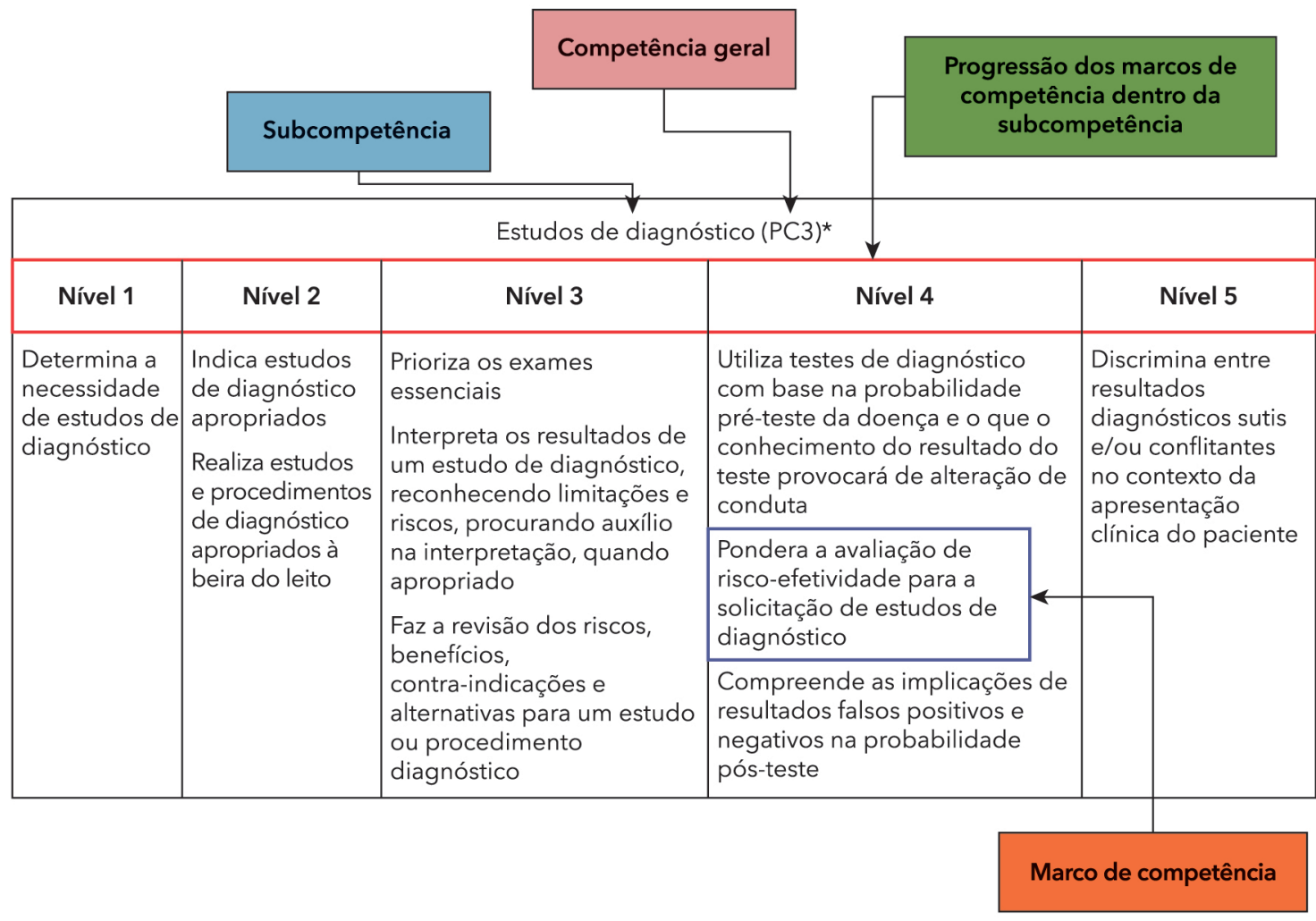

Figura 2. Nomenclaturas dos marcos de competências utilizadas no modelo da ACGME. PC refere-se à primeira competência geral "Assistência ao Paciente" e o número mostra que é a 3a subcompetência relacionada à PC, estando o conjunto progressivo de marcos de competência definidos para cada nível de proficiência, desde a graduação (nível 1), residência médica (níveis 2 a 4) e prática profissional (nível 5). Fonte: adaptada de Beeson et al. (2013b).

Tabela 2. Interpretação geral dos níveis de proficiência. Fonte: traduzida de Accreditation Council for Graduate Medical Education and American Board of Emergency Medicine (2013).

\begin{tabular}{|c|l|}
\hline Nível de proficiência & Definição \\
\hline 1 & $\begin{array}{l}\text { O aluno de Medicina recém-formado, ao entrar na residência médica, demonstra } \\
\text { estes marcos esperados. }\end{array}$ \\
\hline 2 & $\begin{array}{l}\text { O médico-residente está avançando e demonstra marcos adicionais, mas ainda } \\
\text { não atingiu o nível intermediário para o programa de residência. }\end{array}$ \\
\hline 3 & $\begin{array}{l}\text { O médico-residente continua a avançar e demonstrar marcos adicionais, sendo } \\
\text { que a maioria dos marcos de competência direcionados para a área específica da } \\
\text { residência médica está presente nesta subcompetência. }\end{array}$ \\
\hline 4 & $\begin{array}{l}\text { O médico-residente tem avançado de forma a demonstrar que atingiu } \\
\text { substancialmente os marcos de competência previstos para o programa de } \\
\text { residência. Este nível é concebido como o alvo final da residência médica. }\end{array}$ \\
\hline 5 & $\begin{array}{l}\text { O médico-residente tem avançado além das metas de desempenho estabelecidas } \\
\text { para o programa de residência médica. Demonstra metas atingidas para } \\
\text { aspirações maiores, no mesmo nível do profissional que esteja atuante na prática } \\
\text { há vários anos. Espera-se que apenas alguns médicos-residentes de desempenho } \\
\text { excepcional atinjam este nível. }\end{array}$ \\
\hline
\end{tabular}


pende da concepção dos docentes, e, geralmente, possui uma disciplina específica para essas abordagens (MEYER et al., 2017; FILHO et al., 2017).É muito importante que o ensino em Enfermagem e outras áreas da saúde tenham essa evolução para que se possa permitir a educação e o trabalho interprofissional.

\subsection{MARCOS DE COMPETÊNCIA NA RESIDÊNCIA MÉDICA}

Conforme mostrado na Tabela 2, o nível 1 possui os marcos projetados para corresponder ao nível de competência dos estudantes de Medicina ao se formarem, ou seja, antes de entrarem na residência. Esses resultados são úteis para o desenvolvimento de um método válido para a avaliação do desempenho médico dos estudantes. Isso permite que cada instituição possa adequar seu currículo em direção às metas de seus estudantes para alcançarem esses resultados (BARTLETT et al., 2015).

Na avaliação dos programas de residência médica, enquanto os requisitos essenciais se referem à sua estrutura ou processo (por exemplo, volume de serviço de emergência, registros de casos etc.), as exigências de resultados são "declarações que especificam atributos esperados mensuráveis ou observáveis (conhecimentos, habilidades e atitudes) nas várias fases da formação médica" (FRANK, SNELL, SHERBINO, 2015).

Ao padronizar os resultados esperados da aprendizagem na residência médica, os marcos irão definir objetivamente quais os indicadores de conhecimento e aquisição de habilidades a serem monitorados. Isso irá assegurar que o desenvolvimento profissional ocorra antes da certificação pelo programa de formação e que o médico-residente seja minimamente competente para a prática, independentemente de sua especialidade médica (BEESON et al., 2014).

Na outra extremidade desse espectro de formação, os marcos têm o potencial para determinar o grau de desenvolvimento profissional mesmo após o término da residência médica, especialmente no que se refere à manutenção da certificação. Em 2004, o programa de manutenção da certificação foi desenvolvido para assegurar que os médicos estejam comprometidos com a aprendizagem ao longo da vida (educação permanente), mantendo as competências necessárias em sua especialidade (BEESON et al., 2015).

Os marcos de competência tornam transparentes as expectativas dos programas de formação, uma vez que determinados resultados são esperados em termos de competências iniciais para cada etapa. Desta forma, as escolas médicas podem ter uma compreensão muito mais clara do conhecimento básico e das habilidades esperadas dos estudantes de graduação (PECK et al., 2014).

Um tema que tem ganhado cada vez mais importância diz respeito ao conhecimento que os médicos têm sobre o sistema de saúde e sobre a capacidade para torná-lo mais eficaz na assistência aos pacientes. Os médicos devem ser capazes de colaborar com outros membros da equipe de saúde, tanto no ambiente pré quanto intra-hospitalar, além de considerar os custos avaliando riscos e benefícios, melhorando, assim, o desempenho do sistema por meio da identificação de erros de encaminhamento e de comunicação entre os diferentes níveis da rede de atenção à saúde. Além disso, espera-se que os médicos consigam implementar potenciais soluções que contribuam para a melhoria da qualidade da assistência aos pacientes (CHAN et al., 2012).

O próximo desafio para cada especialidade durante a residência médica é o desenvolvimento de medidas de resultados objetivos de avaliação dos marcos das subcompetências. Assim, múltiplos instrumentos de avaliação terão de ser desenvolvidos para fornecer medidas objetivas de uma ou mais subcompetências dentro dos marcos (KOGAN et al., 2009).

Ainda, estudos mais recentes foram desenvolvidos para demonstrar a validade e a confiabilidade dos marcos de competência como um instrumento de avaliação para seu uso disseminado (BEESON et al., 2015; LOMIS et al., 2017).

Com os marcos de competências, a capacidade de agrupar medidas em diferentes configurações possibilita identificar tendências do desempenho do estudante, revelando a necessidade ou não de melhorias. Esses marcos orientam os docentes no processo de desenvolvimento de suas programações dentro da matriz curricular ao longo do curso, bem como no processo de avaliação, gerando um modelo que pode ser compartilhado entre diversas programações no que diz respeito ao conhecimento, habilidades e comportamentos esperados dos estudantes (GONTIJO et al., 2013; SANTEN et al., 2014).

Os relatórios do nível de proficiência deverão ser fundamentados em dados objetivos para garantir uma avaliação coerente e adequada. Isso será um importante aspecto do processo de certificação e sua manutenção. Os instrumentos desse processo ainda devem incluir relatórios padronizados, formação de um comitê de competências clínicas e uso de aquisição dos marcos de competência como re- 
flexo do desempenho do médico-residente e de seu programa (KETTELER et al., 2014).

O comitê de competências clínicas servirá para reunir informações sobre o desempenho de cada médico-residente e dos respectivos programas, ajudando a equalizar as variações das avaliações entre diferentes avaliadores e contribuindo para diminuir a ameaça à integridade dos dados e de seus resultados (KETTELER et al., 2014). Há ainda várias vantagens em relação ao funcionamento deste comitê: embora esta tarefa envolva reuniões frequentes (mensais), não é onerosa. Depois de um certo tempo, duram cerca de uma hora;

- as expectativas dos médicos-residentes são mais claras e, pela natureza dos marcos de competência, são observáveis e tangíveis. O feedback ocorre, geralmente, dentro de uma semana após a reunião com cada médico-residente e gera comentários e metas da direção do programa. O foco dessas reuniões é definir o que os médicos-residentes fazem bem e onde eles deveriam se esforçar para melhorar;

- os preceptores familiarizados com as metas são capazes de treinar mais efetivamente os médicos-residentes, tornando claras as competências, até que eles estejam "de volta ao caminho certo" para a conclusão bem-sucedida do programa de residência;

- os médicos-residentes que não atinjam metas apropriadas podem ser alocados em ações de recuperação para que entendam que o resultado potencial de não alcançarem tais marcos de competências pode determinar repetição de um ano ou até mesmo a exclusão do programa de treinamento;

- a função do comitê e a maior compreensão dos marcos têm ajudado não só a avaliar melhor os médicos-residentes, mas também os estágios necessários para garantir a oferta de experiências que ajudem a alcançar os marcos de competências necessários.

A melhor forma de avaliação do comportamento do médico-residente é a observação direta da prestação de cuidados clínicos em seu ambiente de prática (avaliação no cenário de trabalho). Alguns educadores argumentam que esse é o método ideal de avaliação de competências, porque fornece o contexto da prática profissional, em vez da avaliação simulada ou padronizada (KOGAN et al., 2009).

Os resultados fornecidos pelas avaliações dos marcos de competências servem como alertas sobre o desempenho do currículo. A avaliação de uma turma de estudantes pode mostrar se os resulta- dos das competências desejadas estão sendo obtidos, o que claramente é útil como fonte de dados para discussões sobre melhorias e monitoramento dos impactos potenciais das mudanças curriculares (SANTEN et al., 2014; FRANCO; CUBAS; FRANCO, 2014; FREITAS et al., 2018).

Quanto à sua aplicação, discute-se sobre o contexto em que os marcos serão especificados e observáveis, o número de marcos agrupados dentro de cada nível ou o número total de competências e subcompetências a serem desenvolvidas e avaliadas, o que, eventualmente, pode prejudicar a prática para a avaliação, necessitando de adequações da instituição de ensino (SCHUWIRTH; VAN DER VLEUTEN, 2011; ENGLANDER et al., 2013). Esses questionamentos levaram à introdução do conceito de Entrustable Professional Activities (EPAs) (TEHERANI; CHEN, 2014; TEN CATE et al., 2015).

\section{A EVOLUÇÃO DOS MARCOS DE COMPETÊNCIAS PARA O CONCEITO DE ENTRUSTABLE PROFESSIONAL ACTIVITIES (EPAS)}

Os marcos de competência descrevem de maneira narrativa as competências que se desenvolvem ao longo de um período de formação profissional e que devem ser demonstradas repetidamente ao longo da formação do aprendiz em ambientes clínicos de diferentes níveis de complexidade (KRUPAT; PELLETIER, 2016; WANCATA et al., 2016; LAMBA et al., 2016; PEREIRA, 2015; TEHERANI; CHEN, 2014; TEN CATE et al., 2015).

No entanto, por causa da grande quantidade de marcos de competências existentes e suas características de pouca integração, síntese e aplicabilidade, notou-se a necessidade de uma maior especificidade para avaliação dos aprendizes nas atividades práticas. Assim, foi concebido o conceito de Entrustable Professional Activities (EPAs), ou atividades profissionais confiáveis (o melhor equivalente terminológico em português).

As EPAS são unidades da prática profissional alinhadas aos cuidados clínicos, que traduzem os elementos da prática clínica em níveis de proficiência (PEREIRA, 2015). Trata-se de uma maneira de definir quais seriam as competências necessárias para que o egresso possa exercer sua atividade profissional de maneira confiável.

Na Medicina de Emergência, por exemplo, as EPAs se caracterizam por unidades da prática profissional alinhadas aos cuidados clínicos no setor de urgência (BEESON et al., 2014). Apresentam poten- 
cial para traduzir elementos da prática clínica em níveis de proficiência das subcompetências dos marcos. Como são clinicamente relacionadas, facilitam para o corpo docente avaliar a prática clínica, em comparação com os marcos de competências (BEESON et al., 2014). E cada especialidade médica, de forma específica, definiu seus critérios da forma de apresentação de suas unidades de prática profissional.

Mais recentemente, as várias associações médicas americanas e dos demais países do primeiro mundo vêm discutindo esse modelo conceitual, usado na implementação da educação médica baseada na competência (Figura 3). O tutor/facilitador deve apoiar o estudante como protagonista na sua trajetória rumo à competência e, logo, à independência, em um processo de autonomia crescente, à medida que esteja mais confiante. É complexo o processo do preceptor realizar diuturnamente julgamentos acerca da confiabilidade do estudante para desempenhar as unidades essenciais de prática profissional. Tais atividades profissionais constituem um legítimo instrumento processual de forjamento de profissionais dignos de confiança para desempenhá-las com sucesso, isto é, são genuinamente confiáveis (NEUMANN et al., 2019).

As EPAs são as tarefas ou responsabilidades que os médicos com adequada formação devem executar sem supervisão depois de atingir os níveis de competências específicas considerados suficientes.

As EPAs definem atividades que requerem proficiência em várias competências simultaneamente e são um foco mais adequado para avaliação de competências distintas, sendo independentemente executáveis, observáveis e mensuráveis no seu processo e resultado e, portanto, apropriadas para as deci-

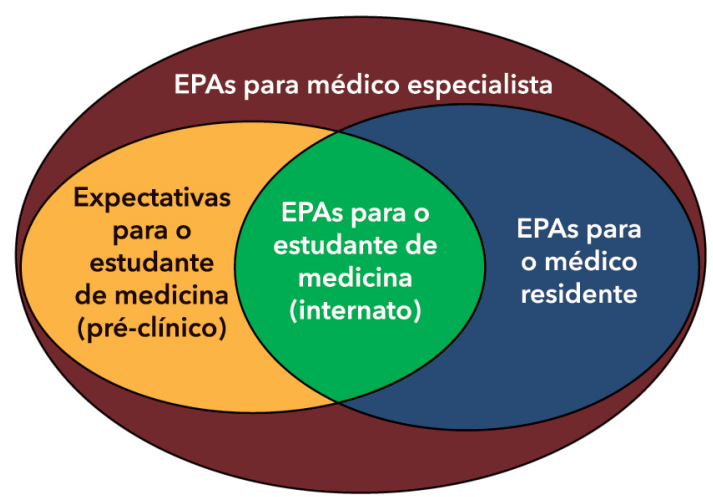

Figura 3. Relações entre as EPAs para cada fase da formação médica. Fonte: adaptada de Association of American Medical Colleges (2014). sões de avaliação e certificação (ASSOCIATION OF AMERICAN MEDICAL COLLEGES, 2014).

As EPAs possuem as seguintes vantagens:

- são atividades que fazem sentido para os professores, os estagiários e também o público;

- representam o trabalho do dia a dia do profissional;

- situam as competências e seus marcos no contexto clínico;

- possibilitam uma avaliação mais prática do que os marcos de competência, utilizando agrupamento de atividades significativas;

- adicionam explicitamente as noções de confiança e supervisão na equação de avaliação.

A relação entre as EPAs e as competências está bem descrita na literatura. As EPAs são unidades de trabalho, enquanto as competências são os conhecimentos, habilidades e atitudes dos indivíduos (EL-HADDAD et al., 2016). As EPAs requerem a integração de várias competências, geralmente entre diferentes competências gerais (domínios) dos marcos (Figura 4).

São necessárias duas premissas fundamentais para toda EPA: confiabilidade e autoconsciência das limitações individuais, que gera comportamento de busca de ajuda. Portanto, essas duas premissas devem ser documentadas para cada aprendiz antes de ser tomada qualquer decisão sobre a avaliação (ASSOCIATION OF AMERICAN MEDICAL COLLEGES, 2014).

Outra característica das EPAs é a necessidade de integração de subcompetências, geralmente entre domínios ou entre competências gerais dos marcos (ASSOCIATION OF AMERICAN MEDICAL COLLEGES, 2014; TEN CATE et al., 2015).

O número de vezes que cada competência foi vinculada a cada EPA é um componente crítico quanto à decisão de avaliação pelo supervisor. As competências gerais de comunicação interpessoal (equipe multiprofissional, pacientes e familiares) e profissionalismo são as mais fundamentalmente citadas para a realização das EPAs (TEN CATE, 2013; ASSOCIATION OF AMERICAN MEDICAL COLLEGES, 2014).

Embora a relação entre EPA e competência seja relativamente bem definida na literatura, sendo que a primeira oferece contexto clínico para a segunda (Tabela 3), a relação entre EPA e marco de competência não o é.

Cada EPA pode ser mapeada para as competências críticas utilizadas para a tomada de decisão durante a avaliação, e cada competência, em seguida, tem marcos associados que representam 


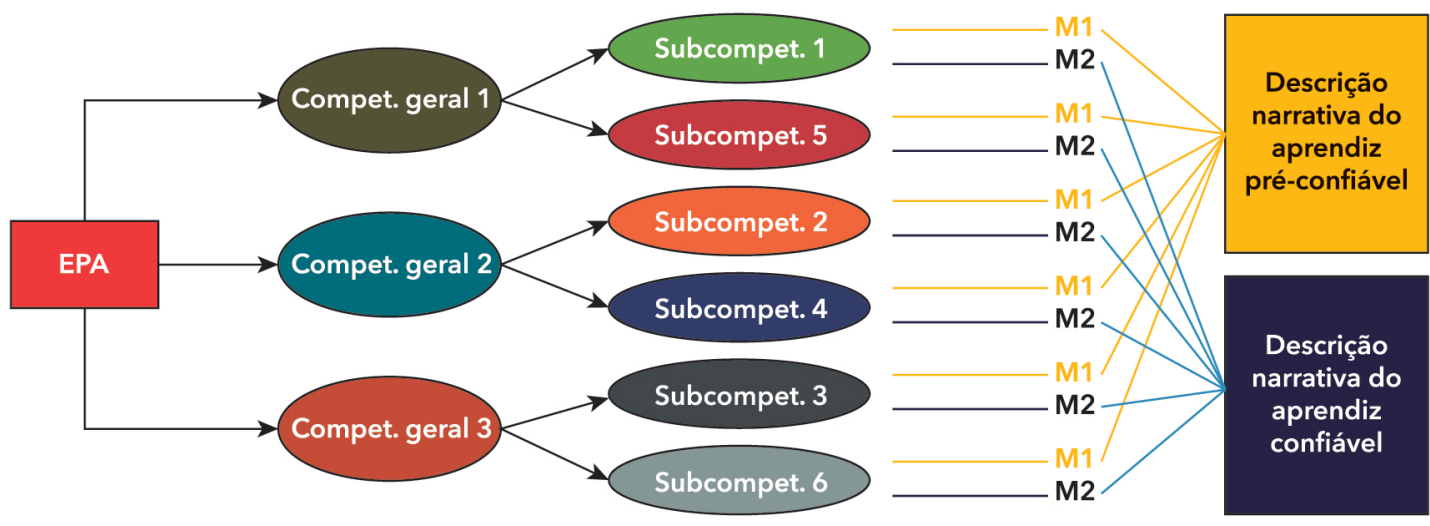

Figura 4. As EPAs requerem a integração de subcompetências, geralmente a partir de dois ou mais domínios (competências gerais). Para cada subcompetência, então, marcos podem ser estabelecidos e, em seguida, sintetizados em narrativas descritivas de comportamentos esperados para os estudantes/médicos-residentes em níveis pré-confiáveis e confiáveis de desempenho. M1 e M2 são marcos de competências para cada subcompetência. Fonte: traduzida de Association of American Medical Colleges (2014).

Tabela 3. A comparação das vantagens e desvantagens dos dois modelos conceituais: competências e EPAs. Fonte: traduzida de Association of American Medical Colleges (2014).

\begin{tabular}{|c|c|c|}
\hline & EPAs & Marcos de competência \\
\hline \multirow{5}{*}{ Vantagens } & $\begin{array}{l}\text { - São “atividades” que fazem } \\
\text { sentido para os professores, os } \\
\text { estagiários e o público. }\end{array}$ & $\begin{array}{l}\text { - As competências têm sido a base } \\
\text { para a avaliação há mais de uma } \\
\text { década. }\end{array}$ \\
\hline & $\begin{array}{l}\text { - Representam o trabalho do dia a } \\
\text { dia do profissional. }\end{array}$ & • No total, definem o "bom médico". \\
\hline & $\begin{array}{l}\text { - Situam competências e marcos } \\
\text { no contexto clínico em que se } \\
\text { vive. }\end{array}$ & $\begin{array}{l}\text { - Têm evidências razoáveis em } \\
\text { torno da avaliação dos domínios } \\
\text { "tradicionais" (conhecimento médico } \\
\text { e assistência ao paciente) }\end{array}$ \\
\hline & $\begin{array}{l}\text { - Permitem avaliação mais } \\
\text { prática por grupos de marcos em } \\
\text { atividades significativas. }\end{array}$ & $\begin{array}{l}\text { - Têm sido utilizados para } \\
\text { o estabelecimento ou o } \\
\text { desenvolvimento de marcos de } \\
\text { desempenho. }\end{array}$ \\
\hline & $\begin{array}{l}\text { - Adicionam explicitamente } \\
\text { noções de confiança e supervisão } \\
\text { na avaliação. }\end{array}$ & \\
\hline \multirow{3}{*}{ Desvantagens } & $\begin{array}{l}\text { - Foram recentemente } \\
\text { introduzidas na literatura. }\end{array}$ & • São abstratos. \\
\hline & $\begin{array}{l}\text { - Houve pouca operacionalização } \\
\text { em todo o mundo. }\end{array}$ & $\begin{array}{l}\text { - São granulares e, portanto, muitas } \\
\text { vezes não refletem a maneira como se } \\
\text { pensa ou se observa os alunos. }\end{array}$ \\
\hline & $\begin{array}{l}\text { - Foram desenhadas } \\
\text { originalmente para a transição da } \\
\text { residência para a vida profissional } \\
\text { subsequente. }\end{array}$ & \\
\hline
\end{tabular}


definições de comportamento para progressão dos níveis de desempenho (DWYER et al., 2016). Assim, uma EPA está diretamente relacionada aos marcos para determinadas competências (TEN CATE, 2013; ASSOCIATION OF AMERICAN MEDICAL COLLEGES, 2014).

Uma vez determinadas as competências críticas para cada EPA, desenvolvem-se metas para cada competência, com dois pontos descritivos: 1) o ponto em que o estudante/médico-residente seria considerado "pré-confiável" (ou seja, ainda não é capaz de realizar a atividade sem supervisão direta); e 2) o ponto em que o estudante/médico-residente poderia ser considerado "confiável" (ou seja, é capaz de realizar a atividade sem supervisão direta). Em seguida, sintetizam-se as metas combinadas do estudante/médico-residente pré-confiável para criar a narrativa e a descrição dos pontos (TEN CATE, 2013; ASSOCIATION OF AMERICAN MEDICAL COLLEGES, 2014). O mesmo foi feito utilizando os marcos de competência para o estudante/médico-residente confiável. Uma vez criadas descrições comportamentais e traduzidas em competências clínicas, estas podem ser usadas como base para avaliação pelo corpo docente (Figura 4).

Os resultados da avaliação baseada nas EPAs permitem apontar em relação ao aprendiz, em qual- quer fase de sua formação, qual o nível específico de supervisão exigida (Tabela 4).

Existem várias características que pesam na decisão de confiar ao aprendiz, em qualquer nível de sua formação, a responsabilidade assistencial de pacientes (TEN CATE et al., 2015):

- qualidades fundamentais, baseadas, principalmente, na competência e raciocínio clínico;

- consciência e confiança nas ações;

- veracidade e honestidade;

- discernimento de suas limitações e propensão a pedir ajuda, se realmente necessário;

- empatia, compreensão e receptividade para com os pacientes;

- habilidade na comunicação e colaboração interprofissional;

- sentimento de autoconfiança e segurança em agir;

- hábitos de autoavaliação, reflexão e desenvolvimento;

- senso de responsabilidade;

- capacidade adequada para lidar com erros próprios e alheios.

Como tais decisões são normalmente tomadas sem muito tempo para deliberação criteriosa, muitas vezes são baseadas em "intuição" e com informações limitadas. Isso não significa, necessariamente,

Tabela 4. Prerrogativas relacionadas aos níveis de supervisão. Fonte: traduzida de Ten Cate et al. (2015).

\begin{tabular}{|c|c|}
\hline Níveis de supervisão & Definição \\
\hline 1 & Estar presente e observar. \\
\hline \multirow{3}{*}{2} & $\begin{array}{l}\text { Atuar com supervisão proativa direta, ou seja, com supervisor fisicamente } \\
\text { presente no local: }\end{array}$ \\
\hline & a) realiza o ato, auxiliado pela supervisão; \\
\hline & $\begin{array}{l}\text { b) age sozinho, com o supervisor presente na sala, pronto para intervir se } \\
\text { necessário. }\end{array}$ \\
\hline \multirow{4}{*}{3} & $\begin{array}{l}\text { Agir com supervisão reativa indireta, ou seja, prontamente disponível a pedido por } \\
\text { meio de telefonia e/ou modalidades eletrônicas: }\end{array}$ \\
\hline & $\begin{array}{l}\text { a) age com supervisor imediatamente disponível, sendo todas as decisões } \\
\text { definidas em conjunto; }\end{array}$ \\
\hline & $\begin{array}{l}\text { b) age com supervisor imediatamente disponível, porém as principais decisões são } \\
\text { definidas em conjunto; }\end{array}$ \\
\hline & $\begin{array}{l}\text { c) age com supervisor disponível a distância (por exemplo, por telefone), devendo } \\
\text { revisar os achados e as decisões. }\end{array}$ \\
\hline 4 & $\begin{array}{l}\text { Agir com supervisão não imediatamente disponível no local, mas com supervisão } \\
\text { distante e vigilante. }\end{array}$ \\
\hline 5 & Fornecer supervisão de aprendizes mais inexperientes. \\
\hline
\end{tabular}


que a tomada de tais decisões seja imprecisa, pois nem tudo que fundamenta uma decisão pode ser traduzida em números, escalas ou mesmo palavras. Às vezes, a supervisão "sente" que pode confiar ou não no aprendiz. Essa confiança presuntiva com base em credenciais anteriores, combinada à confiança inicial após breve observação, pode ser suficiente para se assumir a decisão de deixar o aprendiz realizar ações médicas sobre o paciente, que seriam de responsabilidade profissional da própria supervisão. Em determinado momento da formação, as decisões que demandam anuência para agir sem supervisão devem ser baseadas em avaliações sistemáticas que considerem as qualidades do aprendiz (TEN CATE et al., 2015). Alguns critérios podem fundamentar tais decisões:

- desempenho em exames cognitivos e de habilidades;

- observações diretas por parte dos supervisores, relacionados com o desempenho nas EPAs específicas;

- observação e feedback por parte de pacientes e colegas;

- auditoria da prática e dos registros médicos;

- uso de técnicas de ensino utilizadas pelos preceptores na observação dos aprendizes;

- credenciais anteriores, confiança e reputação relatada pelos colegas;

- verificação amostral da precisão das informações relatadas no item anterior;

- apresentações de casos clínicos nas visitas médicas e discussões que se seguem;

- avaliação de casos atendidos e situações específicas durante o plantão;

- discussões de casos elaborados para esta finalidade;

- exercícios de autorreflexão;

- auditoria e análise de fatos relevantes, identificando as lacunas de aprendizagem;

- feedback de múltiplas fontes sobre habilidades interprofissionais;

- condução de casos clínicos e de investigação por iniciativa própria;

- sinais de preparação e iniciativas/proatividade;

- atribuição de tarefa em que a segurança do paciente pode ser avaliada.

Avançar para o próximo nível de responsabilidade e autonomia exige a coleta de informações válidas sobre os formandos e a utilização sistemática de instrumentos e métodos empregados, principalmente nos cenários de prática (TEN CATE et al., 2015).
Esse esquema pedagógico avaliativo foi introduzido no campo da educação médica pelo holandês Olle ten Cate e permite operacionalizar os processos de confiabilidade que os bons professores clínicos já faziam intuitivamente no dia a dia. $\mathrm{O}$ esquema desse autor coloca a avaliação de competências no contexto adequado da prática médica, justamente por meio da linguagem da confiança, um conceito essencial e nuclear da atenção à saúde. É possível reconhecer a aplicabilidade prática do esquema avaliativo fundamentado nas EPAs durante o internato médico, já que leva em conta não só as definições abrangentes e integrativas de competências, mas também sua conotação legal. Isso significa que o aprendiz adquire por mérito a capacidade e o direito de atuar como profissional (NEUMANN et al., 2019).

Em artigo publicado em português em 2019 na Revista Brasileira de Educação Médica, "Guia Atualizado sobre Atividades Profissionais Confiáveis", Olle ten Cate fez uma revisão do estado da arte do trabalho com as atividades profissionais confiáveis (APCs) em diferentes disciplinas, profissões e países, mostrando que esse conceito surgiu pela primeira vez em 2005 e agora tem se tornado popular nos programas de pós-graduação e, mais recentemente, nos de graduação (TEN CATE, 2019).

Em 2019, diversos autores gaúchos escreveram um livro no qual se encontra a descrição de uma trajetória percorrida por docentes, com o objetivo de ampliar a avaliação por competências no internato, introduzindo o conceito de EPAs - o qual traduziram como atividades profissionais confiabilizadoras -, de reconhecido valor na avaliação de habilidades durante a formação dos profissionais da saúde (NEUMANN et al., 2019).

\section{USO DE MARCOS DE COMPETÊNCIA E EPAS NA SIMULAÇÃO CLÍNICA}

A simulação clínica se apresenta como uma possível estratégia de ensino e/ou avaliação, por meio da qual se pode conquistar e/ou confirmar competências clínicas, otimizar métodos de avaliação na formação profissional, atributos interpessoais, capacidade de raciocínio clínico, tomada de decisão, habilidades técnicas, entre outros (MONTIEL et al., 2012).

Uma revisão sistemática sobre as características e usos de simulações médicas levou à identificação baseada em evidências e proposta de recursos e melhores práticas para o ensino médico eficaz com base em simulação (ISSENBERG et al., 2005): 
1. Feedback.

2. Prática repetitiva/deliberada.

3. Integração curricular.

4. Medição de resultados.

5. Fidelidade da simulação e validade do simulador.

6. Aquisição e manutenção de habilidades.

7. Aprendizado de domínio individualizado.

8. Transferência para a prática.

9. Treinamento de equipe.

10. Teste de alto risco.

11. Treinamento de instrutores.

12. Contexto educacional e profissional.

O princípio da educação baseada em simulação é que haja a transferência das competências adquiridas em atividades simuladas, em que o treinamento permite a aquisição de habilidades cognitivas, afetivas e psicomotoras adquiridas fora do local de trabalho e possa servir na melhor qualificação e segurança para a resolução dos problemas dos pacientes no ambiente clínico. O treinamento com base em simulação está muito próximo desse modelo de aprendizagem em seu design, e o realismo dos ambientes de ensino simulados pode ser um fator que influencia a transferência da aprendizagem cognitiva, afetiva e psicomotora para o local de trabalho (KHAN et al., 2010).

Não há dúvida sobre a necessidade de simulação na educação médica no currículo com base em competências, para que os estudantes possam ter os melhores resultados pela capacitação e treinamento prévio (SAVOLDELLI, VAN GESSEL, 2016).

O pré-treinamento no simulador ou no ambiente simulado antes do encontro com o paciente aborda as questões de segurança nas condutas e procedimentos. Isso salvaguarda as instituições de ensino quando confrontadas por aquele que fizer propaganda negativa de que "os pacientes estão sendo tratados pelos estudantes”.

Para os pacientes, ter estudantes e médicos-residentes treinados em simulação é a garantia de que estes tenham desenvolvido um nível mínimo de competência antes de sua interação clínica. Isso os deixa mais dispostos a permitir que os estudantes realizem procedimentos, uma vez que já tiveram o treinamento em simulação (GRABER et al., 2005).

No entanto, a educação médica baseada em simulação é apenas um complemento e não substitui os muitos métodos e estratégias educacionais existentes no ambiente clínico tradicional para garantir que os graduandos se tornem competentes. Após a experiência de aprendizagem baseada em simulação para desenvolver o nível mínimo de competências para a prestação de cuidados seguros, os estudan- tes precisam praticar sob supervisão em pacientes reais. Isso também vale para as habilidades relacionadas à gestão em saúde: é necessário que o aprendiz realize treinamento em sistemas de prestação de cuidados em equipes para aprender a participar e liderar equipes de saúde (CHACKO, 2017).

Para os estudantes, as experiências de aprendizagem baseada em simulação incorporadas ao currículo oferecem a oportunidade ideal para praticar o atendimento ao paciente longe da beira do leito. Em ambiente simulado, é possível aplicar os princípios da aprendizagem e da prática deliberada para o domínio de conhecimentos e habilidades.

Como há muitos caminhos para desenvolver e avaliar as competências nas atividades simuladas, é necessário desenvolver e aprimorar métodos de ensino e aprendizagem e avaliação de competências que sejam capazes de assegurar resultados confiáveis (MOADEL, EVANS, 2015).

Nesse contexto, os marcos de competências foram desenvolvidos e são utilizados para a avaliação da progressão do aprendiz. Sabe-se que, originalmente, as EPAs foram criadas para serem desenvolvidas no contexto da prática, no entanto há estudos na área médica que demonstram a possibilidade de serem realizadas em simulação clínica, pela capacidade de similitude desse método com o contexto real da prática clínica em saúde (CROFT et al., 2020).

No atual momento, a educação médica baseada em simulação vem procurando estudar e utilizar as melhores práticas, buscando maximizar seus benefícios educacionais no contexto do currículo por competências (CHACKO, 2017). As EPAs podem fornecer uma plataforma para decisões de confiança em torno das principais habilidades, preenchendo, assim, a lacuna entre a teoria e a prática (CROFT et al., 2020).

Existem várias restrições e desafios práticos que precisam ser superados na implementação de programas de treinamento em simulação, como restrições de tempo, falta de capacitação do corpo docente, alto custo do equipamento e de sua manutenção e restrições de espaço necessário para laboratórios educacionais. Como os simuladores não substituem educadores treinados em bons princípios educacionais e técnicas de ensino, esses professores precisam ser identificados e receber treinamentos no uso de simulação (CHACKO, 2017).

Em um estudo, EPAs de complexidade crescente foram propostas para as responsabilidades e competências dos membros do corpo docente que ensinam no laboratório de simulação. A abordagem em camadas das EPAs ajudou os docentes a ganhar 
confiança em suas habilidades e a entender como progrediam, o que era benéfico para eles e seus estudantes, e os julgamentos de competência de nível pessoal eram informados por múltiplas EPAs, diretamente observáveis e mensuráveis. Por isso, é fundamental que se tenha processos bem definidos para garantir maior competência entre os responsáveis pela formação das gerações futuras de provedores de saúde, visto que a implementação de EPAs para líderes de simulação pode ser um método para alcançar esse objetivo (GARDNER; GEE; AHMED, 2018).

Outro estudo desenvolveu uma ferramenta chamada E-ASSESS (EPA Assessment for Structured Simulated Emergency Scenarios) para coletar evidências que apoiassem o uso das EPAs em simulação para fornecer informações de avaliação que pudessem contribuir potencialmente para as decisões sobre confiabilidade. Essa ferramenta pode ser um modelo para outras semelhantes que visam informar decisões sobre independência na realização das atividades práticas (ANDLER et al., 2020).

A incorporação da educação médica baseada em simulação no currículo pode ser alcançada usando a ferramenta de mapeamento do currículo. Por meio dele, é possível identificar e abordar todas as EPAs necessárias.

Para superar esse desafio relacionado ao corpo docente da educação médica baseada em simulação, as instituições devem recompensar adequadamente os educadores por meio de promoções e garantir-lhes um tempo protegido para ensinar, realizar pesquisas adicionais e participar de avaliações periódicas do programa para melhorar a qualidade e a eficácia do treinamento com base em simulação. As instituições também devem priorizar a simulação em seus hospitais (simulação in situ), de acordo com as necessidades curriculares, por meio do mapeamento do currículo, tendo em mente as instalações e oportunidades disponíveis nas enfermarias e ambulatórios e identificando as EPAs que requerem pré-treinamento em simuladores antes que sejam praticadas em pacientes reais (CHACKO, 2017).

Há evidências emergentes sobre como as EPAs podem ser efetivamente introduzidas no treinamento clínico na graduação médica. As EPAs específicas com escalas de supervisão adaptadas ao contexto podem ser úteis, aproveitando melhor seu potencial de avaliação formativa (PINILLA et al., 2021).

Um estudo recente mostrou que a percepção dos estudantes sobre o valor de aprendizagem das atividades baseadas em simulação é muito consis- tente e positiva. Dessa forma, a adoção de currículos com simulação fundamentados em EPAs nos anos clínicos é viável e generalizável, garantindo uma boa avaliação formativa. E a avaliação formativa longitudinal utilizando atividades simuladas é de extrema importância no desenvolvimento eficaz das EPAs essenciais (HERRIGEL et al., 2020).

\section{CONSIDERAÇÕES FINAIS}

As EPAs são tarefas clínicas observáveis e executáveis que refletem uma ou mais competências clínicas. O objetivo é que os estudantes realizem seu trabalho com segurança e eficácia sem supervisão, uma vez que tenham demonstrado competência suficiente e se tornem confiáveis na sua execução. No final do treinamento, a atividade profissional deve ser realizada com segurança. Isso significa que a avaliação do estudante deve ser enfocada na sua capacidade de realizar e de lidar com quaisquer acontecimentos inesperados que ocorram durante a atividade.

A simulação oferece uma oportunidade única para avaliar as EPAs e medir, objetivamente, as habilidades sem ameaça à segurança do paciente.

A avaliação das competências pode ser realizada durante a observação do desempenho de um aprendiz, integrando os vários componentes e subcomponentes dos domínios de cada marco de competência, e é sempre necessária, anteriormente a qualquer decisão de atribuição. Já as competências são medidas e avaliadas para assegurar a sua aquisição por parte do aprendiz, e, se forem avaliadas no contexto do desempenho, apresentam melhores resultados (ASSOCIATION OF AMERICAN MEDICAL COLLEGES, 2014).

A discussão apresentada tem a intenção de ser fonte inspiradora de reflexões para a elaboração e o desenvolvimento de marcos de competências e EPAs nos cursos da área da saúde.

O uso dos marcos de competência permite que o estudante visualize seu roteiro de aprendizagem e se conscientize da necessidade de identificação das lacunas de sua formação para atingir as competências essenciais. Trata-se de um norteador para estudantes e docentes visando à formação de profissionais preparados.

As EPAs permitem que os supervisores sistematizem a avaliação das competências dos aprendizes que devem ser demonstradas de forma confiável na execução das diversas atividades práticas, sendo sua aplicação mais objetiva, sintética e in- 
tegrada, assegurando a qualidade no ensino e avaliação e contribuindo também para a segurança do paciente.

Desta forma, é possível a aplicação dos marcos de competências e das EPAs nos cursos da área da saúde, pois se complementam no processo de en- sino e avaliação de competências, sendo possível utilizá-los para avaliá-las em atividades simuladas.

A incorporação desses conceitos e de sua prática na atualização das matrizes curriculares é uma necessidade obrigatória dos cursos da área da saúde, particularmente na Medicina, nos dias atuais.

\section{REFERÊNCIAS}

ACCREDITATION COUNCIL FOR GRADUATE MEDICAL EDUCATION AND AMERICAN BOARD OF EMERGENCY MEDICINE. The Emergency Medicine Milestone Project, 2013. Disponível em $<$ https://www.abem.org/PUBLIC/_Rainbow/Documents/ EMMilestonesMeeting4_Final1092012.pdf>. Acesso em: 02 ago. 2019.

AL-ERAKY, M.; MAREI, H. A fresh look at Miller's pyramid: assessment at the 'Is' and 'Do' levels. Medical Education, Oxford, v. 50, n. 12, p. 1253-1257, 2016.

AMARAL, E.; DOMINGUES, R. C. L.; ZEFERINO, A. M. B. Métodos tradicionais e estruturadas de avaliação prática de competências clínicas (caso longo estruturado e observação em serviço). In: TIBERIO, I. F. L. C.; DAUD-GALLOTTI, R. M.; TRONCON, L. E. A.; MARTINS, M. A. Avaliação prática de habilidade clínicas em medicina. São Paulo: Editora Atheneu, 2012.

ANDLER, C. et al. E-ASSESS: Creating an EPA Assessment Tool for Structured Simulated Emergency ScenarioS. Journal of Graduate Medical Education, Chicago, v. 12, n. 2, p. 153-158, 2020.

ARAÚJO, D. Noção de competência e organização curricular. Revista Baiana de Saúde Pública, Salvador, v. 31, Supl. 1, p. 32-43, 2007.

ASSOCIATION OF AMERICAN MEDICAL COLLEGES. Core Entrustable Professional Activities for Entering Residency: Curriculum Developers' Guide. Washington: AAMC 2014.

BARASUOL, M. E. C.; POLI, G. Competências necessárias ao enfermeiro e o processo de formação. Revista Saúde e Desenvolvimento, Brazil, v. 6, n. 3, jul.-dez. 2014.

BARTLETT, K. W. et al. Milestone-based assessments are superior to likert-type assessments in illustrating trainee progression. Journal of Graduate Medical Education, Chicago, v. 7, n. 1, p. 75-80, 2015.

BEESON, M. S. et al. Emergency medicine milestones. Journal of Graduate Medical Education, Chicago, v. 5, n. 1S, p. 5-13, $2013 \mathrm{~b}$.

BEESON, M. S. et al. Entrustable professional activities: making sense of the emergency medicine milestones. The Journal of Emergency Medicine, New York, v. 47, n. 4, p. 441-452, 2014.
BEESON, M. S. et al. Initial validity analysis of the emergency medicine milestones. Academic Emergency Medicine, Philadelphia, v. 22, n. 7, p. 838-844, 2015. http:// dx.doi.org/10.1111/acem.12697.

BEESON, M. S. et al. The development of the emergency medicine milestones. Academic Emergency Medicine, Philadelphia, v. 20, p. 724-729, 2013 b.

BERNARDINO, E.; FELLI, V. E. A.; PERES, A. M. Competências gerais para o gerenciamento em enfermagem de hospitais. Cogitare Enfermagem, Curitiba, v. 15, n. 2, p. 349-353, 2010.

BILLETT, S. Learning in the workplace. 1st ed. Crows Nest, NSW, Australia: Allen \& Unwin, 2001.

BILLETT, S. Mimetic learning at work: Learning in the circumstances of practice. 1st ed. Dordrecht: Springer, 2014.

BOLLELA, V. R.; CASTRO, M. Program evaluation on health professions education: basic concepts. Medicina, Ribeirão Preto, v. 47, n. 3, p. 332-342, 2014.

BOLLELA, V. R.; MACHADO, J. L. M. O currículo por competências e sua relação com as diretrizes curriculares nacionais para a graduação em Medicina. Science in Health, São Paulo, v. 1, n. 2, p. 126-142, 2010.

BONFIM, R. A. Competência profissional: uma revisão bibliográfica. Revista Organização Sistêmica, v. 1, n. 1, p. 46-63, 2012.

BRASIL. CONSELHO NACIONAL DE EDUCAÇÃO. CÂMARA DE EDUCAÇÃO SUPERIOR. Resolução CNE/ $\mathrm{CES} \mathrm{N}^{\circ}$ 4, de 7 de novembro de 2001. Diretrizes Curriculares Nacionais do Curso de Graduação em Medicina. Diário Oficial da República Federativa do Brasil, Brasília, DF, 09 nov. 2001a. Seção 1, p. 38.

BRASIL. CONSELHO NACIONAL DE EDUCAÇÃO. Parecer CNE/CES No 3, de 7 de novembro de 2001. Dispõe sobre as Diretrizes Curriculares Nacionais do Curso de Graduação em Enfermagem. Diário Oficial da República Federativa do Brasil, Brasília, DF, 09 nov. 2001b. Disponível em: <http://portal.mec.gov.br/cne/arquivos/pdf/CESO3. pdf $>$ Acesso em: 02 ago. 2019.

BRASIL. MINISTÉRIO DA EDUCAÇÃO. CONSELHO NACIONAL DE EDUCAÇÃO. Câmara de Educação Superior. Resolução No 3, de 20 de Junho de 2014. Diretrizes Curriculares Nacionais do Curso de Graduação 
em Medicina e dá outras providências. Diário Oficial da República Federativa do Brasil, Brasília, DF, 23 jun. 2014. Seção 1, p. 8-11.

CAMELO, S. H. H.; ANGERAMI, E. L. S. Competência profissional: a construção de conceitos, estratégias desenvolvidas pelos serviços de saúde e implicações para a enfermagem. Texto \& Contexto Enfermagem, Florianópolis, v. 22, n. 2, p. 552-560, 2013.

CARRACCIO, C. et al. Shifting paradigms: from Flexner to competencies. Academic Medicine, Philadelphia, v. 77, n. 5 , p. 361-367, 2002.

CHACKO, T. V. Simulation-based medical education: using best practices and curriculum mapping to maximize educational benefits in the context of shift toward competencybased medical education. Archives of Medicine and Health Sciences, Mumbai, v. 5, n. 1, p. 9-15, 2017

CHAN, T. M. et al. Assessing interpersonal and communication skills in emergency medicine. Academic Emergency Medicine, Philadelphia, v. 19, p. 1390-1402, 2012.

CROFT, H. et al. Development and inclusion of an entrustable professional activity (EPA) scale in a simulation-based medicine dispensing assessment. Currents in Pharmacy Teaching \& Learning, Netherlands, V. 12 , n. 2, p. 203-212, 2020.

CRUESS, R. L. et al. A schematic representation of the professional identity formation and socialization of medical students and residents: a guide for medical educators. Academic Medicine, Philadelphia, v. 90, n. 6, p. 718-725, 2015.

CRUESS, R. L.; CRUESS, S. R.; STEINERT, Y. Amending Miller's Pyramid to include professional identity formation. Academic Medicine, Philadelphia, v. 91, n. 2, p. 180-185, 2016.

DIESEL, A.; BALDEZ, A. L. S.; MARTINS, S. N. Os princípios das metodologias ativas de ensino: Uma abordagem teórica. Revista Thema, Lajeado, v. 14, n. 1, p. 268-288, 2017.

DROLET, B. C. et al. Program director perceptions of the general surgery milestones project. Journal of Surgical Education, New York, v. 74, n. 5, p. 769-772, 2017.

DWYER, T. et al. Cognitive and psychomotor entrustable professional activities: can simulators help assess competency in trainees? Clinical Orthopaedics and Related Research, Philadelphia, v. 474, n. 4, p. 926-934, 2016.

EL-HADDAD, C. et al. The ABCs of EPAs: An overview of "Entrustable Professional Activities" in medical education. Internal Medicine Journal, Carlton, v. 46, n. 9, p. 1006-1010, 2016.

ENGLANDER, R. et al. Toward a Common Taxonomy of Competency Domains for the Health Professions and Competencies for Physicians. Academic Medicine, Philadelphia, v. 88, n. 8, p. 1088-1094, 2013.
FERNANDES, C. R. et al. Currículo baseado em competências na residência médica. Revista Brasileira de Educação Médica, Rio de Janeiro, v. 36, n. 1, p. 129-136, 2012.

FERNANDES, J. D.; REBOUÇAS, L. C. Uma década de Diretrizes Curriculares Nacionais para a Graduação em Enfermagem: avanços e desafios. Revista Brasileira de Enfermagem, Brasilia, v. 66, p. 95-101, 2013.

FILHO, L. A. M. et al. Urgency/emergency course content in the education of generalist nurses. REME: Revista Mineira de Enfermagem, Belo Horizonte, v. 21, p. e-1006, 2017.

FLEURY, M. T. L.; FLEURY, A. Construindo o conceito de competência. Revista de Administração Contemporânea, Curitiba, v. 5, p. 183-196, 2001.

FONSECA, A.; OLIVEIRA, M. C. Educação baseada em competências. Arquivos de Medicina, Porto, v. 27, n. 6, p. 272-277, 2013.

FRANCO, C. A. G. S.; CUBAS, M. R.; FRANCO, R. S. Currículo de medicina e as competências propostas pelas diretrizes curriculares. Revista Brasileira Educação Médica, Rio de Janeiro, v. 38, n. 2, p. 221-230, 2014.

FRANK, J. R. et al. Toward a definition of competency-based education in medicine: A systematic review of published definitions. Medical Teacher, London, v. 32, n. 8, p. 631-637, 2010.

FRANK, J. R.; DANOFF, D. The CanMEDS initiative: implementing an outcomes-based framework of physician competencies. Medical Teacher, London, v. 29, n. 7, p. 642-647, 2007.

FRANK, J. R.; SNELL, L.; SHERBINO, J. CanMEDS 2015 Physician Competency Framework. Ottawa: Royal College of Physicians and Surgeons of Canada, 2015.

FREITAS, L. S.; RIBEIRO, M. F.; BARATA, J. L. M. O desenvolvimento de competências na formação médica: os desafios de se conciliar as Diretrizes Curriculares Nacionais num cenário educacional em transformação. Revista Médica de Minas Gerais, Belo Horizonte, v. 28, p. e-1949, 2018.

FRENK, J. et al. Health professional for a new century: transforming education to strengthen health systems in independent world. Lancet, Minneapolis, v. 376, n. 9756, p. 1923-1958, 2010.

FURUKAWA, P. O.; CUNHA, I. C. K. O. Da gestão por competências às competências gerenciais do enfermeiro. Revista Brasileira de Enfermagem, Brasília, v. 63, n. 6, p. 1061-1066, 2010.

GARDNER, A. K.; GEE, D.; AHMED, R. A. Entrustable Professional Activities (EPAs) for Simulation Leaders: The Time Has Come. Journal of Surgical Education, New York, v. 75, n. 5, p. 1137-1139, 2018.

GONTIJO, E. D. et al. Matriz de competências essenciais para a formação e avaliação de desempenho de estudantes de medicina. Revista Brasileira Educação Médica, Rio de Janeiro, v. 37, n. 4, p. 526-539, 2013. 
GRABER, M. A. et al. Does simulator training for medical students change patient opinions and attitudes toward medical student procedures in the emergency department? Academic Emergency Medicine, Philadelphia, v. 12, p. 635-639, 2005.

GRUPPEN, L. D.; MANGRULKAR, R. S.; KOLARS, J. C. The promise of competency-based education in the health professions for improving global health. Human Resources for Health, London, v. 10, p. 43, 2012.

HERRIGEL, D. J. et al. Simulation as a platform for development of entrustable professional activities: Modular, A. Longitudinal Approach. Cureus, Palo Alto, v. 12, n. 10, p. e11098, 2020.

HICKS, P. J. et al. Pediatrics milestone project: next steps toward meaningful outcomes assessment. Journal of Graduate Medical Education, Chicago, v. 2, n. 4, p. 577-584, 2010.

ISSENBERG, S. B. et al. Features and uses of high-fidelity medical simulations that lead to effective learning: A BEME systematic review. Medical Teacher, London, v. 27, p. 10-28, 2005.

KETTELER, E. R. et al. A successful strategy to implement milestone evaluations and competency coaching. Journal of Surgical Education, New York, v. 71, n. 1, p. 36-38, 2014. KETTERER, A. R. et al. Supplemental milestones for emergency medicine residency programs: a validation study. The Western Journal of Emergency Medicine, Orange, v. 18, n. 1, p. 69-75, 2017. http://dx.doi.org/10.5811/ westjem.2016.10.31499.

KHAN, K. et al. Simulation in healthcare education building a simulation programme: A practical guide: AMEE Guide No. 50. Dundee, UK: Association for Medical Education in Europe, 2010.

KLAMEM, D. L. et al. Competencies, milestones and EPAs are those who ignore the past condemned to repeat it? Medical Teacher, London, v. 38, n. 9, p. 904-910, 2016.

KOGAN, J. R.; HOLMBOE, E. S.; HAUER, K. E. Tools for direct observation and assessment of clinical skills of medical trainees: a systematic review. Journal of the American Medical Association, Chicago, v. 302, n. 12, p. 1316-1326, 2009.

KORTE, B. C. et al. The emergency medici- ne Milestones: A validation study. Academic Emergency Medicine, Philadelphia, v. 7, p. 730-735, 2013.

KRUPAT, E.; PELLETIER, S. R. The development of medical student competence: tracking its trajectory over time. Medical Science Educator, Barboursville, v. 26, n. 1, p. 61-67, 2016.

LAMBA, S. et al. A suggested emergency medicine boot camp curriculum for medical students based on the mapping of Core Entrustable Professional Activities to emergency medicine level 1 milestones. Advances in Medical Education and Practice, Auckland, v. 7, p. 115-124, 2016.
LEUNG, K.; TREVENA, L.; WATERS, D. Development of a competency framework for evidence-based practice in nursing. Nurse Education Today, Edinburgh, v. 39, p. 189-196, 2016.

LIMA, V. V. Competência: distintas abordagens e implicações na formação de profissionais de saúde. Interface - Comunicação, Saúde, Educação, Botucatu, v. 9, n. 17, p. 369-379, 2005.

LOMIS, K. D. et al. Competency milestones for medical students: design, implementation, and analysis at one medical school. Medical Teacher, London, v. 39, n. 5, p. 494-504, 2017.

LYLE, B. et al. Do attending surgeons and residents see eye to eye? an evaluation of the Accreditation Council for Graduate Medical Education milestones in general surgery residency. Journal of Surgical Education, New York, v. 73, n. 6, p. e54-e58, 2016.

MAKUCH, D. M. V.; ZAGONEL, I. P. S. Abordagem pedagógica na implementação de programas curriculares na formação do enfermeiro. Escola Anna Nery, Rio de Janeiro, v. 21, n. 4, p. 1-9, 2017.

MEYER, G. et al. Effect of curriculum revision on graduates' transition to practice nurse educator. Nurse Educator, Philadelphia, v. 42, n. 3, p. 127-132, 2017.

MILLER, G. E. The assessment of clinical skills/ competence/performance. Academic Medicine, Philadelphia, v. 65, n. 9, p. 63-S67, 1990.

MOADEL, T.; EVANS, L. A simulation-based curriculum for Evaluating the Entrustable Professional Activities (EPAs) During the Emergency Medicine Clerkship. Western Journal of Emergency Medicine: Integrating Emergency Care with Population Health, Orange, v. 16, n. 4, p. 1, 2015.

MONTIEL, I. D. et al. Evaluación de competencias en ciencias de la salud. México: UNAM: Editorial Médica Panamericana, 2012.

NEUMANN, C. R. et al. Avaliação de competências no internato: atividades profissionais confiáveis essenciais para a prática médica. Porto Alegre: Universidade Federal de Ciências da Saúde de Porto Alegre e Universidade Federal do Rio Grande do Sul, 2019.

PAGE, C. et al. Piloting the mobile medical milestones application (M3App): A multi-institution evaluation. Family Medicine, New York, v. 49, n. 1, p. 35-41, 2017.

PECK, T. C. et al. Practicing emergency physicians report performing well on most emergency medicine milestones. The Journal of Emergency Medicine, New York, v. 47, n. 4, p. 432-440, 2014.

PEREIRA, G. A. et al. O Ensino de Urgência e Emergência de acordo com as novas Diretrizes Curriculares Nacionais e a Lei do Mais Médicos. In: ASSOCIAÇÃO BRASILEIRA DE EDUCAÇÃO MÉDICA. Cadernos da ABEM: Novas Diretrizes Curriculares Nacionais para a Medicina: Avanços e Desafios. Rio de Janeiro: ABEM, 2015. v. 11, p. 20-47.

PEREIRA, I. D. F.; LAGES, I. Diretrizes curriculares para a formação de profissionais de saúde: competências ou 
práxis? Revista Trabalho Educação e Saúde, Rio de Janeiro, v. 11, n. 2, p. 319-338, 2013.

PEREZ, C. F. A.; TOURINHO, F. S. V.; CARVALHO JÚNIOR, P. M. Competências no processo de formação do enfermeiro para o cuidado ao envelhecimento: revisão integrativa. Texto \& Contexto Enfermagem, Florianópolis, v. 25, n. $4,2016$.

PINILLA, S. et al. Working with entrustable professional activities in clinical education in undergraduate medical education: a scoping review. BMC Medical Education, London, v. 21, p. 172, 2021.

PINILLA-ROA, A. E. Evaluacion de competências professionales en salud. Revista de la Facultad de Medicina, Caracas, v. 61, n. 1, p. 53-70, 2013.

PÜSCHEL, V. A. A. et al. Nurses in the labor market: professional insertion, competencies and skills. Revista Brasileira de Enfermagem, Brasilia, v. 70, n. 6, p. 1220-1226, 2017.

RUTHES, R. M.; CUNHA, I. C. K. O. Entendendo as competências para aplicação de enfermagem. Revista Brasileira de Enfermagem, Brasilia, v. 61, n. 1, p. 109-112, 2016.

SANTEN, S. A. et al. Medical student milestones in emergency medicine. Academic Emergency Medicine, Philadelphia, v. 21, p. 905-911, 2014.

SANTOS, W. S. Organização curricular baseada em competência na educação médica. Revista Brasileira de Educação Médica, Rio de Janeiro, v. 35, n. 1, p. 86-92, 2011.

SAVOLDELLI, G. L.; VAN GESSEL, E. F. "Entrustable professional activities": the away to go for competency-based curriculum? European Journal of Anaesthesiology, Oxford, v. 33, n. 8, p. 557-558, 2016.

SCHUWIRTH, L. W.; VAN DER VLEUTEN, C. P. Programmatic assessment: From assessment of learning to assessment for learning. Medical Teacher, London, v. 33, n. 6, p. 478-485, 2011.

SMITH, P. H. et al. Milestone assessment of minimally invasive surgery in pediatric urology fellowship programs. Journal of Pediatric Urology, Kidlington, v. 13, n. 1, p. 110.e1-110.e6, 2017.

SOUZA, E. F. D.; SILVA, A. G.; SILVA, A. I. L. F. Metodologias ativas na graduação em enfermagem: um enfoque na atenção ao idoso. Revista Brasileira de Enfermagem, Presidente Prudente, v. 2, n. 71, p. 80-976, 2018.

SOUZA, R. G. S. Atributos fundamentais dos procedimentos de avaliação. In: TIBERIO, I. F. L. C. et al. Avaliação prática de habilidade clínicas em medicina. São Paulo: Editora Atheneu, 2012.

SPORTSMAN, S. Competency education and validation in the United States: what should nurses know? Nursing Forum, Hillsdale, v. 45, n. 3, p. 140-149, 2010.

SWING, S. R. et al. Educational milestone development in the first 7 specialties to enter the next accreditation system journal of graduate medical education. Journal of Graduate Medical Education, Chicago, v. 5, n. 1, p. 98-106, 2013.

TEHERANI, A.; CHEN, H. C. The next steps in competency-based medical education: milestones, entrustable professional activities and observable practice activities. Journal of General Internal Medicine, Philadelphia, v. 29, n. 8, p. 1090-1092, 2014.

TEN CATE, O. et al. Curriculum development for the workplace using Entrustable Professional Activities (EPAs): AMEE Guide N ${ }^{\circ}$. 99. Medical Teacher, London, v. 37, n. 11, p. 1-20, 2015.

TEN CATE, O. Guia Atualizado sobre Atividades Profissionais Confiáveis (APCs). Revista Brasileira de Educação Médica, Rio de Janeiro, v. 43, n. 1, p. 712-720, 2019.

TEN CATE, O. Nuts and bolts of entrustable professional activities. Journal of Graduate Medical Education, Chicago, v. 5, p. 157-158, 2013.

VAN DER LEE, N. et al. The CanMeds framework: relevant but not quite the whole story. Medical Teacher, London, v. 35, n. 11, p. 949-955, 2013.

VAN LOON, K. A. et al. Experiences with EPAs, potential benefits and pitfalls. Medical Teacher, London, v. 36, n. 8, p. 698-702, 2014.

WANCATA, L. M. et al. Using the ACMGE milestones as a handover tool from medical school to surgery residency. Journal of Surgical Education, New York, v. 74, n. 3, p. 519-529, 2016. 
CAPÍTULO 2

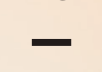

\section{A simulação como enfoque para a segurança do paciente}




\section{Rosana Alves}

Docente de Pediatra

Graduação e Mestrado - FPP

Faculdades Pequeno Príncipe

Pós-doutora em Ensino na Saúde

\section{Gustavo Alves Saldanha}

Estudante Medicina da Escola

Superior de Ciências da Santa Casa de

Misericórdia de Vitória (EMESCAM)

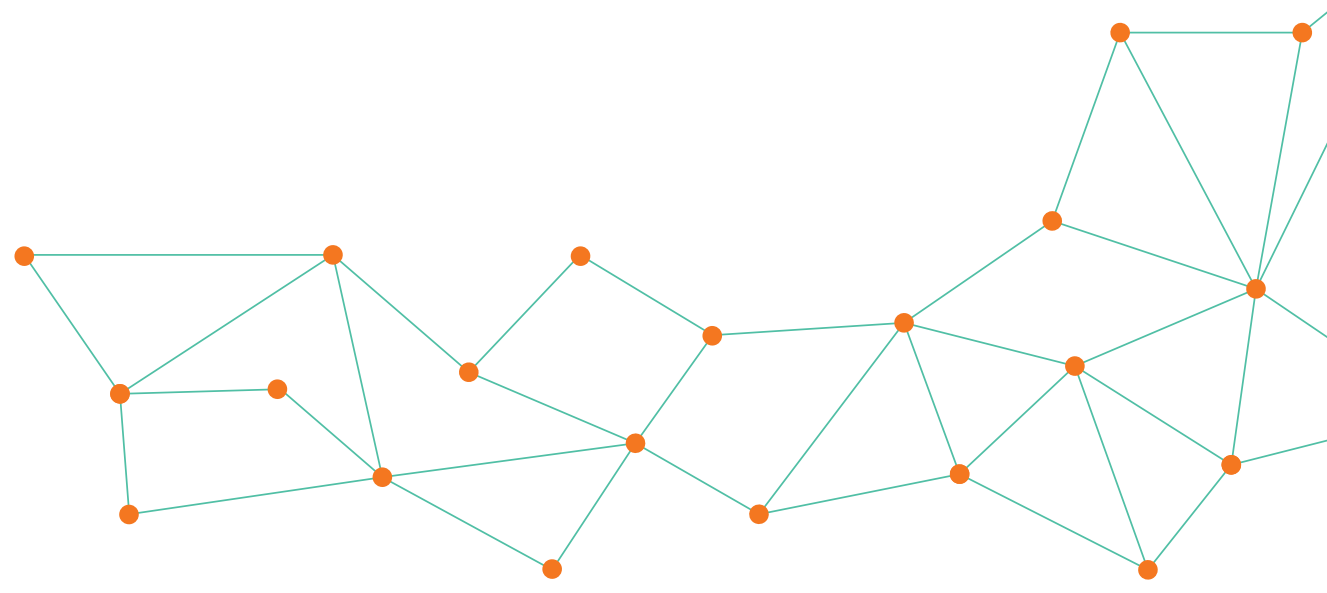

O processo de formação do médico tem passado por mudanças, com a inserção de cenários de prática diversificados desde o início do curso até o internato, sendo um deles a simulação clínica realizada em laboratórios de habilidades institucionais, a qual propõe diminuir os riscos na interação graduando-paciente por meio do treinamento sistematizado em ambiente simulado e, assim, da melhoria da qualidade assistencial nos serviços de saúde.

Dessa forma, a simulação clínica oportuniza aos estudantes de Medicina vivenciar situações de erros e acertos, relatar e discutir sistematicamente esses erros e os quase acidentes, reconhecer condições inseguras, investigar, repetir procedimentos até o acerto, melhorar esses sistemas com uma compreensão completa da falibilidade humana e treinar a comunicação dos erros aos pacientes e familiares.
A partir do relatório To err is human: building a Safer Health system (Errar é humano: construindo um sistema de saúde mais seguro), muitos países se voltaram para os problemas que o cuidado em saúde pode acarretar, ou seja, qualquer atendimento clínico, em qualquer nível de atenção, primária, secundária ou terciária, possui o risco de proporcionar mais mal do que bem. De acordo com o relatório, nos Estados Unidos ocorrem em torno de $48 \mathrm{mil}$ mortes por ano em razão de erros na área da saúde. Atualmente, estima-se no mundo que esse número seja de cerca de 400 mil mortes por ano, a despeito das medidas e políticas instituídas mundialmente (KOHN; CORRIGAN; DONALDSON, 2000).

A segurança do paciente é um desafio da saúde pública mundial, pois busca-se reduzir os danos causados pelos cuidados de saúde. Na Alemanha, existem estratégias claramente definidas para a integra- 
ção do tema segurança do paciente nos currículos dos profissionais de saúde. Assim, para uma reestruturação bem-sucedida dos currículos, incluindo as competências necessárias e as mudanças comportamentais dos alunos, é essencial o apoio da administração das faculdades e dos hospitais de ensino (OPITZ et al., 2020; NIE et al., 2011).

No entanto, a formação para a segurança do paciente não tem acompanhado as exigências do mercado de trabalho. Por isso, as unidades de saúde atualizam suas equipes em relação às boas práticas por meio de treinamentos simulados, que permitem facilitar o entendimento da cultura da segurança do paciente e, ao mesmo tempo, desenvolver competências específicas, tais como habilidades para procedimentos e comunicação.

\section{SEGURANÇA DO PACIENTE}

Segurança do paciente, por definição da Organização Mundial da Saúde (OMS), é reduzir a um mínimo aceitável o risco de dano desnecessário associado ao cuidado da saúde. Trata-se de uma dimensão de qualidade em cuidados de saúde. A cultura de segurança do paciente é considerada um importante componente estrutural dos serviços, visto que favorece a implantação de práticas seguras e a diminuição de incidentes de segurança (ANDRADE et al., 2018).

A cultura de segurança é o produto de valores, atitudes, competências e padrões de comportamentos individuais e coletivos que determinam o compromisso, o estilo e a proficiência da administração de uma organização segura. $\mathrm{O}$ incentivo ao relato de eventos adversos e a mudança da cultura punitiva podem facilitar a detecção de falhas no sistema e a criação de mecanismos de prevenção (WORLD HEALTH ORGANIZATION, 2009; FERMO et al., 2016).

Em 2004, a OMS desenvolveu a Classificação Internacional da Segurança do Paciente (CISP) em inglês, International Classification for Patient Safety (ICPS) -, para que os pesquisadores entendessem o trabalho uns dos outros, o que permitiria análise, comparações e interpretação correta das informações. Em 2009, um total de 48 conceitos-chave foram unificados pela OMS, e, em 2010, o Centro Colaborador para a Qualidade do Cuidado e Segurança do Paciente (Proqualis) os traduziu para o português. Aqui estão listadas as definições dos principais conceitos-chave (WORLD HEALTH ORGANIZATION, 2009; RUNCIMAN et al., 2009; FUNDAÇÃO OSWALDO CRUZ, 2010, 2016):
1. Reação adversa: complicação inesperada decorrente de uma ação justificada que seguiu o procedimento correto para o contexto em que ocorreu o evento.

2. Agente: objeto, substância ou sistema que age para produzir mudança.

3. Atributos: qualidades, propriedades ou características de alguém ou de algo.

4. Características do incidente: determinados atributos de um incidente.

5. Circunstância: situação ou fator que pode influenciar um evento, um agente, uma ou mais pessoas.

6. Circunstância notificável: situação em que houve potencial significativo para dano, mas nenhum incidente ocorreu (incidente com potencial dano ou lesão).

7. Cuidados em saúde: serviços recebidos por indivíduos ou comunidades para promover, manter, monitorar ou restabelecer a saúde.

8. Dano: comprometimento da estrutura ou função do corpo e/ou qualquer efeito dele oriundo, incluindo-se doenças, lesão, sofrimento, morte, incapacidade ou disfunção, podendo, assim, ser físico, social ou psicológico.

9. Dano associado aos cuidados em saúde: dano decorrente ou associado a planos ou ações tomadas durante a prestação de cuidados em saúde, mas não associado a uma doença ou lesão subjacente.

10. Debriefing: compreende o ensino e a reflexão com esclarecimentos relacionados às atividades realizadas nas simulações.

11. Deficiência: qualquer tipo de comprometimento de estrutura ou função orgânica, limitação da atividade e/ou restrição de participação na sociedade, relacionado a um dano passado ou presente.

12. Detecção: ação ou circunstância que resulta na descoberta de um incidente.

13. Disclosure: "revelação" ou "divulgação", como um protocolo adotado para reconhecer e informar pacientes e familiares sobre a ocorrência de um evento adverso na assistência à saúde.

14. Doença: toda disfunção fisiológica ou psicológica.

15. Efeito colateral: efeito conhecido, para além do que era inicialmente pretendido, relacionado às propriedades farmacológicas de uma medicação.

16. Erro: falha na execução de uma ação corretamente planejada ou aplicação de um plano de maneira incorreta. 
17. Evento: algo que acontece a um paciente ou o envolve diretamente.

18. Evento adverso: incidente que resulta em dano ao paciente.

19. Evento sentinela: ocorrência inesperada envolvendo morte, lesão ou risco físico ou psicológico. $\mathrm{O}$ evento é chamado sentinela porque envia um sinal que requer atenção imediata.

20. Evitável: aceito pela comunidade como possível de se evitar em determinado conjunto de circunstâncias.

21. Extensão do dano: severidade e duração do dano, bem como quaisquer implicações terapêuticas, resultantes de um incidente.

22. Fator atenuante: ação ou circunstância que previne ou modera o risco de um incidente causar lesão a um paciente.

23. Fator contribuinte: circunstância, ação ou influência que se acredita ter contribuído para a origem ou o desenvolvimento de um incidente, ou para aumentar o risco dele.

24. Feedback: o docente fornece informações para os estudantes, conduzindo-os nas atividades e, assim, reforçando informações para melhorar a aprendizagem das habilidades.

25. Handover: transferência de cuidado, representada pela passagem de plantão.

26. Handoff: transferência de cuidado, representada pela passagem de caso quando o paciente é transferido de lugar dentro do mesmo estabelecimento e quando a transferência é para outra instituição.

27. Incidente de segurança do paciente: evento ou circunstância que poderia ter resultado, ou de fato resultou, em dano desnecessário a um paciente.

28. Incidente sem dano ou lesão: incidente que atingiu o paciente, mas não resultou em dano perceptível.

29. Incidente com dano (evento adverso): incidente que resultou em dano a um paciente.

30. Infecção associada aos cuidados em saúde: infecção que não existia nem estava incubada na hora da admissão do paciente e que normalmente se manifesta três noites após sua admissão no hospital.

31. Lesão: dano a tecidos causado por um agente ou evento.

32. Near miss (quase erro): incidente que não atingiu o paciente.

33. Perigo: circunstância, agente ou ação com potencial de causar dano.

34. Risco: probabilidade de um incidente ocorrer.
35. Saúde: estado de bem-estar físico, mental e social, e não apenas a ausência de doença ou enfermidade.

36. Segurança: redução, a um mínimo aceitável, do risco de dano desnecessário associado ao cuidado de saúde.

37. Segurança do paciente: redução, a um mínimo aceitável, do risco de dano desnecessário ligado aos cuidados em saúde.

38. Tipo de incidente: termo descritivo de uma categoria formada por incidentes de natureza comum, agrupados por determinadas características compartilhadas.

39. Violação: desvio deliberado de um procedimento, um padrão ou uma regra vigente.

A segurança é um dos seis atributos da qualidade, ao lado da efetividade, do cuidado centrado no paciente, da oportunidade, da eficiência e da equidade. Em 2006, a "Joint Commission International" (JCI), em parceria com a OMS, desenvolveu as seis metas internacionais para a segurança do paciente (CATALANO, 2006):

1. Identificar o paciente corretamente: usar pelo menos duas identificações de três (número do prontuário, nome completo e data de nascimento), antes de qualquer ação assistencial, para qualquer tratamento ou procedimento; não utilizar o número do leito do paciente como identificação; considerar que fatores como queda do nível de consciência do paciente e trocas de setores podem aumentar a incidência de erro de identificação.

2. Melhorar a comunicação entre os profissionais de saúde: implementar um processo para ordens verbais ou por telefone, ou relato verbal de resultados de exames; padronizar 'como', 'por quem' e 'para quem' são transmitidas as informações sobre o paciente (prescrições verbais, resultados de exames críticos e transição de cuidados), bem como a forma de registro dessas informações.

3. Melhorar a segurança de medicamentos de alta vigilância: organizar protocolo de segurança na prescrição, uso e administração de medicamentos; verificar aqueles potencialmente perigosos ou de alta vigilância (com maior risco de dados) e itens como denominação do medicamento, dosagem e via de administração.

4. Garantir o local correto, o procedimento correto e a cirurgia no paciente correto: garantir que o procedimento seja realizado conforme o planejado, atendendo aos cinco certos, que são paciente, procedimento, lateralidade (lado a ser 
operado, quando aplicável), posicionamento e equipamentos; usar um checklist antes de começar o procedimento cirúrgico para assegurar o paciente, o procedimento e o local do corpo correto; usar um checklist para verificar se todos os documentos e equipamentos necessários para cirurgia estão corretos e/ou funcionando bem antes de seu início; marcar o local preciso onde será a cirurgia; usar uma marcação clara e precisa envolvendo o paciente nisso.

5. Reduzir o risco de infecções hospitalares/reduzir o risco de infecção associada ao cuidado: ter protocolos de higiene das mãos.

6. Reduzir o risco de dano ao paciente decorrente de quedas: avaliar e reavaliar periodicamente o risco de queda de cada paciente, incluindo o risco potencial associado com medicação usada ou eliminar os riscos identificados.

O Brasil é um dos países que compõem a Aliança Mundial para a Segurança do Paciente, fundada pela OMS em 2004, com o objetivo de instituir medidas que aumentem a qualidade dos serviços e, por conseguinte, a segurança do paciente. A Agência Nacional de Vigilância Sanitária (ANVISA), a Organização Pan-Americana da Saúde (OPAS) e a Secretaria de Assistência à Saúde (SAS), do Ministério da Saúde (MS), trabalham em conjunto desde então para que esse propósito seja cumprido, contando ainda com a participação de órgãos e entidades da área de saúde, além de instituições de ensino superior (IES) e de pesquisa na área de segurança do paciente.

Em 2009, foi criado o Proqualis, vinculado à Fundação Oswaldo Cruz (Fiocruz)/MS, com a finalidade de organizar e divulgar informações e tecnologias em qualidade e segurança do paciente (FUNDAÇÃO OSWALDO CRUZ, 2016).

E, em 2013, foi criado o Programa Nacional de Segurança do Paciente (PNSP) para contribuir para a qualificação do cuidado em saúde em todos os estabelecimentos de saúde do território brasileiro. A portaria MS/GM n ${ }^{\circ} 529 / 2013$, em seu Art.5 ${ }^{\circ}$, apresenta o objetivo de fomentar a inclusão do tema Segurança do Paciente no ensino da graduação na área da saúde. (BRASIL, 2013a; BRASIL, 2013b).

Em vários países desenvolvidos, existem estratégias claramente definidas para a integração do tema segurança do paciente nos currículos dos profissionais de saúde, incluindo as competências necessárias e as mudanças comportamentais dos alunos. No entanto, é essencial o apoio da administração das faculdades e dos hospitais de ensino para que isso acontece, já que há um consenso entre a comunidade profissional de que os profissionais de saúde em todo o mundo devem estar preparados para um atendimento mais seguro ao paciente desde o início de seu treinamento (BOHOMOL; CUNHA, 2015).

Portanto, toda proposta pedagógica acerca da segurança do paciente deverá ter apoio institucional, pois envolve corpo docente e infraestrutura tanto da IES como da unidade de saúde. Assim, a coordenação pela integração ensino-serviço institucional poderá realizar parceria com o núcleo de segurança do paciente nos estabelecimentos de saúde.

\section{A SIMULAÇÃO PARA A SEGURANÇA DO PACIENTE}

Tradicionalmente, a educação médica baseava-se em conhecimentos individuais, ensinamentos de professores, leituras de evidências científicas e práticas de procedimentos em pacientes reais.

Já o uso da simulação é recente em universidades, escolas médicas e outras áreas da saúde no Brasil. As Diretrizes Curriculares Nacionais para os Cursos de Medicina mudaram esse cenário, promovendo maior integração entre ensino-serviço-comunidade e proporcionando treinamento prévio de habilidades, por meio da simulação, antes do contato real com pacientes (BRASIL, 2001, 2014; KHAN; PATTISON; SHERWOOD, 2011).

A segurança do paciente, por meio de todos os programas, envolve a lista de verificação (checklist), a qual, apesar de simples, tem desempenhado importante papel em prevenir eventos adversos, ou seja, ela é definida como uma série de ações com objetivo principal de garantir que nenhum passo seja esquecido.

A realização de uma lista de verificação de cirurgia segura é uma das ferramentas mais poderosas para evitar eventos adversos, visto que, por ano, são realizadas cerca de 200 milhões de cirurgias no mundo.

O Segundo desafio global para a segurança do paciente: cirurgias seguras salvam vidas, publicado em 2009 pela OMS, mostrou que a taxa de mortes e complicações cirúrgicas caiu mais de $30 \%$ com o uso da lista de verificação (Figura 1) (ORGANIZAÇÃO MUNDIAL DA SAÚDE, 2009; HAYNES et al., 2009; MAIA et al., 2018).

A OMS também publicou uma lista de verificação para partos seguros, a qual é dividida em quatro partes, cada uma aplicada a um momento da assistência ao parto: 1 . na admissão; 2 . antes da expulsão (ou antes da cesariana); 3. logo após o parto (no espaço de 1 hora); e 4 . antes da alta. Publicado em 2016, o Guia de implementação da lista de verifi- 


\begin{tabular}{|c|c|c|}
\hline \multicolumn{2}{|l|}{ Antes da indução anestésica $\longrightarrow$} & $\begin{array}{l}\text { Antes do paciente sair da sala de } \\
\text { operações }\end{array}$ \\
\hline Identificação & Confirmação & Registro \\
\hline \multirow{2}{*}{$\begin{array}{l}\square \text { Paciente confirmou } \\
\text { - Identidade } \\
\text { - Sítio cirúrgico } \\
\text { - Procedimento } \\
\text { - Consentimento }\end{array}$} & $\begin{array}{l}\square \text { Confirmar que todos os membros } \\
\text { da equipe se apresentaram pelo } \\
\text { nome e função }\end{array}$ & \multirow{9}{*}{$\begin{array}{l}\text { O profissional da equipe de } \\
\text { enfermagem ou da equipe } \\
\text { médica confirma verbalmente } \\
\text { com a equipe } \\
\square \text { Registro completo do } \\
\text { procedimento intra-operatório, } \\
\text { incluindo procedimento } \\
\text { executado } \\
\square \text { Se as contagens de instrumentais } \\
\text { cirúrgicos, compressas e agulhas } \\
\text { estão corretas (ou não se } \\
\text { aplicam) } \\
\square \text { Como a amostra para anatomia } \\
\text { patológica está identificada } \\
\text { (incluindo nome do paciente) } \\
\square \text { Se há algum problema com } \\
\text { equipamento para ser resolvido }\end{array}$} \\
\hline & \multirow{4}{*}{$\begin{array}{l}\square \text { Cirurgião, anestesiologista e } \\
\text { a equipe de enfermagem } \\
\text { confirmaram verbalmente: } \\
\text { - Identicação do paciente } \\
\text { - Sítio cirúrgico } \\
\text { - Procedimento }\end{array}$} & \\
\hline$\square$ Sítio demarcado/não se aplica & & \\
\hline $\begin{array}{l}\square \text { Verificação de segurança } \\
\text { anestésica concluída }\end{array}$ & & \\
\hline \multirow{2}{*}{$\begin{array}{l}\text { Oxímetro de pulso no paciente } \\
\text { e em funcionamento }\end{array}$} & & \\
\hline & \multirow{6}{*}{$\begin{array}{l}\text { Eventos críticos previstos } \\
\square \text { Revisão do cirurgião: } \\
\text { Quais são as etapas críticas ou } \\
\text { inesperadas, duração da } \\
\text { operação, perda sanguínea } \\
\text { prevista? } \\
\square \text { Revisão da equipe de } \\
\text { anestesiologia: } \\
\text { Há alguma preocupação } \\
\text { específica em relação ao } \\
\text { paciente? } \\
\square \text { Revisão da equipe de } \\
\text { enfermagem: } \\
\text { Materiais necessários (ex. } \\
\text { instrumentais, próteses) estão } \\
\text { presentes e dentro do prazo de } \\
\text { esterilização? (Incluido resultados } \\
\text { do indicador)? Há questões } \\
\text { relacionadas a equipamentos ou } \\
\text { quaisquer preocupações? }\end{array}$} & \\
\hline O paciente possui & & \\
\hline $\begin{array}{l}\text { Alergia conhecida } \\
\square \text { Não } \\
\square \text { Sim }\end{array}$ & & \\
\hline $\begin{array}{l}\text { Via aérea difícil/risco de aspiração } \\
\square \text { Não }\end{array}$ & & \\
\hline assistência disponíveis & & \multirow{3}{*}{$\begin{array}{l}\text { O cirurgião, o anestesiologista e } \\
\text { a equipe de enfermagem } \\
\text { revisam preocupações essenciais } \\
\text { para a recuperação e o manejo } \\
\text { do paciente (especificar critérios } \\
\text { mínimos a serem observados. Ex: } \\
\text { dor) }\end{array}$} \\
\hline \multirow[t]{2}{*}{$\begin{array}{l}\text { Risco de perda sanguínea } \\
>500 \mathrm{ml} \text { (7 ml/kg em crianças)? } \\
\square \text { Não } \\
\square \text { Sim, e acesso endovenoso } \\
\text { adequado e planejamento } \\
\text { para fluidos }\end{array}$} & & \\
\hline & $\begin{array}{l}\text { A profilaxia antimicrobiana foi } \\
\text { realizada nos últimos } \\
60 \text { minutos? } \\
\square \text { Sim } \\
\square \text { Não se aplica } \\
\text { As imagens essenciais estão } \\
\text { disponíveis? } \\
\square \text { Sim } \\
\square \text { Não se aplica }\end{array}$ & \\
\hline
\end{tabular}

Figura 1 - Lista de verificação de segurança cirúrgica.

Fonte: Organização Mundial da Saúde (2009).

Esta lista de verificação não tem a intenção de ser abrangente. Acréscimos e modificações para adaptação à prática local são recomendados.

cação da OMS para partos seguros: melhorar a qualidade dos partos realizados em unidades de saúde para as mães e os recém-nascidos tem o objetivo de apoiar o uso de práticas essenciais de cuidados maternos e perinatais, com abordagem das principais causas dos óbitos maternos, dos nascimentos mortos relacionados com complicações perinatais e mortes neonatais (ORGANIZAÇÃ̃O MUNDIAL DA SAÚDE, 2016).
A lista de verificação, já aceita para organizar etapas importantes e complexas da assistência à saúde, tem sido utilizada há muito tempo para que pontos essenciais não sejam esquecidos e deve fazer parte de todo programa de treinamento de habilidades na graduação e residência de Medicina e Enfermagem.

Da mesma forma, o desenvolvimento da comunicação eficaz é uma habilidade que deverá ser trei- 
nada durante todo o curso de graduação, por muito mais do que uma transmissão unilateral. Essa preocupação com as transferências de informações tem estimulado pesquisas e recomendações da JCI para que os hospitais americanos padronizem a forma como os handoffs (passagens de plantão) são realizados. Nos Estados Unidos, as falhas de comunicação nas passagens de plantão são a causa primária em $30 \%$ das acusações de erros e más práticas. Geralmente, o profissional aprende a realizar a passagem de plantão só após a formatura, quando passa a ser responsável pelo plantão (COHEN et al., 2012; CRICO STRATEGIES, 2016).

Por isso, é necessário que o processo de ensino e aprendizagem em segurança do paciente seja significativo e que haja apreensão diária de conteúdos por meio de práticas supervisionadas por docentes/preceptores que conheçam a cultura de segurança do paciente.

Desse modo, os profissionais devem saber os princípios de segurança do paciente e contextualizá-los. Para auxiliar nesse processo, o Guia curricular para segurança do paciente, organizado pela OMS em 2011, apresenta estratégias com diversas situações clínicas que podem ser aplicadas em estudos de caso ou em casos simulados (ORGANIZAÇÃO MUNDIAL DA SAÚDE, 2011).

O melhor momento do currículo para aprender sobre a segurança do paciente é quando o estudante inicia a realização de procedimentos e, que idealmente ocorrerá com treinamento de habilidades em laboratórios de simulação, neste período as etapas de cada procedimento podem ser simuladas, avaliadas e discutidas (FLATO, GUIMARÃES, 2011). Além disso, o relato ético e a discussão de situações reais de erros que ocorreram, contextualizam e justificam as etapas do procedimento.

Os tutoriais de estudos de caso podem mostrar o que não deve ser feito (aprender com a experiência negativa) e também o que deve ser feito (aprender com a experiência positiva). Para tal, pode haver um tutorial presencial ou em vídeo, à beira do leito ou em um laboratório de habilidades e simulação (demonstração), junto com um artigo sobre o procedimento ou as diretrizes. Os tutoriais podem ser referentes a pequenos procedimentos, em que apenas um estudante ou profissional de saúde é capaz de realizá-los, ou divididos em partes para grandes situações, como gerenciamento de desastres, em que uma equipe deverá participar da discussão (ORGANIZAÇÃO MUNDIAL DA SAÚDE, 2011).

Ressalta-se que todos os docentes e preceptores que realizam a prática assistencial em ambiente real ou simulado tenham familiaridade com o tema, e isso envolve mudança de postura, e não apenas o acréscimo de um conteúdo.

Em um ambiente de prática assistencial, os estudantes podem observar o modo como docentes e preceptores realizam diversos "procedimentos", desde um cumprimento até uma cirurgia, o que é o chamado de currículo oculto, que pode ser tanto para o bem quanto para o mal. Infelizmente, para o mal, docentes e preceptores "culpam e humilham" quando estudantes, internos ou profissionais de saúde cometem algum erro e, muitas vezes, assumem uma atitude desrespeitosa com membros da equipe, pacientes e familiares. Para o bem, os estudantes visualizam os docentes como um exemplo a seguir, um "espelho". Desta forma, é importante que, no ambiente simulado, sejam destacados somente os aspectos positivos (ORGANIZAÇÃO MUNDIAL DA SAÚDE, 2011), tais como:

- interagir com os pacientes e seus familiares;

- respeitar as vontades dos pacientes e de suas famílias;

- informar aos pacientes e às famílias os riscos;

- levar em conta a relação risco-benefício ao determinar planos de gerenciamento e tratamento;

- responder às perguntas dos pacientes e familiares e os incentivar a perguntar;

- higienizar as mãos entre uma consulta e outra;

- adotar uma abordagem de equipe;

- aceitar conselhos de colegas;

- seguir os protocolos do local de trabalho;

- admitir suas dúvidas;

- reconhecer que a aprendizagem acontece com seus próprios erros e os dos outros;

- resolver problemas de caráter sistêmico;

- cuidar de si mesmo e de seus colegas.

No Quadro 1 a seguir, destacam-se as competências relacionadas à segurança do paciente e as estratégias de avaliação em ambiente simulado. 
Exame clínico objetivo estruturado (OSCE); miniexercício clínico avaliativo (mini-CEX); feedback de fontes múltiplas (MSF).

\begin{tabular}{|c|c|}
\hline Competências & Formatos de avaliação \\
\hline \multicolumn{2}{|l|}{ Cuidados seguros para o paciente: sistemas } \\
\hline $\begin{array}{l}\text { Entender a complexa interação entre ambiente, profissional da } \\
\text { saúde e paciente. }\end{array}$ & $\begin{array}{l}\text { Ensaio; avaliação formativa atesta que o } \\
\text { aluno de cuidados em saúde acompanhou } \\
\text { um paciente durante sua jornada clínica } \\
\text { e que depois participou de uma pequena } \\
\text { discussão de grupo. }\end{array}$ \\
\hline $\begin{array}{l}\text { Tomar ciência quanto aos mecanismos que minimizam erros, } \\
\text { por exemplo, listas de verificação, protocolos clínicos. }\end{array}$ & $\begin{array}{l}\text { Avaliação formativa assinada por } \\
\text { instrutor ou supervisor atesta que o } \\
\text { aluno participou de atividade extra ou } \\
\text { fora de seu expediente. }\end{array}$ \\
\hline Competências & Formatos de avaliação \\
\hline \multicolumn{2}{|l|}{ Cuidados seguros ao paciente: controle de infecções } \\
\hline $\begin{array}{l}\text { Praticar as técnicas antissépticas e corretas de higiene das } \\
\text { mãos. }\end{array}$ & OSCE \\
\hline $\begin{array}{l}\text { Usar sempre métodos para minimizar a transmissão entre } \\
\text { pacientes. }\end{array}$ & OSCE \\
\hline \multicolumn{2}{|l|}{ Cuidados seguros ao paciente: segurança da medicação } \\
\hline $\begin{array}{l}\text { Saber como prescrever e administrar medicações de forma } \\
\text { segura. }\end{array}$ & OSCE \\
\hline \multicolumn{2}{|l|}{ Comunicação } \\
\hline \multicolumn{2}{|l|}{ Interação com o paciente: contexto } \\
\hline $\begin{array}{l}\text { Usar boa comunicação e conhecer seu papel nas relações } \\
\text { eficazes dos cuidados em saúde. }\end{array}$ & OSCE \\
\hline $\begin{array}{l}\text { Desenvolver estratégias para lidar com pacientes difíceis e } \\
\text { vulneráveis. }\end{array}$ & OSCE \\
\hline \multicolumn{2}{|l|}{ Interação com o paciente: respeito } \\
\hline $\begin{array}{l}\text { Tratar os pacientes com cortesia e respeito, demonstrando } \\
\text { consciência e sensibilidade a culturas e históricos diferentes. }\end{array}$ & OSCE/mini-CEX \\
\hline \multicolumn{2}{|l|}{ Manter privacidade e confidencialidade } \\
\hline $\begin{array}{l}\text { Fornecer informações claras e honestas aos pacientes e } \\
\text { respeitar suas escolhas de tratamento. }\end{array}$ & OSCE/mini-CEX \\
\hline \multicolumn{2}{|l|}{ Interação com o paciente: fornecer informações } \\
\hline Compreender os princípios da boa comunicação. & OSCE/mini-CEX /MSF \\
\hline $\begin{array}{l}\text { Comunicar-se com pacientes e cuidadores de forma que eles } \\
\text { entendam. }\end{array}$ & OSCE \\
\hline \multicolumn{2}{|l|}{ Interação com o paciente: como dar más notícias } \\
\hline $\begin{array}{l}\text { Participar das comunicações de más notícias aos pacientes e } \\
\text { cuidadores. }\end{array}$ & OSCE \\
\hline Mostrar solidariedade e compaixão. & OSCE \\
\hline
\end{tabular}

Fonte: adaptado de Organização Mundial da Saúde (2011). 
Continuação...

\begin{tabular}{|l|l|}
\hline Interação com o paciente: a revelação do erro (disclosure) & OSCE \\
\hline $\begin{array}{l}\text { Assegurar que os pacientes sejam apoiados e cuidados após um } \\
\text { evento adverso. }\end{array}$ & OSCE \\
\hline $\begin{array}{l}\text { Demonstrar compreensão com os pacientes que passaram por } \\
\text { um evento adverso. }\end{array}$ & OSCE \\
\hline Interação com o paciente: queixas & OSCE \\
\hline $\begin{array}{l}\text { Responder adequadamente às queixas usando os } \\
\text { procedimentos locais. }\end{array}$ & Adotar comportamentos que evitem queixas. \\
\hline
\end{tabular}

Fonte: adaptado de Organização Mundial da Saúde (2011).

\section{REFERÊNCIAS}

ANDRADE, L. E. L. et al. Cultura de segurança do paciente em três hospitais brasileiros com diferentes tipos de gestão. Ciência \& Saúde Coletiva, Rio de Janeiro, v. 23, n. 1, p. 161-172, 2018.

BOHOMOL, E.; CUNHA, I. C. Ensino sobre segurança do paciente no curso de medicina da Universidade Federal de São Paulo. Einstein, São Paulo, v. 13, n. 1, p. 7-13, 2015.

BRASIL. Ministério da Educação. Resolução CNE/CES n ${ }^{\circ} 4$, de 7 de novembro de 2001. Institui Diretrizes Curriculares Nacionais do Curso de Graduação em Medicina. Diário Oficial da República Federativa do Brasil, Brasília, DF, 9 nov. 2001.

BRASIL. Ministério da Saúde. Agência Nacional de Vigilância Sanitária - ANVISA. Programa Nacional de Segurança do Paciente. Brasília: ANVISA, 2013a. Disponível em: <https://www.saude.gov.br/acoes-eprogramas/programa-nacional-de-seguranca-do-pacientepnsp/sobre-o-programa>. Acesso em:01 mar. /2021.

BRASIL. Ministério da Saúde. Conselho Nacional de Saúde. Portaria $n^{\circ} 529$ de $^{\circ}{ }^{\circ}$ de abril de 2013. Institui o Programa Nacional de Segurança do Paciente (PNSP). Diário Oficial da República Federativa do Brasil, Brasília, DF, 2 abr. 2013b. Disponível em: <http://bvsms.saude.gov.br/bvs/ saudelegis/gm/2013/prt0529_01_04_2013.html>. Acesso em: 01 mar. 2021.

BRASIL. Ministério da Educação. Resolução CNE/CES 3/2014. Institui Diretrizes Curriculares Nacionais do Curso de Graduação em Medicina e dá outras providências. Diário Oficial da República Federativa do Brasil, Brasília, DF, 23 jun. 2014. Seção 1, p. 8-11.

CATALANO, K. JCAHO'S National Patient Safety Goals 2006. Journal of Perianesthesia Nursing, Philadelphia, v. 21, n. 1, p. 6-11, 2006.

COHEN, M. et al. A handoff is not a telegram: an understanding of the patient is co-constructed. Critical Care, London, v. 16, n. 1, p. 1-6, 2012.
CRICO STRATEGIES. Malpractice risks in communication failures 2015: annual benchmarking report. Boston: Crico Strategies, 2016. p. 24. Disponível em: <https://psnet.ahrq.gov/issue/malpractice-riskscommunication-failures-2015-annual-benchmarkingreport>. Acesso em: 01 mar. 2021.

FERMO, V. C. et al. Professional attitudes toward patient safety culture in a bone marrow transplant unit. Revista Gaúcha de Enfermagem, Porto Alegre, v. 37, n. 1, p. e55716, 2016.

FLATO, U. A.; GUIMARÃES, H. P. Educação baseada em simulação em medicina de urgência e emergência: a arte imita a vida. Revista da Sociedade Brasileira de Clínica Médica, São Paulo, v. 9, n. 5, p. 360-364, 2011.

FUNDAÇÃO OSWALDO CRUZ - FIOCRUZ. Centro Colaborador para a Qualidade e Segurança do Paciente - PROQUALIS. Taxonomia: Classificação Internacional para a Segurança do Paciente (CISP). Rio de Janeiro: Instituto de Comunicação e Informação Científica e Tecnológica em Saúde (ICICT), 2010. 35 slides, color. Disponível em: <https://proqualis.net/aula/taxonomiaclassifica\%C3\%A7\%C3\%A3o-internacional-paraseguran\%C3\%A7a-do-paciente-icps>. Acesso em: 01 mar. 2021.

FUNDAÇÃO OSWALDO CRUZ - FIOCRUZ. Centro Colaborador para a Qualidade e Segurança do Paciente - PROQUALIS. Rio de Janeiro, 2016. Disponível em: $<$ https://proqualis.net/sobre-o-proqualis >. Acesso em: 01 mar. 2021

HAYNES, A. B. et al. A surgical safety checklist to reduce morbidity and mortality in a global population. The New England Journal of Medicine, Boston, v. 360, n. 5, p. 491499, 2009.

KHAN, K.; PATTISON, T.; SHERWOOD, M. Simulation in medical education. Medical Teacher, London, v. 33, n. 1, p. 1-3, 2011. 
KOHN, L. T.; CORRIGAN, J. M.; DONALDSON, M. S. (Ed.). To err is human: building a safer health system. Washington (DC): National Academies Press, 2000.

MAIA, C. S. et al. Notificações de eventos adversos relacionados com a assistência à saúde que levaram a óbitos no Brasil, 2014-2016. Epidemiologia e Serviços de Saúde: Revista do Sistema Unico de Saúde do Brasil, Brasília, v. 27, n. 2, p. e2017320, 2018.

NIE, Y. et al. Patient safety education for undergraduate medical students: a systematic review. BMC Medical Education, London, v. 11, n. 33, p. 1-8, 2011. Disponível em: <http://www.biomedcentral.com/1472-6920/11/33>. Acesso em: 01 mar. 2021.

OPITZ, E. et al. Patientensicherheit schon im Studium vermitteln [Teaching patient safety during undergraduate medical studies]. Der Internist, Berlin, v. 61, n. 5, p. 444$451,2020$.

ORGANIZAÇÃO MUNDIAL DA SAÚDE - OMS. Segundo desafio global para a segurança do paciente: cirurgias seguras salvam vidas (orientações para cirurgia segura da OMS). Rio de Janeiro: OMS, 2009. Disponível em: < http:// bvsms.saude.gov.br/bvs/publicacoes/seguranca_paciente_ cirurgias_seguras_guia.pdf $>$. Acesso em: 01 mar. 2021.

ORGANIZAÇÃO MUNDIAL DA SAÚDE - OMS. Guia curricular de segurança do paciente: edição multiprofissional. Rio de Janeiro: Autografia, 2011.

ORGANIZAÇÃO MUNDIAL DA SAÚDE - OMS. Guia de implementação da lista de verificação da OMS para partos seguros: melhorar a qualidade dos partos realizados em unidades de saúde para as mães e os recémnascidos. Geneva: OMS, 2016. Disponível em: <https:// www.who.int/patientsafety/implementation/checklists/ scc_implementation-guide_portuguese/en/>. Acesso em: 01 mar. 2021.

RUNCIMAN, W. et al. Towards an International Classification for Patient Safety: key concepts and terms. International Journal for Quality in Health Care, Oxford, v. 21, n. 1, p. 18-26, 2009.

WORLD HEALTH ORGANIZATION - WHO. WHO conceptual framework for the international classification for patient safety. Geneva: WHO, 2009. Disponível em: $<$ http://www.who.int/patientsafety/en/>. Acesso em: 01 mar. 2021. 
CAPÍTULO 3

-

Conhecimentos básicos para estruturação do treinamento de habilidades e da elaboração das estações simuladas 


\section{Sara Fiterman Lima}

Enfermeira

Professora Adjunta da Universidade

Federal do Maranhão (UFMA)

\section{Aurean D'Eça Junior}

Enfermeiro

Professor Adjunto da Universidade

Federal do Maranhão (UFMA)

Richardson Augusto Rosendo da Silva

Enfermeiro

Professor Adjunto da Universidade

Federal do Rio Grande do Norte (UFRN)

\section{Gerson Alves Pereira Júnior}

Docente de Cirurgia de

Urgência e do Trauma

Universidade de São Paulo (USP)

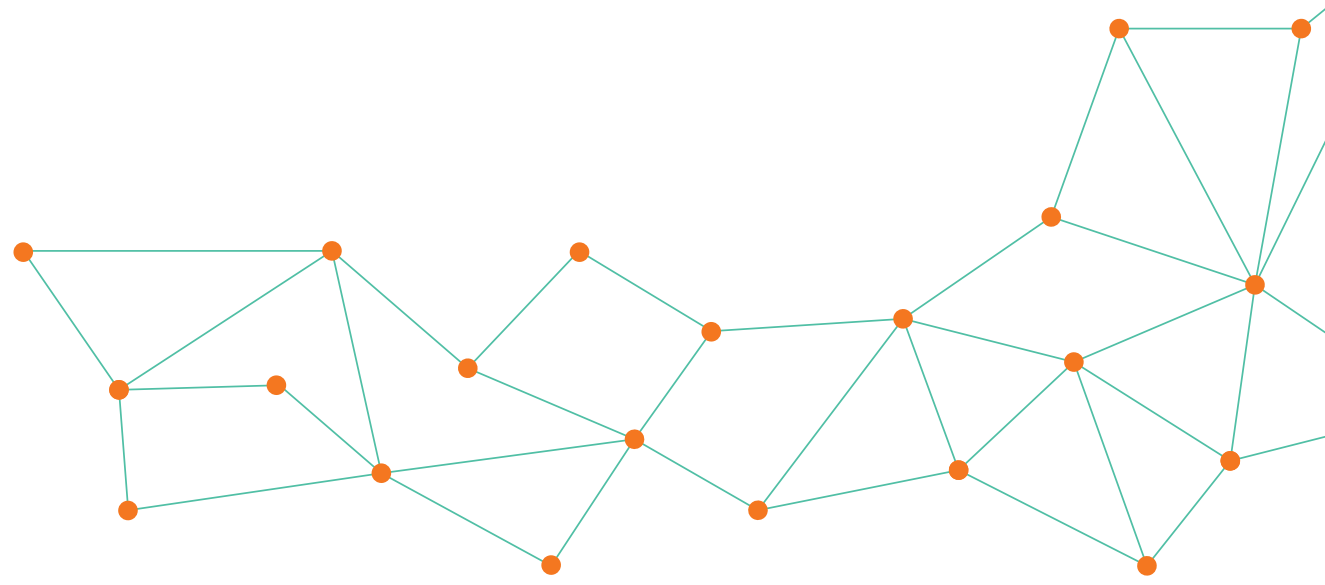

\section{INTRODUÇÃO}

O uso da simulação como ferramenta de ensino e aprendizagem teve seu início há séculos, apontado por diferentes autores em registros bíblicos, nas indústrias de aviação e aeroespacial, no exército, em companhias aéreas comerciais, em usinas nucleares, nos negócios e na Medicina. $\mathrm{Na}$ área da saúde, existem registros que datam desde o início do século XVII, com alguns modelos utilizados para ajudar estudantes de Medicina a aprender estruturas anatômicas, parto na obstetrícia, reanimação na anestesia e em estágios de neurologia com pacientes padronizados (ISSEBERG et al., 2001; AL-ELQ, 2010; BRADLEY, 2006; ORLEDGE et al., 2012; OWEN, 2016).

Todos esses grupos têm em comum o fato de que, para cada um deles, o treinamento ou teste de sistemas no mundo real seria muito caro ou perigoso de se realizar. Assim, o uso da simulação vem evoluindo progressivamente na educação e treinamento de uma variedade de profissões e disciplinas, incluindo a educação em saúde (BRADLEY, 2006; ALINIER; PLATT, 2014; KNEEBONE; AGGARWAL, 2009; ZIV et al., 2003).

A simulação consiste em uma estratégia educacional, que se utiliza de atividades estruturadas, em que são criadas ou replicadas condições para representar situações reais ou potenciais na educação e na prática. Essas atividades permitem que os aprendizes desenvolvam ou aprimorem seus conhecimentos, habilidades e atitudes em um ambiente artificial, onde possam analisar situações semelhantes às da vida real e responder a isso (PILCHER et al., 2012; MEAKIM et al., 2013; LOPREIATO et al., 2020).

Nas últimas duas décadas, o ensino com base em simulação vem gradualmente aumentando, tornando-se, hoje, um componente significativo 
da educação em saúde nos níveis de graduação, pós-graduação, educação continuada e permanente. Existem muitos motivos que podem ser elencados para esse desenvolvimento, incluindo:

- rápido crescimento das informações em saúde, levando a um conteúdo cada vez maior de conhecimentos que desafiam os currículos e demandam melhorias na formação;

- segurança do paciente, pois eticamente não é mais aceitável usar pacientes reais como modelos de aprendizado primário para estudantes e profissionais de saúde;

- aumento nas possibilidades do realismo, uma vez que a tecnologia avançou e permite o uso de simuladores com respostas mais fidedignas;

- redução da disponibilidade de determinados pacientes, haja vista que os avanços no atendimento reduziram o número de portadores de algumas afecções antes comuns, as quais hoje passaram a ser raras, diminuindo as possibilidades de acesso dos estudantes a essas condições durante o rodízio nos seus estágios de formação, principalmente do internato médico;

- crescentes demandas de aprendizagem, que, combinadas com as restrições de horários, limitaram a disponibilidade para oferta do ensino;

- padronização dos cenários, resultantes das pressões para melhores medições de resultados, levando a simulação a evoluir na capacidade de replicação consistente de casos (RODGERS, 2007; CANNON-DIEHL, 2009; TURKOT et al., 2019).

O escopo da simulação como estratégia de ensino e aprendizagem na educação em saúde é, entretanto, complexo, porque, embora existam evidências de que a simulação possa ser eficaz, isso depende da forma como é praticada, já que precisa ser formulada de maneira apropriada para que de fato aumente o conhecimento e melhore as habilidades e os comportamentos profissionais e clínicos dos participantes (TURKOT et al., 2019). Nessa perspectiva, o presente texto vai discorrer sobre conhecimentos básicos para instrumentalizar a estruturação do ensino fundamentado em habilidades e simulação.

\section{A SIMULAÇÃO COMO ESTRATÉGIA DE ENSINO E APRENDIZAGEM NA EDUCAÇÃO EM SAÚDE}

Ensinar nos dias de hoje, diante de uma sociedade do conhecimento, além de ser mais complexo, exige certa versatilidade. Em consequência das novas necessidades no âmbito da saúde, aumentam-se as exigências por profissionais mais criativos e resolutivos. Nesse contexto, o processo de ensino e aprendizagem vem, de certa forma, evoluindo em uma perspectiva de construção de saberes, em que professores e estudantes participam ativamente. A adoção de metodologias ativas para estimular a participação efetiva do estudante em todas as etapas do processo de aprendizagem vem crescendo, e entre estes métodos está a simulação (GONZÁLEZ-HERNANDO et al., 2015; COSTA et al., 2015).

Portanto, se existe uma intenção de trabalhar com a simulação na prática educacional, é indispensável a compreensão enquanto método de ensino e aprendizagem, pois a utilização dos treinamentos simulados em saúde, sem um adequado embasamento teórico, não assegura resultados eficientes para o aprendizado final (JEFFRIES, 2005; COSTA et al., 2015).

\subsection{TEORIAS QUE APOIAM A SIMULAÇÃO COMO ESTRATÉGIA DE ENSINO E APRENDIZAGEM}

A simulação, enquanto método de ensino e aprendizagem, é apoiada por várias teorias da educação. Do construtivismo, são utilizados princípios como: 1) cada pessoa traz a sua própria experiência (única) e um conjunto de conhecimentos prévios para a situação, empregando-os durante a simulação; 2) a aprendizagem ocorre por meio da exploração ativa, quando o conhecimento não se ajusta à experiência vivida, levando o participante a reconstruir esse conhecimento com base em novas informações; e 3) a aprendizagem requer interação dentro de um contexto social, sendo relevante que a simulação ocorra em equipe.

Para a teoria do aprendizado significativo, que se baseia no modelo construtivista, a nova informação precisa ser adquirida mediante um esforço deliberado do aprendiz, para ligá-la a conceitos ou proposições preexistentes ou prévias. Com essa influência, a simulação promove uma aprendizagem significativa, incentivando a disposição do estudante para aprender e buscando incentivar significados lógicos (natureza dos cenários) e psicológicos (experiência individual) no processo de ensino e aprendizagem (AUSUBEL et al., 1980; CARDOSO; DICKMAN, 2012)

Em relação à aprendizagem experiencial, a simulação aproveita os dois componentes principais: 1) experiência ativa, na qual o participante interage com o ambiente de aprendizagem; e 2) o pro- 
cesso reflexivo, que analisa as ações da experiência e identifica áreas para melhoria.

A teoria da aprendizagem de adultos (andragogia) está centrada em seis pressupostos, todos observados no ensino por simulação: 1) os adultos possuem uma necessidade intrínseca de saber; 2) os adultos possuem responsabilidade própria; 3) os adultos possuem experiências de vida inteira; 4) os adultos têm uma prontidão inata para aprender; 5) os adultos têm uma orientação para a aprendizagem centrada na vida; e 6) os adultos têm motivações internas.

$A$ aprendizagem baseada no cérebro (Brain-Based Learning) é uma teoria relativamente nova, que examina como o cérebro aprende. Trata-se de um metaconceito que mistura alguns elementos ecléticos, necessários para a aprendizagem e aplicáveis à simulação: 1) a exposição a diferentes ambientes promove a plasticidade neural e, consequentemente, o aprendizado; 2) o cérebro humano é modulado pela repetição de estímulos; 3) o estresse moderado, ao provocar desafios, estimula a aprendizagem; e 4) o cérebro é social e desenvolve-se melhor em contato com outros cérebros.

Observa-se que a simulação enquanto estratégia de ensino e aprendizagem se apoia nas teorias da educação para promover adequadamente a construção ativa do conhecimento. Nesse sentido, outra referência que tem grande influência para a simulação é a taxonomia de Bloom. Esse pesquisador, em conjunto com seus colaboradores, em 1956, estruturou as dimensões que fazem parte da construção do conhecimento do indivíduo, agrupando-as em três domínios: 1) cognitivo; 2) afetivo; e 3) psicomotor (BLOOM et al., 1956; FOREHAND, 2012; NEGRI et al., 2019). Bloom e sua equipe nunca desenvolveram uma taxonomia para a área psicomotora, mas outros especialistas o fizeram.

Em 2002, Krathwohl publicou uma revisão da taxonomia de Bloom, na qual foram combinados o tipo de conhecimento a ser adquirido (dimensão do conhecimento) e o processo utilizado para a aquisição desse conhecimento (dimensão do processo cognitivo), tornando mais fáceis tanto a tarefa de definir com clareza objetivos de aprendizagem quanto aquela de alinhar esses objetivos com as atividades de avaliação (conhecimento como conteúdo assimilado).

O domínio cognitivo, descrito em 1956, está relacionado à capacidade mental, à aquisição de conhecimentos e ao aprendizado, sendo dividido em seis categorias: 1) (re)lembrar; 2) entender; 3) aplicar; 4) analisar; 5) sintetizar; e 6) criar. Os processos são cumulativos, e uma categoria cognitiva depende da anterior e, por sua vez, dá suporte à seguinte. As referidas categorias são organizadas em um gradiente em termos de complexidade dos processos mentais. A versão revisada do domínio cognitivo, apresentada na Figura 1, dá nomes diferentes aos seis níveis da hierarquia da versão original (conhecimento, compreensão, aplicação, análise, síntese e avaliação) e inverte as posições de "síntese" (agora "criar") e "avaliação" (agora "avaliar") (NEGRI et al., 2019).

O domínio afetivo, descrito em 1964, vincula-se às emoções e sentimentos, estando relacionado a um conjunto de valores pessoais, e compreende as categorias receptividade, resposta, valorização, organização e caracterização (internalização de valores) (KRATHWOHL, 2002).

Este domínio forma uma estrutura hierárquica baseada no princípio da internalização e é organizado de sentimentos mais simples para os mais complexos. Internalização se refere ao processo pelo qual seu afeto em relação a algo vai de um nível de consciência geral a um ponto em que é internalizado e orienta ou controla seu comportamento de forma consistente. Portanto, com movimento para mais complexidade, o estudante se torna mais envolvido, comprometido e com maior motivação intrínseca (HOQUE, 2016).

Na literatura educacional, quase todos os autores afirmam que o domínio afetivo é essencial para a aprendizagem, mas é o menos estudado, o mais frequentemente esquecido, o mais nebuloso e o mais difícil de avaliar dos três domínios de Bloom. Assim, há um valor significativo em perceber o potencial de aumentar a aprendizagem dos estudantes por meio do domínio afetivo. Da mesma forma, os estudantes podem enfrentar obstáculos afetivos à aprendizagem que não podem ser reconhecidos

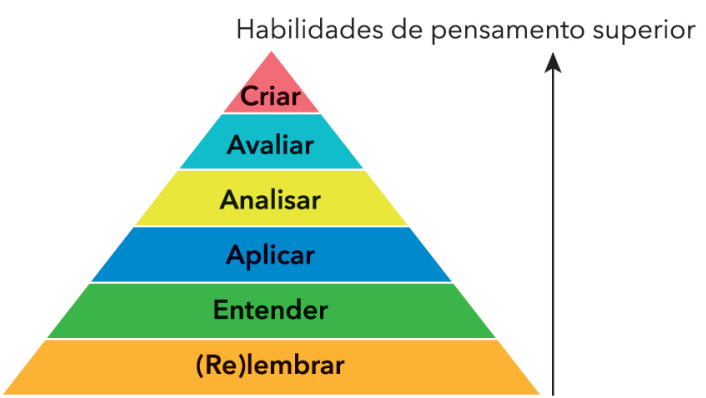

Habilidades de pensamento inferior

Figura 1 - Domínio cognitivo, segundo a taxonomia revisada de Bloom. Fonte: adaptada de Krathwohl (2002). 
nem resolvidos quando se usa uma abordagem puramente cognitiva (KOBALLA, 2007).

É claro que há muito do domínio afetivo que pode ser suscetível ao treinamento, particularmente envolvendo resultados de aprendizagem que visam aumentar a eficácia da avaliação dos mecanismos ou que promovem a interação positiva entre o processamento inteligente do pensamento e reações afetivas. Alguns exemplos óbvios incluem: a) aprender a discernir os estados emocionais de outros, conforme as palavras expressas, o tom de voz, a linguagem corporal e as ações feitas; b) aprender formas de expressar emoções que melhorem a quantidade e a qualidade do relacionamento mútuo e a compreensão entre si e os outros; e c) aprender a aplicar de forma coerente a afetividade, experiência, habilidades intelectuais e mecanismos de enfrentamento, a fim de aumentar a viabilidade, para resolver situações de conflitos, gerar comportamentos morais e solucionar problemas sociais ou contexto pessoal. Cada um desses resultados de aprendizagem, e muitos outros, é entendido em termos da estrutura de viabilidade. Não apenas as habilidades de componentes específicos podem ser identificadas no caso de cada resultado da aprendizagem, mas, dentro da estrutura de viabilidade, o objetivo e o propósito da experiência de ensino e aprendizagem podem ser mais facilmente articulados e compreendidos. Isso prepara o terreno para a análise de resultados de aprendizagem específicos e o início de atividades de design instrucional dentro do domínio afetivo (BRETT FLEEGLER et al., 2012).

O domínio psicomotor, descrito no início da década de 1970, diz respeito à codificação física da informação, ao movimento e/ou às atividades em que os diferentes músculos são usados para expressar ou interpretar informações ou conceitos. Esta área também se refere a respostas ou reflexos naturais e autonômicos. O domínio psicomotor consiste em utilizar habilidades motoras e coordená-las (HOQUE, 2016). Como Bloom não fez a compilação do domínio psicomotor, há três autores muito populares que propõem diferentes categorias: 1) Simpson (1966) - percepção, prontidão para agir, resposta guiada (imitação), mecanicismo, resposta aberta complexa, adaptação e originação (cria novos movimentos); 2) Harrow (1972) - organização de acordo com o grau de coordenação, incluindo respostas involuntárias e capacidades aprendidas, movimentos reflexos, movimento fundamental básico, perceptivo (sinais ambientais que permitem ajustar os movimentos), atividades físicas, movimentos qualificados e comunicação não discursiva (lingua- gem corporal); e 3) Dave (1975) - imitação, manipulação (por meio de instruções), precisão, articulação (duas ou mais habilidades combinadas, sequenciadas e executadas de forma consistente) e naturalização (desempenho é automático com pouco esforço físico ou mental) (HOQUE, 2016).

Uma avaliação abrangente do desempenho dos estudantes nos cursos é importante para a formação de futuros profissionais que sejam capazes de integrar a teoria e a prática aprendidas em qualquer programa de educação de nível superior (BEGAM; THOLAPPAN, 2018).

A taxonomia de Bloom tem sido muito utilizada para o desenvolvimento dos objetivos educacionais nas atividades de simulação, pois esses verbos fornecem estrutura e comunicam as competências que o participante deve alcançar como resultado da participação na atividade de simulação (INTERNATIONAL NURSING ASSOCIATION FOR CLINICAL SIMULATION AND LEARNING, 2016; KRATHWOHL, 2002; CONKLIN, 2005; NEGRI et al., 2019).

Segundo Mager (1984), um objetivo instrucional é uma descrição clara sobre o desempenho e a competência que os educadores gostariam que seus educandos demonstrassem antes de serem considerados conhecedores de determinados assuntos. Esse objetivo está ligado a um resultado intencional diretamente relacionado ao conteúdo e à forma como ele deverá ser aplicado. Os objetivos do domínio cognitivo e psicomotor implicam capacidade de fazer algo (poder fazer), enquanto os objetivos do domínio afetivo respondem a questões de valor e atitude (querer fazer).

De acordo com Anderson et al. (2001), a metacognição envolve o conhecimento cognitivo real, assim como a consciência da aprendizagem individual da amplitude e profundidade de conhecimento adquirido de determinado conteúdo. Essa subcategoria tem se tornado muito importante na área educacional, uma vez que a possibilidade de autoaprendizagem e o controle do aprendizado relacionado à autonomia de aprender devem ser processos cada vez mais conscientes e passíveis de medição. Isso é possibilitado pelo uso da tecnologia da comunicação na educação, pela criação de novas oportunidades educacionais e pela popularização da modalidade a distância. Em contraste com o conhecimento procedural, esse conhecimento é relacionado à interdisciplinaridade. A ideia principal é utilizar conhecimentos previamente assimilados (interdisciplinares) para a resolução de problemas 
e/ou a escolha do melhor método, teoria ou estrutura (FERRAZ; BELHOT, 2010).

O princípio da progressão da complexidade foi mantido do simples para o complexo (cumulatividade e hierarquia), do concreto para o abstrato, mas, novamente, foi atribuída mais flexibilidade ao conceito cumulativo e dependente de cada categoria (eixo comum), pois sabe-se que diferentes disciplinas requerem processos cognitivos diferenciados. Os estilos de aprendizagem possibilitam aos discentes aprender melhor em um estágio mais elevado e depois ter a capacidade de entender os anteriores. Assim, o conceito da metacognição abre espaço para que os estudantes transitem livremente pelas subcategorias com o objetivo de melhorar seu autoaprendizado (KRATHWOHL, 2002).

No modelo da pirâmide de Miller, descreve-se a competência clínica de acordo com a relação entre conhecimentos, habilidades e atitudes. As competências foram classificadas em: 1) sabe; 2) sabe como; 3) mostra; 4) faz (MILLER, 1990; MEHAY, 2012). Atualmente, diversos estudos têm discutido o acréscimo de mais um nível de avaliação na pirâmide de Miller, um nível de desenvolvimento acima do "fazer", que é o nível "ser", no qual a identidade profissional, os valores, os comportamentos, as ações e as aspirações profissionais passam a ser considerados (CRUESS; CRUESS; STEINERT, 2016).

Já o modelo de aquisição de habilidades de Dreyfus possui cinco estágios para adultos e leva em consideração os componentes, a perspectiva, a decisão e o compromisso, para dividir os níveis de habilidade em: 1) principiante; 2) iniciante avançado; 3) competente; 4) proficiente; e 5) especialista/ expert (DREYFUS, 2004; GREENE; LEMIEUX; MCGREGOR, 1993).

(A)

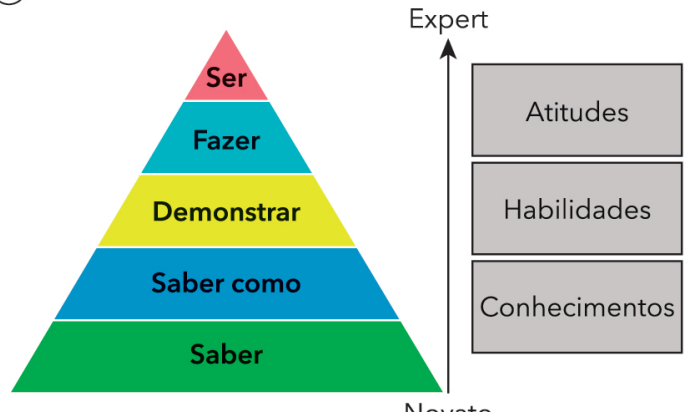

A simulação enquanto estratégia de ensino e aprendizagem busca trabalhar com os níveis de competências necessárias aos estudantes e, nessa perspectiva, apoia-se nos conceitos da pirâmide de Miller atualizada e do modelo de aquisição de habilidades de Dreyfus (Figura 2).

Com a evolução do conceito de competências para os marcos de competências (Milestones), que se referem a um "ponto" dentro de uma competência ou subcompetência em uma progressão contínua do desenvolvimento do aprendiz, este inicia como um estudante principiante e avança ao longo de toda a formação até se tornar competente, podendo atingir o nível de um expert (após anos de prática) da formação do aprendiz. Os marcos são claramente descritos e geralmente específicos da área da graduação ou especialidade (PEREIRA JÚNIOR et al., 2015).

No entanto, as descrições dos marcos de competências são contextuais e independentes; portanto, não definem a complexidade de implementação em ambiente clínico, no qual as habilidades serão demonstradas. Assim, para preencher a lacuna entre a teoria e a prática clínica, foi criado o conceito de Entrustable Professional Activities (EPAs), reconhecidas internacionalmente como uma estrutura para avaliação significativa da competência desde a formação do graduando, residência médica até a recertificação profissional (TEN CATE, 2013).

As EPAs representam uma unidade de prática profissional que pode ser confiada a um estudante ou profissional competente e que requer proficiência em múltiplas competências simultaneamente. Essa abordagem fornece um enfoque amplo e prático para a avaliação, uma vez que não avalia as competências de maneira individual ou isolada (TEN CATE, 2013). Estão vinculadas a decisões de atri-

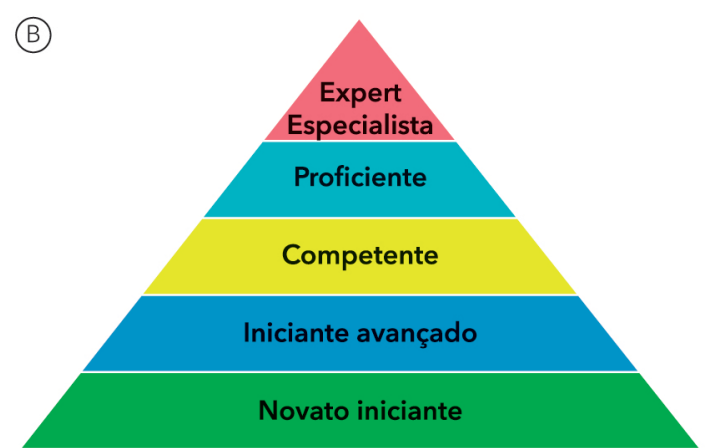

Figura 2 - Modelos de competências. A) pirâmide de Miller atualizada e B) modelo da aquisição de habilidades de Dreyfus. Fonte: adaptada de Park (2015). 
buição, ou seja, avaliam se o aprendiz pode realizar determinadas atividades de prática clínica sob um nível designado de supervisão. Os aprendizes podem ser incumbidos das responsabilidades ou tarefas que devem ser feitas no cuidado ao paciente, as quais podem ser pequenas ou grandes, ou seja, simples ou complexas, mas que normalmente são atividades com início e fim, confiadas somente a pessoas competentes (TEN CATE, 2018).

Assim, as EPAs se caracterizam como uma evolução do conceito educacional fundamentado em competências, em que se aplica o conceito de competências de um aprendiz em contextos específicos

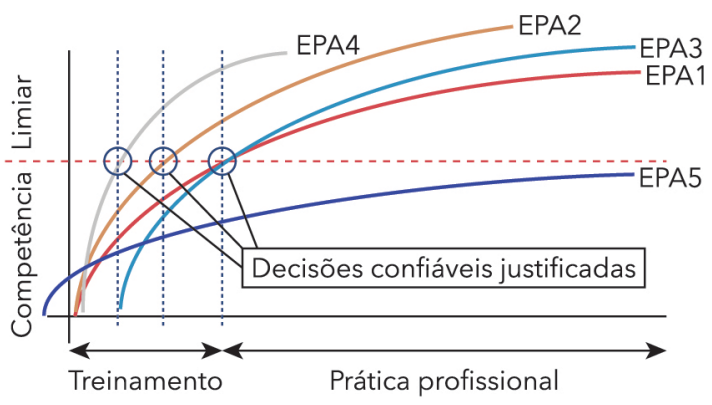

Figura 3 - Em relação ao limiar de competência, o aprendiz é confiável para a execução das EPAs 1, 2, 3 e 4, mas não para a EPA 5. Se não fosse esse modelo de EPAs, não seria possível identificar essa lacuna de conhecimento do aprendiz. no local de prática clínica, constituindo uma descrição do trabalho, independentemente das pessoas (TEN CATE et al., 2015).

Com o uso das EPAs, há a possibilidade de avaliar se os aprendizes podem executar as tarefas de forma independente ou não, permitindo identificar suas lacunas de conhecimentos individuais, como pode ser visto na Figura 3. Pode-se definir também qual o rol de EPAs a serem almejadas pelos aprendizes iniciantes e intermediários ou para aqueles que já possuem expertise suficiente para realização autônoma da atividade prática (TEN CATE et al., 2015).

O modelo de Kirkpatrick também vem sendo utilizado na literatura em associação com a simulação, sendo empregado durante o planejamento pedagógico dos cenários para obtenção de melhores resultados e evidências em relação ao aprendizado (Figura 4) (KIRKPATRICK,1996; MOTOLA et al., 2013).

\subsection{CONCEITOS ESTRUTURANTES DA SIMULAÇÃO COMO ESTRATÉGIA DE ENSINO E APRENDIZAGEM}

Em relação à simulação, esta seção destaca o conceito de Gaba (2007), quando registra que $\boldsymbol{a}$ simulação é uma técnica, não uma tecnologia. A partir de agora, serão discutidos outros conhecimentos importantes para a compreensão adequada da estruturação da simulação enquanto estratégia de ensino e aprendizagem, tais como: 1) fidelidade; 2 ) re-
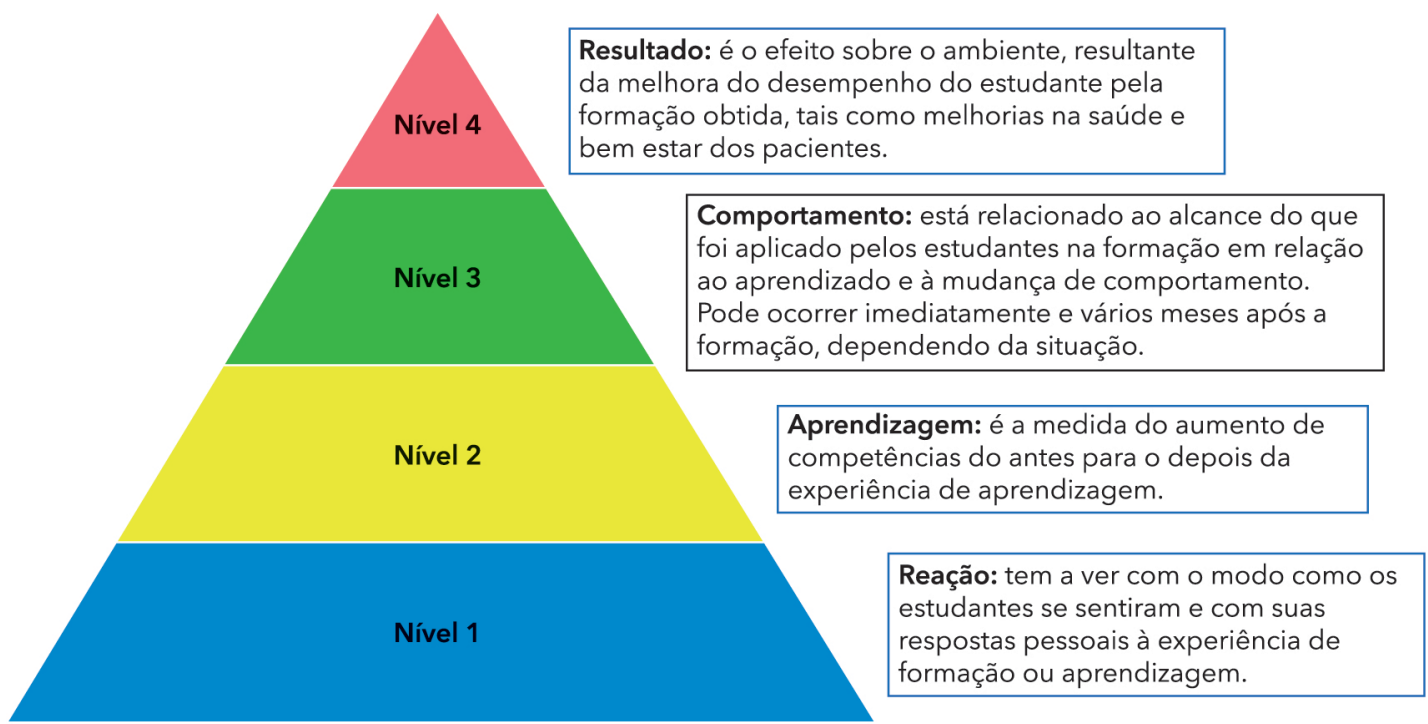

Figura 4 - Modelo de aprendizagem de Kirkpatrick. Fonte: adaptada de Kirkpatrick (1996). 
alismo; 3) suspensão da descrença; 4) contrato de ficção; e 5) complexidade.

Trata-se, portanto, de um método por meio do qual se busca substituir ou amplificar experiências reais, mediante situações guiadas que evocam ou replicam aspectos substanciais do mundo real de uma forma interativa. Assim, um dos conceitos importantes para o exercício da simulação é o de fidelidade (DIECKMANN; GABA; HALL, 2007a; ADVISORY GROUP FOR AEROSPACE RESEARCH AND DEVELOPMENT, 1980; BEAUBIEN; BAKER, 2004).

A fidelidade é uma propriedade intrínseca à simulação e pode ser definida como o grau de precisão com que uma simulação, seja ela física, mental ou ambas, representa determinado quadro de realidade em termos de pistas, estímulos e interações permissíveis (TUN et al., 2015).

O termo "fidelidade" tem sido frequentemente utilizado de forma inconsistente na literatura, sendo observados alguns equívocos terminológicos. Percebe-se, por exemplo, uma associação de fidelidade com sofisticação tecnológica, a despeito da verossimilhança de uma experiência. Assim, o termo é citado de forma unidimensional e atrelado a uma classificação estática dos dispositivos de simulação, o que será discutido mais adiante (ISSENBERG et al., 2005; MARAN; GLAVIN, 2003; BEAUBIEN; BAKER, 2004; TUN et al., 2015).

A rotulagem de fidelidade de simulação como alta, intermediária ou baixa já vem sendo questionada há algum tempo e tem sido considerada por diversos autores como vaga, simplista e inconsistente. Há um reconhecimento da necessidade de extrapolar essa rotulagem unilateral de baixa para alta, uma vez que não fornece informações suficientes para determinar a fidelidade geral de um cenário simulado. Numerosos estudos apontam a falta de entendimento entre autores quanto à definição de fidelidade dentro desse constructo e, na tentativa de novas proposições, destacam diferentes classificações e definições, persistindo a falta de consenso subjacente. Cumpre destacar que, diante de tal problemática, alguns autores já sugeriram inclusive o abandono do termo (REHMANN et al., 1995; TETERIS et al., 2012; COOK et al., 2011; HAMSTRA et al., 2014; ISSENBERG et al., 1999; MATSUMOTO et al., 2002; GROBER et al., 2004).

A fidelidade é multifatorial e variável, de acordo com o contexto de aprendizagem, e, dessa forma, faz-se necessário repensar o termo "fidelidade" na educação baseada em simulação, assim como o termo "simulação realística" (HAMSTRA et al., 2014; TUN et al., 2015).

Entre as diversas proposições existentes na literatura, uma tipologia de fidelidade atualmente muito utilizada na simulação em saúde defende que, para além da 1) fidelidade do equipamento (simulador e engenharia), deve-se ainda considerar a 2) fidelidade ambiental (espaço e recursos) e a 3) fidelidade psicológica (respostas dos participantes) (REHMANN et al., 1995; TETERIS et al., 2012). Para Tun et al. (2015), embora essas dimensões forneçam melhores descrições de fidelidade, elas parecem ser mais adequadas à simulação com máquinas/ robôs do que para situações clínicas. Assim, os autores apresentam uma proposta mais clinicamente orientada para atividades de simulação, com base em aspectos da simulação que seriam eficazes para o treinamento de habilidades em saúde.

A estrutura tridimensional de fidelidade da simulação para educação em saúde, proposta por Tun et al. (2015), parte de um conceito de fidelidade absoluta (tão realística a ponto de não poder ser diferenciada da realidade) e aponta três dimensões (complementares) necessárias para aumentar a fidelidade em cenários de saúde: 1) o paciente; 2 ) o ambiente; e 3) o cenário clínico.

A dimensão do paciente engloba representações de interações com o todo ou com parte de um paciente, como comunicar-se ou realizar um procedimento, e leva em consideração a fidelidade da anatomia e da fisiologia. A dimensão do ambiente engloba representações dos equipamentos clínicos (instrumentos, monitores) e do ambiente (onde ocorre a atividade ou o encontro com o paciente). A dimensão do cenário clínico está relacionada às representações relativas ao roteiro, à progressão do cenário e à complexidade situacional, como a dinâmica da equipe e da família, dependendo do caso simulado, o que inclui o envolvimento dos facilitadores.

Na prática, segundo Tun et al. (2015), a maioria das simulações trabalha com uma fidelidade subabsoluta, pois existem elementos irreais que são utilizados para aumentar o nível de realismo dos cenários. Tais elementos, quando ocultados, geram um engano que pode ter conotação negativa e culminar com a decepção (DIECKMANN et al., 2007b; TUN et al., 2015). Dessa forma, o conceito de fidelidade ainda segue mal interpretado e definido na literatura da simulação em saúde. Entretanto, admite-se que ele ainda é fundamental para compreender a eficácia que qualquer simulação pode ter na preparação de estudantes para seu desempenho clínico (GRIERSON, 2014). 
Outro conceito muito importante para a simulação é o de realismo, o qual, por vezes, é indevidamente utilizado como sinônimo de fidelidade, mas que se sobrepõe a ela, uma vez que a fidelidade é utilizada nas práticas simuladas com o objetivo alcançá-lo (DIECKMANN; GABA; HALL, 2007a; MUCKLER, 2016).

O significado de realismo para simulação pode ser explorado em associação aos três modos de pensamento: 1) físico; 2) semântico; e 3) fenomenológico. Todos são necessários para descrever e especificar qualquer situação clínica a ser simulada (LAUCKEN, 2003; DIECKMANN; GABA; HALL, 2007a).

O modo físico diz respeito a entidades que podem ser medidas em termos físicos e químicos fundamentais por meio de dimensões mensuráveis (por exemplo, centímetros, gramas e segundos). Deste modo, um simulador pode ser descrito em suas dimensões físicas, como o peso ou a força gerada pelo tórax em movimento. $\mathrm{O}$ ambiente de simulação pode ser descrito de forma semelhante em termos de suas características físicas, incluindo qualquer equipamento que resida lá, e de aspectos físicos dos movimentos realizados (por exemplo, a forma e o peso de um ventilador ou os padrões de força necessários para intubar a traqueia do paciente simulado) (LAUCKEN, 2003; DIECKMANN; GABA; HALL, 2007a).

De acordo com o modo físico de pensar, os manequins simuladores existentes têm muitos elementos irrealistas, apesar de sua forma quase humana. Eles são claramente construídos com materiais diferentes dos seres humanos. Seus sons respiratórios são tipicamente distinguíveis qualitativamente dos sons respiratórios reais e não são ouvidos em todos os locais usuais de um paciente real (LAUCKEN, 2003; DIECKMANN; GABA; HALL, 2007a).

O modo semântico diz respeito a conceitos e seus relacionamentos - como teorias, significado ou informações -, apresentados por meio de texto, imagens, sons ou eventos. Por exemplo, dentro do modo semântico, uma simulação de hemorragia pode ser descrita como: se $A$ (sangramento) acontece então $B$ (diminuir a pressão arterial). Nessa situação, é irrelevante como as informações (sobre a hemorragia) são transmitidas. As mesmas informações poderiam ser representadas por meio de um monitor de sinais vitais, uma descrição verbal, a percepção tátil de pulsos cada vez mais palpáveis ou ainda outros meios. Assim, os cenários podem ser semanticamente realistas se as informações apresentadas forem razoavelmente interpretáveis, mesmo que a base física para transportar essa informação não seja realista (seringas cheias de água podem ser usadas como se contivessem um medicamento) (LAUCKEN, 2003; DIEKMANN; GABA; HALL, 2007a).

O modo fenomenológico inclui emoções, crenças e estados cognitivos autoconscientes de pensamento racional que as pessoas vivenciam diretamente enquanto estão em uma situação. $\mathrm{O}$ modo fenomenológico é relevante para simulação, porque descreve os diferentes elementos da experiência. Os participantes vivenciam diretamente o cenário simulado como: 1) uma situação complexa em tempo real (por exemplo, interagindo com o manequim simulador e o equipamento dentro da lógica do caso simulado); e 2) como um evento educacional real que é configurado para se aproximar fisicamente de outra situação real (uma situação clínica com um paciente real). Se a simulação "funcionar", os participantes experimentarão o cenário de simulação relevante para o objetivo da sessão e serão capazes de dar sentido semântico ao cenário, apesar de suas diferenças físicas em relação à situação clínica (LAUCKEN, 2003; DIECKMANN; GABA; HALL, 2007a).

Assim sendo, surge um outro conceito, de base literária e teatral, que também é muito relevante para simulação, mas pouco utilizado e explorado, que é o de suspensão da descrença, reconhecido por diversos autores como uma dimensão que dá sentido ao realismo. Refere-se à capacidade dos participantes de acreditar no inacreditável e resistir ao julgamento da autenticidade da simulação, do ato cognitivo de aceitar um impostor (simulação) como genuíno (clínico), de deixar de lado sua descrença e aceitar o exercício simulado como sendo real durante a aplicação do cenário (GROBER et al., 2004; RUDOLPH et al., 2014; TUN et al., 2015; MUCKLER, 2016).

Quando suspendem a descrença durante a simulação, eles podem verbalizar e completar tarefas como se estivessem engajados em um encontro real com o paciente, e a percepção se desenvolve de maneira aumentada, tornando mais fácil mergulhar na experiência e sentir as emoções que vêm do cenário (RUDOLPH et al., 2014; MUCKLER, 2016).

A suspensão da descrença durante a simulação é de grande relevância para que o participante maximize o aprendizado e a retenção de conhecimento, sendo responsabilidade do facilitador determinar e implementar as técnicas mais eficazes para garantir as dimensões de fidelidade necessárias para a imersão do participante na simula- 
ção: 1) contrato de ficção; 2) segurança psicológica; 3) compromisso emocional; e 4) significado atribuído (WILSON; WITTMAN-PRICE, 2015; MUCKLER, 2016).

O contrato de ficção é um conceito importante para a prática do treinamento simulado atual, pois, antes de imergirem no cenário, os participantes são orientados sobre as limitações da simulação, para encorajar sua imersão e minimizar os efeitos negativos dos elementos irrealistas para o desempenho (TUN et al., 2015). Trata-se de um acordo tácito, em que os facilitadores se comprometem a fazer o melhor possível para otimizar a experiência de simulação, e os estudantes, a fazer o possível para ignorar os aspectos irrealistas e mergulhar na experiência apenas por uma questão de aprendizado (CHENG et al., 2007).

A segurança psicológica consiste em tranquilizar os estudantes de que a intenção da simulação está voltada para a aprendizagem, e não para a repercussão dos erros. Para aproveitar ao máximo uma oportunidade de aprendizado, os indivíduos devem se sentir confiantes o suficiente para assumir riscos, fazer perguntas e superar o medo de serem humilhados ou repreendidos por erros ou tomada de decisões equivocadas. Uma sensação de segurança psicológica os autoriza a superar o medo do constrangimento e do fracasso (RUDOLPH et al., 2014).

O compromisso emocional refere-se à adesão dos participantes para que se envolvam emocionalmente na simulação com o propósito de aprender, e isso ocorre quando eles experimentam um apego e uma conexão emocional ao cenário, aceitando o que imita a realidade, o que depende muito do seu estado de espírito e do enredo do cenário (BAUMAN, 2012).

O significado atribuído à simulação varia de acordo com as experiências psicológicas e sociais do participante, sendo que, quando o conteúdo ou habilidade aprendida é relevante para o estudante e aplicável à sua realidade, a aprendizagem tende a alcançar melhores significados (KNOWLES, 1980; MUCKLER, 2016).

Outro conceito relevante e que vem sendo utilizado de maneira equivocada na simulação é o de complexidade. Neste caso, é importante definir a que complexidade se está referindo: se a complexidade dos equipamentos de simulação (capacidade tecnológica do simulador) ou se a complexidade da própria simulação (cenário), uma vez que há muita confusão dessas dimensões, e isso faz com que a complexidade da simulação seja atrelada somente à tecnologia dos simuladores. Portanto, o que de fato deve determinar o grau de complexidade de uma atividade de simulação não são os níveis de tecnologia incorporados, e sim o número de objetivos do cenário e as ações individuais e conjuntas necessárias para o alcance dos resultados esperados (LIOCE et al., 2020).

Resumindo, é importante estabelecer que a fidelidade geral dos cenários simulados raramente se iguala apenas à fidelidade mecânica dos manequins. Tradicionalmente, a fidelidade geral tem sido descrita como uma soma total de "fidelidade mecânica", "fidelidade ambiental (contexto)" e "fidelidade psicológica", mas há outros dois contribuintes importantes para ela, que são a "fidelidade temporal", que se refere à recriação de eventos ao longo de uma linha do tempo, conforme acontecem na vida real, permitindo intervalos de tempo realistas entre as intervenções e os resultados durante os cenários simulados, e a "fidelidade de ação", que representa as tarefas atribuídas aos alunos, conforme ditadas pelos cenários (KHAN et al., 2010).

Desta forma, a soma total de todas essas fidelidades é denominada "fidelidade de percepção", que é a variável mais importante (Figura 5).

\subsection{CONCEITOS COMPLEMENTARES}

É importante destacar também outros conceitos complementares à simulação:

Ambiente seguro de aprendizagem: ambiente emocional criado por meio da interação entre todos os participantes, no qual se sentem à vontade mesmo cometendo erros ou assumindo riscos (DOMINGUES; NOGUEIRA; MIURA, 2020).

Ambiente de realidade virtual: ambiente de aplicativos fundamentados em computador, comumente associado a características 3D imersivas e altamente visuais, que permite ao participante olhar e navegar em um mundo aparentemente real ou físico (LOPREIATO et al., 2020).

Avatar: refere-se a um objeto virtual utilizado para representar um objeto físico (exemplo, um ser humano) em um ambiente virtual. É uma representação gráfica gerada por computador de um participante em uma simulação ou jogo de realidade virtual (LOPREIATO et al., 2020).

Confiabilidade: representa a consistência de uma medida ou o grau em que um instrumento mede da mesma maneira quando aplicado em uma condição e com participantes semelhantes.

Facilitador (também conhecido como professor/instrutor/tutor): indivíduo treinado que fornece suporte e orientação em parte ou em todos os estágios do ensino fundamentado na simulação. $\mathrm{O}$ faci- 


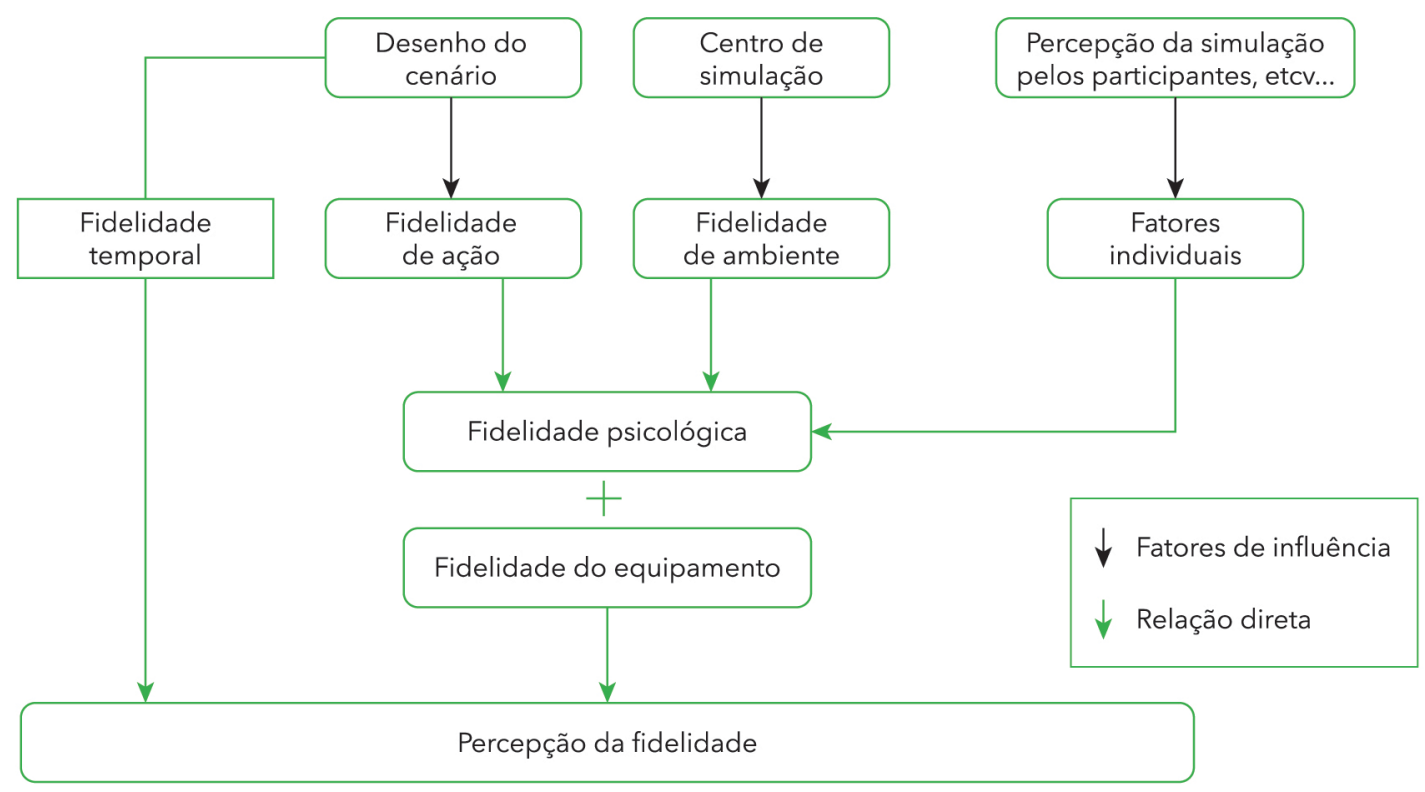

Figura 5 - A interação dos componentes de "fidelidade de percepção". Fonte: adaptada de Khan et al. (2010).

litador deve ter domínio e experiência na atividade clínica, em tecnologias e em comunicação que envolve a simulação que será realizada. Sugere-se que ele tenha formação específica em simulação, fornecida por um curso formal, e/ou com abordagens específicas planejadas junto a um mentor experiente (MENEZES; MOLINA; DOS SANTOS, 2020).

Feedback: informações ou diálogos ocorridos entre participantes, facilitador, simulador ou pares com o objetivo de melhorar a compreensão de conceitos ou de aspectos do desempenho.

Frames: perspectivas pelas quais os indivíduos interpretam novas informações e experiências para tomada de decisão. São formados por experiências prévias e com base em conhecimentos, atitudes, sentimentos, metas, ações (fala e linguagem corporal), atitudes (verbais e não verbais), regras e/ou percepções tanto do participante quanto do facilitador (DOMINGUES; NOGUEIRA; MIURA, 2020).

Gatilhos: um evento ou eventos que movem a simulação de um estado para outro (LOPREIATO et al., 2020).

Guias de aprendizagem: guias de simulação clínica que compõem uma estratégia pedagógica e permitem abordar e integrar conhecimentos, atitudes e práticas dos aprendizes. Esses guias têm como objetivo auxiliar a aprendizagem do participante por meio da autocondução e autoavaliação, assim como permi- tir ao facilitador meios de conduzir ou avaliar determinada habilidade de forma estruturada, clara e objetiva (DOMINGUES; NOGUEIRA; MIURA, 2020).

Habilidade técnica (HT): habilidade necessária para a realização de uma tarefa específica, por exemplo, inserir um dreno torácico ou realizar um exame físico (LOPREIATO et al., 2020).

Habilidade não técnica (HNT): habilidades cognitivas, sociais e pessoais que complementam as habilidades técnicas no desempenho adequado e seguro de tarefas, sendo que existem diversas taxonomias para HNT. Na saúde, os marcadores comportamentais mais comumente usados são: comunicação, liderança/trabalho em equipe, consciência situacional, gerenciamento de tarefas e tomada de decisão (DIECKMANN; ZELTNER; HELSØ, 2016).

Julgamento clínico: compreende o processo mental e comportamental que engloba o atendimento/assistência ao paciente. Refere-se à realização de decisões baseadas nos vários tipos de conhecimentos e é influenciado por experiências prévias individuais e habilidades de resolução de problemas, pensamento crítico e raciocínio clínico.

Life savers: estratégia para gerenciar eventos inesperados que ocorrem durante a simulação baseada em planos predeterminados e/ou intervenções feitas espontaneamente durante os cenários, 
possibilitando que os participantes completem a atividade simulada.

Moulage: a aplicação de maquiagens e moldes nos membros, tórax, cabeça etc. de um ser humano ou do simulador para fornecer elementos de realismo (como sangue, vômito, fraturas expostas etc.) à simulação de treinamento. Trata-se de técnicas usadas para simular lesões, doenças, envelhecimento e outras características físicas específicas de um cenário. A moulage apoia as percepções sensoriais dos participantes e a fidelidade do cenário de simulação por meio do uso de maquiagem, artefatos fixáveis (por exemplo, objetos penetrantes) e cheiros (INTERNATIONAL NURSING ASSOCIATION FOR CLINICAL SIMULATION AND LEARNING, 2016).

Scribe: ato de fazer anotações sobre um cenário e documentar as ações realizadas ou não realizadas (LOPREIATO et al., 2020).

Tomada de decisão: processos mentais (cognitivos) que levam à escolha de um plano de ação para determinada situação.

Dando continuidade à explanação sobre normas para as melhores práticas em simulação, os próximos elementos-chave (design da simulação, resultados e objetivos, facilitação, debriefing, avaliação do participante, integridade profissional e educação interprofissional aprimorada por simulação) serão descritos a seguir.

\subsection{AS DIFERENTES TÉCNICAS DE SIMULAÇÃO E OS SIMULADORES}

Em relação à simulação, existem diversas estratégias, entre as quais se destacam: 1) a simulação clínica para treinamento de habilidades; 2) a simulação clínica com o uso de simuladores de diferentes tipos; (3) a simulação clínica com paciente simulado (simulação cênica); 4) a simulação híbrida; (5) a prática deliberada em ciclos rápidos (PDCR); (6) a simulação virtual; (7) a simulação in situ; e (8) a telessimulação.

A simulação clínica para treinamento de habilidades, também chamada de aula simulada, refere-se ao preparo de ambientes simulados para que os participantes tenham a oportunidade de praticar habilidades psicomotoras, cognitivas e/ou afetivas, com objetivos de aprendizagem predefinidos. Durante a prática da técnica proposta, estimula-se que os participantes discutam os passos técnicos, esclareçam as dúvidas e preencham suas lacunas individuais de conhecimento. $\mathrm{O}$ treinamento de habilidades possibilita que a mesma técnica ou procedimento seja repetido diversas vezes, desenvolvendo competências de menor nível de complexidade. A depender da habilidade a ser desenvolvida, podem ser utilizados simuladores de partes do corpo, como um braço (para técnica de punção venosa) ou um tórax (para técnica de ressuscitação cardiorrespiratória) (BONDUELLE; CHO; ELLOY, 2020).

A simulação clínica com o uso de simuladores de pacientes (manequins) é uma das formas mais utilizadas como estratégia de ensino prático na área da saúde. Ela pode ser realizada com simuladores de baixa ou média tecnologia, quando os objetivos envolvem treinamento de habilidades técnicas específicas, ou com simuladores de alta tecnologia, quando a intenção é praticar treinamentos para o desenvolvimento de raciocínio clínico, tomada de decisão, habilidades técnicas, atuação da equipe multiprofissional ou outras competências mais amplas, a partir de casos clínicos complexos. A construção de casos clínicos contribui para essa estratégia de simulação, seja ela de baixa, média ou alta tecnologia (BERGAMASCO; PASSOS; NOGUEIRA, 2020).

A simulação clínica com paciente simulado (humano) utiliza pessoas para representar sintomas ou problemas clínicos. Nessa modalidade de simulação, é obrigatória a construção de um caso clínico que deverá ser interpretado pelo participante simulado, seguindo um roteiro de encenação (script) e favorecendo uma maior interação durante a aplicação do cenário (AKAIKE et al., 2012).

A utilização de pessoas que desempenham ou assumem papéis nos roteiros de simulação permite diferentes tipos de participação, o que leva a equívocos conceituais. Frequentemente, observa-se na literatura a descrição dos termos "paciente simulado", "paciente estandardizado" e "paciente padronizado" como sendo similares (vide destaque). Definir a diferença entre esses participantes é muito relevante, pois eles exigem estruturas diferentes em sua preparação, desenvolvimento e entrega.

Outro detalhe importante é que, no início da prática de simulação, os representantes de pacientes humanos eram comumente chamados de pacientes padronizados ou simulados, entretanto, mais recentemente, percebendo-se que estes podem representar um escopo expandido de funções (por exemplo, clientes, familiares, profissionais de saúde), o termo "participante simulado" passou a ser utilizado por representar essa função de maneira mais inclusiva (LEWIS et al., 2017)

O role-play, ou "troca de papéis", pode se enquadrar nesse tipo de simulação. Consiste em um método de aprendizagem em que os estudantes são convidados a assumir o papel de outras pessoas 
por meio de dramatização, com objetivo de compreenderem um fenômeno partindo de uma perspectiva diferente da sua. Esse recurso é utilizado na formação de diferentes profissionais da saúde para sensibilizar estudantes em relação a uma temática ou situação (DE OLIVEIRA; DE PRADO; KEMPFER, 2014).

A simulação híbrida é a combinação de mais de uma modalidade de simulação em um único treinamento, como a associação de um paciente simulado com um simulador de qualquer nível de tecnologia. Essa estratégia permite o desenvolvimento de habilidades processuais e de comunicação com uma pessoa, trazendo uma sensação de realismo à atividade que pode não ser alcançada usando atores ou simuladores isoladamente. É uma opção de simulação financeiramente acessível e, ao mesmo tempo, eficaz (BROWN; TORTORELLA, 2020; UNVER et al., 2018).

A PDCR é uma das formas mais recentes de simulação, em que um caso clínico é construído e aplicado a um grupo de participantes ou equipe, que repete o mesmo cenário diversas vezes, até o momento em que a competência desejada seja apreendida. Quando o objetivo desse ciclo é atingido, são adicionadas outras dificuldades ao cenário, aumentando a complexidade do caso, e um novo ciclo se inicia (HUNT et al., 2014).

A simulação virtual (simulação baseada em computador ou realidade virtual) foi proposta a par- tir das inovações tecnológicas e envolve a criação da realidade de um ou mais cenários de simulação na tela do computador. Neste ambiente, o participante exerce um papel central no cumprimento de tarefas específicas e no desenvolvimento de habilidades de interação, tomada de decisão e comunicação no atendimento a pacientes virtuais criados, a partir de uma variedade de configurações clínicas (PADILHA et al., 2019).

A simulação in situ é uma estratégia que amplia a fidelidade, pois leva a atividade simulada diretamente ao local onde a assistência à saúde ocorre. Uma das suas principais vantagens é permitir que a equipe realize práticas simuladas em seu próprio ambiente de trabalho. E esse tipo de simulação contempla tanto a aprendizagem individual quanto em equipe (TUN et al., 2015; BERGAMASCO; PASSOS; NOGUEIRA, 2020).

A telessimulação é uma modalidade inovadora para educação, treinamento e avaliação na área da saúde, que permite o desenvolvimento dos domínios cognitivo e afetivo. Esta estratégia de simulação é definida como um processo pelo qual recursos de telecomunicação e simulação são utilizados para fornecer educação, treinamento e avaliação de participantes em local externo, muitas vezes remoto e de difícil acesso, possibilitando o ensino e a aprendizagem a um grupo maior de participantes (MCCOY et al., 2017).

Paciente simulado é quando um participante de uma simulação representa o papel de um personagem ou pessoa. Essa atuação pode ser desempenhada por atores devidamente treinados ou improvisada entre os participantes da simulação.

Paciente padronizado (standardized patients) diferencia-se do paciente simulado pela capacidade de se comportar de uma maneira consistente e precisa, que pode ser igualmente repetida, a fim de dar a cada aluno uma chance justa e igual de aprendizagem, permitindo ainda uma avaliação das habilidades aprendidas em um ambiente clínico simulado. Assume-se esse papel por meio de um contrato legal junto à instituição de ensino. Esta prática, iniciada com um neurologista em 1963, apresenta considerável crescimento e, hoje, já possui reconhecimento de muitas organizações educacionais, contando também com diversos programas de formação para pacientes padronizados (LEWIS et al., 2017; BEARNSON; WILKER, 2005; CHURCHOSE; MCCAFFERTY, 2012).

Para exercer o papel de paciente padronizado, podem ser utilizados: (1) estudantes de artes cênicas, atores de companhias de teatro amador ou mesmo atores profissionais em simulação, principalmente em processos seletivos ou provas de suficiência, cuidadosamente recrutados e treinados para assumir as características de um paciente; (2) membros da comunidade (criança, adolescente, adulto, idoso ou mesmo portador de alguma doença, que vão responder a qualquer questionamento da história médica e social a partir de sua própria vida) (CHURCHOSE; MCCAFFERTY, 2012).

Esse recurso tem se constituído como possibilidade concreta para prover o ensino e o treinamento no campo das habilidades clínicas, em função do seu potencial para preencher condições mais próximas às ideais, garantindo a fidedignidade da interação humana com a comunicação e a empatia. Por questões éticas e legais, essa não tem sido uma técnica muito utilizada no Brasil. 
Em relação aos simuladores, entende-se que são as ferramentas que permitem a prática de simulações. Como não existe uma classificação padrão, geralmente, ao classificá-los, são considerados seus níveis variados de tecnologia, fidelidade, função fisiológica, entre outras particularidades (TUN et al., 2015; DOMINGUES; NOGUEIRA; MIÚRA, 2020). Para demonstrar essa diversidade de classificações dos simuladores, apresentam-se alguns exemplos comumente citados na literatura.

Chiniara et al. (2012) classificaram os simuladores de acordo com o material de que são constituídos: 1) simuladores orgânicos, como animais, tecidos ou cadáveres e pacientes simulados/atores; ou 2) simuladores sintéticos, que incluem os chamados treinadores de tarefas parciais e simuladores de paciente quando usados para esta finalidade.

Já Tun et al. (2015) citam que os simuladores incluem: 1) treinadores de tarefas parciais; 2) manequins ou simuladores de pacientes; 3 ) pacientes simulados ou padronizados (SP); 4) ambientes fundamentados em tela; e 5) equipamentos simulados e ambientes de saúde. Os autores apontam ainda que os simuladores não precisam ser necessariamente físicos, podendo assumir a forma de software ou até mesmo ocorrer na mente de estudantes envolvidos em atividades imaginárias, como simulações mentais facilitadas.

Por sua vez, Flato e Guimarães (2011) classificaram os simuladores em: 1) de baixa tecnologia; 2) de alta tecnologia; 3) Part-task trainer (parte do corpo ou de algum órgão interno para treinamento de técnicas, procedimentos ou tarefas); 4) realidade virtual; 5) simuladores com base em programas de computadores (Screen Based Simulator); 6) simulações com pessoas (atores e/ou pacientes); e 7) Game Based Simulation.

Seropian et al. (2004) classificaram os simuladores em três categorias distintas, tomando como referência a capacidade de interação, o uso de tecnologia e o mecanismo de controle:

(1) Part-task trainer:

- treinador não dinâmico básico de plástico;

- treinador dinâmico básico de plástico;

- treinador de realidade virtual de baixa fidelidade com haptics;

- treinador de realidade virtual de alta fidelidade com haptics.

(2) Sistema com base em computador:

- pacientes simulados;

- ambiente simulado.

(3) Simulador integrado:

- simulador dirigido por instrutor;

\section{1) EXEMPLOS DE SIMULADORES \\ UTILIZADOS EM SIMULAÇÃO DE BAIXA FIDELIDADE.}

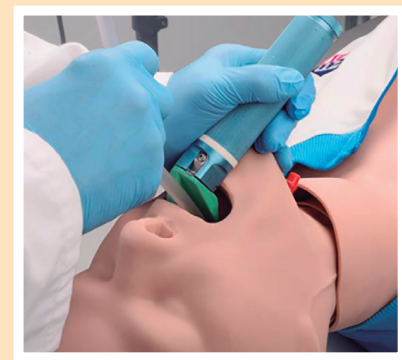

Modelo para treino de habilidades no manejo das vias aéreas em adultos.

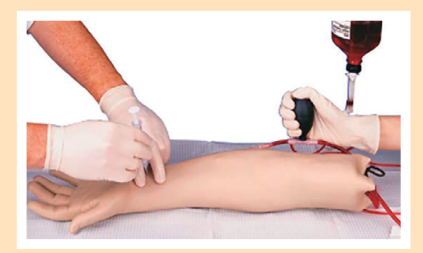

Modelo para treinamento de acesso intravenoso e intra-arterial.

\section{2) EXEMPLOS DE SIMULADORES UTILIZADOS PARA SIMULAÇÕES DE MÉDIA FIDELIDADE.}

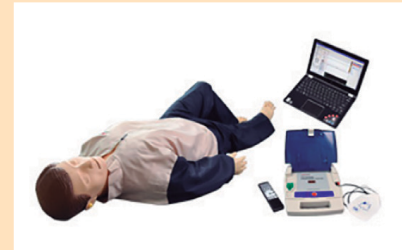

Modelo para treinamento de suporte avançado de vida.

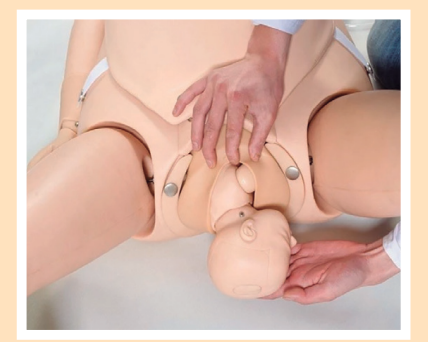

Modelo para treinamento de parto. 
- simulador dirigido por modelo.

Em sua classificação, Seropian et al. (2004) usam o termo "haptics", muito presente na literatura sobre simuladores. Trata-se do processo de reconhecimento de objetos por meio do toque, entregue na forma de vibrações e feedback de força, criado por componentes móveis de um dispositivo e controlado por software integrado. A percepção háptica abrange tanto a percepção tátil somatossensorial mediada pela pele quanto o feedback proprioceptivo cinestésico nos tendões, músculos e ligamentos (RANGARAJAN; DAVIS; PUCHER, 2020).

Observa-se, no entanto, que a classificação que tem sido mais utilizada na literatura é a que está relacionada com a fidelidade, variando desde modelos de baixa fidelidade até modelos de alta fidelidade (PERKINS, 2007). Ressalva-se aqui a necessidade de considerar os aspectos já mencionados sobre a interpretação de fidelidade, pois essa confusão se deve a interesses mais comerciais do que das características do cenário simulado.

Os simuladores utilizados para simulação de baixa fidelidade, geralmente, são aqueles que não interagem com o cenário por causa da ausência de respostas anatômicas, fisiológicas e sensoriais. Podem ser encontrados em corpo completo ou parcial, na forma de membros, órgãos ou suas partes (Part-task trainer) e, normalmente, são utilizados para o desenvolvimento de habilidades específicas, como realização de suturas, acessos para administração de medicamentos, drenagem torácica, manejo das vias aéreas, entre outras.

Em geral, não necessitam de contextualização do cenário, pois sua utilização, na maioria das vezes, consiste em treinamento para realização adequada de determinados procedimentos e demonstração de competências.

Por sua vez, os simuladores utilizados para simulações de média fidelidade permitem maior aproximação com situações reais e apresentam limitadas respostas anatômicas, fisiológicas e sensoriais, que permitem alguma interação com o aprendiz. Ainda, são utilizados para treino individual ou em grupo de habilidades, protocolos e Guidelines (TUN et al., 2015).

São simuladores que apresentam a possibilidade de ausculta de sons respiratórios, cardíacos e abdominais, permitindo a monitorização de traçados eletrocardiográficos, identificação de alguns pulsos e sons vocais, além de possibilitar todos os recursos que o simulador de baixa fidelidade possui para a realização de habilidades específicas (AL-ELQ, 2010; DECKER et al., 2008).
Já os simuladores utilizados para simulações de alta fidelidade são aqueles capazes de criar uma situação com um alto grau de realismo, sentido e vivenciado pelos estudantes, de modo que se transmitam, da melhor forma possível, as intervenções na vida real. Permitem treinar a atenção para patologias em doentes em uma situação clínica estável, instável, crítica ou em situação anestésica, bem como a direção de uma equipe que tem de resolver uma situação concreta, em que a tomada de decisões e o trabalho em equipe são cruciais (ORLEDGE et al., 2012).

Alguns desses simuladores são conduzidos por um software e se apresentam como manequins de corpo inteiro, com grande semelhança anatômica e
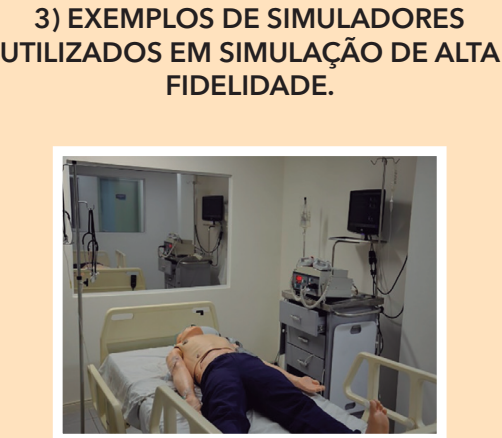

Modelo controlado por computador para atendimento a diferentes situações clínicas.

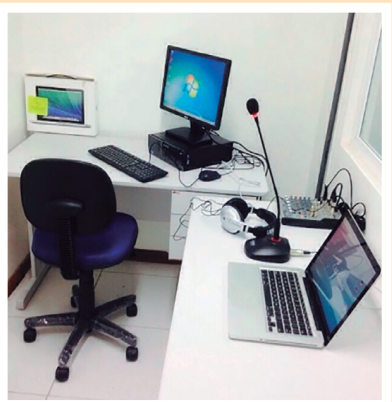

Sala de controle de simuladores de alta tecnologia.

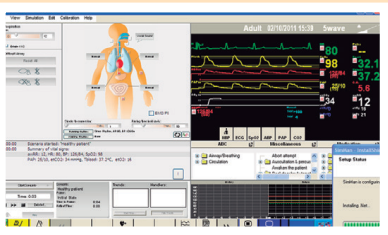

Painel de configuração do simulador. 
fisiológica ao ser humano. Chegam a apresentar movimentos respiratórios, pulsos venosos e arteriais, piscam os olhos, alteram a coloração de mucosas e possibilitam ainda a avaliação de dados da pele, ausculta intestinal, cardíaca, respiratória, entre muitos outros recursos. Esses simuladores podem ser programados para responder a falhas na administração de medicamentos, com ênfase na performance de habilidades na decisão, preparação e administração terapêutica. No entanto, para o desenvolvimento de habilidades de comunicação, uma vez que a comunicação efetiva é competência clínica essencial para o exercício das profissões da área da saúde, esses simuladores não são adequados. As técnicas de comunicação podem ser ensinadas e aperfeiçoadas efetivamente com o uso da dramatização nas práticas simuladas (BAER et al., 2008).

\subsection{A SIMULAÇÃO E A SEGURANÇA DO PACIENTE}

A expressão latina "Primum non nocere", que significa "acima de tudo, não causar dano", é considerada um fundamento da bioética, entretanto o relatório To Err is Human, do Instituto de Medicina (INSTITUTE OF MEDICINE, 1999), revelou que até 98 mil mortes ocorrem em hospitais norte-americanos como um resultado de erro médico a cada ano (AGRAWAL et al., 2010).

Estudos globais sugerem que aproximadamente $10 \%$ dos pacientes internados em hospital sofrem algum tipo de erro de procedimento. A Medicina, tradicionalmente, confia em uma abordagem do tipo "veja e faça" para aprender e experimentar. Isso, inevitavelmente, expõe os pacientes ao atendimento de profissionais de saúde inexperientes e aos perigos e danos associados a isso (DELLIFRAINE; LANGABEER; KING, 2010; AGRAWAL et al., 2010)

Escalar a curva de aprendizado de maneira íngreme não é mais aceitável, pois a prática de tentativa e erro com pacientes reais torna-se cada vez mais inadmissível. A simulação, nesse contexto, emerge como instrumento que auxilia na formação de profissionais de saúde em relação ao treino de habilidades sem expor o paciente a erros evitáveis pela falta de conhecimento adequado (REZNICK; MACRAE, 2006).

Além disso, a simulação tem o potencial de recriar cenários que, raramente, são experimentados e testar profissionais em situações desafiadoras, além de permitir a repetição ou o exame cuidadoso de suas ações, o que favorece a aquisição ou o aperfeiçoamento de determinadas habilidades para $o$ atendimento (AGENCY FOR HEALTHCARE RESEARCH AND QUALITY, 2009).
Assim, para melhorar a educação em diferentes níveis e aumentar a segurança do paciente, $o$ uso da simulação tem crescido em diferentes ambientes de aprendizagem (AGRAWAL et al., 2010).

\section{A ESTRUTURAÇÃO DOS CENÁRIOS SIMULADOS EM SAÚDE}

O desenvolvimento dos cenários é de grande relevância para o treinamento com simulação clínica, para garantir a qualidade e a validade do conteúdo e apoiar os objetivos e resultados esperados. Assim, os cenários devem ser estruturados a partir de caso fundamentado em situações da vida real e com uma história principal, incluindo uma sequência de atividades de aprendizagem e envolvendo tomadas de decisão estratégicas para resolução de problemas, raciocínio inteligente e outras habilidades cognitivas (ALINIER, 2011; NADOLSKI et al., 2008).

Seu design direciona a abordagem de aspectos essenciais da estrutura, processo e resultados da atividade (DOMINGUES; NOGUEIRA; MIÚRA, 2020). Na literatura, são observadas várias propostas para desenvolvimento desses cenários, entretanto a maioria destaca a necessidade de planejamento e desenvolvimento adequados (KHAN et al., 2010).

A simulação serve como atividade de ensino e avaliação. Para tanto, existem diferenças no processo de elaboração e desenvolvimento das estações simuladas que precisam ser conhecidas (Figuras 6 e 7).

No ensino, a simulação é utilizada, principalmente, como uma ferramenta de avaliação formativa. Cada cenário de simulação seguido por um debriefing é um processo de avaliação formativa, e o feedback é um dos principais contribuintes para a melhoria do desempenho. A amostragem da metacognição é possível durante o debriefing, permitindo que os alunos pensem e reflitam sobre suas ações. Os resultados de aprendizagem definidos dos cenários direcionam a avaliação formativa. Assim, o debriefing realizado no final de cada cenário de simulação apresenta uma oportunidade ideal para fornecer ao candidato um feedback relevante e com foco individual ou em grupo, a fim de maximizar a experiência geral de aprendizagem. A Figura 6 resume todo o processo de simulação como ensino.

Na avaliação, a simulação é utilizada, principalmente, como uma ferramenta de avaliação somativa. Um cenário simulado bem projetado pode demonstrar o desempenho diante de situações clí- 


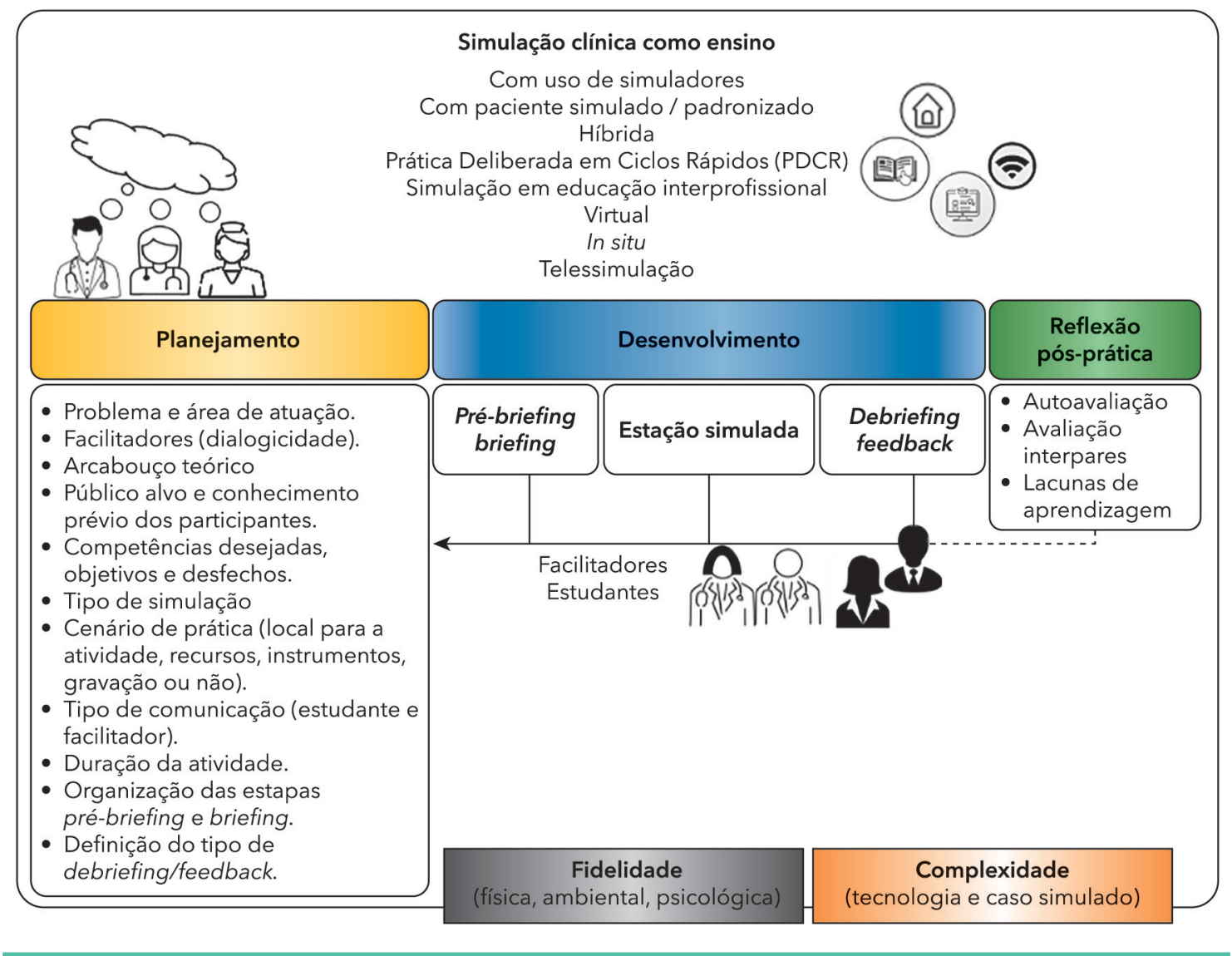

Figura 6 - Proposta para estruturação de cenários simulados para ensino. Fonte: elaborada pelos autores.

nicas simuladas, inferindo o desempenho em ambientes clínicos. A Figura 7 resume todo o processo de simulação como avaliação.

A validade é a capacidade de um conjunto de variáveis de prever resultados com base em informações de outras variáveis e de se relacionar com critérios concretos no "mundo real", assim como a fidedignidade e a reprodutibilidade são as grandes vantagens da utilização da simulação como avaliação, tanto formativa quanto somativa.

\subsection{PLANEJAMENTO DOS CENÁRIOS SIMULADOS}

A estruturação de cenários simulados requer um planejamento prévio, intencional, sistemático e minucioso da atividade proposta. Tal processo deve, preferencialmente, ser inclusivo e dialógico, envolvendo colaboradores com experiência em simulação e/ou a área de conhecimento objeto da prática simulada.

A engenharia de cenários de simulação é a arte de desenvolver aplicações práticas (cenários de simulação) que englobam o conhecimento da Medicina, simuladores, diferentes ambientes clínicos e currículos. O objetivo geral da engenharia de cenário deve ser o de facilitar a entrega e a obtenção de um conjunto de resultados de aprendizagem claros, mantendo a "fidelidade" a mais alta possível (KHAN et al., 2010).

As habilidades necessárias para criar cenários de simulação de alta fidelidade são diferentes daquelas para escrever cenários de ensino para discussões baseadas em casos. É por isso que o conceito de "engenharia de cenário" é mais adequado do que "escrita de cenário". Se os cenários não forem projetados com a devida diligência, eles não apenas impactarão a ação e a fidelidade temporal, mas também reduzirão o impacto educacional da educação baseada em simulação, por não se vincularem diretamente ao currículo. A integração curricular refere-se a cenários de simulação usados como uma ferramenta de rotina na entrega de partes selecionadas do currículo (KHAN et al., 2010). 


\section{Simulação clínica como avaliação}

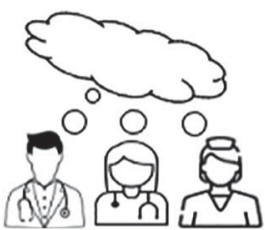

Estudantes e avaliadores presenciais Estudante presencial e avaliador on-line Estudante e avaliador on-line
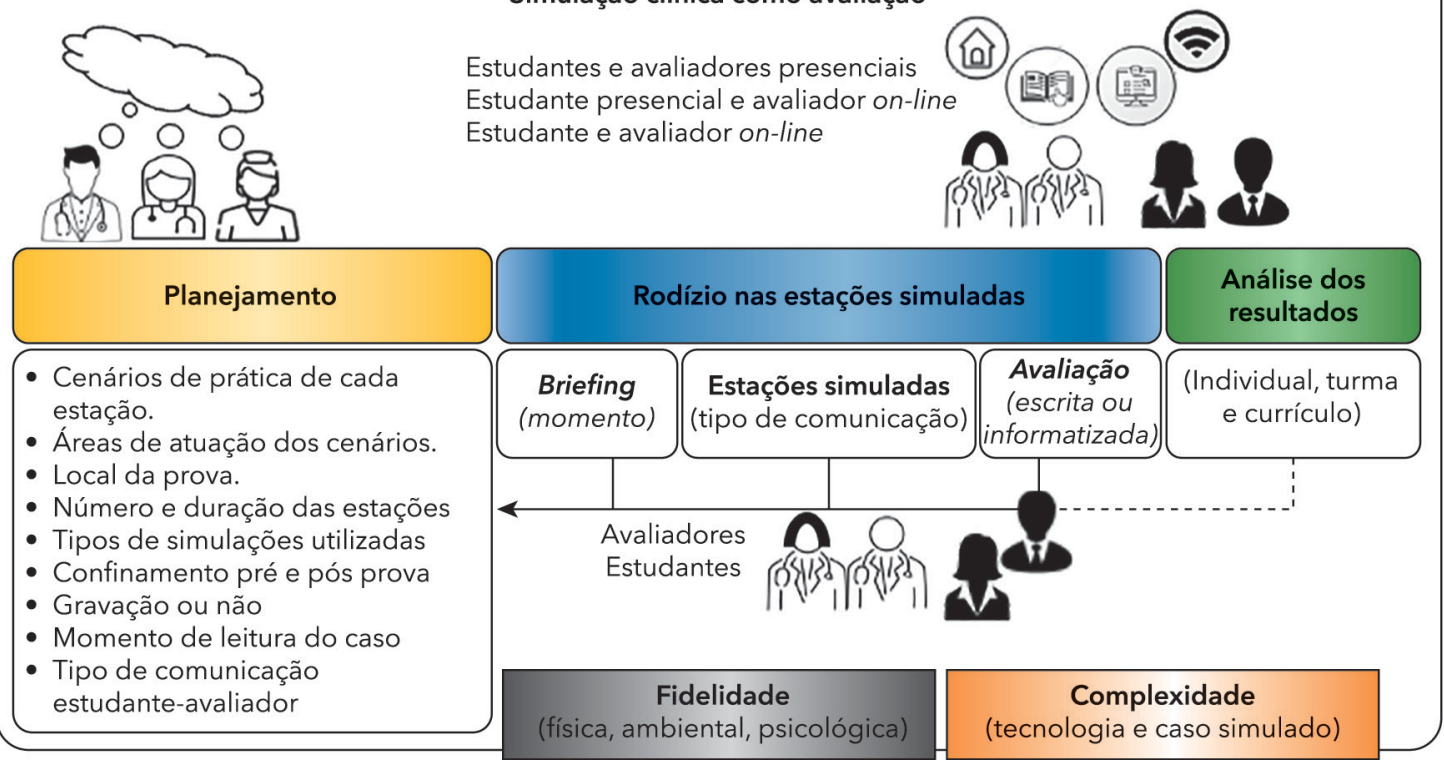

Figura 7 - Proposta para estruturação de cenários simulados para avaliação. Fonte: elaborada pelos autores.

Os cenários adequados dependem desse planejamento detalhado para condução da simulação clínica, podendo variar em relação à complexidade e ao tempo de duração, de acordo com os objetivos de aprendizagem propostos e resultados esperados, sem impedir que outros pontos possam emergir durante a atividade. Dessa forma, o planejamento deve ser retroalimentado, flexível e cíclico, sendo composto por várias escolhas, decisões e construções (ALINIER, 2011; INTERNATIONAL NURSING ASSOCIATION FOR CLINICAL SIMULATION AND LEARNING, 2016).

Casos da vida real costumam ser um bom ponto de partida para o desenvolvimento de cenários, pois costumam trazer consigo boas lições e pontos relevantes para aprendizagem (MURRAY, 2004).

Ao planejar os cenários, é importante lembrar dos conceitos estruturantes apresentados anteriormente ao projetar cenários para trabalhar com fidelidade, buscando realismo e suspensão da descrença.

a) Reconhecimento do problema a ser abordado Ao iniciar a estruturação de um cenário, é importante definir o problema a ser trabalhado e o público-alvo da simulação. Dependendo do local onde será aplicado o cenário, o problema deve estar relacionado aos conteúdos curriculares da graduação e pós-graduação ou a situações ligadas ao trabalho dos profissionais nos serviços de saúde, sejam elas reconhecidas por seus componentes (é interessante quando essa atividade parte das necessidades e expectativas dos participantes) ou secundárias a demandas do contexto da saúde (administrativas, científicas, sociais e políticas). Quanto ao público-alvo, é importante identificar seu conhecimento prévio, pois o cenário simulado deve ser adequado ao seu nível de conhecimento e vivências (NEVES et al., 2017; EPPICH; CHENG, 2015; SANTALUCIA et al., 2016).

\section{b) Definição dos objetivos de aprendizagem}

É uma etapa essencial para a construção do cenário de simulação, pois são as ferramentas de orientação para facilitar a obtenção de resultados e a marca registrada de um projeto educacional sólido.

Os objetivos podem ser amplos ou específicos, e, nesse sentido, a taxonomia de Bloom, apresentada anteriormente, fornece uma estrutura para desenvolver e nivelar objetivos de forma a atender aos resultados esperados. Na taxonomia de Bloom revisada, a hierarquia dos objetivos progride de um nível inferior (lembrar e entender) para um nível superior (aplicar, analisar, avaliar e criar). Esses verbos fornecem a estrutura e se comunicam com as competências que o participante deve alcançar como resultado da participação na atividade de simulação (INTERNATIONAL NURSING 
ASSOCIATION FOR CLINICAL SIMULATION AND LEARNING, 2016).

Para ter resultados alcançáveis, é importante traçar objetivos mensuráveis e claramente definidos. No campo da gestão corporativa, Doran (1981) criou o acrônimo SMART (específico, mensurável, atribuível, realista e relacionado ao tempo) como uma estrutura para desenvolver objetivos mensuráveis e significativos, que pode ser visto no Quadro 1.

No planejamento do cenário, podem ser desenvolvidos objetivos gerais e específicos para atender às necessidades identificadas e otimizar o alcance dos resultados esperados. Os objetivos gerais refletem o propósito da experiência baseada em simulação e estão relacionados com as metas organizacionais, enquanto os objetivos específicos estão relacionados com as medidas de desempenho do participante.

Durante a fase de design, é importante determinar quais objetivos serão ou não disponibilizados para os participantes antes da experiência da simulação. Os objetivos que fornecem informações gerais e contextuais devem ser apresentados para os participantes (por exemplo, realizar cuidados para paciente com insuficiência cardíaca); já aqueles que se referem às medidas de desempenho dos participantes não devem ser apresentados.

\section{c) Identificação das competências a serem trabalhadas}

As competências são domínios construídos e adquiridos em situações cotidianas que necessariamente envolvem a compreensão da ação empreendida e do uso a que essa ação se destina. Portanto, competência é a capacidade de mobilizar recursos cognitivos, emocionais e psicomotores (conhecimentos, habi-

\section{S $\begin{aligned} & \text { Específico: o que exatamente vamos fazer e } \\ & \text { para quem? }\end{aligned}$
M $\begin{aligned} & \text { Mensurável: É passível de quantificar e } \\ & \text { medir? }\end{aligned}$ \\ Atingível: podemos fazer com os recursos e suporte que temos disponíveis? \\ Realista: terá efeito sobre os resultados esperados? \\ $T$ Tempo necessário: quando esse objetivo pode ser alcançado?}

Quadro 1 - Ferramenta SMART. Fonte: adaptado de INACSL (INTERNATIONAL NURSING ASSOCIATION FOR CLINICAL SIMULATION AND LEARNING, 2016). lidades e atitudes) para solucionar, com eficácia, as situações da prática em saúde (BAILLIE; CURZIO, 2009; AGUIAR; RIBEIRO, 2010).

Para definição dessas competências, é válido utilizar a pirâmide de Miller atualizada e o modelo da aquisição de habilidades de Dreyfus, apresentados anteriormente.

Mais atualmente, pode-se empregar os marcos de competências e EPAs para selecionar quais serão utilizados na elaboração do cenário simulado. d) Definição do formato da simulação

Uma vez definidos os objetivos de aprendizagem e o público-alvo da prática simulada, é importante selecionar a modalidade apropriada para a experiência baseada em simulação, escolhendo entre os diversos formatos apresentados até agora. Existem evidências de que a utilização de pacientes simulados treinados (que podem ser atores) nas atividades de simulação aumenta a adesão dos estudantes, tornando a aprendizagem mais significativa.

A definição do cenário de prática que a estação irá simular (unidade básica de saúde, ambulatório, enfermaria, sala de emergência, centro cirúrgico, unidade de terapia intensiva) também é muito relevante.

Deve-se ainda estruturar as experiências baseadas na simulação, incluindo ponto de início, atividades estruturadas do participante e ponto de término. O ponto de início representa as circunstâncias iniciais do paciente ou a situação quando o participante inicia seu envolvimento na experiência baseada em simulação. As atividades estruturadas do participante são compostas para envolvimento do participante (por exemplo, caso simulado ou um desdobramento do cenário e/ou ensino/avaliação das habilidades psicomotoras). O ponto final é o estágio em que se espera que a experiência baseada em simulação termine, geralmente quando os resultados esperados da aprendizagem foram demonstrados, o tempo se esgota ou o cenário não pode prosseguir (KANEKO; LOPES, 2019).

\section{e) Levantamento de recursos}

É importante para determinar as necessidades do cenário simulado a ser elaborado, incluindo recursos materiais e humanos, considerando o cenário de prática que vai ser simulado, os objetivos de aprendizagem e os resultados esperados.

Em relação ao levantamento dos recursos materiais necessários, devem ser incluídos: 1) espaço para a simulação (laboratório de simulação, serviço de saúde ou outro); 2) simuladores (manequins), se forem utilizados; 3) mobiliários (cama, cadeira, ar- 
mários, suporte de soro, biombo); 4) equipamentos (monitor, aspirador, foco); 5) materiais (seringas, sondas, termômetro); 6) documentação de apoio (cartas de encaminhamento, ficha de atendimento, exames complementares); 7) utilização de recursos diagnósticos e terapêuticos, de medicações, de equipamentos; e 8) adereços (roupas, documentos de identificação, embalagens de remédios, exames prévios, dispositivos invasivos, maquiagem, sangue e secreções).

No que se refere ao levantamento dos recursos humanos, devem ser incluídos facilitadores, pacientes simulados ou padronizados, operadores de equipamentos tecnológicos e outros que venham a se fazer necessários.

Quanto mais detalhado o inventário dos recursos necessários, menor será a possibilidade de que um recurso não providenciado previamente ou garantido de última hora interfira na aplicação adequada do cenário.

\section{f) Contexto e detalhamento do cenário simulado}

O contexto deve incluir a realização da documentação para condução das atividades, como presença de relógios para controlar o tempo, scripts e informações a serem oferecidas aos participantes durante o aquecimento da atividade (briefing). Por exemplo: (1) o roteiro do paciente, de forma que quem está falando com o paciente possa, por exemplo, responder às perguntas dos participantes sobre seus sintomas, alergias, medicamentos, história médica anterior, última ingestão e eventos que levaram à sua queixa principal. Esse roteiro deve informar ao paciente como ele deve falar, por exemplo, em frases completas ou não, expressando dor ou desconforto, ser confuso, calmo ou agressivo; (2) roteiro para atores, esclarecendo se eles têm informações adicionais para fornecer aos participantes quando solicitados e se eles devem ser bastante ativos e prestativos, ou apenas responder às solicitações dos participantes; (3) informações para o participante com descrição do caso, tarefa e tempo de realização; (4) caso para o cenário simulado, com descrição sucinta e clara e informações essenciais para o alcance dos objetivos propostos.

Para detalhamento do cenário, deve ser ainda planejada a comunicação entre facilitador e participantes, bem como providenciadas as pistas para fornecer informações quanto à evolução clínica do caso, em resposta às ações do participante. Estas pistas devem ser adicionadas para medida de desempenho e utilizadas para redirecionar o participante quando se desvia do objetivo pretendido. Elas podem ser entregues aos participantes de forma ver- bal (por meio do paciente, facilitador ou um participante incorporado no momento), visual (mudança dos sinais vitais no monitor), por intermédio de dados adicionais (novos resultados de exames), e assim por diante, mas isso deve ser pensado na formulação do cenário.

A organização de um fluxograma para tomada de decisão é importante para auxílio no desenvolvimento do cenário de acordo com a evolução e ações do(s) participante(s). Nesse fluxograma, devem ser descritos os passos esperados dele(s) durante o cenário proposto e as ações a serem realizadas caso alguma atividade seja ou não feita. Nesse caso, a forma oval é utilizada para iniciar e finalizar o processo; a retangular representa uma etapa do processo; e a triangular mostra as decisões a serem tomadas.

Além disso, a realização do checklist contendo as ações/atividades que os participantes devem desenvolver durante a prática simulada, considerando o que é indicado por evidências científicas, os objetivos do cenário e as competências que estão sendo trabalhadas, também representa um recurso interessante tanto para o facilitador quanto para os participantes observadores durante o acompanhamento da simulação (KANEKO; LOPES, 2019).

É importante determinar também se haverá a utilização de distratores, que devem ser pensados com propósito de auxiliar na aprendizagem e aproximar o cenário de condições reais; entretanto, não devem desviar a atenção do participante, afastando-o dos objetivos propostos. É relevante ainda determinar o tempo necessário para a progressão do cenário, para garantir que exista tempo razoável para atingir os objetivos a serem trabalhados.

Recomenda-se ainda construir um roteiro organizado do cenário simulado, incluindo a disposição do mobiliário e das pessoas envolvidas em cena, para sua padronização e reprodutibilidade.

\section{g) Orientações para o facilitador}

Neste passo, devem estar descritas as ações críticas que serão observadas pelo facilitador, as quais sinalizam se os objetivos foram contemplados pelos participantes. Frequentemente, são utilizados instrumentos objetivos, como as listas de tarefas (checklists), possibilitando a padronização da observação e aumentando a sua reprodutibilidade. Esta parte do cenário também deve conter dicas de ações a serem tomadas pelo facilitador no sentido de resolver problemas de execução, sugerindo caminhos alternativos.

Ações prévias do facilitador, como reunião com pacientes simulados para esclarecimento do script 
e pontos fundamentais da atuação cênica, devem ser definidas. O desenvolvimento do cenário, em todas as suas etapas, também deve ser alvo de discussão e detalhamento.

\subsection{DESENVOLVIMENTO DO CENÁRIO SIMULADO}

\section{a) Pré-briefing e briefing}

O pré-briefing deve ser conduzido de forma estruturada antes do desenvolvimento do cenário. Nele, o facilitador pode identificar as expectativas dos participantes. Nessa etapa, realizam-se orientações aos participantes sobre o espaço, equipamento e simulador (INTERNATIONAL NURSING ASSOCIATION FOR CLINICAL SIMULATION AND LEARNING, 2016).

No briefing, devem ser repassadas todas as orientações específicas quanto ao cenário simulado que será desenvolvido, com a apresentação do problema e dos passos relativos à tarefa a ser realizada. Também é interessante estabelecer regras e limites, realizando o contrato de ficção com os participantes, orientação sobre quem são e os papéis dos facilitadores e avaliadores da simulação.

\section{b) Estação simulada}

O momento da ação de simulação é aquele em que a tarefa é realizada de forma prática, sendo observada pelo facilitador e pelos demais participantes, com ou sem gravação audiovisual. Este momento possui ponto de início, atividades estruturadas previstas para o participante e ponto de término. É fundamental que os observadores tenham máxima atenção ao cumprimento dos passos preestabelecidos, de modo a facilitar o debriefing/feedback. Nessa etapa, o facilitador deve estar atento para conduzir a evolução do cenário, estimulando a participação de todos e o trabalho em equipe (INTERNATIONAL NURSING ASSOCIATION FOR CLINICAL SIMULATION AND LEARNING, 2016; NOGUEIRA; DOMINGUES; BERGAMASCO, 2020).

\section{c) Debriefing e sessão de feedback}

O debriefing é uma fase planejada e voltada para a promoção do pensamento reflexivo e o aperfeiçoamento do desempenho futuro do participante que promove o entendimento e apoia a transferência de conhecimentos, habilidades e atitudes.

Deve ser facilitado por uma pessoa competente no processo, desenvolvido em um ambiente que permita a aprendizagem e a confidencialidade, facilitando o envolvimento dos participantes com confiança, comunicação aberta e reflexiva. Além disso, fornece um feedback formativo, planejado para enriquecer o aprendizado e contribuir para a consis- tência da experiência baseada em simulação, tanto para os participantes quanto para os facilitadores, reforçando comportamentos positivos, corrigindo e esclarecendo dúvidas.

Consiste em uma etapa pautada em uma estrutura teórica e deve ser direcionado para os objetivos de aprendizagem e resultados esperados.

$\mathrm{O}$ ambiente do debriefing deve ser positivo e entusiástico, seguindo a visão de "não criticar", utilizando uma condução com questionamentos adequados e permitindo que o estudante/participante memorize as ações, de forma a agir confortavelmente quando um caso real semelhante lhe for apresentado. Assim, auxilia o participante na conceitualização construída na aprendizagem, facilita a reflexão sobre o desempenho individual e permite resumir a aprendizagem fechando as lacunas de conhecimento e desenvolvendo o raciocínio clínico.

No caso de avaliações de habilidades com uso de atividades de simulação, o debriefing pode ser substituído pelo feedback, de modo que os participantes sejam guiados para melhorar ou confirmar sua prática.

No feedback, informações ou diálogos ocorrem entre participantes, facilitador, paciente simulado ou pares, com o objetivo de melhorar a compreensão de conceitos ou de aspectos relacionados ao desempenho.

\subsection{REFLEXÃO PÓS-PRÁTICA}

Por causa da natureza dinâmica do treinamento fundamentado em simulação, essa experiência não se encerra em si mesma. São comuns as reverberações e reflexões decorrentes da vivência de participantes, facilitadores e suas interações.

A aplicação do cenário costuma levar a outras possibilidades valiosas para aprendizagem e a algumas lacunas nesse processo, e a identificação destes pontos deve retroalimentar o planejamento do cenário para que haja um constante aperfeiçoamento dele.

Além da identificação de novas possibilidades e lacunas de aprendizagem, a reflexão pós-prática leva os participantes a um processo de autoavaliação, em que refletem sobre os aspectos específicos de suas condutas e conquistas, e à identificação do que poderia ser melhorado nesse sentido. Ao mesmo tempo, a experiência pode conduzi-los a uma reflexão a respeito do desempenho dos demais participantes, o que pode servir como um balizador para a transformação de condutas. 


\section{CAPACITAÇÃO DOCENTE PARA ELABORAÇÃO DAS ESTAÇÕES SIMULADAS}

No contexto da educação baseada em simulação, o desenvolvimento do corpo docente envolve mais do que apenas o treinamento para executar os cenários de simulação e fornecer feedback de forma eficaz; envolve pelo menos uma compreensão básica de todos os aspectos da simulação, incluindo a manutenção de ambientes de aprendizagem seguros, gerenciamento de fidelidade e engenharia de cenário (KHAN et al., 2010).

O treinamento do corpo docente abaixo do ideal pode levar a uma integração curricular deficiente da simulação com os demais ambientes de ensino, engenharia de cenário inadequada, fraco gerenciamento de fidelidade e debriefing e feedback ineficazes ou contraproducentes. Uma combinação de qualquer um desses fatores pode ser prejudicial à autoconfiança e ao aprendizado dos trainees. Isso poderia, por sua vez, criar uma percepção negativa da educação baseada em simulação, reduzindo a utilidade dessa ferramenta educacional em seus treinamentos futuros. Portanto, é vital treinar o corpo docente com os mais altos padrões possíveis, e isso pode ser alcançado com programas de desenvolvimento do corpo docente cuidadosamente elaborados (KHAN et al., 2010).

Além do uso de simulação para fins de avaliação formativa e somativa, também pode ser usada como uma ferramenta de avaliação diagnóstica, o que ajuda a informar os professores sobre as necessidades dos estudantes e contribui para a modificação e concepção dos planos de ensino ou da matriz curricular com base nos resultados. O uso de simulação em tal contexto pode ser extremamente útil, especialmente no início de um ano ou semestre, antes de passar para a próxima fase (KHAN et al., 2010).
A inserção de simulação nos currículos médicos é mais bem-sucedida quando se torna parte da matriz curricular, e não apenas quando utilizada de forma esporádica (ISSENBERG et al., 2005; MCGAGHIE et al., 2010). Deve-se determinar quais componentes de um currículo são aprimorados usando educação baseada em simulação e incorporando o uso das estações simuladas de forma mais direcionada e sustentada. Esta abordagem tem o benefício adicional de auxiliar a determinar os recursos humanos e materiais, assim como o espaço físico que serão necessários para realizar os treinamentos. Em um currículo já estruturado, permite uma revisão crítica de como o currículo está sendo administrado e como os objetivos de aprendizagem são mais bem alcançados usando as diferentes modalidades de ensino disponíveis. Desenvolvendo-se um plano abrangente antes da sua implementação, certamente irá economizar tempo e recursos valiosos (MOTOLA et al., 2013).

Utilizando-se do conceito de engenharia dos cenários simulados, durante o processo de capacitação docente há o planejamento do processo de instrução em três etapas:

1- escrita do caso clínico selecionado a ser transformado em atividade simulada;

2- montagem dos 15 itens da encomenda da estação simulada (Quadro 2), que é o início da transformação do caso clínico em estação simulada, já permitindo a visualização de como será construída a estação simulada;

3- modelo de construção completa da estação simulada (Quadro 3), que é o roteiro integral do cenário simulado, em que estão as instruções do cenário e tarefas do estudante/candidato, orientações ao avaliador, lista de materiais e equipamentos, mapa de disposição dos móveis e recursos humanos dentro do ambiente físico da estação simulada, script do paciente simulado

Quadro 2 - Itens para estruturação das encomendas dos cenários simulados. Fonte: elaborada pelos autores.

1- Tema/conteúdo a ser abordado (utilizar a matriz de conteúdos): escolher um título que represente o problema a ser trabalhado.

2- Objetivos de aprendizagem/avaliação: o objetivo geral é o resultado que se espera com o aprendizado. Os objetivos específicos são as medidas de desempenho do participante, que geralmente são disponibilizados apenas para os facilitadores. O número de objetivos específicos depende da complexidade e do tempo estabelecido para o cenário. Pode-se utilizar os marcos de competências, que devem ser mobilizados no desenvolvimento da estação.

3- Competências gerais a serem desenvolvidas: conhecimentos, habilidades e atitudes esperadas do participante ao final da atividade, definindo as habilidades específicas a serem demonstradas. 
Quadro 2 - Continuação...

4- Tipo de simulação: definir entre simulação clínica com uso de simulador (manequim), simulação clínica com o uso de paciente simulado (se padronizado), role play, simulação híbrida, prática deliberada de ciclos rápidos, simulação in situ, simulação interprofissional, simulação virtual ou telessimulação.

5- Caso/situação clínica: informações do caso clínico a ser desenvolvido e das tarefas a serem cumpridas, descrevendo-o de maneira sucinta e clara, com informações essenciais para o alcance dos objetivos propostos.

6- Lesões/patologias: definir os achados do exame físico e exames complementares a serem explorados, bem como as decisões críticas de diagnóstico e tratamento.

7- Procedimentos médicos a serem realizados (se houver): definir os materiais e equipamentos que deverão estar presentes no cenário simulado.

8- Distratores: devem ser pensados com o propósito de auxiliar na aprendizagem e aproximar o cenário de condições reais, entretanto não devem desviar a atenção do participante, afastando-o dos objetivos propostos.

9- Cenário de prática: local/referência de local em que será realizado o atendimento/procedimento.

10- Problemas de comunicação: com pacientes, familiares e membros da equipe interprofissional, utilizando as situações mais frequentes de conflitos.

11- Conflitos éticos e jurídicos: caso se apliquem aos objetivos da simulação, realizar a inclusão.

12- Situação interprofissional envolvida: nos casos de utilização, definir as competências comuns e colaborativas.

13- Nível estimado de dificuldade: fácil, médio ou difícil.

14- Informações complementares: inserir outras informações que possam ser úteis na construção da estação.

15- Protocolo/consenso: de orientação para a construção e ponderação do checklist.

Quadro 3 - Itens para estruturação da estação simulada completa. Fonte: elaborada pelos autores.

\section{Definições prévias:}

- Gravação do cenário: definir se será realizada a gravação, bem como os equipamentos e o responsável.

- Tipo de comunicação entre estudante/candidato e avaliadores: formas verbal, escrita, visual.

1- Instruções para o participante/estudante/candidato: informações essenciais para o caso clínico, definição das tarefas e sua duração (estabelecer um limite de duração da atividade com tempo suficiente para que os participantes atinjam os objetivos).

2- Instruções sobre o cenário simulado: realizar a listagem dos recursos de acordo com as necessidades e possibilidades do cenário: 1) espaço para a simulação; 2) simuladores (manequins), se forem utilizados; 3) mobiliários (cama, cadeira, armários, suporte de soro, biombo); 4) equipamentos (monitor, aspirador, foco); 5) materiais (seringas, sondas, termômetro); 6) documentação de apoio (cartas de encaminhamento, ficha de atendimento, exames complementares); 7) utilização de recursos diagnósticos e terapêuticos, de medicações, de equipamentos; e 8) adereços (roupas, documentos de identificação, embalagens de remédios, exames prévios, dispositivos invasivos, maquiagem, sangue e secreções).

3- Checklist de montagem da estação: incluindo a disposição do mobiliário e das pessoas envolvidas em cena, para sua padronização e reprodutibilidade.

4- Recursos humanos para condução do cenário: definir os diferentes papéis a serem desempenhados no cenário para estabelecer o número de participantes e seus pré-requisitos. Em relação ao levantamento dos recursos humanos, devem ser incluídos facilitadores, pacientes simulados ou padronizados, operadores de equipamentos tecnológicos e outros que venham a se fazer necessários. 
Quadro 3 - Continuação...

\section{Definições prévias:}

5- Orientações ao paciente simulado: script e, caso haja necessidade, descrição das observações para moulage, vestimenta e adereços.

6- Orientações e informações ao examinador/avaliador: descrição sequencial e cronológica das condutas a serem tomadas pelo estudante/candidato.

7- Informações sobre o caso e condutas a serem tomadas: descrição das possibilidades de condutas que o estudante/candidato pode tomar e se comportar, definindo como agir.

8- Fluxograma de decisões possíveis das estações: para auxílio no desenvolvimento do cenário de acordo com a evolução e as ações do participante.

9- Checklist do examinador/avaliador: contendo as ações/atividades adequadas que os participantes devem desenvolver durante a prática simulada.

(caso seja simulação cênica, fluxograma de decisão do avaliador e instrumento padronizado de avaliação - checklist).

Na engenharia do cenário simulado, após a definição dos 15 itens da encomenda da estação simulada, os professores que estão sendo capacitados já devem ter decidido por uma série de elementos que permitem a visualização da futura estação simulada. É neste momento que os facilitadores da capacitação docente, com experiência em simulação, fazem as sugestões de viabilidade e fidelidade do cenário simulado. Feito isso, o próximo passo é a utilização do modelo de construção completa da estação simulada pelos professores em capacitação (Tabela 2).

Os checklists representam listas de ações ou itens específicos a serem executados pelo aprendiz, bem como solicitam que os avaliadores atestem ações diretamente observáveis.

A priori, um bom instrumento de avaliação deve idealmente (KUUSKNE, 2017):

- possuir alta confiabilidade entre avaliadores;

- ter alta validade de construção;

- ser viável para aplicar;

- ser capaz de discriminar diferentes níveis de aprendizagem.

É importante que a escolha dos itens do checklist tenha o embasamento em protocolos e consensos para que não haja dúvidas sobre suas escolhas. Isso também irá facilitar a ponderação de cada tópico e de seus itens de avaliação.

Na Quadro 4, pode-se ver o modelo de checklist proposto, com uma estrutura de tópicos que envolvem vários itens de avaliação. Há quatro opções de respostas, sendo que, no processo de elaboração do checklist, é necessário checar os itens individualmente para se definir se serão mantidas todas as opções ou somente as duas extremas, inutilizando as opções intermediárias. No caso de utilização das opções "Adequado" e "Parcialmente adequado", é preciso definir, em cada um dos itens, quais os critérios que diferenciam essas duas opções.

\section{CONSIDERAÇÕES FINAIS}

Neste capítulo, buscamos demonstrar que embora existam evidências de que o uso da simulação como estratégia de ensino e aprendizagem na educação em saúde possa ser eficaz, isso depende da forma como ela é praticada, já que precisa ser formulada de maneira apropriada para que de fato contribua com o aumento do conhecimento, e com a melhoria das habilidades e dos comportamentos profissionais e clínicos dos participantes.

Diante da diversidade de informações que atravessam a literatura sobre o tema, e da ausência de consenços, procuramos problematizar alguns conceitos e práticas, buscando aporte em estudos recentes que partem de questionamentos sobre conteúdos estruturantes para simulação enquanto técnica de ensino, tais como: 1) fidelidade; 2) realismo; 3) suspensão da descrença; 4) contrato de ficção; e 5) complexidade, com vistas a organizar os conhecimentos básicos para estruturação do treinamento de habilidades e da elaboração das estações simuladas.

Outro ponto sobre o qual nos debruçamos foi em relação ao desenvolvimento dos cenários para o treinamento com simulação clínica, trazendo uma sugestão para design, cuidadosamente elaborada e descrita, no intuito de instrumentalizar os leitores em relação a construção e aplicação de simulação para o ensino e para avaliação. 
Quadro 4 - Estrutura de montagem do checklist das estações simuladas. Fonte: elaborada pelos autores.

\begin{tabular}{|l|l|l|l|l|l|}
\hline \multicolumn{2}{|l|}{ Indicadores de avaliação } & Não Fez & Inadequado & $\begin{array}{l}\text { Parcialmente } \\
\text { adequado }\end{array}$ & Adequado \\
\hline A & Tópico avaliado 1 & & & & \\
\hline 1 & Indicador a & & & & \\
\hline 2 & Indicador b & & & & \\
\hline 3 & Indicador c & & & & \\
\hline 4 & Indicador $\mathrm{d}$ & & & & \\
\hline B & Tópico avaliado 2 & & & & \\
\hline 5 & Indicador $\mathrm{f}$ & & & & \\
\hline 6 & Indicador $\mathrm{g}$ & & & & \\
\hline 7 & Indicador h & & & \\
\hline 8 & Indicador $\mathrm{i}$ & & & & \\
\hline C & Tópico avaliado 3 & & & & \\
\hline 9 & Indicador $\mathrm{j}$ & & & & \\
\hline 10 & Indicador $\mathrm{k}$ & & & \\
\hline 11 & Indicador $\mathrm{l}$ & & & \\
\hline 12 & Indicador $\mathrm{m}$ & & & \\
\hline
\end{tabular}

\section{REFERÊNCIAS}

\section{ADVISORY GROUP FOR AEROSPACE RESEARCH AND} DEVELOPMENT - AGARD. Fidelity of simulation for pilot training.. France, 1980. Advisory Report No 159.

AGENCY FOR HEALTHCARE RESEARCH AND QUALITY - AHRQ. Medical errors: the scope of the problem. Rockville, 2009. Ref Type: Pamphlet

AGRAWAL, A. et al. Fuzzy-adaptive-thresholdingthresholding exon prediction. International Journal of Computational Biology and Drug Design, UK, v. 3, n. 4, p. 311-333, 2010.

AGUIAR, A. C.; RIBEIRO, E. C. O. Conceito e avaliação de habilidades e competência na educação médica: percepções atuais de especialistas. Revista Brasileira de Educação Médica, Brasília, v. 34, n. 371-378, 2010.

AKAIKE, M. et al. Simulation-based medical education in clinical skills laboratory. The Journal of Medical Investigation : JMI, Japan, v. 59, n. 1-2, p. 28-35, 2012.

AL-ELQ, A. H. Simulation-based medical teaching and learning. Journal of Family \& Community Medicine, Kingdom of Saudi Arabia, v. 17, n. 1, p. 35-40, 2010.

ALINIER, G. Developing high-fidelity health care simulation scenarios: A guide for educators and professionals. Simulation \& Gaming, v. 42, n. 1, p. 9-26, 2011. http://dx.doi.org/10.1177/1046878109355683.

ALINIER, G.; PLATT, A. International overview of highlevel simulation education initiatives in relation to critical care. Nursing in Critical Care, London, v. 19, p. 42-49, 2014. ANDERSON, L. W. et al. A taxonomy for learning,teaching and assessing: a revison of Bloom's Taxonomy of educational objectives. Nova York: Addison Wesley Longman, 2001. 336 p.

AUSUBEL, D. P.; NOVAK, J. D.; HANESIAN, H. Psicologia Educacional. Rio de Janeiro: Editora Interamericans, 1980. BAER, A. N. et al. Breaking bad news: use of cancer survivors in role-playing exercises. Journal of Palliative Medicine, New Rochelle, v. 11, n. 6, p. 885-892, 2008.

BAILLIE, L.; CURZIO, J. Students' and facilitators' perceptions of simulation in practice learning. Nurse Education in Practice, USA, v. 9, n. 5, p. 297-306, 2009.

BAUMAN, E. B. (2012). Game-based teaching and simulation in nursing and health care. New York, NY: Springer Publishing Company.

BEARNSON, C. S.; WILKER, K. M. Human patient simulators: a new face in baccalaureate nursing education 
at Brigham Young University. The Journal of Nursing Education, Thorofare, v. 44, n. 9, p. 421-425, 2005.

BEAUBIEN, J. M.; BAKER, D. P. The use of simulation for training teamwork skills in health care: How low can you go? Quality \& Safety in Health Care, London, v. 13, p. i51-i56, 2004.

BEGAM, A. A. A.; THOLAPPAN, A. Psychomotor Domain of Bloom's Taxonomy in Teacher Education. Shanlax International Journal of Education, India, v. 6, n. 3, p. 11-14, 2018.

BERGAMASCO, E. C.; PASSOS, I. C. M. D. O.; NOGUEIRA, L. D. S. Estratégias de Simulação In: CONSELHO REGIONAL DE ENFERMAGEM DO ESTADO DE SÃO PAULO. Manual de Simulação Clínica para Profissionais de Enfermagem. São Paulo: COREN, 2020.

BLOOM, B. S. et al. Taxonomy of educational objectives. New York: David Mckay, 1956. 262 p. (v. 1).

BONDUELLE, Q.; CHO, W. S.; ELLOY, M. D. The paediatric tracheostomy parttask trainer: low fidelity, low cost. Annals of the Royal College of Surgeons of England, London, v. 102, n. 1, p. 72, 2020.

BRADLEY, P. The history of simulation in medical education and possible future directions. Medical Education, Oxford, v. 40, n. 3, p. 254-262, 2006.

BRETT FLEEGLER, M. et al. Debriefing assessment for simulation in healthcare: development and psychometric properties. Simulation in Healthcare, Hagerstown, v. 7, n. 5 , p. 288-294, 2012.

BROWN, W. J.; TORTORELLA, R. A. Hybrid medical simulation: a systematic literature review. Smart Learning Environments, v. 7, p. 16, 2020. http://dx.doi.org/10.1186/ s40561-020-00127-6.

CANNON-DIEHL, M. R. Simulation in Healthcare and Nursing: state of the sicence. Critical Care Nursing Quarterly, USA, v. 32, n. 2, p 128-136, 2009. http://dx.doi. org/10.1097/CNQ.0b013e3181a27e0f.

CARDOSO, S. O. O., \& DICKMAN, A. G. (2012). Simulação computacional aliada à teoria da aprendizagem significativa: uma ferramenta para ensino e aprendizagem do efeito fotoelétrico. Caderno Brasileiro de Ensino de Física, Florianópolis, v. 29, n. 2, p. 891-934. Número especial.

CHENG, A. et al. Simulation in paediatrics: An educational revolution. Paediatrics \& Child Health, Oakville, v. 12, n. 6, p. 465-468, 2007.

CHINIARA, G. et al. Simulation in healthcare: A taxonomy and a conceptual framework for instructional design and media selection. Medical Teacher, London, v. 35, n. 8, p. e1380-e1395, 2012.

CHURCHOSE, C.; MCCAFFERTY, C. Standardized patients versus simulated patients: Is there a diference? Clinical Simulation in Nursing, USA, v. 8, n. 8, p. 363365, 2012.

CONKLIN, J .A. Taxonomy for learning, teaching and assessing: a revision of Blooms's taxonomy of education objetives. Educational Horizons, Bloomington, v. 83, n. 3, p. 153-159, 2005.

COOK, D. A. et al. Technologyenhanced simulation for health progressions education: A systematic review and meta-analysis. Journal of the American Medical Association, Chicago, v. 306, n. 9, p. 978-988, 2011.

COSTA, R. R. O. et al. O uso da simulação no contexto da educação e formação em saúde e enfermagem: uma reflexão acadêmica. Revista Espaço para a Saúde, Londrina, v. 16, n. 1, p. 59-65, 2015.

CRUESS, R. L.; CRUESS, S. R.; STEINERT, Y. Amending Miller's Pyramid to Include Professional Identity Formation. Academic Medicine, Philadelphia, v. 91, n. 2, p. 180-185, 2016.

DAVE, R. H. Developing and writing behavioral objectives. London: Educational Innovators Press, 1975. DECKER, S. et al. The evolution of simulation and its contribution to competency. Journal of Continuing Education in Nursing, New Jersey, v. 39, n. 2, p. 74-80, 2008.

DELLIFRAINE, J.; LANGABEER, J.; KING, B. Quality improvement practices in academic emergency medicine: perspectives from the chairs. The Western Journal of Emergency Medicine, Orange, v. 11, n. 5, p. 479-485, 2010. DIECKMANN, P.; GABA, D.; RALL, M. Deepening the theoretical foundations of patient simulation as social practice. Simulation in Healthcare, Hagerstown, v. 2, n. 3, p. 183-193, 2007a.

DIECKMANN, P., ZELTNER, L. G., HELSØ, A.-M. "Handit-on": an innovative simulation on the relation of nontechnical skills to healthcare. Advances in Simulation, USA, v. 1, n. 30, 2016.

DIECKMANN, P. et al. Pistas de realidade e ficção na mídia simulação de paciente cal: Um estudo de entrevista com anestesiologistas. Jornal de Engenharia Cognitiva e Tomada de Decisão, v. 1, p. 148-168, 2007.

DOMINGUES, T. M. A. R.; NOGUEIRA, L. D. S.; MIÚRA, C. R. M. Simulação clínica: principais conceitos e normas de boas práticas. In: CONSELHO REGIONAL DE ENFERMAGEM DO ESTADO DE SÃO PAULO. Manual de Simulação Clínica para Profissionais de Enfermagem. São Paulo: COREN, 2020.

DORAN, G. T. There's a S.M.A.R.T. way to write management's goals and objectives. Management Review, USA, v. 70, n. 11, p. 35-36, 1981.

DREYFUS, S. E. The five-stage model of adult skill acquisition. Bulletin of Science, Technology \& Society, New York, v. 24, p. 177-181, 2004.

EPPICH, W.; CHENG, A. Promoting Excellence and Reflective Learning in Simulation (PEARLS): development and rationale for a blended approach to health care simulation debriefing. Simulation in Healthcare, Hagerstown, v. 10, n. 2, p. 106-115, 2015.

FERRAZ, A. P. C. M.; BELHOT, R. V. Taxonomia de Bloom: revisão teórica e apresentação das adequações 
do instrumento para definição de objetivos instrucionais. Gestão da Produção, São Carlos, v. 17, n. 2, p. 421-431, 2010. FLATO, U.A.P.; GUIMARÃES, H. P. Educação baseada em simulação em medicina de urgência e emergência: a arte imita a vida. Revista da Sociedade Brasileira de Clínica Médica, São Paulo, v. 9, p. 360-364, 2011.

FOREHAND, M. Taxonomia de Bloom. USA: University of Georgia, 2012.

GONZÁLEZ-HERNANDO, C.; MARTÍN-VILLAMOR, P. G.; LÓPEZ-PORTERO, M. D. S. Evaluación por los estudiantes al tutor de enfermeira en el contexto del aprendizage basado en problemas. Enfermería Universitaria, México, v. 12, n. 3, p. 110-115, 2015.

GREENE, L. E.; LEMIEUX, K. G.; MCGREGOR, R. J. Novice to expert: an application of the Dreyfus model to management development in health care. Journal of Health and Human Resources Administration, Montgomery, v. 16, p. 85-95, 1993.

GRIERSON, L. E. M. Information processing, specificity of practice, and the transfer of learning: considerations for reconsidering fidelity. Advances in Health Sciences Education, Dordrecht, v. 19, n. 2, p. 281-289, 2014. http:// dx.doi.org/10.1007/s10459-014-9504-x.

GROBER, E. D. et al. The educational impact of bench model fidelity on the acquisition of technical skill: the use of clinically relevant outcome measures. Annals of Surgery, v. 240, n. 2, 2004.

HAMSTRA, S. J. et al. Reconsiderando a fidelidade no treinamento baseado em simulação. Medicina Acadêmica, Niterói, v. 89, n. 3, p. 387-392, 2014.

HARROW, A. J. (1972). A taxonomy of the psychomotor domain. New York: David McKay Co.

HOQUE, M. E. Three domains of learning: cognitive, affective and psychomotor. The Journal of EFL Education and Research (JEFLER), Bangladesh, v. 2, n. 2, p. 45-52, sept. 2016. Disponível em: <http://lcwu.edu.pk/ocd/cfiles/ Professional\%20Studies/FC/B.ED-307/ArticleBloom. pdf $>$. Acessado em: 5 abr. 2021.

HUNT, E. A. et al. Pediatric resident resuscitation skills improve after "rapid cycle deliberate practice" training. Ressuscitation, USA, v. 85, n. 7, p. 945-951, 2014. https:// doi.org/10.1016/j.resuscitation.2014.02.025.

INSTITUTE OF MEDICINE - IOM. To err is human: building a safer health system. Washington DC: National Academy Press, 1999.

INTERNATIONAL NURSING ASSOCIATION FOR CLINICAL SIMULATION AND LEARNING - INACSL. INACSL Standards of best practice: simulation design. Clinical Simulation in Nursing. v. 12, p. S5-S12, 2016.

ISSENBERG, S. B. et al. Effectiveness of a computer-based system to teach bedside cardiology. Academic Medicine, Philadelphia, v. 74, p. S93-S95, 1999. Supplement 10.

ISSENBERG, S. B. et al. Features and uses of high-fidelity medical simulations that lead to effective learning: a BEME systematic review. Medical Teacher, London, v. 27, n. 1, p. 10-28, 2005.

JEFFRIES, P. R. A Framework for designing, implementing, and evaluating simulations used as teaching strategies in nursing. Nursing Education Perspectives, New York, v. 26, p. 96-103, 2005.

KANEKO, R. M. U., LOPES, M. H. B. M. Cenário em simulação realística em saúde: o que é relevante para a sua elaboração? Revista da Escola de Enfermagem da USP, São Paulo, v. 53, e03453, 2019.

KHAN, K. et al. Simulation in healthcare education building a simulation programme: A practical guide: AMEE Guide No. 50. Medical Teacher, London, 2010.

KIRKPATRICK, D. Great Ideas Revisited. Techniques for evaluating training programs. Revisiting Kirkpatrick's Four-Level Model. Training and Development, USA, v. 50, n. 1, p. 54-59, 1996.

KNEEBONE, R.; AGGARWAL, R. Surgical training using simulation. British Medical Journal, London, v. 338, p. b1001, 2009.

KNOWLES, M. S. The modern practice of adult education: From pedagogy to andragogy. Englewood Cliffs, NJ: Prentice Hall/Cambridge. Cambridge Book Co, 1980.962 p.

KOBALLA, T. Framework for the affective domain in science education. 2007. Disponível em: <https://serc. carleton.edu/NAGTWorkshops/affective/framework. html>. Acesso em: 4 abr. 2021.

KRATHWOHL, D. R. A revision of bloom's taxonomy: an overview. Theory into Practice, USA, v. 41, n. 4, p. 212-218, 2002.

KUUSKNE, M. Simulation-based assessment. 2017. Disponível em: <https://emsimcases.com/2017/11/28/ simulation-based-assessment/> . Acesso em: 22 maio 2021.

LAUCKEN, U. Theoretical Psychology. Oldenburg: Bibliotheks- und Informationssystem der Universita"t Oldenburg, 2003.

LEWIS, K. L. et al. The Association of Standardized Patient Educators (ASPE) Standards of Best Practice (SOBP). Advances in Simulation, USA, v. 2, n. 1, 2017. https://doi. org/10.1186/s41077-017-0043-4.

LIOCE, L. et al. Healthcare simulation dictionary. 2nd ed. Rockville: Agency for Healthcare Research and Quality; 2020.

MAGER, R. F. Preparing instructional objectives. Belmont: Lake Publishers Co., 1984. 136 p.

MARAN, N. J.; GLAVIN, R. J. Low- to high-fidelity simulation - a continuum of medical education? Medical Education, Oxford, v. 37, p. 22-28, 2003. Supplement 1. https://doi.org/ 10.1046/j.1365-2923.37.s1.9.x.

MATSUMOTO, E. D. et al. The effect of bench model fidelity on endourological skills: a randomized controlled study. The Journal of Urology, Baltimore, v. 167, n. 3, p. 1243-1247, 2002. 
MCCOY, C. E. et al. Telesimulation: an innovative tool for health professions education. AEM Education and Training, Medford, v. 1, n. 2, p. 132-136, 2017. https://doi. org/10.1002/aet2.10015.

MCGAGHIE, W. C. et al. A critical review of simulationbased medical education research: 2003-2009. Medical Education, Oxford, v. 44, p. 50-63, 2010.

MEAKIM, C. et al. Standards of best practice: simulation standard I: terminology. Clinical Simulation in Nursing, New York, v. 9, n. 6S, p. S3-S11, 2013. Supplement.

MEHAY, R. Assessment and competence, Miller's pyramid/ prism of clinical competence. In: Mehay, R. (Editor). The essential handbook for GP training and education. London: Radcliffe Publishing, 2012.

MENEZES, P. D. D. T. R.; MOLINA, M. S. A.; DOS SANTOS, J. F. P. O papel do facilitador. In: CONSELHO REGIONAL DE ENFERMAGEM DO ESTADO DE SÃO PAULO. Manual de Simulação Clínica para Profissionais de Enfermagem. São Paulo, 2020.

MILLER, G. The assessment of clinical skills/competence/ performance. Academic Medicine, Philadelphia, v. 65, p. S63-S67, 1990.

MOTOLA, I. et al. Simulation in healthcare education: a best evidence practical guide. AMEE Guide No. 82. Medical Teacher, London, v. 35, n. 10, p. e1511-e1530, 2013.

MUCKLER, V. C. Exploring suspension of disbelief during simulation-based learning. Clinical Simulation in Nursing, v. 13, n. 1, p. 3-9, 2016.

NEGRI, E. C. et al. Construção e validação de cenário simulado para assistência de enfermagem a pacientes com colostomia. Texto \& Contexto Enfermagem, Florianópolis, v. 28, e20180199, 2019.

NEVES, F. F.; IGLESIAS, A. G.; PAZIN-FILHO, A. Construção de cenários simulados. In: SCALABRINI NETO, A.; FONSECA, A. D. S.; BRANDÃO, C. F. S. Simulação realística e habilidades na saúde. Rio de Janeiro: Atheneu, 2017

NOGUEIRA, L. D. S.; DOMINGUES, T. M. M. D.; BERGAMASCO, E. C. Construção do cenário simulado. In: CONSELHO REGIONAL DE ENFERMAGEM DO ESTADO DE SÃO PAULO. Manual de Simulação Clínica para Profissionais de Enfermagem. São Paulo: COREN, 2020.

DE OLIVEIRA, S. N.; DO PRADO, M. L.; KEMPFER, S. S. Utilização da simulação no ensino da enfermagem: revisão integrativa. Revista Mineira de Enfermagem, Belo Horizonte, v. 18, n. 2, pp.487-495, 2014.

ORLEDGE, J. et al. The use of simulation in healthcare. Current Opinion in Critical Care, Hagerstown, v. 18, n. 4, p. 326-332, 2012.

OWEN, H. Simulation in healthcare education. Switzerland: Springer, 2016.

PADILHA, J. M. et al. Clinical virtual simulation in nursing education: randomized controlled. Journal of Medical
Internet Research, Pittsburgh, v. 21, n. 3, p. el1529, 2019. http://dx.doi.org/10.2196/11529.

PARK, J. Proposal for a Modified Dreyfus and Miller Model with simplified competency level descriptions for performing self-rated surveys. Journal of Educational Evaluation for Health Professions, Seoul, v. 12, p. 54, 2015. PEREIRA JÚNIOR, G. A. et al. O Ensino de Urgência e Emergência de acordo com as novas Diretrizes Curriculares Nacionais e a Lei do Mais Médicos. Cadernos ABEM, v. 11, p. 20-47, 2015.

PERKINS, G. D. Simulation in resuscitation training. Resuscitation, London, v. 73, n. 2, p. 202-211, 2007.

PILCHER, J., et al. Simulation-Based Learning: It's Not Just for NRP. Neonatal Network, San Francisco, v. 31, n. 5, p. 281-287, 2012. http://dx.doi.org/10.1891/0730-0832.31.5.281.

RANGARAJAN, K.; DAVIS, H.; PUCHER, P. H. Systematic review of virtual haptics in surgical simulation: a valid educational tool? Journal of Surgical Education, New York, v. 77, n. 2, p. 337-347, 2020.

REHMANN, A.; MITMAN, R.; REYNOLDS, M. (1995). A Handbook of Flight Simulation Fidelity Requirements for Human Factors Research. DOT / FAA / CT-TN96 / 46. Ohio: Crew Systems Ergonomics Information Analysis Center. Wright-Patterson AFB.

REZNICK, R. K.; MACRAE, H. Teaching surgical skillschanges in the wind. The New England Journal of Medicine, UK, v. 355, p. 2664-2669, 2006.

RODGERS, D. L. High-fidelity patient simulation: A descriptive white paper report. Charleston: Healthcare Simulation Strategies, 2007.

RUDOLPH, J. W.; RAEMER, D. B.; SIMON, R. Establishing a safe container for learning in simulation: the role of the presimulation briefing. Simulation in Healthcare, Hagerstown, v. 9, n. 6, p. 339-349, 2014. http://dx.doi. org/10.1097/SIH.0000000000000047.

SANTALUCIA, P. et al. Simulation in medicine, Italian Society for simulation in medicine position paper: executive summary. Internal and Emergency Medicine, Roma, v. 11, n. 4, p. 537-544, 2016.

SEROPIAN, M. A. et al. Simulation: not just a Manikin. The Journal of Nursing Education, New York, v. 43, p. 164-169, 2004.

SIMPSON, E. J. (1966). The classification of educational objectives, psychomotor domain. Washington, DC: U.S. Department of Health, Education, and Welfare.

TEN CATE, O. Nuts and bolts of entrustable professional activities. Journal of Graduate Medical Education, Chicago, v. 5, n. 1, p. 157-158, 2013.

TEN CATE, O. et al. Curriculum development for the workplace using Entrustable Professional Activities (EPAs): AMEE Guide No. 99. Medical Teacher, London, v. 37, n. 11, p. 983-1002, 2015.

TEN CATE, O. A primer on entrustable professional activities. Korean Journal of Medical Education, Seoul, v. 30, n. 1, p. 1-10, 2018. 
TETERIS, E. et al. O treinamento de alunos em simuladores beneficia pacientes reais? Advances in Health Sciences Education : Theory and Practice, Boston, v. 17, p. 137144, 2012. http://dx.doi.org/10.1007/s10459-011-9304-5.

TUN, J. K. et al. Redefining simulation fidelity for healthcare education. Simulation \& Gaming, Newbury Park, v. 46, p. 159-174, 2015.

TURKOT, O. et al. A review of anesthesia simulation in low-income countries. Current Anesthesiology Reports, USA, v. 9, p. 1-9, 2019. http://dx.doi.org/10.1007/ s40140-019-00305-4.
UNVER, V. et al. Integrating simulation based learning into nursing education programs: hybrid simulation. Technology and Health Care, New York, v. 26, n. 2, p. 263-270, 2018. http://dx.doi.org/ 10.3233/THC-170853.

WILSON, L.; WITTMAN-PRICE, R. A. (Ed). (2015). Review manual for the certified healthcare simulation educator (CHSE) exam. New York, NY: Springer Publishing Company.

ZIV, A. et al. Simulation-based medical education: an ethical imperative. Academic Medicine, Philadelphia, v. 78, n. 8, p. 783-788, 2003. 
CAPÍTULO 4

-

Princípios Instrucionais na Simulação: Uso das Diretrizes de Desenho Instrucional na Simulação 


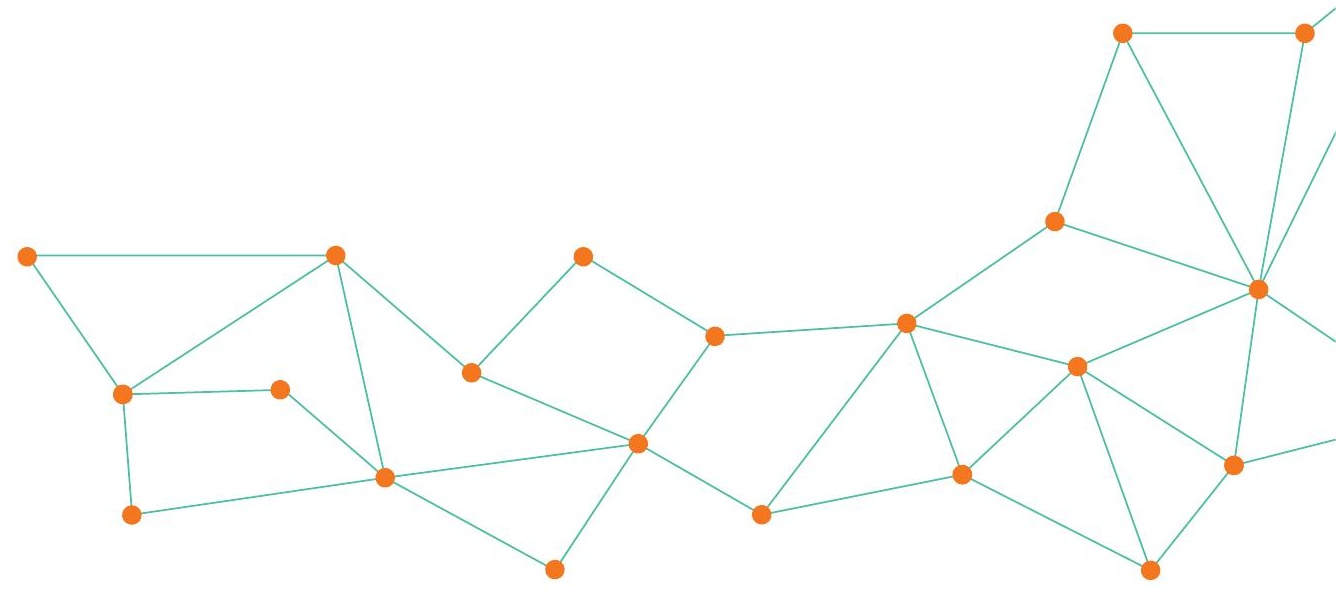

\section{PANORAMA GERAL: POR QUE SIMULAÇÃO?}

Nas últimas décadas, a simulação - replicação de aspectos da realidade em ambiente controlado tem sido cada vez mais adotada como estratégia de treinamento na área de saúde. Historicamente, a simulação foi amplamente adotada nas rotinas de treinamento das indústrias da guerra e da aviação. Ou alguém, em tempos atuais, concebe embarcar em um avião comandado por um piloto sem um número adequado de horas de treinamento em simuladores, com feedback adequado e treinamento de situações adversas? Da mesma forma, na saúde o treinamento em simulação torna-se indispensável para o desenvolvimento das diferentes competências de seus profissionais, tendo a oportunidade de promover: a) treinamento em "ambiente seguro para erros” - eventuais erros não levam a perdas de vidas; b) chance de repetição da prática até a sua excelência; e c) um ambiente para a experimentação de novas práticas (PINTO DE MELO, 2018).

Um marco histórico de disseminação do treinamento em simulação na área da saúde foi o relatório To Err is Human, de 1999, do National Institutes of Health (NIH). De acordo com o documento, a cada ano, 98 mil pessoas morriam em hospitais dos Estados Unidos como resultado de erros médicos evitáveis. Além de chocar a opinião pública da época, o relatório tornou evidente a necessidade de treinamento regulares para os profissionais de saúde - tanto para aqueles em formação quanto os mais experientes. A partir daí, associado ao uníssono objetivo de melhoria nos cuidados com pacientes e nos desfechos deles, houve a disseminação do treinamento em simulação na área da saúde. Atualmente, alguns dados sustentam essa necessidade, por exemplo, o aumento do número de mortes 
maternas nos Estados Unidos (muitas evitáveis) na contramão do panorama mundial de redução de mortes maternas. Ainda, atualizações preocupantes do levantamento realizado pelo NIH apontam para números pelo menos duas vezes maiores de eventos adversos evitáveis do que os anteriormente reportados (KOHN et al., 2000; JAMES, 2013).

A disseminação dos treinamentos em simulação em saúde, frequentemente associada a elevados investimentos financeiros, sem planejamento adequado, contudo, não assegura uma melhoria de resultados para os pacientes. Para uma eficiência e consequente otimização dos recursos, é necessário, portanto, um planejamento instrucional (pedagógico) dos formatos dos treinamentos. Esse planejamento tem o objetivo de maximizar: a) o aprendizado; b) a transferência do conhecimento - tornar o aprendiz capaz de aplicar o conhecimento adquirido em seu ambiente profissional; e c) os resultados - no caso da saúde, uma melhora dos desfechos nos cuidados com os pacientes (KIRKPATRICK, 1996). Metanálises sobre a eficiência dos treinamentos em simulação apontam para essa necessidade de planejamento pedagógico adequado com o uso de elementos instrucionais eficientes (por exemplo, variabilidade e complexidade crescente de casos, feedback) (COOK et al., 2013).

\section{CONSTRUÇÃO DE CENÁRIO PARA APRENDIZAGEM}

A simulação como estratégia instrucional pode ser planejada tanto para o ensino de habilidades manuais pontuais, por exemplo, aprender pontos de suturas, quanto para manejos de situações clínicas complexas. Na prática diária, o manejo real do paciente envolve uma grande interação de elementos, e essa complexidade vivenciada pelo profissional de saúde pode ser aprendida, treinada e praticada (aprendizagem complexa) em um ambiente simulado. Ao se considerar essa necessidade de aprendizagem complexa - a integração de conhecimento, habilidades psicomotoras e atitudes -, fica evidente o quão fundamental é planejar treinamentos eficientes em simulação. A grande vantagem da simulação ocorre por conta de sua característica de possibilitar o estímulo simultâneo de vários dos sentidos, como audição, tato e visão, favorecendo, assim, o aprendizado. Além disso, se bem desenhada sob uma perspectiva instrucional, ela promoverá não apenas o aprendizado, mas, em longo prazo, a capacitação do aprendiz de aplicar o conhecimento adquirido na sua prática profissional (transferência do conheci- mento) (MELO et al., 2018; VAN MERRIËNBOER; KIRSCHNER, 2018).

Para um bom desenho instrucional da simulação, o uso de algumas orientações, organizadas sob forma de diretrizes, deve ser considerado. As diretrizes de desenho instrucional são recomendações práticas para o aprendizado e a transferência dele e derivam de sólidas teorias cognitivas sobre como as pessoas aprendem. Mais adiante, serão apresentadas duas diretrizes de desenho instrucional que sumarizam as principais orientações: os primeiros princípios instrucionais de Merrill - Merrill's First Principles of Instruction - e o modelo de desenho instrucional de quatro componentes $-4 C / I D$ model (MERRILL, 2002; VAN MERRIËNBOER; KIRSCHNER, 2018). Mas, antes, faz-se um resumo de conceitos cognitivos introdutórios sobre o processo de aprendizagem.

\section{COMO APRENDEMOS?}

O modelo de Atkinson e Shiffrin - uma das teorias de memória humana mais aceitas - descreve o processamento de informações pelo cérebro humano em três estágios: registro sensorial, memória de trabalho e memória de longo prazo. O primeiro, o registro sensorial, percebe os diferentes estímulos sensoriais do ambiente a partir dos sentidos: audição, tato, visão e olfato. Naquele momento, o aluno tem a capacidade de reter a informação por apenas algumas frações de segundos. A seguir, apenas parte dessa informação é selecionada e processada pela memória de trabalho - com capacidade de retenção um pouco maior, mas ainda menos de um minuto, e depois facilmente esquecida. Entretanto, é nesse estágio, na memória de trabalho, em que há chance de ocorrer o processo cognitivo, após o qual a informação pode ser processada e retida por mais tempo. Uma vez processada pela memória de trabalho, a informação é então armazenada na memória de longo prazo (ATKINSON; SHIFFRIN, 1968; MELO et al., 2018).

A memória de trabalho é considerada como de "capacidade limitada", conforme sintetizada no conceito tradicional de Miller (MILLER, 1955), do "número mágico sete, mais ou menos dois". De acordo com esse conceito, a memória de trabalho tem a capacidade de processar grupos de informações em blocos de sete mais ou menos duas unidades. Exemplos práticos desse conceito podem ser vistos em números de telefone, códigos de endereçamento postal (CEP) etc. Por fim, a memória de 
longo prazo tem potencial para arquivar um número ilimitado de esquemas cognitivos após processamento na memória de trabalho.

Baseada nessas premissas, a teoria da carga cognitiva diferencia três tipos de cargas: carga intrínseca, determinada pela complexidade das tarefas (por exemplo, a quantidade de elementos de interação que devem ser processados simultaneamente); carga externa ou irrelevante, trazida por desenhos instrucionais subótimos e associados a processos que não contribuem para a aprendizagem (por exemplo, lidar com redundância ou dispersões); e carga cognitiva natural ou relevante, causada por desenho instrucional apropriado e processos associados que contribuem diretamente para a aprendizagem (por exemplo, a indução e a elaboração) (SWELLER, 1994; VAN MERRIËNBOER; SWELLER, 2010).

A Figura 1 representa esse modelo.

Para serem eficientes, as estratégias de instrução, como a simulação, devem facilitar o esforço da memória de trabalho e promover a construção de esquemas cognitivos para o longo prazo, e as diretrizes de desenho instrucional fazem exatamente esse papel (VAN MERRIËNBOER; KESTER; PAAS, 2006; VAN MERRIËNBOER; SLUIJSMANS, 2009; SWELLER; MERRIËNBOER; PAAS, 1998; VAN MERRIËNBOER; SWELLER, 2005; VAN MERRIËNBOER; KIRSCHNER, 2018; PINTO DE MELO, 2018).

\section{DIRETRIZES DE DESENHO INSTRUCIONAL}

A seguir, serão apresentadas duas das principais diretrizes de desenho instrucional: os primeiros princípios instrucionais de Merrill - Merrill's First Principles of Instruction - e o modelo de desenho instrucional de quatro componentes - 4C/ID model (MERRILL, 2002; VAN MERRIËNBOER; CLARK; CROOCK, 2002).

De acordo com Merrill, cinco princípios instrucionais devem ser considerados ao se elaborar um treinamento para promover aprendizagem e transferência da aprendizagem: (1) os aprendizes devem ser estimulados a resolver um problema do mundo real (problema autêntico); (2) o conhecimento prévio dos aprendizes deve ser utilizado como base para a construção de novo conhecimento; (3) deve haver demonstração do que se deseja ensinar; (4) o aprendiz deve ter a oportunidade de aplicar o novo conhecimento; e (5) o aprendiz deve ter a oportunidade de integrar o novo conhecimento ao seu mundo real. A Figura 2 apresenta uma síntese dessa diretriz (MERRILL, 2002).

Já o modelo 4C/ID apresenta quatro componentes: (1) tarefas a serem aprendidas; (2) informação de suporte (ou de apoio); (3) informação de procedimento; e (4) prática parcial (Figura 3). As tarefas a serem aprendidas (o "problema" do cenário) devem visar à integração de conhecimento, práticas e

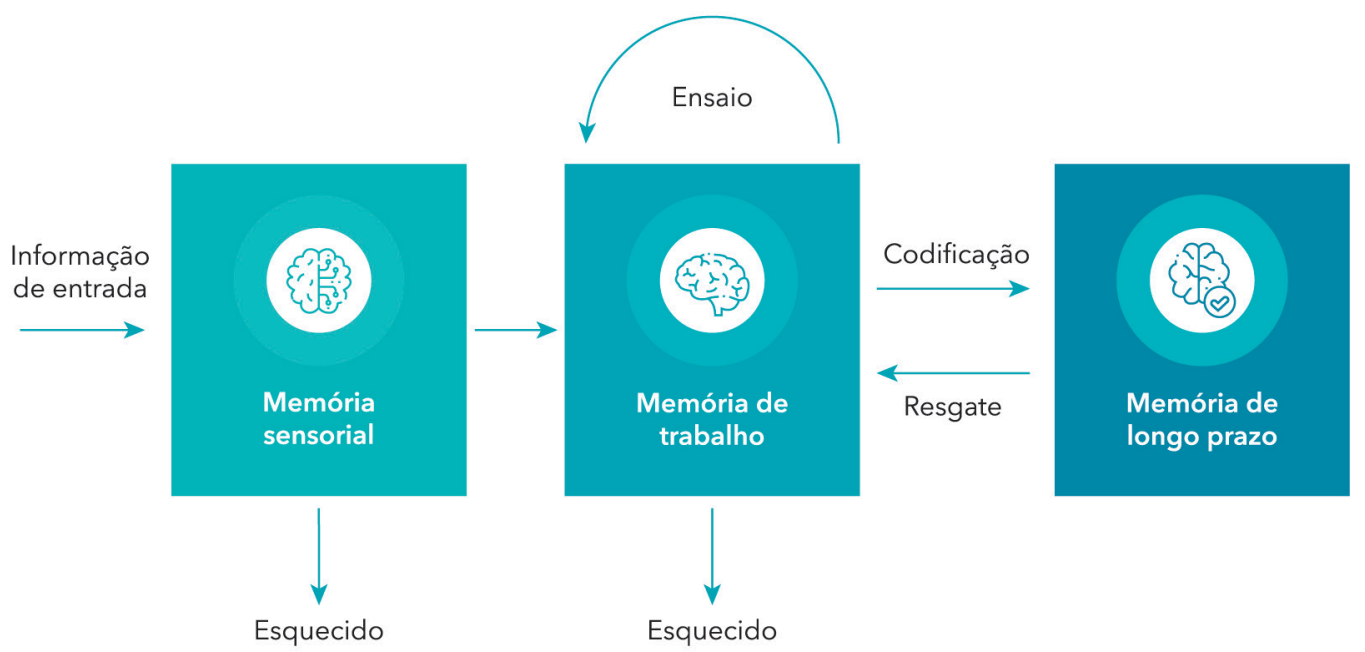

Figura 1 - Modelo de Processamento de Informação. Figura adaptada de Atkinson e Shiffrin (1968), Tradução: Brena Melo, Arte: Bruno Hipólito. 


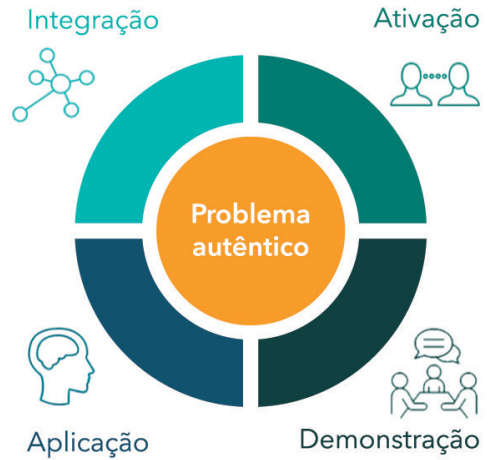

Figura 2 - Primeiros Princípios instrucionais de Merrill (Merrill's First Principles of Instruction) Figura adaptada de Merrill (2002).Tradução: Brena Melo, Arte: Bruno Hipólito. atitudes e promover tarefas completas, não apenas parciais. Elas devem ser autênticas, ou seja, baseadas em problemas factíveis do dia a dia, e devem ser organizadas em tipos de tarefas com ordem crescente de complexidade, com diminuição progressiva do suporte (orientações) a cada tipo diferente de tarefa praticada. O ideal é que haja grande variabilidade das práticas, o que, na simulação, pode ser oferecido por meio de múltiplos cenários.

A informação de suporte (ou de apoio) deve dar suporte à aprendizagem e performance dos aspectos não recorrentes (não automatizados) das tarefas. São roteiros, diretrizes, referências ou resumos sobre o tema a ser ensinado. Ela corresponde ao embasamento teórico do problema (objetivo de aprendizagem) e deve explicar como resolver os problemas e como organizar o conhecimento. A informação

\section{Tarefas a serem aprendidas}

- Buscam integrar habilidades (não-recorrentes e recorrentes), conhecimentos e atitudes

- Oferecem experiências autênticas de modo amplo (holístico) baseadas em tarefas da vida real

- São organizadas em classe de tarefas, de simples a complexas, com redução do suporte a cada etapa (retirada dos andaimes)

- Demonstram grande variabilidade prática

\section{Prática parcial}

- Oferece oportunidade de prática adicional para aspectos recorrentes selecionados para a obtenção de um alto nível de automação

- Oferece oportunidade de uma grande quantidade de repetição

- Começa somente após aspectos recorrentes terem sido completamente apresentados no contexto da tarefa completa

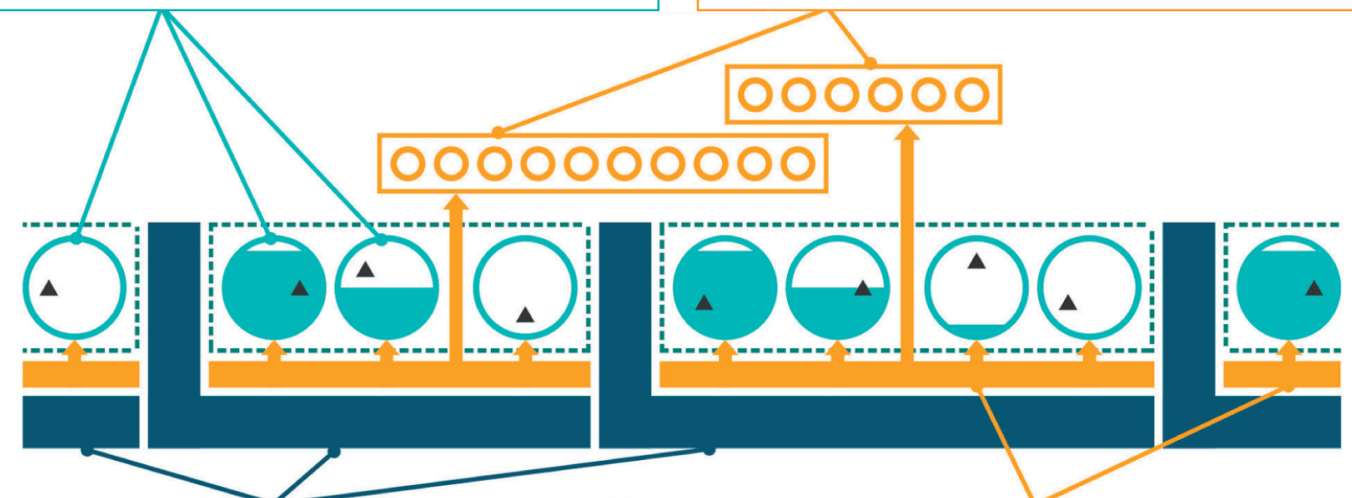

\section{Informação de suporte (ou de apoio)}

- Oferece suporte ao aprendizado e à performance dos aspectos não-recorrentes das tarefas a serem aprendidas

- Explica como abordar os problemas em determinado tema (estratégias cognitivas) bem como o referido tema é organizado (modelos mentais)

- É especificada por classes de tarefas e está sempre disponível
Informação de procedimento

- É pré-requisito para o aprendizado e performance dos aspectos recorrentes da tarefa a ser apreendida

- Especifica precisamente como executar os aspectos recorrentes da tarefa, por exemplo, através de uma instrução passo-a-passo

- É apresentada durante a execução da tarefa (just-in-time) a ser aprendida e imediatamente dispensada assim que o aprendiz adquire expertise

Figura 3 - Representação gráfica dos quatro componentes do Modelo 4C/ID: (a) tarefas a serem aprendidas, (b) informação de suporte (ou de Apoio), (c) informação de procedimento, e (d) prática parcial, by Jeroen J. G. van Merriënboer, 2020. Fonte: Four-Component Instructional Design (2021). 
de suporte (ou de apoio) deve ser específica para cada tipo de tarefa e estar sempre disponível para os aprendizes (VAN MERRIËNBOER; CLARK; DE CROOCK, 2002; VAN MERRIËNBOER; KIRSCHNER, 2018; FREREJEAN et al., 2019; PINTO DE MELO, 2018). Por exemplo, em um treinamento simulado para hemorragia pós-parto (HPP), a informação de suporte (ou de apoio) pode ser representada por um protocolo sintetizando as condutas para o manejo da HPP.

A informação de procedimento deve ser pré-requisito para a aprendizagem e performance dos aspectos recorrentes das tarefas práticas e deve detalhar, de maneira precisa, como realizá-las, com orientações passo a passo. Ela deve ser apresentada no exato momento em que o aprendiz precisa (just-in-time - JIT - information) até poder ser dispensada. Por exemplo, em uma simulação para intubação orotraqueal, o JIT poderia ser representado por um diagrama demonstrando como testar o cuff do tubo orotraqueal antes do procedimento.

Por fim, a prática parcial oferece a oportunidade de praticar alguns aspectos recorrentes das tarefas até que se atinja um grau elevado de automação, e, para isso, a atividade deve oferecer oportunidade de várias repetições (VAN MERRIËNBOER; KIRSCHNER, 2018; VAN MERRIËNBOER; CLARK; DE CROOCK, 2002; FREREJEAN et al., 2019).

As duas diretrizes apresentadas têm como premissas em comum que um treinamento eficiente ou simulação deva apresentar um "problema" ou objetivo de aprendizagem que tenha autenticidade, ou seja, cenários que reproduzam os desafios do dia a dia do aprendiz. Elas também destacam a importância de se oferecer oportunidade de repetição da prática durante o treinamento por meio, por exemplo, de múltiplos cenários; oferecer prática distribuída, com aumento progressivo de dificuldade a cada cenário; promover a interação cognitiva e construir o aprendizado a partir do conhecimento prévio do aprendiz; oferecer diferentes estratégias de aprendizagem; oferecer feedback ou debriefing no caso da simulação; diminuir o suporte ao longo do treinamento; dar oportunidade de praticar e integrar o conhecimento (CHAUVIN, 2015; VAN MERRIËNBOER; KIRSCHNER, 2018; MERRIËNBOER; SWELLER, 2005; CHENG et al., 2014; LEVETT-JONES; LAPKIN, 2014; HATALA et al., 2014).

Na Figura 3, os círculos maiores representam as tarefas a serem aprendidas; as imagens em "L", a informação de suporte; as barras cinzas com setas, a informação de procedimento; e as caixas com bolas menores, a prática parcial. Os preenchimentos decrescentes das bolas maiores indicam a diminuição do suporte ao longo do treinamento.

\subsection{AUTENTICIDADE DO PROBLEMA}

Um elemento fundamental para promover o aprendizado e a transferência de conhecimento a longo prazo é a motivação do aprendiz. Para sentir-se "motivado" a resolver o problema apresentado, o cenário simulado deve parecer autêntico, real. Assim, algumas dimensões devem ser consideradas para se imprimir um clima de motivação e realidade ao cenário.

Primeiramente, o cenário deve refletir um problema passível de ser encontrado pelo profissional em treinamento, seja um evento raro ou frequente no dia a dia do profissional. Além disso, há o grau de fidelidade do cenário, que deve ser considerado em dois aspectos: a fidelidade psicológica e a fidelidade de engenharia. A fidelidade psicológica, ou funcional, refere-se ao quanto a apresentação e o desenho do cenário motivam os aprendizes a resolver o problema apresentado. Se, por exemplo, durante um treinamento simulado os aprendizes afirmam ter, de fato, engajado-se emocionalmente na resolução do problema presente no cenário, houve boa fidelidade psicológica. Em um estudo qualitativo com entrevistas com residentes, após um treinamento simulado um deles afirmou: "Houve uma hora em que todos se estressaram com o caso", o que demonstra uma boa fidelidade psicológica desse treinamento (PINTO DE MELO, 2018).

Já a fidelidade de engenharia, ou física, refere-se ao grau com que o simulador (manequim parcial ou completo, de alta ou baixa fidelidade) ou o ambiente replicam as características físicas da tarefa real. Apesar do debate atual na literatura quanto à exata definição de autenticidade, há um consenso geral de que o importante é provocar os aprendizes a perceber o cenário como "desafiadores", a ponto de sentirem-se motivados a despender o esforço necessário para resolver o problema apresentado (MARAN; GLAVIN, 2003; GRIERSON, 2014; PINTO DE MELO, 2018).

Enquanto a fidelidade psicológica deve ser sempre priorizada, a intensidade da fidelidade de engenharia vai depender, principalmente, do grau de experiência dos alunos. Para os mais experientes (internos ou já profissionais de saúde), há maior necessidade de uma fidelidade do ambiente, do material, ou seja, da fidelidade de engenharia, o que pode ser obtido a partir de uma combinação de um paciente simulado com um simulador parcial de baixo custo, por exemplo. Dessa forma, a in- 
corporação de manequins de alta fidelidade pode se adequar às diferentes realidades orçamentárias sem maiores prejuízos. Para aprendizes noviços, os simuladores devem estar disponíveis, mas a reprodutibilidade do ambiente, como um bloco cirúrgico, pode ser reproduzido em menor riqueza de detalhes (MARAN; GLAVIN, 2003; NORMAN; DORE; GRIERSON, 2012; GRIERSON, 2014).

Outro elemento importante para uma boa transferência do conhecimento é a relevância do conteúdo a ser treinado, ou seja, os objetivos de aprendizagem da simulação devem ser considerados como relevantes pelos aprendizes, pois isso aumenta a chance de o conhecimento adquirido ao longo do treinamento ser aplicado posteriormente no seu dia a dia de trabalho (BALDWIN; FORD, 1988). Como exemplo, pode-se preparar um caso de reanimação cardiovascular para estudantes do final do curso de Medicina e/ou casos de classificação de risco atípicos para estudantes de Enfermagem.

O local onde será oferecido o treinamento também deve ser considerado como importante para a autenticidade do cenário. Um treinamento simulado pode ocorrer "in situ", ou seja, no próprio ambiente de trabalho (uma sala de parto sem pacientes reais), ou "off site", em um centro de simulação (Figura 4). As questões operacionais envolvidas (viabilidade de se bloquear uma sala do centro cirúrgico para treinamento) terminam sendo decisivas nesse processo de escolha. Quando possível, para treinamento de profissionais mais experientes, o treinamento in situ contribui para dar uma maior

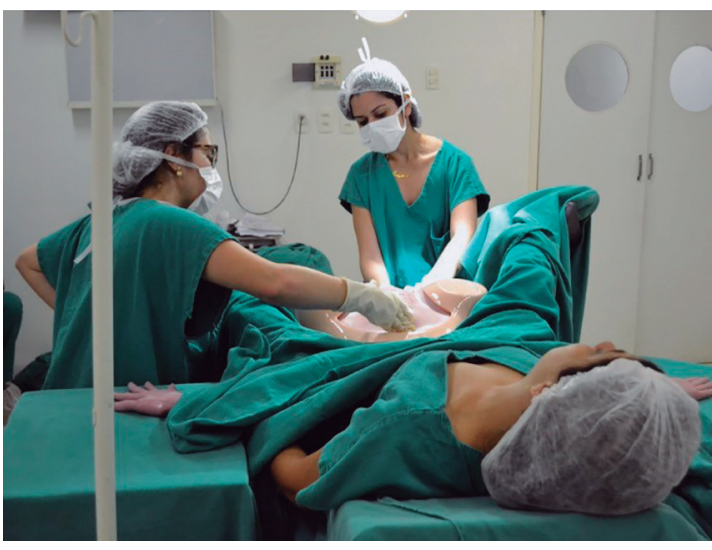

Figura 4 - Treinamento simulado para hemorragia pós-parto realizado em ambiente in situ (dentro do hospital). Foto: Juliano Domingues (imagens autorizadas). autenticidade ao cenário (SØRENSEN et al., 2013, 2017; PINTO DE MELO, 2018).

\subsection{ATIVAÇÃO DO CONHECIMENTO PRÉVIO}

Outro elemento instrucional há muito reconhecido como relevante é a ativação do conhecimento prévio. Por esse motivo, é intrigante que alguns treinamentos continuem a ser desenhados e planejados sem essa etapa. Mesmo diante de um grupo sem qualquer experiência prática sobre o assunto, a ativação prévia de questionamentos e de conceitos ainda imprecisos promove uma maior aprendizagem. Isso porque o arcabouço teórico, ou seja, o esquema cognitivo provocado e montado nessa etapa, pode, então, ser aprimorado e/ou corrigido ao longo do treinamento. Essa etapa deve estar presente em todas as simulações planejadas como treinamento (PINTO DE MELO, 2018; MERRILL, 2002; SWELLER; MERRIENBOER; PAAS, 1998). Por exemplo, pode-se nessa etapa revisar o material teórico enviado previamente para os aprendizes sobre o tema da simulação a ser vivenciada.

\subsection{DEMONSTRAÇÃO}

Depois da elaboração de um cenário autêntico e da ativação do conhecimento prévio, no passo a seguir os objetivos de aprendizagem (por exemplo, inserção de cateter ou manejo adequado de caso clínico) devem ser preferencialmente demonstrados àqueles em treinamento. A demonstração pode ser feita em tempo real, por um instrutor ou monitor, com uso dos manequins, simuladores parciais e/ou pacientes simulados, por vídeos ou outras formas de multimídia (MELO et al., 2017; VAN MERRIËNBOER; KIRSCHNER, 2018).

Nessa etapa de demonstração, deve-se refletir sobre o contexto em que as tarefas a serem aprendidas podem estar inseridas, e, se possível, ele deve ser também demonstrado. Ao se considerar como tarefas a serem aprendidas uma colocação de sonda vesical de demora, os possíveis contextos devem ser incorporados na etapa de demonstração, por exemplo, inserção de sonda em um paciente inconsciente ou colocação de sonda em um paciente com desconforto durante o procedimento.

\subsection{REPETIÇÃO}

Após uma primeira exposição ao cenário, os profissionais em treinamento devem ser expostos a mais de uma oportunidade de praticar os objetivos de aprendizagem. Dessa forma, mais de um cenário deve ser elaborado e oferecido durante cada treinamento. Outro elemento a ser considerado é 
a variabilidade. Os múltiplos cenários oferecidos precisam ter variações nos casos clínicos, apesar do objetivo final de aprendizado em comum. Por exemplo, os diferentes cenários de manejo da hemorragia pós-parto (objetivo de aprendizado global) podem apresentar causas variadas para o sangramento (por exemplo, um caso de HPP pode ser causado por hipotonia isolada; e o outro caso, pela combinação da hipotonia e laceração de trajeto). A variabilidade é um elemento fundamental para a promoção do aprendizado e transferência do conhecimento - maiores detalhes dessa série de estudos serão apresentados adiante (MELO et al., 2017; PINTO DE MELO, 2018; VAN MERRIËNBOER; KIRSCHNER, 2018)

\subsection{PRÁTICA DISTRIBUÍDA OU EFEITO DE ESPAÇAMENTO}

O espaçamento entre exposições a conteúdo e/ou treinamentos é chamado de prática distribuída ou efeito de espaçamento. Durante um treinamento, é importante programar tempos de intervalos de exposição do mesmo tipo de conteúdo, pois essa prática favorece a construção dos esquemas cognitivos e a retenção do conhecimento (CEPEDA et al., 2012; SWELLER; MERRIENBOER; PAAS, 1998; VAN MERRIËNBOER; CLARK; CROOCK, 2002). A programação de intervalos curtos leva a melhores resultados quando comparados a picos concentrados de práticas sem intervalos. A programação de prática parcial das tarefas é importante, uma vez que promove o aprendizado de maneira distribuída e habilita o aprendiz a associar o conteúdo parcial ao conteúdo global (VAN MERRIËNBOER; CLARK; CROOCK, 2002). Pode-se, por exemplo, programar pausas e intervalos ao longo de um dia de treinamento ou entre os cenários de um treinamento simulado.

\subsection{COMPLEXIDADE CRESCENTE}

Quando múltiplos e variados cenários forem oferecidos, eles devem ser organizados em ordem crescente de complexidade, preferencialmente intercalados por uma sessão de feedback ou debriefing. A complexidade das tarefas pode ser definida pelo grau de interatividade entre os diferentes elementos das tarefas (por exemplo, conhecimento, habilidades, atitudes). A oportunidade de acrescer e sedimentar o conhecimento a cada repetição, cada vez mais complexa, favorece a aprendizagem (VAN MERRIËNBOER; KIRSCHNER, 2018; VAN MERRIËNBOER; KESTER; PAAS, 2006).
Em um estudo comparativo realizado sobre o uso de diretrizes de desenho instrucional para o treinamento da HPP, compararam-se dois formatos de treinamento: um com base nas boas práticas disponíveis até então, e outro fundamentado nas diretrizes de desenho instrucional, com os casos apresentados em forma crescente de complexidade (MELO et al., 2017). Nesse formato fundamentado nas diretrizes, o primeiro caso de HPP era de uma retenção placentária simples; no segundo caso, a HPP era causada por uma combinação de laceração e hipotonia uterina, porém responsivas às drogas; no terceiro, último e mais complexo caso apresentado, a HPP não era responsiva às drogas, a paciente evoluía com choque hipovolêmico, e era necessário indicar histerectomia, ou seja, a cada cenário, os aprendizes eram submetidos a uma complexidade crescente dos casos.

\subsection{INTEGRAÇÃO}

Um próximo elemento instrucional que não deve ser negligenciado é a integração do conhecimento adquirido. Em casos de treinamentos para procedimentos, um cenário final deve oferecer a oportunidade de integrar as diferentes dimensões envolvidas nos objetivos de aprendizagem. Por exemplo, um treinamento de inserção de sonda vesical de demora pode apresentar um cenário em que: a) seja avaliada a indicação do procedimento; b) seja realizado o procedimento; e c) haja oportunidade para explicar ao paciente simulado ou acompanhante simulado o procedimento realizado (MERRILL, 2002; VAN MERRIËNBOER; CLARK; CROOCK, 2002).

\section{AVALIAÇÃO DA SIMULAÇÃO}

\subsection{EFETIVIDADE DO TREINAMENTO SIMULADO: MODELO DE KIRKPATRICK}

Para a avaliação do impacto do treinamento, o modelo mais comumente utilizado é o de Kirkpatrick (Figura 5). De acordo com esse modelo, desfechos do treinamento são hierarquizados em quatro níveis: 1) reação do aprendiz - o quanto os aprendizes gostaram do treinamento; 2) aprendizagem - o quanto se aprendeu; 3) comportamento ou transferência da aprendizagem; e 4) resultados - no caso da simulação, os desfechos dos pacientes. Estes níveis são tradicionalmente apresentados em uma ordem hierárquica em que os resultados finais dependem de bons resultados em cada um dos níveis iniciais (PINTO DE MELO, 2018; KIRKPATRICK, 1996). 


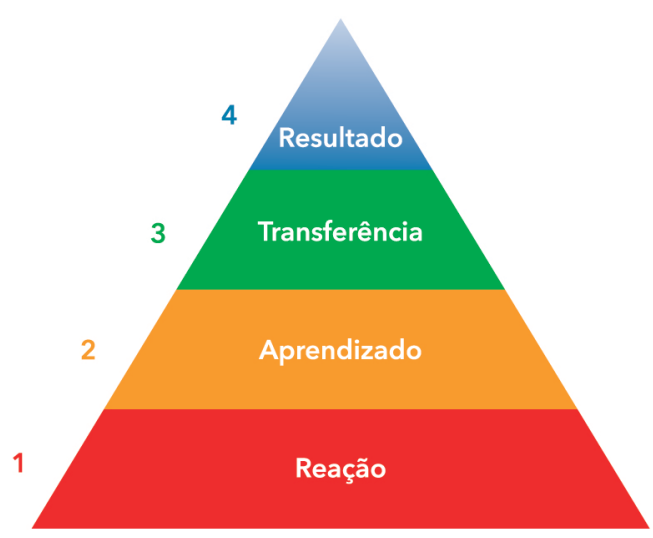

Kirkpatrick Levels of training Evaluation

Figura 5 - O modelo de quatro níveis de avaliação de treinamento de Kirkpatrick. Fonte: elaborada com base em Kirkpatrick (1996).

Mais recentemente, o modelo de Kirkpatrick, muito aplicado ao treinamento na área de negócios, tem sido citado na literatura de treinamento em saúde, particularmente em simulação (SCHAEFER et al., 2011; KIRKPATRICK, 1979; SØRENSEN et al., 2009; AMEH; VAN DEN BROEK, 2015). Apesar do seu uso disseminado por causa de sua fácil aplicação, há algumas críticas quanto ao formato taxonômico de classificação, por não haver detalhamento suficiente dos elementos envolvidos no construto de cada um dos níveis nem das interações entre esses elementos.

O próprio autor argumenta que a simplicidade do modelo teria sido intencional para facilitar seu uso (KIRKPATRICK, 1996; HOLTON, 1996; YARDLEY; DORNAN, 2012; PINTO DE MELO, 2018). Ainda de acordo com os críticos, o primeiro nível de Kirkpatrick, a reação dos aprendizes, seria o mais frágil dos quatro níveis propostos, com menor correlação com aprendizagem. Reconhece-se, então, que a reação (grau de satisfação dos aprendizes com o treinamento) não deve ser priorizada como parâmetro para avaliação da eficiência do treinamento (PINTO DE MELO, 2018).

Em relação aos demais níveis de Kirkpatrick, algumas estratégias podem ser adotadas com o intuito de aprimorar suas avaliações. Por exemplo, para a mensuração do segundo nível de Kirkpatrick (aprendizagem), pode-se fazer uso de diferentes formatos de avaliação na simulação: desde pré-teste e pós-teste, com avaliação simples do conhecimento teórico, a avaliações por vídeo com uso de checklist ou por avaliação global (CHAUVIN, 2015; ILGEN et al., 2015).

Uma outra proposta de avaliação pode ser ainda ser considerada, a do domínio do aprendizado (mastery learning), cujo objetivo final é que todos os aprendizes atinjam todos os objetivos de aprendizagem, com pouca ou nenhuma variação, mesmo que isso demande um tempo maior de treinamento (MCGAGHIE, 2015; COOK et al., 2013b).

É importante destacar que a simulação permite a reprodução de um cenário autêntico em saúde, idealmente com o envolvimento de uma equipe multiprofissional. Dessa forma, esse tipo de treinamento tem o potencial para desenvolver a própria equipe nos mais diferentes domínios: segurança do paciente, tomada de decisões, consciência situacional (situational awareness) e o próprio trabalho em equipe (crew resource management). Por esse motivo, é de grande importância planejar quais os objetivos de aprendizado de um cenário/treinamento elaborado e a quem eles se destinam - a apenas um grupo de profissionais ou a mais de um? À integração entre eles? Apenas após essas definições será possível selecionar os instrumentos de avaliação do treinamento (MCGAGHIE, 2015; EDOZIEN, 2015; BARSUK et al., 2016; COOK et al., 2013a; EPPICH et al., 2011; WEAVER; DY; ROSEN, 2014; ONWOCHEI; HALPERN, 2017; FUNG et al., 2015; SALAS; WILSON; BURKE, 2006; SALAS et al., 2012; PINTO DE MELO, 2018).

Por sua vez, em relação ao terceiro nível de Kirkpatrick, o comportamento, ou transferência da aprendizagem da simulação para o ambiente de trabalho, é importante considerar a influência de fatores presentes antes, no decorrer e depois do treinamento. De acordo com modelo de transferência da aprendizagem de Baldwin e Ford, os fatores presentes antes do treinamento (pré-treinamento) que influenciam a transferência são a motivação do aprendiz em aprender e a relevância do conteúdo do treinamento (COOK; ARTINO, 2016; DYBOWSKI; SEHNER; HARENDZA, 2017; FACTEAU et al., 1995).

Entre os fatores do treinamento em si, destaca-se o desenho instrucional da simulação. Recomenda-se o planejamento instrucional cuidadoso, de preferência por meio das diretrizes de desenho instrucional - principalmente quando for planejada a aprendizagem complexa, como é frequente em simulação na saúde (COOK et al., 2013a; SCHAEFFER et al., 2011; ISSENBERG et al., 2005; MCGAGHIE et al., 2010; MELO et al., 2017).

Os fatores pós-treinamento influenciadores são o feedback institucional e a oportunidade de aplicar o conteúdo no ambiente de trabalho (BALDWIN; 
FORD, 1988; SALAS et al., 2012; MELO et al., 2017). o feedback institucional consiste no monitoramento das ações do aprendiz no ambiente de trabalho, por parte da instituição; já a oportunidade de aplicar o conteúdo está relacionada ao planejamento da atividade, que deve se adequar à realidade profissional do aprendiz (SALAS et al., 2012; BALDWIN; FORD, 1988).

Na já referida série de estudos sobre o uso das diretrizes de desenho instrucional na simulação para a hemorragia pós-parto (HPP), foi demonstrado o impacto positivo do uso de tais diretrizes na eficiência da simulação. No primeiro estudo, realizou-se uma comparação do aprendizado dos residentes de tocoginecologia para o manejo da HPP entre dois tipos de formatos de simulação - um com base em diretrizes de desenho instrucional e o outro fundamentado em um desenho tradicional -, e a comparação foi feita por cenários simulados de pré-teste e pós-teste. No pós-teste, demonstrou-se que o grupo de residentes que atendeu ao treinamento fundamentado em diretrizes de desenho instrucional realizou um número maior de tarefas em um intervalo de tempo mais curto (MELO et al., 2017; MELO et al., 2018, MELO et al., 2019).

Um segundo estudo entrevistou os residentes que participaram dos dois desenhos de simulação para a HPP quanto às suas percepções da transferência do conhecimento a longo prazo, dois anos após o treinamento. Os residentes de ambos os formatos de treinamento em simulação apontaram uma percepção positiva de transferência do conhecimento. Eles destacaram o uso da estratégia do dual-coding como um elemento contribuinte para essa transferência. $\mathrm{O}$ dual-coding consiste em utilizar a combinação também de imagens que sumarizem a discussão e facilitem $o$ armazenamento das informações discutidas (CLARK; PAIVIO, 1991). Houve, contudo, no grupo de residentes que participaram do treinamento desenhado com diretrizes de desenho instrucional, uma maior percepção de transferência do conhecimento, com descrição mais detalhada dessa transferência. Além disso, os residentes desse grupo também descreveram uma melhor capacidade de percepção da situação (situational awareness) após o treinamento (PINTO DE MELO, 2018; EDOZIEN, 2015).

No terceiro estudo da série, ao se analisar o impacto no desfecho das pacientes com HPP antes e depois do treinamento simulado fundamentado nas diretrizes de desenho instrucional, observaram-se resultados positivos após o treinamento. Verificou-se um aumento na dose média de ocitocina por paciente com HPP, com administração de doses terapêuticas de ocitocina em um menor número de mulheres, nos casos de HPP, naquele hospital, após o treinamento. Tais achados sugerem uma melhor situational awareness após o treinamento simulado com base nas diretrizes de desenho instrucional (MELO et al., 2019).

\section{CONSIDERAÇÕES FINAIS}

Os elementos (pedagógicos) instrucionais são fundamentais para promover a aprendizagem, particularmente, na educação de adultos. Além do aprendizado, um treinamento eficiente deve ter por objetivo também promover a transferência do conhecimento, ou seja, o aprendiz deve tornar-se apto a aplicar o conteúdo aprendido no seu próprio ambiente de prática profissional após o treinamento. $\mathrm{E}$ a simulação em saúde, quando associada ao uso das diretrizes de desenho instrucional, oferece as condições ideais para um treinamento eficiente que leve ao aprendizado e promova a transferência do conhecimento (PINTO DE MELO, 2018).

\section{REFERÊNCIAS}

AMEH, C. A.; VAN DEN BROEK, N. Making It Happen: Training health-care providers in emergency obstetric and newborn care. Best Practice \& Research. Clinical Obstetrics \& Gynaecology, v. 29, n. 8, p. 1077-1091, 2015. http://dx.doi.org/10.1016/j.bpobgyn.2015.03.019.

ATKINSON, R. C.; SHIFFRIN, R. M. Human memory: A proposed system and its control processes. Psychology of Learning and Motivation, v. 2, p. 89-195, 1968. http:// dx.doi.org/10.1016/S0079-7421(08)60422-3.

ATKINSON, R. C.; SHIFFRIN, R. M. Human memory: A proposed system and its control processes. In: SPENCE, K. W.; SPENCE, J. T. The psychology of learning and motivation. Vol. 2. New York: Academic Press, 1968. pp. 
89-195. Disponível em: <http://bit.ly/2GId5tg>. Acesso em: 16 jun. 2021.

BALDWIN, T.; FORD, J. K. Transfer of training: A review and directions for future research. Personnel Psychology, v. 41, n. 1, p. 63-105, 1988. http://dx.doi. org/10.1111/j.1744-6570.1988.tb00632.x.

BARSUK, J. H. et al. Developing a simulation-based mastery learning curriculum lessons from 11 years of advanced cardiac life support. Simulation in Healthcare, v. 11, n. 1, p. 52-59, 2016. http://dx.doi.org/10.1097/ SIH.0000000000000120.

CEPEDA, N. J. et al. Spacing effects in learning: A temporal ridgeline of optimal retention. Psychological Science, v. 19, p. 1095-1102, 2012.

CHAUVIN, S. Applying educational theory to simulationbased training and assessment in surgery. The Surgical Clinics of North America, v. 95, n. 4, p. 695-715, 2015. http://dx.doi.org/10.1016/j.suc.2015.04.006.

CHENG, A. et al. Debriefing for technology-enhanced simulation: A systematic review and meta-analysis. Medical Education, v. 48, n. 7, p. 657-666, 2014. http:// dx.doi.org/10.1111/medu.12432.

CLARK, J. M.; PAIVIO, A. Dual Coding Theory and education. Educational Psychology Review, v. 3, p. 149210, 1991.

COOK, D. A. et al. Comparative effectiveness of instructional design features in simulation-based education: Systematic review and meta-analysis. Medical Teacher, v. 35, n. 1, p. e867-e898, 2013a. http://dx.doi.org /10.3109/0142159X.2012.714886.

COOK, D. A. et al. Mastery learning for health professionals using technology- enhanced simulation: A systematic review and meta-analysis. Academic Medicine, v. 88, n. 8, p. 1178-1186, 2013b. http://dx.doi.org/10.1097/ ACM.0b013e31829a365d.

COOK, D. A.; ARTINO, A. R. Jr. Motivation to learn: An overview of contemporary theories. Medical Education, v. 50, n. 10, p. 997-1014, 2016. http://dx.doi.org/10.1111/ medu.13074.

DYBOWSKI, C.; SEHNER, S.; HARENDZA, S. Influence of motivation, self-efficacy and situational factors on the teaching quality of clinical educators. BMC Medical Education, London, v. 17, n. 1, p. el-e8, 2017. http://dx.doi. org/10.1186/s12909-017-0923-2.

EDOZIEN, L. C. Situational awareness and its application in the delivery suite. Obstetrics and Gynecology, v. 125, n. 1, p. 65-69, 2015. http://dx.doi.org/10.1097/ AOG.0000000000000597.

EPPICH, W. et al. Simulation-based team training in healthcare. Simulation in Healthcare, v. 6, p. S14-S19, 2011. http://dx.doi.org/10.1097/SIH.0b013e318229f550.

FACTEAU, J. D. et al. The influence of general perceptions of the training environment on pretraining motivation and perceived training transfer. Journal of Management, v. 21, n. 1, p. 1-25, 1995. http://dx.doi. org/10.1177/014920639502100101.

FOUR-COMPONENT INSTRUCTIONAL DESIGN 4C/ID. 2021. Disponível em: <https://www.4cid.org>. Acesso em: 19 maio 2021.

FREREJEAN, J. et al. Designing instruction for complex learning: 4C/ID in higher education. European Journal of Education, v. 54, p. 513-524, 2019.

FUNG, L. et al. Impact of crisis resource management simulation-based training for interprofessional and interdisciplinary teams: A systematic review. Journal of Interprofessional Care, v. 29, n. 5, p. 433-444, 2015. http://dx.doi.org/10.3109/13561820.2015.1017555.

GRIERSON, L. E. Information processing, specificity of practice, and the transfer of learning: considerations for reconsidering fidelity. Advances in Health Sciences Education : Theory and Practice, v. 19, p. 281-289, 2014. HATALA, R. et al. Feedback for simulation-based procedural skills training: a meta-analysis and critical narrative synthesis. Advances in Health Sciences Education: Theory and Practice, v. 19, n. 2, p. 251-272, 2014. http://dx.doi.org/10.1007/s10459- 013-9462-8.

HOLTON, E. F. 3rd. The flawed four-level evaluation model. Human Resource Development Review, v. 7, n. 1, p. 5-21, 1996. http://dx.doi.org/10.1002/hrdq.3920070103.

ILGEN, J. S. et al. A systematic review of validity evidence for checklists versus global rating scales in simulationbased assessment. Medical Education, v. 49, n. 2, p. 161173, 2015. http://dx.doi.org/10.1111/medu.12621.

ISSENBERG, S. B. et al. Features and uses of high-fidelity medical simulations that lead to effective learning: a BEME systematic review. Medical Teacher, v. 27, n. 1, p. 10-28, 2005. http://dx.doi.org/10.1080/01421590500046924.

JAMES, J. T. A new, evidence-based estimate of patient harms associated with hospital care. Journal of Patient Safety, v. 9, p. 122-128, 2013.

KIRKPATRICK, D. Great Ideas Revisited. Techniques for evaluating training programs. Revisiting Kirkpatrick's Four-Level Model. Training and Development Journal, v. 50, p. 54-59, 1996.

KIRKPATRICK, D. L. Techniques for evaluating training programmes. Training and Development Journal, v. 33, n. 6, p. 78-92, 1979.

KOHN, L. T.; CORRIGAN, J. M.; DONALDSON, M. S. To err is human: building a safer health system. United States of America: Library of Congress Cataloging-inPublication Data, 2000.

LEVETT-JONES, T.; LAPKIN, S. A systematic review of the effectiveness of simulation debriefing in health professional education. Nurse Education Today, v. 34, n. 6, p. e58-e63, 2014. http://dx.doi.org/10.1016/j. nedt.2013.09.020.

MARAN, N. J.; GLAVIN, R. J. Low-to high-fidelity simulation - A continuum of medical education? Medical Education, Oxford, v. 37, Suppl. 1, p. 22-28, 2003. 
MCGAGHIE, W. C. et al. A critical review of simulationbased medical education research: 2003-2009. Medical Education, v. 44, n. 1, p. 50-63, 2010. http://dx.doi. org/10.1111/j.1365-2923.2009.03547.x.

MCGAGHIE, W. C. When I say ... mastery learning. Medical Education, v. 49, p. 558-559, 2015. http://dx.doi. org/10.1111/medu.12679.

MELO, B. C. P. et al. Perspectivas sobre o uso das diretrizes de desenho instrucional para a simulação na saúde: revisão da literature. Science \& Medicine, v. 28, n. 1, p. ID28852, 2018. http://dx.doi.org/10.15448/1980-6108.2018.1.28852.

MELO, B. C. P. et al. The use of instructional design guidelines to increase effectiveness of postpartum hemorrhage simulation training. International Journal of Gynaecology and Obstetrics, v. 137, p. 99-105, 2017. http://dx.doi.org/10.1002/ijgo.12084.

MELO, B. et al. Effects of an in situ instructional design based postpartum hemorrhage simulation training on patient outcomes: An uncontrolled before-and-after study. The Journal of Maternal-Fetal \& Neonatal Medicine, Boca Raton, v. 34, n. 2, p. 1-8, 2019. http://dx.doi.org/10.1 080/14767058.2019.1606195.

MELO, B. et al. Self-perceived long-term transfer of learning after postpartum hemorrhage simulation training. International Journal of Gynecology \& Obstetrics, v. 141, n. 2, p. 261-267, 2018. http://dx.doi.org/10.1002/ijgo.12442.

MERRIËNBOER, J. J. G.; SWELLER, J. Cognitive load theory and complex learning: Recent developments and future directions. Educational Psychology Review, v. 17, n. 2, p. 147-177, 2005. http://dx.doi.org/10.1007/ s10648-005-3951-0.

MERRILL, M. D. First principles of instruction. ETR\&D., v. 50 , n. 3, p. $43-59,2002$. http://dx.doi.org/10.1007/ BF02505024.

MILLER, G. A. The magical number seven, plus or minus two: Some limits on our capacity for processing information. Psychological Review, v. 101, n. 2, p. 343352, 1955. http://dx.doi.org/10.1037/0033-295X.101.2.343.

NORMAN, G.; DORE, K.; GRIERSON, L. The minimal relationship between simulation fidelity and transfer of learning. Medical Education, v. 46, n. 7, p. 636-647, 2012. http://dx.doi.org/10.1111/j.1365-2923.2012.04243.x.

ONWOCHEI, D. N.; HALPERN, S. Teamwork assessment tools in obstetric emergencies a systematic review. Simulation in Healthcare, v. 12, n. 3, p. 165-176, 2017. http://dx.doi.org/10.1097/SIH.0000000000000210.

PINTO DE MELO, B. Simulation design matters: Improving obstetrics training outcomes. Maastricht: Gildeprint, 2018. https://doi.org/10.26481/dis.20181212bm

SALAS, E. et al. The science of training and development in organizations: What matters in practice. Psychological Science in the Public Interest, v. 13, n. 2, p. 74-101, 2012. http://dx.doi.org/10.1177/1529100612436661.

SALAS, E.; WILSON, K. A.; BURKE, C. S. Wightman. Does crew resource management training work? An update, an extension, and some critical needs. Human Factors, v. 48, n. 2, p. 392-412, 2006. http://dx.doi. org/10.1518/001872006777724444.

SCHAEFER, J. J. 3rd et al. Literature Review Instructional Design and Pedagogy Science in Healthcare Simulation. Simulation in Healthcare, v. 6, p. S30-S41, 2011. http:// dx.doi.org/10.1097/ SIH.0b013e31822237b4.

SØRENSEN, J. L. et al. 'In situ simulation' versus 'off site simulation' in obstetric emergencies and their effect on knowledge, safety attitudes, team performance, stress, and motivation: study protocol for a randomized controlled trial. Trials, v. 14, p. 220, 2013. http://dx.doi. org/10.1186/1745-6215-14-220.

SØRENSEN, J. L. et al. Design of simulation- based medical education and advantages and disadvantages of in situ simulation versus off-site simulation. BMC Medical Education, v. 17, p. 20, 2017. http://dx.doi.org/10.1186/ s12909-016-0838-3.

SØRENSEN, J. L. et al. The implementation and evaluation of a mandatory multi-professional obstetric skills training program. Acta Obstet Gynecol., v. 88, n. 10, p. 1107-1117, 2009. http://dx.doi.org/10.1080/00016340903176834.

SWELLER, J. Cognitive load theory, learning difficulty and instructional design. Learning and Instruction, v. 4, p. 295312, 1994. http://dx.doi.org/10.1016/0959-4752(94)90003-5.

SWELLER, J.; MERRIENBOER, J. J. G.; PAAS, F. G. W. C. Cognitive architecture and instructional design. Educational Psychology Review, v. 10, n. 3, p. 251-296, 1998. http://dx.doi.org/10.1023/A:1022193728205.

VAN MERRIËNBOER, J. J. G. (2020). Representação gráfica dos quatro componentes do Modelo 4C/ID. Figura 3. Disponível em: <https://www.4cid.org>. Acesso em: 16 jun. 2021.

VAN MERRIËNBOER, J. J. G.; CLARK, R. E.; DE CROOCK, M. B. M. Blueprints for complex learning: the 4C/ID Model. Educational Technology Research and Development, Washington, v. 50, n. 2, p. 39-61, 2002. http://dx.doi.org/10.1007/BF02504993.

VAN MERRIËNBOER, J. J. G.; KESTER, L.; PAAS, F. Teaching complex rather than simple tasks: Balancing intrinsic and germane load to enhance transfer of learning. Applied Cognitive Psychology, v. 20, n. 3, p. 343-352, 2006. http://dx.doi.org/10.1002/acp.1250.

VAN MERRIËNBOER, J. J. G.; KIRSCHNER, P. A. Ten steps to complex learning: A systematic approach to four-component instructional design. New York: Routledge, 2018.

VAN MERRIËNBOER, J. J. G.; SLUIJSMANS, D. M. A. Toward a synthesis of cognitive load theory, fourcomponent instructional design, and self-directed learning. Educational Psychology Review, v. 21, n. 1, p. 55-66, 2009. http://dx.doi.org/10.1007/s10648-008-9092-5.

VAN MERRIËNBOER, J. J.; SWELLER, J. Cognitive load theory in health professions education: design principles and strategies. Medical Education, v. 44, n. 1, p. 85-93, 2010. http://dx.doi.org/10.1111/j.1365-2923.2009.03498.x. 
WEAVER, S. J.; DY, S. M.; ROSEN, M. A. Team-training in healthcare: A narrative synthesis of the literature. BMJ Quality \& Safety, v. 0, p. el-e14, 2014. http://dx.doi. org/10.1136/bmjqs-2013-001848.
YARDLEY, S.; DORNAN, T. Kirkpatrick's level and education "evidence". Medical Education, v. 46, n. 1, p. 97-106, 2012. http://dx.doi.org/10.1111/ j.1365-2923.2011.04076.x. 
CAPÍTULO 5

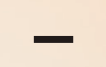

Uso de pacientes simulados no ensino e avaliação em saúde 


\section{INTRODUÇÃO}

A importância da prática de simulação na área médica já é bastante discutida e estudada. Numerosos artigos revelam o olhar para o ensino ou treinamento dos estudantes para o aprimoramento de suas habilidades antes de se tornarem profissionais. Este texto traz a experiência do profissional da área de atuação e direção de elenco, com o objetivo de pensar na produção e no treinamento, entre outras especificidades, do trabalho do paciente simulado/ator neste cenário. Ao se pensar na interpretação como uma ferramenta não só para pacientes simulados/atores em exercício de suas funções, mas também como uma abertura de percepção para médicos em formação, podem-se ampliar as possibilidades de interação e de leitura da relação interpessoal entre médico e paciente.

\section{CONCEITOS}

Na educação em saúde, a simulação é uma prática interdisciplinar utilizada como meio didático e pedagógico que possibilita ao estudante a antecipação das situações clínicas para treinar, retreinar, tirar dúvidas e aprimorar suas competências, antes do encontro com os pacientes reais. Dessa maneira, a simulação clínica apresenta-se como uma possível estratégia de ensino e avaliação por meio da qual se podem conquistar e confirmar competências clínicas, otimizando a capacitação profissional (OSSINI, 2020).

A participação de pacientes simulados na simulação cênica é um dos meios mais eficazes para a avaliação e formação de estudantes de Medicina, atendendo às Diretrizes Curriculares Nacionais, que estipulam 
[...] integralidade e humanização do cuidado por meio de prática médica contínua e integrada com as demais ações e instâncias de saúde [...], qualidade na atenção à saúde, pautando seu pensamento crítico [...], segurança na realização de processos e procedimentos, referenciados nos mais altos padrões da prática médica, de modo a evitar riscos, efeitos adversos e danos aos usuários, a si mesmo e aos profissionais do sistema de saúde. (BRASIL, 2014).

Quando se pensa na avaliação do médico em formação a partir de uma relação direta com o paciente simulado/ator, o interesse também é entender como esse futuro profissional da saúde, a partir de seus conhecimentos teóricos e de sua postura como ser humano, lida com o paciente. $\mathrm{O}$ atendimento humanizado coloca o médico em uma situação mais empática com o paciente, ampliando a qualidade do atendimento e dos processos de trabalho, transformando e possibilitando a abertura de diálogo, promovendo a relação interpessoal em detrimento de uma relação hierárquica e profanando a esfera do divino, creditada aos que têm o poder de curar e manter nossos corpos vivos e saudáveis.

Tanto no ensino como nas avaliações, o paciente simulado é cuidadosamente treinado para assumir as características de um paciente real, a fim de proporcionar ao estudante a oportunidade de aprender e/ou ser avaliado em suas supostas habilidades em primeira mão.

No início da prática de simulação, os representantes de pacientes humanos eram comumente chamados de pacientes padronizados ou simulados, entretanto, mais recentemente, percebendo-se que estes podem representar um escopo expandido de funções (por exemplo, clientes, familiares, profissionais de saúde), o termo "participante simulado" passou a ser utilizado por representar essa função de maneira mais inclusiva (LEWIS et al., 2017).

Há muitos recursos e possibilidades nessas práticas e, consequentemente, algumas nomenclaturas (NEGRI et al., 2017) usadas de acordo com a característica da simulação. A seguir, apresentam-se os termos propostos:

- Role play (jogo de papéis) - consiste na situação em que $o$ aprendiz, facilitador e/ou instrutor assumem papéis diferentes no cenário simulado como se fossem integrantes de um caso clínico, para fins de ensino e treinamento. Essa estratégia fornece oportunidades de aprendizagem, envolvendo tanto o processo afetivo quanto o cognitivo dos estudantes, pois permite o expe- rimento de sensações como a vivência do papel de paciente e de outros profissionais.

- Paciente simulado - é quando um participante de uma simulação assume o papel de um personagem ou pessoa e o representa. Essa atuação pode ser desempenhada por atores devidamente treinados ou improvisada entre os participantes da simulação.

- Paciente padronizado - diferencia-se do paciente simulado pela capacidade de se comportar de maneira consistente e precisa, que pode ser igualmente repetida, a fim de dar a cada aluno uma chance justa e igual de aprendizagem, permitindo ainda uma avaliação das habilidades aprendidas em um ambiente clínico simulado. Assume-se esse papel por meio de um contrato legal com a instituição de ensino. Para exercer o papel de paciente padronizado, podem ser utilizados:

- estudantes de artes cênicas, atores de companhias de teatro amador ou mesmo atores profissionais em simulação, principalmente em processos seletivos ou provas de suficiência, cuidadosamente recrutados e treinados para assumir as características de um paciente;

- membros da comunidade (criança, adolescente, adulto, idoso ou mesmo portador de alguma doença, que vão responder a qualquer questionamento da história médica e social a partir de sua própria vida) (CHURCHOUSE; MCCAFFERTY, 2012).

- Modelo misto - combina paciente simulado com um simulador de baixa complexidade para o desenvolvimento durante um cenário de uma atividade específica. Por exemplo, um braço acoplado a um estudante para compor o cenário de coleta de sangue. Esse modelo proporciona ao aprendiz o desenvolvimento de habilidades técnicas e comportamentais. Nos casos em que há exames mais invasivos, como exposição do corpo nu, toque, apalpações, cenas com bebês, incisões ou até feridas, é necessária a utilização de manequins, bonecos ou exames pré-produzidos na simulação, tudo para evitar possíveis constrangimentos.

Há também a possibilidade dos "pacientes incógnitos", que são aqueles pacientes reais, em ambientes reais, capacitados para avaliar o desempenho do profissional em meio a uma rotina de atendimento.

Apesar de haver diferenças importantes na qualidade de interpretação (técnica de repetição, controle muscular, controle emocional, técnicas inter- 
pretativas) entre atores e membros da comunidade, aqui será adotado o termo "paciente padronizado".

\section{ARTICULAÇÕES NECESSÁRIAS PARA A CRIAÇÃO DE GRUPOS DE PACIENTES SIMULADOS/ATORES PARA PARTICIPAÇÃO COMO PACIENTES SIMULADOS}

A utilização de pacientes simulados pode se dar de várias maneiras, dependendo da estrutura envolvida. Organizações como a Association of Standardized Patient Educators (ASPE), sediada na Flórida, Estados Unidos, e com membros associados em vários países, como Canadá, Turquia, Austrália, Suíça, Chile, entre outros, criam redes especializadas em treinamentos de pacientes simulados no mundo todo. Para a criação de um centro específico de treinamento, deve-se levar em conta não só o orçamento apropriado, mas também a articulação de pessoas capacitadas para a função de recrutamento. Seguindo o modelo da Association for Medical Education in Europe (AMEE) (CLELAND; ABE; RETHANS, 2009), podem-se recrutar pacientes simulados em quatro etapas:

- Etapa 1: em uma entrevista de triagem, incluir perguntas como "por que você está interessado em se tornar um paciente simulado?".

- Etapa 2: informar ao candidato a função do paciente simulado e, se possível, dar a ele a oportunidade de observar um treinamento ou uma dramatização.

- Etapa 3: orientar o trabalho em prol dos objetivos educacionais do programa em acordo mútuo.

- Etapa 4: estabelecer um período de avaliação para poder verificar se o candidato é apto e se gosta de trabalhar como paciente simulado. Reservar esse período de teste no recrutamento também pode ajudar a prever possíveis problemas de execução.

Podem-se também estabelecer vínculos afetivos com grupos de teatro amadores/profissionais, estudantes de artes cênicas e outros cursos para encontrar uma saída de baixo custo e interessante para todos os envolvidos. A remuneração é necessária em todos os casos envolvendo profissionais, mas, quando o compromisso se estabelece também em outras bases, o grupo se fortalece. É muito comum pacientes simulados/atores trabalharem com permutas em suas produções. Grupos recém-formados, estudantes em escolas de teatro e grupos universitários estão sempre dispostos a negociações, na maioria das vezes ligadas à falta de espaços para ensaio de suas produções. Por isso, gerar parcerias com núcleos teatrais ajuda na negociação das contratações, na ampliação da rede de colaboradores e na criação de um grupo capacitado tecnicamente. Ademais, os contratos devem sempre ser documentados e assinados nas bases legais, assim como é aconselhável pedir assessoramento para sindicatos de artistas.

Além do estímulo financeiro ou de permuta, pode-se considerar que, sempre que possível, pacientes simulados/atores e atrizes devem ser requisitados de uma maneira eficaz e contínua, e não de modo intermitente, pois isso mantém o interesse, a habilidade prática e a motivação. Definir uma agenda prévia ajuda a estreitar esses laços e compromissos.

Em outros países, essa prática é utilizada em menores proporções, mas com aporte financeiro fornecido pelas universidades. Jennifer White, administradora do Programa de Pacientes Simulados e Voluntários, trabalha com o modelo misto e recruta pacientes simulados/atores e voluntários a partir do banco de dados da University Hospital Southampton NHS Foundation Trust, na Inglaterra. Na Universidade de Leeds, também nesse país, são recrutados pacientes simulados/atores, e, muitas vezes, os próprios médicos trabalham na dramatização.

Em relação aos valores pagos a pacientes simulados/atores e atrizes, eles variam por período trabalhado. Em Leeds, o cachê é em torno de 100 libras a diária. Já segundo a tabela de valores de cachês feita pelo Sindicato dos Artistas e Técnicos em Espetáculos e Diversões do Estado de São Paulo (2018), o valor da diária do paciente simulado/ator é de $\mathrm{R} \$ 487,08$. Contudo, outros tipos de vínculos podem ser feitos de acordo com a articulação local.

\section{ESTRATÉGIAS PARA CAPACITAÇÃO DO PACIENTE SIMULADO: POSSIBILIDADES DE TREINAMENTO}

Para que haja isonomia nas condições oferecidas aos estudantes ou candidatos que participam das simulações, os pacientes simulados/atores e atrizes que representam o mesmo personagem precisam padronizar a interpretação, o que é um grande desafio quando se trata de uma situação subjetiva e que depende do jogo estabelecido entre os pacientes simulados/atores e candidatos. Dentro da sala de atendimento, a simulação pode ser feita com o ator (seja ele profissional ou não), o candidato/estudante, o médico examinador e, quando possível, também um técnico de áudio e vídeo para o registro da simulação. Toda a estação pode ser gravada, 
e o médico examinador faz a análise de forma síncrona ou assíncrona.

Os pacientes simulados/atores são treinados e estão aptos a improvisar, padronizar a atuação e a repetir as situações diversas vezes, mantendo o mesmo nível de atuação. Essas competências são muito importantes para o sucesso da aplicação desse tipo de prática. Além disso, evita-se a utilização de pacientes reais ou o risco da falta de adequação de um não profissional da área da atuação. Os pacientes simulados/atores são contratados para simular uma situação entre médico e paciente ou qualquer outro personagem por meio da utilização de um roteiro de encenação (script), com a máxima proximidade de um atendimento real. Eles são escolhidos previamente pelo perfil de idade, sexo, etnia e, em algumas ocasiões, com especificidades físicas relacionadas às patologias propostas.

No caso de avaliação utilizando a simulação, a confidencialidade das estações simuladas é fundamental, pois nenhuma informação sobre o caso deve ser passada para o elenco até o dia da avaliação, evitando possíveis recursos judiciais posteriores, principalmente nas situações em que haja concorrência ou seleção a cargos. Em exames de seleção, tais como as provas de residência médica ou o Revalida, a logística deve ser programada para que haja um coordenador de pacientes simulados/ atores circulando pelos locais, sempre atento a qualquer problema que possa surgir. É muito comum que os médicos avaliadores tentem mudar, entre um candidato e outro, o que já foi ensaiado, por entenderem a questão de forma diferente ou por perceberem que alguma informação não está clara. É orientado aos pacientes simulados/atores, caso isso ocorra, relatar ao coordenador para que as mudanças não alterem o conteúdo já treinado. É necessário também haver pacientes simulados/atores extras de cada perfil, possibilitando trocas, rodízios, pausas e momentos de descanso para manter a qualidade das reproduções interpretativas de cada estação simulada. Essas práticas ajudam a evitar estresses e preservar a acurácia da interpretação e a qualidade da atividade simulada.

Na escolha dos pacientes simulados/atores, seus históricos de formação e/ou suas experiências profissionais de palco devem ser levados em conta. A repetição, o controle muscular, a capacidade de improvisar dentro de um tema, a precisão e a escuta são algumas técnicas que pacientes simulados/atores dominam e que são imprescindíveis em pacientes simulados. Após a escolha do elenco, é necessário treinamento específico, que pode variar quanto às técnicas usadas e que deve ser orientado por um profissional da área do teatro, pois há numerosos exercícios que podem chegar ao mesmo resultado. Os itens listados a seguir são questões abordadas em um treinamento para pacientes simulados/atores, aprimorando suas habilidades e conhecimentos específicos para a dramatização:

- Informar as condições de trabalho, características da prova, quantidade de pessoas envolvidas, logística, contratos se houver (consultar o sindicato local), horários de paradas para lanche ou almoço, além de tudo relacionado à parte organizacional e burocrática para que não haja dúvidas e contratempos.

- Fazer um treinamento mais direcionado ao corpo dos pacientes simulados/atores e atrizes. Exercícios de observação, concentração, visão periférica, mimese corporal e controle muscular são importantes para nivelar a técnica dos pacientes simulados/atores e minimizar as diferenças que possam haver em seus aprendizados. Em um trabalho em grupo, há sempre a necessidade de um "nivelamento técnico".

- Fazer um treinamento de padronização de gestos. Aqui acontece um trabalho mais específico de criação de um vocabulário gestual do paciente simulado/ator, como graduar expressões de 1 a 10. Em uma escala visual numérica, a dor abdominal "nível 1", em comparação com a "nível 5", tem diferentes consequências no corpo do paciente simulado/ator. Quais seriam essas diferenças? Como o paciente simulado/ator pode igualar sua interpretação com os demais do grupo?

- Criar partituras corporais (SANTOS, 2010) e vocabulários uníssonos para que os pacientes simulados/atores possam acessá-los com mais facilidade e rapidez.

- Se possível, treinar os pacientes simulados/ atores com modelos de questões de provas dos anos anteriores, ou seja, um ensaio da simulação. Dividir o grupo em duplas facilita o processo, colocando um para representar o médico, e o outro, o paciente. Aquele que treinará o papel do paciente recebe as orientações específicas das perguntas e respostas que devem ser dadas de acordo com o perfil da doença, enquanto o outro que representará o médico improvisa a situação. Já os demais pacientes simulados/atores assistem à improvisação. Também, deve-se reservar um tempo no final para comentários e possíveis dúvidas. 
- Levar questões mais complexas de interpretação e, durante o improviso, problematizar criando obstáculos previsíveis, por exemplo, o candidato passar mal ou falar muito baixo, ou ainda o paciente simulado/ator apresentar sintomas que não eram estipulados no script da prova, enfim, colocar os participantes em situações que são comuns durante as simulações.

- Falar sobre os conceitos de comportamento ético, tais como: não levar o celular para o local da simulação; não fazer comentários sobre o desempenho do candidato em momento algum; não falar alto para não atrapalhar a sala ao lado; manter a interpretação o mais fiel possível ao que foi passado no treinamento e está no script; manter o corpo neutro, evitando expressões involuntárias (tossir, coçar-se, puxar conversa fora do contexto da prova).

Para assegurar que não haja imprevistos ou problemas maiores, deve-se sempre pensar em um elenco extra. O coordenador de pacientes simulados/atores precisa estar atento também à questão de alimentação, intervalos para descanso, banheiro e rodízios periódicos. É preciso lembrar que a relação interpessoal humanizada é um treinamento não só para médicos e pacientes, mas para todos envolvidos no processo, por isso boas conversas e acordos claros evitam problemas.

\section{O PACIENTE SIMULADO/ATOR COMO AVALIADOR COLABORADOR}

Uma das vantagens de se trabalhar com pacientes simulados é a possibilidade de se ter uma avaliação específica sob a perspectiva do paciente. Esse feedback (BOKKEN et al., 2009) pode ser definido como "informações específicas sobre a comparação entre o desempenho observado de um estagiário e um padrão, dado com a intenção de melhorar o desempenho do estudante", podendo ser oral ou escrito, durante ou após a dramatização. Contudo, este tipo de colaboração ainda é pouco usado no Brasil. Em uma instituição pública de ensino superior do interior do Estado de São Paulo, essa estratégia está inserida na graduação nos cursos de Medicina e Enfermagem. Em 2003, com a mudança curricular adotada na instituição, passou-se a utilizar o formato do Exercício de Avaliação da Prática Profissional (EAPP), um:

[...] instrumento que avalia o desempenho do estudante na realização de uma tarefa em uma situação simulada da prática profissional, com a participação de paciente simulado/ator, manequim ou simuladores de sons. O EAPP é um "caso longo" que possibilita a compreensão global (integral) do paciente. As situações utilizadas estão relacionadas às tarefas realizadas pelos estudantes, na respectiva série e derivam das situações reais da prática profissional. (MORAES; ANGELI, 2016).

Atualmente, esse tipo de estratégia de simulação é utilizado tanto para a avaliação do desempenho com caráter formativo e somativo quanto para o processo de ensino e aprendizagem, estando inserido nos cursos de Medicina e Enfermagem. Outro exemplo é o método amplamente utilizado na Escócia: durante a dramatização, o paciente simulado deve responder se o candidato foi compreensivo e se sentiu à vontade em falar com ele. São dadas notas de 0 a 2 para o candidato, sendo $0=$ fraco, 1 = aceitável e 2 = bom. A classificação contribui aproximadamente com $5 \%$ da pontuação geral.

$\mathrm{O}$ acúmulo de funções pode atrapalhar o desempenho do paciente simulado/ator, mas, quando combinada e treinada com antecedência, essa avaliação pode se somar ao resultado final. Ao se pensar em uma avaliação menos técnica, é possível aplicar um checklist simples, com poucas informações, também entre um candidato e outro.

Apesar de haver poucos estudos científicos sobre a prática do feedback de pacientes simulados, seja no ensino ou em situações de avaliação, as possibilidades são várias e heterogêneas. Portanto, não há um padrão para esse treinamento específico que possa ser realizado de acordo com as necessidades de cada grupo.

\section{REDAÇÃO DE UM ROTEIRO DE ENCENAÇÃO (SCRIPT) PARA O PACIENTE SIMULADO}

Nas situações de uso da simulação para ensino, pode-se enviar o script alguns dias antes e até discutir pormenores com os pacientes simulados. Entretanto, em situações de avaliação, o script é entregue aos pacientes simulados/atores somente no dia, depois que todos os envolvidos na avaliação estiverem identificados e sem comunicação com o meio exterior à prova. Como o treinamento da questão específica com o grupo de pacientes simulados/ atores que fará o mesmo personagem geralmente dura entre 60 a 120 minutos, então é aconselhável treinar os examinadores das estações simuladas 
no mesmo grupo. Além disso, utilizar gravação de vídeo de uma simulação de caso também ajuda no aperfeiçoamento dos treinamentos.

Para um script objetivo e eficaz, é possível citar possíveis conteúdos:

- Nome do personagem, idade, sexo e etnia.

- Resumo breve das características principais da atuação, por exemplo, "paciente com muita dor, ansioso pelo resultado do exame”. Informações curtas ajudam o paciente simulado/ator a se lembrar da ação principal.

- Histórico do paciente simulado: informações relevantes que têm ligação direta com a ação dramatizada.

- Frases que DEVEM ser ditas pelo paciente simulado/ator: a exatidão de termos usados evita mal-entendidos.

- Frases que NÃO DEVEM ser ditas pelo paciente simulado/ator: pode acontecer de um paciente simulado/ator em improviso falar algo que induza o candidato ao erro, e isso deve ser evitado.

- A descrição da enfermidade e seus sintomas como dores e lesões, bem como a descrição da situação física pormenorizada: por exemplo, quais movimentos um paciente com dores lombares conseguiria fazer e quais não.

- Objetividade e clareza: evitar sensações, abstrações ou qualquer sintoma subjetivo. Por exemplo, a indicação de uma reação a uma notícia de morte. O paciente simulado/ator deve chorar? Deve gritar? Deve socar a mesa? O entendimento da reação física do paciente simulado/ ator ajuda na padronização da interpretação.

- As perguntas mais óbvias que podem ser feitas pelos candidatos precisam ser previstas e ter suas respostas definidas de forma bem clara.

- É muito comum candidatos fazerem perguntas não previstas ou fora de contexto. Como o paciente simulado/ator responde a essas perguntas? É possível o improviso ou padronizam-se respostas como "não sei sobre isso, doutor" ou "não está previsto no script!”.

- Além das perguntas espontâneas feitas pelos candidatos e previstas no script, também pode-se fazer a previsão de perguntas ativas feitas pelos pacientes simulados em momentos específicos do desenvolvimento da estação simulada, complementando a avaliação dos candidatos. As respostas a serem dadas a essas perguntas ativas dos pacientes simulados podem ser computadas como itens do instrumento padronizado de avaliação (checklist) dos candidatos.
- Alguns candidatos, seguros de seu desempenho e de que nada mais precisa ser feito naquele possível tempo de sobra, quebram o protocolo e entram em um diálogo coloquial sobre a vida dos pacientes simulados/atores, e não do personagem em questão. Descontraídos, tentam quebrar o jogo da encenação fazendo perguntas pessoais aos pacientes simulados/atores, por exemplo, se eles estão em cartaz com alguma peça, ou elogiando a interpretação, entre outros comentários. Os pacientes simulados/atores devem manter o jogo dramático até o final, não conversando com os candidatos.

\section{RELAÇÃO ENTRE A ESTAÇÃO PRÁTICA ELABORADA E A DEFINIÇÃO DE PERFIL DOS PACIENTES SIMULADOS}

Mesmo que haja um roteiro de ficção, o corpo do paciente simulado/ator estará presente, e sua materialidade será significante. Em um exemplo de um caso simulado em que o candidato teria que diagnosticar um problema de tireoide no paciente simulado, uma das atrizes tinha uma cicatriz real localizada no pescoço exatamente na região da glândula analisada. Essa marca aparente deixou o candidato confuso, pois ele entendeu que a cicatriz fazia parte da avaliação. Nesse momento, o avaliador interveio e sinalizou que a cicatriz não era parte da questão. A atriz teve que ser dispensada para que não houvesse mais confusão. Em outro caso, em um modelo misto de simulação, com uma atriz e um bebê boneco, de tamanho e peso real de um recém-nascido, cujas medidas teriam que ser avaliadas no atendimento, o candidato manipulou o boneco sem cuidado, segurando-o pendurado pelos pés, sendo mal avaliado. Esses dois exemplos de relação entre realidade e ficção mostram possibilidades distintas na simulação cênica, um de supervalorização do real e outro de displicência e incredulidade. Há uma tensão entre o corpo fenomenal e o corpo semiótico (FISCHER-LICHTE, 2013), e é preciso se atentar para essa tensão para que não haja prejuízo ao candidato. Por isso, a corporeidade do paciente simulado/ator deve ser levada em conta na seleção do elenco, assim como a etnia, não só pelo fenótipo, mas também pela sua carga cultural.

Aqui o corpo do paciente simulado/ator cria uma tensão dramática entre o que ele é e o que ele representa, evocando diferentes objetivos, como espontaneidade, autenticidade e construção de uma materialidade realística da situação. 
Em alguns casos, a fusão dessa relação real e ficcional está presente na interpretação do paciente simulado/ator. Por exemplo, em uma ação em que o paciente simulado/ator interpretava uma dor lombar que o impedia de se movimentar facilmente. O médico/candidato tinha acertado quase toda a questão, e faltava apenas um item, que se referia a uma exame específico para o qual o paciente simulado/ator deveria estar em outra posição física. Faltavam apenas poucos segundos para terminar a prova quando o candidato se lembrou do exame. Em um impulso, como reação imediata para ajudar o candidato e movido pela relação empática criada, o paciente simulado/ator se posicionou rapidamente para o exame, esquecendo-se de toda a dificuldade de movimentação que o papel exigia. Nesse caso, houve um rompimento do jogo ficcional por força da relação real estabelecida, e o paciente simulado/ator foi advertido pela sua falha Esse não é um comportamento ideal para este tipo de prova, pois interfere no resultado da avaliação.

Há também casos inversos, em que o corpo fenomenal do paciente simulado/ator/atriz esbarra em posturas éticas e impasses práticos. Uma das questões era um exame de mama, e, nesse caso, não era possivel trabalhar com uma atriz, pois a mama teria de apresentar a saliência do nódulo, nem com um manequim, pois a prova também deveria ser resolvida na relação com o paciente simulado/ator/ atriz com base em perguntas e respostas. Para tanto, foram usadas próteses de silicone produzidas com a saliência do nódulo. Como as atrizes não poderiam sobrepor essas próteses às suas próprias mamas, então foram chamados pacientes simulados/ atores que interpretaram mulheres usando essas próteses. Aqui a ficção se sobrepôs ao real para que o resultado fosse mais plausível. Assim, depara-se com uma forma de emergência nessa alternância de percepção. A ordem de presença e sua fenomenologia trazem cuidados minuciosos em relação à leitura do corpo do intérprete.

A cenografia também é manipulada nas simulações para apoiar a especificidade da cena. Objetos como estetoscópios, resultados de exames, macas e leitores de radiografias são colocados, em caso de necessidade para realização do atendimento, transformando o espaço em um set apropriado para cada estação prática simulada. Portanto, a cena é adaptada às necessidades específicas do roteiro a ser seguido, compondo um ambiente físico e psicológico o mais próximo possível do real.

Ainda, em todas as salas das provas práticas, coloca-se também um relógio cronometrando o aten- dimento, sendo um controle visível. Percebe-se que, durante a simulação, a maioria dos candidatos está sempre atenta ao tempo, operando com uma pressão psicológica, já citada, uma pressão intencional, que também faz parte da avaliação.

O ambiente é preparado para reproduzir o cotidiano das salas de atendimento dos hospitais. A realização das provas em salas de atendimento passa por uma questão mais prática e financeira, tentando manter a estética a mais próxima do real. É possível também construir consultórios médicos personalizados conforme o tema em outros espaços. Em ambos os casos, a preservação do ambiente controlado e a similaridade com um consultório são fundamentais para a imersão do candidato em sua relação interpessoal com os pacientes simulados.

\section{OUTRAS POSSIBILIDADES}

Estas relações pessoais têm se transformado com a utilização da internet. A virtualidade vem se estabelecendo e criando muitos conflitos éticos e morais na prática da Medicina. Vista com cautela pelos profissionais da saúde, essa relação entre homem e máquina se coloca como opção para substituir as situações de relações diretas entre humanos. Já existem estudos para a criação do paciente virtual (HUBAL et al., 2000). Trata-se de um paciente padronizado e programado com capacidade para responder a milhares de perguntas, em diferentes cenários e gêneros, simulando traumas e acidentes, com o qual o estudante poderá treinar várias vezes em cenários que reproduzem a realidade por meio de apenas alguns cliques. O AVA TALK ${ }^{\mathrm{TM}}$ (HUBAL; FRANK; GUINN, 1998) é um exemplo desse tipo de tecnologia. Ele minimiza os custos da contratação de pacientes simulados/atores em simulações para aulas diárias nas faculdades de Medicina, facilitando o financiamento, entre outras possibilidades já citadas anteriormente. Contudo, a habilidade em lidar com o encontro real traz consequências diretas ao paciente. Pequenos detalhes não percebidos por máquinas podem definir o futuro de uma pessoa. Em uma questão realizada na prova de residência médica do Hospital das Clínicas em São Paulo, por exemplo, a atriz interpretava uma paciente que sofria abuso doméstico. Ela foi maquiada previamente para caracterizar um olho roxo. $\mathrm{O}$ roteiro indicava que ela simplesmente pedisse informações sobre métodos anticoncepcionais que pudessem ser usados sem o marido perceber. Nesse caso, o candidato simplesmente teria de notar o hematoma no olho 
da atriz e questioná-la, pois era um caso de agressão física do marido alcoólatra e violento, que abusava da esposa, e ela, quando grávida, sofria aborto por conta das seguidas agressões. Aqui o médico teria de indicar o serviço social ou até fazer a denúncia, mas alguns sequer percebiam o olho da atriz ou, mesmo olhando, não relacionavam a história ao achado físico. $\mathrm{O}$ treinamento para esse tipo de olhar mais minucioso prepara o médico para essas situações extremas de violência, salvando vidas não com bisturis ou transplantes, e sim apenas com um olhar mais cuidadoso.

\section{CONSIDERAÇÕES FINAIS}

A simulação de atendimentos médicos, seja em situação de avaliação ou em aulas, aponta para o resgate dos vínculos sociais e a humanização dos atendimentos médicos. Ninguém melhor do que o paciente simulado/ator, um profissional que dedica seu tempo para treinar relações, mergulhar em emoções e no entendimento da alma, para ser uma das peças principais na realização dessa tarefa.

A utilização de pacientes simulados pode regular a conduta do profissional de Medicina a partir da observação da relação dialógica, ou seja, da capacidade que o paciente simulado/ator tem de contro- lar as falas emitidas tão bem quanto as ações, gestos e posturas para que a comunicação aconteça de forma plena. Os estudantes de Medicina ou candidatos, muitos deles bem preparados para o processo seletivo de avaliação, mas sob pressão momentânea, perdem a escuta na interação com o paciente e falham na comunicação. Na pressa de resolverem a estação simulada, atropelam os itens avaliados, por exemplo, o olho no olho já citado, perguntar o nome, lavar as mãos antes do atendimento ou também perceber possíveis doenças causadas por um histórico de hábitos sociais, procedimentos que são de extrema importância na avaliação humanística do profissional (OSSINI, 2020).

Essa interação com o paciente simulado/ator é atravessada o tempo todo pela pressão e pelo nervosismo natural do candidato. Muitos deles já tiveram experiências semelhantes e conseguem lidar melhor com o "contrato de ficção" que se estabelece, mas muitos outros se perdem na ânsia de querer acertar a todo custo. Com o treinamento adequado, o paciente simulado proporcionará aos estudantes uma experiência consistente, aumentando, assim, a validade, a reprodutibilidade e a profundidade da experiência de aprendizado e da avaliação de diferentes domínios de competências. Como resultado desse processo de ensino e avaliação, os candidatos certamente estarão mais preparados e confiantes para suas futuras vidas profissionais (OSSINI, 2020).

\section{REFERÊNCIAS}

BOKKEN, L. et al. Feedback by simulated patients in undergraduate medical education: a systematic review of the literature. Medical Education, Oxford, v. 43, n. 3, p. 202-210, 2009.

BRASIL. Ministério da Educação. Diretrizes Curriculares Nacionais para o curso de Medicina (DCN). Da Atenção à Saúde - Art. $5^{\circ}$. Diário Oficial da República Federativa do Brasil, Brasília, DF, 23 jun. 2014. Seção 1.

CHURCHOUSE, C.; MCCAFFERTY, C. Standardized patients versus simulated patients: Is there a diference? Clinical Simulation in Nursing, New York, v. 8, n. 8, p. 363-365, 2012.

CLELAND, J. A.; ABE, K.; RETHANS, J.-J. The use of simulated patients in medical education: AMEE Guide No 42. Medical Teacher, London, v. 31, n. 6, p. 477-486, 2009.

FISCHER-LICHTE, E. Realidade e ficção no teatro contemporâneo. Sala Preta: Revista do Programa de Pós-Graduação em Artes Cênicas, São Paulo, v. 16, n. 2, p. 14-32, 2013.
HUBAL, R. C. et al. The virtual standardized patient: simulated patient-practitioner dialogue for patient interview training. Studies in Health Technology and Informatics, Amsterdam, v. 70, p. 133-138, 2000.

HUBAL, R. C.; FRANK, G. A.; GUINN, C. I. AVATALK virtual humans for training with computer generated forces. Research Triangle Institute, 1998.

LEWIS, K. L. et al. Padrões de Melhores Práticas (SOBP) da Associação de Educadores de Pacientes Padronizados (ASPE). Advances in Simulation, London, v. 2, n. 1, p. 10, 2017. http://dx.doi.org/10.1186/s41077-017-0043-4.

MORAES, M. A. A.; ANGELI, O. A. Desempenho dos Pacientes Simulados no exercício de avaliação prática profissional. Revista Saúde, Santa Maria, v. 42, n. 2, p. 167-174, 2016.

NEGRI, E. C. et al. Clinical simulation with dramatization: gains perceived by students and health professionals. Revista Latino-Americana de Enfermagem, Ribeirão Preto, v. 25, e2916, 2017. Disponível em: <http://www. 
scielo.br/scielo.php?script=sci_arttext $\&$ pid=S0104$11692017000100604 \& \operatorname{lng}=$ en\&tlng=en $>$. Acesso em: 08 maio 2021.

OSSINI, E. B. Expansões da teatralidade: a participação de atores na prova de admissão de residentes e de especialistas no Hospital das Clínicas de São Paulo e no Revalida do Governo Federal. 2020. 100 f. Dissertação (Mestrado)-Programa de Pós-graduação em Artes Cênicas, Escola de Comunicação e Artes, Universidade de São Paulo, São Paulo, 2020.

SANTOS, A. C. O paciente simulado/ator na cena contemporânea: corpo, imagem e ação. 2010. 107 f.
Dissertação (Mestrado)-Escola de Comunicação e Artes, Universidade de São Paulo, São Paulo, 2010. Disponível em: <https://www.teses.usp.br/teses/disponiveis/27/27155/ tde-01122010-095214/publico/3406620.pdf >. Acesso em: 08 maio 2021.

SINDICATO DOS ARTISTAS E TÉCNICOS EM ESPETÁCULOS E DIVERSÕES DO ESTADO DE SÃO PAULO - SATED. Pauta reivindicatória. São Paulo: SATED, 2018. Disponível em: <https://www.satedsp.org.br/ wp-content/uploads/pdf/dissidio_arte_cenicas_2017-2018. pdf $>$. Acesso em: 08 maio 2021. 
CAPÍTULO 6

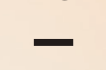

\section{A confecção da Moulage em diferentes cenários simulados}




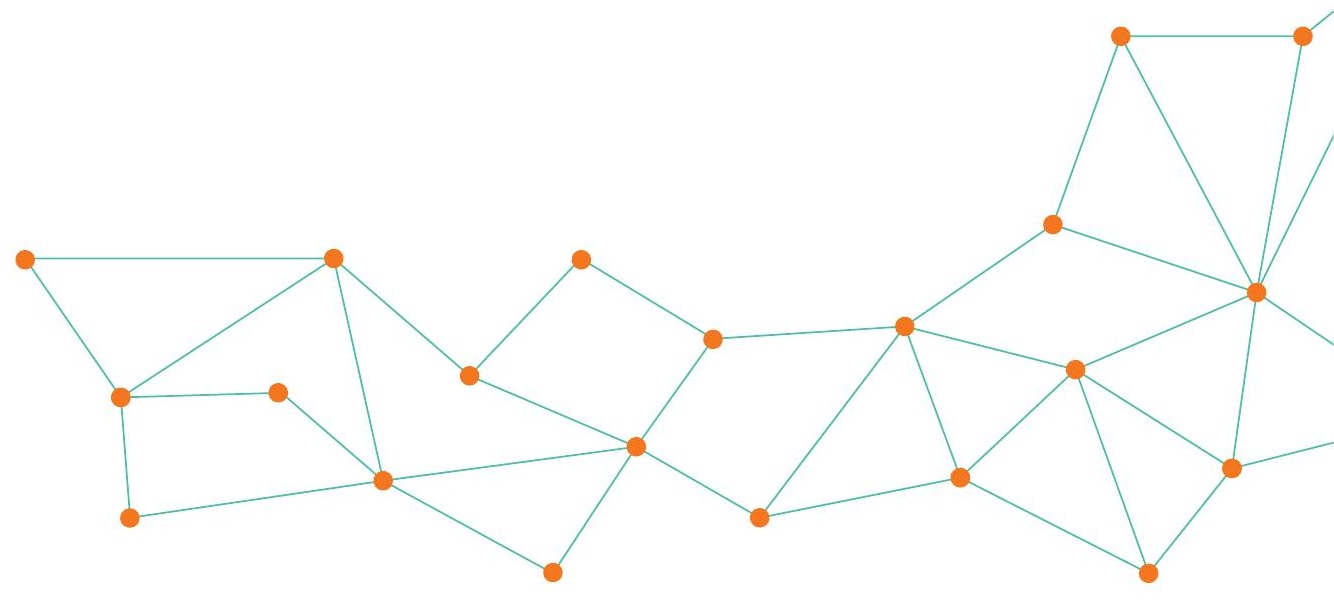

\section{INTRODUÇÃO}

Moulage, palavra de origem francesa que significa fundição ou moldagem, é a arte de criar, imitar ou replicar a fim de promover realismo. Também pode ser definida como o uso de maquiagem de efeitos especiais, que possibilita simular contusões, feridas, sangue, incisões, hematomas, idade do paciente, características clínicas de determinadas doenças ou outros efeitos a um simulador ou paciente simulado (SMITH-STONER, 2011; MERICA, 2011; SWAN, 2013).

Os primeiros registros de moulage foram encontrados em artefatos do Antigo Egito, no processo de caracterização de faraós. Posteriormente, no Renascimento, a moulage começou a ser realizada com modelos de cera para representar características anatômicas, possibilitando o estudo da anatomia humana e animal nas ciências médicas. No início do século XVII, a produção e a cria- ção dos modelos de cera passaram a ser utilizados para caracterizar e investigar a morte de indivíduos e para expandir o conhecimento anatômico (COOKE, 2010).

A moulage perdeu sua popularidade no ensino em meados do século XX por causa da criação da fotografia (STOKES-PARISH; DUVIVIER; JOLLY, 2018), cujo avanço levou ao desenvolvimento da indústria cinematográfica. Consequentemente, a moulage passou a ser utilizada como técnica de elaboração de efeitos especiais. Filmes de terror e ação começaram a empregá-la para trazer realismo às cenas, por imitar com perfeição ferimentos, cortes, sangue, deformidades, entre muitos outros (FALCÃO; SOARES, 2015).

Ainda no século XX, a moulage passou a ser usada no treino militar de guerra, em um tipo de terapia comportamental baseada no princípio do con- 
dicionamento clássico conhecido como "Systematic desensitization", ou "dessensibilização sistemática". Desenvolvida por Wolpe durante os anos 1950, é uma técnica comportamental comumente utilizada para tratar o medo, os transtornos de ansiedade e as fobias. Por meio desse método, a pessoa é gradualmente exposta a um estímulo produtor de ansiedade para conseguir superar o problema (PETERSEN et al., 2017). No treino militar, a moulage era incorporada a pacientes simulados e simulava as vítimas da guerra, para que os militares realizassem o atendimento delas, dando-lhes os primeiros socorros.

Na literatura, os benefícios da moulage em simulação clínica são bem discutidos, evidenciando seu potencial para aumentar o realismo, a confiança, a aprendizagem e a retenção do conhecimento. É um recurso que incrementa fidedignidade ao cenário simulado e tem se tornado essencial para a avaliação clínica e tomada de decisões (SMITH-STONER, 2011).

Quando usada adequadamente na simulação, a moulage pode beneficiar os cenários simulados, sendo uma ferramenta de extrema importância para os educadores. Seu uso garante a criação dos mais variados cenários simulados de acordo com os objetivos de aprendizagem, não os limitando à necessidade de cenários embasados apenas nos simuladores disponíveis nas instituições (WRIGHT et al., 2018).

No Brasil, o uso dessa técnica vem sendo utilizada nos diversos cenários do ensino em saúde, como em feridas (SILVA, OLIVEIRA-KUMAKURA., 2018, ALMEIDA et al., 2021) e estomias intestinais (NEGRI et al., 2019), destacando o realismo e a contribuição no processo de ensino e aprendizagem dos estudantes.

A literatura menciona o uso bem-sucedido da técnica de moulage na avaliação de habilidades e competências de estudantes de Medicina (SABZWARI; AFZAL; NANJI, 2017). No exame clínico objetivo estruturado (OSCE), essa técnica pode ser utilizada em diversos contextos simulando sinais e sintomas do paciente, como hipoglicemia, icterícia, casos traumáticos, feridas, queimaduras, úlceras ou lesões cutâneas, contribuindo para autenticidade e o realismo do processo de avaliação (ELSHAMA, 2020).

Além disso, a moulage diminui a descrença dos estudantes durante a vivência na atividade de simulação, desenvolve o engajamento sensorial e, consequentemente, aumenta o desempenho do tempo de resposta do cenário simulado, proporcionando pistas ao pensamento crítico e ao julgamento clínico
(MERICA, 2011; STOKES-PARISH; DUVIVIER; JOLLY, 2017).

No cenário simulado, a moulage pode auxiliar o estudante a confirmar os sinais físicos e fisiológicos que sustentam a tomada de decisão e o raciocínio clínico. Permite ainda a descoberta de dados pertinentes à avaliação clínica do paciente, como características de lesões, etiologia, processo de cicatrização, sangramento, quantidade de exsudato e odores corporais, entre outros, e ensina a coletar informações relevantes para um correto diagnóstico (MERICA, 2011; STOKES-PARISH; DUVIVIER; JOLLY, 2017).

Mesmo com estudos que fornecem a descrição detalhada da técnica da moulage e a caracterização dos atores e manequins (FOOT et al., 2008; SARMASOGLU et al., 2020; SWAN 2013), além de sites e vídeos disponíveis gratuitamente, o maior dos desafios de sua utilização nos contextos simulados é a capacitação de profissionais qualificados para esta finalidade.

Há um grande investimento de empresas na aquisição de moulages pré-moldadas que acompanham os simuladores para utilizar nos contextos simulados, porém isso exige um alto custo e se limita a um único tipo, o que não permite ao educador a flexibilidade de criar a moulage desejada (MORRISON; CATANZARO, 2010).

Neste contexto, é necessário conhecer alguns produtos que facilitam a sua confecção e ter variação de criatividade, assim será possível realizar uma variedade de cenários simulados.

\section{COMPONENTES DO KIT MOULAGE}

Existe uma variedade de materiais disponíveis para a confecção da moulage que podem ser encontrados em sites e lojas de fantasias, como tintas, sangues falsos, massas de modelagem e pigmentações, conforme apresenta o Quadro 1. Até mesmo, podem ser utilizados os mais variados recursos disponíveis em mercados comuns, como corantes, glucose, mel para realizar sangue, gelatina com glicerina para realizar uma massa de modelagem, entre outros.

Ao adquirir o produto para a moulage, é necessário verificar a compatibilidade com a pele dos simuladores, pois, geralmente, em alguns locais, a pele, que é de plástico ou borracha, não pode ser substituída. Desta maneira, deve-se usar uma barreira protetora para a pele do simulador e do paciente simulado, a menos que o produto já tenha sido testado, garantindo que não altera e danifica permanente- 
Quadro 1 - Produtos utilizados para a confecção da moulage.

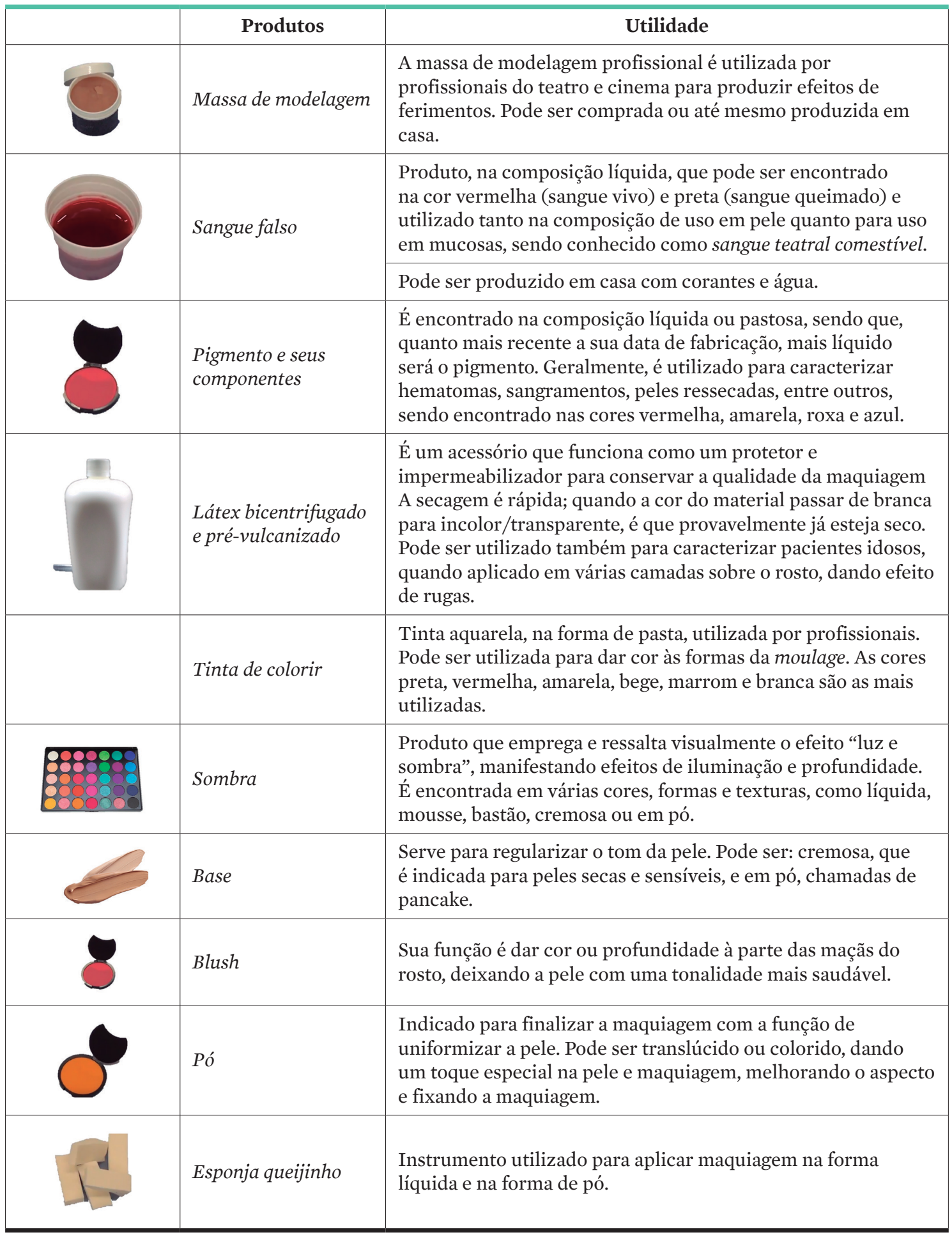

Fonte: direito de imagem do autor. 


\begin{tabular}{|l|l|l|}
\hline \multicolumn{1}{|c|}{ Produtos } & \multicolumn{1}{c|}{ Utilidade } \\
\hline & Espátula de metal & $\begin{array}{l}\text { Instrumento para modelar a maquiagem, mais utilizado para } \\
\text { modelar e dar forma à massa SLUG }{ }^{\circledR}\end{array}$ \\
\hline- & Pincel sombra & $\begin{array}{l}\text { Instrumento utilizado para aplicar maquiagem na forma } \\
\text { líquida e na forma de pó. }\end{array}$ \\
\hline
\end{tabular}

Fonte: direito de imagem do autor.

mente o simulador, e também não causa alergias e irritações no paciente simulado.

Podem ser utilizados como barreira a vaselina antes da maquiagem, o plástico filme transparente, a fita adesiva e o látex pré-vulcanizado, vendido por marcas conhecidas e utilizado para este fim.

Maquiagens do tipo "longa" ou "permanente" devem ser usadas sobre uma barreira rígida, pois há enorme chance de manchar o simulador.

Sempre quando a modulagem for realizada em um paciente simulado, recomenda-se verificar se o indivíduo apresenta alergia a alguma substância.

Ao fazer hematomas, escoriações e petéquias na pele do simulador, é necessário dar prioridade a um pó make-up. Deve-se também evitar aplicar creme base, líquido ou spray de maquiagem diretamente na pele do simulador. A única exceção a essa regra é a maquiagem de creme para rosto.

As lesões simuladas precisam ter relação com o objetivo proposto no cenário. Por isso, planeja-se o tipo de material a ser utilizado antes de se realizar a montagem do cenário. Por exemplo, ao criar hematomas, é preciso basear-se na anatomia e fisiologia para compreender como a cor pode transmitir o tempo do hematoma e a gravidade das contusões. Além da moulage, a caracterização do ambiente do simulador/ator é importante e faz parte do conjunto para aumentar a realidade do cenário.

A seguir são listadas algumas sugestões de moulage simples e de baixo custo que melhoram a caracterização do paciente e do cenário simulado.

\subsection{SUDORESE}

Para simular uma sudorese, por exemplo, em situações de atendimento a pacientes com hipoglicemia e choque hemodinâmico, pode ser utilizada a glicerina líquida diluída em água e posteriormente borrifada com um spray sobre o simulador/ator. A glicerina é facilmente encontrada nas farmácias e a um baixo custo. $\mathrm{E}$ a mistura pode ser feita com uma parte de glicerina e duas partes de água.

\subsection{VÔMITO}

$\mathrm{O}$ vômito pode ser elaborado de acordo com o objetivo do cenário e conter fragmentos de alimentos, sangue (hematêmese), borra de café, aspecto verde-amarelado (bilioso), entre outras possibilidades.

Uma variedade de ingredientes facilmente encontrados na cozinha pode simular o vômito com diferentes odores e características, criando uma aparência autêntica. Podem ser utilizadas sobras de sopas de vegetais, macarrão instantâneo, aveia, cereais matinais, bolachas de água e sal trituradas, suco de laranja, vinagre branco, leite, suco de limão, queijo parmesão, ervilha enlatada, uva-passa, grão de milho, entre outros.

Gotas de corantes alimentícios também podem ser adicionados para criar aspectos de acordo com o objetivo proposto. Para obter consistência, adiciona-se gelatina incolor ou lubrificante à base de água.

\subsection{FEZES}

As fezes podem ser produzidas com consistência sólida, pastosa e diarreica, por meio de uma variedade de ingredientes e restos de alimentos, como grão-de-bico e abóbora cabotiá, que, após cozidos e batidos no liquidificador, formam uma pasta amolecida.

Fezes com presença de sangue são produzidas com ingredientes como chocolate em pó, leite, corante líquido/gel comestível vermelho e amarelo, sendo misturados até obter o efeito desejado (Figura 1). 


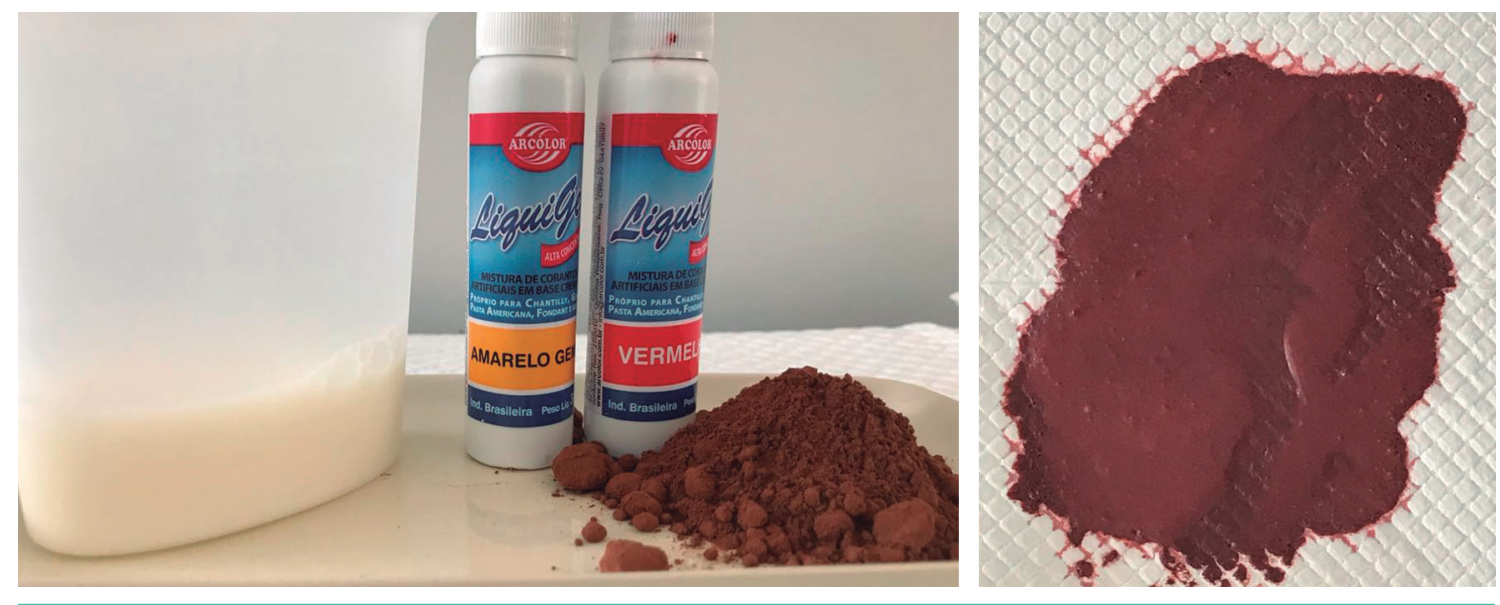

Figura 1- Aspecto de fezes com presença de sangue, produzidas com leite, chocolate em pó, corante líquido/gel vermelho e amarelo.

Fonte: direito de imagem do autor.

A presença de coágulos de sangue nas fezes pode ser simulada acrescentando ameixa em calda ou pedaços de gelatina de cor vermelho-escura com consistência firme, obtida diminuindo a quantidade de água ou colocando gelatina sem sabor durante o preparo. Outra opção é utilizar borra de café ou chocolate em pó misturado com aveia, adicionando água até atingir a consistência desejada, para simular fezes com característica de melena (Figura 2 e 3 ). Para obter odor, pode ser adicionada uma ampola de Fluimuci ${ }^{\circledR}$, medicamento que possui odor sulfúreo (enxofre), contribuindo para o realismo no cenário.

Outro exemplo para simular fezes é o uso de fígado de boi cru e feijão cozido, batendo tudo no liquidificador e mantendo em um saco ou vasilha plástica fechada fora da geladeira por um dia. Essa mistura irá apresentar característica de fezes pastosas e com odor fisiológico, podendo ser utilizada para simular efluentes de colostomia.

\subsection{SANGUE}

Assim como vômito e fezes, o sangue também tem uma variedade de opções. Langford (2018) sugere os seguintes ingredientes: uma colher de sopa de sal, um tubo de gel lubrificante à base de água (tipo gel para ultrassom) ou gel para cabelo incolor e sem álcool, corante líquido/gel comestível vermelho, água, corante líquido/gel azul comestível para ajustar a cor - comprimidos de sulfato ferroso podem ser acrescentados, proporcionando um cheiro realista ao sangue.

Para o preparo, é preciso aquecer a água (morna), dissolver o sal na água e adicionar o gel lubrificante.
Caso o sulfato ferroso seja em drágea, deve-se remover o revestimento que o comprimido possui, mergulhando-o em uma vasilha com água quente. Depois, adiciona-se o tablete à mistura principal e mexe-se até que todos os componentes estejam dissolvidos (LANGFORD, 2018). Já os comprimidos sem revestimento devem ser macerados e misturados ao preparo. Então, deve-se adicionar o corante vermelho até obter a coloração desejada e, após, o corante azul líquido comestível, gota a gota, para ajustar a cor conforme necessário. Por fim, a mistura deve descansar por pelo menos quatro horas antes de ser usada (LANGFORD, 2018).

Como resultado, obtém-se um sangue consistente e mais espesso (Figura 4).

Outra maneira simples é misturar água e corante vermelho, adicionando corante verde com cuidado até atingir a cor desejada. Esse tipo de preparo também pode ser colocado em bolsas de sangue para simular transfusão.

Ingredientes como glicose de milho e corantes alimentares vermelho, azul e amarelo também são ótimas opções para serem utilizadas. Os corantes azul e amarelo aumentam o realismo da pigmentação, no entanto devem ser usados em pouca quantidade, sendo acrescentados conforme o resultado desejado.

Os coágulos de sangue podem ser utilizados em cenários de obstetrícia, traumas, urológicos, entre outros, e produzidos a partir dos seguintes ingredientes: gelatina incolor em pó, água fria, água morna, glicerina biodestilada (umectante para fins alimentícios) e corante líquido/gel vermelho 
e verde. Para obtê-los, deve-se misturar a gelatina incolor em pó em aproximadamente $100 \mathrm{ml}$ de água morna e depois acrescentar $50 \mathrm{ml}$ de água fria e uma colher de glicerina. Em seguida, acrescentam-se o corante líquido vermelho e o verde até obter a tonalidade desejada, deixando, por fim, na geladeira
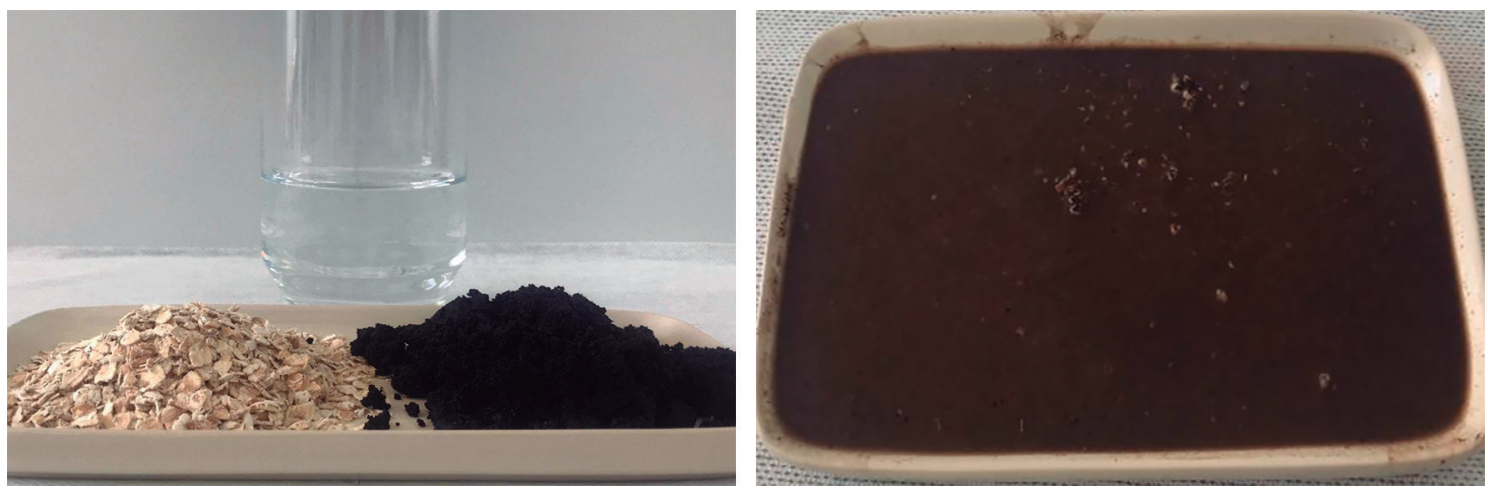

Figura 2 - Aspecto de fezes produzidas com aveia em flocos, borra de café e água. Fonte: direito de imagem do autor.
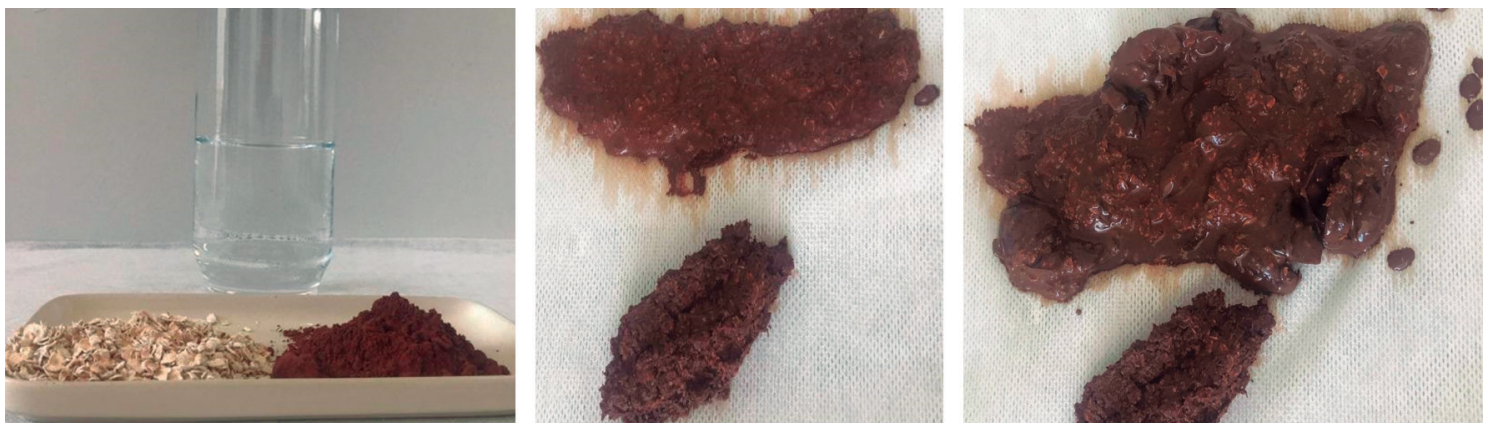

Figura 3 - Aspecto de fezes produzidas com aveia em flocos, chocolate em pó e água.

Fonte: direito de imagem do autor.
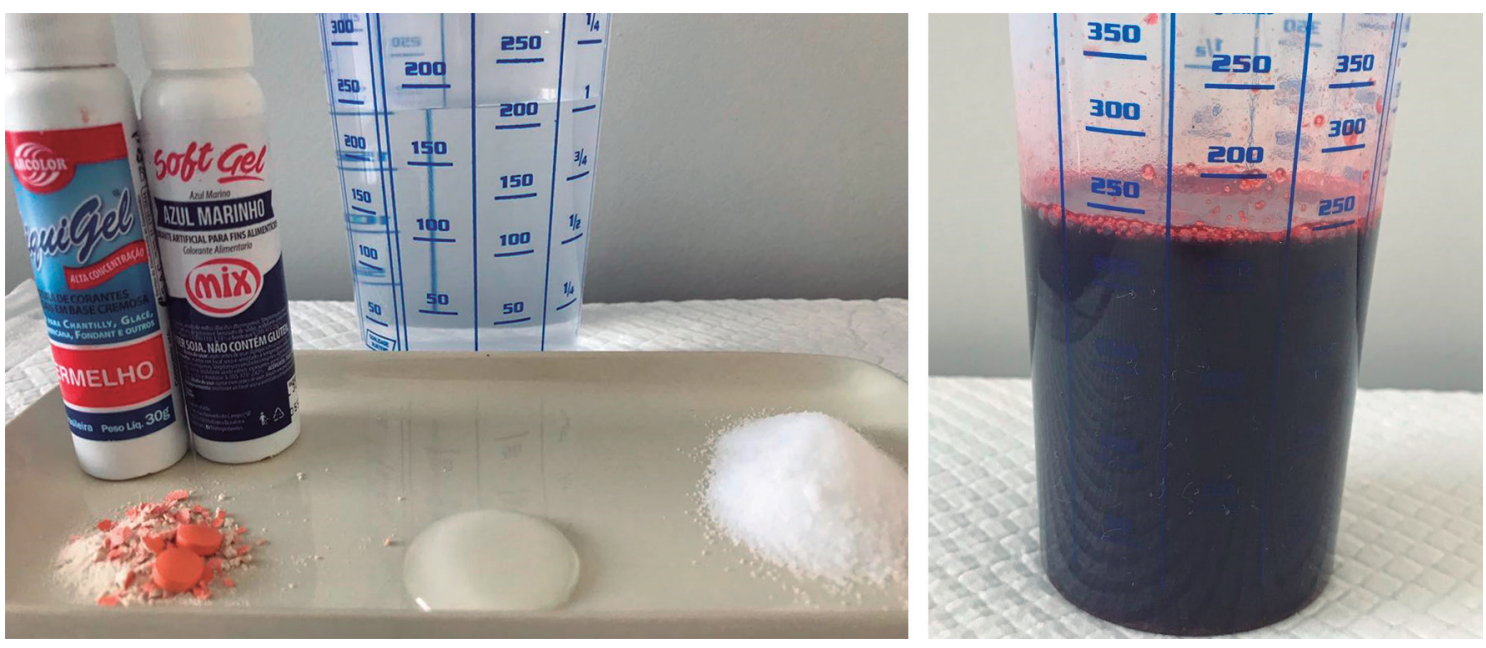

Figura 4 - Aspecto de sangue produzido com corante líquido/gel vermelho e azul, comprimido de ferro, água, gel hidrossolúvel e sal.

Fonte: direito de imagem do autor. 
para obter consistência firme. A adição da glicerina biodestilada e de pouca água proporciona uma maior durabilidade na consistência do coágulo (Figura 5) (CHEZ MOULAGE, 2008).

Outra opção para simular coágulos no sangue é preparar gelatina com sabores de morango, framboesa, frutas vermelhas e uva de forma bem concentrada, diluindo-a apenas em 150-200 ml de água.

\subsection{DRENAGEM GÁSTRICA}

A combinação de ingredientes é importante para produzir a drenagem que se deseja na simulação, por exemplo, em situações de peritonite e de íleo paralítico. Sopa cremosa, borra de café, corante líquido comestível vermelho e água produzem uma drenagem com característica preto-esverdeada (CHEZ MOULAGE, 2008).

Outra opção é diluir $50 \%$ ou menos de cola em água, adicionando gotas de corante líquido/gel verde-escuro para alcançar a cor desejada. Essa combinação se assemelha ao conteúdo GI e PH (Figura 6) (CHEZ MOULAGE, 2008).

A mistura com ingredientes como tomate, salsa ou coentro, cebola, suco de limão, alho picado, milho, água, corante líquido e borra de café proporciona uma drenagem com aspecto vermelho/marrom, associada à sangramento gástrico, cirurgia e outras causas. Para isso, deve-se despejar a quantidade desejada da mistura no liquidificador e bater até triturar o alimento em pequenas partículas, adicionando água para a consistência e corante líquido para coloração desejada. Quando mantida em temperatura ambiente, a mistura começa a azedar dentro de dois-três dias, dando um odor azedo ao conteúdo drenado. Esta opção também pode ser utilizada para simular vômito (CHEZ MOULAGE, 2008).

\subsection{URINA}

Utilizando chá de camomila e corante amarelo, vermelho ou verde, é possível alcançar as cores dese-
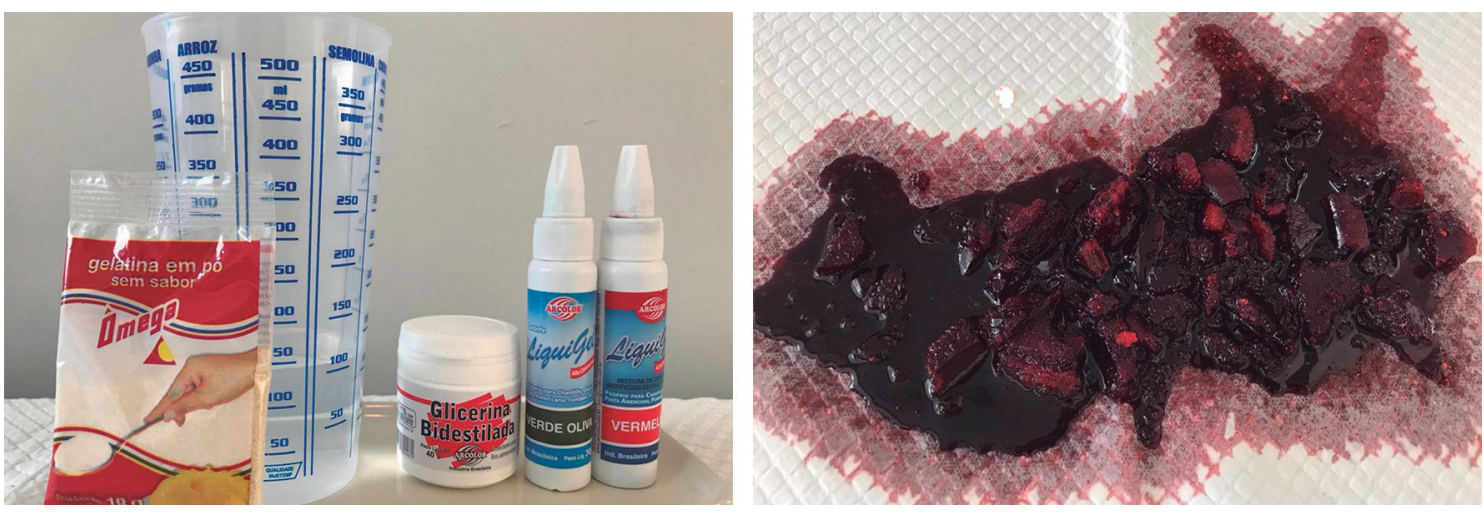

Figura 5 - Coágulos de sangue produzidos com água, gelatina em pó, glicerina, corante comestível líquido/gel verde e vermelho.

Fonte: direito de imagem do autor.
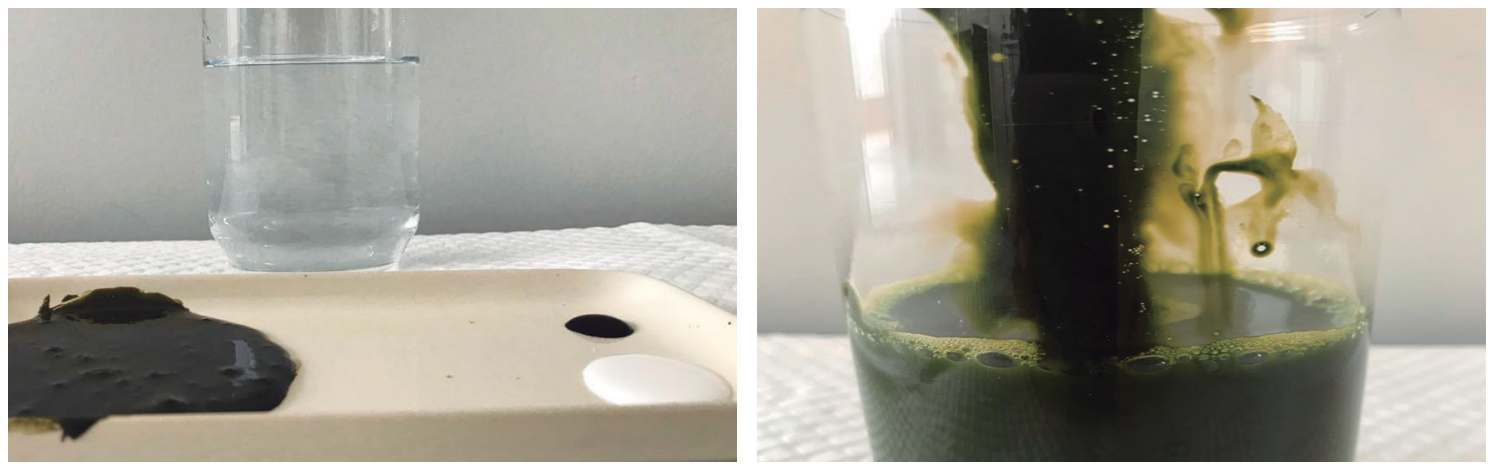

Figura 6 - Aspecto de secreção gástrica para cenário de drenagem nasogástrica.

Fonte: direito de imagem do autor. 
jadas, variando desde aspecto amarelo-claro, amarelo-citrino, amarelo-escuro, hematúria, âmbar e esverdeada turvo-piúria. Os exemplos a seguir (Figura 7 e 8) foram feitos com chá de camomila, alterando a proporção da água na diluição.

Para uma urina de coloração âmbar, adiciona-se leite ou amido de milho. $\mathrm{O}$ acréscimo de detergente líquido neutro de coloração amarela à mistura proporciona um aspecto de diurese com espuma.

Além disso, tinta à base de água amarela misturada com água também pode simular a urina.

Já para simular incontinência urinária, deve-se pulverizar a mistura preparada, acrescentando amônia para obter odor, nas roupas do simulador/ator, roupas de cama e fraldas. Também podem ser obtidos sedimentos por meio da adição de amido ou pó de giz.

Esta mistura também pode ser adicionada em um saco/frasco coletor de urina, comadre ou papagaio, de acordo com os objetivos definidos na atividade proposta.

\subsection{ARRANHÕES E ABRASÕES}

Para obter arranhões e abrasões, é necessário aplicar o sangue falso, batom ou tinta vermelha em uma esponja áspera ou gaze e arrastar na superfície da pele do manequim/ator.

\subsection{LESÃO POR PRESSÃO}

A lesão por pressão pode ser confeccionada em qualquer lugar do corpo, tanto manequim quanto paciente simulado. Vale lembrar que, a partir desta técnica, é possível criar qualquer tipo de lesão desejada, como cortes, fissuras, úlceras arteriais, venosas etc.

Para este caso, são necessários os seguintes ingredientes: látex pré-vulcanizado, massa de modelagem, tintas nas cores amarela e vermelha, sombra branca, rosa, base líquida e pó compacto. A seguir são descritos o passo a passo da confecção de uma lesão por pressão (Figura 9).

Na Figura 10 esta apresentado o resultado final da lesão conforme o passo a passo descrito.

\subsection{PACIENTE QUEIMADO}

A queimadura irá depender do grau e do cenário simulado. Para produzi-la, são necessários os seguintes ingredientes: látex, pigmentação amarela e vermelha e sangue falso vermelho. Deve-se aplicar na área desejada da queimadura três camadas
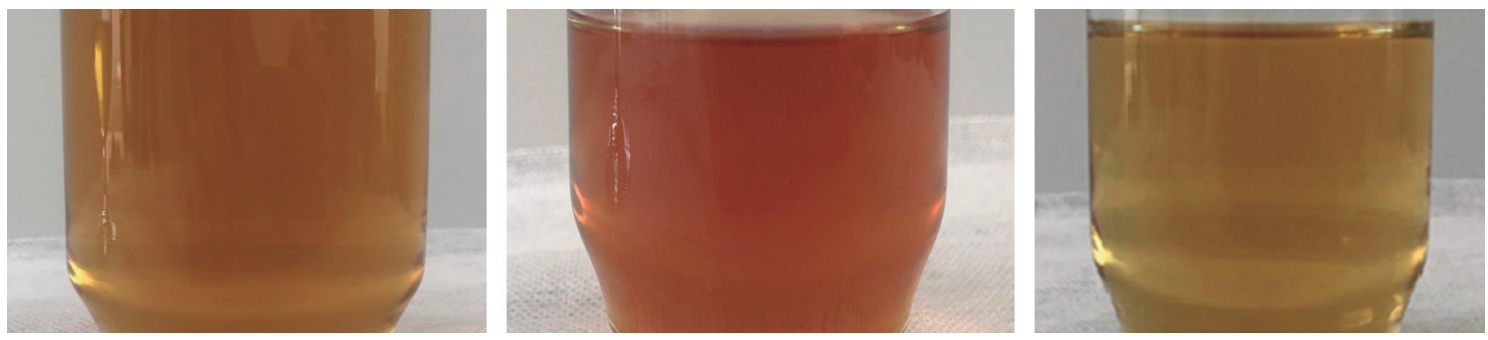

Figura 7 - Aspecto de urina para cenário simulado. Fonte: direito de imagem do autor.
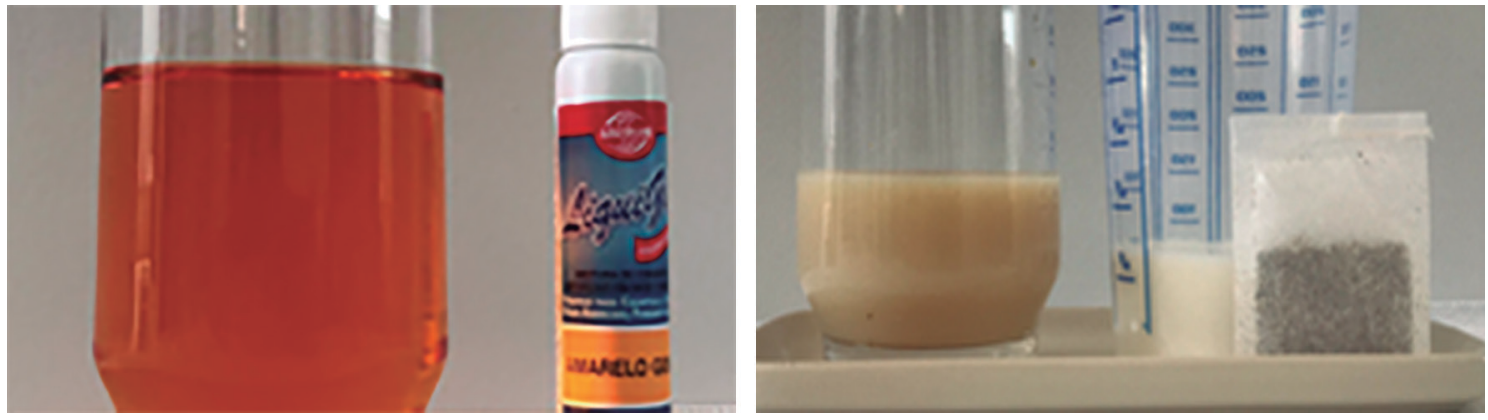

Figura 8 - Aspecto de urina colúrica e com sedimentos.

Fonte: direito de imagem do autor. 


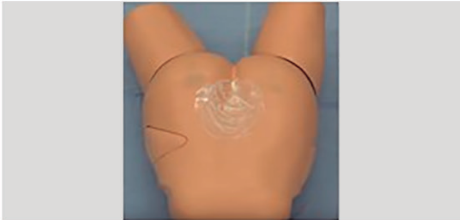

$1 \circ$ passo: aplica-se o látex sobre a pele do simulador ou paciente simulado.

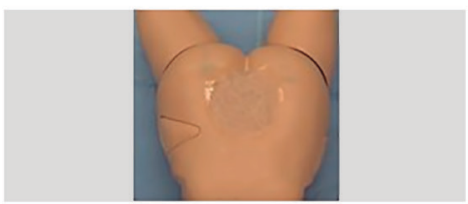

$4^{\circ}$ passo: molham-se as pontas dos dedos em água, aplicando-a sobre a ferida para que esta fique homogênea.

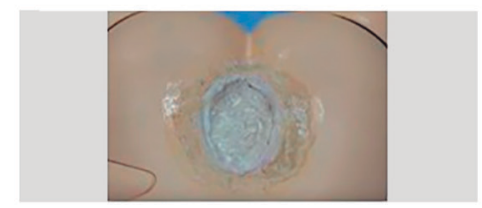

$7^{\circ}$ passo: após o látex secar, aplicam-se, sobre as bordas, base e pó compacto da cor da pele do simulador e do paciente simulado. Depois, sombreiam-se as bordas com sombra vermelha ou rosa para dar impressão de hiperemia, ou sombra branca para dar impressão de maceração.

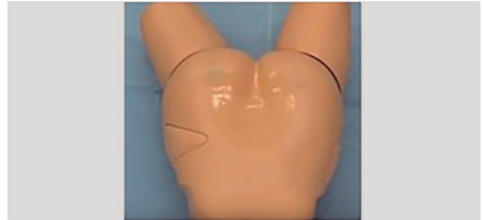

$2^{\circ}$ passo: aguarda-se secar.

\section{$3^{\circ}$ passo: aplica-se a massa de}

modelagem sobre a parte seca do local escolhido da ferida.

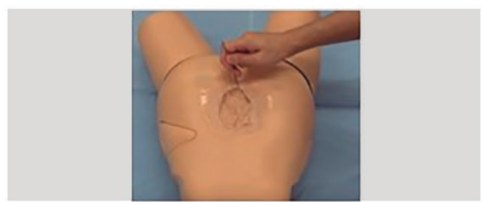

$5^{\circ}$ passo: com uma espátula de metal, faz-se o desenho da lesão desejada. Neste momento, deve-se definir a lesão, podendo ser corte, lesão tumoral, fratura ou lesão por pressão.

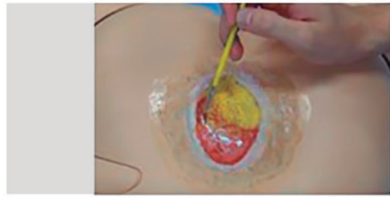

$8^{\circ}$ passo: dentro da lesão, aplicam-se tintas da cor desejada no tecido (amarela para tecido de esfacelo; vermelha para tecido de granulação). Para dar profundidade, aplicam-se cores escuras em volta da ferida.

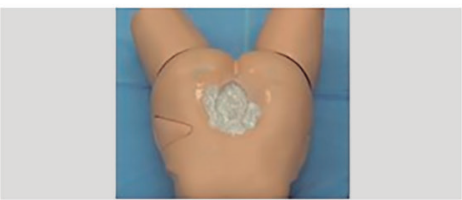

$6^{\circ}$ passo: aplica-se o látex em cima da ferida pronta. Este momento é para fixar a ferida e impermeabilizá-la.

Figura 9 - Passo a passo da criação da lesão por pressão.

Fonte: direito de imagem do autor.
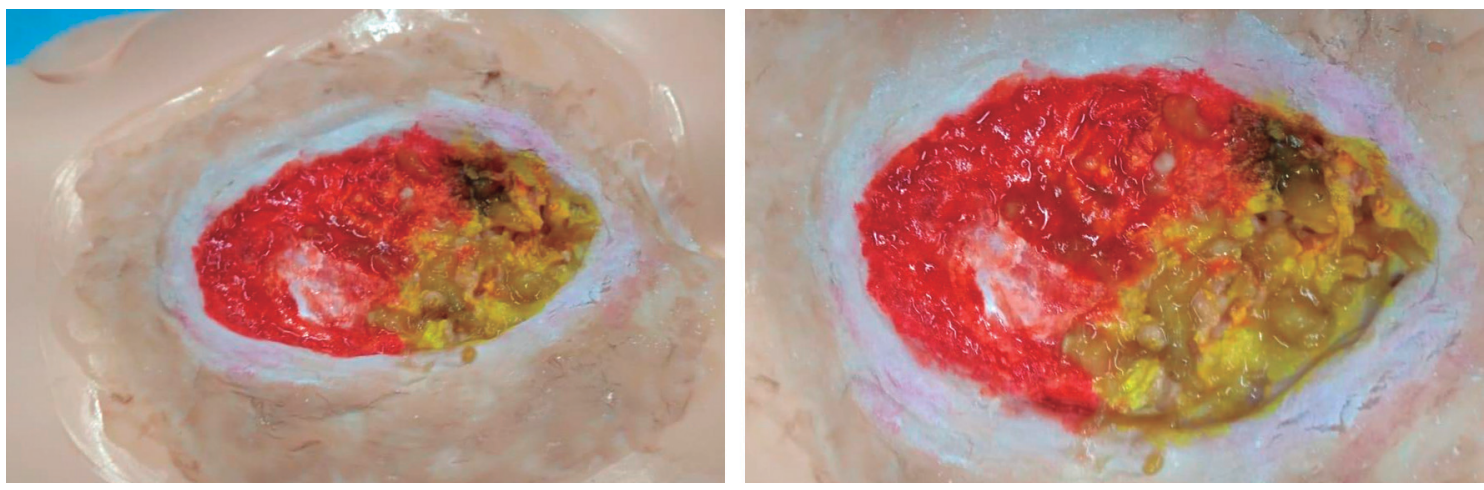

Figura 10 - Moulage de lesão por pressão.

Fonte: direito de imagem do autor. 

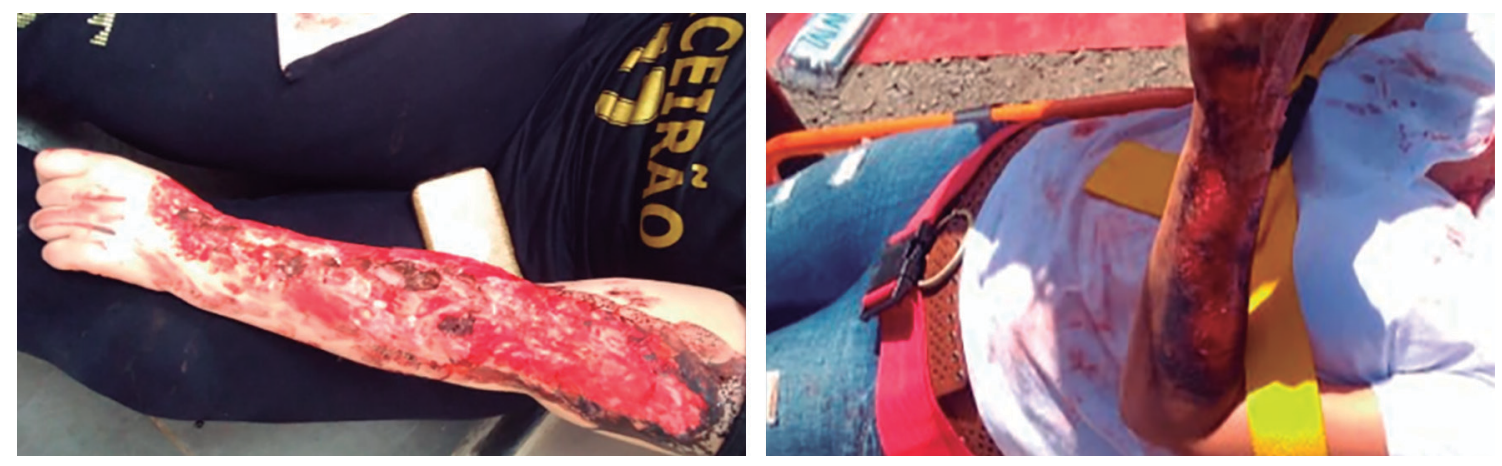

Figura 11 - Moulage de queimadura. Fonte: direito de imagem do autor.
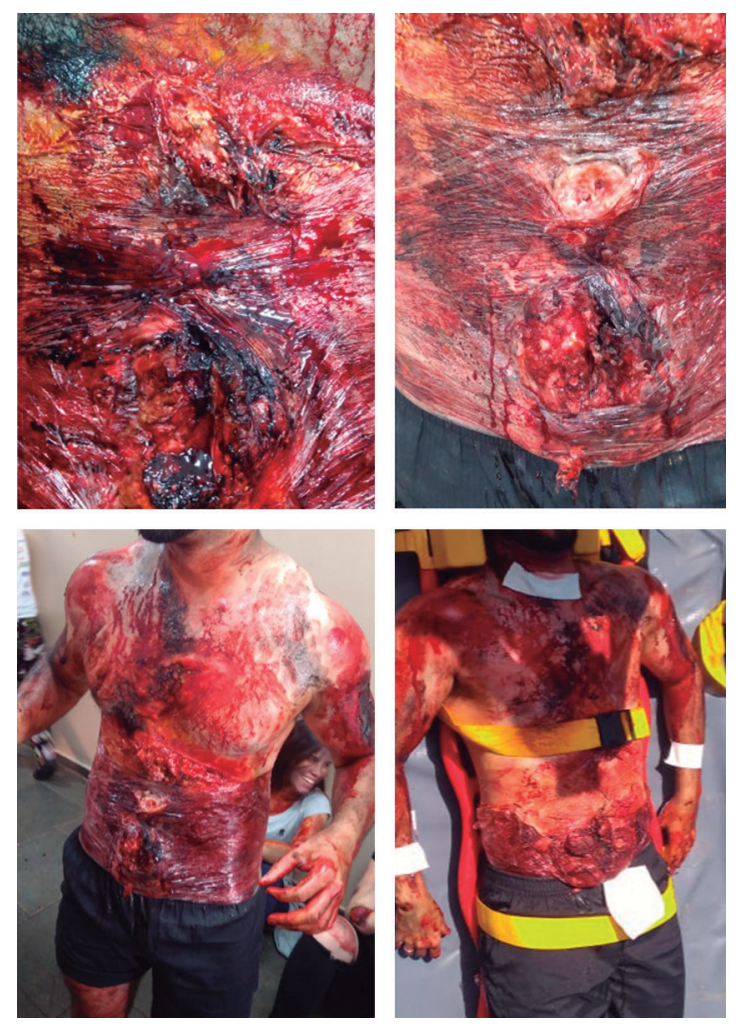

Figura 12 - Moulage paciente eviscerado.

Fonte: direito de imagem do autor.

de látex, esperando secar cada aplicação. Depois de seca, marca-se a área de queimadura desejada e retira-se o látex apenas dela (ficando com aspecto de bolha). Então, aplicam-se, sobre a área de dentro, pigmentação amarela e vermelha e, sobre toda a extensão do braço, sangue falso vermelho ou preto e pigmentação vermelha (Figura 11).

\subsection{PACIENTE EVISCERADO}

Para obter um paciente eviscerado, é preciso de sangue artificial vermelho e sangue queimado, linguiça e papel filme. Deve-se molhar uma esponja com sangue vermelho ou sangue queimado e espalhar sobre toda a área de queimadura desejada. Após, aplica-se o sangue falso em toda a pele da região do tórax e abdome do paciente, adicionam-se pedaços de linguiça sobre o abdome e passa-se papel filme. Com uma espátula, macera-se a linguiça e retira-se parte dela para fora do papel filme. Então, deve-se cobrir toda a região com mais sangue falso (Figura 12).

\section{CONSIDERAÇÕES FINAIS}

A moulage é um recurso que possibilita trazer realismo ao que se deseja mostrar. Trata-se de uma ferramenta importante desde o início da sociedade e se implementou na educação logo no Renascimento, dando um tom realístico para o cinema e a fotografia e tornando-se imprescindível para os cenários simulados.

Como demonstrado neste texto, quando realizada com planejamento, a moulage pode ser utilizada a partir de recursos simples, de fácil aquisição e baixo custo para sua confecção. Investindo em criatividade, é possível criar e recriar diversos cenários simulados ao educador para a simulação clínica. 
ALMEIDA, A. O., et al. Construção, validação e aplicação de cenários de simulação clínica para avaliação de especialistas em estomaterapia. Revista Brasileira de Enfermagem, Brasília, v. 74, n. 1, e20200360, 2021.

CHEZ MOULAGE. Recipe book: making training sessions as realistic as possible. Armonk: Laerdal Medical Corporation, 2008. Disponível em: <https://static1. squarespace.com/static/5121177ae4b06840010a00cl/ t/51487539e4b0d1d31cb2f3a8/1363703097118/Chez Moulage.pdf>. Acesso em: 02 ago. 2019.

COOKE, R. A. A moulage museum is not just a museum. Virchows Archiv, Berlin, v. 457, n. 5, p. 513-520, 2010.

ELSHAMA, S. S. How to use moulage as a simulation tool in medical education? Iberoamerican Journal of Medicine, La Rioja, v. 03, p. 219-222, 2020.

FALCÃO, F.; SOARES, T. A cosmética do sangue: o baixo orçamento como valor nos filmes de terror. Esferas, Brasília, n. 6, 2015.

FOOT, C., et al. Moulage in high-fidelity simulation-a chest wall burn escharotomy model for visual realism and as an educational toll. Journal of the Society for Simulation in Healthcare, Washington, v. 3, n. 3, p. 1-5, 2008.

LANGFORD, J. Moulage Recipes. 2018. Disponível em: $<$ https://fdocuments.in/document/moulage-recipes-byjackie-langford.html.>. Acesso em: 09 jun. 2019.

MERICA, B. J. Medical moulage: how to make your simulations come alive. Philadelphia: FA Davis Company, 2011.

MORRISON, A. M.; CATANZARO, A. M. High-fidelity simulation and emergency preparedness. Public Health Nursing, Boston, v. 27, n. 2, p. 164-173, 2010.

NEGRI, E. C., et al. Construção e validação de cenário simulado para assistência de enfermagem a pacientes com colostomia. Texto \& Contexto-Enfermagem, Florianópolis, v. 28, e20180199, 2019.
PETERSEN, C., et al. Optimization of simulation and moulage in military-related medical training. Journal of Special Operations Medicine, St. Petersburg, v. 17, n. 3, p. 74-80, 2017.

SABZWARI, S. R.; AFZAL, A.; NANJI, K. Mimicking rashes: use of moulage technique in undergraduate assessment at the aga khan university, Karachi. Education for Health, Mumbai, v. 30, n. 1, p. 60-63, 2017.

SARMASOGLU, S., et al. Pediatric severe burn moulage: recipe and evaluation from the burn team. Clinical Simulation in Nursing, Amsterdam, v. 49, p. 32-39, 2020. SILVA, J. L. G.; OLIVEIRA-KUMAKURA, A. R. S. Simulação clínica para ensino da assistência ao paciente com ferida. Revista Brasileira de Enfermagem, Brasília, v. 71, supl. 4, p. 1785-1790, 2018.

SMITH-STONER, M. Using moulage to enhance educational instruction. Nurse Educator, Philadelphia, v. 36, n. 1, p. 21-24, 2011.

STOKES-PARISH, J. B.; DUVIVIER, R.; JOLLY, B. Does appearance matter? current issues and formulation of a research agenda for moulage in simulation. Simulation in Healthcare, Philadelphia, v. 12, n. 1, p. 47-50, 2017.

STOKES-PARISH, J. B.; DUVIVIER, R.; JOLLY, B. Investigating the impact of moulage on simulation engagement-a systematic review. Nurse Education Today, London, v. 64, p. 49-55, 2018.

SWAN, N. A. Burn moulage made easy (and cheap). Journal of Burn Care \& Research, Philadelphia, v. 34, n. 4, p. e215-e220, 2013.

WRIGHT, A., et al. The influence of a full-time, immersive simulation-based clinical placement on physiotherapy student confidence during the transition to clinical practice. Advances in Simulation, London, v. 3, n. 1, p. 1-10, 2018. 
CAPÍTULO 7

-

Confecção e uso de simuladores de baixo custo: experiências da Medicina e Enfermagem 
Médica - Mestre e doutora

em tocoginecologia

Especialista em Educação para

as Profissões da Saúde

Docente da Universidade

Federal de Santa Catarina

Raphael Raniere de Oliveira Costa

Mestre e doutor em Enfermagem

Docente da Escola Multicampi

de Ciências Médicas - EMCM

Universidade Federal do Rio

Grande do Norte - UFRN

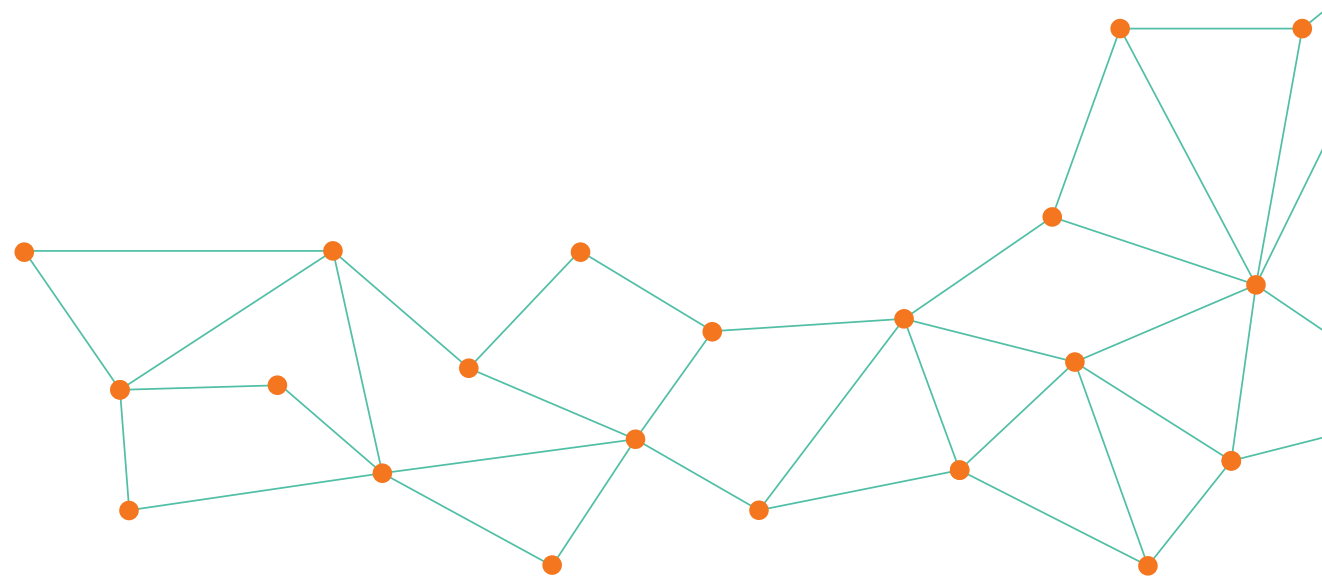

\section{INTRODUÇÃO}

O uso de simuladores e ambientes de simulação para o ensino de profissionais de saúde está bem estabelecido (ELLINAS; DENSON; SIMPSON, 2015; MOTOLA et al., 2013). Embora a qualidade dos estudos seja heterogênea e com indicadores variados, as evidências vêm demonstrando que o ensino com base em simulações é eficaz e leva a resultados melhores e mais duradouros que o ensino tradicional (MCGAGHIE et al., 2011a; HEGLAND et al., 2017). Seu uso pode melhorar as habilidades clínicas, técnicas, de comunicação e de trabalho em equipe, os níveis de satisfação e autoconfiança e o desempenho cognitivo, além de reduzir erros (ELLINAS; DENSON; SIMPSON, 2015; COSTA et al., 2020; ROWSE et al., 2015).

A ideia de simulações com ambientes informatizados/robotizados e com simuladores hiper-realistas torna o uso dessa estratégia inalcançável para a maioria dos campos de ensino. De fato, quando as evidências da efetividade do uso de simulações para o ensino ficaram mais robustas, um problema ficou evidente: o elevado custo desses equipamentos. Tanto sua aquisição quanto sua manutenção têm sido obstáculos para o seu emprego, podendo, não raramente, inviabilizar sua utilização em várias regiões do Brasil e do mundo (ELLINAS; DENSON; SIMPSON, 2015; KNOBEL et al., 2018a; SOUZA et al., 2020).

Os simuladores de alta fidelidade são, geralmente, importados e apresentam-se no mercado com valores que podem chegar a mais de U $\$ 150.000$ (SOUZA et al., 2020); sendo este um dos principais limitadores para a disseminação em larga escala pelas instituições formadoras (ELLINAS; DENSON; SIMPSON, 2015; ROWSE et al., 2015; KNOBEL et al., 2018a; MAGEE; SHIELDS; NOTHNAGLE, 2013; PEROSKY et al., 2011). 
Mas, em algum momento de sua formação, quase todo estudante de Medicina, de Enfermagem e de outras profissões de saúde utilizou simuladores artesanais, mesmo sem saber que era isso o que estava fazendo. É o caso da aplicação de injeções em frutas e carnes de animais, do treinamento de pontos cirúrgicos amarrando fios de algodão nas cadeiras do "estar médico". Essas simulações eram parte, geralmente, de um ensino informal e não eram validadas e estudadas como instrumentos de ensino.

A simulação e o uso de ambientes simulados podem ser utilizados mesmo com recursos limitados. O baixo custo e, por vezes, até a baixa fidelidade de um simulador não representam um empecilho ao seu uso. Não há evidência demonstrando que a hiper-realidade do simulador melhore a aprendizagem do participante (DESTEPHANO et al., 2015; SCHAUMBERG; SCHRÖDER; SANDER, 2017). Portanto, a depender dos objetivos de aprendizagem estabelecidos, simuladores de baixo custo podem ser eficazes no processo de ensino e aprendizagem (ROWSE et al., 2015; MAGEE; SHIELDS; NOTHNAGLE, 2013; RAMSEYER; LUTGENDORF, 2019; DESTEPHANO et al., 2015).

Entretanto, é importante destacar que, em razão de seu caráter recente, sobretudo no contexto brasileiro, ainda há uma lacuna de resultados educacionais quando se comparam modelos de baixo custo a outros modelos de diferentes níveis de fidelidade. Portanto, é indispensável que pesquisadores e estudiosos na área da simulação clínica incluam em suas agendas de pesquisas objetivos relacionados a esse problema.

Nessa perspectiva, o objetivo deste texto é apresentar conceitos e uma descrição do processo de criação, validação e uso de simuladores artesanais, mostrar alguns exemplos de simuladores já desenvolvidos e discutir possibilidades de uso e inserção deles no ensino de Medicina e Enfermagem.

\section{SIMULADORES DE BAIXO CUSTO E ARTESANAIS}

Simuladores são tecnologias que reproduzem dispositivos, peças físicas e/ou representações de serviços (SHAH et al., 2019). A literatura aponta para diferentes classificações, sendo a mais comum a relacionada à fidelidade do simulador, a saber: baixa, média e alta (COSTA et al., 2020; PEREIRA DA SILVA et al., 2018; SEROPIAN et al., 2014). Essa classificação diz respeito ao aparato tecnológico e feedback dos modelos. Mais recentemente, apareceu outra classificação, que se refere aos custos de aquisição, reposição e manutenção dessas tecnologias (SOUZA et al., 2020; TEMPERLY et al., 2018).

Nessa perspectiva, surge a definição de simulador de baixo custo, cujo conceito não está definido na literatura e, evidentemente, é bastante diverso conforme a realidade socioeconômica do local. Assim, provavelmente o que é baixo custo para uma universidade nos Estado Unidos é diferente do que é para uma universidade no Brasil. A ideia da construção e validação de alternativas com simuladores de baixo custo, os quais objetivam apresentar um menor custo sem necessariamente perder a qualidade, com a vantagem de necessitar de gasto mínimo para a sua conservação, é viável para países em desenvolvimento na América Latina e África (RAMSEYER; LUTGENDORF; 2019; CORTÉS et al., 2019; BULAMBA et al., 2019).

Em geral, os simuladores considerados de baixo custo apresentam atributos relacionados ao desenvolvimento de modelos - de diferentes níveis de fidelidade - geralmente com materiais alternativos a um custo bastante inferior aos modelos de referência disponíveis na indústria de simuladores para o ensino em saúde (ELLINAS; DENSON; SIMPSON, 2015; KNOBEL et al., 2018a; SOUZA et al., 2020; MCCLELLAND et al., 2019; KNOBEL et al., 2020; PEREIRA DA SILVA et al., 2018; PEROSKY et al., 2011; KNOBEL et al., 2018b; DE OLIVEIRA et al., 2017).

A produção de simuladores artesanais é menos estudada, embora existam diversos exemplos deles (KNOBEL et al., 2018b; GRAHEM et al., 2017; RAMSEYER; LUTGENDORF, 2019; SHEA; ROVERA, 2015; GOMES; SOARES; PESSOA, 2011). Destaca-se que simulação de baixo custo e simuladores artesanais não são, necessariamente, sinônimos. Como a própria denominação demonstra, o baixo custo se refere aos gastos de aquisição e manutenção. Já a denominação "artesanais", ou "home made", diz respeito aos materiais e ao próprio processo de montagem.

Em geral, simuladores artesanais são de baixo custo, mas é importante estar atento a esse fato. Por exemplo, um simulador artesanal que utiliza um peito de peru, com inclusões de azeitonas para simular punções de nódulos de mama guiadas por ultrassom (GIEBUROWSKI, 2018), é artesanal, mas não é, necessariamente, barato, já que a matéria-prima (carne de peru), além de seu preço, é perecível e pode ser utilizada para um número limitado de simulações. Em algumas ocasiões, os simuladores comerciais podem ser mais baratos. 
Nos últimos cinco anos, pode-se observar um crescimento exponencial no desenvolvimento de pesquisas - estudos metodológicos, projetos-piloto e validação - relacionadas ao desenvolvimento de simuladores de baixo custo. Na Medicina, destaca-se a área de cirurgia (GRAHEM et al., 2017; MCCLELLAND et al., 2019; BING et al., 2019; TEMPERLY et al., 2018; GOMES; SOARES; PESSOA, 2011). Entretanto, identificam-se iniciativas em diversas outras especialidades (ROWSE, P. G. et al., 2015; MCGAGHIE et al., 2011b) como as experiências em obstetrícia, que buscam aprimorar o treinamento para parteiras, profissionais de Enfermagem e médicos (MAGEE; SHIELDS; NOTHNAGLE, 2013; RAMSEYER; LUTGENDORF, 2019; PEROSKY et al., 2011). Especificamente para Enfermagem, também há um aumento de publicações (COSTA et al., 2020; KNOBEL et al., 2020; PEREIRA DA SILVA et al., 2018).

Para além da simulação em si, a construção de simuladores estimula a criatividade, a resolução de problemas, o trabalho em equipe, o trabalho multiprofissional e a comunicação entre pares e outros agentes. São algumas competências necessárias para a formação de profissionais de saúde, geralmente com poucas oportunidades de serem trabalhadas durante os cursos de graduação e residência.

Como toda tecnologia, os simuladores de baixo custo apresentam vantagens e limitações. O Quadro 1 traz uma síntese dessas variáveis.

\section{PROCESSO DE MONTAGEM}

Espera-se que, neste momento, os leitores já estejam convencidos de que montar simuladores artesanais de baixo custo pode ser uma forma acessível de realizar simulações. Além disso, é importante considerar que não há só uma maneira e/ou método para o desenvolvimento de projetos e protótipos.

A expertise do proponente guiará a escolha pelo método mais adequado e viável. Estudos metodológicos, projetos-piloto e Design Thinking são alguns métodos que podem ser utilizados. A seguir, o Quadro 2 apresenta um resumo das etapas do processo de montagem de um simulador.

\section{EXPERIÊNCIAS NACIONAIS E INTERNACIONAIS NO ENSINO EM SAÚDE}

Na Escola Multicampi de Ciências Médicas (EMCM) da Universidade Federal do Rio Grande do Norte, há a oferta de um módulo optativo intitulado "Inovação Tecnológica em Saúde", que possui carga horária de 30 horas e é ofertado uma vez por ano. Faz parte da estrutura curricular do curso de Medicina da EMCM e recebe 20 estudantes de diferentes semestres do curso.

O módulo se propõe a desenvolver noções de inovações tecnológicas e de tecnologias educacionais e criar protótipos de simuladores de baixo custo a partir do despertar da criatividade e do estudo de materiais e métodos que permitam o desenvolvimento e a avaliação de recursos materiais para o ensino médico.

A experiência tem sido bastante produtiva e tem gerado alguns projetos de iniciação científica relacionados ao desenvolvimento e validação de simuladores de baixo custo. Na Figura 1, apresenta-se um compilado de experiências desenvolvidas no módulo.

Na Universidade Federal de Santa Catarina, um projeto de extensão propôs a criação e o compartilhamento de simuladores artesanais para o ensino em saúde em uma página $w e b^{1}$. A ideia deste site é divulgar ideias para que todos possam copiar, de uma forma simples e barata, seguindo o conceito de "open source", ou de "código aberto", que inicialmente se referia apenas a softwares e passou a servir para hardwares e todos os processos.

Os simuladores estão sendo criados e compartilhados desde 2017. A maioria dos simuladores é para o ensino de obstetrícia e contém o passo a passo (DIY - Do It Yourself) para confecção e utilizaçãoAs Figuras 2 e 3 trazem alguns exemplos de modelos

Recentemente, a Federación Latinoamericana de Simulación Clínica y Seguridad del Paciente (FLASIC) publicou um e-book com 44 diferentes experiências de construção de simuladores de baixo custo, provenientes de diversos países do mundo, incluindo o Brasil. Além dos simuladores, são compartilhados os objetivos de aprendizagem, o custo estimado em dólares americanos, os materiais e os passos para o desenvolvimento (MARTÍNEZ et al., 2019).

\section{EXPECTATIVAS PARA O FUTURO}

Ao reconhecer e apostar no potencial desse fenômeno, tanto para a melhoria das práticas educativas no ensino em saúde quanto para a popularização e o amplo uso da simulação clínica enquanto

\footnotetext{
1 A página está disponível para consulta e uso em: https:// saudesimuladores.paginas.ufsc.br/.
} 
Quadro 1 - Vantagens e limitações relacionadas aos simuladores de baixo custo.

\begin{tabular}{|l|}
\hline \multicolumn{1}{|c|}{ Vantagens } \\
\hline Baixo custo (aquisição de materiais e manutenção). \\
\hline Reprodutibilidade: os modelos podem ser reproduzidos e melhorados constantemente. \\
\hline $\begin{array}{l}\text { Estímulo à criação (e consequente ampliação de conhecimentos e técnicas): estudantes, docentes, técnicos } \\
\text { de laboratórios e pesquisadores podem desenvolver seus próprios modelos. }\end{array}$ \\
\hline O desenvolvimento de modelos conforme necessidade e especificidade da área/especialidade. \\
\hline $\begin{array}{l}\text { Ampliação das possibilidades de treinar procedimentos de diferentes complexidades em modelos ainda não } \\
\text { desenvolvidos pelo mercado. }\end{array}$ \\
\hline Reposição de peças/elementos do modelo mais simples e acessível. \\
\hline Desenvolvimento/aquisição de modelos em instituiçães com limitação de orçamento. \\
\hline Ampliação das práticas simuladas e das oportunidades de aprendizagem. \\
\hline $\begin{array}{l}\text { Possibilidade de participação em uma comunidade de prática com desenvolvimento e melhoria de } \\
\text { simuladores de tecnologia aberta. }\end{array}$ \\
\hline $\begin{array}{l}\text { Possibilidade de utilizar modelos híbridos - com materiais já existentes ou que possam ser "vestidos” por } \\
\text { pacientes simulados. }\end{array}$ \\
\hline Limitaçães \\
\hline $\begin{array}{l}\text { Dificuldades de aquisição de alguns materiais alternativos, sobretudo por instituições públicas e por } \\
\text { processos de licitações. }\end{array}$ \\
\hline Tempo para desenvolver os projetos e suas etapas. \\
\hline $\begin{array}{l}\text { Requisição de conhecimentos específicos, como delineamentos de pesquisa, conhecimento de informática e } \\
\text { parcerias entre outras áreas do conhecimento (engenharias), o que pode ser mais difícil em universidades/ } \\
\text { locais mais remotos. }\end{array}$ \\
\hline $\begin{array}{l}\text { Com simuladores mais simples, pode haver dificuldade de os estudantes sentirem que estão vivenciando a } \\
\text { situação clínica real, principalmente para aqueles mais avançados. }\end{array}$ \\
\hline
\end{tabular}

Quadro 2 - Etapas do processo de montagem de simuladores artesanais de baixo custo.

\begin{tabular}{|l|l|}
\hline \multicolumn{1}{|c|}{ Etapas } & \multicolumn{1}{c|}{ Comentários } \\
\hline \multirow{3}{*}{$\begin{array}{l}\text { Identificar } \\
\text { uma } \\
\text { necessidade } \\
\text { educacional }\end{array}$} & $\begin{array}{l}\text { Identificar um “gap”, uma necessidade dos aprendizes (ELLINAS; DENSON; SIMPSON, } \\
\text { 2015), a qual pode ser de conhecimento (por exemplo, conhecer as camadas anatômicas } \\
\text { da parede abdominal), de habilidades (a maioria dos simuladores treina habilidades - } \\
\text { por exemplo, intubação orotraqueal, punção de cistos, sutura de diferentes estruturas } \\
\text { anatômicas) ou atitudes (trabalho em equipe, comunicação). }\end{array}$ \\
\cline { 2 - 3 } & $\begin{array}{l}\text { É importante se atentar também às necessidades do laboratório e/ou centro de simulação. } \\
\text { Em alguns casos, as instituições possuem simuladores de referência/comercial em } \\
\text { quantidades limitadas. Dessa forma, a confecção pode ser um "plus" no acervo de } \\
\text { tecnologias. }\end{array}$ \\
\hline \multirow{3}{*}{$\begin{array}{l}\text { Procurar } \\
\text { ideias e } \\
\text { inspirações }\end{array}$} & $\begin{array}{l}\text { Buscar formas de trabalhar a necessidade levantada (ELLINAS; DENSON; SIMPSON, } \\
\text { 2015; KNOBEL et al., 2020) e procurar se já existem outros simuladores. Alguns } \\
\text { questionamentos podem guiar esse levantamento, como “Alguém já criou um simulador } \\
\text { semelhante?" ou “O que é necessário simular?". Fazer buscas em artigos científicos, na } \\
\text { literatura cinzenta e em outros espaços (em sites de busca, como Google, e em canais de } \\
\text { compartilhamentos de vídeos, como YouTube). }\end{array}$ \\
\hline
\end{tabular}


Quadro 2 - Continuação...

\begin{tabular}{|c|c|}
\hline Etapas & Comentários \\
\hline \multirow{2}{*}{$\begin{array}{l}\text { Procurar } \\
\text { ideias e } \\
\text { inspirações }\end{array}$} & $\begin{array}{l}\text { Caso seja encontrado simulador semelhante, deve-se examinar os materiais utilizados e as } \\
\text { etapas e buscar alternativas locais para a simulação. }\end{array}$ \\
\hline & $\begin{array}{l}\text { Em diversas ocasiões, não haverá o simulador buscado. Por isso, esta também é uma } \\
\text { vantagem da criação de simuladores artesanais: estimular a criatividade. }\end{array}$ \\
\hline \multirow{4}{*}{$\begin{array}{l}\text { Fazer um } \\
\text { piloto }\end{array}$} & $\begin{array}{l}\text { Montar um simulador inicial. É necessário adquirir os materiais e planejar o processo de } \\
\text { montagem. }\end{array}$ \\
\hline & $\begin{array}{l}\text { Se a ideia é inicial, devem ser feitos diversos modelos diferentes, utilizando variadas } \\
\text { estruturas, materiais e processos e sempre avaliando vantagens e desvantagens, custos e } \\
\text { benefícios. }\end{array}$ \\
\hline & $\begin{array}{l}\text { Por exemplo, se a necessidade é treinar técnicas específicas de sutura, um modelo com } \\
\text { carne de frango pode ser adequado. Porém, ele será perecível e trará algumas dificuldades } \\
\text { em termos de local de realização e limpeza do material. Se a necessidade não incluir a } \\
\text { verossimilhança com a estrutura (treinar técnica de manipulação de instrumentos, de dar } \\
\text { nós específicos), um modelo de couro sintético ou espuma pode ser suficiente. }\end{array}$ \\
\hline & $\begin{array}{l}\text { A depender do desenho, pode ser interessante o planejamento do modelo/simulador } \\
\text { em programas de modelagem } 2 \mathrm{D} \text { e } 3 \mathrm{D} \text {. Além disso, a impressão desses modelos pode ser } \\
\text { necessária para a etapa de adequações e testes. }\end{array}$ \\
\hline \multirow[t]{2}{*}{ Testar } & $\begin{array}{l}\text { Certificar-se de que o simulador funciona conforme planejado e fazer a simulação com } \\
\text { pessoas mais experientes e/ou pequenos grupos - verificar se atinge os objetivos de } \\
\text { aprendizagem. }\end{array}$ \\
\hline & Deve-se refazer o piloto quantas vezes forem necessárias. \\
\hline \multirow{4}{*}{ Validar } & Validar o projeto (MOKKINK et al., 2010). \\
\hline & $\begin{array}{l}\text { Validade de face - aspecto, realismo, simulação da estrutura pretendida, apresentação das } \\
\text { características necessárias para o que se pretende simular. }\end{array}$ \\
\hline & Validade de conteúdo - valor pedagógico, efetividade em resolver o problema proposto. \\
\hline & $\begin{array}{l}\text { Pode-se também ofertar cursos de curta duração e/ou workshop. Esses momentos podem } \\
\text { ser excelentes oportunidades para a validação do modelo. }\end{array}$ \\
\hline \multirow{4}{*}{ Implementar } & É hora de colocar o simulador para funcionar. \\
\hline & $\begin{array}{l}\text { Deve-se encontrar um momento adequado durante o curso ou disciplina para inserir o uso } \\
\text { do simulador. }\end{array}$ \\
\hline & $\begin{array}{l}\text { É importante lembrar que o simulador em si é apenas uma parte do processo de } \\
\text { aprendizagem, por isso é preciso planejar toda a estratégia educacional envolvida. }\end{array}$ \\
\hline & Às vezes, no momento da implementação, novas mudanças são necessárias no simulador. \\
\hline Avaliar & $\begin{array}{l}\text { Há diversas maneiras de avaliar a efetividade de uma simulação. Seguindo o modelo de } \\
\text { Kirkpatrik (DORRI; AKBARI; SEDEH, 2016), podem ser avaliados: dados de satisfação do } \\
\text { aprendiz, desempenho nas simulações, desempenho clínico, mudança de indicadores de } \\
\text { saúde na instituição etc. }\end{array}$ \\
\hline Compartilhar & $\begin{array}{l}\text { Compartilhar a criação pode ajudar outras pessoas ao redor do mundo (KNOBEL et al., } \\
\text { 2020). Inclusive, elas podem também sugerir mudanças e aperfeiçoar as criações. Assim, } \\
\text { pode-se criar uma comunidade de tecnologia aberta que está sempre crescendo e se } \\
\text { fortalecendo. Ainda, devem-se fornecer os créditos das ideias que inspiraram a simulação! }\end{array}$ \\
\hline
\end{tabular}



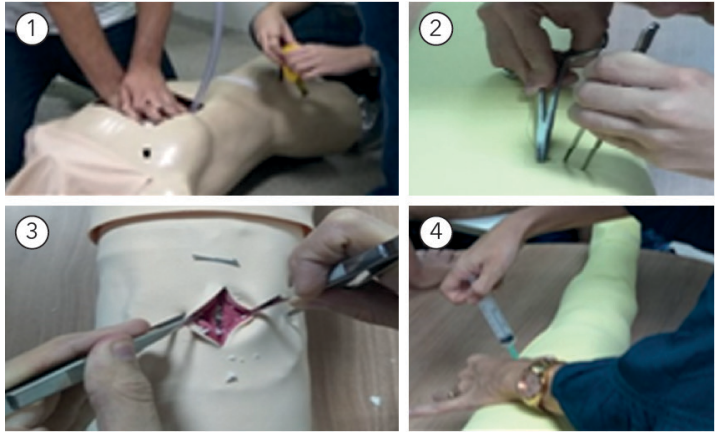

Figura 1 - Experiências com o desenvolvimento de simuladores de baixo custo na EMCM. 1 - Simulador de massagem cardíaca; 2 - simulador de rafia; 3 - simulador de traqueostomia; 4 - simulador de administração de medicamentos.

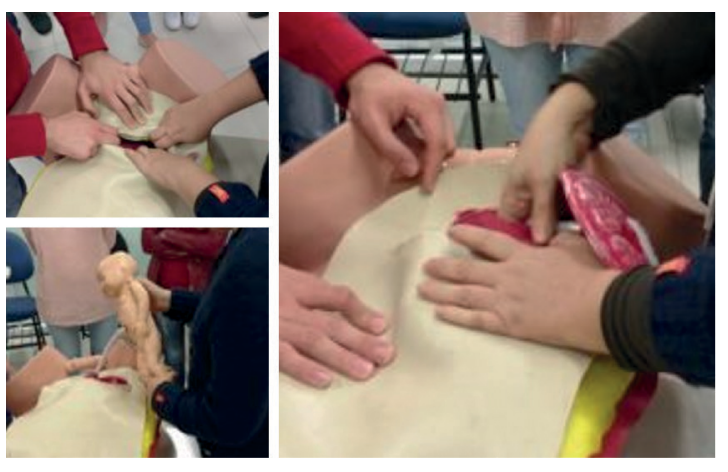

Figura 2 - Camadas da parede abdominal para cirurgia cesariana - modelo com diversos materiais confeccionados pelos alunos, simulando as sete camadas da parede abdominal. Na imagem, o modelo está sendo utilizado com um simulador comercial de pelve obstétrica com bebê.

método, espera-se que, nos próximos anos, os estudos e a divulgação de experiências exitosas possam contribuir para diminuir as arestas das incertezas e as limitações relacionadas à efetividade dessas tecnologias de baixo custo.

Anseia-se pelo aperfeiçoamento coletivo dos produtos construídos, seja do ponto de vista de seus materiais e métodos ou pela validação do protótipo. Com isso, essas tecnologias vão encorajar experiências que ultrapassem os muros dos centros de pesquisa e dos laboratórios de simulação, tais como ações voltadas para educação permanente de profissionais da saúde ou para a educação em saúde da própria comunidade.

Para tanto, convidam-se pesquisadores e curiosos da área a unir forças e compartilhar projetos,
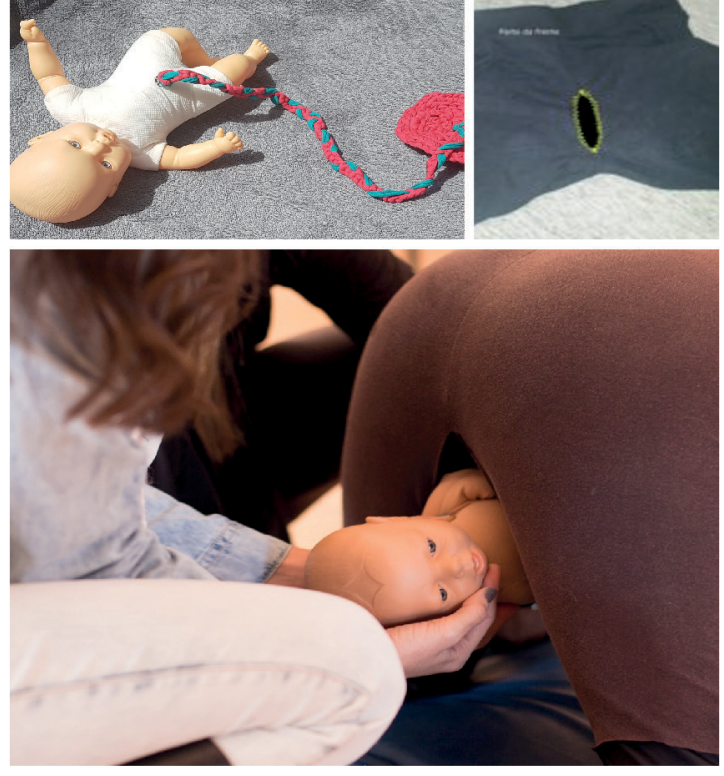

Figura 3 - Bermuda e boneco comercial para simulação de parto e exemplo de simulação.

anseios e perspectivas. Além disso, espera-se um maior apoio das instituições de ensino, laboratórios de habilidades e simulação clínica, e dos órgãos de fomento para o financiamento em editais e a divulgação em periódicos da saúde.

\section{CONSIDERAÇÕES FINAIS}

Neste texto, foi feita uma contextualização do uso de simuladores de baixo custo e artesanais no ensino e aprendizagem de estudantes e profissionais de saúde. Além de uma análise e diferenciação entre esses dois conceitos centrais, discutiu-se sobre os aspectos gerais relacionados às suas vantagens e limitações.

Foram apresentadas as etapas e a descrição delas relacionadas ao processo de criação de modelos. Com isso, elucidaram-se os passos imprescindíveis para a execução de projetos dessa natureza. Somado a isso, foram compartilhadas experiências nacionais e internacionais, bem como os anseios dos autores sobre o futuro dessa área de estudo e pesquisa. Espera-se que este material possa contribuir para o despertar e a ampliação do interesse entre curiosos e amantes da simulação clínica. Pense, planeje, execute e compartilhe! 
BING, E. G. et al. Using low-cost virtual reality simulation to build surgical capacity for cervical cancer treatment. Journal of Global Oncology, Alexandria, v. 5, p. 1-7, 2019. BULAMBA, F. et al. Feasibility of simulation-based medical education in a low-income country. Society for Simulation in Healthcare, Washington, v. 14, p. 113-120, 2019.

CORTÉS, H. E. O. et al. Marco conceptual para el desarrollo de un simulador de bajo costo. In: MARTINEZ, R. R.; CORVETT, M.; CORTÉS, H. E. O. (Ed.). Simuladores de bajo costo realizados en casa. Federación Latinoamericana de Simulación Clínica y Seguridad de Paciente FLASIC, 2019. p. 5-10.

COSTA, R. R. O. et al. Satisfaction and self-confidence in the learning of nursing students: Randomized clinical trial. Escola Anna Nery, Rio de Janeiro, v. 24, p. 2020, 2020.

DE OLIVEIRA, H. F. et al. A feasible, low-cost, reproducible lamb's head model for endoscopic sinus surgery training. PLoS One, San Francisco, v. 12, p. e0180273, 2017.

DESTEPHANO, C. C. et al. A randomized controlled trial of birth simulation for medical students. American Journal of Obstetrics and Gynecology, Saint Louis, v. 213, p. 91.e1-91.e7, 2015.

DORRI, S.; AKBARI, M.; SEDEH, M. Kirkpatrick evaluation model for in-service training on cardiopulmonary resuscitation. Iranian Journal of Nursing and Midwifery Research, Mumbai, v. 21, p. 493, 2016.

ELLINAS, H.; DENSON, K.; SIMPSON, D. Low-Cost simulation: How-To Guide. Journal of Graduate Medical Education, Poland, v. 7, p. 257-258, 2015.

GIEBUROWSKI, A. T. Treinamento em punção aspirativa por agulha fina de nódulos mamários em simuladores inanimados: validade preditiva da aprendizagem em simulador de peito de peru comparado com o simulador sintético. 2018. Dissertação (Mestrado). Universidade Federal de Santa Catarina, Florianópolis, 2018.

GOMES, A. A. R.; SOARES, F. V. C.; PESSOA, S. G. P. Modelo de treinamento em palatoplastia. Revista Brasileira de Cirurgia Plástica, São Paulo, v. 26, p. 691-695, 2011.

GRAHEM, H. D. et al. Treinamento de anastomoses vasculares de baixo custo: o cirurgião vai à feira. Jornal Vascular Brasileiro, São Paulo, v. 16, p. 262-266, 2017.

HEGLAND, P. A. et al. Simulation-based training for nurses: Systematic review and meta-analysis. Nurse Education Today, Edinburgh, v. 54, p. 6-20, 2017.

KNOBEL, R. et al. A craft low-cost simulator for training to rteat postpartum hemorrhage - FIGO Poster Abstracts. International Journal of Gynaecology and Obstetrics, Delhi, v. 143, p. 543-991, 2018 a.

KNOBEL, R. et al. Simple, reproducible and low-cost simulator for teaching surgical techniques to repair obstetric anal sphincter injuries. Revista Brasileira de Ginecologia e Obstetrícia, Rio de Janeiro, v. 40, p. 465470, 2018b.
KNOBEL, R. et al. Planning, construction and use of handmade simulators to enhance the teaching and learning in Obstetrics. Revista Latino-Americana de Enfermagem, Ribeirão Preto, v. 28, p. e3302, 2020.

MAGEE, S. R.; SHIELDS, R.; NOTHNAGLE, M. Low cost, high yield: simulation of obstetric emergencies for family medicine training. Teaching and Learning in Medicine, Mahwah, v. 25, p. 207-210, 2013.

MARTÍNEZ, R. R. et al. Simuladores de Bajo Costo Realizados en Casa. Federación Latinoamericana de Simulación Clínica y Seguridad de Paciente - FLASIC, 2019. MCCLELLAND, T. J. et al. Low-fidelity paediatric surgical simulation: description of models in low-resource settings. World Journal of Surery, New York, v. 43, p. 1193-1197, 2019. MCGAGHIE, W. C. et al. Does simulation-based medical education with deliberate practice yield better results than traditional clinical education? A meta-analytic comparative review of the evidence. Academic Medicine, Philadelphia, v. 86, p. 706-711, 2011a.

MCGAGHIE, W. C. et al. Evaluating the impact of simulation on translational patient outcomes. Simulation in Healthcare, Philadelphia, v. 6, p. S42-S47, 2011 b.

MOKKINK, L. B. et al. The COSMIN checklist for assessing the methodological quality of studies on measurement properties of health status measurement instruments: An international Delphi study. Quality of Life Research, Oxford, v. 19, p. 539-549, 2010.

MOTOLA, I. et al. Simulation in healthcare education: A best evidence practical guide. AMEE Guide No. 82 . Medical Teacher, Basingstoke, v. 35, p. e1511-e1530, 2013. PEREIRA DA SILVA, J. et al. Construção e validação de simulador de baixo custo para capacitação de pacientes com diabetes mellitus e/ou de seus cuidadores na aplicação de insulina. Escola Anna Nery, Rio de Janeiro, v. 22, p. 20170387, 2018.

PEROSKY, J. et al. A low-cost simulator for learning to manage postpartum hemorrhage in Rural Africa. Simulation in Healthcare: Journal of the Society for Simulation in Healthcare, v. 6, p. 42-47, 2011.

RAMSEYER, A. M.; LUTGENDORF, M. A. Implementation of low-cost obstetric hemorrhage simulation training models for resident education. Military Medicine, Washington, v. 184, n. 11-12, p. e637-e641, 2019. http:// dx.doi.org/10.1093/milmed/usz098.

ROWSE, P. G. et al. Assimilating endocrine anatomy through simulation: A pre-emptive strike! American Journal of Surgery, New York, v. 209, p. 542-546, 2015.

SCHAUMBERG, A.; SCHRÖDER, T.; SANDER, M. Notfallmedizinische Ausbildung durch Simulation. Der Anaesthesist, Berlin, v. 66, p. 189-194, 2017.

SEROPIAN, M. et al. Simulation: not just a manikin. The Journal of Nursing Education, Thorofare, v. 43, n. 4, p. 164-169, 2014. 
SHAH, A. et al. Simulation-based education and team training. Otolaryngologic Clinics of North America, Philadelphia, v. 52, p. 995-1003, 2019.

SHEA, K. L.; ROVERA, E. J. Vaginal examination simulation using citrus fruit to simulate cervical dilation and effacement. Cureus, v. 7, p. 1-8, 2015.
SOUZA, F. X. et al. Modelo simulador de baixo custo para treinamento de septoplastia. Revista Eletrônica Acervo Saúde, Ouro Fino, v. 42, p. e2827, 2020. http://dx.doi. org/10.25248/reas.e2827.2020.

TEMPERLY, K. S. et al. Development and validation of a low-cost tracheostomy simulator. Scientia Medica, Porto Alegre, v. 28, p. 1-10, 2018. 
CAPÍTULO 8

-

A colaboração como fundamento para o trabalho interprofissional em saúde 


\section{Marcelo Viana da Costa}

Enfermeiro

Universidade Federal do

Rio Grande do Norte

Escola Multicampi de Ciências

Médicas - Caicó/RN

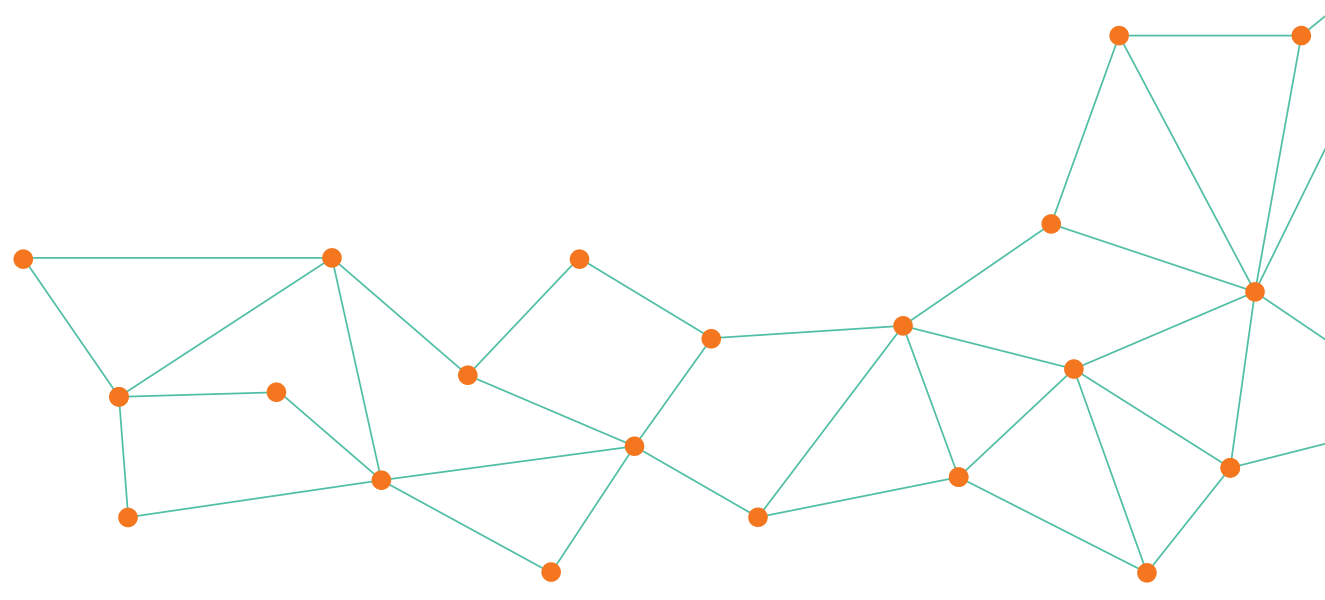

\section{INTRODUÇÃO}

O contexto atual impõe importantes desafios ao trabalho e à formação em saúde. Transformações nos perfis demográficos e epidemiológicos, com incremento de novos riscos infecciosos, ambientais e comportamentais, evidenciam a necessidade de repensar o atual modelo de formação e de trabalho em saúde. Os problemas e as necessidades desse campo se apresentam cada vez mais complexos e exigem uma mudança de paradigma na produção dos serviços de saúde, colocando os usuários e suas necessidades na centralidade do processo (CRISP; CHEN, 2014; FRENK et al., 2010).

Apesar desse cenário, a lógica da produção dos serviços de saúde ainda está orientada por forte divisão do trabalho, fragmentando os atos e expondo, muitas vezes, os usuários à repetição, o que acaba aumentando os riscos de erros e os custos com os serviços de saúde (REEVES, 2016).
A tendência à superespecialização no trabalho em saúde - embora importante para a produção de novos conhecimentos e escopo de práticas - também produz como um dos resultados a forte competição entre os profissionais (FAULCONBRIDGE; MUZIO, 2012). A dimensão técnica do trabalho em saúde como manifestação do saber, status e poder das profissões vem servindo para a intensificação da competição em detrimento da colaboração princípio fundamental para o efetivo trabalho em equipe (BAKER et al., 2011; PIPPITT et al., 2015).

A produção dos serviços de saúde apresenta como uma de suas características a pressão pelo tempo para dar as respostas necessárias às necessidades existentes. A complexidade do trabalho nessa área se materializa nos contextos marcados pela necessidade de articular aspectos da dimensão individual, da equipe e da instituição para a garantia 
dos melhores resultados de saúde (HOOKER et al., 2008).

Estudos indicam que mortes evitáveis nos serviços de saúde assumem proporções preocupantes, em grande parte, por causa da dificuldade do trabalho em equipe. A melhora na precisão diagnóstica e nas terapêuticas depende do nível e da qualidade das relações interprofissionais. Outras pesquisas evidenciam também que a redução da mortalidade em unidade de terapia intensiva foi observada a partir de maior investimento na melhora das relações interprofissionais no trabalho em equipe. Por isso, a segurança do paciente fica fortemente comprometida em cenários de frágil comunicação entre os profissionais de saúde (FREYTAG et al., 2017; KÄMMER et al., 2017). Tomando por base essas e outras evidências, organismos internacionais vêm estimulando cada vez mais estratégias de formação em saúde capazes de desenvolver competências para o efetivo trabalho em equipe (WORLD HEALTH ORGANIZATION, 2010).

Problemas de comunicação entre os profissionais da equipe, limitada clareza dos papéis profissionais, competição entre as profissões e inexistência de identidade de equipe são problemas que trazem prejuízos para a dinâmica do trabalho em equipe, mas podem ser abordados nos processos formativos dos diferentes profissionais de saúde. A publicação "Interprofessional education and collaboration: a call to action for emergency medicine", por exemplo, destaca a importância dessa colaboração, defendendo a implementação da educação interprofissional (EIP) na formação de profissionais para o enfrentamento desses aspectos (WILBUR, 2014).

Considerando essas problemáticas, a compreensão do conceito de equipe é um ponto de partida importante para se assumir a melhor perspectiva de trabalho e formação em saúde e oferecer serviços de qualidade e resolutivos.

Importante contribuição para essa compreensão pode ser encontrada em publicação recente de Peduzzi et al. (2020), em que revisita alguns conceitos relacionados ao trabalho em equipe, interprofissionalidade e práticas colaborativas. Nesse sentido, a autora descreve dois formatos de equipe: a equipe do tipo agrupamento e a equipe do tipo integração. Na primeira configuração, os profissionais dividem um mesmo espaço de trabalho, mas o foco são as competências específicas nas produções de atos, muitas vezes fragmentadas. Uma marca desse modelo é a frágil comunicação entre os diferentes profissionais de saúde. A equipe do tipo integração é a que mantém forte articulação entre as dife- rentes práticas profissionais e que, para o contexto brasileiro, exerce peculiar importância por sua coerência com o princípio da integralidade da atenção (PEDUZZI et al., 2020).

Outros autores também apresentam uma tipologia de trabalho em equipe que contribui para esse debate. São definições que associam o formato de equipe a diversos aspectos, tais como integração, colaboração, identidade de equipe, papel do usuário na ordenação do trabalho, compartilhamento de objetivos, entre outros (REEVES; XYRICHIS; ZWARENSTEIN, 2018).

Esse debate inspira importantes inquietações: quais aspectos influenciam a integração e a interdependência entre os profissionais na produção dos serviços de saúde? Será que a formação dos profissionais de saúde está desenvolvendo competências para o efetivo trabalho em equipe? Há competências capazes de fortalecer a perspectiva do efetivo trabalho em equipe?

São questões complexas que exigem um pouco de adensamento, e este texto não tem a pretensão de esgotar essa discussão, mas de fornecer subsídios para ampliá-la e para compreender as implicações desse debate para as mudanças no modelo de atenção à saúde.

\section{COLABORAÇ̃̃O COMO PRINCÍPIO CENTRAL DO TRABALHO INTERPROFISSIONAL}

D'Amour et al. (2005), em um texto clássico, traz uma assertiva de grande profundidade: embora se reconheça a importância do trabalho em equipe, não há clareza do caráter complexo da colaboração. Considerando a necessidade de clarificar o conceito de colaboração e suas implicações para o processo de trabalho em saúde, a autora apresenta seus quatro pilares fundamentais: compartilhamento, parceria, interdependência e poder (D'AMOUR et al., 2005).

A Figura 1 sintetiza os pilares apresentados por D’Amour et al. (2005). Não se trata de uma relação linear, mas de aspectos que se mantêm interdependentes para que a colaboração aconteça.

A Figura 1 apenas ilustra os pilares da colaboração e não tem a pretensão de simplificar um debate que é de grande complexidade. Colaborar, antes de tudo, representa o desejo de se integrar às demais práticas profissionais, reconhecendo a importância do papel do outro colega para a produção dos serviços de saúde. Embora a intencionalidade individual seja fundamental para que ocorra a cola- 


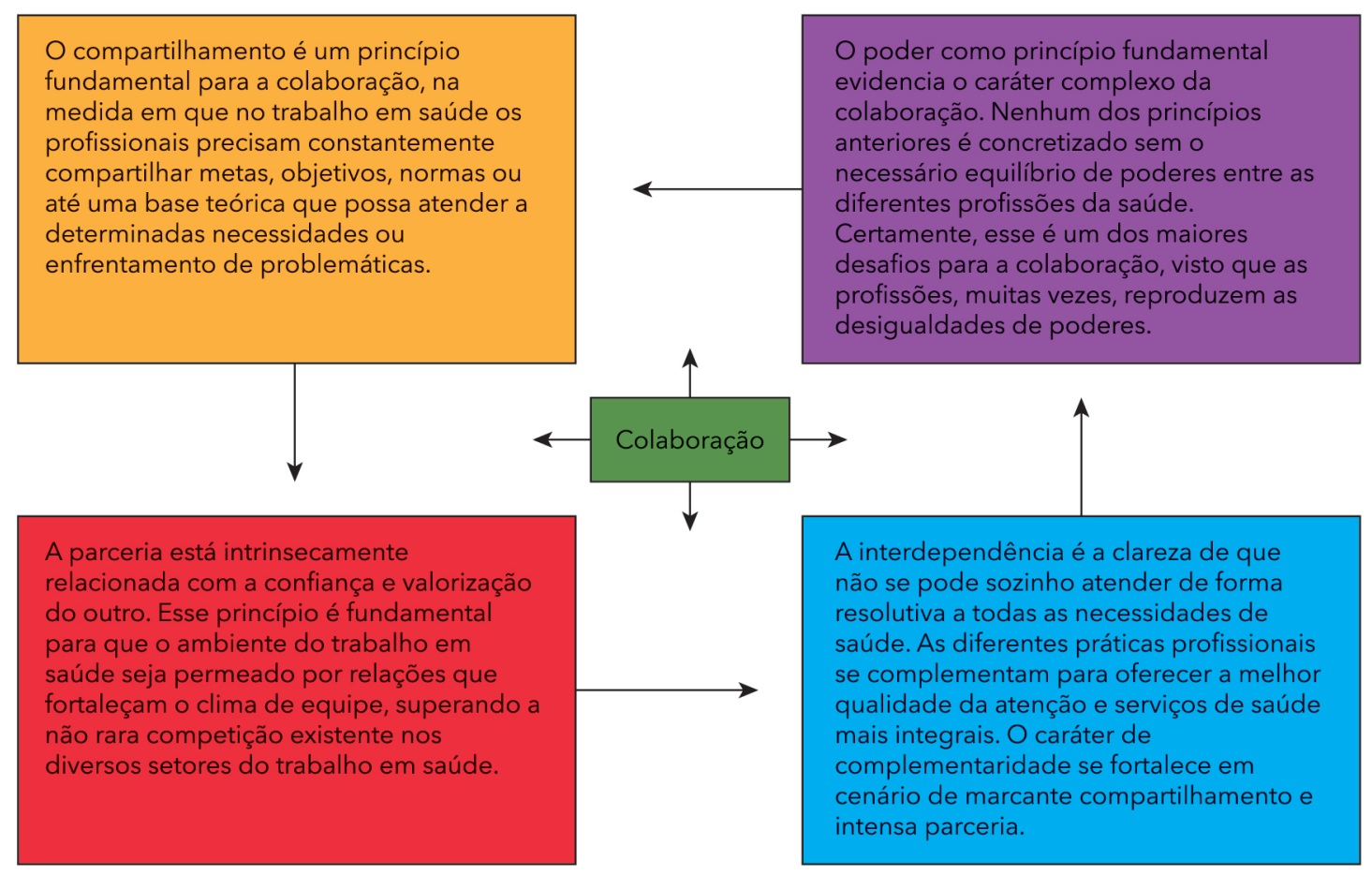

Figura 1 - Pilares da colaboração: compartilhamento, parceria, interdependência e poder. Fonte: adaptada a partir de D'Amour et al. (2005).

boração, não é razoável atribuir toda a responsabilidade aos profissionais de saúde.

Apesar do reconhecimento da colaboração como princípio do trabalho interprofissional, muitas vezes as dimensões política, institucional e cultural estimulam a competição entre as profissões, cuja regulação frequentemente acentua os conflitos e a desigualdade entre elas. Em contextos institucionais, normas e regimentos podem desencorajar a colaboração e fomentar a competição. A dimensão cultural se expressa na tendência de centrar atenção na expertise do profissional, colocando-o como centro do processo, e a busca por status e reconhecimento social se torna justificativa para conflitos com outros colegas no trabalho em saúde (OANDASAN; REEVES, 2005).

\section{A EDUCAÇÃO INTERPROFISSIONAL E O DESENVOLVIMENTO DE COMPETÊNCIAS COLABORATIVAS}

O processo de formação em saúde com ênfase na dimensão técnica foi se consolidando ao longo da história como demasiadamente conteudista (COSTA et al., 2016). A necessidade de desenvolvimento de competências específicas para o exercício das profissões deu sustentação ao modelo disciplinar de formação, com pouco ou nenhum diálogo entre os diferentes campos do conhecimento. A estrutura departamental das universidades, muitas vezes, constituiu uma barreira para a articulação de saberes, até mesmo no interior de um único curso da área da saúde (COSTA, 2014).

Entretanto, a pouca articulação não ficou restrita apenas aos diferentes campos do conhecimento. A tendência de separação das áreas também gerou pouca ou nenhuma interação entre as práticas profissionais. A formação dos profissionais, orientada por marcos teórico-conceituais para sustentar as práticas, estabeleceu uma lógica que pouco favorece a formação de profissionais mais aptos à colaboração - fundamento central do efetivo trabalho em equipe (PEDUZZI et al., 2013).

Na contramão dessa realidade, as necessidades de saúde, ao longo dos anos, tornam-se cada vez mais complexas, evidenciando limites desse modelo conteudista e disciplinar que orienta a for- 
mação dos profissionais de saúde. Nesse sentido, outros conhecimentos, habilidades e atitudes passam a ser necessários para complementar as práticas profissionais. Partindo da necessidade de fornecer elementos para o desenvolvimento do perfil profissional coerente com as demandas apresentadas pelo conjunto da sociedade, insere-se a relevância da educação baseada em competências no contexto da formação em saúde.

Tomando por base essas problemáticas, o debate sobre a EIP vem crescendo em todo o mundo (BARR, 2015). Definida como a oportunidade em que membros de duas ou mais profissões aprendem em conjunto e de forma interativa, com o propósito explícito de melhorar a colaboração e a qualidade dos cuidados, a EIP vem se mostrando capaz de orientar mudanças no processo de formação com foco no desenvolvimento de profissionais mais preparados e comprometidos com a oferta de serviços de saúde mais efetivos e resolutivos (REEVES et al., 2016).

Iniciativas de EIP têm contribuído para a maior clareza de papéis dos colegas de outras profissões, melhoram a comunicação no processo de aprendizagem e tomada de decisões, estimulam a valorização dos usuários como centro do processo de produção dos serviços de saúde e (re)significam os estilos de lideranças, permitindo um deslocamento de uma tendência mais centralizadora para a colaboração, entre outras competências. No trabalho em saúde, a perspectiva interprofissional e colaborativa contribui para a racionalização dos custos, a redução dos eventos adversos e da duplicação dos atos e a melhora da satisfação dos trabalhadores de saúde e usuários (FELGOISE et al., 2019).

Apesar das reconhecidas implicações da EIP para o desenvolvimento de profissionais mais aptos ao trabalho em equipe, ainda são expressivos os desafios para assegurar os efeitos sobre as transformações na lógica de produção dos serviços de saúde. As iniciativas em todo o mundo são muito diversas, e, algumas vezes, há uma compreensão equivocada de que reunir profissionais ou estudantes em um mesmo espaço qualifica a iniciativa como interprofissional. Para que se perceba os efeitos da EIP, é fundamental garantir rigor teórico-conceitual e metodológico e explícita intencionalidade no desenvolvimento de competências interprofissionais (LANGLOIS et al., 2020).

Outro aspecto que merece destaque é a necessidade de elaborar estudos que possam produzir evidências científicas mais robustas - que consigam expressar aspectos para além das percepções ou mudanças de atitudes dos participantes. Estudos longitudinais mais robustos, que integrem distintas abordagens e que busquem analisar as influências da EIP sobre a melhoria da qualidade da atenção e dos resultados em saúde, são imperativos para o fortalecimento da EIP como base capaz de contribuir para reorientar o modelo de formação e o trabalho em saúde (XYRICHIS, 2020).

Nesse sentido, a EIP exige uma intencionalidade expressa nas propostas pedagógicas, nas metodologias adotadas e nos processos de avaliação. A produção elaborada por Barr (1998) traz importantes contribuições para ampliar a compreensão sobre competências a serem incorporadas no processo de formação e no trabalho em saúde, na perspectiva interprofissional e colaborativa. $\mathrm{O}$ autor define três grandes grupos de competências: específicas ou complementares, comuns e colaborativas (BARR, 1998, 2013).

As competências específicas, ou complementares, referem-se ao conjunto de conhecimentos, habilidades e atitudes que fundamentam o exercício das práticas dos diferentes profissionais. Para simplificar, seriam as competências que orientam as práticas específicas de cada profissão. É interessante notar que Barr (1998) também define esse grupo de competências como complementares, reiterando a compreensão da relação de interdependência entre as profissões.

Competências comuns são aquelas compartilhadas por todos os profissionais de saúde (BARR, 1998). São conhecimentos, habilidades, atitudes e valores compartilhados pelo conjunto de profissionais de saúde, e o desenvolvimento dessas competências por diferentes profissionais não representa desrespeito aos limites de cada profissão. Também podem ser entendidas como um campo comum de práticas (DE OLIVEIRA; DE SOUSA CAMPOS, 2015).

As competências colaborativas, por sua vez, dizem respeito ao conjunto de conhecimentos, habilidades, atitudes e valores que fortalecem as relações interprofissionais para o efetivo trabalho em equipe. Esse conjunto de competências estimula o desenvolvimento dos pilares da colaboração como fundamento para a oferta de serviços de saúde mais integrais e resolutivos (REEVES et al., 2011).

$\mathrm{Na}$ apresentação dessas competências, é comum alguma confusão em relação às competências comuns e colaborativas como se elas fossem sinônimas. Competências colaborativas também são compartilhadas por todos os profissionais. $\mathrm{O}$ diferencial é que elas asseguram relações interprofis- 
sionais mais horizontais, fortalecimento da identidade de equipe e inserção cada vez mais forte do usuário como corresponsável pela produção dos serviços de saúde.

A diferenciação entre os três grupos de competências é feita para fins didáticos, e há intensa articulação dessas competências com contextos de materialização do trabalho em equipe. As competências colaborativas são fundamentais para a integração das competências específicas e comuns no trabalho em saúde.

Considerando a importância dessa discussão, pesquisadores, instituições formadoras e responsáveis pela formulação de políticas centraram esforços na elaboração de marcos teórico-conceituais capazes de contribuir para o desenvolvimento de competências colaborativas. Esses marcos de competências são grandes contribuições no sentido de garantir a intencionalidade na formação do perfil profissional mais apto ao efetivo trabalho em equipe (THISTLETHWAITE et al., 2014).

A Figura 2 traz uma síntese desses marcos de competências para que se tenha um panorama geral dos aspectos considerados relevantes para o fortalecimento das relações interprofissionais com vistas à colaboração na produção dos serviços de saúde.

A matriz do Reino Unido - a primeira sistematização de competências colaborativas - naquele momento histórico usava a terminologia "capacidades" para se referir ao escopo de conhecimento, habilidades e atitudes com foco no desenvolvimento de competências para o efetivo trabalho em equipe. As demais matrizes adotaram o termo "competências”, a partir da definição exposta anteriormente.

Todas as matrizes são importantes e buscaram elaborar uma matriz coerente com as demandas do processo de formação e do sistema de saúde. No entanto, para fins de exemplificar esta discussão, na Figura 3 estão apresentadas a descrição do domínio de competências (conhecimentos, habilidade, atitudes e valores) da matriz canadense como forma de fornecer subsídios para a inserção desses pontos das estratégias de formação dos profissionais de saúde (PANEL, 2011).

O escopo de competências específicas, comuns e colaborativas fundamenta a escolha de conteú-

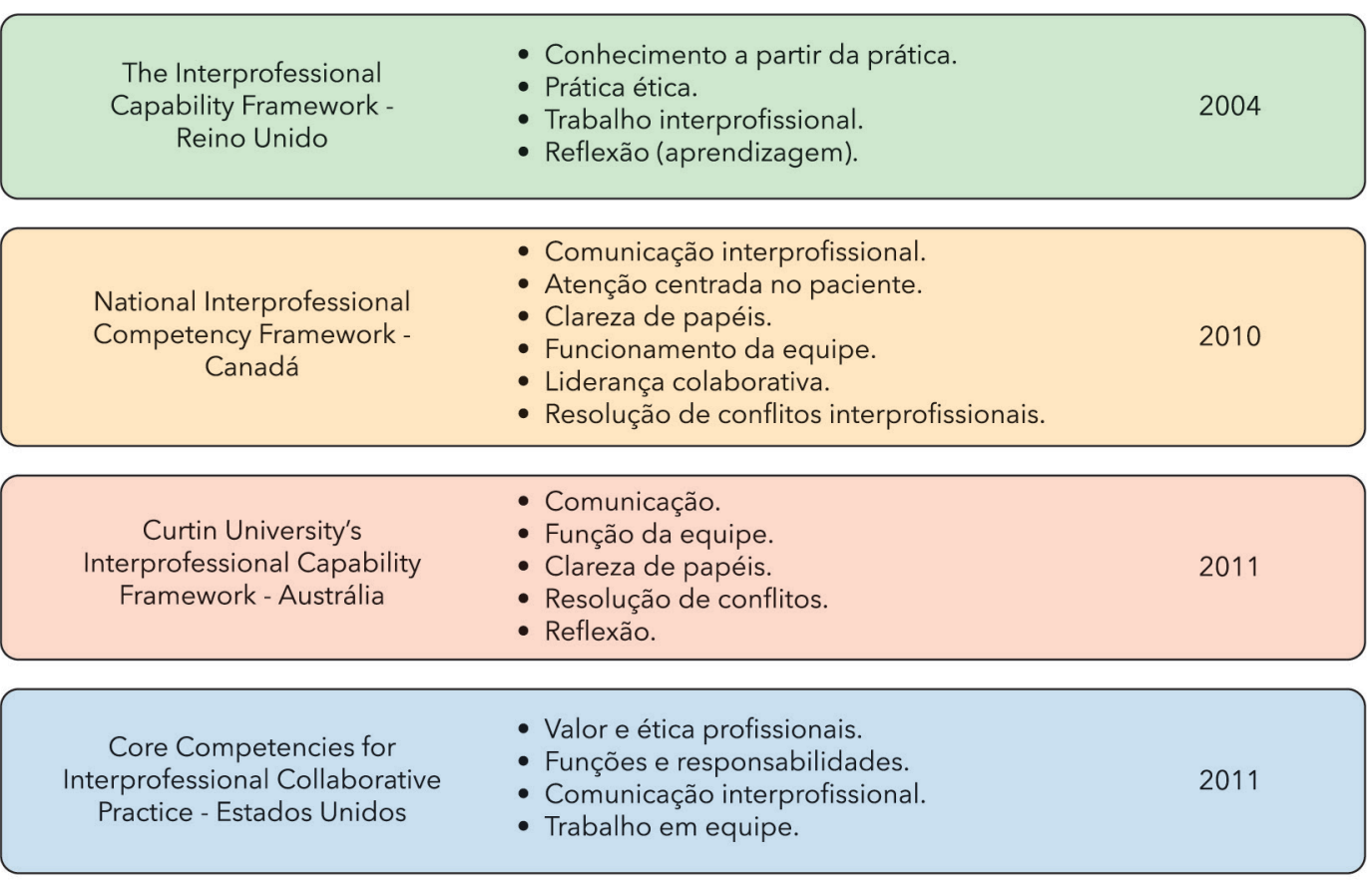

Figura 2 - Matrizes de competências interprofissionais.

Fonte: adaptada de Thistlethwaite et al. (2014). 
- Estudantes e profissionais compreendem seu prório papel e o de outras profissões e usam esse conhecimento adequadamente para estabelecer e alcançar objetivos na atenção à saúde centrada no paciente / família / comunidade.

Atenção centrada no paciente/familia/comunidade
- Estudantes e profissionais buscam, integram e valorizam a contribuição e o envolvimento do paciente / família / comunidade na concepção e implementação de cuidados / serviços de saúde.

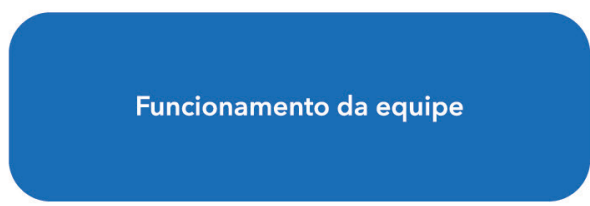

- Estudantes e profissionais compreendem os princípios da dinâmica e dos processos de trabalho em equipe para permitir uma colaboração interprofissional resultiva, integral e de qualidade.

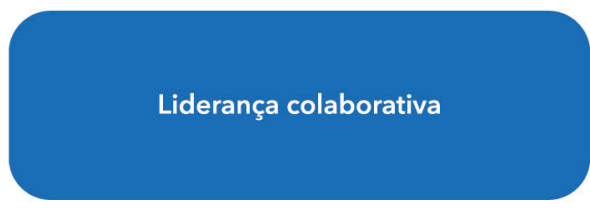

- Estudantes e profissionais compreendem e podem aplicar princípios de liderança que apoiam um modelo de prática colaborativa.

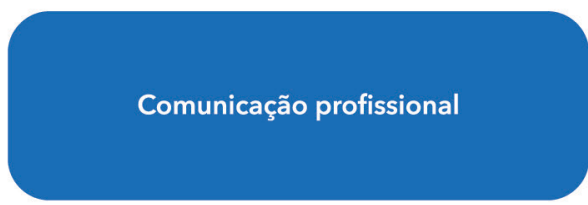

- Estudantes e profissionais de diferentes profissões se comunicam de maneira colaborativa, ágil e responsável.

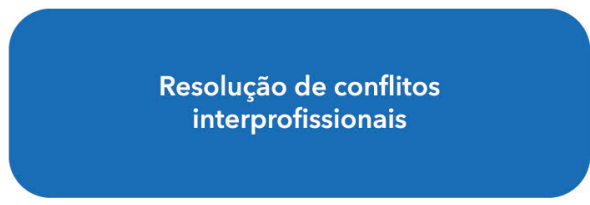

- Estudantes e profissionais se envolvem ativamente com os demais colegas de outras profissões, incluindo o paciente e a família, na abordagem positiva e construtiva dos conflitos interprofissionais

Figura 3 - Descrição do domínio de competências.

Fonte: traduzida e adaptada de Canadian Interprofessional Health Collaborative (2010).

dos, cenários de aprendizagem, metodologias de ensino e avaliação da aprendizagem e de processo. Algumas experiências organizam seus processos formativos, assegurando a intencionalidade na formação de profissionais de saúde mais aptos à colaboração por meio da inserção das competências colaborativas como um dos objetivos educacionais.

O Centro de Ciências da Saúde e Educação Interprofissional, da Escola de Medicina do Norte de Ontário, com esse objetivo, estabeleceu três níveis de aprendizagem em iniciativas de EIP: exposição, imersão e avançado. Para cada um dos níveis de aprendizagem, definiu o conjunto de competências colaborativas esperadas como resultados dos produtos formativos (JECKER et al., 2015).
O Quadro 1 traz exemplos de objetivos de aprendizagem para cada domínio de competência. Não se trata de modelos, mas de subsídios teórico-conceituais e metodológicos que podem contribuir para pensar na inserção dessas competências como um dos objetivos no processo de formação em saúde.

A intencionalidade no desenvolvimento de competências colaborativas, sem dúvida, é um desafio para o contexto da formação dos profissionais de saúde. Entretanto, esses exemplos subsidiam o debate para que a colaboração realmente se faça presente na dinâmica da formação e do trabalho em saúde. Certamente, o sistema de saúde sairá mais fortalecido e os usuários terão acesso a serviços mais resolutivos e integrais. 
Quadro 1 - Domínios de competências colaborativas e exemplos de objetivos de aprendizagem.

\begin{tabular}{|c|c|}
\hline $\begin{array}{l}\text { Domínios de } \\
\text { competências } \\
\text { colaborativas }\end{array}$ & Objetivos de aprendizagem \\
\hline \multirow{7}{*}{ Clareza dos papéis } & $\begin{array}{l}\text { - Desenvolver confiança no escopo da prática no contexto do trabalho } \\
\text { interprofissional. }\end{array}$ \\
\hline & $\begin{array}{l}\text { Adaptar o papel profissional a diferentes contextos/ambientes do trabalho } \\
\text { interprofissional. }\end{array}$ \\
\hline & $\begin{array}{l}\text { - Acumular e integrar os diferentes papéis profissionais para aumentar a } \\
\text { eficiência e melhorar a atenção à saúde. }\end{array}$ \\
\hline & $\begin{array}{l}\text { - Abordar a atuação da equipe diante da sobreposição das práticas e/ou ausência } \\
\text { de profissionais no trabalho em equipe. }\end{array}$ \\
\hline & $\begin{array}{l}\text { - Defender a representação de papéis profissionais ausentes no trabalho em } \\
\text { equipe. }\end{array}$ \\
\hline & - Articular as habilidades pessoais com os demais membros da equipe. \\
\hline & $\begin{array}{l}\text { - Defender outras profissões e discutir aspectos relacionados aos estereótipos e } \\
\text { hierarquias profissionais. }\end{array}$ \\
\hline \multirow{5}{*}{$\begin{array}{l}\text { Comunicação } \\
\text { interprofissional }\end{array}$} & $\begin{array}{l}\text { - Valorizar feedback de uma variedade de fontes, incluindo paciente, família e } \\
\text { comunidade. }\end{array}$ \\
\hline & · Fornecer feedback efetivo sob circunstâncias difíceis ou complexas. \\
\hline & $\begin{array}{l}\text { - Analisar e empregar o uso apropriado da tecnologia no compartilhamento de } \\
\text { informações entre os membros da equipe. }\end{array}$ \\
\hline & $\begin{array}{l}\text { - Pesquisar atos sobre possíveis/reais violações na confidencialidade como forma } \\
\text { de assegurar uma prática coerente com políticas e legislações institucionais. }\end{array}$ \\
\hline & $\begin{array}{l}\text { - Integrar habilidades de comunicação verbal e não verbal com os demais } \\
\text { membros da equipe, pacientes e famílias em situações difíceis ou complexas. }\end{array}$ \\
\hline \multirow{2}{*}{$\begin{array}{l}\text { Resolução de conflitos } \\
\text { interprofissionais }\end{array}$} & $\begin{array}{l}\text { - Analisar, minimizar e resolver conflitos de forma apropriada em situações } \\
\text { difíceis ou complexas. }\end{array}$ \\
\hline & $\begin{array}{l}\text { - Utilizar ferramentas reflexivas para demonstrar a autoconsciência e a } \\
\text { autorregulamentação de sua atuação profissional. }\end{array}$ \\
\hline \multirow{5}{*}{$\begin{array}{l}\text { Funcionamento da } \\
\text { equipe }\end{array}$} & $\begin{array}{l}\text { - Integrar de forma dinâmica os comportamentos dos diferentes profissionais } \\
\text { para apoiar a atuação da equipe. }\end{array}$ \\
\hline & $\begin{array}{l}\text { - Atuar nos casos em que há falta de respeito ou confiança na equipe ou exclusão } \\
\text { de algum de seus membros. }\end{array}$ \\
\hline & · Demonstrar abertura para novas ideias em discussões e tomada de decisão. \\
\hline & $\begin{array}{l}\text { Contribuir para as mudanças necessárias para melhorar os resultados da } \\
\text { equipe. }\end{array}$ \\
\hline & $\begin{array}{l}\text { - Utilizar ferramentas reflexivas para fortalecer os processos do trabalho em } \\
\text { equipe. }\end{array}$ \\
\hline
\end{tabular}

Fonte: traduzida e adaptada de Jecker et al. (2015). 
Quadro 1 - Continuação...

\begin{tabular}{|c|c|}
\hline $\begin{array}{l}\text { Domínios de } \\
\text { competências } \\
\text { colaborativas }\end{array}$ & Objetivos de aprendizagem \\
\hline \multirow{3}{*}{$\begin{array}{l}\text { Atenção centrada } \\
\text { no paciente/família/ } \\
\text { comunidade }\end{array}$} & $\begin{array}{l}\text { Apoiar e defender o envolvimento do paciente como membro da equipe no } \\
\text { trabalho interprofissional. }\end{array}$ \\
\hline & $\begin{array}{l}\text { Defender a mudança nos modelos de atenção à saúde ao paciente no contexto } \\
\text { da instituição de saúde, quando necessário. }\end{array}$ \\
\hline & $\begin{array}{l}\text { - Garantir e defender a centralidade do paciente no trabalho interprofissional e } \\
\text { nos serviços de saúde. }\end{array}$ \\
\hline \multirow{5}{*}{ Liderança colaborativa } & - Integrar feedback às práticas profissionais e da equipe. \\
\hline & $\begin{array}{l}\text { - Estimular a participação do paciente/família/comunidade em contextos de } \\
\text { barreiras institucionais para acessar ou usar informações em saúde. }\end{array}$ \\
\hline & · Defender mudanças organizacionais para reduzir as barreiras à colaboração. \\
\hline & $\begin{array}{l}\text { Defender novas tecnologias e estratégias para superar as barreiras à } \\
\text { colaboração. }\end{array}$ \\
\hline & $\begin{array}{l}\text { - Atuar com base na reflexão para melhoria de processos de trabalho e } \\
\text { organização dos sistemas de saúde. }\end{array}$ \\
\hline
\end{tabular}

Fonte: traduzida e adaptada de Jecker et al. (2015).

\section{CONSIDERAÇÕES FINAIS}

A oferta de serviços de saúde de qualidade, resolutivos e seguros exige valorização e fortalecimento da colaboração na dinâmica do trabalho em saúde. Trata-se de uma mudança paradigmática em que a lógica da produção dos serviços de saúde transita de um modelo centrado no profissional para outro centrado nas necessidades complexas e dinâmicas das pessoas. Embora esse seja o caminho óbvio, a realidade evidencia que há limitações na superação de um modelo que tende a fragmentar as práticas em saúde, situando o usuário no papel de receptor de atos e serviços de saúde.

Reconhecer a relevância da colaboração como pressuposto para o fortalecimento das práticas colaborativas certamente é um avanço para a reorientação das práticas e do processo de formação em saúde. Entretanto, é imprescindível que se tenha clareza das enormes tensões que ainda se colocam como barreiras para as práticas interprofissionais e colaborativas. A cultura das profissões em atuar isoladamente, o contexto marcado pela competição como mote das relações na sociedade globalizada, as normativas institucionais que legitimam a fragmentação dos atos em saúde e a rigidez curricular no interior das instituições formadoras são alguns dos desafios que estão postos, evidenciando que esse debate requer ampliação e aprofundamento para que mudanças futuras possam ser sentidas na melhoria dos resultados e dos sistemas de saúde.

No contexto brasileiro, o movimento de valorização da colaboração interprofissional precisa reconhecer a trajetória de lutas e acúmulos históricos em torno da consolidação e fortalecimento do Sistema Único de Saúde. Compreender as muitas interlocuções dessa discussão com os princípios e diretrizes do SUS assegura um debate em defesa de um sistema de saúde forte, resolutivo e comprometido com a superação das muitas desigualdades que se expressam no acesso aos serviços de saúde.

É oportuno afirmar, portanto, que o debate da colaboração interprofissional se junta a outros avanços na resistência aos muitos ataques que historicamente se realizam ao SUS. Defender as relações horizontais entre os diferentes profissionais de saúde, o protagonismo e a centralidade dos usuários na produção dos serviços de saúde mais integrais e resolutivos e um SUS forte é princípio humanitário que retoma a defesa da vida como principal bandeira de luta e sentido da produção dos serviços de saúde. 
BAKER, L. et al. Relationships of power: implications for interprofessional education. Journal of Interprofessional Care, Abingdon, v. 25, n. 2, p. 98-104, 2011.

BARR, H., and the Competent to collaborate. Towards a competency-based model for interprofessional education. Journal of Interprofessional Care, Abingdon, v. 12, n. 2, p. 181-187, 1998.

BARR, H. Toward a theoretical framework for interprofessional education. Journal of Interprofessional Care, Abingdon, v. 27, n. 1, p. 4-9, 2013.

BARR, H. Interprofessional Education: the genesis of a global movement. United Kingdon: Center For The Advancement of Inteprofessional Care, 2015.

Canadian Interprofessional Health Collaborative - CIHC. A national interprofessional competence framework. Vancouver: CIHC, 2010.

COSTA, M. V. A educação interprofissional como abordagem para a reorientação da formação profissional em saúde. Natal, RN: Universidade Federal do Rio Grande do Norte, 2014.

COSTA, M. V. et al. The interprofessional education in Brazilian context: some reflections. Interface, Botucatu, v. 20, n. 56, p. 197-198, 2016.

CRISP, N.; CHEN, L. Global Supply of Health Professionals. The New England Journal of Medicine, Boston, v. 370, n. 10, p. 950-957, 2014.

D'AMOUR, D. et al. The conceptual basis for interprofessional collaboration: core concepts and theoretical frameworks. Journal of Interprofessional Care, Abingdon, v. 19, p. 116-131, 2005.

DE OLIVEIRA, M. M.; DE SOUSA CAMPOS, G. W. Apoios matricial e institucional: analisando suas construções. Ciencia \& Saude Coletiva, Rio de Janeiro, v. 20, n. 1, p. 229-238, 2015.

FAULCONBRIDGE, J. R.; MUZIO, D. Professions in a globalizing world: Towards a transnational sociology of the professions. International Sociology, London, v. 27, n. 1, p. 136-152, 2012.

FELGOISE, S. H. et al. Interprofessional education: Collaboration and learning in action. The Journal of the American Osteopathic Association, Chattanooga, v. 119, n. 9, p. 612-619, 2019.

FRENK, J. et al. Health professionals for a new century: Ttransforming education to strengthen health systems in an interdependent world. Lancet, London, v. 376, n. 9756, p. 1923-1958, 2010.

FREYTAG, J. et al. Improving patient safety through better teamwork: how effective are different methods of simulation debriefing? Protocol for a pragmatic, prospective and randomised study. BMJ Open, v. 7, n. 6, p. e015977, 2017.

HOOKER, R. S. et al. Emergency medicine services: interprofessional care trends. Journal of
Interprofessional Care, London, v. 22, n. 2, p. 167-178, 2008.

JECKER, J. et al. Interprofessional learning guide. Ontário: Northern Ontario School of Medicine, 2015.

KÄMMER, J. E. et al. The potential of collective intelligence in emergency medicine: pooling medical students' independent decisions improves diagnostic performance. Medical Decision Making, Cambridge, v. 37, n. 6, p. 715-724, 2017.

LANGLOIS, S. et al. The COVID-19 crisis silver lining: Interprofessional education to guide future innovation. Journal of Interprofessional Care, Oxfordshire, v. 34, n. 5, p. 587-592, 2020.

OANDASAN, I.; REEVES, S. Key elements of interprofessional education. Part 2: Factors, processes and outcomes. Journal of Interprofessional Care, Oxfordshire, v. 19, p. 39-48, 2005.

PANEL, I. E. C. E. Interprofessional Education Collaborative Expert Panel. Core competencies for interprofessional collaborative practice: Report of an expert panel. Washington, DC: Interprofessional Education Collaborative, 2011.

PEDUZZI, M. et al. Educação interprofissional: formação de profissionais de saúde para o trabalho em equipe com foco nos usuários. Revista da Escola de Enfermagem da USP, São Paulo, v. 47, n. 4, p. 977-983, 2013.

PEDUZZI, M. et al. Trabalho em equipe: uma revisita ao conceito e a seus desdobramentos no trabalho interprofissional. Trabalho, Educação e Saúde, Rio de Janeiro, v. 18, Supl. 1, 1-20, 2020.

PIPPITT, K. et al. Collaboration versus competition: An interprofessional education experience. Family Medicine, Kansas City, v. 47, n. 4, p. 298-301, 2015.

REEVES, S. et al. A scoping review to improve conceptual clarity of interprofessional interventions. Journal of Interprofessional Care, Oxfordshire, v. 25, n. 3, p. 167174, 2011.

REEVES, S. Why we need interprofessional education to improve the delivery of safe and effective care. Interface: Comunicação, Saúde, Educação, Botucatu, v. 20, p. 185197, 2016.

REEVES, S. et al. A BEME systematic review of the effects of interprofessional education: BEME Guide No. 39. Medical Teacher, London, v. 38, n. 7, p. 656-668, 2016.

REEVES, S.; XYRICHIS, A.; ZWARENSTEIN, M. Teamwork, collaboration, coordination, and networking: Why we need to distinguish between different types of interprofessional practice. Journal of Interprofessional Care, London, v. 32, n. 1, p. 1-3, 2018.

THISTLETHWAITE, J. E. et al. Competencies and frameworks in interprofessional education: a comparative analysis. Academic Medicine, Philadelphia, v. 89, n. 6, p. 869-875, 2014. 
WILBUR, L. Interprofessional education and collaboration: a call to action for emergency medicine. Academic Emergency Medicine, Philadelphia, v. 21, n. 7, p. 833-834, 2014.

WORLD HEALTH ORGANIZATION. Framework for action on interprofessional education $\&$ collaborative practice. Geneva: WHO, Department of Human Resources for Health, 2010.

XYRICHIS, A. Interprofessional science: an international field of study reaching maturity. Journal of Interprofessional Care, Abingdon, Oxfordshire, v. 34, n. 1, p. 1-3, 2020. 
CAPÍTULO 9

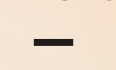

\section{A utilização da simulação na educação interprofissional}




\section{Sara Fiterman Lima}

Enfermeira

Universidade Federal do

Maranhão (UFMA)

\section{Cristiano Gil Regis}

Enfermeiro

Universidade Federal do Acre (UFAC)

\section{Marcelo Viana da Costa}

Enfermeiro

Universidade Federal do Rio

Grande do Norte (UFRN)

\section{Gerson Alves Pereira Júnior}

Docente de Cirurgia de

Urgência e do Trauma

Universidade de São Paulo (USP)

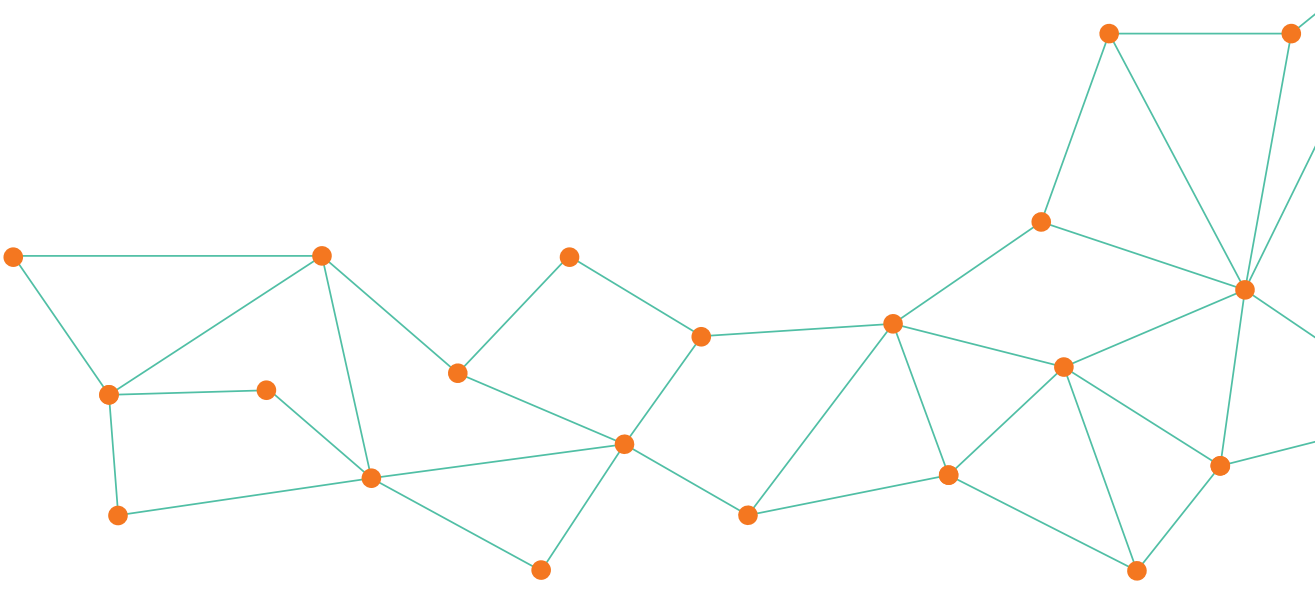

\section{INTRODUÇÃO}

As necessidades cada vez mais complexas dos usuários dos serviços de saúde e da população em geral levaram as profissões a caminhar historicamente em busca de formas de cuidado mais sofisticadas, para que dessem conta dessa realidade. Tradicionalmente, as instituições de educação têm perpetuado uma formação em saúde de modo departamentalizado, levando ao desenvolvimento de silos uniprofissionais e invisibilizando a necessidade de preparo para o trabalho conjunto nas equipes de saúde (INSTITUTE OF MEDICINE, 2001; BENNER et al., 2010; REEVES, 2016).

Com o tempo, evidenciou-se que essa abordagem isolada perpetua uma cultura de baixa colaboração, comunicação deficiente e trabalho em equipe pouco efetivo, resultando em graves prejuízos para a qualidade da atenção em saúde (WORLD HEALTH ORGANIZATION, 2010).

Diante dessa realidade, surge uma demanda por integração e interações entre estudantes (de forma precoce na formação) e profissionais de saúde de diferentes áreas por meio de espaços dialógicos, nos quais possam aprender com os outros, sobre os outros e entre si, para um adequado enfrentamento dos problemas de saúde, com colaboração e interdependência (BARR et al., 2005; REEVES, 2016; TOASSI, 2017).

A necessidade de compartilhamento das histórias de cada profissão, equipes de saúde, organizações e indivíduos passa a ser devidamente enfatizada em consequência do reconhecimento mundial de que as lacunas no trabalho em equipe constituem ameaças à segurança do paciente e à qualidade dos serviços de saúde (PALAGANAS; EPPS; RAEMER, 2014). Assim, a interprofissionalidade ganha destaque com a proposta de garantir uma interação contínua e compartilhamento de conhecimento entre diferentes profissionais, organizados para resolver ou explorar em conjunto uma variedade de questões de educação e assistência (PAIGE et al., 2015). 
Neste contexto, a educação interprofissional (EIP) surge como estratégia em que estudantes e/ ou profissionais da saúde de duas ou mais profissões aprendem juntos e de forma interativa, com o propósito explícito de melhorar a colaboração e a qualidade dos cuidados (REEVES, 2016; ORGANIZAÇÃO MUNDIAL DA SAÚDE, 2010). Portanto, ela é relevante para formação de uma força de trabalho de saúde colaborativa e preparada para a prática, pois incentiva os profissionais a trabalhar juntos, melhorando as capacidades dos recursos humanos para responder às necessidades locais de saúde e prestando serviços mais abrangentes e dinâmicos. Seus resultados, em última instância, permitem significativos avanços e fortalecem os sistemas de saúde (ORGANIZAÇÃO MUNDIAL DA SAÚDE, 2010; TOASSI, 2017).

A utilização da EIP já possui reconhecimento pela Organização Mundial da Saúde (OMS) e seus parceiros, que, após quase 50 anos de pesquisa, admitiram a existência de evidências suficientes para mostrar que a EIP proporciona uma prática colaborativa eficaz. A OMS reconheceu ainda a colaboração interprofissional na formação e nas práticas em saúde como uma estratégia inovadora com potencial para desempenhar um papel importante na redução da crise de saúde mundial (ORGANIZAÇÃO MUNDIAL DA SAÚDE, 2010).

Diante dessa relevância reconhecida, estudiosos passaram a buscar evidências sobre o melhor momento para a implementação da EIP em instituições de ensino e de assistência à saúde. Alguns autores defendem sua inclusão no início da graduação como forma de superar os estereótipos já existentes em relação a outros grupos profissionais. Essa integração no início do processo de formação pode apoiar a socialização interprofissional. Outros, no entanto, defendem essa inclusão após a graduação, visto que já existiria uma melhor compreensão da identidade profissional e de seu papel entre os participantes. Existem também aqueles que defendem o início precoce e contínuo da EIP na trajetória formativa, de forma transversal, desde a formação inicial até a vida profissional (Figura 1). Considerando que os objetivos e a natureza da EIP diferem dependendo do estágio de aprendizado, essa abordagem tem se mostrado mais coerente e apropriada (REEVES, 2016; LIE et al., 2016).

Buscando assegurar os resultados da EIP, iniciativas bem-sucedidas utilizam a orientação em diferentes teorias de aprendizagem. A teoria da aprendizagem de adultos vem sendo amplamente adotada por subsidiar métodos de aprendizagem que permi-

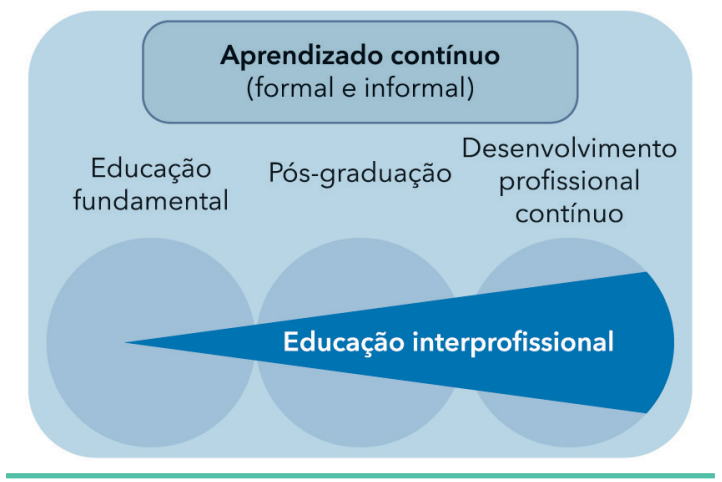

Figura 1 - Modelo de aprendizado contínuo interprofissional. Fonte: adaptada de Toassi (2017).

tem uma interatividade explícita entre os participantes. Esta interatividade e o repertório de conhecimentos prévios possibilitam o desenvolvimento de competências necessárias para a colaboração interprofissional (BARR et al., 2005; REEVES, 2016). Além da teoria educacional, é importante que haja rigor na definição do método de ensino e aprendizagem, o qual deve ser ativo, interativo e reflexivo, criando oportunidades para comparar e contrastar papéis, responsabilidades, conhecimentos, habilidades e atitudes (BARR et al., 2016).

Não se pode ignorar que um dos pressupostos-chave da EIP é explicitamente a interação entre diferentes profissionais de saúde, a qual deve orientar a escolha de métodos de aprendizagem que permitam essa interatividade (REEVES, 2016). Entre os diferentes tipos de métodos que se aplicariam a essa premissa, Reeves (2016) indica algumas possibilidades metodológicas:

- Aprendizagem baseada em seminário.

- Aprendizagem baseada em observação (shadowing).

- Aprendizagem baseada em problemas.

- Aprendizagem baseada em simulação.

- Aprendizagem baseada na prática clínica.

- Aprendizagem e-learning (por exemplo: discussões on-line).

- Aprendizagem híbrida (integrando e-learning com outro método tradicional).

Tais métodos de aprendizagem devem ser escolhidos de acordo com os objetivos da iniciativa de formação, dos participantes e dos recursos disponíveis. Entretanto, há um consenso de que a simulação, em todas as suas modalidades, é uma potente estratégia para a EIP (PALAGANAS; EPPS; RAEMER, 2014). 
Embora se reconheça a efetividade de diversos métodos para formação das competências colaborativas e destacando que a combinação de diferentes métodos interativos de aprendizagem em uma iniciativa de EIP pode contribuir para um maior aprendizado, este texto vai discutir sobre o uso da simulação.

\section{A SIMULAÇÃO E A EDUCAÇÃO INTERPROFISSIONAL}

A primeira iniciativa documentada de EIP mediada por simulação data de 1947 e enfocou a educação inter e transdisciplinar. O manuscrito não utilizou as palavras específicas "educação interprofissional" ou "simulação", mas exemplificou uma situação em que os estudantes aprenderam com os outros, sobre os outros e entre si por meio do uso de atores treinados para facilitar as atividades de dramatização entre as profissões (JANTSCH, 1970; PALAGANAS; EPPS; RAEMER, 2014).

As melhorias na simulação utilizada em EIP emergiram na década de 1950 por meio de simulações computadorizadas para sociologia, psicologia, ciências comportamentais e teoria organizacional. Na década de 1960, essa literatura foi ampliada, provavelmente, em decorrência de estudos dos fatores humanos e trabalho em equipe. Na mesma década, a colaboração passou a ser referida como o futuro para prestação de cuidados de saúde (PALAGANAS; EPPS; RAEMER, 2014).

O treinamento da equipe de saúde com simulação surgiu na década de 1980, com o MedTeams (inspirado no programa de treinamento da tripulação desenvolvido pela indústria da aviação) e com o treinamento de gerenciamento de recursos de crise em simulações de anestesia (MCCONAUGHEY, 2008; GABA, 1997).

A EIP e a simulação em saúde evoluíram historicamente como estratégias distintas, entretanto se sobrepuseram naturalmente em um campo mesclado. Assim, em 2011, a Society for Simulation in Healthcare (SSH) e a National League for Nursing (NLN) identificaram uma oportunidade de aprimorar os resultados da EIP, ao compreender e aproveitar melhor a sua interseção com a simulação (Figura 2). A simulação em EIP é a sobreposição da pedagogia da simulação e da EIP, proporcionando uma abordagem colaborativa para o desenvolvimento e o domínio das competências colaborativas (INACSL STANDARDS COMMITTEE, 2016).

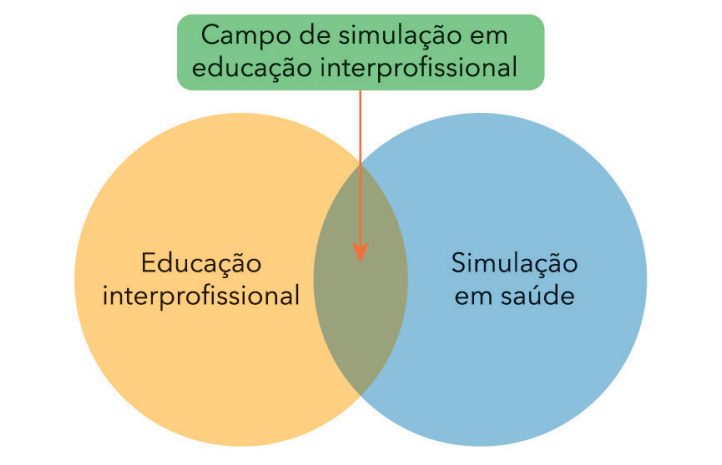

Figura 2 - Relação entre educação interprofissional e simulação em saúde. Fonte: adaptada de Wilhaus et al. (2013).

Sendo a simulação um método de aprendizagem que se utiliza de cenários, nos quais determinado conjunto de condições é (re)criado artificialmente para possibilitar a aprendizagem experimental de situações que acontecem no mundo real, ela pode auxiliar na formação de profissionais mais aptos ao trabalho em equipe (GABA, 2004; AL-ELQ, 2010).

Estudos apontam a metodologia da simulação como uma das melhores práticas para implementação da EIP. Por meio da integração de participantes de duas ou mais profissões, ela organiza a formação em torno de uma disciplina e realidade específica, em que cada profissão examina a base de seu conhecimento e os papéis de outras profissões, com respeito, confiança e apoio mútuos, e compartilha, assim, um propósito comum de moldar seus conhecimentos e habilidades (SMITH, 2016; NATIONAL LEAGUE FOR NURSING ACCREDITING COMMISSION, 2012; PALAGNAS, 2012; PINAR, 2015). Dessa forma, a simulação está cada vez mais sendo usada em EIP, porque oferece aos profissionais de saúde a oportunidade de atuar em equipe e trabalhar de forma colaborativa para resolver problemas e prestar atendimento em um ambiente seguro (NIMMAGADDA; MURPHY, 2014).

\section{A UTILIZAÇÃO DA SIMULAÇÃO PARA A FORMAÇÃO INTERPROFISSIONAL}

Conforme apontado anteriormente, a EIP se faz necessária em todos os momentos da formação em saúde para que sejam trabalhadas as competências colaborativas. Mais de $75 \%$ dos erros na área de saúde envolvem um elemento de comunicação 
deficiente e outros fatores humanos, sendo irrefutável que um bom trabalho em equipe, com colaboração entre todos os profissionais de saúde, é vital. Com a simulação, pode-se criar um ambiente livre de riscos e tolerante a erros, em que estudantes, em diferentes estágios de aprendizado e de diferentes profissões, podem interagir para melhorar o trabalho em equipe e a colaboração (ZHANG et al., 2011; O'BRIEN; MOULD, 2016).

Além disso, o uso da simulação, incluindo diferentes profissões com foco em fatores humanos (como comunicação, consciência situacional, liderança e trabalho em equipe), permite que profissionais e estudantes se tornem cada vez mais conscientes da relevância desses fatores em um contexto de uma situação clínica e da contribuição da interação social para um cuidado de saúde adequado (O'BRIEN; MOULD, 2016). Assim, a simulação para EIP pode ser utilizada em diferentes combinações de profissões e contextos, incluindo a graduação, a pós-graduação e a educação permanente, além de estar presente em diferentes áreas da saúde, como atenção primária, pediatria, clínica médica, cirurgia, obstetrícia, psiquiatria, urgência e emergência, entre outras (PALAGNAS, 2012; PINAR, 2015).
Para o uso da simulação em EIP, faz-se necessária a compreensão de que colocar em um cenário membros de diferentes profissões não é suficiente para assegurar a aprendizagem interprofissional entre os participantes. Por ser inerentemente interativa, a interprofissionalidade demanda que as atividades realizadas assegurem a integração desses sujeitos no processo de ensino e aprendizagem, para que haja o desenvolvimento das competências colaborativas (REEVES; GOLDMAN; ZWARENSTEIN, 2009). Nesse sentido, a importância da interação se complementa por outro importante aspecto, que é a intencionalidade. Os pressupostos da EIP precisam estar intencionalmente inseridos na proposta pedagógica, na escolha dos conteúdos, na construção dos objetivos, nas competências esperadas, na organização do cenário e na avaliação da aprendizagem (COSTA et al., 2019).

Essa intencionalidade deve se expressar na inclusão de competências colaborativas no processo de formação, visto que são tais competências que conferem a aprendizagem interprofissional. Essas competências colaborativas podem ser encontradas em diferentes matrizes. Nesse sentido, apresentam-se algumas dessas matrizes (Quadro 1), que foram elaboradas por instituições

Quadro 1 - Quatro matrizes de competências interprofissionais publicadas.

\begin{tabular}{|c|c|c|c|}
\hline Fonte e autoria & $\begin{array}{l}\text { País e ano de } \\
\text { publicação }\end{array}$ & Intenção e justificativa & Domínios \\
\hline \multirow{4}{*}{$\begin{array}{l}\text { The } \\
\text { Interprofessional } \\
\text { Capability } \\
\text { Framework } \\
\text { (Universities } \\
\text { Interprofessional } \\
\text { Learning Unit). }\end{array}$} & \multirow{4}{*}{$\begin{array}{l}\text { Reino Unido, } \\
2004\end{array}$} & \multirow{4}{*}{$\begin{array}{l}\text { Para permitir uma abordagem } \\
\text { mais coerente, integrada e } \\
\text { centrada no paciente; modernizar } \\
\text { a contribuição educacional em } \\
\text { relação a futuros profissionais } \\
\text { de saúde; promover o trabalho } \\
\text { em equipe, com parceria e } \\
\text { colaboração entre os profissionais } \\
\text { e as agências com os pacientes. }\end{array}$} & $\begin{array}{l}\text { 1) Conhecimento a partir da } \\
\text { prática. }\end{array}$ \\
\hline & & & 2) Prática ética. \\
\hline & & & 3) Trabalho interprofissional. \\
\hline & & & 4) Reflexão (aprendizagem). \\
\hline \multirow{6}{*}{$\begin{array}{l}\text { National } \\
\text { Interprofessional } \\
\text { Competency } \\
\text { Framework } \\
\text { (Canadian } \\
\text { Interprofessional } \\
\text { Health Collaborative } \\
\text { Working Group). }\end{array}$} & \multirow{6}{*}{ Canada, 2010} & \multirow{6}{*}{$\begin{array}{l}\text { Para desenvolver, por meio da } \\
\text { colaboração entre diferentes } \\
\text { profissionais, um quadro } \\
\text { nacional de competências } \\
\text { interprofissionais. }\end{array}$} & $\begin{array}{l}\text { 1) Comunicação } \\
\text { interprofissional. }\end{array}$ \\
\hline & & & 2) Atenção centrada no paciente. \\
\hline & & & 3) Clareza de papéis. \\
\hline & & & 4) Funcionamento da equipe. \\
\hline & & & 5) Liderança colaborativa. \\
\hline & & & $\begin{array}{l}\text { 6) Resolução de conflitos } \\
\text { interprofissionais. }\end{array}$ \\
\hline
\end{tabular}

Fonte: adaptado de Thistlethwaite et al. (2014). 
Quadro 1 - Continuação...

\begin{tabular}{|c|c|c|c|}
\hline Fonte e autoria & $\begin{array}{l}\text { País e ano de } \\
\text { publicação }\end{array}$ & Intenção e justificativa & Domínios \\
\hline \multirow{4}{*}{$\begin{array}{l}\text { Core Competencies } \\
\text { for Interprofessional } \\
\text { Collaborative } \\
\text { Practice } \\
\text { (Interprofessional } \\
\text { Education } \\
\text { Collaborative Expert } \\
\text { Panel). }\end{array}$} & \multirow{4}{*}{$\begin{array}{l}\text { Estados } \\
\text { Unidos, } 2011\end{array}$} & \multirow{4}{*}{$\begin{array}{l}\text { Para transformar a educação das } \\
\text { profissões de saúde e atender } \\
\text { à necessidade de construir } \\
\text { sistemas de saúde mais seguros, } \\
\text { mais centrados no paciente e } \\
\text { orientados para a comunidade. }\end{array}$} & 1) Valor e ética profissionais. \\
\hline & & & 2) Funções e responsabilidades. \\
\hline & & & $\begin{array}{l}\text { 3) Comunicação } \\
\text { interprofissional. }\end{array}$ \\
\hline & & & $\begin{array}{l}\text { 4) Trabalho em equipe e } \\
\text { cuidado realizado em equipe. }\end{array}$ \\
\hline \multirow{5}{*}{$\begin{array}{l}\text { Interprofessional } \\
\text { Capability } \\
\text { Framework (Curtin } \\
\text { University) }\end{array}$} & \multirow{5}{*}{$\begin{array}{l}\text { Austrália, } \\
2011\end{array}$} & \multirow{5}{*}{$\begin{array}{l}\text { Para promover as capacidades } \\
\text { necessárias aos profissionais } \\
\text { de saúde, para que sejam } \\
\text { colaborativos, prontos para } \\
\text { uma prática eficaz e eficiente } \\
\text { e para o trabalho em equipe } \\
\text { interprofissional, e aptos a } \\
\text { fornecer serviços e cuidados } \\
\text { seguros e de alta qualidade para } \\
\text { clientes, famílias e comunidades. }\end{array}$} & 1) Comunicação. \\
\hline & & & 2) Trabalho em equipe. \\
\hline & & & 3) Clareza de papéis. \\
\hline & & & 4) Resolução de conflitos. \\
\hline & & & 5) Reflexão. \\
\hline
\end{tabular}

Fonte: adaptado de Thistlethwaite et al. (2014).

formadoras, pesquisadores e representantes políticos e que devem ser consideradas no planejamento das atividades de simulação interprofissional, pois são extremamente úteis como guias para atividades de aprendizagem e avaliações adequadamente alinhadas (ORGANIZAÇÃO MUNDIAL DA SAÚDE, 2010; PALAGANAS; EPPS; RAEMER, 2014; THISTLETHWAITE et al., 2014).

Em relação às competências colaborativas, ao se considerar os serviços de saúde como a organização na qual os profissionais atuam em equipe, infere-se que os referenciais de competência interprofissional são relevantes para todos os profissionais, sendo úteis para educadores que estão realizando a EIP em seus programas (THISTLETHWAITE et al., 2014).

\section{CONSTRUÇÃO DE CENÁRIOS SIMULADOS EM EDUCAÇÃO INTERPROFISSIONAL}

Os cenários simulados em EIP podem ser definidos como o planejamento de uma situação clínica que possibilita o desenvolvimento de objetivos específicos para aprendizagem interprofissional, devendo ser verossímil, envolver estratégias para comunicação, raciocínio crítico, tomada de decisões e solução de problemas (ALINIER, 2011; NEVES et al., 2017).
As simulações podem promover a aprendizagem colaborativa entre alunos, instrutores e outros profissionais de saúde para fornecer um ambiente em que todos trabalhem juntos, imitando o que realmente é feito na vida real. Entretanto, para que sejam efetivas, as práticas simuladas interprofissionais devem ser planejadas por meio da construção de tais cenários, com vistas a permitir uma experiência simulada entre representantes de diferentes profissões, intencionalmente organizadas, de forma a possibilitar aos participantes a vivência de experiências cognitivas, afetivas e psicomotoras, com base em uma situação clínica que envolva a necessidade do trabalho em equipe. Nos cenários simulados, os participantes podem integrar conteúdos teóricos e habilidades técnicas e não técnicas (JEFFRIES, 2005; LIOCE et al., 2020; PINAR, 2015; NOGUEIRA; DOMINGUES; BERGAMASCO, 2020).

O trabalho em equipe ocorre quando há coordenação de esforços, troca dinâmica de recursos e adaptação a fatores situacionais variáveis. Trata-se de um conjunto inter-relacionado de pensamentos, comportamentos e sentimentos dos membros da equipe, para que funcionem como uma unidade (SWEZEY; MELTZER; SALAS, 1994). 
Para que os participantes se sintam os mais próximos possíveis das situações reais, os cenários devem ser adequadamente planejados e servir como recurso para otimizar a prática das competências colaborativas, incluindo na organização meios que permitam a utilização dos conhecimentos, habilidades e atitudes dos participantes (NOGUEIRA; DOMINGUES; BERGAMASCO, 2020; NIMMAGADDA; MURPHY, 2014).

Vários modelos são encontrados na literatura para orientar a construção de cenários de simulação, entretanto optou-se por sugerir uma estruturação de cenários simulados para EIP em três etapas fundamentais para estruturação do ensino simulado (Figura 3).

\subsection{PLANEJAMENTO E ESTRUTURAÇÃO DE CENÁRIOS SIMULADOS EM EDUCAÇÃO INTERPROFISSIONAL}

Todas as experiências baseadas em simulação requerem planejamento intencional, minucioso e sistemático, ainda que flexível e cíclico. Para que os objetivos de aprendizagem sejam devidamente explorados, e os resultados esperados possam ser alcançados, o design e o desenvolvimento da simulação devem considerar critérios que facilitam a efetividade das experiências baseadas em simulação. Existem vários modelos que orientam esse planejamento. Nesse caso, serão aproveitadas as orientações da International Nursing Association for Clinical
Simulation and Learning (INACSL STANDARDS COMMITTEE, 2016), com algumas adaptações (Figura 4):

Sugere-se, inicialmente, partir do problema a ser abordado, o qual, por sua vez, deve estar relacionado aos conteúdos curriculares da graduação e pós-graduação ou a situações relacionadas ao trabalho da equipes profissionais nos serviços de saúde, sejam estas reconhecidas por seus componentes (é interessante quando se parte das necessidades e expectativas dos participantes) ou secundárias a demandas do contexto da saúde (administrativas, científicas, sociais e políticas) (NEVES et al., 2017; PALAGANAS; EPPS; RAEMER, 2014).

Outro ponto relevante se refere à escolha do arcabouço teórico que irá fundamentar a prática simulada e a aprendizagem dos participantes, pautada nas melhores evidências científicas. Como a maioria das estações simuladas se aplica a situações associadas a conteúdos clínicos específicos e também à prática colaborativa, deve-se trabalhar com dois tipos de referenciais: aqueles voltados para temática em saúde explorada e aqueles voltados para EIP. Esta é uma etapa para reconhecimento de possibilidades, por isso recomenda-se que toda e qualquer fonte de referência a ser utilizada na construção do cenário seja listada, para dar credibilidade e validar sua confecção (NOGUEIRA; DOMINGUES; BERGAMASCO, 2020; NEVES et al., 2017).

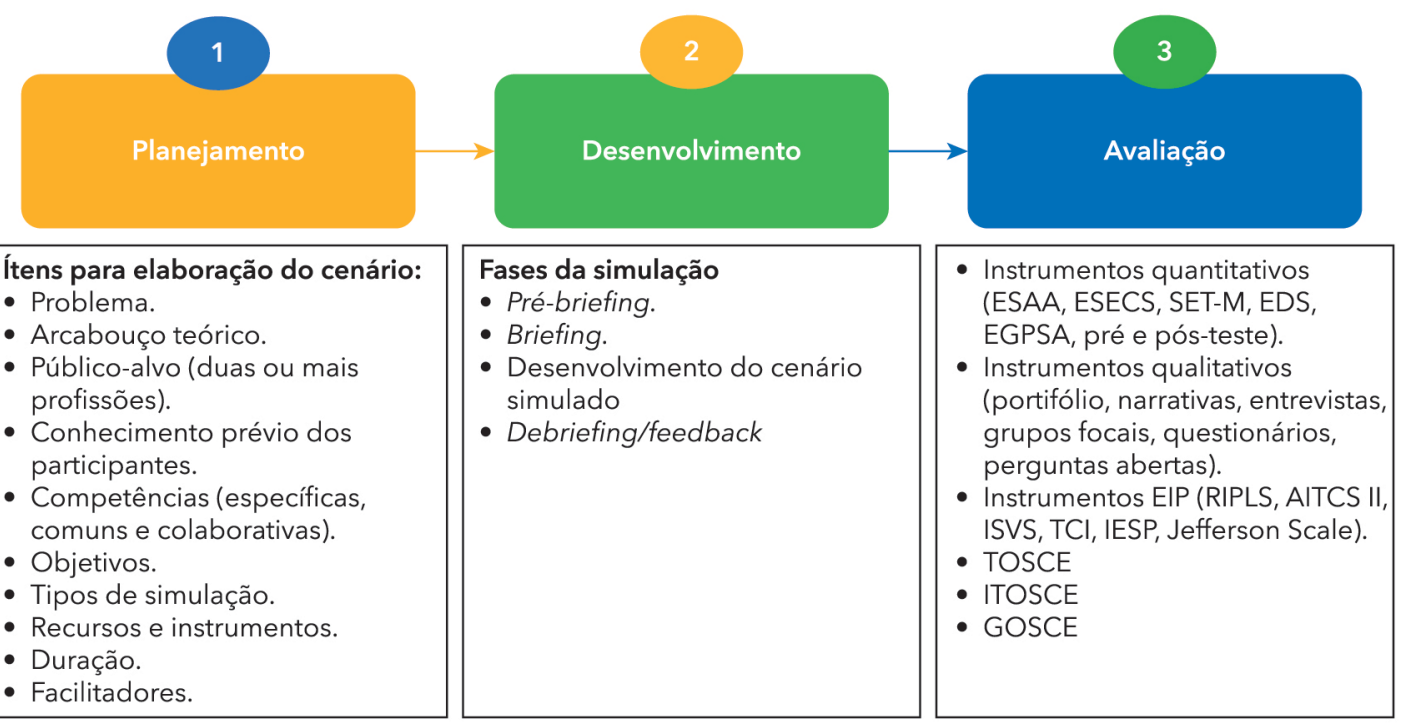

Fonte: Elaborada pelos autores

Figura 3 - Etapas para construção de cenários simulados em EIP. 


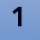

2

3

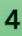

5

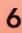

7
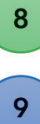

10

11

Realizar a avaliação das necessidades para providenciar evidências fundamentais e indispensáveis para o design adequado das experiências baseadas em simulação.

Construir objetivos mensuráveis.

Estruturar o formato da simulação com base no propósito, teoria e modalidade da experiência baseada em simulação.

4 Construir o cenário ou o caso para fornecer o contexto da experiência baseada em simulação.

Utilizar vários tipos de finalidade para criar a percepção requerida de realismo.

6 Manter uma bordagem facilitadora centrada no participante e direcionada aos objetivos, conhecimento ou nível de experiência do participante e resultados esperados.

Iniciar a experiência baseada em simulação com um pré-briefing

8 Seguir a experiência baseada em simulação com o debriefing e/ou sessão de feedback

9 Incluir avaliação dos participantes, facilitadores, experiência baseada em simulação, instalações e time de suporte.

Fornecer materiais e recursos para promover aos participantes capacidade para atingir os objetivos propostos e alcançar os resultados esperados com a experiência.

Realizar um teste-piloto antes de implementar a experiência baseada em simulação.

Figura 4 - Melhores práticas para o planejamento da simulação. Fonte: adaptada de INACSL STANDARDS COMMITTEE (2016).

A simulação em EIP deve incluir um conjunto de estratégias teoricamente embasadas para: (1) aumentar as competências do trabalho colaborativo em equipe para uma melhor assistência; (2) dar aos membros da equipe oportunidades para ganhar experiências com uso dessas competências, de forma segura.

Uma vez definidos o problema e o arcabouço teórico, pode-se partir para a definição do público-alvo (lembrando que, para ser interprofissional, deve-se envolver duas ou mais profissões). É fundamental definir as categorias profissionais que participarão da atividade simulada e o número de participantes. Também é importante identificar qual o conhecimento prévio deles, pois é relevante a adequação do cenário ao nível de conhecimento e vivências dos participantes. Essas informações serão úteis para definição das competências a serem trabalhadas na simulação e para elaboração dos objetivos de aprendizagem congruentes com tais competências (NEVES et al., 2017; EPPICH; CHENG, 2015; SANTALUCIA et al., 2016).
Para definir as competências, durante o planejamento é necessário entendê-las como domínios construídos e adquiridos em situações cotidianas que, necessariamente, envolvem a compreensão da ação empreendida e do uso a que essa ação se destina. Portanto, competência é a capacidade de mobilizar recursos cognitivos, emocionais e psicomotores (conhecimentos, habilidades e atitudes) para solucionar, com eficácia, algumas situações (BAILLIE; CURZIO, 2009; AGUIAR; RIBEIRO, 2010). Para isso, Aguiar e Ribeiro (2010) destacam que, frequentemente, observa-se o uso do termo "competências" para expressar objetivos de ensino quanto a "condutas e práticas observáveis", em que se acrescenta um "ser capaz de", expressão que caracteriza uma ação, sem haver uma preocupação com a transferência de conhecimentos para aplicação em contextos diversos ou sua mobilização em situações complexas, que são indiscutivelmente necessárias para uma competência. Por esse motivo, é importante garantir que a simulação exceda uma experiência unicamente prática e sem sustentação teórica. 
Ao usar a simulação em EIP, muitos dos objetivos e resultados de aprendizagem permanecerão os mesmos para todas as profissões, entretanto são necessárias algumas variações nas atribuições das profissões individuais e nas diretrizes clínicas. Assim, embora o planejamento esteja voltado para a formação interprofissional, o cenário pode enfocar também a aquisição, a manutenção ou a avaliação das competências específicas e comuns, para além das colaborativas, mas os objetivos podem incluir a avaliação de saúde, o plano de cuidados, a avaliação de cuidados e os cuidados de acompanhamento (NEVES et al., 2017; NIMMAGADDA; MURPHY, 2014).

Quanto aos objetivos de aprendizagem, eles devem espelhar os resultados esperados por meio da simulação, levando em consideração o trabalho em equipe em sua formulação. Ao planejar os objetivos, deve-se envidar esforços para que estes fiquem claros, concisos e mensuráveis, explicitando os desempenhos desejados. Dessa forma, não se pode esquecer da inclusão de competências colaborativas em sua construção, pois é nessa atitude intencional que se garante a presença da interprofissionalidade na aprendizagem. Para isso, é possível recorrer às matrizes indicadas no Quadro $1 \mathrm{e}$ à pergunta: Quais competências deverão ser desenvolvidas pela equipe nesta atividade? (KANEKO; LOPES, 2019; COSTA; AZEVEDO; VILAR, 2019).

Destaca-se ainda que, ao planejar os objetivos, estes podem ser divididos em gerais (relacionados às metas organizacionais da estação) e específicos (relacionados às medidas de desempenho esperadas dos participantes). Além disso, os objetivos gerais devem ser disponibilizados aos participantes antes do início da atividade simulada, enquanto os específicos devem ficar restritos aos facilitadores, já que direcionam o processo de acompanhamento e avaliação (KANEKO; LOPES, 2019; NOGUEIRA; DOMINGUES; BERGAMASCO, 2020).

Outro ponto importante no planejamento é a modalidade/estratégia de simulação que será utilizada. Uma atividade de simulação pode ser conduzida por diferentes modalidades, e a escolha do melhor método deve ser pautada nos objetivos propostos e nos desempenhos esperados dos participantes. Entre as diversas estratégias de simulação, destacam-se o treinamento de habilidades e os diversos tipos de simulação clínica com o uso de simuladores (manequins) e paciente simulado (ator), simulação híbrida (simulador mais paciente simulado), prática deliberada em ciclos rápidos (PDCR), simulação virtual (realidade virtual), simulação in situ e telessimulação (BERGAMASCO et al., 2020).

Ainda no planejamento, deve-se realizar um levantamento dos recursos necessários, incluindo $o$ ambiente no qual a atividade será desenvolvida, simuladores, materiais/equipamentos, equipe audiovisual, pacientes padronizados, moulage, adereços, recursos diagnósticos e terapêuticos. A complexidade do problema a ser resolvido deve determinar a magnitude dos recursos a serem utilizados (NEVES et al., 2017).

A construção de uma lista de itens essenciais sobre a organização da experiência simulada é uma estratégia efetiva para essa fase do planejamento, pois os registros irão facilitar a conferência de todos os aspectos necessários que devem compor o cenário final antes de sua aplicação (NOGUEIRA; DOMINGUES; BERGAMASCO, 2020).

O conjunto dessas atividades de planejamento vão garantir o nível de fidelidade do cenário, destacando aqui que fidelidade não é um sinônimo de tecnologia, e sim uma propriedade intrínseca da simulação, que pode ser definida como o grau de precisão com que uma simulação, seja ela física, mental ou ambas, representa determinado quadro de realidade em termos de pistas e estímulos e interações possíveis (TUN et al., 2015).

Uma vez planejado o cenário, ele deve ser organizado para que possa ser aplicado. Nessa etapa, os itens indicados no planejamento devem ser garantidos, o que inclui a reserva dos recursos existentes e a criação e a aquisição de recursos inexistentes necessários para condução da estação simulada.

Um cenário é útil quando tem um bom potencial instrutivo, ou seja, facilita a contemplação dos objetivos de aprendizagem, exercitando cada participante para enfrentar as situações reais vivenciadas em equipe, estimulando-os para o alcance dos resultados esperados (INACSL STANDARDS COMMITTEE, 2016).

A estratégia de EIP será mais eficaz quando as ferramentas, métodos de entrega e conteúdo disponíveis são combinados:

Quando se trata de um cenário para trabalhar a EIP, é interessante considerar diferentes experiências profissionais. Assim, é indicado que estes cenários sejam desenvolvidos e revisados por representantes das profissões envolvidas na simulação, para que sejam respeitadas e valorizadas as especificidades de cada uma. Entretanto, outro ponto fundamental consiste em criar oportunidades de aprendizagem pro- 
positais, estabelecendo metas mútuas entre as profissões envolvidas na experiência, para garantir a sua integração (INACSL STANDARDS COMMITTEE, 2016; PINAR, 2015).

Com base no problema definido e nos objetivos de aprendizagem, organiza-se um caso (que pode ser hipotético ou com base em experiências reais) e, a partir dele, realizam-se os instrumentos necessários para o desenvolvimento da simulação.

Alguns instrumentos para construção de cenários simulados:

1) Orientação para montagem do cenário, contendo listagem dos recursos e as indicações para sua distribuição no ambiente;

2) Caso descrito de maneira sucinta e clara, contendo apenas as informações essenciais e relevantes para o desenvolvimento da atividade;

3) Roteiro com informações a serem oferecidas aos participantes durante $o$ aquecimento da atividade (Briefing);

4) Informações a serem oferecidas aos participantes para orientar a sua participação durante a atividade, contendo a descrição do caso, o tempo e a tarefa a ser realizada;

5) Scripts dos atores simulados e documentação de apoio;

6) Orientações e informações para o examinador/ avaliador;

7) Fluxograma de acordo com as decisões possíveis das estações;

8) Checklist do caso para examinador/avaliador.

Como se trata de uma simulação interprofissional, o cenário deve, preferencialmente, ser criado por facilitadores de diferentes profissões, de maneira colaborativa. A simulação consiste em uma atividade viva, sendo necessário realizar uma descrição completa das possíveis progressões para o caso, respeitando os papéis de cada profissional e valorizando a interdependência entre os participantes.

Os roteiros devem ser elaborados de maneira detalhada, para propiciar dados para todos os en- volvidos na condução do cenário. Esse detalhamento descrito do cenário facilitará a comunicação e a atuação dos participantes, dos facilitadores, das equipes de apoio e dos atores durante a simulação. Além disso, no planejamento da atividade, podem-se incluir distrações, planejadas a partir de possíveis ocorrências em um cenário real, e questões éticas, para conferir maior fidelidade ao cenário (KANEKO; LOPES, 2019; INACSL STANDARDS COMMITTEE, 2016).

O caso descrito, ou a história de fundo, fornece um ponto de início realístico para as atividades estruturadas, mas o cenário tem seus desdobramentos, em que as demais informações podem ser oferecidas ao grupo participante verbalmente, encontradas em documentação de suporte, como prontuário, ou ser reveladas à medida que emergirem as perguntas adequadas por parte dos participantes (INACSL STANDARDS COMMITTEE, 2016).

Assim, outro ponto necessário é organizar as respostas às ações dos participantes, incluindo falas padronizadas e pistas que possam direcioná-los quando se desviam do objetivo pretendido. Essas pistas podem ser fornecidas verbalmente (pelo facilitador ou paciente padronizado), visualmente (pelo monitor) ou por meio de dados adicionais (novos resultados de exames) ((INACSL STANDARDS COMMITTEE, 2016).

O uso da árvore de tomada de decisões ou fluxograma também é uma ferramenta muito útil, pois auxilia no desenvolvimento do cenário de acordo com a evolução e ações do(s) participante(s). Ressalta-se que esse roteiro do cenário ou caso desenvolvido necessita de consistência e padronização para permitir a sua reprodutibilidade e confiabilidade (INACSL STANDARDS COMMITTEE, 2016).

Além disso, um checklist contendo as ações/ atividades que o(s) participante(s) voluntário(s) deve $(\mathrm{m})$ desenvolver durante a prática simulada também representa um recurso instrucional interessante tanto para o facilitador quanto para os participantes observadores durante o acompanhamento da simulação, facilitando, posteriormente, o direcionamento do debriefing e a reflexão do grupo (NOGUEIRA; DOMINGUES; BERGAMASCO, 2020).

Nos cenários com pacientes simulados, devem ser definidas as quantidades necessárias de envolvidos, garantindo sua presença na simulação; em alguns casos, é preciso realizar o treinamento dos atores pautado em um roteiro detalhado, bem como uma caracterização (vestimentas e moulage), quando necessário, para garantir o rea- 
lismo e o sucesso do cenário (KUMAKURA; SILVA; GONÇALVES, 2018).

Estabelecer um limite de duração da atividade simulada que garanta tempo suficiente para que os participantes atinjam os objetivos é fundamental, e, mesmo quando as intervenções esperadas não forem alcançadas no período definido, o cenário deve ser encerrado, e o insucesso da resolução, discutido posteriormente no debriefing da equipe (NOGUEIRA; DOMINGUES; BERGAMASCO, 2020).

A escassez de tempo pode aumentar o estresse dos participantes, por outro lado, cenários com ritmo excessivamente lento podem reduzir o grau de imersão dos mesmos na atividade (NEVES et al., 2017).

Além disso, a seleção de facilitador que conduzirá a atividade simulada deve considerar o conhecimento do tema proposto e a experiência na estratégia, pois ele é o principal agente apoiador para o processo de aprendizagem. É o facilitador que ajuda a melhorar um desempenho insatisfatório ou reforça um bom desempenho do participante, por meio da reflexão guiada sobre a experiência da simulação, tendo, assim, um importante papel durante e após a realização no cenário. Portanto, sua escolha é fundamental para garantir o sucesso do cenário (MENEZES; MOLINA; DOS SANTOS, 2020).

\subsection{APLICANDO A SIMULAÇÃO INTERPROFISSIONAL}

$O$ início da aplicação de uma simulação interprofissional deve acontecer por meio de um pré-briefing, em que o facilitador irá saudar os participantes, mostrar os tipos de simuladores que podem estar relacionados ao cenário, estabelecer o "contrato de ficção" e identificar as expectativas dos participantes, as quais, dependendo do nível de experiência e bagagem teórica de cada um, podem ser diferentes. Também é interessante estabelecer regras e limites (IGLESIAS; PAZIN FILHO, 2015; INACSL STANDARDS COMMITTEE, 2016).

Após o pré-briefing com as instruções gerais da simulação, ocorre o momento do briefing com as instruções específicas, logo antes da aplicação do cenário simulado. Nesta etapa, há a apresentação do problema e dos passos relativos à tarefa a ser realizada, os quais devem ser apresentados de forma clara, objetiva e sucinta, podendo ser expostos em cartazes para rápida consulta e visualização. É importante que o componente cognitivo da competência esteja internalizado e seja de domínio dos participantes antes do momento presencial, o que pode ser realizado por: 1) sala de aula invertida com o envio de referências para estudo prévio (textos e vídeos) dos aprendizes; 2) exposição dialogada prévia do instrutor, de preferência gravada; 3 ) busca ativa pelos aprendizes como complemento ao estudo prévio; e 4) ensino por metodologias ativas (IGLESIAS; PAZIN FILHO, 2015).

É interessante ainda que o briefing seja estruturado, planejado com consistência e completo, aplicado imediatamente antes do cenário/caso e que o plano do briefing seja escrito ou gravado para padronização do processo e utilizações futuras (INACSL STANDARDS COMMITTEE, 2016).

O momento de desenvolvimento do cenário de simulação é aquele em que a tarefa é realizada de forma prática, sendo observada pelo instrutor e pelos demais participantes, com ou sem gravação audiovisual. Este momento possui ponto de início, atividades estruturadas para o participante e ponto de término. É fundamental que os observadores tenham máxima atenção ao cumprimento dos passos preestabelecidos, de modo a facilitar o feedback. Nesta etapa, o facilitador deve estar atento para conduzir a evolução do cenário, estimulando a participação de todos e o trabalho em equipe (INACSL STANDARDS COMMITTEE, 2016; NOGUEIRA; DOMINGUES; BERGAMASCO, 2020).

Ao final da ação de simulação como ensino, tem-se o debriefing, que é o momento de estímulo para o levantamento de ideias e possibilidades de abordagens diferentes, o que propicia o ensino de diferentes habilidades específicas (cognitivas, de comunicação, procedurais, de colaboração, entre outras), e também ocorre o feedback sobre o desempenho dos estudantes que participaram do cenário simulado. Trata-se de um momento de reflexão que pode levar a novas interpretações pelos participantes. O debriefing promove o entendimento e apoia a aquisição de conhecimento, habilidades e atitudes visando às práticas recomendadas para promover o tratamento seguro e de boa qualidade ao paciente, além de desenvolver a função profissional do participante. As habilidades do facilitador são importantes para assegurar os melhores resultados de possíveis aprendizagem (INACSL STANDARDS COMMITTEE, 2016; MONTANDON et al., 2020).

$\mathrm{O}$ ambiente do debriefing deve ser positivo e entusiástico, seguindo a visão de "não criticar", por meio de uma condução com questionamentos adequados (Figura 5), e permitindo que o aluno/participante memorize as ações, de forma a agir confortavelmente quando um caso real semelhante lhe for apresentado. 


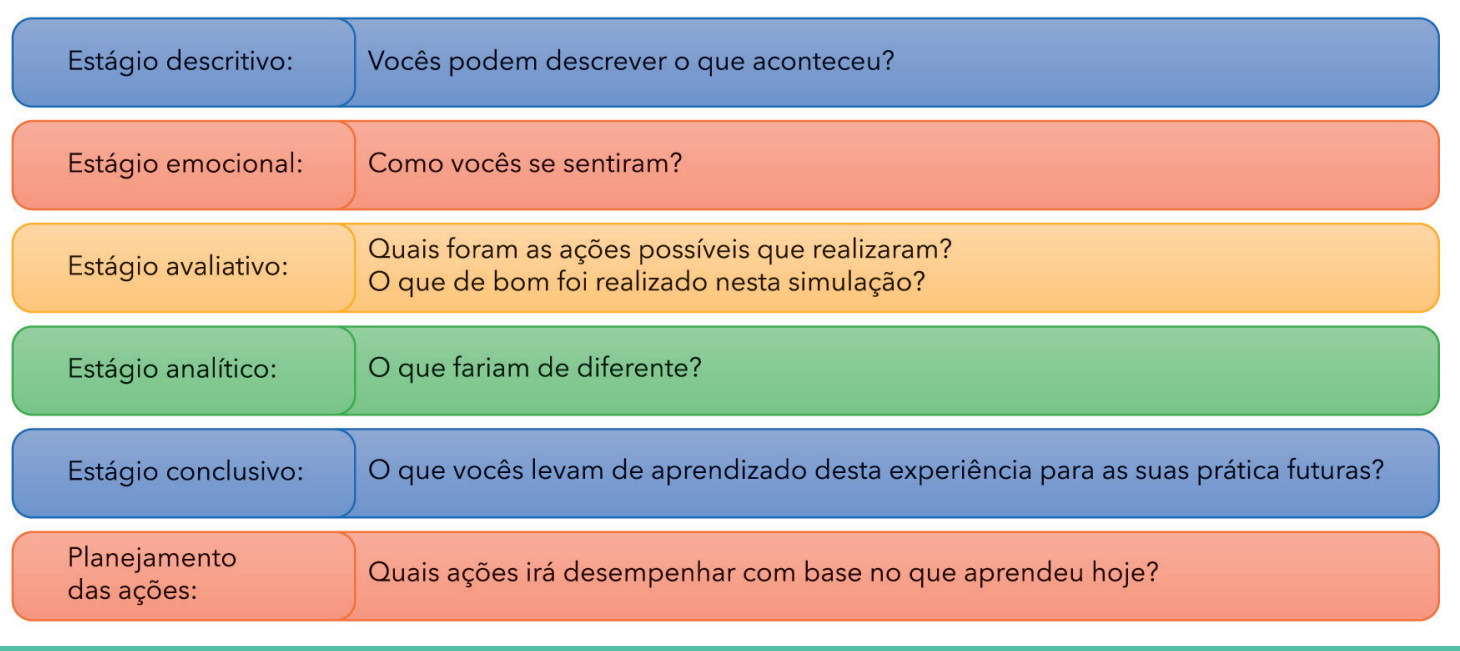

Figura 5 - Perguntas estruturadas para o debriefing. Fonte: adaptada de Gibbs (1988).

Apesar de relatos positivos, com muitos desfrutando de atividades de aprendizagem em equipe, a integração da EIP na educação clínica permanece limitada. Nesse sentido, o trabalho simulado em equipe ainda apresenta muitas barreiras que podem impactar na EIP (JEFFRIES, 2005; PALAGNAS, 2012; INTERPROFESSIONAL EDUCATION COLLABORATIVE EXPERT PANEL, 2011).

\subsection{A AVALIAÇÃO DA SIMULAÇÃO INTERPROFISSIONAL}

Partindo de uma perspectiva formativa, a avaliação de simulação interprofissional não se encerra em si, ou seja, seu objetivo não é simplesmente atribuir nota e classificar os estudantes como aprovados ou reprovados. Ela deve fazer parte de um processo formativo que se inicia no planejamento da unidade curricular ou curso que assumiu a EIP como uma de suas estratégias formativas e, dessa forma, propõe intencionalmente atividades para o desenvolvimento de competências colaborativas.

Avaliar se e como os objetivos de aprendizagem foram alcançados gera informações sobre a aprendizagem interprofissional dos estudantes e sobre $o$ ensino proposto (que envolve corpo docente, equipe de apoio, infraestrutura, cenário/caso escolhido, entre outros) para o replanejamento do processo de ensino e aprendizagem. A avaliação da simulação realizada pelos participantes, facilitadores e toda equipe envolvida é fundamental para auxiliar na melhoria do processo de qualidade.

Importa também ressaltar que a avaliação não é uma atividade pontual que se dá ao final da expe- riência formativa. Na simulação, o debriefing é um momento privilegiado para a reflexão e revisão das práticas, visando mudar o comportamento dos estudantes. Porém, é possível aplicar um teste de verificação de conhecimentos prévios ou uma escala para checar a prontidão/disponibilidade dos estudantes para a EIP no momento do briefing. Ademais, realizar observação com preenchimento de checklist durante a ação da simulação é uma importante forma de avaliar o desempenho dos estudantes. Todas essas são possibilidades interessantes, desde que os estudantes tenham conhecimento prévio do método de avaliação ao qual serão submetidos na prática simulada.

Além de uma avaliação sistematizada com a utilização de instrumentos validados, encorajar a reflexão contribuiu para o aprendizado e para o caráter formativo da avaliação. Para os estudantes, algumas questões norteadoras sobre o momento do pré-briefing e briefing são:

o Eu estava preparado para esta simulação?

o Que bagagem (conhecimentos, habilidades, atitudes, expectativas, medos, anseios, dificuldades, preconceitos) eu trouxe para esta atividade?

o Eu me sentia confortável com a proposta de trabalhar com estudantes de outras profissões?

o Eu compreendi o problema e os passos da tarefa a ser realizada?

No que concerne à ação da simulação, os estudantes podem refletir:

o Eu consegui mobilizar recursos cognitivos, emocionais e psicomotores para solucionar a situação apresentada? 
o Como eu me senti atuando com estudantes de outras profissões?

o Quais foram as minhas dificuldades?

o O que eu aprendi que me torna um profissional mais colaborativo?

o Qual foi o meu desempenho geral?

o Qual foi o nosso desempenho geral?

Sobre o debriefing, algumas questões norteadoras são:

o Como eu me sinto em relação ao feedback que está sendo dado pelos docentes e pelos demais estudantes sobre minha atuação?

o Como posso utilizar o feedback para melhorar minha prática interprofissional?

Para a equipe que promoveu a simulação (docentes, facilitadores, monitores e apoio), as questões para a reflexão são:

o O cenário/caso proposto foi o mais adequado para o desenvolvimento da(s) competência(s) colaborativa(s) escolhida(s)? Por quê?

o Os objetivos de aprendizagem traçados foram alcançados? Em que nível?

o Como podemos melhorar a simulação para o alcance dos objetivos e o desenvolvimento de competências colaborativas?

Como já comentado, a avaliação do desempenho dos participantes deve estar vinculada aos objetivos de aprendizagem e à complexidade do cenário. Ela é realizada por meio de instrumentos válidos e confiáveis que permitam mensurar os resultados esperados (INACSL STANDARDS COMMITTEE, 2016; NOGUEIRA; DOMINGUES; BERGAMASCO, 2020) e também por instrumentos qualitativos que investiguem a aprendizagem interprofissional a partir da percepção dos participantes.

Neste segundo caso, portfólios, narrativas, entrevistas, grupos focais e questionários com perguntas abertas são instrumentos potentes, que permitem a compreensão da experiência vivenciada e consideram o ponto de vista dos estudantes, não apenas do avaliador.

Em se tratando de instrumentos quantitativos para avaliar a simulação, uma série de escalas pode ser encontrada na literatura científica, como: Escala de Satisfação e Autoconfiança no Aprendizado (ESAA), Escala de Satisfação com Experiências Clínicas Simuladas (ESECS), Simulation Effectiveness Tool - Modified (SET-M), Escala do Design da Simulação (EDS) e Escala de Ganhos Percebidos com a Simulação de Alta Fidelidade (EGPSA). A criação destas e de novas escalas acontece em consulta com especialistas, ou seja, estatísticos, pesquisadores e psicometris- tas (INACSL STANDARDS COMMITTEE, 2016; NOGUEIRA; DOMINGUES; BERGAMASCO, 2020). Questionários de avaliação do conhecimento adquirido pelos participantes antes e/ou depois da atividade simulada (pré e pós-teste) também são amplamente utilizados (NOGUEIRA; DOMINGUES; BERGAMASCO, 2020).

No que tange à simulação interprofissional, o número de instrumentos é menor, dada a especificidade dessa questão. No Brasil, uma série de instrumentos está sendo validada (originais e adaptados à realidade brasileira), e seu uso em diversas iniciativas de EIP, não apenas em simulação, tem sido crescente. Sua utilização em simulações interprofissionais produz dados sobre variados aspectos da interprofissionalidade, como colaboração, socialização e prontidão para a EIP. Desses instrumentos, importa citar:

o Escala de Prontidão para o Aprendizado Interprofissional (Readiness for Interprofessional Learning Scale - RIPLS).

o Escala de Avaliação de Colaboração em Equipe Interprofissional (Assessment of Interprofessional Team Collaboration Scale II - AITCS II).

o Escala de Socialização e Valorização Interprofissional (Interprofessional Socialisation and Valuing Scale - ISVS).

o Escala de Clima de Equipe (Team Climate Inventory - TCI).

o Escala de Percepção de Educação Interprofissional (Interprofessional Education Perception Scale - IESP).

o Escala Jefferson de Atitudes em Relação à Colaboração Interprofissional (Jefferson Scale of Attitudes Toward Interprofessional Collaboration).

o Escala de avaliação de atitudes de estudantes em relação à EIP na graduação em saúde.

O Exame Clínico Estruturado Observado (Objective Structured Clinical Examination - OSCE) é uma estratégia padrão para avaliar as competências clínicas em cursos de graduação em Medicina em todo o mundo. Dado o crescente interesse em iniciativas interprofissionais e de segurança do paciente, a Universidade McMaster e a Universidade de Ottawa estimularam entre seus educadores o desenvolvimento do Encontro Clínico Estruturado Observado em Equipe (Team Observed Structured Clinical Encounter - TOSCE) para a avaliação de competências colaborativas (MCMASTER UNIVERSITY, 2010).

O TOSCE, assim como outras variações oriundas do OSCE (Inter-Professional Team Objective Structured Clinical Examination - ITOSCE - e Group 
Structured Clinical Examination - GOSCE) encontra estreita relação com os fundamentos da EIP, por permitir a avaliação do trabalho interprofissional em situações de simulação (SYMONDS et al., 2003; GONTIJO; FREIRE FILHO; FORSTER, 2019; NAJARKOLAI et al., 2016). O TOSCE propõe um checklist para ser preenchido por um observador durante a simulação. Os participantes recebem pontuação de 1 (bem abaixo do esperado) a 9 (bem acima do esperado) para seis domínios de competências colaborativas: comunicação, colaboração, papéis e responsabilidades, atenção centrada no paciente/ família, gerenciamento de conflitos e funcionamento da equipe.

Percebe-se que a seleção de um instrumento já validado ou a elaboração de um novo instrumento específico para a simulação interprofissional proposta são duas possibilidades possíveis e desejáveis. A criação e a validação de novos instrumentos, além de resultar em instrumentos que cumprem bem o papel de avaliar simulação interprofissional, ampliam as possibilidades de uso.

\section{REFERÊNCIAS}

AGUIAR, A. C.; RIBEIRO, E. C. O. Conceito e avaliação de habilidades e competência na educação médica: percepções atuais de especialistas. Revista Brasileira de Educação Médica, Rio de Janeiro, v. 34, p. 371-378, 2010. AL-ELQ, A. H. Simulation-based medical teaching and learning. Journal of Family \& Community Medicine, Al-Khobar, v. 17, n. 1, p. 35-40, 2010.

ALINIER, G. Developing high-fidelity health care simulation scenarios: a guide for educators and professionals. Simulation \& Gaming, Newbury Park, v. 42, n. 1, p. 9-26, 2011.

BAILLIE, L.; CURZIO, J. Students' and facilitators' perceptions of simulation in practice learning. Nurse Education in Practice, Edinburgh, v. 9, n. 5, p. 297-306, 2009.

BARR, H. et al. Effective interprofessional education: Argument, assumption and evidence. Oxford: Blackwell, 2005.

BARR, H. et al. Interprofessional education: guidelines 2016. Centre for the advancement of interprofessional education. England: CAIPE, 2016.

BENNER, P. et al. Educating nurses: A call for radical transformation. San Francisco, CA: Jossey- Bass, 2010.

BERGAMASCO, E. C. et al. Estratégias de Simulação. In: CONSELHO REGIONAL DE ENFERMAGEM DO ESTADO DE SÃO PAULO. Manual de Simulação Clínica para Profissionais de Enfermagem. São Paulo, SP: COREN, 2020.

COSTA, M. V.; AZEVEDO, G. D.; VILAR, M. J. P. Aspectos institucionais para a adoção da Educação Interprofissional na formação em enfermagem e medicina. Saúde Debate, Rio de Janeiro, v. 43, n. Spe. 1, p. 64-76, 2019.

EPPICH, W.; CHENG, A. Promoting Excellence and Reflective Learning in Simulation (PEARLS): Development and rationale for a blended approach to health care simulation debriefing. Simulation in Healthcare, Washington, v. 10, n. 2, p. 106-115, 2015.
GABA, D. M. Simulators in anesthesiology. Advances in Anesthesia, Chicago, v. 14, p. 55-94, 1997.

GABA, D. M. The future vision of simulation in health care. Quality and Safety in Health Care, London, v. 13, Suppl. 1, p. i2-i10, 2004.

GIBBS, G. Learning by doing: A guide to teaching and learning methods. Oxford: Further Education Unit, 1988. GONTIJO, E. D.; FREIRE FILHO, J. R.; FORSTER, A. C. Educação interprofissional em saúde: abordagem na perspectiva de recomendações internacionais. Caminhos do Cuidado, Rio de Janeiro, v. 3, n. 2, p. 20-38, 2019.

IGLESIAS, A. G.; PAZIN-FILHO, A. Emprego de simulações no ensino e na avaliação. Revista de Medicina de Ribeirão Preto, Ribeirão Preto, v. 48, n. 3, p. 233$240,2015$.

INACSL STANDARDS COMMITTEE. INACSL standards of best practice: Simulation Design. Clinical Simulation in Nursing, New York, v. 12, p. S5-S12, 2016.

INSTITUTE OF MEDICINE. Crossing the quality chasm. Washington, DC: National Academies Press, 2001.

INTERPROFESSIONAL EDUCATION COLLABORATIVE EXPERT PANEL - IPECEP. Core competencies for interprofessional collaborative practice: report of an expert panel. Washington, D.C.: Interprofessional Education Collaborative, 2011.

JANTSCH, E. Inter- and transdisciplinary university: a systems approach to education and innovation. Policy Sciences, New York, v. 1, n. 4, p. 403-428, 1970.

JEFFRIES, P. A framework for designing, implementing, and evaluating simulations used as teaching strategies in nursing. Nursing Education Perspectives, Edinburgh, v. 26, p. 96-103, 2005.

KANEKO, R. M. U.; LOPES, M. H. B. M. Cenário em simulação realística em saúde: o que é relevante para a sua elaboração? Revista da Escola de Enfermagem da USP, São Paulo, v. 53, p. 1-8, 2019. 
LIE, D. A. et al. Interprofessional education and practice guide no. 5: Interprofessional teaching for prequalification students in clinical settings. Journal of Interprofessional Care, London, v. 30, n. 3, p. 324-330, 2016.

LIOCE, L., et al. Healthcare Simulation Dictionary. 2nd ed. Rockville: Agency for Healthcare Research and Quality, 2020.

MCCONAUGHEY, E. Crew resource management in healthcare: The evolution of teamwork training and MedTeams. Journal of Perinatal \& Neonatal Nursing, Frederick, v. 22, n. 2, p. 96-104, 2008.

MCMASTER UNIVERSITY. History of the Development and Use of the TOSCE Toolkit. McMaster University, 2010. Disponível em: <https://fhs.mcmaster.ca/tosce/ en/history_developed.html>. Acesso em: 18 mar. 2021.

MENEZES, P. D. D. T. R.; MOLINA, M. S. A.; DOS SANTOS, J. F. P. O papel do facilitador. In: CONSELHO REGIONAL DE ENFERMAGEM DO ESTADO DE SÃO PAULO. Manual de Simulação Clínica para Profissionais de Enfermagem. São Paulo, SP: COREN, 2020.

MONTANDON, D. S. et al. Elaboração e validação de cenário de simulação de comunicação de cancelamento do vínculo institucional para a enfermagem. Advances in Nursing and Health, Londrina, v. 2, p. 1-15, 2020.

NAJARKOLAI, A. R. et al. Inter-Professional Team Objective Structured Clinical Examination (ITOSCE): teaching and assessment strategies of the inter professional approach. Bali Medical Journal, Edmonton, v. 5, n. 3, p. 111-117, 2016.

NATIONAL LEAGUE FOR NURSING ACCREDITING COMMISSION. Accreditation Manual. Atlanta: NLNAC, 2012.

NEVES, F. F.; IGLESIAS, A. G.; PAZIN-FILHO, A. Construção de cenários simulados. In: NETO, A. S.; FONSECA, A. D. S.; BRANDÃO, C. F. S. Simulação realística e habilidades na saúde. Rio de Janeiro: Atheneu, 2017.

NIMMAGADDA, J.; MURPHY, J. I. Using Simulations to Enhance Interprofessional Competencies for Social Work and Nursing Students. Social Work Education: The International Journal, v. 33, n. 4, p. 539-548, 2014.

NOGUEIRA, L. D. S.; DOMINGUES, T. M. M. D.; BERGAMASCO, E. C. Construção do cenário simulado. In: CONSELHO REGIONAL DE ENFERMAGEM DO ESTADO DE SÃO PAULO. Manual de Simulação Clínica para Profissionais de Enfermagem. São Paulo, SP: COREN, 2020.

O'BRIEN, R. P.; MOULD, J. Interprofessional education. In: RILEY, R. H. (Ed.). Manual of simulation in healthcare. 2nd ed. New York: Oxford University Press, 2016. p. 141-150.

ORGANIZAÇÃO MUNDIAL DA SAÚDE. Marco para ação em educação interprofissional e prática colaborativa. Genebra: Departamento de Recursos Humanos para a Saúde, 2010.
PAIGE, J. T. et al. Using simulation in interprofessional education. The Surgical Clinics of North America, Philadelphia, v. 95, n. 4, p. 751-766, 2015.

PALAGANAS, J. C.; EPPS, C.; RAEMER, D. B. A history of simulation-enhanced interprofessional education. Journal of Interprofessional Care, London, v. 28, n. 2, p. 110-115, 2014.

PALAGNAS, J. Exploring healthcare simulation as a platform for interprofessional education. 2012. Doctoral Dissertation - Loma Linda University, Loma Linda, California, 2012.

PINAR, G. U. L. Simulation-enhanced interprofessional education in health care. Creative Education, Irvine, v. 6, p. 1852-1859, 2015.

REEVES, S. Why we need interprofessional education to improve the delivery of safe and effective care. Interface: Comunicacao, Saude, Educacao, Botucatu, v. 20, n. 56, p. 185-197, 2016.

REEVES, S.; GOLDMAN, J.; ZWARENSTEIN, M. An emerging framework for understanding the nature of interprofessional interventions. Journal of Interprofessional Care, Abingdon, v. 23, n. 5, p. 539-542, 2009.

SANTALUCIA, P. et al. SIMMED Simulation in Medicine, Italian Society for simulation in medicine position paper: executive summary. Internal and Emergency Medicine, Rome, v. 11, n. 4, p. 537-544, 2016.

SMITH, M. K. Student perceptions of socialsim for simulation-based interprofessional education in healthcare. 2016. Dissertation. Michigan State University, Michigan, Estados Unidos, 2016.

SWEZEY, R. W.; MELTZER, A. L.; SALAS, E. Some issues involved in motivating teams. In: O'NEIL, H. F.; DRILLINGS, M. (Ed.). Motivation: theory and research. Hillsdale: Lawrence Erlbaum Associates, 1994. p. 141-169.

SYMONDS, I. et al. Evaluation of a formative interprofessional team objective structured clinical examination (T-OSCE): A method of shared learning in maternity education. Medical Teacher, London, v. 25, n. 1, p. 38-41, 2003.

THISTLETHWAITE, J. E. et al. Competencies and frameworks in interprofessional education: a comparative analysis. Academic Medicine, Washington, v. 89, n. 6, p. 869-875, 2014.

TOASSI, R. F. C. Interprofissionalidade e formação na saúde: onde estamos? 1. ed. Porto Alegre: Rede Unida, 2017. TUN, J. K. et al. Redefining Simulation Fidelity for Healthcare Education. Simulation \& Gaming, Newbury Park, v. 46, n. 2, p. 159-174. 2015.

WILHAUS, J. et al. Interprofessional education and healthcare simulation symposium: A consensus report. SSH, Josiah Macy Jr. Foundaion, National League for Nursing, 2013. Disponível em: < http://www.nln.org/docs/ default-source/professional-development-programs/ white-paper-symposium-ipe-in-healthcare-simulation2013-(pdf).pdf?sfvrsn=0>. Acesso em: 18 mar. 2021. 
WORLD HEALTH ORGANIZATION. Framework for action on interprofessional education and collaborative practice. Geneva: WHO; 2010.
ZHANG, C.; THOMPSON, S.; MILLER, C. A review of simulation-based interprofessional education. Clinical Simulation in Nursing, New York, v. 7, p. el17-e126, 2011. 


\section{A utilização da simulação na Gestão do Fator Humano e Riscos Assistenciais na área da saúde}

(Crew Resource Management) 
Gerson Alves Pereira Júnior

Docente de Cirurgia de

Urgência e do Trauma

Universidade de São Paulo

Coordenador do Programa

ABEM de Simulação

\section{Alexandre Slullitel}

Médico anestesista

Mestrado em Ciências da Saúde

Universidade de São Paulo

\section{Haggeas da Silveira Fernandes}

Médico intensivista

Diretor de Práticas Médicas e Qualidade

Hospital Israelita Albert Einstein

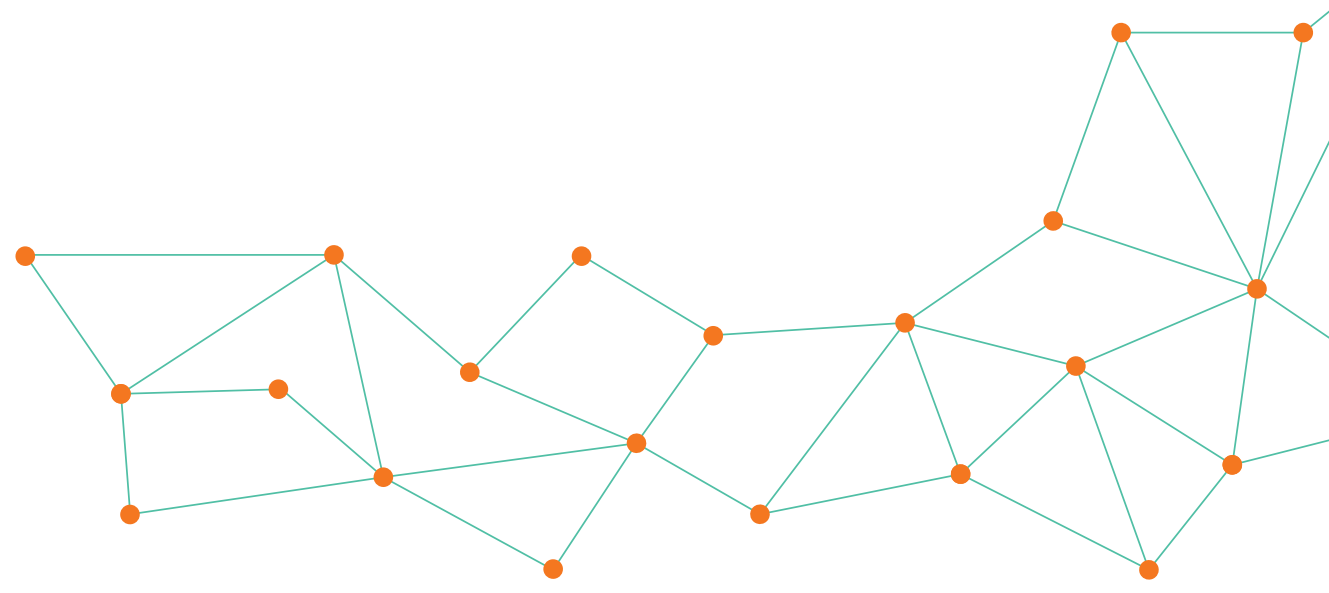

\section{INTRODUÇÃO}

"Nem toda situação pode ser prevista ou antecipada. Não existe checklist para tudo.”

\section{Chesley B. Sullenberger}

A Gestão do Fator Humano - atualmente conhecida como Crew Resource Management, Crisis Resource Management ou mesmo Corporate Resource Management (CRM) -, utilizada por organizações em locais onde eventos catastróficos podem ocorrer na ausência de medidas de controle, em razão da natureza de sua atividade de risco, envolve a preparação de profissionais de um time multidisciplinar na prevenção, mitigação e aprendizado com situações de risco e eventos adversos evitáveis. Apesar dessa variação na forma como é mencionada, a CRM, no geral, refere-se ao aperfeiçoa- mento das chamadas habilidades não técnicas, que promove, em conjunto, o desenvolvimento da cultura de segurança, da responsabilidade mútua e do trabalho em equipe, reduzindo o erro cognitivo produzido pelo fator humano e sua participação efetiva nas operações organizacionais (ROSENBAUM, 2019; NICKSON, 2020)

Em 1977, no aeroporto de Tenerife, um Boeing 747 da empresa holandesa KLM colidiu com outra aeronave do mesmo porte, da empresa americana PAN AM, durante o procedimento de decolagem, a despeito dos avisos da torre de comando, causando a morte de 583 pessoas, no que se tornou o maior acidente da história da aviação (ROSENBAUM, 2019). Essa catástrofe, associada a outros acidentes aéreos graves, levou o Conselho Nacional de Segurança de Transportes dos Estados Unidos a procurar solu- 
ções que tornassem o setor da aviação comercial e militar absolutamente seguro e à "prova de erros". O fato surpreendente foi a constatação de que o erro humano contribuiu para mais de $70 \%$ dos acidentes aéreos estudados (HELMREICH et al., 1999). As ações, a partir de então, passariam a ser não somente com foco em melhorias ergonômicas e tecnológicas, mas também em treinamentos com todos os recursos disponíveis (debriefings, discussões de casos e simulações) que conseguissem abordar o erro cognitivo e preparar o indivíduo para gerenciar riscos e crises no seu ambiente de trabalho.

Esse reconhecimento crítico levou ao desenvolvimento de programas de treinamento de "gerenciamento de recursos da tripulação", com base em simulação, que se concentraram nos comportamentos principais do trabalho em equipe, como liderança, comunicação, consciência situacional e utilização adequada dos recursos disponíveis. $\mathrm{O}$ treinamento de gerenciamento de recursos da tripulação tem sido um padrão global na aviação desde a década de 1990 e agora é um componente obrigatório do treinamento (HELMREICH; MERRITT; WILHELM, 1999).

O termo provém originalmente de Cockpit Resource Management (CRM), cunhado pela indústria de aviação para treinamento de pilotos, copilotos e engenheiros de voo, profissionais que estavam no comando das aeronaves à época.

Com a evolução dos conhecimentos, a segunda era do treinamento de fatores humanos evoluiu para o Crew Resource Management. Houve, nesse momento, o claro reconhecimento da importância de envolver profissionais que diretamente lidavam com a operação de um avião e que, consequentemente, poderiam envolver-se em falhas, lapsos e acidentes de diferentes origens. O objetivo passou a ser, nessa fase, reconhecer as equipes como disfuncionais e apoiá-las para a correção cognitiva, o desenvolvimento e a sustentação da cultura de segurança e colaboração (NICKSON, 2020).

Nas fases mais recentes, a aviação promoveu o treinamento de Corporate Resource Management, entendendo a importância do envolvimento de profissionais de áreas como manutenção, atendimento ao cliente, controle de voo.

A aviação é um exemplo clássico de Organizações de Alta Confiabilidade (HROs), as quais são definidas como aquelas que operam em ambientes com alta exposição a condições de risco, porém acabam por adaptar-se a mudanças não esperadas de cenários, conduzindo sua entrega final próxima à margem zero de erro e sem eventos catastróficos
(POWELL-DUNFORD et al., 2017). Para tal, sempre estão em busca de duas abordagens essenciais: - Prevenção (antecipação): envolve identificar riscos que podem levar a eventos não planejados, criando processos para evitá-los.

- Resiliência (contenção): refere-se à habilidade de manter ou recuperar um status de estabilidade na presença de estresse.

A história por trás da alta confiabilidade está na pesquisa conduzida na Universidade de Berkeley, Califórnia, por Laporte, Rochlin e Roberts, que examinaram semelhanças entre controle do tráfego aéreo, companhias comerciais de aviação e plantas nucleares. Os autores destacaram que a utilização adequada das habilidades não técnicas (soft skills) e a implementação de processos que apoiam o profissional em tarefas complexas, o que pode ser facilitado pela utilização de tecnologias ((POWELL-DUNFORD et al., 2017).

Os princípios e definições das HROs são (OSTER; BRAATEN; BARNSTEINER, 2016):

A- Preocupação com a falha: ação preemptiva e proativa na prevenção de acidentes. Caso ocorram, eles servirão como aprendizado para evitar futuros eventos. Os profissionais são treinados para reconhecer defeitos e anormalidades e agir, atuando com elevada segurança psicológica, ou seja, capacidade de expor suas preocupações a despeito da hierarquia e sem medo de ser criticado.

B- Relutância em simplificar interpretações: qualquer condição de risco é avaliada com o mesmo nível de intensidade, evitando a análise individual e estimulando a opinião em equipe.

C- Sensibilidade a operações: interações e compartilhamento de informações sobre fatores organizacionais e humanos que criam o "big picture", de forma que ajustes são feitos evitando o acúmulo de situações que podem levar ao erro.

D- Compromisso com a resiliência: fundamental para o desenvolvimento de cooperação, contenção e recuperação de falhas, lapsos e deslizes que ocorrem antes de um evento catastrófico, ou seja, há uma adaptação a condições não esperadas.

E- Deferência à expertise: princípio que escalona decisões, em momentos de crise ou sério problema, para pessoas que possuem expertise e experiência no problema em questão, independentemente da hierarquia ou representação de autoridade.

Erros humanos são inevitáveis e causados por complexos fatores. Aceitar esse fato é o passo fundamental para um efeito positivo no desenvolvimento 
da alta confiabilidade no setor de saúde. Porém, ignorar a inevitabilidade do erro humano significa manter a frustração de lidar sempre com eventos que causam danos aos pacientes e seus familiares.

A aplicação do conceito e ações operacionais em ambiente de saúde, principalmente nas áreas de alto risco (terapia intensiva, emergências, salas de trauma, centro cirúrgico, salas de parto), é absolutamente possível. É necessária, porém, a mudança de paradigmas que envolvem a busca pela Medicina baseada em valor, centrada no paciente, tornando a gestão da qualidade estratégica e prioritária, com investimentos financeiros e regulamentação adequada e envolvimento de todos os players, incluindo os médicos, naturais líderes pela busca da alta confiabilidade.

A segurança dos pacientes depende de alguns fatores que vão desde habilidades específicas de cada profissional que integra determinada equipe até a vigilância, a capacidade de percepção do cenário e o julgamento (tomada de decisão) desses mesmos integrantes de uma equipe multidisciplinar.

A saúde é um setor muito propenso a crises, o que é especialmente verdadeiro para especialidades de cuidados agudos, como anestesiologia e medicina de emergência, em que os profissionais devem tratar pacientes criticamente doentes, enfrentando ambiguidade diagnóstica, limitações de recursos e numerosas interrupções em ambientes de trabalho que podem se tornar caóticos (LEI; PALM, 2021).

A anestesiologia foi a primeira especialidade a incorporar princípios da CRM na formação de seus clínicos, desde o final da década de 1980, com a im- plementação do gerenciamento de recursos de crise de anestesia (ACRM), um curso com base em simulação que se concentrou em habilidades cruciais de trabalho em equipe, como a tomada de decisão dinâmica, a comunicação interpessoal e a liderança da equipe (HOWARD et al., 1992; GABA, 2010).

Para fornecer assistência médica segura e eficaz, os profissionais médicos devem executar estratégias altamente coordenadas à equipe. A gestão de recursos de equipe (CRM) é composta por um conjunto de princípios que lidam com comportamentos cognitivos e interpessoais, contribuindo para o desempenho ideal da equipe (CHENG et al., 2012).

O objetivo do treinamento de CRM é melhorar o desempenho e minimizar erros na realização de uma tarefa complexa envolvendo uma equipe profissional nos citados ambientes de risco.

O modelo de queijo suíço de causas de acidentes, apresentado na Figura 1, é utilizado na análise de gerenciamento de riscos em vários setores de atividade humana, incluindo segurança de aviação, engenharia, saúde e organizações de serviços de emergência. Como princípio de segurança em camadas, leva em conta múltiplas fatias de queijo suíço, empilhadas, lado a lado, em que o risco de uma ameaça vai se tornando uma realidade e superando as diferentes camadas e tipos de defesas. Portanto, em teoria, os lapsos e as fraquezas, uma vez desafiados por barreiras de defesa, não permitem que o risco se materialize em evento adverso, já que outras barreiras estão presentes evitando o ponto da falha (LAROUZEEA; COZEB, 2020).

A razão de erro é definida como "um ermo genérico para abranger todas as ocasiões em que uma

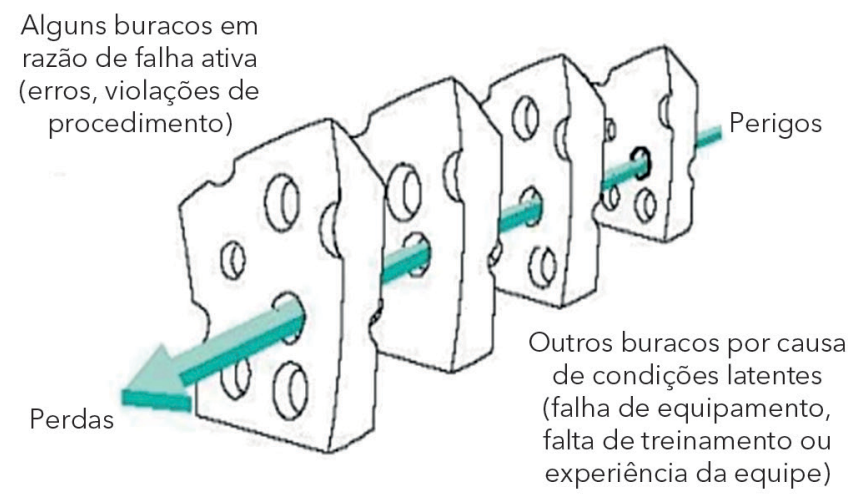

Sucessivas camadas de defesas, barreiras e proteções

Figura 1 - Teoria do queijo suíço. 
sequência planejada de atividades mentais ou físicas não atinge seu resultado pretendido". Essa sequência de "atos inseguros" e lapsos poderiam ocorrer durante ações em estado de automação (aqui definido como um estado em que o indivíduo realiza a tarefa sem o devido raciocínio ou capacidade de julgamento para possíveis falhas ou desvios da normalidade) (LAROUZEEA; COZEB, 2020).

Após o sucesso na aviação e na anestesiologia, os programas de treinamento de CRM com base em simulação foram logo desenvolvidos em outras especialidades médicas, incluindo medicina de emergência (PARSONS et al., 2018), medicina intensiva (BARRÉ; NEUSCHWANDER; TESNIÈRE, 2017) e neonatologia (KRISTEN et al., 2011). Atualmente, os cursos de CRM também foram incorporados em quase todas as especialidades médicas e cirúrgicas (OUNOUNOU et al., 2019), bem como em outras profissões de saúde, incluindo Enfermagem (COPPENS et al., 2018), Farmácia (TREMBLAY, 2018) e serviços médicos pré-hospitalares de emergência (GILLMAN et al., 2016). Vale frisar que esse treinamento oferece um valor de entrega maior e definitivo, quando os diferentes profissionais interagem, discutem sobre seu ambiente de trabalho e geram uma ajuda mútua na detecção de oportunidades, durante simulações e debriefings.

Portanto, pode-se definir CRM como um sistema de gerenciamento com utilização otimizada de recursos disponíveis, tais como recursos humanos, procedimentos operacionais e equipamentos, visando promover a segurança operacional em situações críticas. Esse conceito envolve a observação contínua do ambiente de trabalho em busca de aperfeiçoamentos e melhoria contínua, apoiado por treinamento por meio da simulação e por pessoas ou grupo de pessoas, na abordagem de situações de grande risco, como desastres, catástrofes e emergências. Tem como objetivo final o cumprimento de tarefas e respostas de forma eficaz e eficiente, priorizando o trabalho em equipe e enfocando as competências necessárias, tais como comunicação, coordenação e colaboração, para a prevenção de erros e a promoção de um ambiente seguro (NASCIMENTO; TRAVASSOS, 2010).

\section{FATORES DETERMINANTES PARA O DESEMPENHO DE TAREFAS COMPLEXAS}

Entre os fatores que podem afetar a realização de tarefas complexas, incluem-se aqueles relacionados à tarefa propriamente dita ao indivíduo, à equipe e ao ambiente ou cenário (NICKSON, 2020).

Em relação à tarefa, a complexidade dela, o risco inerente associado (doença com risco de vida, implicações médico-legais), a limitação de tempo para a execução dela e a falta de informação adequada são considerados fatores determinantes para sua realização. Quanto ao indivíduo, podem ocorrer privações individuais (fome, irritação, atraso, cansaço ou estresse), falta de sono, alterações do estado emocional, problemas pessoais de saúde ou sofrimento físico, inexperiência e falta de conhecimento técnico. Tais fatores podem interferir no desempenho da equipe, mas outros fatores também podem ocorrer, como treinamento insuficiente, confusão de funções/responsabilidades, falta de comunicação adequada e relacionamentos disfuncionais. Já no que se refere ao ambiente, podem ocorrer interrupções, ruídos, pressão produtiva, falha de equipamentos, falta de familiaridade com o ambiente ou equipamento e passagem de plantão (MAHANKALI; NAIR, 2019).

Existem semelhanças entre a área de saúde e outras indústrias, embora haja várias características que as distinguem. Apesar de tais diferenças, o aprendizado com processos de qualidade e segurança de outras áreas de conhecimento e atuação humana é marcante. A anestesia, em particular, tem sido a líder entre as especialidades médicas na adoção de práticas inovadoras de várias indústrias, em um esforço para melhorar a segurança do paciente e a qualidade do atendimento e reduzir o desperdício e a ineficiência (GABBA et al., 2015).

\section{PRINCÍPIOS BÁSICOS DA CRM}

Os princípios básicos da CRM são:

1. Conhecer o ambiente.

2. Antecipar e planejar.

3. Chamar ajuda precocemente.

4. Exercer liderança.

5. Distribuir tarefas.

6. Mobilizar recursos disponíveis.

7. Comunicar-se efetivamente.

8. Usar toda informação disponível.

9. Prevenir e gerir erros de fixação.

10. Realizar dupla verificação.

11. Usar auxílios cognitivos.

12. Reavaliar repetidamente.

13. Usar trabalho em equipe.

14. Alocar atenção de forma inteligente.

15. Definir prioridades de forma dinâmica. 
Para que tais tarefas sejam executadas de forma adequada, algumas categorias de habilidades não cognitivas (FLIN; MARAN, 2015), mencionadas na sequência, são identificadas como fundamentais. A Gestão de Riscos e Conformidades (GRC) é a coleção integrada de recursos que permite que uma organização alcance objetivos de maneira confiável, resolva as incertezas e aja com integridade. Visa identificar e desenvolver tais habilidades para obter o resultado esperado de acabamento da tarefa desejada.

\section{PRINCIPAIS CATEGORIAS DE HABILIDADES NÃO TÉCNICAS (HNTS)}

Existem princípios básicos para a execução de tarefas que são comuns à grande variedade de cenários críticos (FLIN; MARAN, 2015; KUUSKNE, 2017):

- comunicação;

- execução de tarefas;

- percepção situacional;

- tomada de decisão;

- liderança;

- trabalho em equipe;

- enfrentamento do estresse;

- gestão da fadiga.

As HNT, ou soft skills (habilidades interpessoais, em tradução livre do inglês) (BERSIN, 2019), tornaram-se cada vez mais importantes em ambientes profissionais onde novas tecnologias, proporcionadas pela Quarta Revolução Industrial, irão substituir atividades laborais rotineiras ou repetitivas (WORLD ECONOMIC FORUM, 2016), e de forma significativa na área da saúde. Em um prazo de aproximadamente cinco anos, cerca de um terço das habilidades que são consideradas importantes para a força de trabalho atual deverá ter mudado.

Em 2017, uma publicação da Royal College of Physicians and Surgeons of Canada fez uma excelente estruturação da gestão para melhorar a segurança do paciente e o desempenho da equipe (BRINDLEY; CARDINAL, 2017).

Os mecanismos básicos e os processos que geram recorrentes formas de uma gama ou tipos de erros são descritos por um autor sob a forma do sistema de modelos gerais de erros (generic error-modelling system - GEMS), apresentado no Quadro 1, que tem como objetivo precípuo delimitar as origens dos tipos básicos de erro humano (REASON, 2003).
Com a mudança para a educação baseada em competências, o uso da simulação tem desempenhado um papel importante na avaliação das competências dos estudantes. As avaliações com base em simulação permitem avaliar diretamente o conhecimento individual, habilidades técnicas, raciocínio clínico e trabalho em equipe. Dessa forma, toda a estruturação para a adequada construção e avaliação dos cenários simulados pode ser utilizada para as situações de CRM.

Dessa forma, a CRM é importante porque (DOWHOS; ALIFERIS; CHIN, 2015):

- Otimiza o desempenho da equipe em ambientes de rápidas respostas.

- Reduz o erro médico.

- Melhora a segurança do paciente.

Os três princípios-chave da CRM são (DOWHOS;

ALIFERIS; CHIN, 2015):

- Comunicação de circuito fechado:

- O transmissor envia mensagem.

- O destinatário confirma o recebimento.

- O receptor confirma que a tarefa foi concluída, fazendo seu fechamento.

- Clareza do papel:

- Cada membro da equipe tem uma função explicitamente delegada pelo líder da equipe.

- As funções são diferentes com cada cenário clínico. Uma dica importante é atribuir uma única tarefa por vez para cada membro da equipe.

- Consciência situacional:

- Esteja ciente das mudanças na condição do paciente.

- Compartilhe seu modelo mental.

- Reúna o feedback de sua equipe.

6. CHECKLISTS X ESCALAS GLOBAIS DE AVALIAÇÃO (EGA)

Os exercícios simulados constituem a espinha dorsal da CRM e devem abranger as habilidades cognitivas e as HNTs que serão avaliadas em seus vários quesitos. Alguns instrumentos de avaliação podem ser utilizados, tais como escalas globais de avaliação (KUUSKNE, 2017) e checklists, como o exemplificado na Tabela 1.

A EGA é uma ferramenta que permite que os avaliadores julguem o desempenho geral dos participantes ou forneçam uma impressão geral do de- 
sempenho em subtarefas específicas. Os checklists, ou listas de verificação, representam listas de ações ou itens específicos a serem executados pelo aprendiz e solicitam que os avaliadores atestem ações diretamente observáveis.

A priori, um bom instrumento de avaliação deve idealmente (KUUSKNE, 2017):

- Possuir alta confiabilidade entre avaliadores.
- Ter alta validade de construção.

- Ser viável para aplicação.

- Ser capaz de discriminar diferentes níveis de aprendizagem.

A Tabela 2 elenca as principais diferenças entre ambos os métodos de avaliação.

Algumas das limitações das EGAs estão relacionadas à subjetividade, pois também dependem da

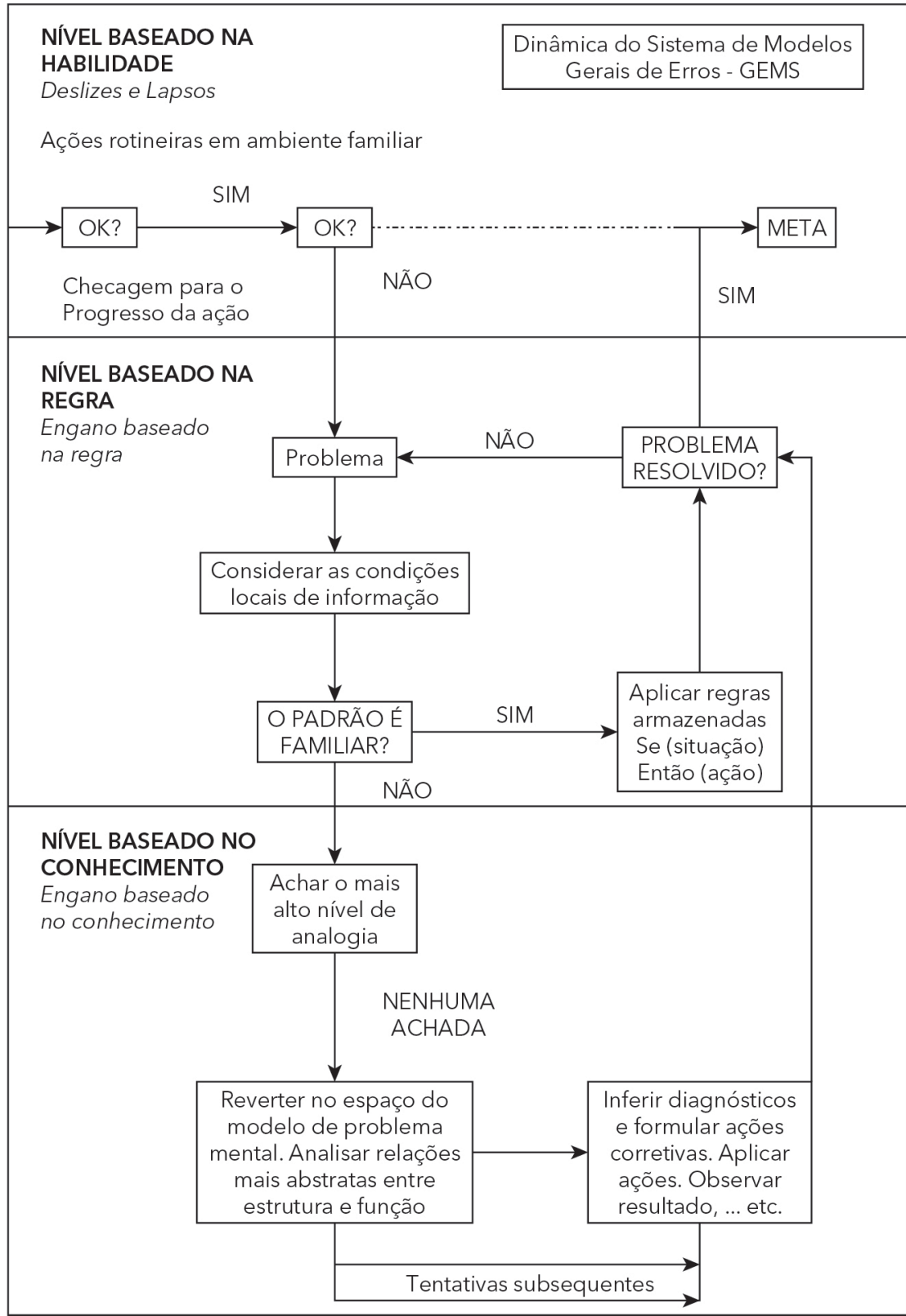

Quadro 1 - Dinâmica de modelos gerais de erros. Fonte: Nascimento, 2010 
Tabela 1 - Checklist para avaliação de liderança.

\begin{tabular}{|l|l|l|}
\hline \multicolumn{2}{|c|}{ Checklist - Liderança (exemplo) } \\
\hline Parâmetros e indicadores de liderança & Sim/Não (+ ou -) & Observações \\
\hline $\begin{array}{l}\text { Havia um líder de equipe nitidamente } \\
\text { reconhecido. }\end{array}$ & & \\
\hline $\begin{array}{l}\text { O líder da equipe sabia a missão da sua } \\
\text { equipe. }\end{array}$ & & \\
\hline $\begin{array}{l}\text { O líder de equipe demonstrou percepção } \\
\text { situacional. }\end{array}$ & & \\
\hline $\begin{array}{l}\text { O líder da equipe demonstrou habilidades } \\
\text { na solução de problemas e na tomada de } \\
\text { decisão. }\end{array}$ & & \\
\hline $\begin{array}{l}\text { O líder de equipe demonstrou habilidades de } \\
\text { planejamento para a resposta (inclusive de } \\
\text { planos de contingência). }\end{array}$ & & \\
\hline
\end{tabular}

Tabela 2 - Prós e contras das escalas globais de avaliação e checklists (KUUSKNE, 2017).

\begin{tabular}{|c|c|c|}
\hline & Prós & Contras \\
\hline \multirow{3}{*}{$\begin{array}{l}\text { Escalas globais } \\
\text { de avaliação }\end{array}$} & Maior confiabilidade interna. & Menor precisão. \\
\hline & $\begin{array}{l}\text { Maior sensibilidade ao definir o nível de } \\
\text { treinamento. }\end{array}$ & $\begin{array}{l}\text { Subjetividades de julgamento e tomada } \\
\text { de decisão pelo avaliador. }\end{array}$ \\
\hline & $\begin{array}{l}\text { Maior confiabilidade entre estação e } \\
\text { generalidade. }\end{array}$ & $\begin{array}{l}\text { Necessidade de peritos ou avaliadores } \\
\text { mais treinados para avaliar os } \\
\text { aprendizes. }\end{array}$ \\
\hline \multirow{4}{*}{ Checklists } & $\begin{array}{l}\text { Melhor adequação a medidas de etapas ou } \\
\text { componentes específicos do desempenho. }\end{array}$ & Menor confiabilidade. \\
\hline & Maior objetividade. & $\begin{array}{l}\text { Dicotomização da avaliação, com perda } \\
\text { eventual de informação. }\end{array}$ \\
\hline & Maior facilidade de execução. & \\
\hline & $\begin{array}{l}\text { Maior facilidade para identificar ações } \\
\text { para o feedback do aprendiz. }\end{array}$ & \\
\hline
\end{tabular}

opinião de "especialistas" para poder classificar os alunos de maneira eficaz e confiável. Os checklists, por outro lado, são considerados menos subjetivos e, quando bem elaborados, são fáceis de aplicar; assim, qualquer avaliador pode usá-los (e não depender de especialistas para administrar a ferramenta). Ao medir comportamentos definidos e específicos, os checklists podem ajudar a orientar o feedback para os aprendizes (KUUSKNE, 2017).

Uma ferramenta de avaliação ideal para avaliar a simulação seria confiável, válida, abrangente e permitiria a discriminação entre as habilidades dos es- tudantes. Cada um dos instrumentos apresentados - a escala de classificação global e as listas de verificação (checklists) - tem suas próprias vantagens e armadilhas e pode ser usado para a avaliação de medidas de resultado específicas. Estudos sugerem que a EGA tem algumas vantagens importantes sobre as listas de verificação, embora a evidência para estas pareça ligeiramente melhor do que no passado. Ainda assim, seja qual for a ferramenta escolhida, é fundamental projetá-la e testá-la para garantir que avalie adequadamente o resultado desejado. Se possível, o uso de uma lista de verificação e escala de avaliação 
global ajudaria a otimizar a eficácia da educação baseada em simulação (KUUSKNE, 2017).

Uma avaliação comparativa de desempenho de habilidades técnicas também pode ser verificada empregando-se um ou outro padrão de avaliação, como pode ser visto na Tabela 3.
Uma prática de CRM consta da avaliação de competências na prova do título de especialista em anestesiologia em Israel desde 2003. Neste contexto, uma das cinco estações simuladas ao qual o aprendiz (médico-residente) é submetido é sobre esse assunto (BERKENSTADT et al., 2006).

Tabela 3 - Checklist e avaliação global de intubação sequencial rápida (habilidades técnicas) em um exame clínico objetivo estruturado (Hall et al. 2012).

\begin{tabular}{|c|c|c|c|c|}
\hline & Não executado & Executado & Bem executado & $\begin{array}{l}\text { Impossível de } \\
\text { verificar }\end{array}$ \\
\hline \multicolumn{5}{|l|}{$\begin{array}{l}\text { Pré-oxigenação } 100 \% \text { de } \\
\mathrm{O}_{2} \text { c/ BMV }\end{array}$} \\
\hline $\begin{array}{l}\text { Posicionamento } \\
\text { otimizado (supina, } \\
\text { cabeceira, altura do } \\
\text { leito, suporte de cabeça } \\
\text { - } 4 \text { itens) }\end{array}$ & & $\operatorname{Min} 1 / 4$ & $\operatorname{Min} 3 / 4$ & \\
\hline $\begin{array}{l}\text { Agente de indução } \\
\text {-opção }\end{array}$ & & Cetamina & $\begin{array}{l}\text { Etomidato/ } \\
\text { propofol }\end{array}$ & \\
\hline \multicolumn{5}{|l|}{$\begin{array}{l}\text { Agente de indução - } \\
\text { dose cetamina } 1-2 \mathrm{mg} / \\
\mathrm{kg} \text {; etomidato } 0,3 \mathrm{mg} / \mathrm{kg} \text {; } \\
\text { propofol } 1-2 \mathrm{mg} / \mathrm{kg}\end{array}$} \\
\hline $\begin{array}{l}\text { Bloqueador } \\
\text { neuromuscular - opção }\end{array}$ & & $\begin{array}{l}\text { Succinilcolina/ } \\
\text { rocurônio }\end{array}$ & & \\
\hline \multicolumn{5}{|l|}{$\begin{array}{l}\text { Bloqueador } \\
\text { neuromuscular - } \\
\text { dose SCC 1-2 mg/kg; } \\
\text { rocurônio } 1,2 \mathrm{mg} / \mathrm{kg}\end{array}$} \\
\hline \multicolumn{5}{|l|}{$\begin{array}{l}\text { Laringoscopia - } \\
\text { intervalo de tempo }\end{array}$} \\
\hline \multicolumn{5}{|l|}{$\begin{array}{l}\text { Laringoscopia } \\
\text { - segurança }\end{array}$} \\
\hline \multicolumn{5}{|l|}{$\begin{array}{l}\text { Intubação de forma } \\
\text { segura }\end{array}$} \\
\hline \multicolumn{5}{|l|}{$\begin{array}{l}\text { Confirmação com } \\
\mathrm{ETCO}_{2}\end{array}$} \\
\hline \multicolumn{5}{|l|}{$\begin{array}{l}\text { Confirmação com } \\
\text { ausculta }\end{array}$} \\
\hline \multicolumn{5}{|l|}{$\begin{array}{l}\text { Solicitação de Rx de } \\
\text { tórax }\end{array}$} \\
\hline \multicolumn{5}{|l|}{$\begin{array}{l}\text { Sedação pós-intubação } \\
\text { (+/- BNM) }\end{array}$} \\
\hline Sonda nasogástrica & & & & \\
\hline
\end{tabular}


Tabela 3 - Continuação...

\begin{tabular}{|c|c|c|c|c|}
\hline & Não executado & Executado & Bem executado & $\begin{array}{c}\text { Impossível de } \\
\text { verificar }\end{array}$ \\
\hline PONTUAÇÃO TOTAL & & & & \\
\hline \multicolumn{5}{|c|}{ AVALIAÇÃO GLOBAL } \\
\hline 1 & 2 & 3 & 4 & 5 \\
\hline FALHA & MARGINAL & SATISFATÓRIO & $\begin{array}{c}\text { ACIMA DA } \\
\text { MÉDIA }\end{array}$ & EXELENTE \\
\hline
\end{tabular}

\section{CONSIDERAÇÕES FINAIS}

Fazer a coisa certa no momento certo requer proficiência dinâmica na tomada de decisões, liderança, comunicação e gerenciamento de equipe. Várias tarefas devem ser priorizadas e coordenadas para manter a segurança do paciente até que informações suficientes se tornem disponíveis para definir o diagnóstico adequado e realizar a terapêutica apropriada.

As equipes de saúde também devem entender que suas ações ou a falta delas carregam consequ- ências potencialmente desastrosas. Durante situações de crise, os recursos perceptivos e cognitivos de cada membro da equipe são mais propensos a se tornarem sobrecarregados, especialmente quando as situações são desconhecidas ou os recursos são inadequados.

Dessa forma, a antecipação das situações de risco, que podem ocorrer na operação de rotina na área da saúde, é essencial e tem na gestão de fatores humanos e no treinamento com simulação excelente estratégia para apoiar as organizações na busca pela alta confiabilidade.

\section{REFERÊNCIAS}

BARRÉ, J.; NEUSCHWANDER, A.; TESNIÈRE, A. Benefits of CRM education and simulation in intensive care and emergency medicine. ICU Management \& Practice, v. 17, n. 4, p. 230-232, 2017.

BERKENSTADT, H. et al. Incorporating simulationbased objective structured clinical examination into the Israeli National Board Examination in Anesthesiology. Anesthesia and Analgesia, v. 102, p. 853-858, 2006.

BERSIN, J. LinkedIn 2019 Talent Trends: Soft Skills, Transparency and Trust. 2019. Disponível em: <https:// www.linkedin.com/pulse/l inkedin-2019-talent-trendssoft-skills-transparency-trust-bersin/>. Acesso em: 22 mar. 2021.

BRINDLEY, P. G.; CARDINAL, P. Optimizing crisis resource management to improve patient safety and team performance. Royal College of Physicians and Surgeons of Canada, 2017. Disponível em: $<$ https://www. royalcollege.ca/rcsite/documents/practice-performanceinnovation/optimizing-crisis-resource-managementimprove-patient-safety-team-performance-e.pdf $>$. Acesso em: 22 mar. 2021.

CHENG, A. et al. Simulation-based crisis resource management training for pediatric critical care medicine: a review for instructors. Pediatric Critical Care Medicine, v. 13, n. 2, p. 197-203, 2012.

COPPENS, I. et al. The effectiveness of crisis resource management and team debriefing in resuscitation education of nursing students: A randomised controlled trial. Journal of Clinical Nursing, v. 27, n. 1-2, p. 77-85, 2018.

DOWHOS, K.; ALIFERIS, A.; CHIN, A. Crisis Resource Management (CRM) in medical simulation, 2015. Disponível em: <https://canadiem.org/wp-content/ uploads/2021/01/CRM-in-Medical-Simulation-Dec-30-1. pdf $>$. Acesso em: 22 mar. 2021.

FLIN, R.; MARAN, N. Basic concepts for crew resource management and non-technical skills. Best Practice \& Research. Clinical Anaesthesiology, v. 29, p. 27-39, 2015.

GABA, D. M. Crisis resource management and teamwork training in anaesthesia. British Journal of Anaesthesia, v. 105, n. 1, p. 3-6, 2010.

GABBA, D. M. et al. Crisis Management in Anesthesiology. In: GABBA, D. M. et al. Principles of anesthesia crisis resource management. 2nd Ed., Philadelphia: ElsevierSaunders, 2015. pp. 25-53. 
GILLMAN, L. M. et al. S.T.A.R.T.T. Plus: addition of prehospital personnel to a national multidisciplinary crisis resource management trauma team training course. Canadian Journal of Surgery, v. 59, n. 1, p. 9-11, 2016.

HALL, A. K.; PICKETT, W.; DAGNONE, J. D. Development and evaluation of a simulation-based resuscitation scenario assessment tool for emergency medicine residents. Canadian Journal of Emergency Medical Care, v. 14, p. 139-146, 2012.

HELMREICH, R. L.; MERRITT, A. C.; WILHELM, J. A. The evolution of Crew Resource Management training in commercial aviation. The International Journal of Aviation Psychology, v. 9, n. 1, p. 19-32, 1999.

HOWARD, S. K. et al. Anesthesia crisis resource management training: teaching anesthesiologists to handle critical incidents. Aviation, Space, and Environmental Medicine, v. 63, n. 9, p. 763-770, 1992.

KRISTEN, E. et al. Development of a neonatal intensive care multidisciplinary crisis resource training program. Newborn and Infant Nursing Reviews; NAINR, v. 11, n. 1, p. 17-22, 2011.

KUUSKNE, M. Simulation-Based Assessment. 2017. Disponível em: <https://emsimcases.com/2017/11/28/ simulation-based-assessment/> Acesso em: 22 mar. 2021.

LAROUZEEA, J.; COZEB, J. C. Good and bad reasons: The Swiss cheese model and its critics. Safety Science, v. 126, p. 11, 2020.

LEI, C.; PALM, K. Crisis Resource Management Training in Medical Simulation. In: StatPearls. Treasure Island (FL): StatPearls Publishing, 2021.

MAHANKALI, S. S.; NAIR, P. Beyond the borders: Lessons from various industries adopted in anesthesiology. Journal of Anaesthesiology, Clinical Pharmacology, v. 35, p. 295-301, 2019.
NASCIMENTO, N. B.; TRAVASSOS, C. M. R. O erro médico e a violação às normas e prescrições em saúde: uma discussão teórica na área de segurança do paciente. Physis, Rio de Janeiro, v. 20, n. 2, p. 625-651, 2010. [online]. NICKSON, C. Crisis Resource Management. 2020. Disponível em: <https://litfl.com/crisis-resourcemanagement-crm/>. Acesso em: 22 mar. 2021.

OSTER, C.; BRAATEN, J.; BARNSTEINER, J. High reliability organizations. In: LATNEY, C. R. The need for a paradigma shift in healthcare culture: old versus new, 1st ed., Indianapolis, IN: Sigma Theta Tau, 2016. p. 3-24. OUNOUNOU, E. et al. Nontechnical Skills in Surgery: A systematic review of current training modalities. Journal of Surgical Education, v. 76, n. 1, p. 14-24, 2019.

PARSONS, J. R. et al. Filling the Gap: Simulation-based crisis resource management training for emergency medicine residents. The Western Journal of Emergency Medicine, v. 19, n. 1, p. 205-210, 2018.

POWELL-DUNFORD, N. et al. Transferring Aviation Practices into Clinical Medicine for the Promotion of High Reliability. Aerospace Medicine and Human Performance, v. 88, p. 487-491, 2017.

REASON, J. Human error. London: Cambridge University Press, 2003. 302 p.

ROSENBAUM, L. Divide we fall. The New England Journal of Medicine, v. 380, p. 684-688, 2019.

TREMBLAY, M. L. Simulation-based crisis resource management in pharmacy education. American Journal of Pharmaceutical Education, v. 82, n. 6, p. 6531, 2018. WORLD ECONOMIC FORUM. Global Challenge Insight Report. The Future of Jobs Employment, Skills and Workforce Strategy for the Fourth Industrial Revolution. 2016. Disponível em: <https://www.weforum.org/reports/ the-future-of-jobs> Acesso em: 22 mar. 2021. 
CAPÍTULO 11

\section{Estruturação do ensino, treinamento e avaliação de habilidades}




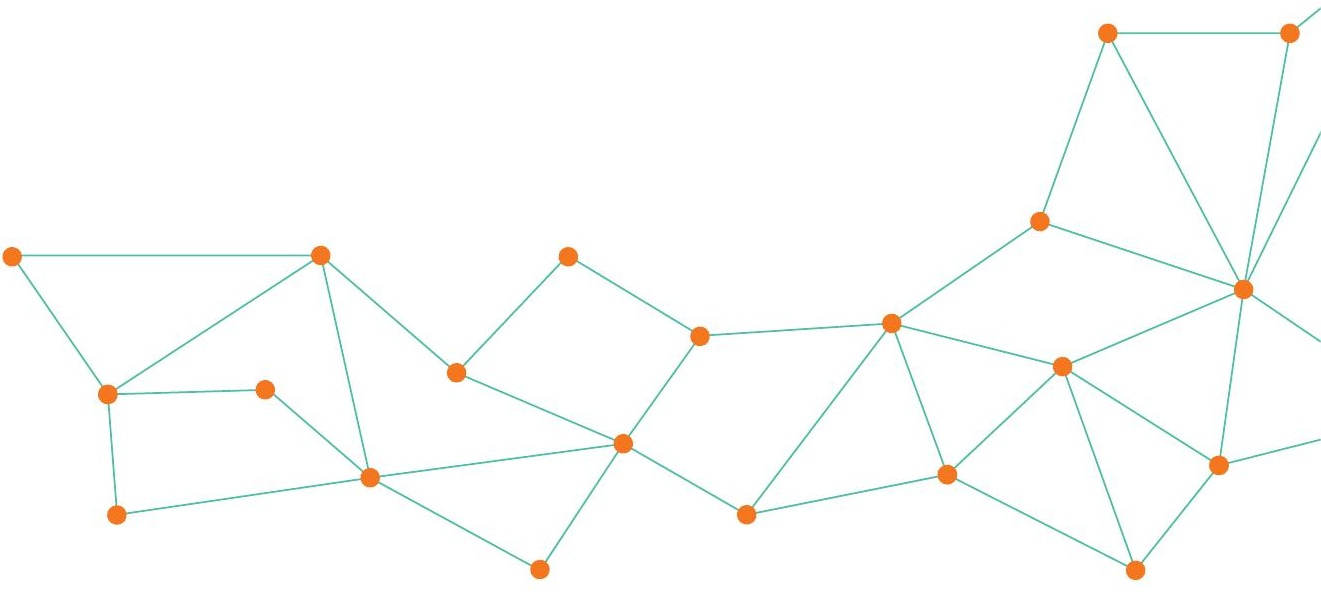

A atual geração de estudantes apresenta necessidades de aprendizagem associadas à tecnologia e está prontamente preparada para se adaptar aos avanços vistos desde a virada do século, esperando que métodos ativos de ensino substituam os tradicionais. Consequentemente, é necessário haver estratégias de ensino e aprendizagem para melhorar o conhecimento, a compreensão, a competência e as habilidades exigidas pelos estudantes (DALEY; CAMPBELL, 2013).

A aquisição de habilidades clínicas psicomotoras é parte integrante de qualquer curso de formação profissional em saúde; assim, o ensino deve capacitar os aprendizes para que aprimorem suas habilidades, resolvam problemas, desenvolvam suas abordagens reflexivas e de pensamento crítico, aumentem a competência e autonomia para atuarem profissionalmente (BERRAGAN, 2011; MOULE, 2011, SUNDLER; PETTERSSON; BERGLUND, 2015; RYAN; DECI, 2000).
No entanto, não é incomum que os estudantes das diferentes áreas da saúde cheguem ao final da graduação sem nunca terem realizado algumas habilidades psicomotoras consideradas básicas em um paciente no ambiente clínico, principalmente em pacientes pediátricos e de cuidados intensivos (LEIGHTON, 2013). Dessa forma, as habilidades psicomotoras que são praticadas na prática clínica ficam comprometidas, o que reforça e justifica o uso da prática simulada nas últimas décadas (FOTHERINGHAM, 2010; SAEYER et al., 2015).

Atualmente, a simulação é amplamente usada e estabelecida para motivar a aprendizagem dos estudantes, fornecendo inúmeras oportunidades para o desenvolvimento de suas habilidades clínicas (BERRAGAN, 2011; MOULE, 2011; SUNDLER; PETTERSSON; BERGLUND, 2015; RYAN; DECI, 2000).

É necessário entender que as habilidades cognitivas estão diretamente associadas à aquisição de 
habilidades psicomotoras em diferentes contextos. Assim, ao desenvolver uma intervenção técnica, o estudante deverá apresentar não apenas conhecimento e competência na execução das etapas do componente, mas uma compreensão profunda da teoria subjacente, a fim de que ocorra uma adaptação da habilidade para se adequar ao contexto da assistência (ROURKE, 2020; FOTHERINGHAM, 2010; SAEYER et al., 2015).

O ensino por meio de simulação é visto como uma forma de minimizar a lacuna existente entre cognitivo e psicomotor (JOSEPHINE SCULLY, 2011; MONAGHAN, 2015) e pode evitar as experiências potencialmente desastrosas de erros cometidos durante a assistência direta a um paciente da vida real (LEWIS et al., 2012).

A frase "A educação fornece conhecimento, mas só a prática gera competência" (POIKELA; POKEILA, 2012) traz a reflexão de que a repetição da prática aprimora a capacidade profissional mais rapidamente.

O ensino de habilidades por meio da simulação normalmente ocorre em laboratórios de habilidades, usando task trainer para o resgate de procedimentos hands on com uso de manequins, práticas deliberadas de ciclo rápido (PDCR), simulação baseada em computadores por aplicativos de softwares e serious games (jogos sérios) como um complemento ou substituição para o treinamento presencial, telessimulação, uso de atores humanos (pacientes simulados) para replicar cenários clínicos ou tarefas procedimentais para o treino das habilidades não técnicas (WELLER et al., 2012; WANG et al., 2016; DONOVAN et al., 2018).

Treinar habilidades faz parte do processo que proporciona o desenvolvimento do aprendiz até se tornar expert. O task trainer é um simulador projetado para treinar os elementos-chave do procedimento ou habilidade a ser aprendida, representando uma parte ou região do corpo humano, como um braço, um tórax, uma pelve, entre outras. Pode apresentar interfaces mecânicas ou eletrônicas para ensinar e fornecer feedback sobre as habilidades manuais, como inserção intravenosa, reanimação cardiopulmonar, varredura de ultrassom, sutura etc. Esses simuladores normalmente são utilizados para desenvolvimento de habilidades procedimentais, mas podem ser usados em conjunto com outras tecnologias de aprendizagem para criar situações clínicas integradas (LOPREIATO, 2016).

Outra estratégia de simulação para treinar habilidades é o uso da PDCR, cujo objetivo é melhorar a performance dos participantes para que alcancem a maestria em uma habilidade. É organizada para promover repetição de tarefas e proporcionar feedback imediato com base em evidências, por intermédio de um facilitador (HUNT et al., 2014).

$\mathrm{O}$ uso de pacientes simulados é reconhecido como uma alternativa para o estudante desenvolver habilidades clínicas, possibilitando até mesmo a participação do paciente com feedback formativo e podendo ser aplicado na avaliação da aquisição de habilidades clínicas (SUNDLER; PETTERSSON; BERGLUND, 2015).

A realidade virtual para o ensino e a capacitação de recursos humanos em saúde se caracteriza como emergente, porém essa metodologia tem se consagrado como uma ferramenta de apoio em atividades didáticas, destacando-se no desenvolvimento de habilidades motoras e de senso crítico, tomada de decisão e raciocínio clínico, permitindo a repetição do treino e o julgamento crítico para fundamentar a destreza manual no paciente real (SANTOS et al., 2017).

Para Santos et al. (2017), em revisão integrativa, na maior parte dos estudos de desenvolvimento de habilidades motoras foi utilizado o conceito de haptic, termo relacionado à resposta que o usuário tem ao tocar uma superfície interativa, permitindo ofeedback imediato e a avaliação de tutores e aprendizes.

Estudos revelam que o uso de treinamento de habilidades invasivas, como punções, intervenções clínicas e cirúrgicas na formação médica (VAUGHAN et al., 2016), na enfermagem e em conceitos gerais na educação de saúde (HAMMER; SOUERS, 2004; ULRICH; MANCINI, 2013), tem se tornado rotina (KHAN et al., 2018; SAMADBEIK et al., 2018).

$\mathrm{O}$ fornecimento de experiências educacionais para alunos em locais externos pode ser realizado com recursos de telecomunicações e simulação, pois os modelos teóricos que servem de base para o treinamento eficaz de simulação não exige que o aluno e o instrutor estejam fisicamente no mesmo local. A telessimulação permite que os benefícios da simulação se estendam além das paredes de um centro de simulação, sendo particularmente útil onde: há limitações de distância que impedem a instrução eficaz/eficiente; ocorrem restrições de tempo que tornam impraticável a viagem para o aluno ou o local do instrutor; ou faltam educadores disponíveis com conhecimento de conteúdo específico. Ela fornece valores no campo educacional nas áreas da aprendizagem dos domínios psicomotor, cognitivo (pensamento) e afetivo (sentimento) (MCCOY et al., 2017).

O processo de avaliação de habilidades envolve fazer um julgamento, incluindo pontos fortes e fra- 
cos apresentados pelo estudante. A avaliação mede a qualidade e a produtividade em relação a um padrão de desempenho (BOURKE; IHRKE, 2016; LOPRIEATO, 2016). Do ponto de vista da avaliação das habilidades psicomotoras, a definição do procedimento operacional padrão (POP) das várias intervenções práticas (sondagens gástrica e vesical, curativos etc.), mostrando a sequência de passos corretos para sua execução, deve compor os instrumentos pré-elaborados (checklists) de aferição dos desempenhos dos aprendizes.

A avaliação de habilidades pode envolver uma avaliação formativa, em que o foco do facilitador está no progresso do participante em direção ao alcance da meta por meio de critérios predefinidos. Ela pode ser direcionada apenas a um indivíduo ou a um grupo, com o propósito de fornecer feedback construtivo (NATIONAL LEAGUE FOR NURSING, 2013; LOPRIEATO, 2016).

A avaliação de habilidades também pode estar associada à avaliação somativa, e, ao final de um período de aprendizagem ou em um momento discreto, os participantes recebem feedback sobre a obtenção do resultado por meio de critérios predefinidos. É caracterizada como um processo para determinar a competência técnica de um participante engajado na atividade de saúde, podendo estar associada a uma nota atribuída (LOPRIEATO, 2016).

Os estudantes em saúde devem aprender e ser avaliados quanto a habilidades psicomotoras não apenas no início, mas também durante todo o seu percurso da graduação. Uma vez que a competência é avaliada no laboratório de habilidades, o estudante, normalmente no campo de prática, recebe a permissão para executar essas habilidades sob supervisão direta do docente, até que este o considere seguro executá-las por conta própria (LEIGHTON, 2013).

Uma maneira de conduzir a avaliação de habilidades é por meio do Objective Structured Clinical Examination (OSCE), que se caracteriza como uma abordagem para a avaliação da competência clínica ou profissional, em que os componentes de competência são avaliados de forma planejada e estruturada, com atenção sendo dada à objetividade do exame (HARDEN, 1988). Trata-se de um método de avaliação em que os estudantes, em um ambiente simulado de trabalho, realizam habilidades e comportamentos específicos, que podem ser desenvolvidos por meio de uma ou diversas séries de estações clínicas projetadas para avaliar a competência de desempenho em habilidades clínicas individuais ou outras habilidades profissionais (LOPRIEATO, 2016).
Os estudantes são avaliados por meio de observação direta, checklists ou exercícios de acompanhamento por escrito, de caráter formativo com feedback ou somativo.

Os checklists são elaborados para gerar feedback aos estudantes após a realização de um procedimento simulado. Embora sejam conhecidos como ferramentas de avaliação práticas e de baixo custo, eles podem ter várias deficiências inerentes, pois avaliam medidas subjetivas que podem ser enviesadas por muitas variáveis relacionadas às avaliações dos facilitadores/observadores sobre parâmetros qualitativos (ATESOK et al., 2017).

O feedback permite que, por meio da demonstração das habilidades técnicas ou não técnicas, os participantes se expressem e que o entendimento da ação esperada seja explorado (ERAUT, 2000). É uma atividade na qual as informações são retransmitidas para os estudantes. Com caráter construtivo, assertivo e respeitoso, o feedback aborda os aspectos específicos do desempenho e sempre deve ser direcionado conforme os objetivos de aprendizagem. O compartilhamento de informações entre os participantes, facilitador, paciente simulado ou colega de cena proporciona melhorias na compreensão de conceitos ou aspectos do desempenho (MEAKIM et al., 2013). O feedback pode ser fornecido por um instrutor, uma máquina, um computador, um paciente simulado ou por outros alunos, desde que faça parte do processo de aprendizagem. Ademais, independentemente de como o feedback for estruturado, sempre deve apresentar uma abordagem sensível, aberta e flexível (SUNDLER; PETTERSSON; BERGLUND, 2015).

O Objective Structured Assessment of Technical Skills (OSATS) é uma ferramenta confiável e válida para avaliar as habilidades técnicas e baseia-se em uma abordagem de classificação global para estruturar a avaliação de habilidades técnicas por especialistas. Os avaliadores trabalham a partir de uma lista de competências operacionais, cada uma classificada em uma escala do tipo Likert de 5 pontos, ancorada por descritores comportamentais. Estudos recentes na área médica têm utilizado a ferramenta OSATS para avaliação simulada de procedimentos cirúrgicos (ANDERSON et al., 2016; ATESOK et al., 2017).

O uso de vídeo para avaliar, posteriormente, as habilidades pode complementar a avaliação em tempo real. Neste caso, um observador deve estar pronto no laboratório para avaliar o desempenho de um estudante com um checklist. O feedback com base em vídeo é um método prático que permite a 
avaliação do desempenho por meio das ferramentas avaliativas, no momento em que for mais conveniente para o avaliador. Permite também que diferentes avaliadores examinem a mesma gravação de vídeo e pontuem o desempenho, o que pode ser eficaz na redução do viés (ATESOK et al., 2017).

Embora os processos específicos e as estratégias educacionais associadas ao desenvolvimento de habilidades não sejam totalmente conhecidos, não esclarecendo especificamente o impacto do uso da simulação para examinar as habilidades clínicas de graduandos e, consequentemente, o impacto de tais exames para o aprendizado dos estudantes (SUNDLE; PETTERSSON; BERGLUND,
2015), o fato de proporcionar uma experiência de treino simulado e repetitivo para o aprendiz poder praticar suas habilidades sem causar danos a um paciente real, certamente, pode ser uma oportunidade de aquisição de conhecimentos e competências (ORIQUE; PHILLIPS, 2018).

É evidente que os benefícios da simulação são notáveis. No entanto, deve-se lembrar de que a prática clínica não deve ser completamente substituída pela simulação (SUNDLE; PETTERSSON; BERGLUND, 2015), pois existe a necessidade de pacientes reais e da prática. Portanto, a simulação precisa ser um complemento à colocação clínica.

\section{REFERÊNCIAS}

ANDERSON, D. D. et al. Objective structured assessments of technical skills (OSATS) does not assess the quality of the surgical result effectively. Clinical Orthopaedics and Related Research, Philadelphia, v. 474, n. 4, p. 874$881,2016$.

ATESOK, K. et al. Measuring surgical skills in simulationbased training. Journal of the American Academy of Orthopaedic Surgeons, Rosemont, v. 25, n. 10, p. 665672, 2017.

BERRAGAN, L. Simulation: An effective pedagogical approach for nursing? Nurse Education Today, Edinburgh, v. 31, n. 7, p. 660-663, 2011.

BOURKE, M. P.; IHRKE, B. A. Introduction to the evaluationprocess. In: BILLINGS, D.; HALSTEAD, J. (Eds.), Teaching in nursing: A guide for faculty. 5th ed. St. Louis: Elsevier, 2016. p. 385-397.

DALEY, K. M.; CAMPBELL, S. H. Integrating simulationfocusedpedagogy into curriculum. In: CAMPBELL, S. H.; DALEY, K. M. (Eds.). Simulation scenarios for nursing educators. 2nd ed. New York: Springer, 2013. p. 9-15

DONOVAN, L. M. et al. Computer-based simulation: Effective tool or hindrance for undergraduate nursing students? Nurse Education Today, v. 69, p. 122-127, 2018.; pub July 2018. http://dx.doi.org/10.1016/j.nedt.2018.07.007.

ERAUT, M. Non-formal learning, implicit learning and tacit knowledge in professional work. Journal of Educational Psychology, v. 70, p. 113-136, 2000.

FOTHERINGHAM, D. Triangulation for the assessment of clinical nursing skills: A Review of theory, use and methodology. International Journal of Nursing Studies, Elmsford, v. 47, n. 3, p. 386-391, 2010.

HAMMER, J. A.; SOUERS, C. Infusion therapy: A multifaceted approach to teaching in nursing. Journal of Infusion Nursing, v. 27, p. 151-156, 2004.
HARDEN, R. M. What is an OSCE? Medical Teacher, v. 10, p. 19-23, 1988.

HUNT, E. A. et al. Pediatric resident resuscitation skills improve after "rapid cycle deliberate practice" training. Resuscitation, London, v. 85, n. 7, p. 945-951, 2014.

JOSEPHINE SCULLY, N. The theory- practice gap and skill acquisition: an isue for nurisng education. Collegian (Royal College of Nursing), Australia, v. 18, p. 93-98, 2011.

KHAN, R. et al. Virtual reality simulation training for health professions trainees in gastrointestinal endoscopy. Cochrane Database of Systematic Reviews, v. 8, n. 8, p. CD008237, 2018. http://dx.doi.org/10.1002/14651858. CD008237.pub3.

LEIGHTON, K. Simulation in Nursing. In: LEVINE, A. I. et al. (Eds.). The comprehensive textbook of healthcare simulation. New York: Springer Science+Business Media, 2013.

LEWIS, R.; STRACHAN, A.; SMITH, M. M. Is high fidelity simulation the most effec- tive method for the development of non-technical skills in nursing? A review of the current evidence. The Open Nursing Journal, Netherlands, v. 6, p. 82-89, 2012. http://dx.doi.org/10.2174/1874434601 206010082.

LOPRIEATO, J. O. Healthcare simulation dictionary. Rockville, MD: Agency for Healthcare Research and Quality, 2016. AHRQ Publication, No. 16.

LOPREiATO, J. O. (Ed.). Terminology \& Concepts Working Group: Healthcare simulation dictionary. Orlando: SSH, 2016. Disponível em: <http://www.ssih. org/dictionary>. Acesso em: 15 ago. 2016.

MCCOY, C. E. et al. Telesimulation: An innovative tool for health professions education. AEM Education and Training, Medford, v. 1, n. 2, p. 132-136, 2017. 
MEAKIM, C. et al. Standards of best practice: Simulation Standard I: Terminology. Clinical Simulation in Nursing, v. 9, n. 6S, p. S3-S11, 2013. http://dx.doi.org/10.1016/j. ecns.2013.04.001.

MONAGHAN, T. A critical analysis of the literature and theoretical perspectives on theory-practice gap amongst newly qualified nurses within the United Kingdom. Nurse Education Today, Edinburgh, v. 35, p. el-e7, 2015.

MOULE, P. Simulation in nurse education: past, present and future. Nurse Education Today, Edinburgh, v. 31, n. 7, p. 645-646, 2011.

NATIONAL LEAGUE FOR NURSING - NLN. Simulation Innovation Resource Center Glossary. Disponível em: $<$ http://www.sirc.nln.org/mod/glossary/view.php >. Acesso em: 09 nov. 2013.

ORIQUE, S. B.; PHILLIPS, L. J. The effectiveness of simulation on recognizing and managing clinical deterioration: Meta-Analyses. Western Journal of Nursing Research, v. 40, n. 4, p. 582-609, 2018. http:// dx.doi.org/10.1177/0193945917697224.

POIKELA, E.; POIKELA, P. Towards simulation pedagogy: Developing nursing simulation in a european network. Rovaniemi: Rovaniemi University of Applied Sciences, 2012. Publication Series A, n. 2. 115 p.

ROURKE, S. How does virtual reality simulation compare to simulated practice in the acquisition of clinical psychomotor skills for pre-registration student nurses? A systematic review. International Journal of Nursing Studies, Oxford, v. 102, p. 103466, 2020.

RYAN, R.; DECI, E. Self-determination theory and the facilitation of intrinsic motivation, social development, and well-being. The American Psychologist, Washington, v. 55 , p. $68-78,2000$.
SAEYER, T. et al. Learn, see, practice, prove, do, maintain: an evidence - Based pedagogical frame-work for procedural skill in medicine. Academic Medicine, Philadelphia, v. 90, p. 1025-1033, 2015.

SAMADBEIK, M. et al. The applications of virtual reality technology in medical groups teaching. Journal of Advances in Medical Education \& Professionalism, v. 6, n. 3, p. 123-129, 2018.

SANTOS, C. A. et al. Jogos sérios em ambiente virtual para ensino-aprendizagem na saúdeSerious games in virtual environments for health teaching and learning. Revista da Rede de Enfermagem do Nordeste, Fortaleza, v. 18, n. 5, p. 702-709, 2017.

SUNDLER, A. J.; PETTERSSON, A.; BERGLUND, M. Undergraduate nursing students' experiences when examining nursing skills in clinical simulation laboratories with high-fidelity patient simulators: A phenomenological research study. Nurse Education Today, v. 35, n. 12, p. 1257-1261, 2015.; pub April 2015. http://dx.doi.org/10.1016/j. nedt.2015.04.008.

ULRICH, B.; MANCINI, B. Mastering simulation: A handbook for success. Indianapolis: Sigma Theta Tau International, 2013. p. 49-86.

VAUGHAN, N. et al. A review of virtual reality based training simulators for orthopaedic surgery. Medical Engineering \& Physics, v. 38, n. 2, p. 59-71, 2016. http:// dx.doi.org/10.1016/j.medengphy.2015.11.021.

WANG, C. et al. Using multimedia tools and high-fidelity simulations to improve medical students' resuscitation performance: An observational study. BMJ Open, v. 6, n. 9, p. e012195, 2016.

WELLER, J. M. et al. Simulation in clinical teaching and learning. The Medical Journal of Australia, v. 196, n. 9, p. 594, 2012. http://dx.doi.org/10.5694/mjal0.11474. 


\section{CAPÍTULO 12 \\ - \\ Avaliação na educação em saúde com o uso da simulação}




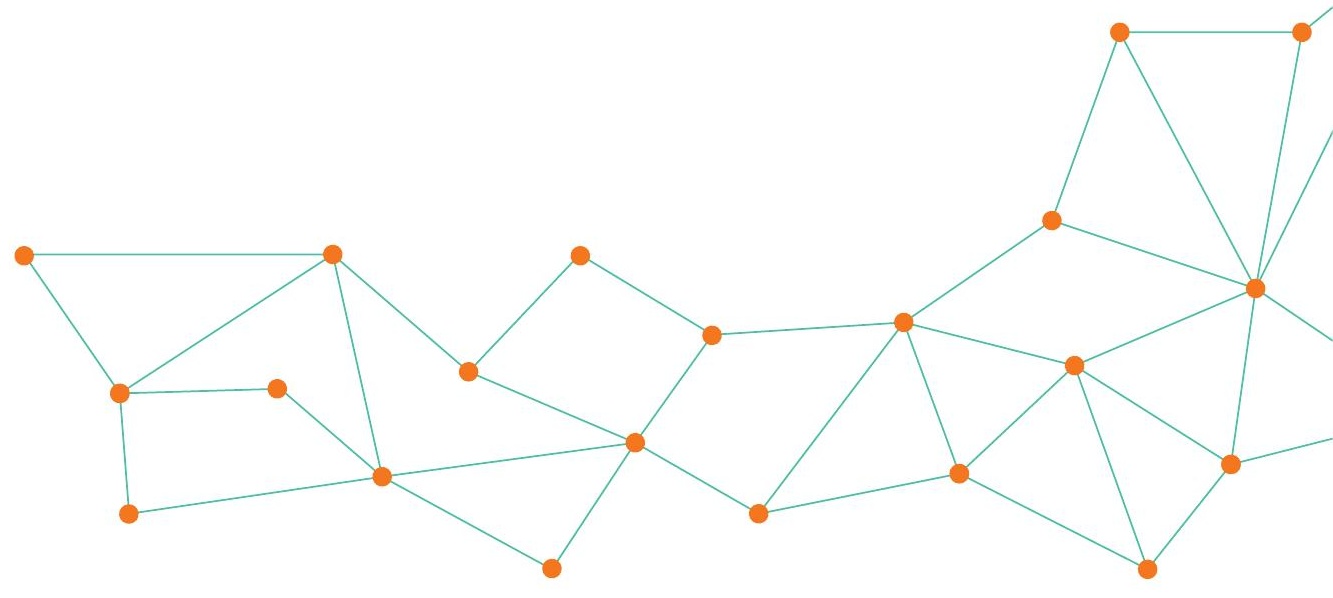

A aprendizagem é muito mais significativa à medida que o novo conteúdo é incorporado às estruturas do conhecimento de um estudante e adquire significado para ele a partir da relação com seu conhecimento prévio. No processo tradicional, ao contrário, a aprendizagem se torna mecânica ou repetitiva, uma vez que se produziram menos essa incorporação e atribuição de significados, e o novo conteúdo passa a ser armazenado isoladamente ou por meio de associações arbitrárias na estrutura cognitiva (PELIZZARI et al., 2002).

Para haver aprendizagem significativa, são necessárias duas condições:

1) o estudante precisa ter disposição para aprender. Se ele quiser memorizar o conteúdo arbitrária e literalmente, então a aprendizagem será mecânica.

2) o conteúdo a ser aprendido tem que ser potencialmente significativo, ou seja, tem que ser ló- gica e psicologicamente significativo: o significado lógico depende somente da natureza do conteúdo, e o significado psicológico é uma experiência individual. Cada aprendiz faz uma filtragem dos conteúdos que têm significado ou não para si. Ausubel propõe que os conhecimentos prévios dos estudantes sejam valorizados, para que possam construir estruturas mentais utilizando como meio os mapas conceituais, os quais permitem descobrir e redescobrir outros conhecimentos, caracterizando, assim, uma aprendizagem prazerosa e eficaz (PELIZZARI et al., 2002).

A aprendizagem se faz por vários meios, entre os quais as metodologias ativas de ensino e aprendizagem, cujo aperfeiçoamento é tema de estudos constantes. O professor exerce a sua habilidade de mediador das construções de aprendizagem, e mediar é intervir para promover mudanças. Os desafios 
que a educação atualmente busca se referem a três aprendizagens básicas: aprender a conhecer, aprender a fazer e aprender a ser (ZEFERINO, 2007a).

$O$ aprender a conhecer requer assimilação, interpretação do conteúdo e raciocínio de como aplicar esse conhecimento à prática do indivíduo. Não se deve ofertar a aprendizagem de saberes inúteis à sua formação e que sobrecarregam currículos, sem resultar em uma formação profissional de qualidade. É necessário selecionar as informações que, de fato, possam ser contextualizadas com a realidade e com o objetivo proposto para o curso, estando sempre atento ao perfil do estudante que se pretende formar e desenvolvendo habilidades para que ele construa o conhecimento (ZEFERINO, 2007a).

Aprender a fazer requer a habilidade de colocar em prática o conhecimento adquirido. Essa habilidade não significa apenas saber executar determinada tarefa, mas também como executá-la utilizando a criatividade, as evidências científicas e a ética, transformando o progresso do conhecimento em novas possibilidades. Muitos educadores acreditam que, se o estudante demonstra adequadamente a prática do conhecimento, o domínio cognitivo também foi alcançado (ZEFERINO, 2007a).

Para uma formação integral do estudante, o aprender a ser é essencial para que ele adquira uma postura condizente com a formação que obteve. O objetivo principal é desenvolver nele atitudes e condutas adequadas à sua profissão, estimulando o pensamento autônomo e crítico sobre o conhecimento adquirido e as evidências científicas encontradas (ZEFERINO, 2007a).

A avaliação é parte integrante do processo de ensino e aprendizagem e tem como meta a superação de limites e obstáculos. Deve ser coerente com a metodologia do trabalho do docente, favorecendo a aprendizagem, auxiliando o estudante a entender suas necessidades nos diferentes momentos do seu estágio de desenvolvimento e indicando as correções necessárias. No contexto educacional, a avaliação implica obter informações, por meio da aplicação de métodos específicos, que podem subsidiar a tomada de decisões que interessam tanto ao processo do aprendizado como ao educando (TRONCON, 1996). A forma e o conteúdo das avaliações são importantes, visto que constituem um poderoso determinante de como os estudantes estudam e aprendem (GODFREY, 1995).

Neste sentido, a avaliação pode ser definida como um processo de obtenção de informações, visando à tomada de medidas para o aprimoramento do processo educacional e à interferência positiva no aprendizado do estudante (TRONCON, 1996). Assim, a avaliação deve efetivamente fornecer informações e retroalimentar ajustes de condutas (MIQUELANTE et al., 2017).

Existem dois propósitos distintos da avaliação: alguns se referem aos objetivos da administração da instituição; outros, às metas educativas e pedagógicas. Os primeiros estão fundamentados na avaliação somativa e por normas; os últimos, na avaliação formativa e por critérios e diagnósticos (TRONCON, 1996).

A avaliação diagnóstica indica o ponto de partida do processo de ensino e aprendizagem para o alcance dos objetivos de aprendizagem traçados e possibilita o ajuste dos processos metodológicos para tal fim. Já a avaliação formativa é parte integrante do processo e orienta docentes e estudantes para o alcance dos objetivos de aprendizagem traçados, provocando a junção de métodos e atividades, com o único objetivo de se alcançar tal fim. Atribui também importância ao estudante e tem como foco a motivação, a regularidade do seu esforço, a forma de abordar as tarefas e as estratégias de resolução de problemas que utiliza. Por fim, a avaliação somativa é um juízo final e de síntese e tem como função estimar valores do processo de ensino e aprendizagem finalizado, certificando o progresso e o próprio processo de ensino e aprendizagem (MIQUELANTE et al., 2017).

Como não existe um único método de avaliação capaz de atingir todos estes elementos (conhecimentos, habilidades e atitudes), entende-se que apenas a combinação de métodos é capaz de produzir os resultados esperados da avaliação (NORCINI; MCKINLEY, 2007). Desta forma, cabe às escolas médicas se mobilizarem e criarem condições adequadas para que estudantes e docentes consigam desenvolver uma nova cultura de avaliação, como instrumento de aprendizado e crescimento profissional.

\section{A AVALIAÇÃO DE COMPETÊNCIAS}

As Diretrizes Curriculares Nacionais para o Curso de Medicina, de 2014, no parágrafo único do Artigo $8^{\circ}$ do Capítulo II, definem competência como a " $\mathrm{ca}$ pacidade de mobilizar conhecimentos, habilidadese atitudes, com utilização dos recursos disponíveis, $e$ exprimindo-se em iniciativas e ações que traduzem desempenhos capazes de solucionar, com pertinência, oportunidade e sucesso, os desafios que se apre- 
sentam à prática profissional, em diferentes contextos do trabalho em saúde, traduzindo a excelência da prática médica, prioritariamente, nos cenários do Sistema Único de Saúde - SUS" (BRASIL, 2014).

O reconhecimento de uma competência não passa apenas pela identificação de situações a serem controladas, de problemas a serem resolvidos, de decisões a serem tomadas, mas também pela explicitação dos saberes, das capacidades, dos esquemas de pensamento e das orientações éticas necessárias (PERRENOUD, 2002).

Na educação médica, as competências envolvidas constituem, quase sempre, habilidades complexas e que compreendem inter-relações variadas entre os domínios cognitivo, psicomotor e afetivo da taxonomia de Bloom. O contexto da avaliação por competências é influenciado por diversos fatores, como o tipo de paciente (crianças, mulheres, adultos e idosos), o conteúdo envolvido (condições de natureza variada, relacionadas aos diferentes sistemas orgânicos de forma isolada ou combinada), as circunstâncias de cada situação (gravidez, diversas patologias traumáticas ou não traumáticas, sendo cirúrgicas ou não), bem como as características de personalidade do médico (ou estudante) e o efeito modulador de experiências prévias semelhantes (TRONCON, 1996).

A noção de educação baseada em competência foi associada à avaliação de objetivos comportamentais. Para os objetivos de aprendizagem que merecem ser avaliados, adotou-se o conceito de performance ou desempenho, ou seja, as ações efetivamente manifestas, nas quais o estudante deveria realizar dado desempenho, definindo o nível de performance considerado aceitável (GONTIJO et al., 2013).

Desta forma, não se avalia competência; avaliam-se desempenhos que traduzem a ação profissional considerada competente, e, por meio dos desempenhos, infere-se a competência. A avaliação de competências não deve se restringir à execução de uma série de tarefas discretas, definidas de modo meramente técnico e avaliadas por uma abordagem descontextualizada com a aplicação de um instrumento padronizado de avaliação (checklist). Essa abordagem simplista subestima o desenvolvimento e a avaliação dos atributos relacionados aos desempenhos e os fundamenta, reduzindo a aprendizagem ao cumprimento de tarefas (AGUIAR; RIBEIRO, 2010).

Essas capacidades podem ser avaliadas por meio de situações simuladas e/ou práticas profissionais em contextos reais (não simulados). A melhor forma de avaliar desempenho é definir a tarefa a ser realizada em dado contexto e verificar a capacidade do estudante de mobilizar, naquela situação particular, seus atributos de forma adequada para efetuar a tarefa. A competência pode ser aprimorada no dia a dia, no processo de ensino e aprendizagem e na vivência do sujeito, na qual ele sofistica seu conhecimento tácito (AGUIAR; RIBEIRO, 2010).

Na educação baseada em competências, a aprendizagem não deve ser vista como uma transferência de conhecimentos, mas deve partir da análise de situações e atitudes para derivar o conhecimento, abrangendo, entre outras características, conhecimento, capacidade de execução, habilidade para a execução, raciocínio, pensamento crítico, postura profissional e ética, relacionamento humano, comportamento, valores, mudança de atitude e até certa independência para a produção do saber (BORDENAVE; PEREIRA, 1982).

A definição de currículos fundamentados em competência requer uma opção conceitual em relação ao entendimento da competência como resultante da relação entre o mundo da aprendizagem e o mundo do trabalho. A articulação de tarefas e capacidades verificáveis pelo desempenho permite a inferência de competência para determinada área profissional, a partir de padrões ou critérios pactuados, considerados necessários e desejáveis para práticas de saúde de qualidade adequada (LIMA, 2004).

\section{SIMULAÇÃO CLÍNICA NO ENSINO E AVALIAÇÃO}

Nas mais diversas ciências e, mais enfaticamente, na formação em saúde, entre as diversas estratégias que têm sido utilizadas com sucesso para o ensino e a avaliação de profissionais, tem merecido destaque o uso da simulação clínica.

A simulação é uma tentativa de imitar e antecipar as peculiaridades de determinada situação real, almejando sua melhor compreensão e gestão. É uma estratégia que recorre a um ambiente artificial, recriando uma situação real, com o propósito de praticar, aprender, avaliar, testar ou desenvolver a compreensão dos sistemas ou ações humanas (QUIRÓS; VARGAS, 2014). Não se limita ao desenvolvimento ou teste de alguns objetos de ensino e aprendizagem, mas, sobretudo, integra tecnologias, competências, habilidades e trabalho em equipe, promovendo a resolução de situações-problema e incentivando o raciocínio crítico em um ambiente completamente seguro, não ameaçador, que preserva eticamente o paciente e o profissio- 
nal. Ainda, integra os domínios cognitivo e afetivo e é um excelente método de ensino e de avaliação (MAZZO et al., 2017).

Segundo Gaba, a simulação pode ser entendida como um processo educacional que replica cenários de cuidados ao paciente em um ambiente próximo à realidade, com o objetivo de analisar e refletir as ações realizadas de forma segura. É necessário enfatizar que a simulação é uma técnica que evoca, substancialmente, aspectos do mundo real em um ambiente interativo, e não exclusivamente uma tecnologia que tem por objetivo substituir ou amplificar uma experiência real com supervisão (GABA, 2009).

Um princípio básico no uso da simulação no ensino da Medicina é que, quanto mais o estudante acreditar que a situação que experiencia é real, melhor será a sua utilidade (MURPHY et al., 2007). Desta forma, esse "contrato de ficção" precisa ficar bem explícito entre professores e estudantes, permitindo a "suspensão da descrença", com o uso adequado de materiais e equipamentos, em um ambiente simulado que deve ser bem próximo ao real, fazendo todos os passos dos procedimentos de forma bastante fiel e mostrando a importância da autenticidade das situações recriadas (LATEEF, 2010).

Determinado pelos objetivos de aprendizagem ou de avaliação, o método, em diferentes graus de complexidade e fidelidade (simulação de baixa fidelidade/complexidade, simulação de média fidelidade/complexidade e simulação de alta fidelidade/complexidade), pode incorporar uma infinidade de recursos para maior realismo dos cenários simulados.

O que determina o grau de fidelidade da atividade simulada não são os níveis de tecnologia incorporados, e sim as ações individuais e conjuntas necessárias à resolução dos problemas, que permitem o raciocínio clínico, a tomada de decisão, o trabalho em equipe, a liderança e todas as situações complexas do cotidiano da prática clínica em saúde. A complexidade tecnológica dos simuladores robóticos, frequentemente, tem sido confundida com sua fidelidade. A fidelidade do simulador é a sua capacidade de imitar o ser humano na sua aparência e reações. No entanto, por mais fidedigno que seja o modelo escolhido, é importante lembrar que ele nunca será um indivíduo (LOPREIATO et al., 2016; MAZZO et al., 2017).

Em simulação, os objetivos de aprendizagem ou de avaliação da atividade devem indicar os recursos a serem utilizados. A grande vantagem do uso da simulação é facilitar a integração de conhe- cimentos interdisciplinares e complexos de uma forma contextualizada e global, o que abre amplas vertentes de cenários e situações clínicas. Os parâmetros-chave do processo de aprendizagem de simulação são: contexto, ambiente e participação ativa dos estudantes (ALINIER, 2007).

Ao variar os parâmetros dos cenários simulados, é possível expor os estudantes a uma ampla diversidade de comportamentos e resultados, comparativamente aos que iriam encontrar na prática clínica em um certo período de tempo (ALINIER, 2007).

Assegura também que os estudantes ganhem experiência clínica sem dependerem do inesperado dos casos clínicos disponíveis em determinado serviço, em certo dia, possibilitando o contato com patologias raras ou situações incomuns (LATEEF, 2010). Deve-se levar em consideração que os estudantes não têm sempre acesso a uma gama de experiências educacionais com casos reais, o que acarreta uma menor oportunidade de observar e avaliar os pacientes com uma grande variedade de doenças, sinais físicos e sintomas (BRANDÃO; COLLARES; MARIN, 2014).

Independentemente de ser adquirida em condições simuladas ou na vida real, a experiência repetida e acumulada melhora a performance e a confiança dos estudantes (HOFMANN, 2009). Esta prática repetitiva é precisamente um elemento da simulação que facilita a aprendizagem. A simulação permite uma intervenção mais ativa pelos estudantes, uma vez que incita a autoavaliação, a autorreflexão e o espírito crítico sobre a sua performance (WAYNE; MCGAGHIE, 2010). A identificação das lacunas de conhecimento e dos pontos fracos no desempenho leva à melhoria prática da sua performance. Vários estudos comprovam o melhor desempenho técnico alcançado com a prática de procedimentos em simuladores (SALAS, 2009). Alguns desses simuladores demonstraram, inclusive, encurtar significativamente a curva de aprendizagem (BRUNCKHORST et al., 2016).

A educação baseada em simulação permite integrar o fator humano, uma vez que é possível treinar e avaliar as habilidades não técnicas aplicadas em diferentes contextos, principalmente o trabalho em equipe, os diferentes tipos de comunicação, as capacidades de resolução de problemas e tomadas de decisão, o profissionalismo, a ética e a liderança (EVAIN et al., 2019; GORDON et al., 2019).

Outro grande potencial da educação baseada em simulação está na possibilidade de recriar situações complexas enquanto é mantida a segurança dos pacientes. Isso pode melhorar não apenas a perfor- 
mance técnica, mas também o crescimento intrínseco do conhecimento clínico e autoconfiança, o que abrange aprender a lidar com o estresse, a incerteza e até o medo (KNEEBONE, 2009).

Um fato interessante é que os estudantes podem ser expostos a procedimentos que até então lhes estavam vedados e praticá-los em um ambiente seguro. Isso é extremamente motivante e pode despertar o interesse por áreas com as quais teriam menos contato. Estudos apontam para um impacto positivo a longo prazo da simulação em estudantes de Medicina na área de cirurgia vascular, podendo desempenhar um papel importante no recrutamento de estudantes para futuros programas de residência médica (LEE et al., 2009).

Apesar da valiosa contribuição da educação baseada em simulação, não se deve esquecer de que suas várias modalidades não substituem a experiência clínica e que, como qualquer outra intervenção em Medicina, a sua utilização deve ser sustentada em evidências, pois existem riscos quando os estudantes são habilitados apenas com certos tipos de simuladores em detrimento dos pacientes reais.

Apesar das inúmeras vantagens, é essencial comprovar se esses benefícios se traduzem na prática clínica. Quanto à execução de procedimentos, foi demonstrado que o volume de experiência reduz as taxas de complicação nos pacientes, melhorando o desempenho antes mesmo de esses procedimentos serem realizados no cenário real de prática (DOMURACKI et al., 2009). As pesquisas sobre educação baseada em simulação, muitas vezes, não abordam a questão mais relevante da validade preditiva, isto é, se as capacidades adquiridas em ambiente simulado podem ser generalizadas para situações clínicas reais. Uma vez que há dificuldade em delinear e executar estudos que permitam verificar essa hipótese, já que exigiria um seguimento dos estudantes a longo prazo, a transferência desse aprendizado da simulação para a prática clínica e cirúrgica continua por ser compreendida. Assim, é fundamental reconhecer que essa metodologia pode não ser apropriada em todos os casos, estabelecendo quais situações de uso da simulação trarão vantagens. É também necessário esclarecer se há manutenção das competências aprendidas por um longo período de tempo.

Shanks et al. (2010) averiguaram as perspectivas dos internos de Medicina sobre o uso de simuladores no seu percurso na graduação, apontando como principais obstáculos a limitação de tempo, o grande número de estudantes para cada instrutor, a disponibilidade condicionada dos simulado- res e a ausência de realismo de alguns modelos. Os próprios estudantes reconheceram a importância do formador e seu papel crucial na demonstração do procedimento, a observação da execução da técnica pelos aprendizes e o feedback.

Para otimizar tudo o que foi colocado a respeito do uso da simulação clínica nas matrizes curriculares dos cursos da área da saúde, particularmente da Medicina, é possível a implementação de mudanças que desenvolvam uma aprendizagem multidisciplinar com integração vertical e longitudinal do conhecimento (em espiral), valorizando a aprendizagem significativa.

A utilização apropriada de diversas metodologias ativas de ensino e aprendizagem e de avaliação permite a monitorização do processo de ensino e avaliação por meio da introdução de novas abordagens, que incentivam o comportamento do estudante como sujeito ativo da construção do seu conhecimento, e possibilita a análise sequencial da sua progressão ao longo dos semestres do curso.

Há uma infinidade de procedimentos que podem ser simulados, como ausculta cardíaca e pulmonar, exame do fundo ocular, toque retal, punção lombar, intubação endotraqueal ou desfibrilação. Isso permite a inserção de habilidades e cenários simulados ao longo de todo o curso médico, em diferentes complexidades, e que estejam adequados ao momento de formação dos estudantes, para que possam simular em ambiente controlado e, logo em seguida, usar tal treinamento para a assistência de pacientes reais.

O uso da simulação clínica também pode ser uma forma de antecipar a contextualização das ciências básicas no complexo ambiente clínico, favorecendo a sua compreensão e valorização, e acelerando a aquisição de correlações translacionais no ensino médico (GORDON et al., 2019). A integração simultânea dos princípios e conteúdos das ciências básicas e clínicas no processo de ensino e aprendizagem, como ocorre nas correlações fisiológicas e clínicas de sinais e sintomas, e nas correlações anatomorradiológicas, particularmente, com o uso de ultrassom, permite uma aprendizagem significativa, de modo a facilitar o entendimento e a correlação de conhecimentos mais precoces dos estudantes, o que colabora enormemente para sua motivação intrínseca.

Todavia, para direcionar a escolha dos recursos, é indispensável levar em conta a sua disponibilidade e a relação entre custos e benefícios. Simuladores de alta complexidade são onerosos, têm dispendiosos e complexos processos de manutenção e atua- 
lização e, por isso, nem sempre se encontram disponíveis na grande maioria das instituições. Além disso, se fossem considerados como as únicas possibilidades de se fazer atividades simuladas, inviabilizariam quaisquer processos de larga escala de ensino e avaliação. Existem situações em que os recursos da simulação cênica são capazes de promover maior veracidade da interação, principalmente utilizando a comunicação verbal e não verbal.

\subsection{A SIMULAÇÃO CÊNICA NOS PROCESSOS DE AVALIAÇÃO}

A simulação cênica é um recurso de menor custo quando comparada à aquisição de simuladores. Pode ser definida como uma representação teatral ou dramatização, a partir de determinado foco ou tema, com o objetivo de expressar ideias, conceitos e argumentos de um estudo de caso.

Na saúde, possibilita ao profissional e ao estudante:

1) vivenciar comportamentos frequentes da relação profissional/paciente, por exemplo, a avaliação de atitudes e decisões em um ambiente controlado, sem risco de efeitos negativos, como seria na prática direta com o paciente real;

2) verificar o desempenho de intervenções que exigem raciocínio clínico competente, como a coleta de dados a partir do passado relevante e histórico da doença atual.

No ensino com simulação cênica, podem ser utilizados o role player, ou jogo de papéis, os pacientes simulados, os modelos mistos (híbridos) e os pacientes padronizados (MAZZO et al., 2017; NEGRI et al., 2017).

$\mathrm{O}$ role player, ou jogo de papéis, permite ao participante experimentar sensações diversas que devem ser levadas em consideração e estimuladas como pontos da reflexão durante ofeedback da atividade. Nessa modalidade, o estudante, docente ou facilitador podem desempenhar personagens no cenário simulado, como se fossem integrantes do caso clínico. Os personagens desempenhados, geralmente, estão relacionados a representações dos profissionais (médicos, enfermeiros, recepcionistas etc.), pacientes, familiares, acompanhantes, entre outros.

Os pacientes simulados são utilizados tanto com a finalidade de ensino como de avaliação. Nesta técnica, durante o desenvolvimento do cenário, podem-se contratar atores treinados para desempenhar o papel de pacientes. Geralmente, eles são intérpretes contratados pela instituição, mas existem relatos da participação de ex-pacientes, estudan- tes de artes cênicas e cursos de teatro ou de profissionais de outras áreas vinculados à instituição de ensino, devidamente preparados para tal situação.

O modelo misto (ou híbrido) de simulação permite a realização de procedimentos durante o role player ou o uso de pacientes simulados, ao se associar um simulador estático ao indivíduo que está desenvolvendo o personagem, para que sejam realizados os procedimentos do cenário simulado (NEGRI et al., 2017).

$\mathrm{O}$ uso de pacientes padronizados pode ser considerado como uma modalidade que suscita questionamentos éticos, relacionados à vulnerabilidade do paciente e ao comprometimento ético e profissional com os achados encontrados. Consiste no uso de indivíduos normais (crianças, adolescentes, adultos e idosos), determinados profissionais (médicos, enfermeiros, nutricionistas, entre outros) ou ainda pacientes reais (com patologia diagnosticada, por exemplo, neoplasia de mama), que estabelecem um contrato comercial para protagonizar um personagem em um cenário clínico. Apesar de bastante difundida em outros países, essa modalidade de simulação não tem sido muito utilizada nos cenários simulados do Brasil (NEGRI et al., 2017).

Pelo fato de desempenharem um papel uniformizado, em algumas situações pacientes simulados ou padronizados também podem participar das avaliações dos estudantes (BOKKEN et al., 2009).

A simulação cênica com uso de pacientes simulados tem sido empregada em diversas provas práticas simuladas, seja na progressão do estudante durante o curso de graduação, em programas de aperfeiçoamento, educação corporativa e especialização (como as provas de residência médica) e/ou na revalidação de diplomas. No âmbito de instituições de saúde e mesmo em outras áreas, os editais de concursos têm começado a utilizar a simulação como parte dos processos de seleção.

\section{O PROCESSO DE AVALIAÇÃO UTILIZANDO A SIMULAÇÃO}

Testes escritos não avaliam competências em sua completude, pois, geralmente, a observação direta é necessária para isso. Tradicionalmente, a avaliação de competências clínicas (capacidade de colher história, realizar exame físico, efetuar procedimentos, utilizar o raciocínio clínico, tomar conduta, comunicar-se com paciente e outros profissionais e adotar conduta ética) é realizada por meio de casos longos ou curtos (KAUFMAN; MANN, 2010). 
Embora essas modalidades mais tradicionais de avaliação possam fornecer dados relevantes sobre o nível de competência clínica dos estudantes, carecem de maior objetividade e de padronização. Os resultados obtidos são fortemente influenciados pelo tipo de paciente disponível para determinado exame, e toda a avaliação depende muito do avaliador. Além disso, cada estudante é avaliado em condições muito diferentes, o que dificulta a comparação dos resultados entre os avaliandos. Essas particularidades concorrem para que esses métodos sejam considerados como de reduzida fidedignidade. Dessa forma, a simulação clínica, com sua alta reprodutibilidade, fidedignidade e validade, ganhou importância na avaliação de desempenho dos estudantes (SAMPAIO; PRICINOTE; PEREIRA, 2014).

Assim, além de a simulação ser o modo ideal de aprendizagem sem causar prejuízo ou inconveniente aos pacientes, é também um método muito conveniente para avaliar competências, já que permite recriar situações realistas que colocam os participantes perto do topo da pirâmide de Miller (ALINIER, 2007). O examinador, com o auxílio de instrumentos de registro predefinidos (checklist), enfoca a atenção no desempenho de habilidades específicas, objetivando a avaliação.

Como em todo processo avaliativo bem planejado, a avaliação com uso de simulação é complexa, ampla e multidimensional. No contexto de ensino e aprendizagem, necessita-se levar em consideração os conhecimentos, as experiências prévias, as características pessoais dos avaliados, e nos processos de seleção/certificação, garantir que os parâmetros preestabelecidos considerados adequados sejam atingidos.

O uso da simulação permite a apresentação dos problemas e situações clínicas da mesma forma para cada examinando e minimiza a variabilidade inerente ao uso de casos clínicos com pacientes reais. Essa reprodutibilidade torna-se, particularmente, importante nas decisões para avaliações em processos seletivos.

Com a simulação clínica, podem ser testadas múltiplas competências de forma simultânea, tais como assistência aos pacientes, conhecimento médico, habilidades psicomotoras para procedimentos, profissionalismo e habilidades interpessoais, entre outras, permitindo tanto o desenvolvimento e a avaliação de competências individuais em situações semelhantes que ocorrem no dia a dia quanto a colaboração efetiva em equipe e construção de uma cultura orientada para a segurança.

\section{A) AVALIAÇÃO DE HABILIDADES}

As habilidades estão relacionadas às destrezas necessárias para o desenvolvimento do trabalho e podem traduzir-se em práticas motoras, sociais e/ou comportamentais, as quais, agregadas, formam as competências necessárias ao profissional.

Em simulação clínica, as habilidades são parte integrante de uma curva de aprendizado e, geralmente, são desenvolvidas em peças anatômicas ou simuladores inanimados de menor custo que possibilitam o treino repetido das práticas, as quais devem ser oferecidas em número suficiente aos estudantes, com a substituição rotineira de peças danificadas.

Durante o treino de habilidades, é imprescindível incorporar realismo à prática realizada, por exemplo, a saída de urina ao se cateterizar a uretra, a aspiração de sangue em uma punção ou de secreção em uma broncoaspiração de vias aéreas.

O treino de habilidades aumenta a autoconfiança dos estudantes na realização dos procedimentos, e alguns autores têm associado o treino precoce à maior satisfação e confiança na profissão (BING-YOU et al., 2018).

A avaliação de habilidades deve ser vista como algo construtivo pelos estudantes, com o objetivo de maximizar seus desempenhos no decorrer da formação e da vida profissional, dentro de um necessário processo de educação permanente. Nesse sentido, o uso de checklists que direcionem o comportamento do facilitador, o feedback e o debriefing são ferramentas muito importantes. Os parâmetros desejados de qualidade das habilidades clínicas devem ter como base o protocolo operacional padrão (POP).

O debriefing e o feedback são pontos-chave do processo de ensino utilizando simulação, pois pressupõem uma constante colaboração, com a finalidade de partilhar e discutir se as atitudes aprendidas foram efetuadas de forma correta, da mesma que forma que a reunião entre os participantes, em que se recolhem informações de como ocorreu certa tarefa, exigindo a assistência contínua de um facilitador (WAYNE; MCGACHIE, 2010).

Os checklists são listas de verificação que devem ser rigorosa e metodicamente cumpridas para que um procedimento se desenvolva com o máximo de segurança e qualidade (SANTOS, 2011). A simplificação dos procedimentos em várias etapas, que viabiliza a oportunidade de simular cada uma das tarefas isoladamente, pode representar uma vantagem considerável para a aquisição de habilidades clínicas e cirúrgicas. 
Após a realização da simulação, faz-se necessária a reflexão do atendimento realizado pelos estudantes por meio do debriefing. Nessa fase, o professor que acompanhou o atendimento terá uma postura de facilitador da discussão em grupo sobre as impressões dos participantes do cenário simulado, bem como dos demais observadores, o que, no final, permitirá discutir os acertos e oportunidades de melhorias do aprendizado após a identificação das lacunas de conhecimento (DIECKMANN, 2009). A realização do debriefing pode ser auxiliada ou não com as imagens gravadas do atendimento simulado, esclarecendo e revivendo, de forma pontual, os momentos cruciais do cenário utilizado (FAROOQ et al., 2017).

Os feedbacks devem ser realizados de maneira construtiva, assertiva e respeitosa, em ambiente reservado, de forma a possibilitar a reflexão do estudante sobre o seu aprendizado (ZEFERINO et al., 2007b).

\section{B) OBJECTIVE STRUCTURED CLINICAL EXAMINATION (OSCE)}

Desde 1975, o Objective Structured Clinical Examination (OSCE) tem sido amplamente utilizado. Trata-se de uma ferramenta avaliativa muito versátil, na qual o aprendiz demonstra suas habilidades quando se depara com cenários simulados muito semelhantes a situações e casos clínicos reais. Pode ser usado para avaliar diversos resultados de aprendizagem em diferentes fases da formação e em várias profissões de saúde, além de ser muito utilizado para exames práticos na área médica (PATRICIO et al., 2013).

Dessa forma, o advento do OSCE permitiu que as avaliações clínicas tivessem vantagens equivalentes às provas escritas objetivas de conhecimento (HARDEN et al., 1975).

Na graduação médica, sua aplicação praticamente tem se tornado universal. A Association of American Medical Colleges (AAMC) publicou que, em 2016, das 184 escolas de Medicina existentes, 133 fizeram com que seus estudantes concluíssem o OSCE institucional no final do curso e 108 exigiram uma nota de aprovação mínima no exame para obterem o título da graduação (JAYAKUMAR, 2018).

O OSCE apresenta uma gama de contextos relatados em diferentes formatos, além de flexibilidade e possibilidade de adaptação às situações locais. Ele avalia os conhecimentos, habilidades e atitudes do aprendiz, sendo uma estratégia que permite que a maioria dos conhecimentos dos estudantes sejam testados, uma vez que as variáveis, a complexidade e os objetivos da atividade são facilmente controlados e passíveis de serem atingidos (PATRICIO et al., 2013).

São projetados para serem objetivos e estruturados e permitem a aquisição e a demonstração de conhecimento clínico. Como originalmente descrito por Harden e colaboradores, o OSCE consiste em uma série de "estações procedimentais", seguidas de "estações de perguntas e respostas". As estações de procedimentos, geralmente, usam pacientes simulados, mas podem apresentar uma tarefa determinada (como interpretar um teste de diagnóstico ou demonstrar uma habilidade usando um simulador de baixa fidelidade). O OSCE também fornece oportunidades para feedback formativo, no qual o desempenho do estudante é realizado por escrito ou por meio de feedback verbal individual, ou em sessões de esclarecimento em grupo. As avaliações objetivas e o feedback tornam essa ferramenta um excelente método de avaliar as principais competências em um ambiente simulado (PRINCE et al., 2014).

A elaboração de ambientes simulados deve ser a mais próxima possível da realidade, podendo ser desafiadoras as estações que envolvem elementos subjetivos, como comunicação e sentimentos. Quanto mais próximos da prática, maior relevância e significado dos cenários simulados para os estudantes (FRANCO et al., 2015).

O estudo de Weinberg, Sinha e Saleh (2014) mostrou que, em estações apenas com o uso simuladores de baixa fidelidade ou de peças anatômicas, por exemplo, um braço inanimado para coleta de sangue, a estratégia se torna extremamente artificial, pois as habilidades não técnicas, como a comunicação, que é extremamente importante nesse tipo de procedimento, não ocorre. Para isso, o uso da simulação híbrida, na qual os manequins são associados a pacientes simulados, representa um importante recurso e pode contribuir para o aumento da autenticidade e do realismo das estações práticas.

Os parâmetros desejados de qualidade no desempenho dos estudantes nas estações práticas de cenários simulados devem ter como base os protocolos clínicos e diretrizes terapêuticas (PCDTs) fundamentados nas melhores evidências clínicas disponíveis.

O OSCE possui excelente validade (capacidade de avaliar, efetivamente, "o que deve realmente ser avaliado") e fidedignidade, que é a característica que se relaciona à precisão, à acurácia, à objetividade e à reprodutibilidade do instrumento, fatores que, por sua vez, determinam a confiabilidade e a consistência dos resultados obtidos. O maior problema rela- 
tado ao seu uso é a viabilidade ou a praticidade de sua execução. Alguns estudos revelam dificuldades na implementação do OSCE, como as complexidades da organização logística, o tempo para planejamento e implementação, os recursos físicos e materiais necessários, os custos associados a pacientes simulados e examinadores, a carga horária do corpo docente, entre outros. No entanto, apesar desses fatores associados, os estudos revelam que realizar um OSCE é aconselhável por causa dos benefícios educacionais alcançados (SKRZYPEK et al., 2017). As estratégias utilizando a gravação dos vídeos com o desempenho dos estudantes/candidatos e posterior avaliação de forma assíncrona pelos examinadores, e o OSCE realizado de forma on-line, com estudantes e avaliadores também on-line, diminuem muito o custo dessas provas práticas.
Neste contexto, a avaliação clínica estruturada vem se popularizando na educação em saúde em todo o mundo e também no Brasil, e vem sendo vastamente referida por vários autores. Além do formato do OSCE, diversos procedimentos de avaliação prática podem ser utilizados conforme o contexto institucional a ser avaliado, com possibilidade de várias modificações: Practical Assessment of Clinical Examination Skills (PACES), Objective Structured Long Case Examination Record (OSLER), Objective Structured Assessment of Technical Skills (OSATS), Clinical Skills Assessment (CSA), Mini-Clinical Evaluation Exercise (MINI-CEX), Direct Observation of Procedural Skills (DOPS), Multi-Source Feedback (MSF) e Global Rating Scale (Conceito Global). A Tabela 1 mostra o conceito de cada uma dessas modificações do OSCE.

Tabela 1 - Diferentes tipos de avaliação clínica estruturada.

\begin{tabular}{|c|c|}
\hline Técnica & Descrição \\
\hline $\begin{array}{l}\text { Practical Assessment of } \\
\text { Clinical Examination } \\
\text { Skills (PACES) - } \\
\text { (PACES, 2000) }\end{array}$ & $\begin{array}{l}\text { São criadas cinco estações, cada uma com dois avaliadores e com duração } \\
\text { de } 20 \text { minutos, para avaliar um exame clínico (dos sistemas respiratório, } \\
\text { cardiovascular, neurológico, endócrino e locomotor e da parte abdominal, ocular } \\
\text { e dermatológica), coleta de história, comunicação e ética profissional. Esta } \\
\text { técnica é utilizada pelo Royal College of Physicians. }\end{array}$ \\
\hline $\begin{array}{l}\text { Objective Structured } \\
\text { Long Case Examination } \\
\text { Record (OSLER) - } \\
\text { (GLEESON, 1997) }\end{array}$ & $\begin{array}{l}\text { Caracteriza-se pelo emprego de, pelo menos, dois casos longos em sequência; } \\
\text { da atuação simultânea de, pelo menos, dois observadores diferentes; e, } \\
\text { especialmente, do uso de um instrumento padronizado, no qual o número e } \\
\text { o tipo de julgamentos a serem feitos pelos dois examinadores, em cada caso } \\
\text { clínico, são predefinidos e compreendem um conjunto suficientemente amplo } \\
\text { de itens relevantes de observação (quatro itens da história, três itens do exame } \\
\text { físico e três itens de raciocínio clínico e conduta). }\end{array}$ \\
\hline $\begin{array}{l}\text { Objective Structured } \\
\text { Assessment of Technical } \\
\text { Skills (OSATS) - } \\
\text { (MARTIN et al., 1997) }\end{array}$ & $\begin{array}{l}\text { A avaliação é dividida em duas partes: na primeira, do procedimento em si; e na } \\
\text { segunda, do conhecimento, da destreza na manipulação dos instrumentos e do } \\
\text { registro da ação. Foi criado pelo Surgical Education Group, da Universidade de } \\
\text { Toronto, para ser um teste em sala de aula de habilidades cirúrgicas. }\end{array}$ \\
\hline $\begin{array}{l}\text { Clinical Skills } \\
\text { Assessment (CSA) - } \\
\text { (MUNRO et al., 2006) }\end{array}$ & $\begin{array}{l}\text { Muito semelhante ao OSCE, tem como principal diferença o fato de que, em cada } \\
\text { estação, o estudante deve cumprir todo o conjunto de tarefas necessárias para que } \\
\text { a abordagem do paciente se complete. Em cada situação, o estudante encontra um } \\
\text { paciente que deve ser entrevistado, com vistas à obtenção da sua história clínica, } \\
\text { realização do exame físico, e, em seguida, informado orientado sobre as medidas } \\
\text { diagnósticas e terapêuticas necessárias para a solução do referido problema. } \\
\text { A principal vantagem desta modalidade é a abordagem integral do caso, em } \\
\text { condições mais próximas da realidade da prática profissional. }\end{array}$ \\
\hline $\begin{array}{l}\text { Mini-Clinical } \\
\text { Evaluation Exercise } \\
\text { (MINI-CEX) - } \\
\text { (NORCINI et al., 2003) }\end{array}$ & $\begin{array}{l}\text { Instrumento utilizado para avaliação direta dos estudantes em atendimentos } \\
\text { reais. O tutor observa diretamente o desempenho deles e, por meio de um } \\
\text { checklist, aponta os ganhos de aprendizado em cada etapa do exame clínico e } \\
\text { pontua a performance dos estudantes, utilizando uma escala de cinco pontos, } \\
\text { dando um feedback imediato. }\end{array}$ \\
\hline
\end{tabular}


Tabela 1 - Continuação...

\begin{tabular}{|l|l|}
\hline Técnica & Descrição \\
\hline $\begin{array}{l}\text { Direct Observation of } \\
\text { Procedural Skills (DOPS) } \\
\text { - (MOORTHY et al., } \\
2003)\end{array}$ & $\begin{array}{l}\text { Variação do Mini-CEX, em que o avaliador observa o estudante quando ele está } \\
\text { fazendo o procedimento (por exemplo, administrando uma injeção, retirando } \\
\text { sangue, inserindo um tubo), e a performance é pontuada conforme uma escala, } \\
\text { dando um feedback. }\end{array}$ \\
\hline $\begin{array}{l}\text { Multi-Source Feedback } \\
\text { (MSF) - (LOCKYER, } \\
2003)\end{array}$ & $\begin{array}{l}\text { É o mesmo que avaliação } 360^{\circ} \text {. Envolve uma avaliação externa de performance } \\
\text { por um longo período de tempo por supervisores ou observadores com } \\
\text { conhecimento de similar prática (1), colegas (2), mas não com a mesma profissão, } \\
\text { por exemplo, enfermeiras ou pessoal administrativo avaliando médicos, } \\
\text { pacientes (3) e o próprio profissional (4). }\end{array}$ \\
\hline $\begin{array}{l}\text { Global Rating Scale } \\
\text { (Conceito Global) - } \\
\text { (COHEN, 1991) }\end{array}$ & $\begin{array}{l}\text { Atribui ao estudante um conceito de maneira retrospectiva (MINI-CEX } \\
\text { retrospectivo) no final de um estágio, utilizando categorias gerais, em vez de } \\
\text { comportamentos específicos. Este conceito deve ser construído com itens que } \\
\text { especifiquem o que está sendo avaliado, contemplando os atributos necessários } \\
\text { (conhecimentos, atitudes, valores e habilidades) para o desempenho profissional } \\
\text { esperado. }\end{array}$ \\
\hline
\end{tabular}

\section{INSTRUMENTOS DE AVALIAÇÃO UTILIZADOS EM SIMULAÇÃO}

Com a crescente propagação do uso da simulação clínica na educação em saúde, percebe-se uma disseminação de diversos instrumentos destinados a apoiar as mais variadas estratégias de avaliação do desempenho dos participantes nas práticas simuladas (KARDONG-EDGREN; ADAMSON; FITZGERALD, 2010).

Em estudo de revisão, os itens avaliados em simulação clínica que apareceram com maior frequência foram as habilidades procedimentais e de comunicação. Para apoio ao processo de avaliação, foram utilizados checklists, escalas validadas e/ou construídas pelos próprios autores com base em programas de qualidade e segurança do paciente e, até mesmo, o Mini-CEX (MIRANDA; MAZZO; PEREIRA JÚNIOR, 2018).

O Mini-CEX é um instrumento criado pela American Board of Internal Medicine para desenvolver a formação, a avaliação e a promoção da melhora do desempenho clínico de profissionais da saúde. Sua confiabilidade e impacto educacional positivo têm sido relatados em muitas especialidades; todavia, foi criado para a observação direta na prática clínica de anamnese, exame físico e habilidades de comunicação.

A Tabela 2 apresenta os principais instrumentos utilizados para avaliação de práticas simuladas nos últimos 15 anos.

\section{A EVOLUÇÃO DO CONCEITO DE COMPETÊNCIAS}

No processo de avaliação, deve ser possível identificar o avanço do estudante na aquisição de conhecimentos, habilidades, atitudes, valores e aptidões, os quais, em conjunto, estruturam as competências. É necessário identificar e reforçar os pontos fortes e as lacunas de aprendizagem de cada estudante, estabelecendo as estratégias corretivas e melhorias no processo de ensino e aprendizagem, estimulando a capacidade de autoavaliação e determinando a eficácia da ação do facilitador, assim como dos métodos de ensino empregados. O objetivo final deve ser a obtenção do mais alto nível de competência profissional dos aprendizes, justificando os recursos materiais, financeiros, estruturais e humanos investidos, e certificando com segurança a qualidade do estudante, a fim de garantir que a sociedade seja atendida por um profissional competente e autorizado para exercer a profissão (MONTIEL et al., 2012).

Diante das modificações do aprendizado clínico e da diversificação dos cenários de aprendizagem, os métodos de avaliação de competências em saúde necessitaram se adaptar aos novos métodos de ensino e aprendizagem, como a simulação clínica. Uma tendência do ensino em saúde é a utilização de estratégias que facilitem o processo de avaliação do estudante na observação durante o desenvolvimento de habilidades técnicas e não técnicas nas práticas clínicas (NOGUEIRA; RABEH, 2014). 
Tabela 2 - Diferentes instrumentos utilizados para avaliação de práticas simuladas.

\begin{tabular}{|c|c|c|c|}
\hline Estudo & Autores & $\begin{array}{l}\text { Instrumentos utilizados para } \\
\text { avaliação }\end{array}$ & Itens avaliados na simulação \\
\hline 1 & Yoo, M.S.; Yoo, Y. & $\begin{array}{l}\text { Checklist construído pelos } \\
\text { autores. }\end{array}$ & $\begin{array}{l}\text { Habilidades de comunicação e cuidados } \\
\text { com os pacientes. }\end{array}$ \\
\hline 2 & Baez, A. & $\begin{array}{l}\text { Checklist construído pelos } \\
\text { autores. }\end{array}$ & $\begin{array}{l}\text { Comunicação do estudante com paciente } \\
\text { em entrevistas clínicas. }\end{array}$ \\
\hline 3 & $\begin{array}{l}\text { Quest, T.E.; } \\
\text { Ander, D.S.; } \\
\text { Ratcliff, J.J. }\end{array}$ & $\begin{array}{l}\text { Checklist construído pelos } \\
\text { autores, denominado Affective } \\
\text { Competency Score (ACS). }\end{array}$ & $\begin{array}{l}\text { Comunicação e afetividade com o paciente } \\
\text { e familiar. }\end{array}$ \\
\hline 4 & $\begin{array}{l}\text { Kurz, J.M.; } \\
\text { Mahoney, K.; } \\
\text { Martin-Plank, } \\
\text { L.; Lidicker, J. }\end{array}$ & $\begin{array}{l}\text { Checklist construído pelos } \\
\text { autores. }\end{array}$ & Comunicação e atendimento clínico. \\
\hline 5 & $\begin{array}{l}\text { Jarzemsky, P.; } \\
\text { McCarthy, J.; } \\
\text { Ellis, N. }\end{array}$ & $\begin{array}{l}\text { Quality and Safety in the } \\
\text { Education of Nurses (QSEN). }\end{array}$ & $\begin{array}{l}\text { Conhecimentos, habilidades e atitudes nos } \\
\text { cuidados centrados no paciente, trabalho } \\
\text { em equipe, prática baseada em evidências, } \\
\text { segurança e recursos de informática. }\end{array}$ \\
\hline \multirow{3}{*}{6} & \multirow{3}{*}{$\begin{array}{l}\text { Carvalho, } \\
\text { I.P.; Pais, V.G.; } \\
\text { Almeida, S.S.; } \\
\text { Ribeiro-Silva, } \\
\text { R. et al. }\end{array}$} & 1) SEGUE framework. & $\begin{array}{l}\text { 1) Comunicação em momentos críticos, } \\
\text { podendo ser aplicado a diferentes } \\
\text { profissionais de saúde. }\end{array}$ \\
\hline & & $\begin{array}{l}\text { 2) Interpersonal and } \\
\text { Communication Skills Checklist } \\
\text { (ICSC). }\end{array}$ & $\begin{array}{l}\text { 2) Habilidades interpessoais e de } \\
\text { comunicação durante o início e o final da } \\
\text { entrevista com o paciente. }\end{array}$ \\
\hline & & 3) Self-efficacy. & $\begin{array}{l}\text { 3) Autoconfiança nas habilidades de } \\
\text { sensibilidade psicológica, sensibilidade } \\
\text { emocional, gestão da somatização, comunicação } \\
\text { diretiva e não diretiva com o paciente. }\end{array}$ \\
\hline \multirow{4}{*}{7} & \multirow{4}{*}{$\begin{array}{l}\text { Armstrong, } \\
\text { K.J.; Walker, S.; } \\
\text { Jarriel, A.J. }\end{array}$} & $\begin{array}{l}\text { Checklists construídos pelos } \\
\text { autores: }\end{array}$ & $\begin{array}{l}\text { 1) Opinião do paciente simulado sobre o } \\
\text { atendimento do estudante. }\end{array}$ \\
\hline & & $\begin{array}{l}\text { 1) Interpersonal skills/ } \\
\text { attributes evaluated by SPs } \\
\text { (avaliação dos pacientes } \\
\text { simulados). }\end{array}$ & 2) Habilidades técnicas e não técnicas. \\
\hline & & $\begin{array}{l}\text { 2) Standardized patient history } \\
\text { and physical examination } \\
\text { checklist: concussion evaluation } \\
\text { (avaliação do facilitador). }\end{array}$ & $\begin{array}{l}\text { 3) Autoavaliação respondida pelo } \\
\text { estudante. }\end{array}$ \\
\hline & & $\begin{array}{l}\text { 3) Student self-evaluation of } \\
\text { standardized patient evaluation: } \\
\text { autoavaliação do estudante. }\end{array}$ & \\
\hline 8 & $\begin{array}{l}\text { Cates, L.A.; } \\
\text { Wilson, D. }\end{array}$ & $\begin{array}{l}\text { National Association of } \\
\text { Neonatal Nurse Practitioners } \\
\text { (NANNP) Core Competencies. }\end{array}$ & $\begin{array}{l}\text { Competências para cuidados com } \\
\text { pacientes neonatais. }\end{array}$ \\
\hline 9 & $\begin{array}{l}\text { Kubota, Y.; } \\
\text { Yano, Y.; Seki, S.; } \\
\text { Takada, K. et al. }\end{array}$ & $\begin{array}{l}\text { Roter Interaction Analysis } \\
\text { System (RIAS). }\end{array}$ & $\begin{array}{l}\text { Comunicação entre profissionais e } \\
\text { pacientes. }\end{array}$ \\
\hline
\end{tabular}


Tabela 2 - Continuação...

\begin{tabular}{|c|c|c|c|}
\hline Estudo & Autores & $\begin{array}{l}\text { Instrumentos utilizados para } \\
\text { avaliação }\end{array}$ & Itens avaliados na simulação \\
\hline \multirow{2}{*}{10} & \multirow{2}{*}{$\begin{array}{l}\text { Young, K.H.; } \\
\text { Eun, K.; Lee, E.S. }\end{array}$} & $\begin{array}{l}\text { 1) Instrumento desenvolvido } \\
\text { por Yoo (2001). }\end{array}$ & $\begin{array}{l}\text { 1) Habilidades de comunicação com } \\
\text { paciente. }\end{array}$ \\
\hline & & $\begin{array}{l}\text { 2) Instrumento desenvolvido } \\
\text { por Yang e Park (2004). }\end{array}$ & 2) Competência clínica. \\
\hline 11 & $\begin{array}{l}\text { Waterval, } \\
\text { E.M.E.; Stephan, } \\
\text { K.; Peczinka, D.; } \\
\text { Shaw, A. }\end{array}$ & $\begin{array}{l}\text { Checklist construído pelos } \\
\text { autores. }\end{array}$ & $\begin{array}{l}\text { Habilidades de competência e teste de } \\
\text { avaliação de conhecimento, com base } \\
\text { na política do hospital e procedimento } \\
\text { padrão dos profissionais. }\end{array}$ \\
\hline \multirow{4}{*}{12} & \multirow{4}{*}{$\begin{array}{l}\text { Hinton, J.E.; } \\
\text { Mays, M.Z.; } \\
\text { Hagler, D.; } \\
\text { Randolph, } \\
\text { P. et al. }\end{array}$} & $\begin{array}{l}\text { 1) Nursing Performance Profile } \\
\text { (NPP). }\end{array}$ & 1) Competência dos enfermeiros. \\
\hline & & $\begin{array}{l}\text { 2) Instrument Taxonomy of } \\
\text { Error, Root Cause Analysis } \\
\text { Practice Responsibility } \\
\text { (TERCAP). }\end{array}$ & $\begin{array}{l}\text { 2) Competências relacionadas à segurança } \\
\text { do paciente. }\end{array}$ \\
\hline & & $\begin{array}{l}\text { 3) Nursing Performance Profile } \\
\text { (NPP) instrument competency } \\
\text { categories. }\end{array}$ & $\begin{array}{l}\text { 3) Responsabilidade profissional, defesa } \\
\text { do paciente, atenção, raciocínio clínico } \\
\text { percebido, raciocínio clínico entendido, } \\
\text { comunicação, prevenção, competência } \\
\text { processual, documentação. }\end{array}$ \\
\hline & & $\begin{array}{l}\text { 4) Clinical Competency } \\
\text { Assessment of Newly Licensed } \\
\text { Nurses (NCSBNs). }\end{array}$ & 4) Competência clínica. \\
\hline \multirow{3}{*}{13} & \multirow{3}{*}{$\begin{array}{l}\text { Hsu, L.L.; } \\
\text { Huang, Y.H.; } \\
\text { Hsieh, S.I. }\end{array}$} & $\begin{array}{l}\text { 1) Communication Competence } \\
\text { Scale (CCS). }\end{array}$ & 1) Competência em comunicação. \\
\hline & & $\begin{array}{l}\text { 2) Communication Self-Efficacy } \\
\text { Scale (CSES). }\end{array}$ & $\begin{array}{l}\text { 2) Comunicação com pacientes e } \\
\text { familiares. }\end{array}$ \\
\hline & & $\begin{array}{l}\text { 3) Communication Performance } \\
\text { Checklist (CPC). }\end{array}$ & $\begin{array}{l}\text { 3) Comunicação com pacientes } \\
\text { hospitalizados. }\end{array}$ \\
\hline \multirow{3}{*}{14} & \multirow{3}{*}{$\begin{array}{l}\text { Eun, K.; Kim, } \\
\text { H.Y. }\end{array}$} & $\begin{array}{l}\text { 1) Instrumento desenvolvido } \\
\text { por Yoon (2004). }\end{array}$ & 1) Pensamento crítico. \\
\hline & & $\begin{array}{l}\text { 2) Instrumento desenvolvido } \\
\text { por Yang e Park (2004). }\end{array}$ & 2) Competência clínica. \\
\hline & & $\begin{array}{l}\text { 3) Instrumento desenvolvido } \\
\text { por Woo (2000). }\end{array}$ & 3) Processo de resolução de problemas. \\
\hline 15 & $\begin{array}{l}\text { Franklin, A.E.; } \\
\text { Sideras, S.; } \\
\text { Gubrud-Howe, } \\
\text { P.; Lee, C.S. }\end{array}$ & $\begin{array}{l}\text { Creighton Simulation } \\
\text { Evaluation Instrument (CSEI). }\end{array}$ & Avaliação de competências. \\
\hline 16 & $\begin{array}{l}\text { Milner, K.A.; } \\
\text { Watson, S.M.; } \\
\text { Stewart, J.G.; } \\
\text { Denisco, S. }\end{array}$ & $\begin{array}{l}\text { Mini-Clinical Evaluation } \\
\text { Exercise (Mini-CEX). }\end{array}$ & $\begin{array}{l}\text { Habilidades e competências clínicas } \\
\text { gerais. }\end{array}$ \\
\hline
\end{tabular}


Tabela 2 - Continuação...

\begin{tabular}{|c|c|c|c|}
\hline Estudo & Autores & $\begin{array}{l}\text { Instrumentos utilizados para } \\
\text { avaliação }\end{array}$ & Itens avaliados na simulação \\
\hline \multirow[b]{2}{*}{17} & \multirow{2}{*}{$\begin{array}{l}\text { Bodamer, C.; } \\
\text { Feldman, M.; } \\
\text { Kushinka, J.; } \\
\text { Brock, E. }\end{array}$} & $\begin{array}{l}\text { 1) Standardized Simulation- } \\
\text { Based Examination (SSBE). }\end{array}$ & 1) Conhecimento e atitudes relacionados. \\
\hline & & $\begin{array}{l}\text { 2) United States Medical } \\
\text { Licensing Examination } \\
\text { (USMLE). }\end{array}$ & 2) Teste de conhecimento. \\
\hline 18 & $\begin{array}{l}\text { Franco, C.A.G.S.; } \\
\text { Franco, R.S.; } \\
\text { Santos, V.M.; } \\
\text { Uiema, L.A. }\end{array}$ & $\begin{array}{l}\text { Checklist construído pelos } \\
\text { pesquisadores. }\end{array}$ & Comunicação. \\
\hline
\end{tabular}

Em um ambiente simulado, a avaliação por competências vai muito além de um enfoque exclusivo em determinada ação. Engloba avaliar os conhecimentos, as habilidades e as atitudes dos aprendizes de maneira formativa, deliberada e contínua, em um processo complexo que vem sendo gradativamente construído (NOGUEIRA; RABEH, 2014). Pode abranger a solução de problemas, decisões éticas, tomada de decisão e desenvolvimento de intervenções. Ainda podem ser avaliadas competências globais para a prática clínica, como o trabalho em equipe, a tomada de decisão em situações com maiores complexidades, a comunicação com pacientes, familiares e profissionais, a liderança, entre outros (MAZZO et al., 2017).

Os marcos de competências são descrições narrativas de comportamentos em uma progressão contínua do desenvolvimento do aprendiz, em que ele inicia como um estudante principiante e avança ao longo de toda a formação até se tornar competente, podendo chegar a atingir o nível de um expert (após anos de prática deliberada) (PEREIRA JÚNIOR et al., 2015).

Um marco refere-se a um "ponto" dentro de uma competência ou subcompetência no progresso e confiabilidade da formação do aprendiz. Os marcos são claramente descritos e geralmente específicos da área da graduação ou especialidade. Por exemplo, um marco de competência para a medicina de emergência pode ser a habilidade de gerenciamento de vias aéreas para um paciente com insuficiência respiratória.

O uso dos marcos de competências supera todas as expectativas do aprendiz, pois o deixa ciente do que necessita desempenhar, desde as etapas iniciais de sua formação até as práticas educacionais supervisionadas finais, quando se espera que obtenha a especialização em determinada competência para atender às necessidades da assistência à saúde (ACCREDITATION COUNCIL FOR GRADUATE MEDICAL EDUCATION; AMERICAN BOARD OF EMERGENCY MEDICINE, 2013).

O progresso do aprendiz é mensurado, sendo possível determinar se houve progressão, estagnação ou regressão no desenvolvimento como uma indicação da ausência ou de necessidades específicas de correções. O marco de competência é equivalente ao comportamento observável dentro de cinco níveis de proficiência, e por meio deles os estudantes demonstram os conhecimentos, habilidades, atitudes e desempenho que refletem cada um desses níveis de desenvolvimento (PEREIRA JÚNIOR et al., 2015).

Essas descrições narrativas do comportamento dos aprendizes têm sido efetivas para organizar ações mais complexas e em grande quantidade, permitindo a possibilidade de feedback formativo para estímulo a mudanças nos comportamentos observados, além de possibilitar uma maior precisão na aplicação de escalas e estratégias avaliativas (LOMIS et al., 2017).

No entanto, as descrições das competências são contextuais e independentes, portanto não definem a complexidade de implementação em ambiente clínico, no qual as habilidades serão demonstradas (TEN CATE, 2013). Assim, Olle Ten Cate buscou preencher a lacuna entre a teoria e a prática clínica, apresentando as Entrustable Professional Activities (EPAs), reconhecidas internacionalmente como uma estrutura para avaliação significativa da competência durante a formação do graduando, a residência médica e a recertificação profissional. (TEN CATE, 2013). 
As EPAs representam uma unidade de prática profissional que pode ser confiada a um estudante ou ao profissional competente e que requer proficiência em múltiplas competências simultaneamente. Essa abordagem fornece um enfoque amplo e prático para a avaliação, uma vez que não avalia as competências de maneira individual ou isolada (TEN CATE, 2013).

As EPAs estão vinculadas a decisões de atribuição, ou seja, avaliam se o aprendiz pode realizar determinadas atividades de prática clínica sob um nível designado de supervisão. Os aprendizes podem ser incumbidos das responsabilidades ou tarefas que devem ser feitas no cuidado ao paciente, as quais podem ser pequenas ou grandes, ou seja, simples ou complexas, mas que normalmente são atividades com início e fim, e são confiadas somente a pessoas competentes (TEN CATE, 2018).

Assim, as EPAs caracterizam-se como uma evolução do conceito educacional com base em competências, em que se aplica o conceito de competências de um aprendiz em contextos específicos no local de prática clínica, constituindo uma descrição do trabalho e sendo independentes das pessoas (TEN CATE et al., 2015).

As EPAs definem operacionalmente uma profissão, formando uma lista de tarefas específicas que devem ocorrer em um período de tempo planejável; já as competências estão ligadas às pessoas. Para os aprendizes se tornarem profissionais confiáveis, eles devem adquirir competências, que incluem conhecimento, habilidades e atitudes (TEN CATE, 2018).

Assim, existe a possibilidade de avaliar se os aprendizes podem executar as tarefas de forma independente ou não. Pode-se definir qual o rol de EPAs a serem almejadas pelos aprendizes iniciantes e intermediários ou para aqueles que já possuem expertise suficiente para a realização autônoma da atividade prática (TEN CATE et al., 2015).

Conforme Ten Cate (2018), as EPAs só podem ser delegadas aos estudantes se eles forem considerados competentes para desenvolvê-las. A decisão de transferir a responsabilidade para um aprendiz é chamada de atribuição, que são decisões tomadas para as responsabilidades futuras que o estudante deve apresentar a partir de determinado momento. $O$ estudante é avaliado com base na sua capacidade e, consequentemente, conquista o direito e o dever de estar envolvido no atendimento clínico dos pacientes.

Os níveis de supervisão são detalhados como: 1) não há permissão para agir, apenas observar;
2) permissão para agir com supervisão direta, e o supervisor presente na sala;

3) permissão para agir com supervisão indireta, não presente, mas rapidamente disponível se necessário;

4) permissão para atuar sob supervisão distante, não diretamente disponível ("sem supervisão");

5) permissão para fornecer supervisão a jovens estagiários (TEN CATE et al., 2015).

Enquanto em currículos tradicionais essas oportunidades são oferecidas aos estudantes no final do curso, em currículos fundamentados em EPAs elas ocorrem em vários momentos ao longo da formação, ou seja, assim que houver uma confiança fundamentada e justificada de que o estudante tenha demonstrado os objetivos propostos para exercer a EPA determinada. Desta forma, em currículos com base em EPAs, a progressão dos estudantes é baseada em competências, e não apenas no tempo (TEN CATE, 2018).

Os marcos de competência fornecem um roteiro da aprendizagem para que os aprendizes tenham uma visão geral da evolução necessária e esperada do seu desempenho ao longo da formação, enquanto o uso das EPAs apresenta as seguintes vantagens (PEREIRA JÚNIOR et al., 2015):

- são atividades que fazem sentido para professores, estagiários e público;

- representam o trabalho do dia a dia do profissional;

- situam as competências e seus marcos no contexto clínico;

- fazem uma avaliação mais prática por marcos utilizando agrupamento de atividades significativas;

- adicionam explicitamente as noções de confiança e supervisão na equação de avaliação.

\section{OS PROCESSOS DE AVALIAÇÃO EM LARGA ESCALA COM PROVAS PRÁTICAS: A EXPERIÊNCIA DO REVALIDA}

Existe uma crescente pressão no sentido de comprovar que o ensino traz efetivamente resultados. Isso faz com que as instituições acadêmicas e as organizações profissionais se autorregulem e estipulem parâmetros de referência de qualidade, mas representa, principalmente, uma resposta à exigência do público para assegurar que os médicos são competentes e confiáveis, sobretudo em um cenário de abertura de grande número de escolas médicas em todo o país. 
Na Medicina, as experiências com avaliações simuladas têm sido diversas e realizadas em diferentes escalas de números de candidatos, como nas provas de residência médica e de revalidação de diplomas.

A prova de revalidação de diplomas de médicos formados no exterior para atuação no Brasil, chamada de Revalida, foi iniciada por meio da Portaria Interministerial MEC/MS n ${ }^{\circ} 278$, de 17 de março de 2011, com aplicação em duas fases: primeira fase com avaliação teórica (100 questões de múltipla escolha e 5 questões discursivas, sendo, respectivamente, 20 testes e uma discursiva de cada uma das cinco grandes áreas da Medicina - pediatria, clínica médica, cirurgia geral, ginecologia/obstetrícia e saúde coletiva/medicina de família e comunidade), de caráter eliminatório para quem não atingiu a nota corte; e segunda fase com avaliação prática, também de caráter eliminatório. A prova prática é composta por 10 estações práticas simuladas, sendo 2 de cada grande área da Medicina. A duração de cada estação é de 10 minutos, sendo realizadas 5 estações (uma de cada área) no sábado e as outras 5 no domingo, em sistema de rodízio após confinamento dos candidatos, divididos em um grupo no período da manhã e outro no da tarde. O confinamento garante a ausência de contato entre candidatos que já fizeram a prova prática e aqueles que ainda farão.

As provas teóricas e práticas são elaboradas por uma subcomissão de professores médicos especialistas, selecionados pelo Instituto Nacional de Estudos e Pesquisas Educacionais Anísio Teixeira (INEP) com total sigilo do conteúdo.

A subcomissão do Revalida elabora as questões de múltipla escolha e discursivas que são enviadas aos professores, os quais se cadastram no Banco Nacional de Itens (BNI) e selecionam as questões finais que irão compor a prova da primeira fase do exame nacional. Também elabora as 10 estações práticas que irão compor a prova prática da segunda fase. A montagem da prova prática conta com instruções para os candidatos, examinadores e pacientes simulados (scripts de atuação), bem como lista os materiais necessários e orienta a disposição geográfica de mesas, cadeiras e macas na sala de avaliação, além da posição dentro da sala onde deverão ficar o candidato, o examinador e o videomaker. A subcomissão também elabora os itens do instrumento padronizado de avaliação (checklist) que o examinador irá utilizar na avaliação dos candidatos, sendo capacitado para preenchê-lo no dia anterior ao início do exame nacional. Cada checklist é composto de diferentes números de tópicos com um conjunto de subitens (em geral, no total não mais que 20), com diferentes ponderações definidas pela subcomissão.

A prova prática da segunda fase do Revalida nos anos de 2011, 2012 e 2013 foi realizada em apenas um local (Brasília/DF) por causa do pequeno número de candidatos: 96, 98 e 155, respectivamente. Em 2014, também foi realizada em um único local (São Paulo/SP), porém com 843 candidatos, o que causou muitos transtornos. Nas edições de 2015 e 2016, a prova adquiriu características de avaliação em larga escala, tendo, respectivamente, 1.920 e 2.400 candidatos. Em razão disso, foram necessárias várias mudanças logísticas para aplicação da prova prática, sendo, em 2016, realizada simultaneamente em 7 cidades (Porto Alegre/RS 2 locais -, Florianópolis/SC, Curitiba/PR, São Paulo/ SP, Brasília/DF - 3 locais -, Fortaleza/CE e São Luiz/MA) com 10 locais de aplicação.

Os pacientes simulados foram selecionados em cada cidade de aplicação da prova prática e capacitados em um curso de 32 horas uma semana antes da prova prática por um grupo de professores de artes cênicas. Os examinadores foram selecionados e participaram de capacitação de 8 horas na tarde anterior ao início da segunda fase do Revalida.

No início da manhã de cada dia da aplicação da prova prática, os pacientes simulados e examinadores selecionados para as estações, já confinados, recebiam as orientações escritas e assistiam aos vídeos com as instruções sobre as cinco estações práticas a serem realizadas naquele dia, tanto no sábado como no domingo. Os pacientes simulados também estudavam seus scripts com os examinadores que estariam responsáveis pela avaliação das mesmas estações práticas, aproveitando-se nesse momento para tirar as dúvidas.

Por uma questão legal presente no edital, todas as provas práticas realizadas pelos candidatos foram filmadas para eventuais recursos jurídicos que pudessem ser impetrados com solicitações de reavaliação das notas. Assim, para cada candidato presente na segunda fase do Revalida, havia 10 filmagens de 10 minutos de cada estação prática realizada pelo candidato. Entre as queixas dos candidatos estavam incluídas a falta de padronização do desempenho dos pacientes simulados. Assim, indaga-se como era a relação desses indivíduos com os examinadores; se a performance dos candidatos afetava o processo de avaliação; e se as questões éticas relacionadas ao nível do exame interferiam no processo e no seu nível de formação.

O Gráfico 1 mostra o comparativo dos resultados na $1^{\text {a }}$ fase e a variação percentual de aprovação 
nas edições do Revalida de 2011 a 2020. A série histórica demonstra que o exame tem ampliado progressivamente a quantidade de participantes na $1^{\text {a }}$ fase a cada edição, mostrando o grande número de formandos no exterior, a maioria de brasileiros que tenta revalidar seus diplomas médicos no Brasil.

Em 2018 e 2019, não ocorreram edições do Revalida por causa da grande quantidade de recursos judiciais (1.377) impetrados pelos candidatos na edição de 2017. Com isso, a edição de 2017 ocorreu apenas em novembro de 2018.

A Gráfico 2 mostra o comparativo dos resultados da $2^{\text {a }}$ fase e a projeção de variação percentual do Revalida de 2011 a 2017. Neste gráfico, consideram-se inscritos os mesmos apresentados na referência à $1^{a}$ fase. Identifica-se expansão no número de aprovados na $2^{\text {a }}$ fase, como no caso de 2015 , com 1.683 aprovados, porém houve decréscimo em 2016. Quando se analisa a variação percentual, identifica-se aumento expressivo do número de aprovados, atingindo aumento de $2.255 \%$ em 2016, comparado com 2011.
Na edição de 2017, dos 7.379 médicos formados no exterior que tentaram revalidar o diploma, 963 foram considerados aptos na primeira etapa do processo. Desse total, 941 fizeram as provas de habilidades clínicas da segunda etapa e apenas 389 passaram $(5,27 \%)$ e conseguiram do governo federal a autorização para validar seus diplomas e exercerem a Medicina no Brasil.

Dessa forma, a cada edição do Revalida, considerando a aplicação da $1^{\mathrm{a}}$ e $2^{\mathrm{a}}$ fases, o percentual de aprovados é mostrado na Tabela 3.

Na edição de 2020, dos 15.580 candidatos inscritos, 13.961 (89,6\%) efetivamente fizeram as provas objetiva e discursiva da primeira fase, as quais ocorreram no mesmo dia (06/12/2020). Na correção da prova objetiva, 3.031 candidatos $(21,7 \%)$ superaram a nota de corte e tiveram suas provas discursivas corrigidas. Desse total, 2.402 candidatos (ou seja, 79,2\% dos candidatos que superam a nota de corte da prova objetiva) passaram para a $2^{\text {a }}$ fase, sendo selecionados para a realização da prova prática de habilidades médicas. Até a finali-

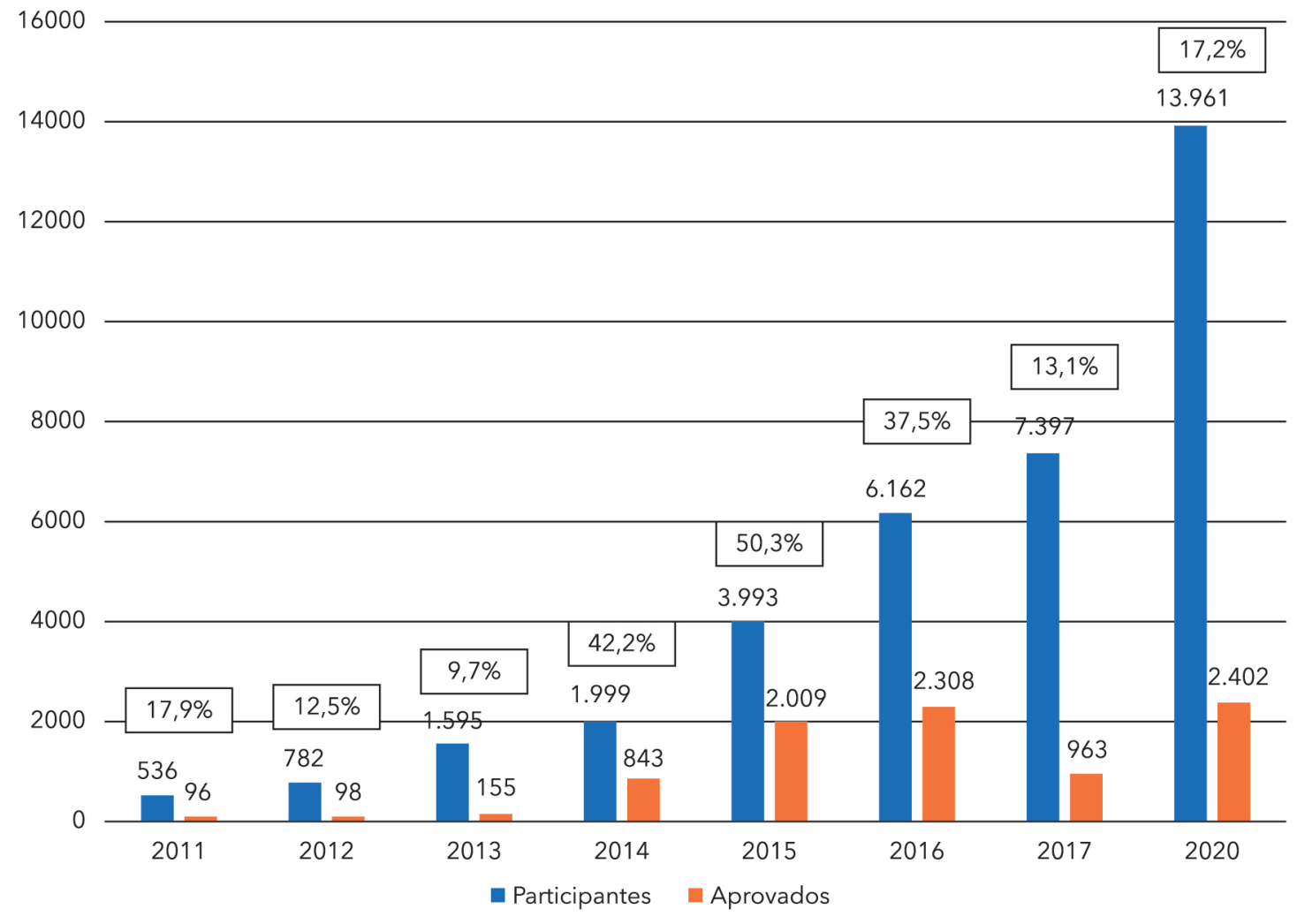

Gráfico 1 - Número de candidatos participantes e aprovados na 1ª fase (provas objetivas) do Revalida de 2011 a 2020. Nos retângulos, está o percentual de aprovação a cada edição da $1^{\text {a }}$ fase em todas as edições. 


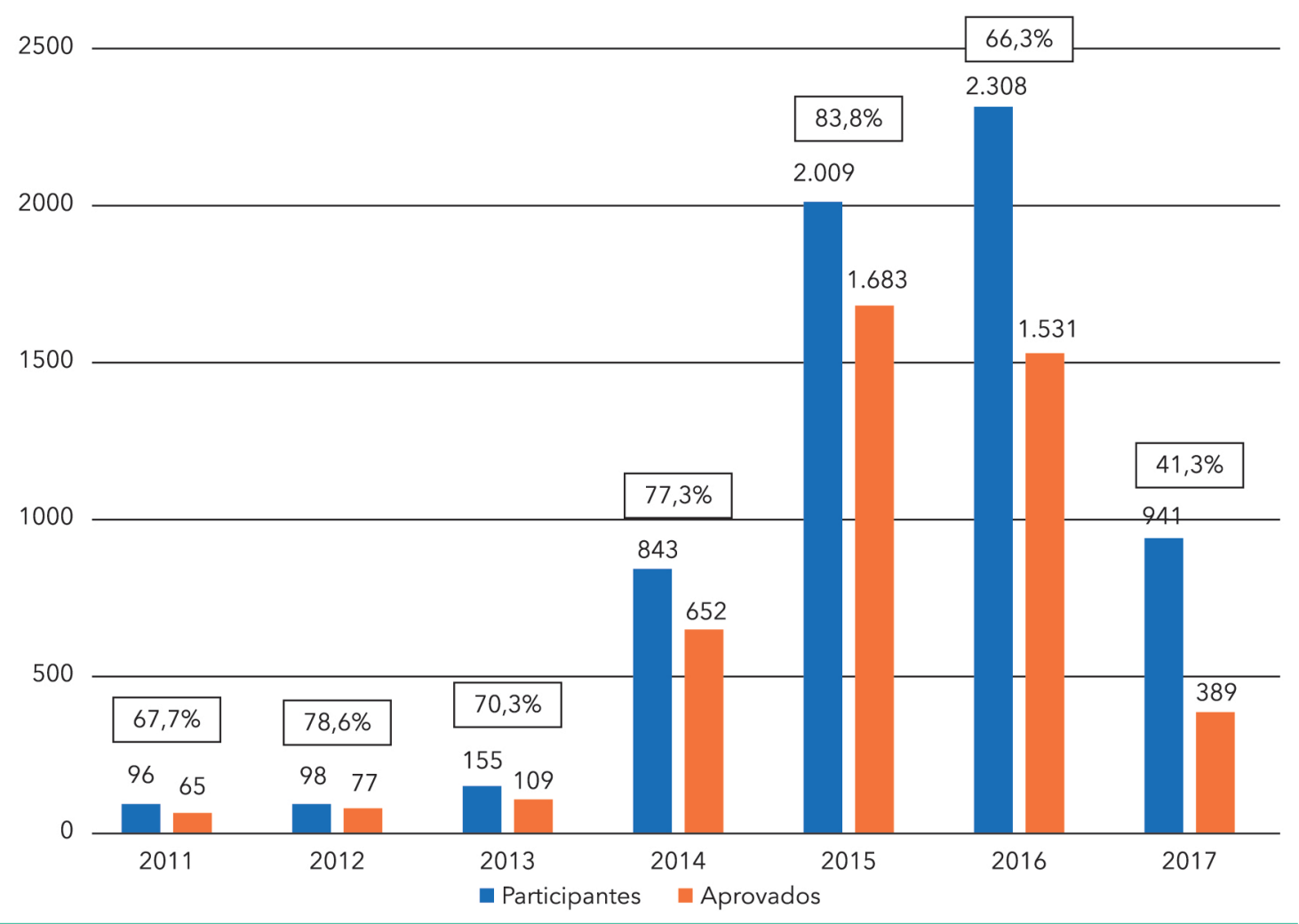

Gráfico 2 - Número de candidatos participantes e aprovados na 2a fase (prova prática) do Revalida de 2011 a 2017 . Nos retângulos, está o valor percentual de aprovação a cada edição da $2^{a}$ fase em todas as edições.

Tabela 3 - Percentual de aprovação dos candidatos inscritos nas duas fases do Revalida a cada edição.

\begin{tabular}{|c|c|c|c|c|c|c|c|}
\hline Edição & $\mathbf{2 0 1 1}$ & $\mathbf{2 0 1 2}$ & $\mathbf{2 0 1 3}$ & $\mathbf{2 0 1 4}$ & $\mathbf{2 0 1 5}$ & $\mathbf{2 0 1 6}$ & $\mathbf{2 0 1 7}$ \\
\hline Aprovados & $12,10 \%$ & $9,85 \%$ & $6,83 \%$ & $32,6 \%$ & $42,1 \%$ & $24,84 \%$ & $5,27 \%$ \\
\hline
\end{tabular}

zação deste texto, não havia sido realizada a $2^{\mathrm{a}}$ fase do Revalida 2020.

\section{CONSIDERAÇÕES FINAIS}

Um programa de avaliações planejado e executado de modo criterioso, com foco no debriefing/feedback e na identificação/correção das lacunas de aprendizagem, promove o crescimento pessoal e profissional do aprendiz e contribui para o aprimoramento do processo educacional. Deve ser abrangente, incluindo os diversos atributos que compõem a formação pessoal e profissional, priorizando as habilidades de comunicação e relacionamento, a avaliação reflexiva e a consciência precoce da necessidade de educação permanente, não se restringindo apenas às habilidades cognitivas, psicomotoras e afetivas, mas também às habilidades não técnicas. Isso possibilita a formação de profissionais com melhor compreensão das necessidades de saúde da população e mais capacitados para o desempenho de suas atividades.

Os problemas utilizados na prática avaliativa devem refletir o mundo real, cujos problemas têm se apresentado cada vez mais complexos e indeterminados, fazendo com que os estudantes tenham que tomar decisões sob condições de incerteza, lidando com a ambiguidade e alguns "aparentes" paradoxos. Se isso não for superado pelas práticas academicamente estruturadas, haverá a formação de profis- 
sionais sem o adequado preparo para o mundo real do trabalho a que estarão expostos.

Desta forma, a melhor articulação entre teoria e prática no contexto acadêmico e profissional durante a formação profissional implica o estabelecimento de relações entre a produção de vários tipos de conhecimento, seu uso no contexto profissional e a educação permanente.

Quando se aprofunda na avaliação das atividades práticas, tendo em vista a construção da integralidade da assistência, não há como deixar de reconhecer a dificuldade que ocorre pela falta da interdisciplinaridade, do trabalho em equipe e do cuidado que deveria ser organizado de forma multiprofissional. Esses fatores são muito pouco contemplados nos processos formativos, e, assim, fica difícil trabalhar junto profissionalmente no futuro, se houver uma formação sem essa necessária valorização.

O resultado disso é a prevalência da visão corporativista das categorias profissionais, que acaba sendo prejudicial ao melhor interesse dos pacientes. A maneira de reverter a situação atual é a construção de uma educação interprofissional para os cursos da área da saúde. A integralidade da atenção precisa estar contemplada nos objetivos de aprendizagem dos cursos. Para isso, as diversas competências necessárias devem estar bem definidas, e os cenários de prática devem privilegiar a vivência dos estudantes com os pacientes e com a comunidade dentro de sua realidade social e dos serviços de saúde. Nesta conjuntura, diversas maneiras de avaliação formativa, que permitam a reflexão sobre as ações desempenhadas, devem integrar a aquisição das competências.

A consolidação de uma nova "cultura avaliativa" na área da saúde que supere a atual abordagem punitiva demandará aprofundamento de conceitos de construção de currículos, objetivos de aprendizagem, seleção de conteúdos, aplicação de metodologias ativas, utilização de diferentes tecnologias de informação e comunicação, pactuação de critérios, elaboração de instrumentos de avaliação e capacitação dos professores como elaboradores e revisores de itens e de estações práticas para que esses conhecimentos sejam democratizados e reorientem o processo de ensino e aprendizagem.

\section{REFERÊNCIAS}

ACCREDITATION COUNCIL FOR GRADUATE MEDICAL EDUCATION; AMERICAN BOARD OF EMERGENCY MEDICINE. The Emergency Medicine Milestone Project. East Lansing: ACGME, ABEM, 2013. AGUIAR, A. C.; RIBEIRO, E. C. O. Conceito e avaliação de habilidades e competência na educação médica: percepções atuais dos especialistas. Revista Brasileira de Educação Médica, Brasília, v. 34, n. 3, p. 371-378, 2010.

ALINIER, G. A typology of educationally focused medical simulation tools. Medical Teacher, London, v. 29, p. 243250, 2007.

BING-YOU, R. et al. The art (and artifice) of seeking feedback: clerkship students' approaches in asking for feedback. Academic Medicine, Philadelphia, 2018.

BOKKEN, L. et al. Feedback by simulated patients in undergraduate medical education: a systematic review of the literature. Medical Education, Oxford, v. 43, p. 202-210, 2009.

BORDENAVE, J. E. D.; PEREIRA, A. M. Estratégias de ensino- aprendizagem. 4. ed. Petrópolis, RJ: Vozes, 1982.

BRANDÃO, C. F. S.; COLLARES, C. F.; MARIN, H. F. A simulação realística como ferramenta educacional para estudantes de medicina. Scientia Medica, Porto Alegre, v. 24, n. 2, p. 187-192, 2014.
BRASIL. CONSELHO NACIONAL DE EDUCAÇÃO. Câmara de Educação Superior. Resolução no ${ }^{\circ}$. 3, de 20 de junho de 2014. Institui Diretrizes Curriculares Nacionais do Curso de Graduação em Medicina e dá outras providências. Diário Oficial da República Federativa do Brasil, Brasília, DF, 23 jun. 2014. Seção 1, p. 8-11.

BRUNCKHORST, O. et al. Training, simulation, the learning curve, and how to reduce complications in urology. European Urology Focus, Amsterdam, v. 2, n. 1, p. 10-18, 2016.

COHEN, R. et al. Validity and generalizability of global ratings in an objective structured clinical examination. Academic Medicine, Philadelphia, v. 66, p. 545-548, 1991.

DIECKMANN, P. et al. The art and science of debriefing in simulation: ideal and practice. Medical Teacher, London, v. 31, p. 287-294, 2009.

DOMURACKI, K. et al. Learning on a simulator does transfer to clinical practice. Resuscitation, London, v. 80, p. 346-349, 2009.

EVAIN, J. N. et al. Team planning discussion and clinical performance: a prospective, randomised, controlled simulation trial. Anaesthesia, v. 74, n. 4, p. 488-496, 2019. FAROOQ, O. et al. Comparison of oral and video debriefing and its effect on knowledge acquisition following 
simulation-based learning. BMJ Simulation \& Technology Enhanced Learning, London, v. 3, p. 48-53, 2017.

FRANCO, C. A. G. S. et al. OSCE para competências de comunicação clínica e profissionalismo: relato de experiência e meta-avaliação. Revista Brasileira de Educação Médica, Brasília, v. 39, n. 3, p. 433-441, 2015.

GABA, D. M. Do as we say, not as you do: using simulation to investigate clinical behavior in action. Simulation in Healthcare, Hagerstown, v. 4, n. 2, p. 67-69, 2009.

GLEESON, F. AMEE Education Guide No. 9: Assessment of Clinical Competence using the Objective Structured Long Examination Record (OSLER) Dundee: Association for Medical Education in Europe, 1997.

GODFREY, R. C. Undergraduate examinations - A continuing tyranny. BMJ (Clinical Research Ed.), v. 345, p. 765-767, 1995.

GONTIJO, E. D. et al. Matriz de Competências Essenciais para a Formação e Avaliação de Desempenho de Estudantes de Medicina. Revista Brasileira de Educação Médica, Brasília, v. 37, n. 4, p. 526-539, 2013.

GORDON, M., FARNAN, J., GRAFTON-CLARKE, C., AHMED, R., GURBUTT, D., MCLACHLAN, J., et al. Nontechnical skills assessments in undergraduate medical education: A focused BEME systematic review: BEME Guide no. 54. Medical Teacher, v. 8, p. 1-14. 2019.

HARDEN, R. M. C. G. et al. Assessment of clinical competence using objective structured examination. British Medical Journal, London, n. 1, p. 447-451, 1975.

HOFMANN, B. Why simulation can be efficient: on the preconditions of efficient learning in complex technology based practices. BMC Medical Education, v. 9, n. 48, p. $1-6,2009$.

JAYAKUMAR, K. L. Realism challenges in documentation components of objective structured clinical examinations. Academic Medicine, Philadelphia, v. 93, n. 1, p. 10-11, 2018. KARDONG-EDGREN, S.; ADAMSON, K. A.; FITZGERALD, C. A. Review of Currently Published Evaluation Instruments for Human Patient Simulation. Clinical Simulation in Nursing, v. 6, n. 1, p. 25-35, 2010.

KAUFMAN, D. M.; MANN, K. V. Teaching and learning in medical education: how theory can inform practice. In: SWANWICK, T. Understanding Medical Education: evidence, Theory and practice. Oxford, London: WileyBlackwell, 2010. p. 246-258.

KNEEBONE, R. Perspective: simulation and transformational change: the paradox of expertise. Academic Medicine, Philadelphia, v. 84, n. 7, p. 954-957, 2009.

LATEEF, F. Simulation based learning: just like the real thing. Journal of Emergencies, Trauma and Shock, New Delhi, v. 3, p. 348-352, 2010.

LEE, J. T. et al. The utility of endovascular simulation to improve technical performance and stimulate continued interest of preclinical medical students in vascular surgery.
Journal of Surgical Education, New York, v. 66, p. 367373, 2009.

LIMA, V. V. Avaliação de Competência nos Cursos Médicos. In: MARINS, J. J. N.; REGO, S., LAMPERT, J. B., ARAÚJO, J. G. (Orgs.). Educação Médica em Transformação: instrumentos para a construção de novas realidades. São Paulo: Hucitec; Rio de Janeiro: Abem; p.123-40, 2004.

LOCKYER, J. Multisource feedback in the assessment of physician competencies. The Journal of Continuing Education in the Health Professions, New York, v. 23, n. 1, p. 4-12, 2003.

LOMIS, K. D. et al. Competency milestones for medical students: design, implementation, and analysis at one medical school. Medical Teacher, London, v. 39, n. 5, p. 494-504, 2017.

LOPREIATO, J. O. et al. Terminology \& Concepts Working Group. Healthcare simulation dictionary. Orlando: $\mathrm{SSH}$, 2016.

MARTIN, J. A. et al. Objective structured assessment of technical skill (OSATS) for surgical residents. British Journal of Surgery, v. 84, p. 273-278, 1997.

MAZZO, A. et al. Simulação: conceitos básicos. In: SCALABRINI NETO, A.; FONSECA, A.S.; BRANDÃO, C.F.S. Simulação realística e habilidades na saúde. 1. ed. Rio de Janeiro: Atheneu, 2017. cap.6. p. 49-57.

MIQUELANTE, M. A. et al. As modalidades da avaliação e as etapas da sequência didática: articulações possíveis. Trabalhos em Linguística Aplicada, Campinas, v. 56, n. 1, p. 259-299, 2017.

MIRANDA, F.B.G.; MAZZO, A.; PEREIRA JUNIOR, G.A. Avaliação de competências individuais e interprofissionais de profissionais de saúde em atividades clínicas simuladas: scoping review. Interface, v. 22, n. 67, p. 1221-1234, 2018.

MONTIEL, I. D. et al. 2012. Evaluación de competencias en ciencias de la salud. México: UNAM: Editorial Médica Panamericana.

MOORTHY, K. et al. Objective assessment of technical skills in surgery. BMJ (Clinical Research Ed.), v. 327, n. 7422, p. 1032-1037, 2003.

MUNRO, N. et al. Developing a new clinical skills assessment (CSA) for licensing UK general practitioners: the why, the how and the when. Education for Primary Care, v. 17, n. 4, p. 301-310, 2006.

NEGRI, E. C. et al. Clinical simulation with dramatization: gains perceived by students and health professionals. Revista Latino-Americana de Enfermagem, Ribeirão Preto, v. 25, p. e2916, 2017.

NORCINI, J. J. et al. The mini-CEX: a method for assessing clinical skills. Annals of Internal Medicine, v. 138, n. 6, p. 476-481, 2003.

NORCINI, J. J.; MCKINLEY, D. W. Assessment methods in medical education. Teaching and Teacher Education, v. 23, p. 239-250, 2007.

MURPHY, J. G. et al. Is simulation-based medicine training the future of clinical medicine? European Review for 
Medical and Pharmacological Sciences, v. 11, n. 1, p. 1-8, 2007.

NOGUEIRA, P. C.; RABEH, S. A. N. Avaliação por competência no ensino simulado. In: MARTINS, J.C.A. et al. A simulação no ensino de enfermagem. Ribeirão Preto: SOBRACEN, 2014.

PACES. Practical Assessment of Clinical Examination Skills. The new MRCP(UK) Clinical Examination. Journal of the Royal College of Physicians of London, London, v. 34, n. 1, p. 57-60, 2000.

PATRÍCIO, M. F. et al. Is the osce a feasible tool to assess competencies in undergraduate medical education. Medical Teacher, v. 35, n. 6, p. 503-514, 2013.

PELIZZARI, A. et al. Teoria da aprendizagem significativa segundo Ausubel. Revista PEC, Curitiba, v. 2, n. 1, p. 37-42, 2002 .

PEREIRA JÚNIOR, G. A. et al. O Ensino de Urgência e Emergência de acordo com as novas Diretrizes Curriculares Nacionais e a Lei do Mais Médicos. Cadernos ABEM, v. 11, p. 20-47, 2015.

PERRENOUD, P. As competências para ensinar no século XXI: A formação dos professores e o desafio da avaliação. Porto Alegre: ArtMed; 2002

PRINCE, L. K. et al. Expanding the role of objectively structured clinical examinations in nephrology training. American Journal of Kidney Diseases, v. 63, n. 6, p. 906912, 2014.

QUIRÓS, S. M.; VARGAS, M. A. O. Simulação clínica: uma estratégia que articula práticas de ensino e pesquisa em enfermagem. Texto Contexto Enferm, Florianópolis, v. 23, n. 4, p. 813-814, 2014.

SALAS, E. et al. Performance measurement in simulationbased training: A review and best practices. Simulation \& Gaming, v. 40, p. 328, 2009.

SAMPAIO, A. M. B.; PRICINOTE, S. C. M. N.; PEREIRA, E. R. S. Avaliação clínica estruturada. Revista Eletrônica Gestão \& Saúde, v. 5, n. 2, p. 410-426, 2014.

SANTOS, J. E. M. Checklist. Jornal Português de Gastrenterologia, Lisboa, v. 18, n. 2, p. 93-94, 2011.

SHANKS, D. et al. Use of simulator-based medical procedural curriculum: the learner's perspectives. BMC Medical Education, v. 10, n. 77, p. 1-7, 2010.

SKRZYPEK, A. et al. The objective structured clinical examination (OSCE) from the perspective of $3 \mathrm{rd}$ year's medical students - A pilot study. Folia Medica Cracoviensia, v. 58, n. 3, p. 67-75, 2017.

TEN CATE, O. Nuts and bolts of entrustable professional activities. Journal of Graduate Medical Education, v. 5, n. 1, p. 157-158, 2013.

TEN CATE, O. et al. Curriculum development for the workplace using Entrustable Professional Activities (EPAs): AMEE Guide No. 99. Medical Teacher, v. 37, n. 11, p. 983$1002,2015$.

TEN CATE, O. A primer on entrustable professional activities. Korean Journal of Medical Education, v. 30, n. 1, p. 1-10, 2018.

TRONCON, L.E.A. Avaliação do Estudante de Medicina. Medicina, Ribeirão Preto, v. 29, p. 429-439, 1996.

WAYNE, D. B.; MCGAGHIE, W. C. Use of simulation-based medical education to improve care quality. Resuscitation, v. 81, p. $1455-1456,2010$.

WEINBERG, D.; SINHA, Y.; SALEH, M. Manikins in objective structured clinical examinations: personal experiences. The Clinical Teacher, v. 11, n. 6, p. 429430, 2014.

WOO, O. H. The effects of a PBL (Problem-based learning) on the problem solving process students by their meta-cognitive levels. Cheongwon: Korea National University of Education, 2000.

YANG, J.; PARK, M. The relationship of clinical competence and self-directed learning in nursing students. Journal of Korean Academic Society of Nursing Education, Korea, v. 10, n. 2, p. 271-277, 2004.

YOO, M. S. The effectiveness of standardized patient managed instruction for a fundamental nursing course. Journal of Korean Academic Society of Nursing Education, Korea, v. 7, n. 1, p. 94-112, 2001.

YOON, J. Development of an instrument for the measurement of critical thinking disposition in nursing. Seoul, Korea: The Catholic University of Education, 2004. p. 69.

ZEFERINO, A. M. B; PASSERI, S. M. R. R. Avaliação da aprendizagem do estudante. Cadernos ABEM, Rio de Janeiro, v. 3, p. 39-43, 2007a.

ZEFERINO, A. M. B.; DOMINGUES, R. C. L.; AMARAL, E. Feedback como Estratégia de Aprendizado no Ensino Médico. Revista Brasileira de Educação Médica, v. 31, n. 2, p. 176-179, 2007b. 
CAPÍTULO 13

-

\section{Avaliação com o uso de Checklists e Escalas de Avaliação Global}




\section{Renato Soleiman Franco}

Psiquiatra

Professor Adjunto - Curso

de Medicina da PUCPR

Coordenador do Programa de Residência

Médica em Psiquiatria da Prefeitura

Municipal de Curitiba, SMS/FEAS.

\section{Camila Ament Giuliani}

\section{dos Santos Franco}

Médica de Família e Comunidade

Professora Adjunta - Curso

de Medicina - PUCPR

Professora no Curso de Medicina

nas Faculdades Pequeno

Príncipe, Curitiba, PR.

Preceptora responsável pela

disciplina de Comunicação Clínica na

Residência Médica em Medicina de

Família e Comunidade - Residência

Integrada, Curitiba, PR.

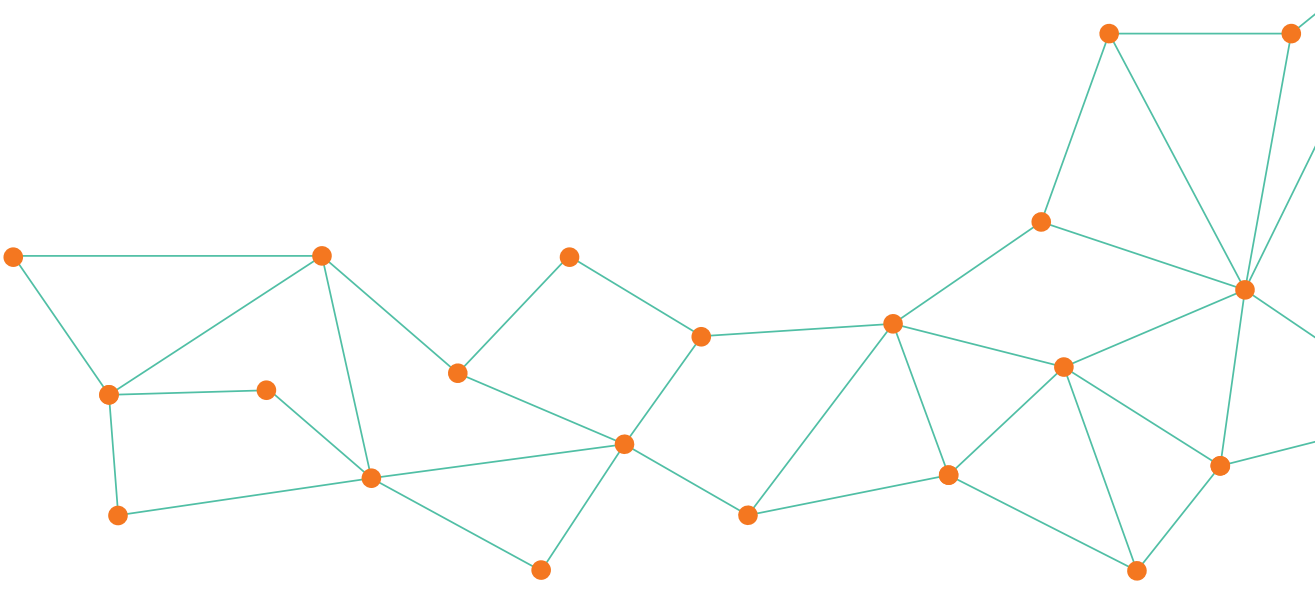

\section{INTRODUÇÃO}

Os checklists e as escalas globais são utilizados para avaliação em diversos contextos na simulação e podem estar presentes tanto em avaliações formativas quanto somativas. Ambos têm como objetivo oferecer um parâmetro objetivo do que é esperado que seja realizado. É preciso que sejam elaborados com bastante cuidado e atenção, uma vez que, muitas vezes, são a base para discutir os elementos de aprendizagem tanto com professores (ou tutores) quanto com os trainees. De forma geral, checklists consistem em itens detalhados de desempenho, como, por exemplo, "lavou as mãos", "introduz-se para o paciente" ou "mede a pressão arterial com um manguito de tamanho apropriado." Esses itens normalmente são qualificados em escalas binárias, como "concluído" ou "não concluído", "realizado ou não realizado", escalas com gradação, escalas tipo Likert, entre outras (SWANSON; VAN DER VLEUTEN, 2013).

Assim, os checklists avaliam o desempenho de cada elemento observável de determinada competência. Por outro lado, a avaliação global é uma avaliação geral ou subdividida em subdomínios de competências (ILGEN et al., 2015). Por exemplo: o exame físico e as habilidades de comunicação podem ser dois subdomínios diferentes. Ao utilizar o checklist, o avaliador irá definir cada comportamento observável no exame físico e nas habilidades de comunicação. Já na avaliação global, haverá uma impressão geral sobre o desempenho quanto às habilidades de comunicação e quanto ao exame físico. 


\section{PREPARAÇÃO DE CHECKLISTS E ESCALAS GLOBAIS}

Cada item, nas escalas globais, compreende uma série de comportamentos, habilidades e atitudes. Dessa forma, as ferramentas que utilizam Escalas de Avaliação Global (do inglês - Global Rate Scale - GRS) apresentam número bem menor de itens em torno de 6, diferente dos checklists, em torno de 19 (ILGEN et al., 2015). As GRSs podem ser dicotômicas, descritivas (o avaliador descreve a sua avaliação) ou escalonadas (de baixa até alta performance; novato/intermediário/expert; afirmativas, com - concordo totalmente até discordo totalmente - ou até mesmo entre 0 e 100) (MA et al., 2014).

Os checklists e as GRSs podem ser utilizados para as mais variadas habilidades/competências, como, por exemplo, habilidades de comunicação, exames clínicos ou procedimentos cirúrgicos (VAN HOVE et al., 2010; CÖMERT et al., 2016). A escolha dos itens em um checklist deve estar de acordo com o objetivo de aprendizagem e o cenário de ensino (o quê, para quem, para o quê, por quem e como) (Tabela 1 e 2):

\section{GRADAÇÃO DO CHECKLIST}

A partir da definição do objetivo de aprendizagem e do cenário de ensino, é possível definir com maior clareza como será o checklist. Há uma maleabilidade grande quanto ao checklist. Por exemplo, em uma revisão sistemática sobre cateterismo venoso central, os autores identificaram o uso de checklists que variam entre 1 e 63 itens (MA et al., 2014). Nessa mesma revisão, os autores observaram que os checklists eram em sua maioria binários, ou seja, do tipo suficiente/insuficiente, realizou ( $\operatorname{sim} /$ não), entre outros. Mas também observaram escalas do tipo Likert, por exemplo, com gradação entre 1 e 4.

No caso das escalas do tipo Likert, é possível transcrever os objetivos de aprendizagem como uma afirmativa e graduar o nível de concordância do avaliador. Por exemplo: "O estudante realizou de forma adequada a palpação do pulso radial' frente a isso, o avaliador pode graduar: concordo totalmente (1), concordo parcialmente (2), nem concordo ou discordo (3), discordo parcialmente (4) e discordo totalmente (5). Alguns estudos incluem uma categoria de gradação, como o "não realizado", para elementos não observados pelo examinador. Apesar de haver inúmeras possibilidades, cada uma delas terá pontos positivos e negativos.

Entre os tipos de gradação de checklist, o modelo binário demonstra maior confiabilidade entre examinadores e é mais fácil de ser reproduzido. No entanto, traz uma diferenciação menor entre os participantes e capta com menor precisão diferentes níveis de habilidades e competências. Muitas vezes, os avaliadores gostariam de classificar diferentes níveis de expertise dentro da realização da competência ou habilidade proposta e não conseguem alcançar tal classificação com modelos binários. Não há um modelo certo e outro errado, mas deve-se ter noção de que, ao escolher um modelo de gradação no checklist, um grande passo está sendo tomado. Por exemplo, em uma avaliação que tem como objetivo uma maior reprodutibilidade, esca-

Tabela 1 - Objetivos de aprendizagem para elaboração do checklist e da GRS

\begin{tabular}{|l|l|}
\hline O que será ensinado? & Objetivo da atividade - Quais competências a serem desenvolvidas? \\
\hline Para quem será ensinado? & Sujeitos - Qual o nível de treinamento/especialização pretendido? \\
\hline Para o quê (motivo)? & $\begin{array}{l}\text { Motivo do uso do Checklist - Qual o propósito? O chekclist será um apoio } \\
\text { para avaliação formativa, somativa, com ou sem feedback? }\end{array}$ \\
\hline \multirow{2}{*}{$\begin{array}{l}\text { Por quem será realizado o } \\
\text { checklist? }\end{array}$} & $\begin{array}{l}\text { O checklist pode ser completado por professores, preceptores, pacientes, } \\
\text { pacientes simulados, monitores, pares ou pelo próprio aprendiz } \\
\text { (autoaplicáveis). É possível que haja mais de um avaliador da mesma } \\
\text { categoria ou de categorias diferentes. }\end{array}$ \\
\hline \multirow{2}{*}{ Como será ensinado? } & Tempo - Qual a duração da atividade? \\
\cline { 2 - 3 } & $\begin{array}{l}\text { Local - Qual contexto (simulação, OSCE, role play, entre outros) e } \\
\text { recursos disponíveis? }\end{array}$ \\
\hline
\end{tabular}

Dos autores, Renato Soleiman Franco e Camila Ament Giuliani dos Santos Franco. 
Tabela 2 - Roteiro preparatório para elaboração de Checklist e GRS

\begin{tabular}{|c|c|}
\hline Preparação para realização do Cl & \\
\hline 1) Objetivo da atividade & \\
\hline Objetivo geral - Nessa atividade, & o deverá ser capaz de: \\
\hline Domínios envolvidos: & Habilidades/Competências específicas \\
\hline ( ) Habilidades de comunicação & \\
\hline ( ) Exame físico & \\
\hline ( ) Raciocínio Clínico & \\
\hline ( ) Procedimentos & \\
\hline ( ) Outro - Qual? & \\
\hline 2) Sujeitos & \\
\hline Número de sujeitos envolvidos: & Trabalho em equipe: ( ) sim ( ) não \\
\hline Categorias profissionais: & \\
\hline Grau de especialização: & ( ) estudante/graduação ( ) residentes ( ) especialistas \\
\hline ( ) Outro grau - Qual? & \\
\hline 3) Motivo(s) do uso do Checklist & \\
\hline ( ) Avaliação formativa & ( ) Avaliação somativa \\
\hline ( ) Feedback & ( ) Processo de seleção \\
\hline ( ) Suporte ao ensino & ( ) Outro motivo - Qual? \\
\hline 4) Por quem será realizado o che & \\
\hline ( ) pares & ( ) pacientes simulados \\
\hline ( ) professores & ( ) preceptores \\
\hline ( ) outros - quem? & \\
\hline 5) Ambiente & \\
\hline Qual contexto: ( ) simulação, ( ) & ( ) role play ( )outros - Quais? \\
\hline Recursos disponíveis/utilizados & \\
\hline Tempo: & \\
\hline
\end{tabular}

Referência - Camila Ament Giuliani dos Santos Franco e Renato Soleiman Franco - baseado no processo de validação dos OSCEs do artigo: Franco et al. (2015).

las binárias podem ser melhores; já para utilizar a escala para auxiliar no feedback, modelos com mais itens de gradação podem ser mais apropriados. No entanto, isso não é uma regra universal e o professor/facilitador deve ponderar riscos/benefícios e sempre reavaliar se sua escolha tem alcançado seus objetivos.

\section{AVALIAÇÃO DE HABILIDADES/COMPETÊNCIAS}

Utilizamos o acrônimo SMART (simples, mensurável, atingível, realista e tempo adequado) para definir os itens a serem avaliados no checklist e nas GRSs (CHATTERJEE; CORRAL, 2017). Os itens podem ser: idênticos/semelhantes a checklists/GRS já 
validados, adaptados a partir de modelos teóricos ou teórico-práticos consagrados ou definidos a partir da necessidade da atividade que será realizada.

Os itens devem estar dispostos em uma sequência clara que facilite a avaliação, não devem ser muito longos e precisam ser claros. Um exemplo de item longo seria: realizou a palpação abdominal com as manobras corretas para percussão e palpação hepáticas com ênfase no volume do fígado. Ao ter que marcar sim ou não, o avaliador ficará muito confuso. Caso forem realizadas algumas manobras e outras não, ou então, se não forem realizadas as manobras corretas, mas for avaliado o tamanho de uma forma não convencional, também haverá dificuldade para o avaliador. A presença de muitas habilidades ou procedimentos em um mesmo item deve ser cuidadosamente avaliada pelos professores/ facilitadores.

No entanto, se a presença de todos esses elementos for essencial e for necessária uma associação entre eles, justifica-se a presença em conjunto. Contudo, devem-se considerar os riscos e benefícios desse modelo de item mais longo e complexo. Nesse caso, se o item fosse: Realizou a hepatimetria utilizando a manobra $\mathrm{X}$, haveria maior clareza, objetividade e menor dúvida na qualificação. Um exercício interessante é buscar em cada área de interesse escalas e checklists já utilizados, mas é igualmente prudente adaptá-los aos cenários de simulação e objetivos das atividades a serem realizadas.

Muitas vezes, por dificuldades quanto à disponibilidade de simuladores, professores, salas ou até mesmo porque é importante que competências diversas sejam envolvidas, os checklists podem se tornar extensos e envolver diversos domínios de competências ou diferentes habilidades. Isso é possível de ser realizado, mas deve-se estar atento para o tempo disponibilizado para os cenários, assim como com a expertise do examinador. Quanto maior o número de itens no checklist, maiores a complexidade e a exigência para o examinador.

É importante lembrar que estações que avaliam habilidades muito específicas exigem menos itens. No exemplo acima, o objetivo poderia estar relacionado com "demonstra ser capaz de realizar a hepatimetria". Agora, se o cenário é um ambiente de trauma, que envolve desde manejo do ambiente, habilidades de comunicação, habilidades ligadas a manobras de reanimação cardiopulmonar e raciocínio clínico, certamente o checklist será mais extenso e, consequentemente, o tempo para realizar a estação também). É importante destacar que o checklist deve contemplar todos os domínios de competência a serem avaliados.

Além de utilizar modelos validados, é possível construir checklists e escalas globais. Ao elaborar um modelo para a avaliação, é possível enfatizar determinada competência ou habilidade a ser desenvolvida, como, por exemplo, quanto às competências de comunicação (Figura 1).

\section{IMPORTÂNCIA DE VALIDAR CHECKLIST E GRS}

A primeira etapa na construção do checklist/GRS é discutir o seu objetivo de aprendizagem e cenário de ensino (o quê, para quem, para quê, por quem e como); subsequente a isso, é importante realizar um estudo aprofundado do tema a ser avaliado pelo checklist/GRS e decidir se:

A) aquela habilidade e/ou competência é passível de ser mensurada a partir do checklist/GRS;

B) existem checklists/GRS que sejam referências já validadas - em caso positivo, para qual contexto, ou se o checklist/GRS será elaborado de acordo com as necessidades dos objetivos do cenário - baseados ou não em modelos prévios, e C) realizar um piloto com o uso do checklist/GRS. A validação do conteúdo e o consenso entre os avaliadores são elementos essenciais para construção do checklist e da GRS. Existem várias formas de realizar essa validação, mas o objetivo é ter um checklist e uma GRS de boa qualidade, e que sejam confiáveis. Se possível, incluir nessa atividade especialistas na área - para validar o conteúdo - e não especialistas. Os não especialistas valorizam a forma e apresentam uma impressão global, assim como, quando o cenário for desenvolvido para residentes ou estudantes, auxiliam muito na categorização dos graus de dificuldade. Geralmente, as pessoas envolvidas na validação do checklist/ GRS recebem antes a descrição do cenário, os objetivos e os checklists/GRS, e podem assim contribuir com apontamentos e sugestões para uma reunião de consenso. A reunião de consenso e validação pode ser realizada a partir da gravação de um vídeo e da solicitação de preenchimento pelos avaliadores, ou mesmo em ambiente simulado em tempo real. Na reunião de consenso, em geral, são apresentados o objetivo de aprendizagem e o cenário. A partir disso, os avaliadores discutem (Tabela 3):

1) Existem algumas habilidades/competências que poderiam ser incluídas e que não estejam representadas nesses itens? 


\begin{tabular}{|c|c|c|c|c|c|c|}
\hline \multicolumn{7}{|c|}{ Checklist Estação 1 - Suzana } \\
\hline \multicolumn{7}{|c|}{ No identificação Aluno: ___ Avaliador (professor): } \\
\hline \multicolumn{5}{|c|}{ Competência Apresentada } & Não & Sim \\
\hline \multicolumn{7}{|c|}{ Cumprimenta o paciente e pergunta o seu nome } \\
\hline \multicolumn{7}{|c|}{ Identifica-se (nome e função) } \\
\hline \multicolumn{7}{|c|}{ Demonstra respeito e empatia } \\
\hline \multicolumn{7}{|c|}{ Inicia a entrevista com pergunta aberta } \\
\hline \multicolumn{7}{|c|}{$\begin{array}{l}\text { Identifica e confirma o motivo da consulta (pergunta o motivo da consulta e se tem mais alguma } \\
\text { outra preocupação) }\end{array}$} \\
\hline \multicolumn{7}{|c|}{$\begin{array}{l}\text { Estimula que o paciente conte a sua história (por exemplo: pergunta aberta, silêncio, linguagem } \\
\text { não verbal, facilitadores...) }\end{array}$} \\
\hline \multicolumn{7}{|c|}{$\begin{array}{l}\text { Explora as preocupações do paciente sobre o problema [Considera além das queixas e sintomas } \\
\text { (disease), levando em conta as preocupações (illness)] }\end{array}$} \\
\hline \multicolumn{7}{|c|}{ Encoraja o paciente a expressar seus sentimentos/emoções } \\
\hline \multicolumn{7}{|c|}{ Demonstra linguagem não verbal apropriada (tom de voz, postura, olhar...) } \\
\hline \multicolumn{7}{|c|}{ De uma forma geral, como avalia o desempenho do estudante: } \\
\hline $0-10-20$ & $21-30-40$ & $41-50-60$ & $61-70-80$ & \multicolumn{3}{|c|}{$81-90-100$} \\
\hline Muito ruim & Ruim & Regular & Bom & \multicolumn{3}{|c|}{ Muito bom } \\
\hline \multicolumn{7}{|c|}{$\begin{array}{l}\text { No geral, esse estudante comunicou-se adequadamente com o paciente simulado: } \\
\text { ( ) Sim ( ) Não }\end{array}$} \\
\hline \multicolumn{7}{|l|}{ Observações: } \\
\hline
\end{tabular}

Figura 1 - Modelo utilizado pelos autores para avaliação de comunicação clínica

Modelo de checklist e GRS elaborado por Camila Ament Giuliani dos Santos, baseado no Guia Calgary-Cambridge de Comunicação.

Tabela 3 - Roteiro para validação do conteúdo do Checklist ou GRS

Nome - Avaliador(a):

Checklist (Exemplo): Gradação de cada item: sim/não - Nessa estação, o estudante:

Cumprimentou a paciente

Disse seu nome e função

Iniciou a entrevista com perguntas abertas

Investigou se havia ideação suicida

Investigou se havia planejamento suicida

Perguntou sobre suporte familiar

Fez perguntas que possibilitassem avaliar a afetividade da paciente

Fez perguntas que possibilitassem avaliar a sensopercepção

Pediu que a paciente chamasse por ajuda

Solicitou que a paciente esperasse, acompanhada de um membro da equipe, até que seu/sua responsável chegasse

Referência - Camila Ament Giuliani dos Santos Franco e Renato Soleiman Franco - baseado no processo de validação dos OSCEs do artigo: Franco et al. (2015). 
Tabela 3 - Continuação...

Deixou-se disponível e certificou que a paciente não tinha mais nada a dizer

Avalie de forma Global: Investigação do Risco de Suicídio foi adequada?

Avalie de forma Global: A conduta frente ao Risco de Suicídio foi adequada?

Avalie de forma Global: Houve uma condução adequada do caso, de acordo com as diretrizes nacionais para acolhimento dos (as) pacientes com risco de suicídio?

Favor realizar uma análise do checklist abaixo e responder:

1) Existem algumas habilidades/competências que poderiam ser incluídas nesse checklist e não estão representadas?

2) Quais itens geraram dúvida no preenchimento?

3) Há itens extensos que precisariam ser desmembrados?

4) Foi possível avaliar o objetivo do cenário com esse checklist?

5) O nível exigido é o adequado para os sujeitos em treinamento?

6) Como foi o tempo para o preenchimento?

7) Sugestões

Referência - Camila Ament Giuliani dos Santos Franco e Renato Soleiman Franco - baseado no processo de validação dos OSCEs do artigo: Franco et al. (2015).

2) Quais itens geraram dúvida no preenchimento?

3) Há itens extensos que precisariam ser desmembrados?

4) Foi possível avaliar o objetivo do cenário com esse checklist?

5) O nível exigido é o adequado para os sujeitos em treinamento?

6) Como foi o tempo para o preenchimento?

7) Após isso, faz-se uma checagem quanto à concordância (sugestão - não realizar a checagem da concordância antes de avaliar o construto de uma forma global, como apresentado nos itens acima).

8) Após a correção, pode-se seguir uma nova rodada de correções até que o checklist/GRS seja considerado adequado.

Em avaliações que exigem alta fidelidade, como exames finais ou concursos, pode-se realizar um teste-piloto. No teste-piloto, além da reunião de consenso e dos passos realizados anteriormente, programa-se com um grupo de cerca de 5 a 10 sujeitos (ou maior, conforme necessidade) a realização das estações/cenários com o preenchimento dos checklists/GRS. Como, geralmente, o número de participantes no piloto é pequeno, uma análise qualitativa dos preenchimentos é mais apropriada.

\section{CONSIDERAÇÕES FINAIS}

Apesar de o Checklist e a GRS serem modelos de escalas diferentes, a correlação entre eles é boa. A confiabilidade entre os avaliadores para ambos os tipos de escala era similarmente elevada. As GRSs apresentam maior confiabilidade entre os itens e entre as estações. Os valores de confiabilidade para ambos os modelos são menores para habilidades menos objetivas, como as de comunicação. Geralmente, os checklists são validados com base em opiniões de especialistas, já as GRS têm maior fundamento em modelos teóricos/referenciais (ILGEN et al., 2015). Um exemplo é a Avaliação Objetiva Estruturada de Habilidades Técnicas (OSATS), que tem sido modificada para diferentes propósitos, como descrito em um estudo Brasileiro por Barreto et al. (2019).

Há autores que consideram os checklists melhores para discriminar eventuais dificuldades do estudante em determinados comportamentos/habilidades, além de possibilitarem um feedback mais objetivo (ILGEN et al., 2015). Por outro lado, no preenchimento da GRS, nota-se uma correlação maior com o objetivo da estação. O foco não é na observação de cada passo ou cada habilidade, mas sim em alcançar o resultado de uma forma global. Não ra- 
ramente, os estudantes conseguem fazer isso por vias não previamente determinadas e que, portanto, não estariam no checklist (WALZAK et al., 2015). Por outro lado, tem sido mais fácil o balizamento dos checklists do que das avaliações globais, lembrando que avaliadores menos experientes preferem os checklists (SEO; THOMAS, USPAL, 2019).

Fica claro que GRS e checklists têm seus pontos positivos e negativos. Na prática, sugerimos que sejam inseridos, após os itens dos checklists, itens de avaliação global. O essencial é alinhar o modelo de instrumento desenvolvido com os objetivos de aprendizagem e com as razões pelas quais decidiu utilizar o instrumento (por exemplo, para feedback, para avaliação de um caso longo, para um OSCE, entre outros). A partir disso, podem-se fazer avaliações e análises psicométricas em testes-piloto e após seu uso.

\section{REFERÊNCIAS}

BARRETO, R. M S. et al. Validação de um Programa de Treinamento Simulado de Habilidades Laparoscópicas por Residentes de Cirurgia. Revista Brasileira de Educação Médica, Brasília, v. 43, n. 2, p. 106-113, 2019. Disponível em: <http://www.scielo.br/scielo.php?script=sci_ arttext\&pid=S0100-55022019000200106\&lng=pt\&tlng =pt $>$. Acesso em: 7 dez. 2018.

CHATTERJEE, D.; CORRAL, J. How to write welldefined learning objectives. The Journal of Education in Perioperative Medicine : JEPM, Richmond, v. 19, n. 4, p. E610, 2017. Disponível em: <http://www.ncbi.nlm.nih. gov/pubmed/29766034>. Acesso em: 7 dez. 2018.

CÖMERT, M. et al. Assessing communication skills of medical students in objective structured clinical examinations (OSCE) - A Systematic Review of Rating Scales. PLoS One, San Francisco, v. 11, n. 3, p. e0152717, 2016. Disponível em: <http://dx.plos.org/10.1371/journal. pone.0152717>. Acesso em: 7 dez. 2018.

FRANCO, C. A. G. S. et al. OSCE para competências de comunicação clínica e profissionalismo: relato de experiência e meta-avaliação. Revista Brasileira de Educação Médica, Brasília, v. 39, n. 3, p. 433-441, 2015.

ILGEN, J. S. et al. A systematic review of validity evidence for checklists versus global rating scales in simulationbased assessment. Medical Education, Oxford, v. 49, n. 2, p. 161-173, 2015.
MA, I. W. et al. Measuring competence in central venous catheterization: a systematic-review. SpringerPlus, USA, v. 3, n. 1, p. 33, 2014. Disponível em: <https://springerplus. springeropen.com/articles/10.1186/2193-1801-3-33>. Acesso em: 7 dez. 2018.

SEO, S.; THOMAS, A.; USPAL, N. A global rating scale and checklist instrument for pediatric laceration repair. MedEdPORTAL - The Journal of Teaching and Learning Resources, Washington, v. 15, p. 10806, 2019. Disponível em: <https://www.mededportal.org/publication/10806>. Acesso em: 7 dez. 2018.

SWANSON, D. B.; VAN DER VLEUTEN, C. P. M. Assessment of clinical skills with standardized patients: state of the art revisited. Teaching and Learning in Medicine, Hillsdale, v. 25, p. S17-S25, 2013. Supplement 1.

VAN HOVE, P. D. et al. Objective assessment of technical surgical skills. British Journal of Surgery, Bristol, v. 97, n. 7, p. 972-987, 2010.

WALZAK, A. et al. Diagnosing technical competence in six bedside procedures. Academic Medicine, Philadelphia, v. 90, n. 8, p. 1100-1108, 2015. Disponível em: < http://content. wkhealth.com/linkback/openurl?sid=WKPTLP:landin gpage \&an=00001888-201508000-00027>. Acesso em: 7 dez. 2018. 
CAPÍTULO 14

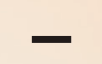

\section{O uso de Feedback e Debriefing na Simulação}




\section{Renato Soleiman Franco}

Psiquiatra

Professor Adjunto - Curso de

Medicina da PUCPR

Coordenador do Programa de

Residência Médica em Psiquiatria

da Prefeitura Municipal de

Curitiba, SMS/FEAS.

\section{Camila Ament Giuliani}

dos Santos Franco

Médica de Família e Comunidade

Professora Adjunta - Curso de

Medicina - PUCPR

Professora no Curso de Medicina

nas Faculdades Pequeno

Príncipe, Curitiba, PR.

Preceptora responsável pela

disciplina de Comunicação

Clínica na Residência Médica em

Medicina de Família e Comunidade -

Residência Integrada, Curitiba, PR.

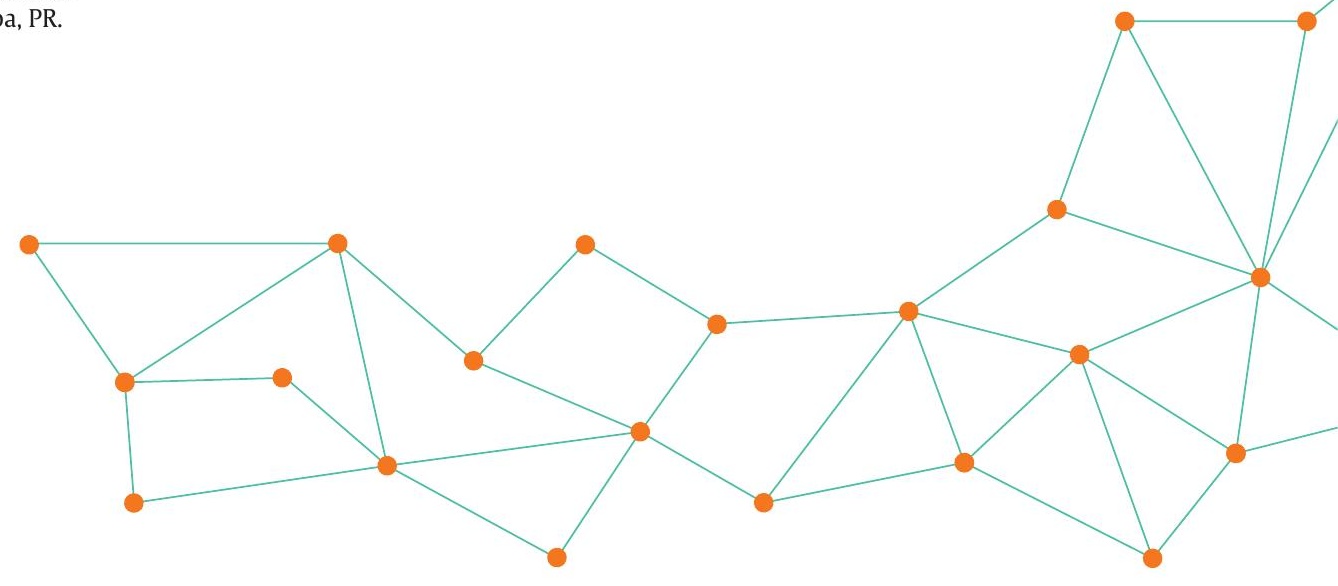

\section{OBJETIVOS DO CAPÍTULO}

O feedback e o debriefing são elementos essenciais para que uma simulação consiga estimular a aprendizagem e o desenvolvimento de competências. Neste capítulo, o feedback e o debriefing serão contextualizados no panorama da simulação. Serão apresentados conceitos e discutidos a aplicabilidade, os modelos e os requisitos para a realização de feedback e debriefing de forma adequada.

\section{FEEDBACK EM EDUCAÇÃO MÉDICA - UM BREVE HISTÓRICO}

Há quase 40 anos, foram propostos os objetivos e as diretrizes do feedback. Ele visa apresentar e esclarecer as falhas e os pontos positivos com o objetivo de melhorar a performance.
Em 1980, um artigo publicado no NEJM por Eichna (1980) sobre a educação médica entre os anos 1975 e 1979, nos EUA, destaca que muitos estudantes passavam pelo curso de medicina sem terem sido observados e, por conseguinte, sem receber uma devolutiva ou avaliação de sua performance (EICHNA, 1980). Três anos após, Jack Ende (1983) faz uma revisão sobre a importância do feedback em Educação Médica. Já nessa data, propõem uma linha guia para orientar o feedback nas escolas médicas (Tabela 1) (ENDE, 1983).

Assim, há quase 40 anos, o feedback em Educação Médica já tem seu objetivo e suas diretrizes propostas:

- Apresentar e clarificar as falhas e aquilo que está sendo bem feito com o objetivo de "melhorar a performance" - hoje em dia - "qualidade 
Tabela 1 - Guia para um feedback adequado, baseado em Ende (1983) (2)

\begin{tabular}{|l|l|}
\hline \multicolumn{1}{|c|}{ Sugestões para um feedback efetivo: } & \multicolumn{1}{c|}{ O que fazer? } \\
\hline $\begin{array}{l}\text { 1) Os professores (que realizarão o feedback) e } \\
\text { estudantes (que receberão o feedback) devem estar } \\
\text { alinhados e com objetivos em comum }\end{array}$ & $\begin{array}{l}\text { Os professores/tutores devem esclarecer os } \\
\text { objetivos, que devem fazer sentido para os alunos } \\
\text { e estar inseridos dentro de um contexto de } \\
\text { aprendizagem claro. }\end{array}$ \\
\hline 2) Deve ser oportuno e esperado & $\begin{array}{l}\text { É importante avisar os estudantes qual o momento } \\
\text { em que receberão feedback, quem fará o feedback e } \\
\text { quem estará presente. }\end{array}$ \\
\hline $\begin{array}{l}\text { 3) Baseado naquilo que é observado, apresentado } \\
\text { pelo professor/tutor em uma linguagem descritiva }\end{array}$ & $\begin{array}{l}\text { Focar o feedback no que foi observado e não em } \\
\text { explicações ou teorias que tentem analisar o } \\
\text { comportamento. Descrever o comportamento de } \\
\text { forma clara e objetiva. }\end{array}$ \\
\hline $\begin{array}{l}\text { 4) Deve ser adequado em quantidade e limitado a } \\
\text { comportamentos que sejam remediáveis }\end{array}$ & $\begin{array}{l}\text { Além de focar no comportamento observado, defina } \\
\text { uma lista de prioridades, pois há um limite para } \\
\text { recepção do feedback. Considerar a tolerância do } \\
\text { grupo quanto a receber feedback. }\end{array}$ \\
\hline $\begin{array}{l}\text { 5) Lidar com desempenhos específicos, não com } \\
\text { generalizações. Trabalhar a partir de decisões } \\
\text { e ações, em vez de intenções assumidas ou de } \\
\text { interpretações }\end{array}$ & $\begin{array}{l}\text { Não se devem inferir comportamentos em outros } \\
\text { cenários e até mesmo na prática real no momento } \\
\text { do feedback. Não generalizar, deve ficar claro que } \\
\text { isso foi observado em determinado contexto e nesse } \\
\text { momento. }\end{array}$ \\
\hline $\begin{array}{l}\text { 7) Oferecer dados subjetivos, mas que devem ser } \\
\text { apresentados e discutidos como tal }\end{array}$ & $\begin{array}{l}\text { Alguns dados podem ser mais subjetivos, como } \\
\text { impressões, reações não verbais, entre outros. } \\
\text { Isso deve ser checado com os participantes e ficar } \\
\text { claro que é uma impressão subjetiva. Deve-se estar } \\
\text { sempre aberto para rever essas impressões. }\end{array}$ \\
\hline
\end{tabular}

*Tabela elaborada pelos autores com base em um modelo para feedback (2).

e segurança”. Notem! É quase que o mesmo objetivo da simulação!!!

Atualmente, além da melhoria da qualidade e segurança, o feedback eficaz sobre o desempenho é considerado parte integrante do treinamento clínico e deve:

- Permitir que o estudante (residente, médico ou qualquer outro profissional) reflita criticamente sobre seu desenvolvimento.

Assim, pode parecer redundante, mas deve ficar claro que, apesar de informar (postura passiva), o principal objetivo do feedback é promover a reflexão do estudante (postura ativa) sobre o que está fazendo. Para fornecer um feedback eficaz, precisamos levar em conta: 1) o desempenho em si; 2) o cenário em que o feedback é oferecido, e 3) os resultados esperados do encontro (ISKANDER, 2015). Para que o feedback tenha um efeito significativo na aprendizagem, os professores precisam desenvolver a sensibilidade e estarem atentos ao estudante.
Ao dar qualquer retorno ao estudante, é essencial que os professores façam o exercício de perceber as necessidades e aquilo que cada estudante é capaz de receber. Assim, podemos dizer que o feedback deve ser centrado no estudante, nas suas necessidades e possibilidades, e ser realizado com atenção e compaixão por parte do professor.

Todos poderiam se beneficiar de receber feedback, entretanto o feedback nem sempre é considerado bem-sucedido ou benéfico (VAN DER LEEUW; SLOOTWEG, 2013). Alguns estudos mostram uma piora na performance com uso de feedback, em especial, feedbacks massivos após todos os eventos. Para minimizar esse insucesso, devemos ter muito claro que o objetivo é mostrar de uma forma efetiva o que foi feito e o que poderia ser melhorado. Para isso, aquele que realiza (ou fornece) o feedback deve conseguir adaptá-lo não somente aos cenários, objetivos e resultados esperados, mas para cada pessoa avaliada. 
Dica.$^{\circ} 1$ : $O$ feedback deve ser adaptado para aquele que o recebe. Devemos promover uma discussão que faça sentido e de uma forma que promova diálogo e reflexão. Assim, devemos lidar com a resistência e as dificuldades tanto daquele que recebe quanto daquele que fornece o feedback.

Conceito-chave: Feedback em Educação Médica - Objetivo final: melhoria da qualidade, melhoria da segurança do paciente/profissional e desenvolvimento de uma autoavaliação que seja crítica, reflexiva e ativa.

\section{QUEM REALIZA O FEEDBACK EM SIMULAÇÃO?}

A aplicação do feedback em simulação é ampla e, por ser realizada por pacientes estandardizados (Standardized Patient - sigla do inglês, SP), incluindo atores e pacientes experts (BOKKEN et al., 2009), pares (estudantes ou profissionais no mesmo nível/ nível semelhante de treinamento)(CUSHING et al., 2011), professores/instrutores, gestores, entre outros, ou seja, há uma grande variedade se possibilidades. Alguns autores desencorajam que seja realizado feedback por pessoas que não estiveram envolvidas na avaliação (formativa ou somativa), na qual foram obtidas as informações sobre o desempenho.

A formação em técnicas de feedback é essencial para o sucesso das atividades que envolvem essa prática (BOKKEN et al., 2009). O feedback por múltiplos avaliadores, apesar de envolver um maior treinamento da equipe e uma maior discussão entre os envolvidos quanto aos resultados esperados, parece trazer um benefício superior para aprendizagem (JOSHI; LING; JAEGER, 2004; LAMIANI et al., 2011).

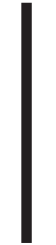

\section{Dica n. ${ }^{\circ}$ 2: Quem poderá fornecer o feedback? Todos os envolvidos no processo da simulação - no entanto, devem ter treinamento ou, no mínimo, serem apresentados às regras de um feedback adequado.}

Deve-se tomar cuidado para que todos os envolvidos no feedback recebam algum treinamento em feedback e realizem a avaliação com cuidado e respeito (vale a pena sempre repetir isso). $\mathrm{O}$ ambiente deve prezar pela segurança, em especial emocional, dos participantes e todos os envolvidos. Essas estratégias devem ser avaliadas quanto a sua qualidade e aplicabilidade. Assim, por exemplo, tanto os SP, os observadores/avaliadores, os pares e demais participantes podem participar do feedback.

Como o feedback é realizado a partir de cenários ou situações elaboradas para fins específicos, é possível que os professores previamente elaborem instrumentos de avaliação. Esses instrumentos podem ser escalas mais gerais ou conter itens específicos, como em escalas do tipo Likert (a construção desses instrumentos será detalhada no capítulo sobre escalas e checklists). Os professores podem ter esses instrumentos consigo, assim como os observadores e, ao final ou antes do começo, os próprios estudantes. Para isso, é essencial desenvolver instrumentos de avaliação que possam ser facilmente compreendidos e utilizados como guia. É importante que os objetivos de aprendizagem e os itens a serem avaliados sejam compreendidos por todos os envolvidos na avaliação e no feedback. Entretanto, o feedback não deve se restringir aos guias. Esses guias frequentemente não abrangem toda a complexidade de um cenário e é essencial que os avaliadores estejam atentos a isso. Além disso, todo comportamento é somente a ponta de um iceberg, tudo o que está por baixo só pode se tornar evidente num processo de feedback que envolva o diálogo cuidadoso entre estudantes e professores.

Por exemplo, através da "gap analysis - análise de lacunas", há uma comparação entre as pontuações globais obtidas de um grupo de avaliadores e as autoavaliações dos participantes. Assim, os avaliadores realizam sua avaliação, checam com a autoavaliação dos participantes e, dessa forma, faz-se uma discussão com o enfoque naquilo que foi mais divergente. Isso pode ser um começo para a discussão e o feedback, mas ficar somente nisso pode reduzir o processo a um encontro impessoal e que não se aprofunda nas raízes das dificuldades ou dos potenciais encontrados.

\section{FEEDBACK - QUANDO REALIZAR?}

Considera-se que o melhor momento para realizar o feedback é o mais próximo possível de quando foi realizada a atividade de simulação. Uma vez que o feedback é a análise da performance do trainee, ele pode ser realizado tanto durante o debriefing (aqui, 
a proximidade conceitual com o debriefing é muito grande) quanto em outros momentos.

Há possibilidade de o feedback ser mais diretivo, sendo fornecido aos estudantes sem necessariamente ser realizado debriefing ou uma discussão mais aprofundada. Para o debriefing, é essencial que os participantes descrevam o que aconteceu, apontem aquilo que aconteceu durante a cena para iniciar o processo do debriefing. No caso do feedback, poderia ser uma devolutiva mais pontual sobre determinado comportamento ou performance. Assim, por exemplo, um SP após uma simulação pode se reunir com o trainee ou com a equipe que realizou a performance e apresentar as lacunas de desempenho e as sugestões de melhoria. $\mathrm{Ou}$, em outro caso, durante a própria simulação, o observador intervém mostrando o que e como deve ser feito; após isso, o aprendiz realiza a atividade novamente e continua o cenário. Ou mesmo após a simulação, um profissional mais treinado faz o feedback do que aconteceu e como deveria ter acontecido, mostrando sua técnica.

Quando o feedback não se foca no próprio movimento (internal-focus feedback) mas em seu resultado, a melhora é significativamente maior. Esses estudos de "external-focus feedback" têm orientado cada vez mais para a importância de se avaliar o impacto do feedback e o modelo instrutivo utilizado (WULF et al., 2010). Apesar de as experiências em educação médica serem restritas, as experiências com o foco atencional do feedback (interno vs. externo)(STURMBERG et al., 2013) podem trazer novas perspectivas e modelos mais eficazes de feedback. Parece ser mais importante avaliar o resultado do que foi feito do que se a forma seguiu todas as etapas ou preceitos elaborados pelo avaliador. É possível que os estudantes realizem atividades de forma competente de maneiras diferentes daquelas que foram previstas. É evidente que os meios para os resultados são importantes e não podem fugir daquilo que seria adequado, mas o avaliador deve considerar essas inúmeras possibilidades de que o estudante pode lançar mão.

\section{Dica n. ${ }^{\circ}$ 3: $\mathrm{O}$ feedback pode acontecer em diversas etapas da simulação.}

\section{FEEDBACK - MODELOS ESTRUTURADOS}

O feedback pode mostrar desde uma forma com maior estruturação até uma forma com menor estruturação. Um método estruturado de feedback em simulação foi realizado por Pfeiffer et al. (2005) (Figura 1). Aqui fica claro que o modelo é com foco na performance e no treinamento de performance e não tanto na discussão e na reflexão. Pode ser utilizado durante a simulação (um modelo específico para o feedback durante a simulação - "corretivo" será apresentado a seguir) ou após o término da mesma.

Outro método para realizar o feedback é o Ask-Tell-Ask - Pergunte-Conte-Pergunte (FRENCH et al., 2015). Nele, inicialmente, é solicitada a autoavaliação do estudante/trainee. Após ouvir atentamente e reconhecer a opinião do estudante/trainee (sugerimos que o avaliador anote $o$ que é dito na autoavaliação), o avaliador apresenta/

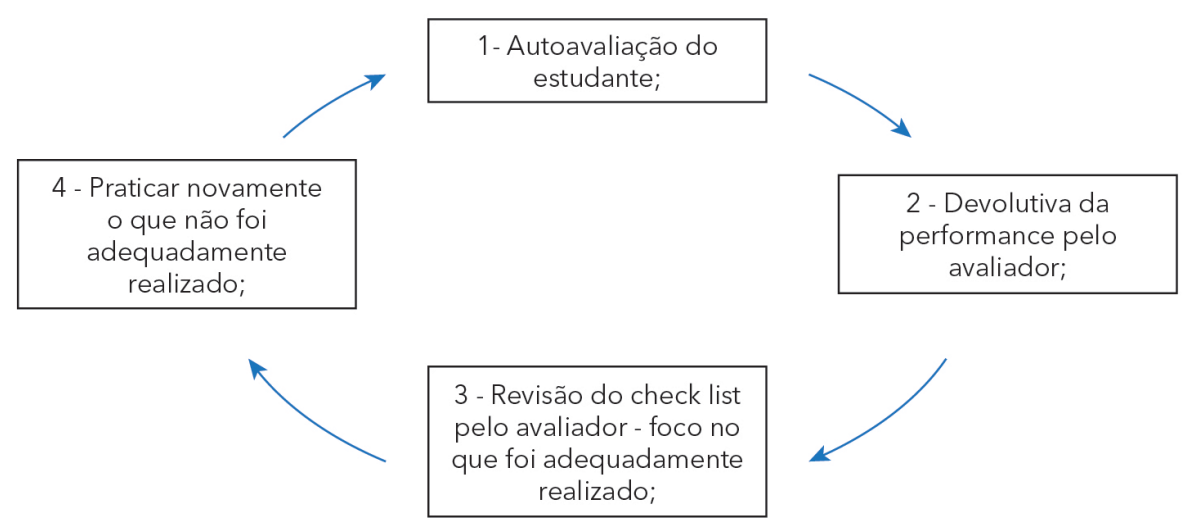

Figura 1 - Modelo Estruturado de Feedback - Foco em Performance (Pfeiffer, 2005). 
conta o que observou; geralmente, começa com um ponto positivo/algo que foi bem realizado e pontua o que poderia ter sido melhorado, na sua visão. Pergunta novamente o que o estudante/trainee avalia dessa nova informação. Após a resposta do estudante/trainee, $\mathrm{o}$ avaliador apresenta de forma objetiva e clara como o comportamento ou a habilidade desejada pode ser alcançada. Nesse momento, pode pedir mais uma autoavaliação sobre outro ponto observado ou promover uma discussão com destaque aos pontos que são relevantes ao estudante. Além disso, o avaliador apresenta e/ou negocia algumas estratégias de aprendizagem para que o resultado seja obtido. (Tabela 2).
Dica n. ${ }^{\circ}$ 4: Comece o feedback perguntando. Os dois modelos sugerem isso - não utilizamos isso somente no feedback-minuto.

Feedback-minuto: No contexto da simulação, o feedback pode ser usado numa variedade de contextos, como, por exemplo, durante os Exames Clínicos Estruturados Objetivos (OSCE - do inglês). O tempo para o feedback é um importante limitador para o tipo de feedback realizado. Baseados na experiência em "One Minute Preceptor" - Preceptor Minuto, os autores deste capítulo realizaram o que chamam de Feedback- Minuto. É evidente que isso

Tabela 2 - Modelo: Pergunte-Conte-Pergunte Tabela adaptada pelos autores - Foco Reflexão, adaptado pelos autores

\begin{tabular}{|c|c|c|}
\hline Fase & Descrição & Sugestões \\
\hline Pergunte: & $\begin{array}{c}\text { a autoavaliação do estudante/ } \\
\text { trainee. }\end{array}$ & $\begin{array}{l}\text { Agradecer, reconhecer e abordar } \\
\text { as preocupações do estudante }\end{array}$ \\
\hline Escute: & $\begin{array}{c}\text { atentamente/anote a percepção } \\
\text { do estudante/trainee. }\end{array}$ & \\
\hline Reconheça: & $\begin{array}{l}\text { a autoavaliação do estudante e } \\
\text { o que observou considerando a } \\
\text { autoavaliação do estudante. }\end{array}$ & \\
\hline Conte: & $\begin{array}{l}\text { novamente o que o estudante/ } \\
\text { trainee avalia dessa nova } \\
\text { informação. }\end{array}$ & \\
\hline Pergunte: & $\begin{array}{c}\text { atentamente/anote a percepção } \\
\text { do estudante/trainee. }\end{array}$ & $\begin{array}{l}\text { Aborde no máximo } 1 \text { a } 2 \\
\text { habilidades para melhoria }\end{array}$ \\
\hline Escute: & $\begin{array}{c}\text { a nova autoavaliação do } \\
\text { estudante. }\end{array}$ & \\
\hline Reconheça: & $\begin{array}{l}\text { de forma objetiva e clara como o } \\
\text { comportamento ou a habilidade } \\
\text { desejada pode ser alcançada. }\end{array}$ & \\
\hline \multicolumn{3}{|l|}{ Conte: } \\
\hline Pergunte: & $\begin{array}{l}\text { sobre a compreensão do } \\
\text { estudante sobre o processo, } \\
\text { as dúvidas ou até mesmo as } \\
\text { sugestões. }\end{array}$ & $\begin{array}{l}\text { Apresentar as propostas de } \\
\text { forma clara, objetiva, e verificar a } \\
\text { compreensão do estudante }\end{array}$ \\
\hline Conte/Encerre: & $\begin{array}{c}\text { sua avaliação do processo - ao } \\
\text { final, pode discutir um plano } \\
\text { de aprendizagem - como o } \\
\text { estudante vai alcançar o que } \\
\text { foi identificado que precisa } \\
\text { aprimorar. }\end{array}$ & \\
\hline
\end{tabular}


pode modificar o desempenho do estudante/trainee, mas parece ter uma boa aceitação pelos estudantes e é simples de ser realizado. Acreditamos que ele não exclui a importância do debriefing ou de um feedback mais detalhado. Na nossa experiência, logo depois de uma estação de OSCE, o observador lia o checklist e descrevia sumariamente (lendo o chekclist) o que foi observado (FRANCO et al., 2015). Dessa forma mesmo e simples assim... Leitura do checklist e descrição do que o estudante realizou e o que não realizou.

\section{FEEDBACK DURANTE A SIMULAÇÃO}

O feedback que ocorre durante a simulação tem sido chamado de Feedback Focal e Corretivo (Focused and Corretive Feedback) e tem sido usado na sua maior parte para treino de habilidades (KIM et al., 2017), mas pode também ser utilizado para correção das habilidades de comunicação e atitudes.

É importante que seja avisado para os participantes, durante o briefing, que isso poderá acontecer. Na maioria das experiências, ele é focal e circunscrito à realização da técnica, sendo a discussão sobre o que foi feito realizada no debriefing.

Os outros modelos de feedback apresentados até aqui também podem ser feitos durante a simulação, mas o modelo "corretivo", mais comumente usado, segue as etapas:

1) Identificação da situação (pelo examinador/ observador/participante);

2) Realização do procedimento/intervenção da forma desejada pelo examinador/observador;

3) Continuação da simulação.

Esse tipo de feedback é tido como "corretivo", ou seja, o observador/avaliador demonstra e/ou explica o que deveria ser feito. Apesar de ser utilizado, o feedback durante a simulação parece ser menos efetivo do que aquele feito após (por exemplo, debriefing), em especial para aprendizes novatos como os estudantes da graduação (HATALA et al., 2014).

\section{FEEDBACK - POTENCIALIZAÇÃO - USO DE TECNOLOGIAS}

Além do direcionamento do feedback, há possibilidade de potencialização do feedback com recursos voltados para os diferentes sentidos, como, por exemplo, visão, audição e tato (SIGRIST et al., 2013). O objetivo dessas estratégias é apresentar ao estudante ou trainee uma informação mais clara sobre a performance. Assim, por exemplo, através de um recurso visual, pode-se mostrar algo que, através de um checklist ou pela fala do observador, não seria possível. Como, por exemplo, no caso do observador/facilitador ter notado um momento em que a comunicação entre dois profissionais tornou-se agressiva e, a partir de então, a equipe começou a brigar e não cooperar. Ao relatar isso no debriefing, o líder da equipe, que realizou a simulação, não reconhece e nem se lembra do evento. Mostrar isso em um vídeo poderia ser benéfico e esclarecedor.

Modelos de feedback utilizando o vídeo têm sido aplicados, mas o princípio de potencialização deve ser seguido. Caso o vídeo não acrescente informação ou seja dispensável, não deve ser utilizado. Caso se opte por utilizá-lo, deve-se ter em mente que essa estratégia demanda tempo e tecnologia de qualidade, e que muitas vezes desvia a atenção do feedback.

$O$ uso do vídeo pode acontecer no momento do feedback quando o observador/avaliador apresenta seu ponto de vista ou considerações. Assim, faz essa etapa de forma guiada. Para isso, é importante ter anotado o tempo exato da gravação em que o ponto avaliado aconteceu, o que muitas vezes demanda a presença de um técnico que auxilie nisso.

O uso do vídeo pode ser utilizado também para autoavaliação e feedback por pares em atividades de treinamento, nas quais, guiados por instrumentos, os estudantes avaliam sua performance e, em alguns experimentos, repetem aquilo que foi realizado (PHILLIPS et al., 2017). Isso é uma espécie de feedback autoguiado que é facilitado por vídeo e seria muito difícil de ser realizado sem o uso deste. $O$ feedback pode ainda ser realizado de forma verbal ou escrita, em meio eletrônico ou físico, individualmente ou na presença do grupo.

Dica n. ${ }^{\circ}$ 5: Para usar a tecnologia de apoio no feedback, é preciso tempo e, possivelmente, auxílio para editar e passar somente as sequências de vídeo necessárias. $O$ vídeo com a gravação pode ser utilizado quando o professor/tutor apresenta aquilo que observou.

\subsection{FEEDBACK - COMUNICAÇÃO E EMOÇÕES}

Os diversos elementos de competência médica, incluindo habilidades procedimentais, atitudes e co- 
municação, podem integrar a simulação e receber qualquer um dos modelos de feedback apresentados. No entanto, há algumas estratégias específicas para determinadas situações de feedback.

Lidar com as próprias emoções é uma necessidade diária na prática clínica em diversos ambientes de atuação dos profissionais de saúde. As emoções despertadas pelo caso, em geral, acontecem durante o debriefing.

A preparação do caso deve contemplar cenários e situações que revelem aquilo que se deseja discutir, como, por exemplo, a angústia causada em uma comunicação de óbito ou a tensão em uma comunicação de má notícia, entre outros. A situação precisa incluir a complexidade das relações e da prática em saúde, mostrando a fragilidade dos pacientes, dos profissionais e as dificuldades que a equipe enfrenta ao realizar escolhas ou determinados tratamentos. As reflexões, como, por exemplo, "que médico eu gostaria de ser" ou "que medicina eu gostaria de praticar" frente a situações complexas e desafiadoras ajudam a reflexão frente a essas situações (SCHWELLER et al., 2018).

O observador/avaliador deve reconhecer que o feedback focado nas emoções pode levar mais tempo e, muitas vezes, além de opiniões e pontos de vista, podem ser discutidos valores e atitudes. Deve-se ter muito cuidado para considerar a complexidade das situações e não perder o foco de que a discussão está baseada no comportamento observado e não no julgamento pessoal do estudante/trainee. As reflexões ultrapassam o caso e a simulação, e devem ser compreendidas como tal. Sensibilidade, cautela, treinamento e ambiente seguro são essenciais para que esse tipo de feedback aconteça.

Apesar de a comunicação ser tratada muitas vezes como uma competência ou habilidade "não-técnica", há diversas referências técnicas e teóricas que embasam determinados modelos ou teorias de comunicação.

Assim, a comunicação pode envolver diversos aspectos, como Liderança, Comunicação Interprofissional e Comunicação Clínica com o paciente (FRANCO et al., 2018). Cada um desses domínios da comunicação tem referenciais específicos e modelos para serem adotados como desejados na performance do profissional. Por vezes, é difícil que o estudante/trainee que realizou a simulação tenha uma ideia clara da maneira como se comunica. Nesses casos, pode-se utilizar o vídeo como uma ferramenta para esclarecer as atitudes, linguagens não verbais, a comunicação verbal, entre outros.
Nesses cenários, assim como no debriefing com foco nas emoções, é de grande valia a contribuição de atores. O feedback dos atores nesses casos é enriquecedor; no entanto, deve-se promover treinamento para esses atores para um feedback efetivo e cuidadoso.

Apresentamos diversas formas de Feedback em simulação e algumas bases conceituais sobre como esse retorno pode ser feito. Em simulação, a diferença entre feedback e debriefing não é muito clara, mas há alguns elementos que aproximam esses dois conceitos e outros elementos que os afastam. Por ora, apresentamos primeiro o Feedback por ser um termo mais geral em Educação em Saúde e que guiou muito do que se faz no Debriefing, que não deixa de ser um retorno (feedback) feito ao final da simulação.

\section{DEBRIEFING}

A simulação começa antes mesmo da apresentação do cenário e dos objetivos da atividade aos participantes. Assim, antes do debrifieng, é importante contextualizar outras etapas, como pré-briefing e briefing.

\subsection{CONTEXTUALIZAÇÃO E DEFINIÇÃO DO BRIEFING}

O briefing em simulação pode ser definido como o momento em que as informações relativas às atividades de simulação são transmitidas aos estudantes e/ou aos facilitadores, para que haja uma maior compreensão do que acontecerá durante a experiência. O briefing pode ser descrito como um processo de três fases: pré-briefing, orientações e briefing do cenário (ORIOT; ALINIER, 2018). Um briefing eficaz no início da sessão de simulação destina-se a evitar complicações durante toda a simulação, incluindo o debriefing (BOET et al., 2014). Ao elaborar o cenário, deve-se ter clareza de quais elementos de competência serão trabalhados. A simulação e seu objetivo podem envolver prioritariamente habilidades e decisão clínica, comportamentos, atitudes, comunicação interpessoal, entre outros. Isso deve ser esclarecido para os participantes desde o briefing. Muitas vezes, os observadores/avaliadores têm o desejo de inserir diversos elementos de competência, no entanto é essencial considerar as limitações dos participantes e do próprio cenário. Note-se que, muitas vezes, temos de focar em um dos elementos de competência e restringir nossos objetivos. 
Dica n. ${ }^{\circ}$ 6: Defina o objetivo do cenário - saiba quem são seus facilitadores, participantes e o que terá à sua

disposição. Utilize uma linguagem de fácil compreensão para informar aos envolvidos na simulação o que acontecerá naquele dia. Se achar necessário, pode preparar um material impresso ou audiovisual.

\subsection{A PRIMEIRA FASE DO BRIEFING: PRÉ-BRIEFING}

Nessa fase, os anseios e as dúvidas dos participantes em relação a todo processo da simulação devem ser conhecidos e abordados. É importante, nessa fase, perceber as angústias e ansiedades, pois é muito frequente que o estudante tenha medo de julgamento, crítica, erro, entre outros. Portanto, é essencial que a confidencialidade e o respeito entre os participantes e facilitadores sejam estimulados. Construir um ambiente de aprendizagem seguro para os seus participantes é fundamental ((KOLBE; GRANDE; SPAHN, 2015)

No dia a dia da simulação, é no pré-briefing que se deve:

1) fornecer informações gerais sobre o que é esperado quanto à aprendizagem;

2) informar se, durante a simulação, podem pedir ajuda ou se os observadores/avaliadores darão feedback (há casos nos quais o observador/avaliador pode realizar feedback durante a simulação);

3) indicar quem irá participar do cenário e, muitas vezes, deixar que os participantes explorem o cenário;

4) informar o que deve ser efetivamente feito ou o que será somente informado sobre a sua execução (por exemplo: retirar sangue e encaminhar para cultura - isso pode ser somente informado - "Estou aqui retirando o sangue" - ou pode ser realizado em um modelo);

5) informar qual o comportamento esperado;

6) especificar quais as limitações do cenário;

7) se, no caso, o paciente pode morrer ou não, dependendo da ação do participante, ou se o paciente, em nenhuma circunstância, irá morrer;

8) informar quanto ao sinal específico para o término do cenário;

9) orientar para que os participantes, assim que terminarem a simulação, se dirijam para o debriefing (usualmente não devem conversar ou discutir após o término - reservar esse espaço ao debriefing) (ORIOT; ALINIER, 2018);

10) informar como ocorrerá o debriefing e quem participará.
Dica $n^{\circ} 7:$ Na etapa do pré-briefing, o objetivo é a preparação do grupo, com destaque aos OBJETIVOS daquela simulação, e a criação de um ambiente seguro e de confiança entre os participantes. A explicação adequada de como será toda simulação está relacionada a melhores resultados, pois estimula o julgamento crítico, diminui o estresse $e$ aumenta os processos reflexivos, tornando os estudantes ativos no seu processo de aprendizagem (SHAROFF, 2015).

\subsection{A SEGUNDA FASE DO BRIEFING: FASE DE ORIENTAÇÃO DO AMBIENTE, DO EQUIPAMENTO E DA TECNOLOGIA DE SIMULAÇÃO}

Devem-se fornecer todas as informações necessárias para que o participante se localize dentro do cenário, bem como devem ficar claras todas as funcionalidades do ambiente que fogem ao esperado. É importante informar se há algum outro suporte, como, por exemplo, telefone ou equipe de resgate. Devem ser descritas todas as características do simulador, informando as suas limitações e suas características mais reais. Deve ficar claro para os participantes o que é possível e o que não é possível avaliar nos simuladores/manequins/ pacientes simulados (ORIOT; ALINIER, 2018).

Dica n. ${ }^{\circ}$ 8: Esclareça sobre o cenário e seus recursos. Caso houver dúvidas sobre a tecnologia ou o funcionamento dos equipamentos, elas devem ser sanadas.

\subsection{A TERCEIRA FASE DO BRIEFING: BRIEFING DO CENÁRIO}

Nesta fase, o cenário é explicado e são apresentados os papéis dos facilitadores e atores. Os aprendizes devem ser orientados se haverá mais de um cenário e mais de um papel para o participante (ORIOT; ALINIER, 2018).

Nessa fase, serão apresentados a situação, o contexto, o ambiente e o tempo, e serão esclarecidas as dúvidas antes de iniciar a performance da simulação. O adequado briefing resulta em simulações com melhores resultados de aprendizagem. Os estudantes que compreendem adequadamente o briefing diminuem a ansiedade para a realização tanto da simulação quanto do debriefing (SHAROFF, 2015).

Assim, o cenário é apresentado, bem como o que é esperado e os papéis de todos os envolvidos. Caso 
haja tempo delimitado, este deve ser previamente informado. Somente deve-se passar para performance do cenário se os participantes tiverem compreendido o briefing. Após o briefing, a simulação começa; na prática, utilizamos algum aviso sonoro ou uma contagem regressiva que prepare os participantes. Ao terminar a simulação, haverá o debriefing, etapa essencial da simulação. É a base para fixação e correção dos comportamentos. Nos próximos temas, serão descritos feedback e debriefing. Optamos por iniciar com o feedback por ser um conceito mais abrangente. Além disso, mesmo durante a simulação, pode acontecer feedback; já para o debriefing, a performance da simulação deve ter terminado. Mas isso é assunto para o próximo tema.

\section{Dica n. ${ }^{\circ}$ 9: Faça um teste da explicação da situação clínica. Reúna um grupo de estudantes ou professores que não irá participar e treine o briefing. É muito importante que esteja tudo muito claro.}

\section{9 - HISTÓRICO DO DEBRIEFING}

Um dos precursores do debriefing na Educação em Saúde foi o seu uso em atividades militares, quando os participantes retornavam de uma determinada missão e se reuniam para discuti-la. Essa discussão militar teria três objetivos principais:

1) educacional (aprendizagem);

2) operacional (programação de ações futuras e continuidade da missão), e

3) função terapêutica - psicológica.

Nesse último objetivo, os participantes reconstruíam a missão (o que aconteceu), os significados para cada um dos envolvidos e compartilhavam suas impressões - construções cognitivas - para um alívio psicológico (FANNING; GABA, 2007).

\subsection{DEFINIÇÃO E OBJETIVO DO DEBRIEFING}

Ao caracterizar o debriefing, Cheng et al. (2014) destacam que, no campo da educação, em especial da educação em saúde, o debriefing pode ser considerado como uma técnica específica de feedback. Os autores propõem, para o uso do termo debriefing em simulação, como um processo interativo, bidirecional e reflexivo de discussão (CHENG et al., 2014).

O debriefing ocorre na sequência da performance da simulação, com a reunião dos participantes (em situações com SP - a presença deles no debriefing depende do modelo utilizado pelo facilitador e/ou objetivos de aprendizagem). Pode ser coordenado por um observador/facilitador ou até mesmo ser autoguiado pelos participantes da simulação, sendo a primeira opção a mais utilizada.

Assim, o debriefing é uma forma de análise, após determinada experiência (no caso, simulação), avaliando e integrando tudo o que foi aprendido a partir de um modelo que torna os participantes conscientes tanto daquilo que experimentaram e aprenderam, quanto dos seus esquemas de aprendizagem (GARDNER, 2013).

Entre os principais objetivos do debriefing, podemos citar: facilitar reflexão, aprendizagem, conceptualização e contextualização entre a simulação e a prática real em ambiente de trabalho (não simulado) (SO et al., 2019).

Dica n. ${ }^{\circ}$ 10: É essencial, muito importante, crucial - para não dizer, elementar - que o debriefing inclua a análise da situação, não somente da performance! Imagine que o debriefing teve como inspiração as atividades militares. Era preciso que os participantes avaliassem não somente sua performance/desempenho, mas a situação como um todo. Por isso, a descrição da situação é uma etapa fundamental do debriefing, enquanto, no feedback, ela não é obrigatória.

\subsection{SIMULAÇÃO, FEEDBACK E DEBRIEFING}

Os termos feedback e debriefing se confundem em vários artigos. Consideramos e reconhecemos que feedback é um termo anterior ao debriefing em educação médica, bem como que é aplicado a variados ambientes e em cada um poderá ter sua definição/ aplicação adaptada. Aqui, no contexto da simulação, trataremos do feedback como o ato instrucional de dar a devolutiva ao trainee quanto a sua performance, desempenho, habilidade, atitude ou outros elementos de aprendizagem (MAIA et al., 2018). Assim, o feedback pode acontecer associado a um debriefing ou até mesmo ser realizado durante ou mesmo após a simulação em momentos outros que o debriefing. No entanto, ambos, feedback ou debriefing, exigem que o professor/facilitador tenha muito cuidado, atenção e atitude compassiva em relação ao estudante/trainee e devem ser realizados de acordo com a necessidade do estudante e a sua receptividade. 
Mais importante do que definir ou categorizar esse entrelaçamento de conceitos é compreender ou discutir os possíveis motivos para isso. O feedback é tido como um elemento central e aspecto essencial para o aprendizado, em especial, no aprendizado baseado ou apoiado pela simulação (MCGAGHIE et al., 2010). Por exemplo, em uma revisão sobre a Educação Baseada em Simulação (SBE - Simulation Based Medicine) de 2010, os termos feedback e debriefing aparecem em algumas frases como sinônimos ("feedback or debriefing...”) (MCGAGHIE et al., 2010).

\subsection{O QUE PODE DIFERENCIAR UM FEEDBACK DO DEBRIEFING?}

O debriefing seria a troca entre os participantes de uma simulação ou determinado evento com um avaliador ou observador, que acontece após a simulação. Essa diferença foi importante no trabalho que Cheng et al. (2014) realizaram, pois puderam comparar modelos em que houve trocas (debriefing) com aqueles mais diretivos, como vídeo-feedback ou feedback (CHENG et al., 2014). Assim, Cheng et al. utilizam o feedback para eventos mais diretivos. As outras formas de feedback apresentadas que ocorrem após a simulação e envolvem a discussão e reflexão do que aconteceu no ambiente simulado seriam consideradas, por eles, debriefing.

Outra questão importante é que o feedback pode ser realizado em qualquer momento da simulação. Os instrutores/professores podem, a qualquer etapa da simulação, oferecer o feedback com correção ou não do comportamento ou da habilidade.

Concluímos, assim, que os termos se confundem e se mesclam quanto aos objetivos e autores, mas há algumas características necessárias para se considerar uma "devolutiva" como feedback ou debriefing.

Dica n. ${ }^{\circ}$ 11: É amplamente aceito
que o debriefing acontece APÓS A
SIMULAÇÃo (logo após). Assim, é quase
consenso que as práticas que acontecem
durante a simulação são feedback!
Os modelos de feedback que geram
discussão/reflexão entre os participantes
e avaliadores descritos no capítulo de
feedback podem ser utilizados na etapa
do debriefing para sua estruturação.

\subsection{O PROCESSO DO DEBRIEFING}

Apesar de o debriefing ser um dos momentos finais da simulação, ele tem sua preparação realizada desde os primeiros momentos da simulação, até mesmo antes da performance, desde o pré-briefing. O local onde será realizado e os participantes do debriefing podem variar. Em geral, é preferível que seja realizado no ambiente onde foi praticada a simulação, mas pode ser realizado em outro ambiente. Muitas vezes, há observadores externos, que não participaram diretamente da performance. Esses observadores podem presenciar o debriefing ou podem também observar a partir de sala de espelho ou por transmissão de vídeo. Apesar de o uso do vídeo trazer alguns benefícios, muitas vezes, não há diferença entre o debriefing assistido por vídeo ou não. Ambos têm impacto na melhora da performance, mas sem diferença significativa entre eles, em algumas situações (LEVETT-JONES; LAPKIN, 2012).

Com a participação de observadores externos (não participaram diretamente da simulação nem fazem parte da equipe dos facilitadores/tutores/ avaliadores/instrutores), deve-se prezar ainda mais pela segurança, pelo respeito e pelo bem-estar dos participantes.

O facilitador deve primeiro se dirigir aos participantes, iniciar o processo de debriefing com eles e, caso for decidido incluir os observadores com

Partindo de um conceito mais global e universal de feedback em Educação Médica, poderíamos dizer que: $\boldsymbol{o}$ debriefing é um tipo específico de feedback, realizado ao final de uma atividade (simulada ou não), na qual os participantes analisam a situação como um todo, incluindo o desempenho dos participantes. Além disso, há uma discussão com os outros envolvidos na simulação (tutores, examinadores e instrutores - pode incluir outros participantes também como observadores) - que visa auxiliar na aprendizagem e no incremento das competências/ habilidades/atitudes dos trainees

Por outro lado, há definições mais categóricas em que o feedback é uma devolutiva ao trainee, focada em seu desempenho, com o objetivo de melhoria de suas competências/habilidades/atitudes. Assim, as outras formas de devolutiva em que há discussão e reflexão que ocorrem após uma situação com a equipe/indivíduo participante são denominadas debriefing. 
perguntas ou algum feedback, isso deve ser feito com cuidado e instrução de todos os envolvidos.

A construção de um ambiente de segurança e confiança mútua, a apresentação dos objetivos de aprendizagem e a apresentação dos cenários ocorrem antes da realização do debriefing, mas são essenciais e praticamente formam um processo contínuo entre pré-briefing e debriefing. Em especial, os objetivos do debriefing devem ser bem claros para o instrutor/avaliador - é essencial, ao iniciar o debriefing, que esteja claro, para quem for facilitar o debrieng, "o que são" e "quais são" os principais aspectos que precisam ser abordados. Em geral, dois elementos contribuem para definir sobre o que será o debrienfing: os objetivos de aprendizagem e a performance (ORIOT; ALINIER, 2018). No entanto, algum aspecto adicional pode surgir e, se for relevante, precisará ser explorado. Além disso, o tempo disponível é fundamental e deve-se tentar ao máximo se ater ao cronograma determinado (Tabela 3).

\subsection{INICIANDO O DEBRIEFING}

As regras devem ser explicadas e além disso deve ser verificado se houve compreensão por parte de todos os envolvidos na simulação sobre como será todo o processo, em especial, do debriefing.

Regras para iniciar o Debriefing (ORIOT; ALINIER, 2018) - Informa-se aos participantes que:
1) Deve-se manter um ambiente calmo e ordenado;

2) A discussão somente deve ser iniciada após todos estarem preparados; tanto para perguntas como para respostas aos questionamentos, devem ser mantidos ordem e respeito pela fala de cada um dos envolvidos;

3) Evitar julgamentos ou críticas aos participantes - preferir perguntas abertas para compreender e não julgar o que aconteceu;

4) Confidencialidade do que for discutido e observado.

As regras são simples e, apesar de serem apresentadas mesmo antes de iniciar a simulação, precisam ser reforçadas antes do início do debriefing.

\section{MODELOS DE DEBRIEFING}

O debriefing é considerado um encontro no qual, a partir de um facilitador, há reflexão baseada em uma aprendizagem por experiência (experiential learning episode) (19). Para Mort e Donahue (2004), o debriefing deve contemplar quatro elementos (4 "Es"- Eventos; Emoções; Empatia - pelos participantes e entre os participantes -, e Explicações) (MORT; DONAHUE, 2004) (Tabela 4).

De uma forma sintetizada, podemos considerar três fases do debriefing: 1) Reação emocional - permitir que os participantes diminuam a ten-

Tabela 3 - A preparação para o Debriefing começa no Briefing (pré-briefing)

\begin{tabular}{|c|c|c|}
\hline Briefing & $\begin{array}{c}\text { Objetivo da Simulação e do Debriefing / Uso ou não de tecnologia auxiliar } \\
\text { (vídeo/outros) / Definição e apresentação do local para o Debriefing / } \\
\text { Apresentação de quem participará do Debriefing / Breve introdução do que será } \\
\text { feito após a simulação - ambiente seguro/respeito. }\end{array}$ \\
\hline $\begin{array}{c}\text { Durante a Simulação / } \\
\text { Performance }\end{array}$ & $\begin{array}{c}\text { Quem for realizar o debriefing pode ter um instrumento com o desempenho } \\
\text { esperado, a avaliação global ou a escala Likert, anotar as informações } \\
\text { importantes - Muita atenção! Se houver mais de um facilitador, divida tarefas. }\end{array}$ \\
\hline Debriefing & Com toda a preparação anterior, a chance de sucesso é muito maior! \\
\hline
\end{tabular}

* Dos autores Renato Soleiman Franco e Camila Ament Giuliani dos Santos Franco.

Tabela 4 - Aspectos Gerais do Debriefing

\begin{tabular}{|c|c|}
\hline Término do cenário & Iniciar o debriefing no local indicado. \\
\hline Iniciando o Debriefing & $\begin{array}{l}\text { Informar as regras novamente (de uma forma mais rápida, pois já tinham sido } \\
\text { abordadas no Briefing) }\end{array}$ \\
\hline Durante o Debriefing & $\begin{array}{l}\text { Lembrar dos } 4 \text { Es. - Evento/Emoção/Empatia/Explicações - de Mort e Donahue } \\
\text { (2004). }\end{array}$ \\
\hline
\end{tabular}

* Dos autores Renato Soleiman Franco e Camila Ament Giuliani dos Santos Franco. 
são (relaxamento) e verbalizem os sentimentos; 2) Análise - para descobrir o que aconteceu e por quê, e 3) Generalização - integrar a experiência de simulação na prática clínica do mundo real para melhorar o desempenho (GARDEN et al., 2015). Essas três fases devem fazer parte dos objetivos dos avaliadores/observadores quando promovem um debriefing. Independentemente do modelo de feedback adotado durante o debriefing, deve-se promover que esses três elementos estejam presentes.

Outro modelo utilizado é o de Rudolph (2008), com quatro etapas: 1) observar lacunas (gaps) de desempenho relacionadas aos objetivos predeterminados; 2) fornecer feedback descrevendo a lacuna; 3) investigar a base da lacuna explorando os quadros e as emoções que contribuem para o nível de desempenho atual, e 4) ajudar a reduzir a lacuna de desempenho por meio de discussões ou instruções específicas sobre princípios e habilidades relevantes para o desempenho (RUDOLPH et al., 2008). Esse modelo de Rudolph é mais ligado à etapa de análise e generalização do modelo de três fases. Assim, ao tentar entender o que aconteceu e o motivo para tal desfecho, pode-se iniciar solicitando para que os participantes descrevam as lacunas (o que faltou) frente aos objetivos propostos; segue-se a isso, a avaliação do observador frente a essas lacunas e ele pergunta a impressão dos participantes sobre o motivo de terem realizado a performance de determinada maneira, e finalmente se discute de forma objetiva como solucionar esses problemas.

O framework PEARLS (Promoting Excellence and Reflective Learning in Simulation) é um modelo de quatro fases bastante utilizado: 1) Reações - Objetivo: Explorar as emoções e a percepção dos participantes sobre a simulação/performance - pessoal e do grupo; 2) Descrição - Objetivo: Esclarecer o que aconteceu - promover uma compreensão compartilhada sobre a simulação - descrever simulação / performance / diagnóstico / conduta; 3) Análise - Objetivo: Explorar os diversos domínios de performance/lacunas de aprendizagem (descrito no capítulo de feedback) - muitas vezes, as lacunas já são descritas nas fases anteriores - pode ser feita uma síntese e promover maior discussão; 4) Sumarização/Aplicação - Objetivo: Identificar as principais mensagens - podem ser realizadas observações centradas no estudante/trainee - a partir daquilo que eles levantaram/discutiram, bem como centradas no instrutor - a partir daquilo que eram os objetivos de aprendizagem e os apontamentos definidos pelo avaliador/facilitador. A fase de Análise, talvez seja a que exige maior habilidade, pois nesta são destacadas três abordagens: 1) autoavaliação do estudante/trainee - promover reflexão perguntando sobre a própria performance; 2) Facilitação - explorar profundamente aspectos-chave da performance, e 3) Prover informações - a partir das lacunas (gaps), oferecer conhecimento ou comportamentos que auxiliariam na resolução do problema (BAJAJ et al., 2018; EPPICH; CHENG, 2015).

Esses modelos de debriefing apresentados se assemelham com o feedback (Ask-Tell-Ask Pergunte-Conte-Pergunte) (9), que pode ser utilizado na análise dialogada entre os participantes e o facilitador. Na opinião dos autores deste capítulo, é essencial que o debriefing envolva:

1) Descrição do que aconteceu (framework - quadro de trabalho para a análise - descrição da performance);

2) Autoavaliação dos participantes quanto às emoções e performance (pode-se fazer uma rodada de questionamentos sobre as emoções e depois sobre a performance);

3) Análise dialogada entre os participantes e os observadores/avaliadores sobre as lacunas (o que era esperado e o que foi realizado), e

4) Refletir sobre a aplicabilidade prática e como alcançar o melhor desempenho - Elaborar um plano de aprendizagem.

O Debriefing é tão importante que alguns autores destacam que a própria simulação é um pretexto para o debriefing (GARDNER, 2013). Isso reforça a importância do treinamento e da clareza de informações que devem ser fornecidas para os participantes (aqueles que participaram ativamente da performance) e observadores (aqueles que observaram externamente ao cenário). Independentemente do modelo, é importante conseguir identificar o modelo mental internalizado pelos participantes e promover reflexão. Esse modelo mental é a forma com a qual os processos de aprendizagem, no caso a simulação, passaram do meio externo (vivência, comportamento, observação, entre outros) para o meio interno através da cognição e das emoções/ afetos. Nesse processo de aprendizagem, promover reflexão passa a ser papel central do debriefing.

\subsection{REFLEXÃO E DEBRIEFING}

Apesar de haver diversos modelos de debriefing, a reflexão parece ser um objetivo comum. Assim, ao desenvolver, aplicar e avaliar o debriefing, o mais importante é analisar se o processo de interação com os estudantes gerou um processo reflexivo voltado para o crescimento e a melhoria dos par- 
ticipantes quanto aos conhecimentos, habilidades ou atitudes. Assim, apresentaremos brevemente alguns conceitos relacionados à reflexão.

A reflexão pode ser considerada um processo metacognitivo (pensar sobre pensar ou pensar sobre as próprias atitudes/comportamentos) (SANDARS, 2009). Isso acontece, pois, na reflexão, é inevitável avaliar uma questão sobre diversos pontos de vista, inclusive o ponto de vista daquele que reflete. Assim, reflexão torna-se uma análise multifacetada e crítica de qualquer elemento ou situação.

O enfoque em reflexão utilizando a simulação vai desde os objetivos de aprendizagem, passa pela construção dos cenários e termina na simulação propriamente dita, incluindo o debriefing. Assim, a reflexão não é algo que deve fazer parte somente do debriefing, mas também de seu desenvolvimento, que precisa ser planejado em todas as etapas que envolvem a simulação. Além disso, é importante preparar os estudantes para isso, pois um ambiente reflexivo, muitas vezes, é um ambiente cercado de dúvidas e incertezas. Esses dois últimos, os principais disparadores de reflexão.

Em 2015, Kumagai e Naidu tencionaram sobre a necessidade emergente de espaços reflexivos e de diálogo na formação médica (KUMAGAI; NAIDU, 2015). Para conseguir formar médicos capazes de promover um cuidado ético, socialmente responsável e centrado no paciente, é de vital importância promover que os estudantes tenham um pensamento crítico reflexivo (MANN, GORDON, MACLEOD, 2009). A promoção de espaços e diálogos no sentido de estimular a reflexão é realizada quando se proporcionam espaços de enga- jamento, trocas e vivências (KUMAGAI; NAIDU, 2015). Assim, considerar a simulação como um espaço que promove reflexão seria extrapolar a visão estritamente biomédica da simulação e compreender o estudante/trainee dentro de suas dimensões biopsicossociais. Pode parecer abstrato, mas seria considerar e prezar, em especial no debriefing, pelo background do estudante, valorizando suas experiências de vida, valores e perspectivas, incluindo sua criatividade e diferentes formas de conseguir resolver problemas. Tudo isso em um ambiente protegido e acolhedor com respeito e possibilidade de diálogo.

O diálogo no contexto de uma prática reflexiva envolvem a inclusão dos afetos e as dimensões experienciais e cognitivas de aprendizagem, com foco na descoberta de novas perspectivas, insights e questionamentos. Um debriefing reflexivo que leva os participantes naturalmente a uma descoberta é menos diretivo e mais colaborativo. Frente à falta de espaços reflexivos na formação médica e em outras áreas da saúde, ter na simulação um ambiente protegido para refletir, certamente, elevará o status da simulação quanto à importância na formação da identidade profissional dos profissionais de saúde. É evidente que, para isso, o treinamento de toda a equipe para oferecer esse tipo de debriefing é fundamental. Promover esse clima e ambiente reflexivo é mais do que fazer o estudante pensar ou analisar o que fez, é valorizar seus sentimentos, valores, conhecimentos, habilidades e atitudes. Além disso, é preciso promover o processo de educação a partir de um diálogo humanístico e próximo às necessidades dos estudantes/trainees.

\section{REFERÊNCIAS}

BAJAJ, K. et al. The PEARLS Healthcare Debriefing Tool. Academic Medicine, Philadelphia, v. 93, n. 2, p. 336, 2018. BOET, S. et al. Twelve tips for a successful interprofessional team-based high-fidelity simulation education session. Medical Teacher, Basingstoke, v. 36, n. 10, p. 853-857, 2014.

BOKKEN, L. et al. Feedback by simulated patients in undergraduate medical education: a systematic review of the literature. Medical Education, Basingstoke, v. 43, n. 3, p. 202-210, 2009

CHENG, A. et al. Debriefing for technology-enhanced simulation: A systematic review and meta-analysis. Medical Education, v. 48, n. 7, p. 657-666, 2014.
CUSHING, A. et al. Peer feedback as an aid to learning What do we want? Feedback. When do we want it? Now! Medical Teacher, Basingstoke, v. 33, n. 2, p. e105-e112, 2011. EICHNA, L. W. Medical-School Education, 1975-1979. The New England Journal of Medicine, Boston, v. 303, n. 13, p. 727-734, 1980. Disponível em: <http://www.nejm. org/doi/abs/10.1056/NEJM198009253031304>. Acesso em: 19 jul. 2021.

ENDE, J. Feedback in clinical medical education. Journal of the American Medical Association, Chicago, v. 250, n. 6, p. 777-781, 1983. Disponível em: <http://www.ncbi.nlm. nih.gov/entrez/query.fcgi?cmd=Retrieve $\& \mathrm{db}=$ PubMed $\& \mathrm{~d}$ opt=Citation\&list_uids=6876333 $>$. Acesso em: 19 jul. 2021. 
EPPICH, W.; CHENG, A. Promoting Excellence and Reflective Learning in Simulation (PEARLS). Society for Simulation in Healthcare, Hagerstown, v. 10, n. 2, p. 106-115, 2015.

FANNING, R. M.; GABA, D. M. The role of debriefing in simulation-based learning. Simulation in Healthcare, Hagerstown, v. 2, n. 2, p. 115-125, 2007.

FRANCO, C. A. G. S. et al. Clinical communication skills and professionalism education are required from the beginning of medical training - a point of view of family physicians. BMC medical education, England, v. 18, n. 1, p. 43, 2018.

FRANCO, C. A. G S., et al. OSCE para Competências de Comunicação Clínica e Profissionalismo: Relato de Experiência e Meta-Avaliação. Revista Brasileira de Educação Médica, Rio de Janeiro, v. 39, n. 3, p. 433-441, 2015. Disponível em: <http://www. scielo.br/scielo.php?script=sci_arttext $\&$ pid=S010055022015000300433\&lng=pt\&tlng=pt $>$. Acesso em: 7 dez. 2018.

FRENCH, J. C. et al. Targeted feedback in the milestones era: Utilization of the Ask-tell-ask feedback model to promote reflection and self-assessment. Journal of Surgical Education, v. 72, n. 6, p. e274-e279, 2015. http:// dx.doi.org/10.1016/j.jsurg.2015.05.016.

GARDEN, A. L. et al. Debriefing after simulation-based non-technical skill training in healthcare: A systematic review of effective practice. Anaesthesia and Intensive Care, Sydney, v. 43, n. 3, p. 300-308, 2015.

GARDNER, R. Introduction to debriefing. Seminars in Perinatology, v. 37, n. 3, p. 166-174, 2013. Disponível em: <https://linkinghub.elsevier.com/retrieve/pii/ S014600051300030X>. Acesso em: 19 jul. 2021.

HATALA, R. et al. Feedback for simulation-based procedural skills training: A meta-analysis and critical narrative synthesis. Advances in Health Sciences Education, Dordrecht, v. 19, n. 2, p. 251-272, 2014. Disponível em: <http://www.ncbi.nlm.nih.gov/pubmed/23712700>. Acesso em: 12 ago. 2014.

ISKANDER, M. Offering effective feedback to trainees. Medical Teacher, Basingstoke, v. 37, n. 1, p. 92-93, 2015. Disponível em: <http://www.tandfonline.com/doi/full/1 0.3109/0142159X.2014.916786>. Acesso em: 19 jul. 2021.

JOSHI, R. M.; LING, F. W. M.; JAEGER, J. M. Assessment of a 360-Degree Instrument to Evaluate Residents' Competency. Academic Medicine, v. 79, n. 5, p. 458-463, 2004.

KIM, Y. M. et al. Focused and corrective feedback versus structured and supported debriefing in a simulationbased cardiac arrest team training: A pilot randomized controlled study. Simulation in Healthcare, Hagerstown, v. 12, n. 3, p. 157-164, 2017.

KOLBE, M.; GRANDE, B.; SPAHN, D. R. Briefing and debriefing during simulation-based training and beyond: Content, structure, attitude and setting. Best Practice \& Research. Clinical Anaesthesiology, London, v. 29, n. 1, p. 87-96, 2015.
KUMAGAI, A. K.; NAIDU, T. Reflection, dialogue, and the possibilities of space. Academic Medicine, Philadelphia, v. 90 , n. 3, p. 283-288, 2015.

LAMIANI, G. et al. Assessment of communication skills and self-appraisal in the simulated environment: Feasibility of multirater feedback with gap analysis. Simulation in Healthcare: Journal of the Society for Simulation in Healthcare, Hagerstown, v. 4, n. 1, p. 22-29, 2011.

LEVETT-JONES, T.; LAPKIN, S. The effectiveness of debriefing in simulation-based learning for health professionals: A systematic review. JBI Database of Systematic Reviews and Implementation Reports, v. 10, n. 51, p. 3295-3337, 2012. Disponível em: <https://insights.ovid. com/crossref?an=01938924-201210510-00001 >. Acesso em: 19 jul. 2021.

MAIA, I. L. et al. Estratégia Adaptada de Feedback Voltado para Ambulatórios de Graduação. Revista Brasileira de Educação Médica, Brasília, v. 42, n. 4, p. 29-36, 2018. Disponível em: <http://www. scielo.br/scielo.php?script=sci_arttext\&pid=S0100$55022018000400029 \& \operatorname{lng}=$ pt\&tlng=pt $>$. Acesso em: 19 jul. 2021.

MANN, K.; GORDON, J.; MACLEOD, A. Reflection and reflective practice in health professions education: a systematic review. Advances in Health Sciences Education: Theory and Practice, Netherlands, v. 14, n. 4, p. 595-621, 2009. Disponível em: <http://link.springer. com/10.1007/s10459-007-9090-2>. Acesso em: 19 jul. 2021.

MCGAGHIE, W. C. et al. A critical review of simulationbased medical education research: 2003-2009. Medical Education, Basingstoke, v. 44, n. 1, p. 50-63, 2010.

MORT, T. C.; DONAHUE, S. P. Debriefing: the basics. In: Dunn WF, editor. Simulators in critical care and beyond. Des Plaines: Society of Critical Care Medicine; 2004.

ORIOT, D.; ALINIER, G. Pocket Book for Simulation Debriefing in Healthcare. Cham: Springer International Publishing; 2018.

PFEIFFER, C. A. et al. Face-to-Face Clinical Skills Feedback: Lessons from the analysis of standardized Patient' Work. Teaching and Learning in Medicine, Hillsdale, v. 17, n. 3, p. 254-256, 2005.

PHILLIPS, A. W. et al. Individualised expert feedback is not essential for improving basic clinical skills performance in novice learners: A randomized trial. Journal of Surgical Education, v. 74, n. 4, p. 612-620, 2017. Disponível em: <https://linkinghub.elsevier.com/ retrieve/pii/S1931720416301994>. Acesso em: 19 jul. 2021.

RUDOLPH, J. W. et al. Debriefing as Formative Assessment: Closing Performance Gaps in Medical Education. Academic Emergency Medicine, v. 15, n. 11, p. 10101016, 2008. Disponível em: <http://doi.wiley.com/10.11 11/j.1553-2712.2008.00248.x>. Acesso em: 19 jul. 2021.

SANDARS, J. The use of reflection in medical education: AMEE Guide No. 44. Medical Teacher, Basingstoke, v. 31, n. 8, p. 685-695, 2009. Disponível em: <http://www. 
tandfonline.com/doi/full/10.1080/01421590903050374>. Acesso em: 19 jul. 2021.

SCHWELLER, M. et al. Simulated medical consultations with standardized patients: In-depth debriefing based on dealing with emotions. Revista Brasileira de Educação Médica, Rio de Janeiro, v. 42, n. 1, p. 84-93, 2018.

SHAROFF, L. Simulation: Pre-briefing preparation, clinical judgment and reflection. What is the connection? Journal of Contemporary Medicine, v. 5, n. 2, 2015.

SIGRIST, R. et al. Augmented visual, auditory, haptic, and multimodal feedback in motor learning: A review. Psychonomic Bulletin \& Review, Austin, v. 20, n. 1, p. 21-53, 2013.

SO, H. Y. et al. Simulation in medical education. The Journal of the Royal College of Physicians of Edinburgh, v. 49, n. 1, p. 52-57, 2019. Disponível em: <https://www. rcpe.ac.uk/sites/default/files/jrcpe_49_1_so.pdf >. Acesso em: 19 jul. 2021.

STURMBERG, C. et al. Attentional focus of feedback and instructions in the treatment of musculoskeletal dysfunction: a systematic review. Manual Therapy, Scotland, v. 18, n. 6, p. 458-467, 2013.

VAN DER LEEUW, R. M.; SLOOTWEG, I. A. Twelve tips for making the best use of feedback. Medical Teacher, Basingstoke, v. 35, n. 5, p. 348-351, 2013. Disponível em: <http://www.tandfonline.com/doi/full/10.3109/01421 59X.2013.769676>. Acesso em: 19 jul. 2021.

WULF, G. et al. Frequent external-focus feedback enhances motor learning. Frontiers in Psychology, Switzerland, v. 1, n. Nov., p. 1-7, 2010. 


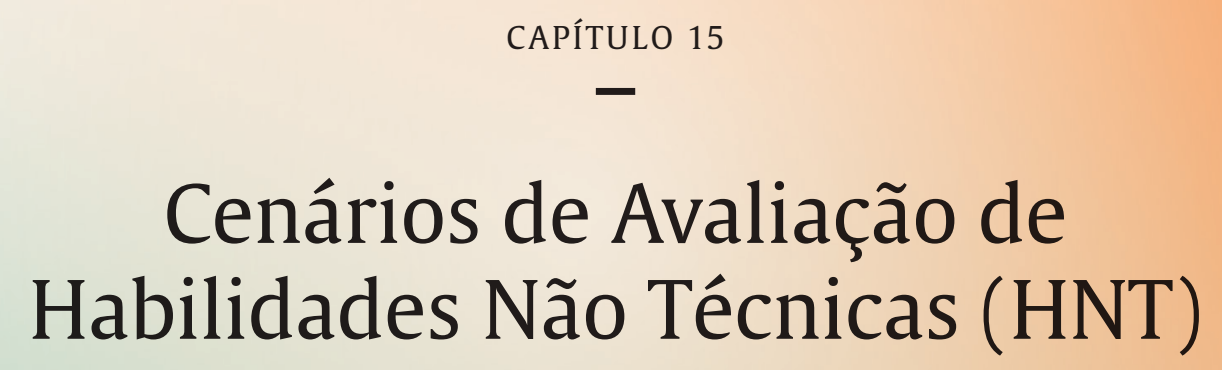




\section{Camila Ament Giuliani dos}

Santos Franco

Médica de Família e Comunidade

Professora Adjunta do Curso

de Medicina - PUCPR

Professora no Curso de Medicina

nas Faculdades Pequeno

Príncipe, Curitiba, PR.

Preceptora responsável pela

disciplina de Comunicação Clínica na

Residência Médica em Medicina de

Família e Comunidade - Residência

Integrada, Curitiba, PR.

\section{Renato Soleiman Franco}

Psiquiatra

Professor Adjunto - Curso

de Medicina da PUCPR

Coordenador do Programa de Residência

Médica em Psiquiatria da Prefeitura

Municipal de Curitiba, SMS/FEAS.

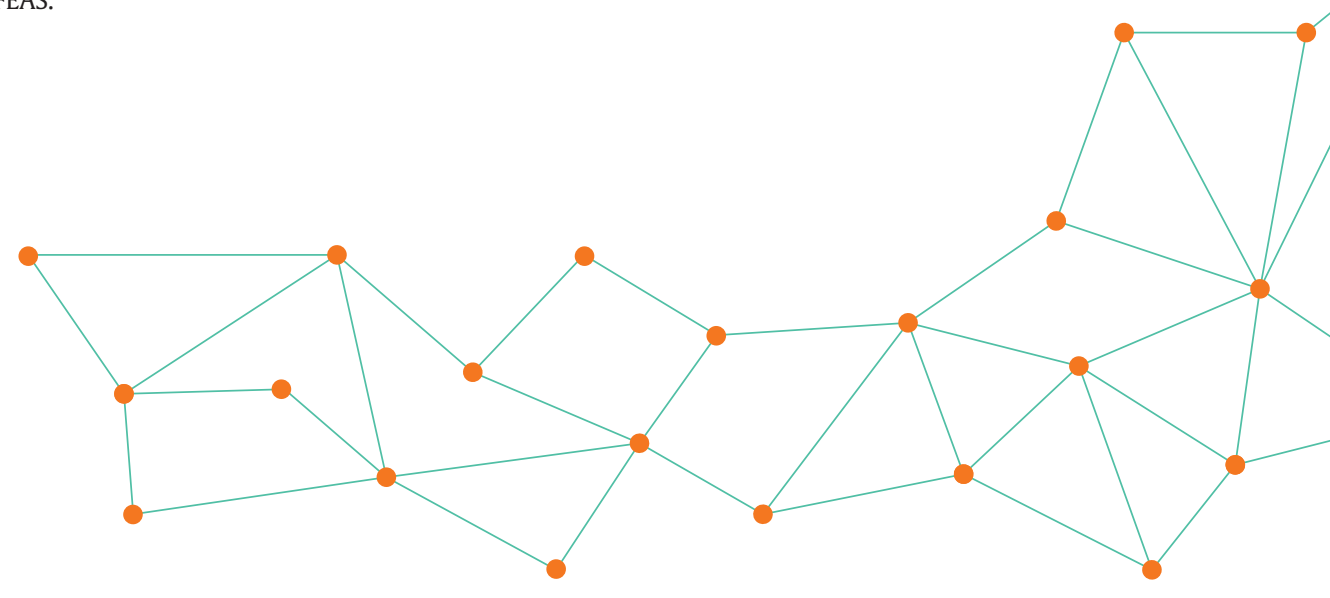

\section{INTRODUÇÃO}

Conceituar habilidades não técnicas (soft skills) é algo difícil, a começar pela sua nomenclatura. Apesar de ser um nome classicamente empregado e reconhecido, o termo pode trazer uma conotação de que não são habilidades treinadas e desenvolvidas por repetição ou que seriam habilidades de importância secundária para o profissional de saúde. O desenvolvimento das HNT requer mais do que a repetição, exige uma prática reflexiva e uma análise crítica de comportamentos e desempenhos. Assim, decidimos manter esse título (HNT) no capítulo pelo uso corrente do termo, mas destacar que são habilidades complexas e compreendem o desenvolvimento de processos cognitivos e afetivos.

Estudos apontam que a falta de HNT é responsável pela grande maioria de processos médicos, além de impactar decisivamente nos resultados do cuidado ao paciente (KIERAN; JENSEN;
ROSENBAUM, 2018). O ambiente simulado tem sido um dos mais utilizados tanto para o desenvolvimento quanto para a avaliação das HNT (GORDON et al., 2019). Entretanto, vale a pena ressaltar que cenários simulados e checklists podem ter uma abordagem reducionista frente a habilidades tão complexas (CHUNG et al., 2016). Assim, o observador/avaliador deve ter bastante sensibilidade, estar atento e promover um feedback e/ou debriefing adequados para maximizar a aprendizagem nesses cenários.

Podemos considerar as habilidades não técnicas como os recursos cognitivos, sociais e pessoais que complementam as habilidades técnicas e contribuem para o desempenho seguro e eficiente das tarefas (FLIN et al., 2003). Na área da saúde, essas habilidades incluem trabalho em equipe, liderança, habilidades de comunicação clínica, consci- 
ência situacional, manejo do cansaço e raciocínio clínico/tomada de decisão (HIGHAM et al., 2019).

Desse modo, ao definir que o cenário envolverá HNT, é importante destacar quais dos seus elementos (domínios) serão abordados. Os cinco principais são (Quadro 1):

É importante lembrar que o domínio comunicação envolve tanto a comunicação entre os profissionais quanto entre profissionais e paciente, familiares e cuidadores. Outras importantes categorias que integram as HNT são profissionalismo e manejo de estresse (HIGHAM et al., 2019).

Os cenários para avaliação irão depender do objetivo e contexto da atividade, dos recursos disponíveis e do nível de treinamento desejado. No entanto, não se deve afastar do objetivo primordial do trabalho com as HNT, que é a melhoria na qualidade da assistência e no desenvolvimento profissional. Assim, por exemplo, a comunicação não pode ser somente um fim em si mesma, mas deve estar atrelada a uma melhoria no processo de cuidado. Isso é relevante, pois senão o trabalho com essas habilidades terá uma utilidade questionável.

\section{$\mid$}

\section{Dica n. ${ }^{\circ}$ 1: Defina o objetivo do} cenário - alinhe com os avaliadores/ instrutores o que é esperado das HNT (e quais dentre as HNT). Dê preferência para o uso de termos que deixem mais claro o foco da simulação, como, por exemplo: Comunicação - entre os profissionais e entre profissionais e paciente/familiares/cuidadores; Liderança/trabalho em equipe; Consciência situacional; Gerenciamento de tarefas, ou Tomada de decisão.

\section{CENÁRIOS DE URGÊNCIA / PACIENTES GRAVES - TERAPIA INTENSIVA, AMBIENTE CIRÚRGICO (INCLUINDO ANESTESIA), TRAUMAS E URGÊNCIA/ EMERGÊNCIA}

A Gestão de Recursos em Crises (GRC) é amplamente discutida no capítulo referente à simulação em cenários de emergência. Frisamos neste capítulo que as possíveis respostas dos participantes frente aos cenários devem ser antecipadas e os avaliadores devem estar preparados para lidar com isso. Nicolaides et at. (2019) propõem uma série de cenários para o ensino e aprendizagem de HNT, (NICOLAIDES et al., 2019) a maioria deles envol-
Quadro 1 - Domínio das HNT

\begin{tabular}{|l|}
\hline Comunicação \\
\hline Liderança/trabalho em equipe \\
\hline Consciência situacional \\
\hline Gerenciamento de tarefas \\
\hline Tomada de decisão \\
\hline
\end{tabular}

vem GRC. Deve-se desenvolver o cenário em GRC para a avaliação, de acordo com:

1) Objetivo educacional: qual ou quais elementos das HNT os participantes pretendem desenvolver (comunicação; liderança/trabalho em equipe; consciência situacional, entre outros).

2) Para quais sujeitos será aplicado - nível ou níveis de treinamento.

3) Para quantos sujeitos - adequar espaço, recursos e professores.

4) Quais recursos: manequim, paciente simulado, pares, salas, vídeo, entre outros.

5) No desenvolvimento das estações, é importante discutir se o paciente simulado irá morrer caso o cuidado não seja adequado; se o cenário já começa com o paciente em estado crítico ou se o estado crítico irá se instalar aos poucos.

Com isso, é possível definir quais as habilidades precisarão ser desenvolvidas e avaliadas. Caso o foco seja a comunicação com o paciente/familiares ou cuidadores, o uso de pacientes simulados (atores ou outros) é importante. Entretanto, é possível realizar simulação com HNT sem pacientes simulados (atores ou outros), mas o foco será no relacionamento entre a equipe, na consciência situacional, na tomada de decisão ou no gerenciamento de tarefas. Assim, a partir dos recursos disponíveis, as possibilidades de simulação em GRC são variadas.

A criatividade é sempre uma grande aliada na preparação de cenários. Por exemplo, um estudo recente investigou o impacto de um planejamento rápido entre a equipe antes do manejo da resposta à crise. Os autores criaram cenários e dividiram os participantes entre equipes que tiveram tempo para se planejar e outras que não tiveram esse tempo. Nesse caso, o foco não era o GRC, mas o impacto do planejamento no desfecho. Os autores concluíram que um tempo de planejamento, mesmo que curto (quatro minutos), trouxe benefícios nos desfechos clínicos, no manejo da crise e na diminuição do estresse (EVAIN et al., 2019). 
Esse tipo de estratégia inovadora deve ser estimulada e nasce a partir da participação de sujeitos com prática e atuação nos campos a serem ensinados pela simulação. Assim, devemos nos perguntar quais habilidades, fluxos ou processos que envolvem HNT devem ser estimulados e aprimorados, ou quais outros podem ser melhorados através das HNT.

Alguns modelos de avaliação das GRM são: TEAM (COOPER et al., 2010), Observational Teamwork Assessment for Surgery (OTAS) (UNDRE et al., 2006), Oxford NOnTECHnical Skills (Oxford NOTECHS) (MISHRA; CATCHPOLE; MCCULLOCH, 2009), Non-Technical Skills for Surgeons (NOTSS) (YULE et al., 2006) e Ottawa CRM Global Rating Scale (KIM et al., 2006) (Tabela 1).

\section{CENÁRIOS DE PRÁTICA CLÍNICA AMBULATORIAL}

Nos cenários ambulatoriais (atenção primária ou secundária), as HNT estão mais associadas à comunicação entre o médico e o paciente (ou familiar/cuidador), às tomadas de decisão e ao raciocínio clínico. No entanto, também é possível elaborar cenários de interação entre a equipe e a liderança.

A comunicação clínica tem sido destacada como um elemento essencial da graduação, em especial no currículo médico (FRANCO et al., 2018). Os referenciais teóricos em comunicação clínica são bons norteadores para a elaboração de cenários de avaliação que contemplem a comunicação clínica. Entre as referências, o Guia Calgary- Cambridge (KURTZ; SILVERMAN; DRAPER, 1998), o Consenso de Kalamazoo (DUFFY et al., 2004) e o Método Clínico Centrado na Pessoa (STEWART et al., 2014) destacam uma prática clínica orientada para um cuidado clínico empático, compartilhado e com foco em uma comunicação eficaz.
Há alguns checklists que são validados e se baseiam nesses referencias (CÖMERT et al., 2016), entre eles o EPSCALE- Explanation and Planning Scale (SILVERMAN et al., 2011) (baseado no Guia Calgary-Cambridge) e o CG - Common Ground Instrument (baseado no Kalamazoo) (LANG et al., 2004), entretanto, não há consenso entre o melhor modelo para avaliação da comunicação clínica (SETYONUGROHO; KENNEDY; KROPMANS, 2015). Na prática, a maioria dos estudos toma como base esses referenciais, mas acaba por adaptá-los segundo sua necessidade.

Os cenários podem contemplar uma consulta ou outra atividade completa desde o início até o final, ou então, serem focados em determinadas etapas. As próprias referências em comunicação fornecem dicas importantes sobre a abordagem nos cenários. Por exemplo, o Guia Calgary-Cambrigde avalia a consulta incluindo etapas (não necessariamente sequenciais) transversais e longitudinais (que perpassam toda consulta). Um outro modelo é o Método Clínico Centrado na Pessoa (MCCP), que também apresenta componentes não necessariamente sequenciais (Tabela 2 ).

Por exemplo, ao elaborar uma estação para o ensino do início da consulta, deve-se atentar para a preparação do ambiente, a primazia pelo conforto do paciente, a ergonomia do profissional, a identificação do motivo da consulta, a escuta ativa, entre outros. Nesse sentido, diversos cenários poderiam ser elaborados, assim como subsequentes checklists ou outros modelos de escalas de avaliação que sejam objetivas e focadas em comportamentos observáveis.

Uma leitura mais profunda dos modelos pode auxiliar bastante na preparação dos cenários. O artigo de Campos e Rios (2018) e o de Franco et al. (2015) são referências nacionais que apresentam de forma clara modelos de comunicação e cenários possíveis em ambientes simulados.

Tabela 1 - Domínios de HNT em Cirurgia/Emergência.

\begin{tabular}{|c|c|c|c|c|}
\hline OTAS & NOTSS & Ottawa CRM & Oxford NOTECHS & TEAM \\
\hline $\begin{array}{l}\text { - Liderança } \\
\text { - Comunicação } \\
\text { - Coordenação } \\
\text { - Cooperação } \\
\text { - Monitorização. }\end{array}$ & $\begin{array}{l}\text { - Liderança. } \\
\text { - Comunicação } \\
\text { - Trabalho em } \\
\text { equipe } \\
\text { - Consciência } \\
\text { situacional } \\
\text { - Tomada de } \\
\text { decisão }\end{array}$ & $\begin{array}{l}\text { - Liderança } \\
\text { - Comunicação } \\
\text { - Resolução de } \\
\text { problemas } \\
\text { - Consciência } \\
\text { situacional } \\
\text { - Utilização de } \\
\text { recursos }\end{array}$ & $\begin{array}{l}\text { - Liderança e gestão } \\
\text { - Trabalho } \\
\text { em equipe e } \\
\text { cooperação } \\
\text { - Resolução de } \\
\text { problemas e } \\
\text { tomada de decisão } \\
\text { - Consciência da } \\
\text { situação }\end{array}$ & $\begin{array}{l}\text { - Liderança } \\
\text { - Trabalho em } \\
\text { equipe } \\
\text { - Gerenciamento } \\
\text { de tarefas } \\
\text { - Avaliação global }\end{array}$ \\
\hline
\end{tabular}


Tabela 2 - Referências em Abordagem Clínica na Consulta.

\begin{tabular}{|c|c|}
\hline Calgary-Cambridge & MCCP \\
\hline $\begin{array}{l}\text { - Etapas transversais: } \\
\text { - Início da consulta } \\
\text { - Coleta de informações } \\
\text { - Exame físico } \\
\text { - Explicação e planejamento } \\
\text { - Encerramento da consulta } \\
\text { - Etapas longitudinais: } \\
\text { - Promover estrutura para a consulta } \\
\text { - Construir o relacionamento com o paciente }\end{array}$ & $\begin{array}{l}\text { - Explorando a saúde, a doença e a experiência da } \\
\text { doença } \\
\text { - Entendendo a pessoa como um todo } \\
\text { - Elaborando um plano conjunto de manejo dos } \\
\text { problemas } \\
\text { - Intensificando a relação entre a pessoa e o médico }\end{array}$ \\
\hline
\end{tabular}

A comunicação em cenários ambulatoriais vai além da comunicação clínica e inclui liderança e trabalho em equipe (FRANCO et al., 2018). Além disso, raciocínio clínico, tomada de decisão e consciência situacional também envolvem HNT na prática ambulatorial.

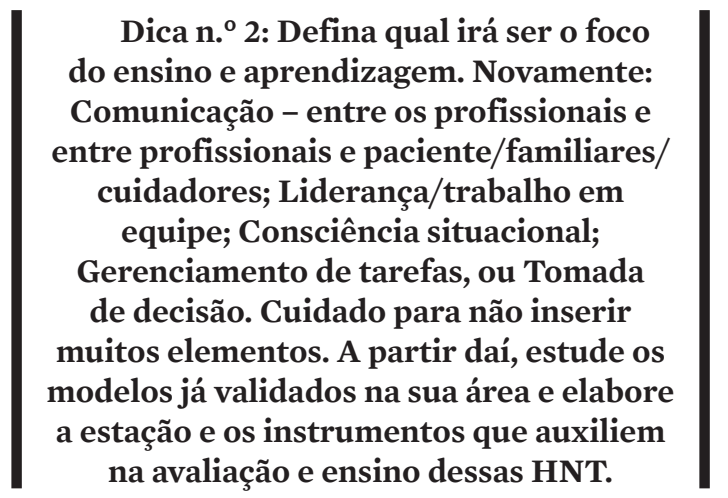

\section{COMUNICAÇÃO DE NOTÍCIAS DIFÍCEIS OU CONVERSAS DIFÍCEIS}

A comunicação de notícias difíceis é um tópico de muita importância em simulação e pode ser realizada em diferentes cenários e contextos, e para diversos públicos alvo. As conversas difíceis/comunicações de notícias difíceis, em geral, envolvem a comunicação em conjunto com a tomada de decisão. Em um cenário completo, o profissional de saúde não somente realiza a comunicação do problema ou condição como também o seu manejo e a tomada de decisão.

A comunicação de notícia difícil envolve qualquer informação que afete negativa e seriamente um indivíduo, de acordo com a sua própria opinião e perspectiva (BUCKMAN, 1984). Assim, qualquer diagnóstico ou situação pode condizer com uma notícia difícil uma vez que é necessário considerar não somente qual doença ou problema, mas a opinião e o contexto do sujeito.

Em cenários com essa abordagem, o foco é na comunicação de determinada condição e na tomada de decisão frente a ela. $\mathrm{O}$ conceito de conversa difícil inclui não somente o diagnóstico ou situação, mas amplia o cenário para questões relacionadas com o contexto, o paciente ou o próprio médico.

Por exemplo, um médico que numa emergência atende um colega pode encontrar maior dificuldade não no diagnóstico em si, mas na relação médico-paciente. Além disso, lidar com pacientes mais ansiosos, irritados ou com outros perfis pode tornar a situação difícil.

$\mathrm{O}$ uso de modelos e protocolos deve ser realizado com muito cuidado. Temos observado que a empatia, a escuta ativa e o foco no bem-estar do paciente/familiar/cuidador são essenciais. Assim, ao utilizar os protocolos, deve-se ter cuidado para não reforçar uma abordagem mecanicista. Um dos protocolos mais utilizados é o SPIKES (Tabela 3 (BAILE et al., 2000).

Os cenários podem envolver uma situação completa de comunicação difícil ou ter o foco em um dos elementos que envolvem esse tipo de comunicação. Por exemplo, para discutir a preparação para a notícia (primeiro "S"), o cenário deve incluir a privacidade, o envolvimento de pessoas de confiança (caso necessário e desejado pelo paciente/ familiar/cuidador), o conforto (médico e paciente, pelo menos, sentados), o contato e a comunicação não verbais, o manejo do tempo e de interrupções por outros profissionais, entre outros.

É essencial adequar a comunicação difícil à realidade do aprendiz, bem como não dramati- 
Tabela 3 - Protocolo SPIKES

\begin{tabular}{|l|l|}
\hline S & Preparando-se para o encontro (Setting up) \\
\hline P & Percebendo o paciente (Perception) \\
\hline I & Convidando para o diálogo (Invitation) \\
\hline K & Transmitindo as informações (Knowledge) \\
\hline E & Expressando emoções (Emotions) \\
\hline S & Resumindo e organizando estratégias (Strategy and Summary) \\
\hline
\end{tabular}

BAILE, W. F. et al. SPIKES-A six-step protocol for delivering bad news: application to the patient with cancer. The Oncologist, Dayton, v. 5, n. 4, p. 302-311, 2000.

zar demais as situações. Ela deve ser real e factível para promover o aperfeiçoamento dos envolvidos. Um maior aprofundamento nos modelos de comunicação difícil pode ser útil na construção desses cenários (BAILE et al., 2000; BAILE; BLATNER, 2014; BONNAUD-ANTIGNAC et al., 2010; BOWYER et al., 2010; CRUZ; RIERA, 2016; LINO et al., 2011; MEITAR; KARNIELI-MILLER; EIDELMAN, 2009), mas, no geral, deve-se prezar pela segurança e pelo bem-estar do paciente/familiar/cuidador, realizar a comunicação em forma de diálogo (evitar extensas exposições descontextualizadas), transmitir as informações na quantidade e da forma adequada, permitir que o paciente/familiar/cuidador expresse suas emoções e responder de maneira adequada (verbal e não verbalmente), realizando síntese e reconhecimento daquilo que o paciente compreendeu.

\section{SÍNTESE}

As habilidades não técnicas (HNT) correspondem a um grupo de habilidades complexas e diversas, que devem ser valorizadas no processo de ensino e aprendizagem da área da saúde. São habilidades que afetam o desfecho clínico, a segurança do paciente e até mesmo o bem-estar do profissional.

A elaboração de cenários nas HNT é uma atividade complexa que demanda conhecimento dos referenciais teóricos nessa área. Ao preparar os cenários, deve-se ter muito cuidado com o nível de expertise dos participantes, bem como com o treinamento dos avaliadores/observadores. É essencial que o ambiente seja protegido, seguro e de boa convivência.

Uma vez que, muitas vezes, as HNT remetem a atitudes e valores, o cuidado, o respeito e a sensibilidade são essenciais para promover seu ensino e aprendizagem. Treinamento e expertise em debriefing e feedback, bem como a preparação cuidadosa dos cenários, são cruciais para o sucesso no treinamento das HNT em simulação. As HNT envolvem elementos cognitivos diversos, como o raciocínio e as emoções. Ao preparar cenários de simulação voltados para esse fim, deve-se ter sempre em mente que mesmo quando as emoções (dos pacientes e dos profissionais) não forem o foco, elas estarão fortemente em pauta. Assim, ao desenvolver os cenários, é essencial incluir os aspectos emocionais e preparar professores/facilitadores para lidar com essas demandas. No capítulo sobre feedback e debriefing, descrevemos elementos essenciais para lidar com essas questões.

\section{REFERÊNCIAS}

BAILE, W. F. et al. SPIKES-A six-step protocol for delivering bad news: application to the patient with cancer. The Oncologist, Dayton, v. 5, n. 4, p. 302-311, 2000.

BAILE, W. F.; BLATNER, A. Teaching communication skills: using action methods to enhance role-play in problem-based learning. Simulation in Healthcare, Philadelphia, v. 9, n. 4, p. 220-227, 2014.
BONNAUD-ANTIGNAC, A. et al. Videotaped simulated interviews to improve medical students' skills in disclosing a diagnosis of cancer. Psycho-Oncology, Hoboken, v. 19, n. 9, p. 975-981, 2010.

BOWYER, M. W. et al. Teaching breaking bad news using mixed reality simulation. The Journal of Surgical Research, Amsterdam, v. 159, n. 1, p. 462-467, 2010. 
BUCKMAN, R. Breaking bad news: why is it still so difficult?. British Medical Journal Clinical Research, London, v. 288, n. 6430, p. 1597-1599, 1984.

CAMPOS, C. F. C.; RIOS, I. C. Qual guia de comunicação na consulta médica é o mais adequado para o ensino de habilidades comunicacionais na atenção primária à saúde brasileira? Revista Brasileira de Educação Médica, Rio de Janeiro, v. 42, n. 3, p. 108-118, 2018.

CHUNG, H. O. et al. Educational interventions to train healthcare professionals in end-of-life communication: a systematic review and meta-analysis. BMC Medical Education, London, v. 16, n. 1, p. 131, 2016.

CÖMERT, M. et al. Assessing communication skills of medical students in objective structured clinical examinations (OSCE): a systematic review of rating scales. PLoS One, San Francisco, v. 11, n. 3, p. e0152717, 2016.

COOPER, S. et al. Rating medical emergency teamwork performance: development of the Team Emergency Assessment Measure (TEAM). Resuscitation, Amsterdam, v. 81, n. 4, p. 446-452, 2010.

CRUZ, C O.; RIERA, R. Comunicando más notícias: o protocolo SPIKES TT. Diagnóstico \& Tratamento, São Paulo, v. 21, n. 3, p. 106-108, 2016.

DUFFY, F. D. et al. Assessing competence in communication and interpersonal skills: the Kalamazoo II report. Academic Medicine, Washington, v. 79, n. 6, p. 495-507, 2004.

EVAIN, J. N. et al. Team planning discussion and clinical performance: a prospective, randomised, controlled simulation trial. Anaesthesia, Hoboken, v. 74, n. 4, p. 488496, 2019.

FLIN, R. et al. Development of the NOTECHS (nontechnical skills) system for assessing pilots' CRM skills. Human Factors and Aerospace Safety, London, v. 3, n. 2, p. 95-117, 2003.

FRANCO, C. A. G. D. S. et al. Clinical communication skills and professionalism education are required from the beginning of medical training: a point of view of family physicians. BMC Medical Education, London, v. 18, n. 1, p. 43, 2018.

FRANCO, C. A. G. S. et al. OSCE para competências de comunicação clínica e profissionalismo: relato de experiência e meta-avaliação. Revista Brasileira de Educação Médica, Rio de Janeiro, v. 39, n. 3, p. 433-441, 2015.

GORDON, M. et al. Non-technical skills assessments in undergraduate medical education: a focused BEME systematic review: BEME Guide no. 54. Medical Teacher, London, v. 41, n. 7, p. 732-745, 2019.

HIGHAM, H. et al. Observer-based tools for nontechnical skills assessment in simulated and real clinical environments in healthcare: a systematic review. BMJ Quality \& Safety, London, v. 28, n. 8, p. 672-686, 2019.
KIERAN, K.; JENSEN, N. M.; ROSENBAUM, M. See, do, teach? A review of contemporary literature and call to action for communication skills teaching in urology. Urology, New York, v. 114, p. 33-40, 2018.

KIM, J. et al. A pilot study using high-fidelity simulation to formally evaluate performance in the resuscitation of critically ill patients: the University of Ottawa critical care medicine, high-fidelity simulation, and crisis resource management i study. Critical Care Medicine, Philadelphia, v. 34 , n. 8, p. 2167-2174, 2006.

KURTZ, S.; SILVERMAN, J.; DRAPER, J. Calgary Cambridge guide to the medical interview - communication process. Medical Education, Hoboken, v. 30, p. 83-89, 1998.

LANG, F. et al. Communication assessment using the common ground instrument: psychometric properties. Family Medicine, Portland, v. 36, n. 3, p. 189-198, 2004.

LINO, C. A. et al. Uso do protocolo Spikes no ensino de habilidades em transmissão de más notícias. Revista Brasileira de Educação Médica, Rio de Janeiro, v. 35, n. 1, p. 52-57, 2011.

MEITAR, D.; KARNIELI-MILLER, O.; EIDELMAN, S. The impact of senior medical students' personal difficulties on their communication patterns in breaking bad news. Academic Medicine, Washington, v. 84, n. 11, p. 15821594, 2009.

MISHRA, A.; CATCHPOLE, K.; MCCULLOCH, P. The Oxford NOTECHS system: reliability and validity of a tool for measuring teamwork behaviour in the operating theatre. British Medical Journal Quality \& Safety, London, v. 18, n. 2, p. 104-8. 2009.

NICOLAIDES, M. et al. Advancing medical students' non-technical skills in a group-based setting. Journal of Investigative Surgery, London, v. 34, n. 1, p. 39-43, 2019. http://dx.doi.org/10.1080/08941939.2019.1602691.

SETYONUGROHO, W.; KENNEDY, K. M.; KROPMANS, T. J. B. Reliability and validity of OSCE checklists used to assess the communication skills of undergraduate medical students: a systematic review. Patient Education and Counseling, Amsterdam, v. 98, n. 12, p. 1482-1491, 2015.

SILVERMAN, J. et al. Initial evaluation of EPSCALE, a rating scale that assesses the process of explanation and planning in the medical interview. Patient Education and Counseling, Amsterdam, v. 82, n. 1, p. 89-93, 2011. http:// dx.doi.org/10.1016/j.pec.2010.02.022.

STEWART, M. et al. Patient-centered medicine: transforming the clinical method. 3rd ed. London: Radcliffe Publishing, 2014. 426 p.

UNDRE, S. et al. Observational assessment of surgical teamwork: a feasibility study. World Journal of Surgery, Portland, v. 30, n. 10, p. 1774-1783, 2006.

YULE, S. et al. Development of a rating system for surgeons' non-technical skills. Medical Education, Hoboken, v. 40, n. 11, p. 1098-1104, 2006. 
CAPÍTULO 16

-

O uso de instrumentos para a avaliação do ensino, da aprendizagem e de outros atributos nos laboratórios simulados 


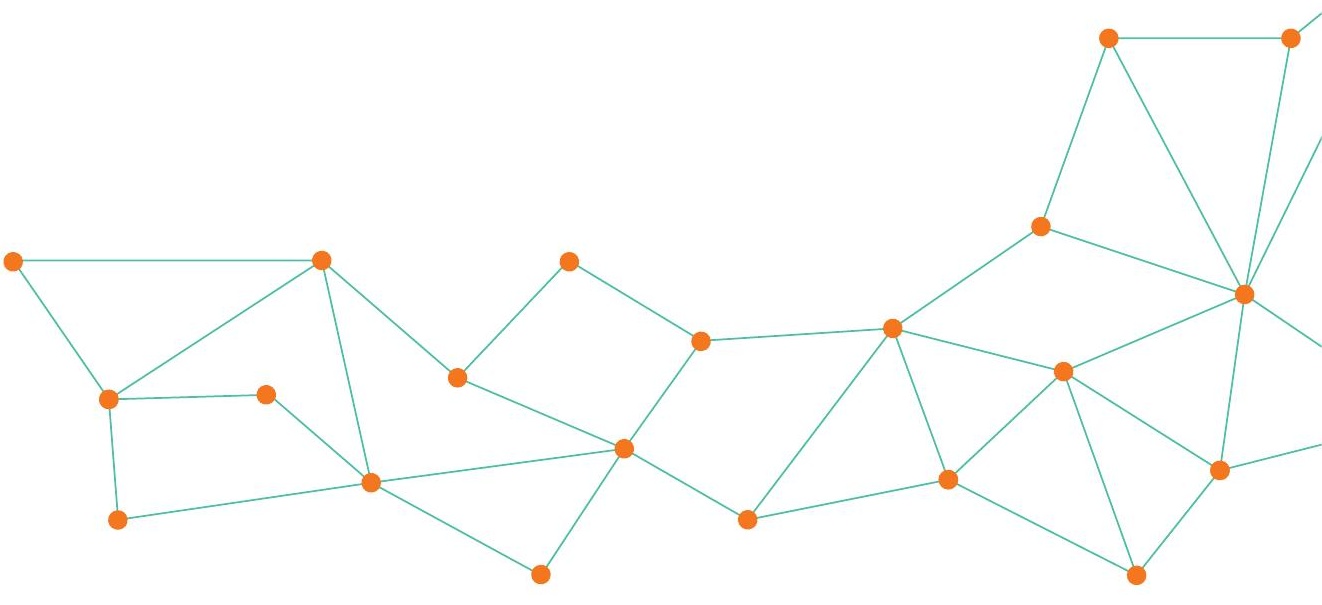

A simulação contribui com a aprendizagem ao longo da vida, o continuum educacional, proporcionando a resolução de problemas, a autoavaliação dos participantes, o pensamento crítico, entre outros (OGDEN et al., 2013).

Os cenários e o treino simulado são reconhecidos como estratégias de ensino essenciais para a formação de profissionais de saúde. São estratégias pelas quais transcorrem o ensino e a avaliação da graduação até o nível da pós-graduação, bem como durante toda a vida profissional, promovendo impactos em estudantes, profissionais e pacientes, $\mathrm{e}$ nas instituições de assistência à saúde (MARTINS; CARLOS, 2017).

Os cenários simulados, quando bem elaborados, permitem incluir e avaliar as competências relacionadas ao atendimento ao paciente, ao conhecimento profissional, à aprendizagem baseada na prática, à habilidade interpessoal e de comunicação, ao profissionalismo, à prática baseada em evidências, en- tre outras (OGDEN et al., 2013). Reconhecida como uma estratégia de educação cognitiva e comportamental, pode promover altos níveis de autoestima, autoconfiança, satisfação, motivação, entre outras (CAMACHO, 2011).

Concomitante, a literatura compartilha instrumentos e ferramentas para colaborarem com os educadores na mensuração e no desenvolvimento da simulação. Descrevemos, a seguir algumas possibilidades que podem colaborar a depender dos objetivos da simulação.

\section{AVALIAÇÃO DA ESTRUTURAÇÃO DOS CENÁRIOS SIMULADOS}

\section{ESCALA DE DESIGN DA SIMULAÇÃO}

A avaliação da estruturação dos cenários simulados pode ser através da Escala de Design da Simulação 
originalmente desenvolvida pela National League for Nursing (NLN). A escala foi traduzida e validada para a o português brasileiro por Almeida et al. (2015a), sendo composta por cinco dimensões: 1) objetivos e informações; 2) apoio; 3) resolução de problemas; 4) feedback, e 5) reflexão; realismo. Estas dimensões têm contemplados 20 itens, que se dividem em duas subescalas: concordância e importância.

Essa escala tem sido utilizada em diferentes cenários, como, por exemplo, para identificar a percepção dos estudantes de Enfermagem e as dimensões estruturais do design em cenários materno-infantis (BRASIL et al., 2018) e em cenários de simulação de alta fidelidade na imunização de adultos, no contexto da atenção primária à saúde (COSTA et al., 2019)

\section{AVALIAÇÃO DE SATISFAÇÃO E AUTOCONFIANÇA}

Nos últimos anos, a literatura mostrou que a avaliação da satisfação e da autoconfiança dos aprendizes em ambientes simulados tem despertado grande interesse na prática e na pesquisa, e, consequentemente, tem sido investigada nos mais diversos contextos (ALMEIDA et al., 2015b).

A simulação de alta fidelidade proporciona um aumento da autoconfiança e melhorias nas habilidades técnicas e não técnicas (HOADLEY, 2008; GORDON; BUCKLEY, 2009; STEFANSKI, ROSSLER; 2009; HOADLEY, 2009). Observa-se também que a satisfação do aprendiz após a prática simulada pode minimizar os sentimentos de medo e ansiedade perante a prática profissional (YING; YIWEN; RABIAH, 2014),

A teoria de autoeficácia de Bandura (1983) refere que o aumento da autoeficácia ou autoconfiança permite que os profissionais sejam mais propensos a aceitar novos desafios e a enfrentar melhor as situações de insucessos.

\section{ESCALA DE SATISFAÇÃO DE ESTUDANTES E AUTOCONFIANÇA COM A APRENDIZAGEM}

A Escala Student Satisfaction and Self-Confidence in Learning, originalmente criada pela National League for Nursing $(N L N)$, foi traduzida e validada para o português brasileiro por ALMEIDA et al. (2015b) denominada Escala de Satisfação de Estudantes e Autoconfiança com a Aprendizagem. Trata-se de uma escala tipo Likert de cinco pontos dividida nas duas dimensões, a satisfação e a autoconfiança do indivíduo, indicada para ser aplicada na simulação de alta fidelidade.

\section{ESCALA DE SATISFAÇÃO COM AS EXPERIÊNCIAS CLÍNICAS SIMULADAS (ESECS)}

Outra escala que mensura satisfação é a Escala de Satisfação com as Experiências Clínicas Simuladas (ESECS) construída e validada por Baptista et al. (2014). Essa escala avalia a satisfação dos estudantes de Enfermagem com as experiências clínicas simuladas. Conta com 17 itens, perante os quais o estudante expressa a sua opinião sobre cada um, numa escala tipo Likert com variação de um a dez, em que o valor um representa o menor nível de satisfação e o valor dez, o maior nível de satisfação (BAPTISTA et al., 2014).

Estudos têm aplicado a escala, como podemos ver em Meska et al. (2018), que verificaram a satisfação e a autoconfiança dos estudantes de Enfermagem em cenários com e sem a presença de odores; em Franzon et al. (2020), a escala foi aplicada em atividades clínicas simuladas sobre medidas de conforto e higiene ao paciente usuário de fraldas descartáveis; em Bortolato-Major (2017), ocorreu a avaliação do desenvolvimento da competência clínica de estudantes de Enfermagem, especificamente para o atendimento a casos de disfunção cardíaca, neurológica e respiratória, usando a Escala de Satisfação de Estudantes e Autoconfiança com a Aprendizagem (ALMEIDA et al., 2015b) e a Escala de Satisfação com as Experiências Clínicas Simuladas (ESECS) (BAPTISTA et al., 2014), com as experiências clínicas simuladas.

Essa escala também foi utilizada para verificação da autoconfiança e da satisfação de aprendizes submetidos ao método de ensino tradicional com aula expositiva e ao método de ensino com simulação realística (Ferreira et al., 2018).

\section{SELF-CONFIDENCE SCALE (SCE)}

Para avaliar a autoconfiança de estudantes em situações críticas, existe a Self-Confidence Scale (SCE) (HICKS; COKE; LI, 2009), adaptada culturalmente para o português em cenários simulados de emergência (MARTINS et al., 2014). Essa escala possui itens que identificam a capacidade do estudante em reconhecer os sinais e sintomas de alterações fisiológicas respiratórias, cardíacas e neurológicas, e possibilita a avaliação precisa do paciente, a intervenção apropriada e a avaliação da eficácia das intervenções implementadas.

\section{DEBRIEFING}

Reconhecido como um processo analítico de reflexão a ser desempenhado após ou durante os cenários simulados, o debriefing é a etapa responsável por 
cerca de $80 \%$ da aprendizagem obtida pelos participantes em uma atividade simulada, contribuindo com o desenvolvimento de conhecimentos, habilidades e atitudes, obtidos através da reflexão sobre a ação, da consolidação dos saberes e da mudança de comportamentos errados (NASCIMENTO, et al. 2020; COUTINHO et al., 2014). Na última década, mais de 30 métodos e 10 técnicas de debriefing foram descritos (NASCIMENTO et al., 2020).

\section{ESCALA DE AVALIAÇÃO DO DEBRIEFING ASSOCIADO À SIMULAÇÃO (EADAS) E ESCALA DE EXPERIÊNCIA COM O DEBRIEFING}

Em 2014, justificada pela inexistência de instrumentos de avaliação de debriefing na língua portuguesa, a Escala de Avaliação do Debriefing associado à Simulação (EADaS) contendo 34 itens, foi construída e validada com 209 estudantes de uma universidade portuguesa por Coutinho et al. (2014).

A escala americana, a Debriefing Experience Scale, desenvolvida por Reed (2012), foi traduzida e validada para ser utilizada em Simulação de Alta Fidelidade. A versão brasileira foi nomeada como "Escala de Experiência com o Debriefing" (ALMEIDA et al., 2016) e apresenta 20 itens distribuídos em quatro fatores: 1) Analisando os pensamentos e sentimentos; 2) Aprendendo e fazendo conexões; 3) Habilidade do professor em conduzir o debriefing, e 4) Orientação apropriada do professor.

\section{TRÊS ESTÁGIOS DO DEBRIEFING HOLÍSTICO}

$\mathrm{Na}$ vertente de que ainda hoje faltam evidências a respeito da capacidade de educadores, instrutores ou debriefers para apoiar, orientar, observar, avaliar e direcionar as ações, discussões para promover a aprendizagem reflexiva durante a Simulação de Alta Fidelidade (SAF), um guia holístico de debriefing foi construído e validado em inglês e português brasileiro (GOES; JACKMAN, 2020).

As autoras utilizaram o referencial sobre o processo de debriefing de Lederman e o referencial de aprendizagem de Zabala como base teórica para promover a aprendizagem reflexiva. $\mathrm{O}$ instrumento é dividido em: 1) Primeiro estágio do debriefing: Autorreflexão imediata do aluno após a Experiência Prática/Debriefing Focalizado;2) Segundo estágio do debriefing: Facilitar a Discussão/Reflexão/Debriefing Formativo em Grupo, e 3) Terceiro estágio do debriefing: Resumo Final do Aprendizado Obtido na Experiência de Simulação (Debriefing Somativo).

Nos três itens, é sugerido o período de tempo para conclusão de cada estágio da simulação, incluindo o pré-briefing. Cada uma dessas etapas é de- talhada, inclusive com exemplos de pergunta-guia para a orientação em cada um dos estágios, a fim de facilitar que os educadores iniciantes realizem discussões com foco nas melhores práticas pedagógicas (GOES; JACKMAN, 2020)

\section{INSTRUMENTOS, ROTEIROS OU ESCALAS PARA AVALIAÇÃO DE COMPETÊNCIAS TÉCNICAS E COGNITIVAS}

A avaliação de competências clínicas por facilitadores em ambientes simulados necessita ser guiada por instrumentos, roteiros ou escalas válidos e confiáveis, visando à observação sistematizada, criteriosa e imparcial, além de estes serem imprescindíveis para o reconhecimento das lacunas de conhecimento de cada estudante (VILARINHO et al., 2020).

A Scoping Review de Miranda, Mazzo e Pereira-Junior (2018) identificou instrumentos e métodos variados, utilizados para a avaliação de competências individuais e interprofissionais em atividades clínicas simuladas na formação e capacitação de profissionais da área de saúde.

Entre as habilidades mais avaliadas, destacaram-se a habilidade de comunicação e procedimentais (MIRANDA; MAZZO; PEREIRA-JUNIOR, 2018).

Nesse contexto, nos últimos anos, diversos estudos permeiam em busca de construir, validar e adaptar culturalmente ferramentas que possam colaborar em atividades simuladas.

O estudo de Cancino et al. (2020) validou um roteiro de avaliação de administração segura de medicamentos em estudantes de Enfermagem; o roteiro validado apresenta oito subprocessos (revisão da prescrição do medicamento, avaliação, transcrição, preparação, administração, notificação de erros de medicação, acompanhamento e monitoramento, e informação e educação ao paciente), avaliados por 58 itens ajustados em ambiente simulado de baixa fidelidade e prática clinica. Para os autores, o roteiro contribui para a avaliação dessa prática, principalmente em ambientes simulados.

O instrumento denominado Lasater Clinical Judgment Rubric (LCJR) mensura o julgamento clínico (LASATER, 2007). Propõe a avaliação dos participantes em 11 comportamentos do julgamento clínico, sendo esses: 1) observação focada; 2) reconhecimento de desvios dos padrões esperados; 3) busca por informações; 4) priorização dos dados; 5) compreensão dos dados; 6) atuação calma e confiante; 7) comunicação clara; 8) intervenção bem pla- 
nejada; 9) habilidade técnica; 10) avaliação/autoanálise, e 11) comprometimento com o aperfeiçoamento.

Esse escores estão relacionados a quatro níveis de desenvolvimento do participante: iniciante, em desenvolvimento, proficiente ou exemplar. No Brasil, esse instrumento passou por adaptação transcultural e avaliação de confiabilidade (NUNES et al., 2016; MORAIS et al., 2018).

O estudo de Carvalho e Zem-Mascarenhas (2020) utilizou o referido instrumento para avaliar o julgamento clínico do enfermeiro no manejo da sepse.

No contexto de avaliação de competências, o instrumento Creighton Competency Evaluation Instrument (CCEI) foi traduzido e adaptado transculturalmente para a língua portuguesa brasileira, originando a versão Instrumento Creighton para Avaliação de Competências Clínicas (CCEI-Br) versão português do Brasil, que apresenta os domínios avaliação, comunicação, julgamento clínico e segurança do paciente (VILARINHO et al., 2020).

Uma competência fundamental para o trabalho em saúde é a comunicação, pois permite a transmissão, de um indivíduo para outro, de informações claras e objetivas, tornando possível uma interação social. No entanto, a avaliação da comunicação é uma tarefa complexa, pois envolve empatia, clareza, objetividade, segurança, entre outros requisitos (PETERSON; CARVALHO, 2011; MIRANDA; MAZZO; PEREIRA-JUNIOR, 2018).

A Health Communication Assessment Tool (HCAT) (CAMPBELL et al., 2013) foi adaptada culturalmente para o Brasil (REIS et al., 2018). A versão original da HCAT contém 22 afirmações analisadas a partir de uma escala que varia de um a cinco pontos, sendo: 1 - concordo fortemente; 2 - concordo; 3 - indeciso; 4 - discordo; 5 - discordo fortemente. Esse instrumento possibilita analisar comportamentos verbais ou não verbais; vínculo, estímulo, capacitação e valorização entre profissional, paciente e familiares (REIS et al., 2018).

Essa escala tem sido utilizada em diferentes contextos para avaliar a comunicação professional em saúde. O estudo de Bianchini et al. (2020) verificou o uso da simulação clínica na formação de Técnicos em Enfermagem em relação às suas capacidades na comunicação com pacientes e seus familiares. O uso da referida escala na atividade simulada mostrou que, mesmo após a participação simulada, os estudantes demostraram pouco preparo para comunicar-se, o que leva à reflexão de que a simulação como atividade isolada pode surtir reflexos apenas indiretos na aprendizagem da comunicação. A escala também foi utilizada para avaliar comunicação em saúde do estudante de Enfermagem na realização de procedimentos técnicos usando a dramatização (GÓES et al., 2017).

Ressalta-se que a escala contém afirmações sobre comunicação verbal e não verbal, compatíveis de serem analisadas para qualquer profissional da saúde.

A Organização Pan-Americana da Saúde (OPAS) e a Organização Mundial da Saúde (OMS) recomendam os métodos de simulação clínica para a educação transformadora, para aumentar a educação e a qualificação de trabalho interprofissional da saúde. Assim, a necessidade de produção científica de novos instrumentos, a adaptação transcultural dos existentes e sobretudo a aplicação em diferentes contextos de educação profissional, visando atingir os melhores resultados aos aprendizes, tornam-se fundamentais.

Para Campbell (2019), o uso da simulação é uma ferramenta valiosa para formação de profissionais de saúde. No entanto, os facilitadores necessitam entender a aplicação da teoria e serem capacitados para o desenvolvimento de todas as fases, principalmente da fase de avaliação na aprendizagem simulada (CAMPBELL, 2019).

As normas da International Nursing Association for Clinical Simulation and Learning (INACSL) (2016) referem que o processo de avaliação deverá incluir os estudantes e os facilitadores, à experiência baseada em simulação, bem como as instalações e também a equipe de apoio. Ressalta-se ainda que é necessário determinar o processo de avaliação na fase de construção do design do cenário, para garantir a qualidade e a efetividade da experiência baseada na simulação; além disso, é essencial adotar uma estrutura de avaliação para guiar a seleção e/ou o desenvolvimento de uma ferramenta válida e confiável para medir os resultados esperados.

Deverá ser garantido que todos os participantes do cenário tenham clareza dos métodos de avaliação, se estes tratam de aplicação de uma avaliação formativa, somativa e/ou alta performance, antes ou no início da simulação. O processo avaliativo deverá ser realizado entre os participantes ou aos pares e é importante que os resultados possam ser utilizados para auxiliar na avaliação da atividade ou programa de simulação para melhoria do processo de qualidade (INACSL STANDARDS COMMITTEE, 2016).

Assim, é importante ressaltar que essas escalas e instrumentos devem ser considerados como recursos auxiliares para aprimorar as práticas de avaliação nos diferentes contextos de ensino profissional em saúde. 
ALMEIDA, R. G. S. et al. Validação para a língua portuguesa da escala Student Satisfactionand Self-Confidence in Learning. Revista Latino-Americana de Enfermagem, Ribeirão Preto, v. 23, n. 6, p. 1007-1013, 2015b. http://dx.doi. org/10.1590/0104-1169.0472.2643.

ALMEIDA, R. G. et al. Validation for the portuguese language of the simulation design scale. Texto \& Contexto Enfermagem, Florianópolis, v. 24, n. 4, p. 934-940, 2015a. http://dx.doi.org/10.1590/0104-0707201500004570014.

ALMEIDA, R. G. S. et al. Validation to portuguese of the debriefing experience scale. Revista Brasileira de Enfermagem, Brasília, v. 69, n. 4, p. 658-664, 2016. http:// dx.doi.org/10.1590/0034-7167.2016690413i.

BANDURA, A. Self-efficacy determinants of anticipated fears and calamities. Journal of Personality and Social Psychology, Washington, v. 45, n. 2, p. 464-469, 1983. http://dx.doi.org/10.1037/0022-3514.45.2.464.

BAPTISTA, R. C. N. et al. Satisfação dos estudantes com as experiências clínicas simuladas: validação de escala de avaliação. Revista Latino-Americana de Enfermagem, Ribeirão Preto, v. 22, n. 5, p. 709-715, 2014. https://doi. org/10.1590/0104-1169.3295.2471

BIANCHINI, A. et al. Aprendendo a comunicar-se com simulação: satisfação, confiança e autopercepção de estudantes de Educação Profissional de Nível Médio em Enfermagem. Boletim Técnico Do Senac, Rio de Janeiro, v. 46, n. 2, 2020. http://dx.doi.org/10.26849/bts.v46i2.808.

BORTOLATO-MAJOR, C. O Ensino Baseado em Simulação e o desenvolvimento de competência clínica de estudantes de enfermagem. 2017. 180f. Tese (Doutorado em Enfermagem) - Universidade Federal do Paraná, Curitiba, 2017.

BRASIL, G. C. et al. Use of the design and self-confidence scales in the assessment of maternal-child realistic simulation. Revista de Enfermagem Referência, v. 4, Série, p. 117-126, 2018.

CAMACHO, H. M. Simulación cibernética en las ciencias de la salud. Recuento histórico en el mundo y en Colombia y su impacto en la educación. Revista Colombiana de Cardiología, Colombia, v. 18, n. 6, p. 297-304, 2011.

CAMPBELL, S. et al. Development of the health communication assessment tool: enhancing relationships, empowerment, and power-sharing skills. Clinical Simulation in Nursing, v. 9, p. 543-550, 2013. http:// dx.doi.org/10.1016/j.ecns.2013.04.016.

CAMPBELL, S. H. Simulação clínica para o ensino em saúde. Revista Eletrônica de Enfermagem, Goiânia, v. 21, p. 57250, 2019. https://doi.org/10.5216/ree.v21.57250.

CANCINO, K. D. et al. Development of a safe drug administration assessment instrument for nursing students. Revista Latino-Americana de Enfermagem, São Paulo, v. 28, p. e3246, 2020. http://dx.doi. org/10.1590/1518-8345.2989.3246.
CARVALHO, L. R.; ZEM-MASCARENHAS, S. H. Construction and validation of a sepsis simulation scenario: a methodological study. Revista da Escola de Enfermagem da USP, São Paulo, v. 54, p. e03638, 2020.

COSTA, R. R. O. et al. Percepções de estudantes de enfermagem acerca das dimensões estruturais da simulação clínica. Science \& Medicine, Porto Alegre, v. 29, n. 1, p. e32972, 2019. http://dx.doi. org/10.15448/1980-6108.2019.1.32972.

COUTINHO, V. R. D.; MARTINS, J. C. A.; PEREIRA, M. F. C. R. Construção e Validação da Escala de Avaliação do Debriefing associado à Simulação (EADaS). Revista de Enfermagem Referência, Coimbra, v. 4, n. 2, p. 4150, 2014. Disponível em: <http://www.scielo.mec.pt/pdf/ ref/vserIVn2/serIVn2a05.pdf>. Acesso em: 30 set. 2018.

FERREIRA, R. P. N. et al. Simulação realística como método de ensino no aprendizado de estudantes da área da saúde. Revista de Enfermagem do Centro Oeste Mineiro, Minas Gerais, v. 8, p. e2508, 2018. https://doi. org/10.19175/recom.v8i0.2508.

FRANZON, J. C. et al. Implicações da prática clínica em atividades simuladas: satisfação e autoconfiança dos estudantes. Revista Mineira de Enfermagem, Belo Horizonte, v. 24, p. e-1274, 2020. http://www.dx.doi. org/10.5935/1415-2762.20200003.

GÓES, F. S. N. et al. Simulação com pacientes padronizados: habilidades de comunicação em saúde do estudante de enfermagem. Rev Rene, Fortaleza, v. 18, n. 3, p. 383-389, 2017. https://doi.org/10.15253/2175-6783.2017000300014. GÓES, F. S. N.; JACKMAN, D. Development of an instructor guide tool: 'Three Stages of Holistic Debriefing'. Revista Latino-Americana de Enfermagem, Ribeirão Preto, v. 28, p. e3229, 2020. http://dx.doi. org/10.1590/1518-8345.3089.3229.

GORDON, C. J.; BUCKLEY, T. The effect of highfidelity simulation training on medical-surgical graduate nurses' perceived ability to respond to patient clinical emergencies. Journal of Continuing Education in Nursing, Pitman, v. 40, n. 11, p. 491-498, 2009. https:// doi.org/10.3928/00220124-20091023-06

HICKS, F.; COKE, L.; LI, S. Report of findings from the effect of high-fidelity simulation on Nursing students' knowledge and performance: a pilot study. Chicago, IL: NCSBN Research Brief, 2009. v. 40.

HOADLEY, T. A. Comparing the effects of low and high fidelity simulation on learning in advanced cardiac life support classes. 2008. $281 \mathrm{f}$. Dissertação (Doctor in Philosophy) - University of Northern Colorado, Colorado, 2008.

HOADLEY, T. A. Learning advanced cardiac life support: A comparison study of the effects of low and high-fidelity simulation. Nursing Education Perspectives, New York, v. 30, n. 2, p. 91-95, 2009. 
INACSL STANDARDS COMMITTEE. INACSL Standards of best practice: Simulation ${ }^{\mathrm{sm}}$ Simulation Design. Clinical Simulation in Nursing, v. 12, n. S, p. S5-S12, 2016.

LASATER, K. Clinical judgment development: using simulation to create an assessment rubric. The Journal of Nursing Education, v. 46, n. 11, p. 496-503, 2007. http:// dx.doi.org/10.3298/01484834-20071101-04.

MARTINS, A. et al. Isabel Amélia Autoconfiança para intervenção em emergências: adaptação e validação cultural da Self-confidence Scale em estudantes de Enfermagem. Revista Latino-Americana de Enfermagem, Ribeirão Preto, v. 22, n. 4, p. 554-561, 2014.

MARTINS, A.; CARLOS, J. Aprendizagem e desenvolvimento em contexto de prática simulada. Referência - Revista de Enfermagem, Coimbra, v. 4, n. 12, p. 155-161, 2017.

MESKA, M. H. G. et al. Satisfação e autoconfiança dos estudantes de enfermagem em cenários clínicos simulados com presença de odores desagradáveis: ensaio clínico randomizado. Science \& Medicine, Porto Alegre, v. 28, n. 1, p. ID28693, 2018. http://dx.doi. org/10.15448/1980-6108.2018.1.28693.

MIRANDA, F. B. G.; MAZZO, A.; PEREIRA JUNIOR, G. A. Avaliação de competências individuais e interprofissionais de profissionais de saúde em atividades clínicas simuladas: scoping review. Interface (Botucatu), Botucatu, v. 22, n. 67, p. 1221-1234, Dec. 2018. http://dx.doi. org/10.1590/1807-57622017.0628.

MORAIS, S. C. R. V. et al. Confiabilidade e validade da Lasater Clinical Judgment Rubric: Brazilian version. Acta Paulista de Enfermagem, v. 31, n. 3, p. 265-271, 2018. http://dx.doi.org/10.1590/1982-0194201800038.

NASCIMENTO, J. S. G. et al. Métodos e técnicas de debriefing utilizados em simulação na enfermagem. Revista Gaúcha de Enfermagem, Porto Alegre, v. 41, p. e20190182, 2020. https://doi.org/10.1590/1983-1447.2020.20190182.

NUNES, J. G. P. et al. Adaptação para cultura brasileira do instrumento Lasater Clinical Judgment Rubric.
Revista de Enfermagem UFPE, Recife, v. 10, n. 6, p. 4828-4836, 2016. http://dx.doi.org/10.5205/ relou.8200-71830-3-SM.1006sup20161514.

OGDEN, E. P. et al. Simulation in Internal Medicine. In: LEVINE, A. I. et al. The comprehensive textbook of healthcare simulation. New York: Springer Science+Business Media, 2013. p. 391-400. https://doi. org/10.1007/978-1-4614-5993-4_26.

PETERSON, A. A.; CARVALHO, E. C. Comunicação terapêutica na Enfermagem: dificuldades para o cuidar de idosos com câncer. Revista Brasileira de Enfermagem, Brasília, v. 64, n. 4, p. 692-697, 2011.

REED, S. Y. Debriefing experience scale: development of a tool to evaluate the student learning experience in debriefing. Clinical Simulation in Nursing, United States, v. 8, n. 6, p. 211-217, 2012.

REIS, N. et al. Adaptação cultural da ferramenta de avaliação de comunicação em saúde (HCAT) para a língua portuguesa, Brasil. Revista Eletrônica de Comunicação, Informação e Inovação em Saúde, Rio de Janeiro, v. 12, n. 4, 2018. http://dx.doi.org/10.29397/reciis.v12i4.1501.

STEFANSKI, R. R.; ROSSLER, K. L. Preparing the novice critical care nurse: a community-wide collaboration using the benefits of simulation. Journal of Continuing Education in Nursing, Pitman, v. 40, n. 10, p. 443-451, 2009. http://dx.doi.org/10.3928/00220124-20090923-03.

VILARINHO, J. O. V. et al. Validação psicométrica do instrumento Creighton para avaliação de competências clínicas em simulação. Acta Paulista de Enfermagem, São Paulo, v. 33, p. eAPE20200314, 2020. https://doi. org/10.37689/acta-ape/2020ao03146.

YING, L. S.; YIWEN, K.; RABIAH, D. Easing student transition to graduate nurse: a simulated professional learning environment (SIMPLE) for final year student nurses. Nurse Education Today, Edinburgh, v. 34, n. 3, p. 349-355, 2014. 
CAPÍTULO 17

-

Redesenho dos espaços

físicos de acordo com o uso das metodologias ativas de aprendizagem e a convergência tecnológica: orientações na montagem dos Centros de Simulação 
Gerson Alves Pereira Júnior

Docente de Cirurgia de

Urgência e do Trauma

Universidade de São Paulo

Coordenador do Programa

ABEM de Simulação

\section{Hugo Silva Ferreira}

Engenheiro Civil

Diretor de Desenvolvimento

de Infraestrutura

Csanmek Tecnologia

\section{Luciane Reginato Dobrowski}

Bióloga

Especialista em Microbiologia

Clínica e Industrial

Especialista em Engenharia

Ambiental

Claudio Soares de Santana

Gestor em Saúde

CEO Csanmek Tecnologia

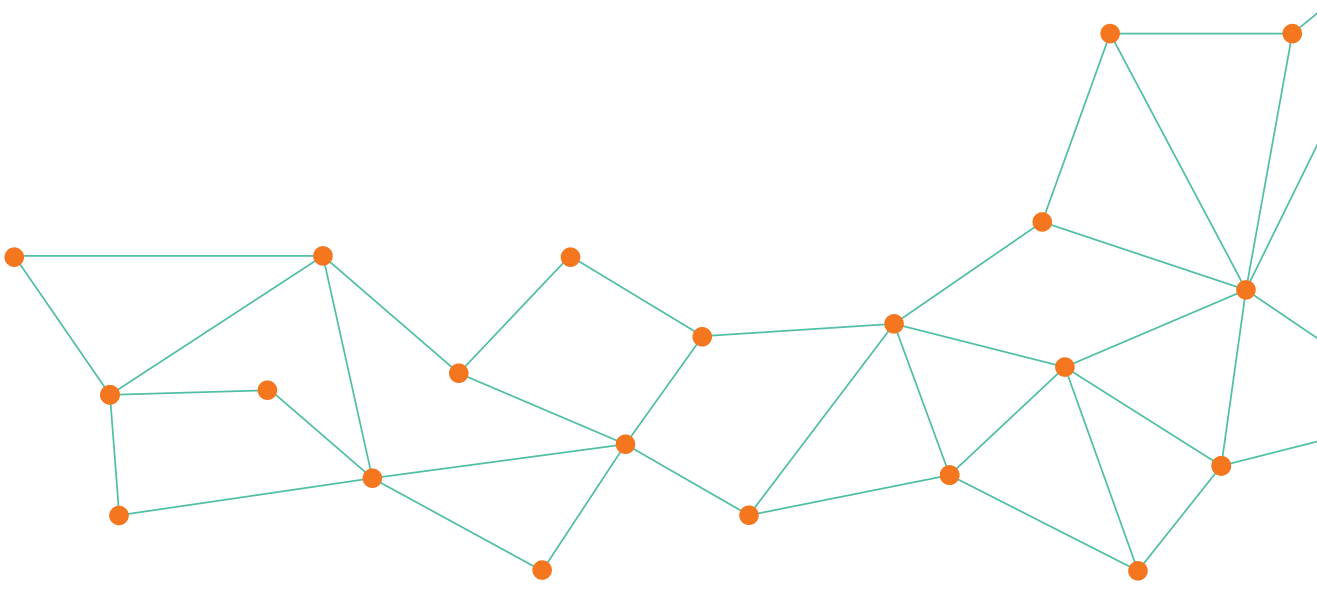

\section{INTRODUÇÃO}

As instituições educacionais atentas às mudanças necessárias para a atualização contínua de seus projetos pedagógicos escolhem fundamentalmente dois caminhos: um mais suave, com mudanças progressivas, ou outro mais amplo, com mudanças profundas. No caminho mais suave, elas mantêm o modelo curricular disciplinar de forma predominante, mas priorizam o envolvimento maior do aluno, com metodologias ativas, como o ensino por projetos de forma mais interdisciplinar, o ensino híbrido ou blended learning e a sala de aula invertida. Outras instituições propõem modelos mais inovadores, disruptivos, sem disciplinas, que redesenham o projeto pedagógico com introdução de diversas metodologias ativas de aprendizagem, baseadas em atividades, desafios, problemas e jogos, pelas quais cada aluno aprende no seu próprio ritmo e necessidade, e também aprende com os outros, em grupos e pro- jetos, com supervisão de professores orientadores (MORAN, 2015).

Em ambas as situações de mudanças, principalmente na mais profunda, é necessária uma completa readequação dos ambientes físicos dos cursos, tanto as salas de aula quanto os laboratórios de ensino.

As diferentes concepções de currículo orientam para a prevalência de um currículo construído na prática social e implicam superação na abordagem pedagógica, alicerçada na transmissão de informações, englobando conteúdos, métodos, procedimentos, instrumentos culturais, experiências prévias e atividades (GIMENO SACRISTÁN, 1998), com vistas a propiciar o desenvolvimento da aprendizagem em ambientes que instigam a curiosidade epistemológica, estimulam a pergunta, a invenção/reinvenção e a transformação, como formas de avançar no conhecimento (ALMEIDA \& VALENTE, 2012). 
Os métodos tradicionais, que privilegiam a transmissão de informações pelos professores, faziam sentido quando o acesso à informação era difícil. Com a Internet e a divulgação aberta de muitos cursos e materiais, podemos aprender em qualquer lugar, a qualquer hora e com muitas pessoas diferentes. Isso é complexo, necessário e um pouco assustador, porque não temos modelos prévios bem sucedidos para aprender de forma flexível numa sociedade altamente conectada (ALMEIDA \& VALENTE, 2012).

O ensino híbrido é uma das maiores tendências da educação no século XXI. Essa nova metodologia tem como objetivo aliar métodos de aprendizado online e presencial. A utilização prática dos conceitos de aprendizagem personalizada, colaborativa e orientada, nos dias de hoje, é fundamental. A aprendizagem se constrói num processo equilibrado entre três movimentos principais: a construção individual, em que cada aluno percorre seu caminho; a construção grupal, em que aprendemos com os semelhantes (pares), e a construção orientada, em que aprendemos com alguém mais experiente, com um especialista ou um professor (BACICH; TANZI NETO; TREVISANI, 2015).

O que a tecnologia traz hoje é a integração de todos os espaços e tempos. O ensinar e o aprender acontecem numa interligação simbiótica, profunda e constante entre o que chamamos mundo físico e mundo digital. Não são dois mundos ou espaços, mas um espaço estendido, uma sala de aula ampliada. Por isso, a educação formal é cada vez mais blended, misturada, híbrida, porque não acontece só no espaço físico da sala de aula, mas nos múltiplos espaços do cotidiano, que incluem os digitais. $\mathrm{O}$ professor precisa seguir comunicando-se face a face com os alunos, mas também digitalmente, com as tecnologias móveis, equilibrando a interação com todos e com cada um (MORAN, 2015).

No caso dos cursos da área da saúde, o espaço cotidiano mais importante é a integração ensino-serviço, pois o contato precoce com a realidade dos problemas da população e dos trabalhadores, e com espaços físicos dos serviços de saúde, assim como o entendimento das diferentes formas de gestão, habilita os futuros profissionais em formação a terem uma vivência profissional que os tornará mais aptos e competentes, quando estiverem inseridos no mercado de trabalho. Essa mescla, entre sala de aula e ambientes virtuais, e a integração ensino-serviço nos cursos da área da saúde são fundamentais para abrir a escola para o mundo e trazer o mundo para dentro da escola.
A integração das Tecnologias Digitais de Informação e Comunicação (TDIC) e currículo propicia a articulação dos contextos de formação e aprendizagem com as situações de experiências autênticas, potencializando o desenvolvimento do currículo como construção permanente de práticas intencionais, com significado cultural, histórico e social (PACHECO, 2005). Este processo reconstrutivo encontra suporte em conteúdos oriundos de distintas fontes e são representados em linguagens (VALENTE, 2011).

A maior parte do tempo, na educação presencial e a distância, ensinamos com materiais e comunicações escritos, orais e audiovisuais, previamente selecionados ou elaborados. As metodologias precisam acompanhar os objetivos pretendidos. Se queremos que os alunos sejam proativos, precisamos adotar metodologias em que os alunos se envolvam em atividades cada vez mais complexas, em que tenham de tomar decisões e avaliar os resultados, com apoio de materiais relevantes. Se queremos que sejam criativos, eles precisam experimentar inúmeras novas possibilidades de mostrar sua iniciativa (MORAN, 2015).

Os processos pedagógicos, que têm como objetivo auxiliar o aprendiz a construir conhecimento, adotam como principal eixo articulador de suas atividades o desenvolvimento de projetos em busca de respostas a questões, que tenham significado para a própria vida e o contexto dos aprendizes (COOREY, 2016). Tais processos se tornam mais viáveis com a disseminação das tecnologias móveis, com conexão sem fio à Internet, associadas com as facilidades de manuseio das ferramentas e interfaces gratuitas, com potencial de interação, autoria e colaboração. Além do acesso à Educação de qualquer lugar e tempo, sem que as pessoas necessitem deslocar-se fisicamente, estas tecnologias propiciam a participação em processos formativos que integram as situações de trabalho e a aprendizagem em contextos reais, nos quais se desenvolvem as experiências (KEEGAN, 2007; ALMEIDA, 2011).

Desafios e atividades podem ser dosados, planejados, acompanhados e avaliados com apoio de tecnologias. Os desafios bem planejados contribuem para mobilizar as competências desejadas, intelectuais, emocionais, pessoais e comunicacionais. Exigem pesquisar, avaliar situações e pontos de vista diferentes, fazer escolhas, assumir alguns riscos, aprender pela descoberta e caminhar do simples para o complexo. Nas etapas de formação, os alunos precisam de acompanhamento de profissionais mais experientes para ajudá-los a tornar 
conscientes alguns processos, a estabelecer conexões não percebidas, a superar etapas mais rapidamente e a confrontá-los com novas possibilidades (MORAN, 2015).

Outra mescla, ou blended, é a de prever processos de comunicação mais planejados, organizados e formais com outros mais abertos, como os que acontecem nas redes sociais, nas quais há uma linguagem mais familiar, uma espontaneidade maior, uma fluência de imagens, ideias e vídeos (MORAN, 2015).

As competências necessárias para cada etapa da formação profissional utilizando a aprendizagem significativa devem estar bem definidas com as informações pertinentes a cada momento e que combinam percursos pessoais com participação estimulada em grupos, por meio de plataformas adaptativas, que reconhecem cada aluno e, ao mesmo tempo, aprendem com suas interações, sendo que, para tudo isso, deve-se combinar o uso de diversas tecnologias adequadas.

Dessa forma, a construção de um currículo inovador deve integrar as TDIC em processos que expandem os tempos e espaços educativos; envolvem busca, organização, interpretação e articulação de informações; estimulam a reflexão crítica; o compartilhamento de experiências; e a produção de novos conhecimentos na compreensão histórica do mundo e da ciência

\section{REDESENHO DOS ESPACOS FÍSICOS DE} APRENDIZAGEM E A CONVERGÊNCIA TECNOLÓGICA

O ambiente físico das salas de aula, dos laboratórios e da escola como um todo também precisa ser redesenhado dentro dessa nova concepção mais ativa, mais centrada no aluno. A sala de aula tradicional é asfixiante para todos, principalmente para os mais novos. (MORAN, 2013). As salas de aula podem ser mais multifuncionais, que combinem facilmente atividades de grupo, de plenário e individuais. Os ambientes precisam estar conectados em redes sem fio, para uso de tecnologias móveis, o que implica uma banda larga que suporte conexões simultâneas necessárias (MORAN, 2015).

As escolas como um todo precisam repensar esses espaços tão quadrados para espaços mais abertos, onde lazer e estudo estejam mais integrados. O que impressiona nas escolas com desenhos arquitetônicos e pedagógicos mais avançados é que os espaços são mais amplos, agradáveis, permitindo mais contato com a natureza, que têm vantagens inegáveis para projetos de ecologia de aprendiza- gem mais integral, em que os estudantes estão em grupos e os professores circulam entre eles como orientadores (VALENTI, 2015).

As novas formas de ensino e aprendizagem precisam de novas configurações de salas de aulas e laboratórios. Cada vez mais universidades estão reorganizando ambientes de aprendizagem para acomodar aprendizagem mais ativa, para facilitar pedagogias emergentes e estratégias, como a sala de aula invertida (LAMBERT, 2012).

As configurações educacionais são cada vez mais adaptadas para apoiar projetos baseados em interações, com atenção para maior mobilidade, flexibilidade e uso de vários dispositivos. As instituições terão de atualizar a largura de banda sem fio para criar "salas inteligentes" que suportam conferências na web e outros métodos de comunicação remota e colaborativa (INSTRUCTIONAL \& INFORMATION TECHNOLOGY SERVICES, 2020). Televisões de telas grandes e monitores estão sendo instalados para permitir a interação colaborativa entre projetos digitais e apresentações informais. Como o ensino superior está com tendências à educação centrada nos estudantes, abandonando as aulas tradicionais baseadas em palestras e substituindo-as por mais cenários práticos, as salas de aulas devem começar a se parecer com o real ambiente de trabalho do mundo real e do âmbito social, que facilitam as interações entre indivíduos e serviços para a resolução de problemas interdisciplinares.

Um estudo descobriu que os estudantes eram mais propensos a envolver-se em espaços de aprendizagem inovadores (IS, 2017).

Essa integração dos espaços físicos e virtuais de aprendizagem introduziram uma nova maneira de pensar sobre o aprendizado combinado (QUEENSLAND UNIVERSITY, 2019). Aprendizagem polissíncrona refere-se a uma mistura de canais com momentos presenciais, assíncronos e síncronos de comunicação online. A participação dos estudantes em diversos locais é citada como um benefício principal, o que exige que as salas de aula físicas sejam projetadas para permitir que os estudantes se comuniquem perfeitamente com outras pessoas de forma presencial e virtual (HIGHER ED IQ, 2015).

A Internet e as tecnologias móveis revolucionaram a forma como as pessoas encontram, consomem e interagem com os conteúdos didáticos. Uma manifestação dessa tendência é a remoção de livros e periódicos em série das prateleiras de bibliotecas acadêmicas e de pesquisa, o que provou con- 
troverso para algumas comunidades acadêmicas. Bibliotecas estão substituindo suas pilhas de livros por novos tipos de espaços que oferecem áreas de estudo, tanto individuais quanto coletivas, para maior colaboração entre os estudantes e melhor atender às suas necessidades com móveis, tecnologia e espaços. As necessidades mais atuais dos espaços de aprendizagem adaptáveis são adicionar mais lugares sentados, WIFI, espaços de estudo em grupos, pontos de tomadas de energia e móveis ajustáveis, tais como sofás e puffs (NEW ENGLAND BOARD OF HIGHER EDUCATION, 2015; WONG, 2016).

A convergência tecnológica exige mudanças muito mais profundas que afetam a escola em todas as suas dimensões: infraestrutura, projeto pedagógico, formação docente e mobilidade. Os ambientes devem estar cada vez mais adaptados para uso de tecnologias móveis.

As tecnologias permitem o registro e a visibilização do processo de aprendizagem de cada um e de todos os envolvidos. Mapeiam os progressos, apontam as dificuldades e podem prever alguns caminhos para os que têm dificuldades específicas (plataformas adaptativas). Elas facilitam como nunca antes múltiplas formas de comunicação horizontal, em redes, em grupos e de forma individualizada. É fácil o compartilhamento, a coautoria, a publicação, produzir e divulgar narrativas diferentes. A combinação dos ambientes mais formais com os informais (redes sociais, wikis, blogs), feita de forma inteligente e integrada, nos permite conciliar a necessária organização dos processos com a flexibilidade de poder adaptá-los a cada aluno e grupo (MORAN, 2013).

As tecnologias nos libertam das tarefas mais penosas, principalmente as repetitivas, e nos permitem concentrar-nos nas atividades mais criativas, produtivas e fascinantes. As plataformas adaptativas monitoram os avanços de cada aluno em tempo real, sugerem alternativas e permitem que cada um estude sem professor no seu próprio ritmo, até um determinado ponto. Cada aluno conta com um dashboard, um quadro em que visualiza o percentual de conclusão de cada tema ou atividade e mais estatísticas do seu desenvolvimento. Ele consegue perceber quais temas domina mais e os de maior dificuldade, que demandam mais ajuda. Em paralelo, o professor visualiza, em um quadro em tempo real, o desempenho dos estudantes em cada tema (HORN; STAKER, 2015).
3. AS DIFERENTES OPÇÕES INSTITUCIONAIS DE PROCESSOS DE MUDANÇAS CURRICULARES COM USO DE METODOLOGIAS ATIVAS DE APRENDIZAGEM

As metodologias ativas de aprendizagem são caminhos para avançar para um currículo mais flexível, mais centrado no estudante, nas suas necessidades e expectativas. A maior parte das escolas e universidades quer mudar, mas está presa na cultura disciplinar transmissiva e paternalista. Na dependência da cultura e do clima organizacional de cada instituição, das condições em que se encontra e do percurso de mudança já trilhado, a opção pode ser por mudanças mais rápidas ou lentas, mais superficiais ou mais profundas.

Na maioria das instituições, as mudanças curriculares mais viáveis são as progressivas, que partem dos modelos disciplinares para níveis de integração cada vez mais amplos. A primeira mudança é dentro de cada disciplina, introduzindo metodologias ativas, principalmente a sala de aula invertida, o que permite avanços rápidos pela maior qualidade da discussão presencial, com maior aprofundamento dos conteúdos. O caminho para avançar na integração é organizar atividades com conteúdos que envolvam mais de uma disciplina: projetos comuns, atividades integradoras, ampliando o uso das metodologias ativas e dos modelos híbridos. A instituição pode propor a criação de eixos de formação para a integração longitudinal e transversal de conteúdos de diferentes disciplinas, o que é importante para o estudante desenvolver uma visão mais ampla do que já aprendeu, irá aprender nesse momento e o que ainda será aprendido futuramente.

O próximo nível é o da integração entre as diversas disciplinas por meio de um projeto mais amplo, planejando atividades conjuntas. A adoção do ensino híbrido também aumenta com maior inserção das tecnologias digitais. A partir daí, a instituição já estará mais preparada para implementar um currículo muito mais integrador, flexível, com foco em projetos, e terá tido tempo de acompanhar outras instituições que já implementaram currículos mais ousados e que terão uma avaliação mais precisa do que vale a pena trazer para a própria instituição.

Dependendo da maturidade de professores, gestores e estudantes, também é possível uma mudança curricular simultânea. Uma forma de acelerar as mudanças sem por em risco a cultura da instituição é começar a inovação em pequena escala, em uma área que tem maior abertura, com gestores e professores mais empreendedores. Esses projetos 
são acompanhados por todos, avaliados para depois serem incorporados mais rapidamente pelos demais cursos. Ir da experiência focada e avaliada para a estrutural é um caminho que tem muitas vantagens: todos aprendem com o grupo experimental e se preparam melhor para implementar um novo projeto mais ousado. O importante neste processo é que a discussão do projeto inovador seja feita previamente por toda a comunidade acadêmica, que deve acompanhar e avaliar sua implantação.

Também são possíveis transformações mais profundas nos projetos pedagógicos sem estrutura de gestão baseada em departamentos, com currículos mais abertos, não baseados em disciplinas, com programações de conteúdos interdisciplinares com integrações horizontais e verticais ao longo da matriz curricular, geralmente com roteiros de aprendizagem dos ambientes de ensino. O planejamento dos ambientes físicos das salas de aula e dos laboratórios deve considerar as metodologias ativas utilizadas e a convergência digital de diversas tecnologias de informação e comunicação. Uma plataforma educacional adaptativa associada a uma central de análises de dados de acessos aos conteúdos e às atividades didáticas permite atividades presenciais $\mathrm{e}$ virtuais, de forma síncrona e assíncrona, além de avaliações formativas e somativas dos diversos ambientes de ensino dos cursos.

\section{AMBIENTES DE APRENDIZAGEM DA ÁREA DA SAÚDE E USO DE METODOLOGIAS ATIVAS}

Particularmente nos cursos de Medicina para atingir os marcos de competências a cada momento da formação dos estudantes, os projetos pedagógicos mais modernos utilizam várias metodologias ativas de ensino, de acordo com o ambiente de ensino e os objetivos de aprendizagem.

Basicamente, os cursos de medicina têm quatro ambientes de ensino, sendo dois complementares para o desenvolvimento cognitivo (tutorias e sistemas orgânicos integrados, sendo esse último a integração dos conteúdos das áreas básicas - anatomia, fisiologia, histologia, biologia celular e molecular, embriologia etc.), um para o treinamento prévio de atividades práticas de habilidades e simulação, e outro para integração ensino-serviço-comunidade.

Em cada um desses ambientes de ensino, há diferentes relações adequadas entre o número de estudantes por professor/facilitador e estudantes, assim como o uso de diversas metodologias ativas de aprendizagem em cada um deles: 1) Tutorias - aprendizagem baseada em problemas (DAVIS \& HARDEN, 1999; DOLMANS et al., 2005); 2) Sistemas Orgânicos Integrados - aprendizagem baseada em equipes (BURGESS et al., 2017; OLIVEIRA et al., 2018); 3) Laboratório de Habilidades e Simulação - sala de aula invertida (HURTUBISE et al., 2015; DERUISSEAU, 2016) e simulação clínica (KRISHNAN; KELOTH; UBEDULLA, 2017; BATTISTA; NESTEL, 2018), e 4) Atenção Integral à Saúde - problematização com uso do Arco de Maguerez (BERBEL; GAMBOA, 2012; VIEIRA; PANÚNCIO-PINTO, 2015), aprendizagem baseada em casos (THISTLETHWAITE et al., 2012; MCLEAN SF, 2016) e/ou em projetos (DILEKLI, 2020; SI, 2020).

Nas programações dos diversos conteúdos, deve haver um encadeamento progressivo dos temas de cada problema das tutorias com objetivos de aprendizagem bem definidos e alinhados aos dos demais ambientes de ensino, permitindo a integração vertical não apenas das ciências básicas e clínicas, mas também o entendimento dos fatores biopsicossociais e das necessidades de saúde da população, no ambiente de atenção integral à saúde.

\section{O LABORATÓRIO DE HABILIDADES E SIMULAÇÃO COMO AMBIENTE DE ENSINO}

As competências médicas são adquiridas por meio de habilidades cognitivas (conhecimento), psicomotoras (prática) e atitudinais (afetiva). As habilidades não técnicas, como comunicação, julgamento clínico e planejamento, são já inseridas na formação teórico-clínica básica da educação médica (HEMMING, 2012). Para aprender e melhorar as habilidades técnicas/psicomotoras e as habilidades interpessoais, a prática repetida e a simulação são necessárias, permitindo a automação de habilidades manuais e destreza. O uso das ferramentas e técnicas de simulação na educação médica é chamado de Educação em Saúde baseada em Simulação (EMBS).

Um Laboratório de Habilidades e Simulação (LHS) é um centro de treinamento para estudantes de graduação, médicos residentes ou profissionais de saúde, que permite adquirir/treinar habilidades e procedimentos em um ambiente seguro e protegido. Essas instalações também são amplamente conhecidas como Centros de Simulação.

Um Centro de Simulação pode ser usado para diversas finalidades:

- treinamento de graduação (no estudo de anatomia, funções fisiológicas, técnicas de anam- 
nese e exame médico, além de procedimentos cirúrgicos);

- treinamento de residência (refinamento de habilidades e técnicas processuais;

- para as pesquisas de pós-graduação em educação em saúde;

- treinamento de equipes multiprofissionais (por exemplo, treinamento em habilidades práticas, competências baseadas em equipe);

- para a educação permanente dos profissionais de saúde, como contrapartida pelo uso da rede pública de saúde;

- para provas práticas de graduandos e médicos residentes;

- para provas práticas de processos seletivos de variados tipos de profissionais de saúde de instituições públicas ou privadas, e

- para oferta de cursos privados que envolvem estações práticas simuladas (como ATLS, ACLS, PALS, ALSO etc.).

A implantação de Centros de Simulação tem as seguintes fases:

1) Objetivos;

2) Plano de desenvolvimento e Ações;

3) Recursos humanos;

4) Infraestrutura;

5) Organização e regras de funcionamento;

6) Desenvolvimento curricular para inserção de atividades simuladas;

7) Agenda de capacitação docente em simulação;

8) Acervo de simuladores e materiais;

9) Estrutura de monitoramento de ações e avaliação;

10) Engajamento dos apoiadores internos e externos, $\mathrm{e}$

11) Fases de implementação e plano de tempo.

Cada instituição de ensino e curso deve avaliar as finalidades a que se destinam seus Centros de Simulação e, com isso, definir as fases de implantação individuais que pretendem.

Existem numerosos exemplos de cada uma dessas fases, principalmente sobre as regras de utilização e funcionamento do Laboratório de Habilidades e Simulação de diversos cursos de medicina disponíveis nos buscadores da Internet.

Neste capítulo, o foco será a avaliação dos espaços físicos disponíveis aos Centros de Simulação e as sugestões de mobiliários e recursos tecnológicos, visando à melhor adequação dos objetivos de aprendizagem e avaliação dos currículos inovadores com utilização de metodologias ativas de aprendizagem.

\section{CARACTERÍSTICAS DOS ESPAÇOS FÍSICOS DO CENTRO DE SIMULAÇÃO}

O Centro de Simulação pode ter vários espaços físicos, de acordo com as características e complexidades de treinamento de cada local. Pode haver salas específicas para capacitação de radiologia intervencionista, hemodiálise, hemodinâmica cardíaca, UTI neonatal, entre outras. No entanto, os espaços físicos que devem estar presentes em qualquer centro de simulação são:

- ambiente multifuncional central - para reuniões de grupos de aprendizes antes e/ou depois das atividades simuladas;

- setor clínico - deve ter um número variável de consultórios simples multifuncionais, leitos de enfermaria e de UTI, e leitos para simulação de alta complexidade;

- setor cirúrgico - com previsão de bancada de lavagem das mãos, salas multifuncionais para treinamentos de técnicas cirúrgicas básicas (paramentação, curativos e suturas) e avançadas (treinamento individual e de equipes em diversos procedimentos cirúrgicos nas diferentes áreas - cirurgia geral, especialidades cirúrgicas, ginecologia/obstetrícia etc.);

- setor de discussão das atividades práticas (debriefing e feedback) com possibilidade de uso de diversos recursos tecnológicos;

- salas de backstage para consultórios, nos quais será utilizada a simulação de alta complexidade;

- área técnica - para preparo das práticas;

- almoxarifado - para guarda do acervo de simuladores e demais equipamentos;

- setor de armários para guarda dos pertences dos aprendizes - que deve estar antes da recepção de entrada e segurança do centro de simulação; - sala de controle das gravações de áudio e vídeo dos diversos ambientes físicos do centro de simulação, e

- salas de coordenação.

O número total de salas do Centro de Simulação é muito importante para o planejamento da realização periódica das avaliações práticas por estações (OSCEs) para graduandos de cursos da área da saúde. Isso torna o Centro de Simulação autossuficiente para a avaliação prática, utilizando suas próprias salas, sem a necessidade de transporte de simuladores e equipamentos para outros setores. E também evita a ociosidade da construção de salas próprias para provas tipo OSCE, que existem em muitos locais. 
O ambiente físico para discussão prévia ou posterior às atividades simuladas com o grupo de aprendizes deve ser amplo o suficiente para o número de aprendizes em cada atividade, podendo conter a turma inteira ou em grupos menores para rodízios. De preferência, deve ser um espaço multifuncional, com possibilidades de uso de vários recursos tecnológicos de imagem, não deve ter cadeiras fixas e o mobiliário deve ser acolhedor. A melhor alternativa para esse ambiente é um hall central, como apresentado na Figura 1.

O setor clínico do Centro de Simulação pode ter um número variável de consultórios simples multifuncionais, leitos de enfermaria e de UTI, e leitos para simulação de alta complexidade, de acordo com o número total de aprendizes e os rodízios de pequenos grupos planejados. Na Figura 2, podemos ver um exemplo de consultório simples multifuncional que, de preferência, deve ter paredes retráteis para a versatilidade desse ambiente físico em relação ao número de aprendizes que estão presentes.

Na dependência do número de aprendizes que farão a atividade simulada, poderá ser necessário um espaço físico para os que não estiverem participando diretamente da atividade de simulação terem diferentes opções de áudio e vídeo, e compreendam melhor o que ocorre no cenário de simulação, como pode ser visto na Figura 3.

Na Figura 4, podemos observar a sala de simulação de alta complexidade por meio da sala de $b a$ ckstage, com espelho de visão unidirecional.

Na Figura 5, podemos notar duas opções de leitos de enfermaria ou de Terapia Intensiva, que podem ser utilizadas no Centro de Simulação.

O setor cirúrgico do Centro de Simulação necessita da previsão de bancadas de lavagem das mãos, como pode ser visto na Figura 6, salas multifuncionais para treinamentos de técnicas cirúrgicas básicas (paramentação, curativos e suturas), vistos na Figura 7, e técnicas cirúrgicas avançadas (treinamento individual e de equipes em diversos procedimentos cirúrgicos nas diferentes áreas - cirurgia geral, especialidades cirúrgicas, ginecologia/obstetrícia etc.), na Figura 8.

No setor de discussão das atividades práticas, temos de prever salas de debriefing e feedback, com possibilidade de uso de diversos recursos tecnológicos para utilização de áudios e vídeos gravados durante as atividades simuladas. Na Figura 9, podemos notar uma opção de sala de debriefing.

Em cada instituição de ensino ou curso, é necessária a adequação do Centro de Simulação ao uso de atividades didáticas de simulação clínica, que

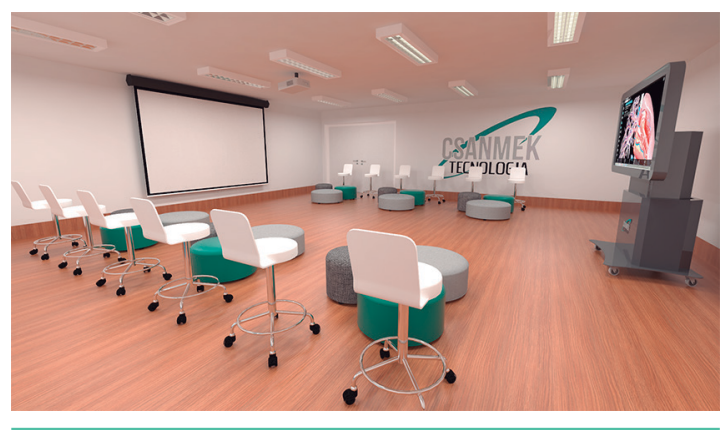

Figura 1 - Hall central para discussão pré e pós-atividades simuladas.

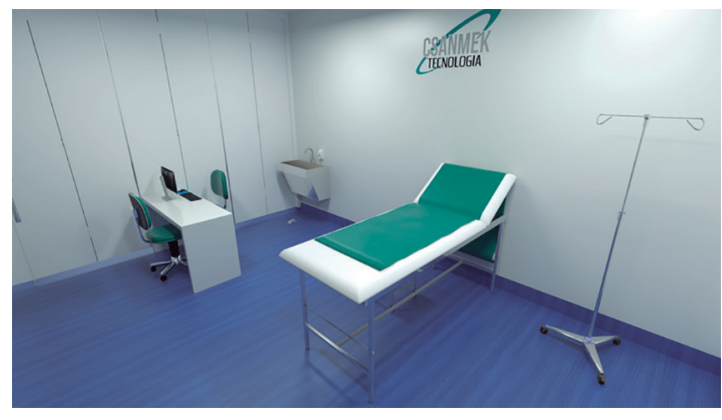

Figura 2 - Consultório simples multifuncional. Notar as paredes retráteis.

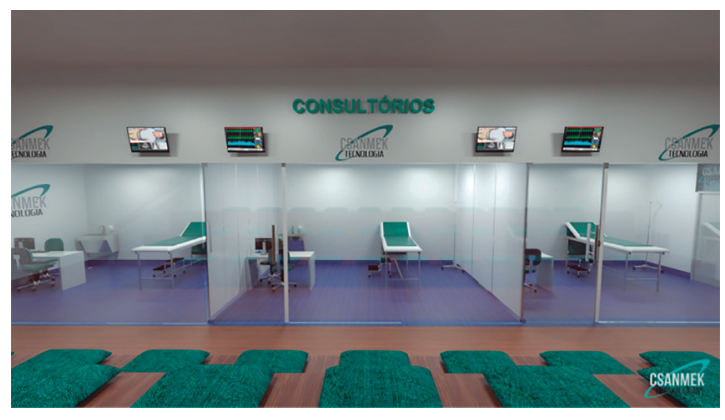

Figura 3 - Uma opção para realização de atividades simuladas semelhantes ou diferentes em salas sucessivas com visualização e escuta do áudio independente para cada uma.

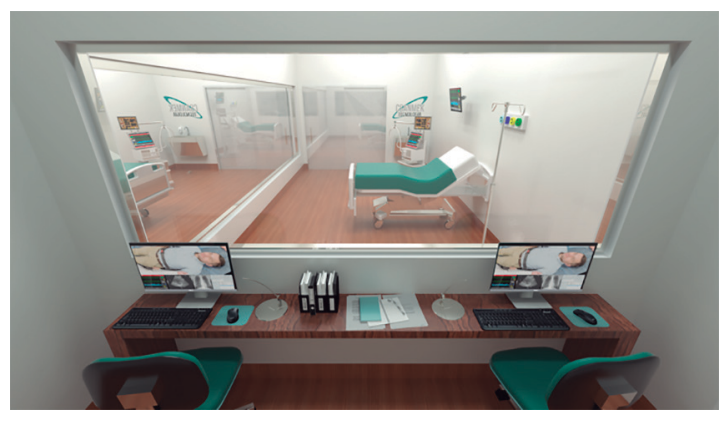

Figura 4 - Visão unidirecional por meio do espelho da sala de controle para a sala de simulação de alta complexidade. 
devem cada vez mais estar presentes nas programações das matrizes curriculares ao longo de toda duração da graduação e também de acordo com os objetivos previstos de utilização do espaço físico, conforme suas diversas finalidades. Como a maioria dos cursos já possui um Centro de Simulação, geralmente muito pequeno, é necessária uma redesenho dos espaços físicos disponibilizados, assim como readequação da infraestrutura de tomadas elétricas e pontos de Internet, para a convergência tecnológica de diversos recursos que podem ser utilizados para melhor aproveitamento pedagógico.

Após essa avaliação individual de cada espaço destinado ao Centro de Simulação de cada instituição ou curso, deve-se elaborar um projeto de layout, da organização interna dos ambientes do imóvel.
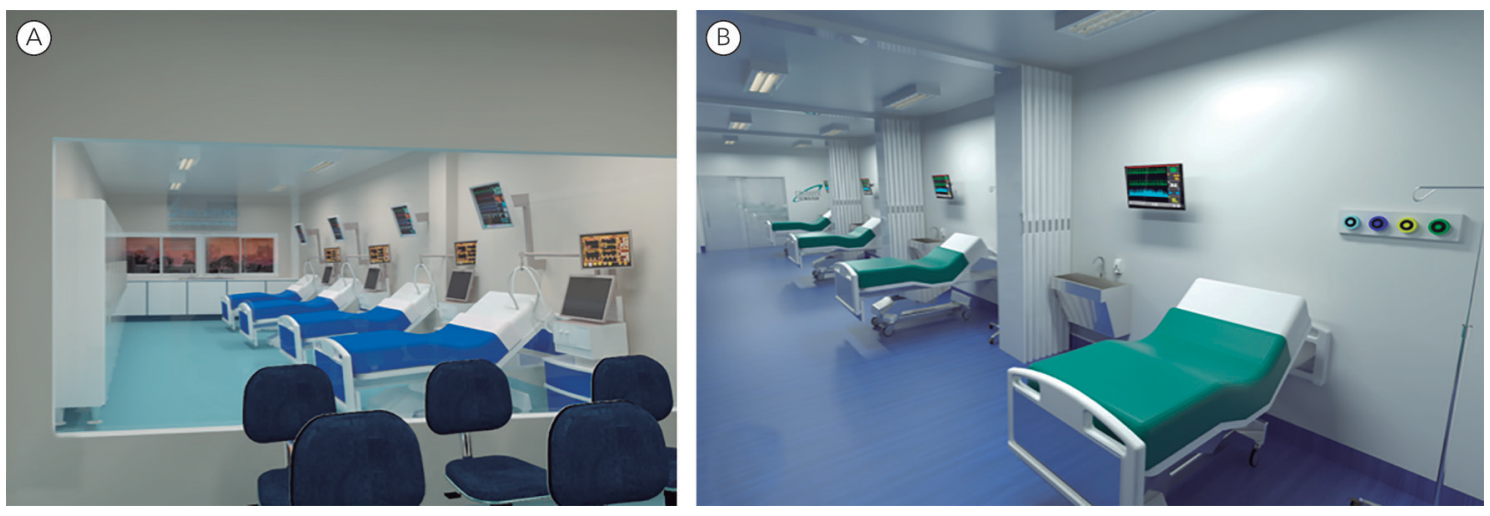

Figura 5 - Visão de duas diferentes opções (A e B) para os leitos de enfermaria ou de Terapia Intensiva do Centro de Simulação.
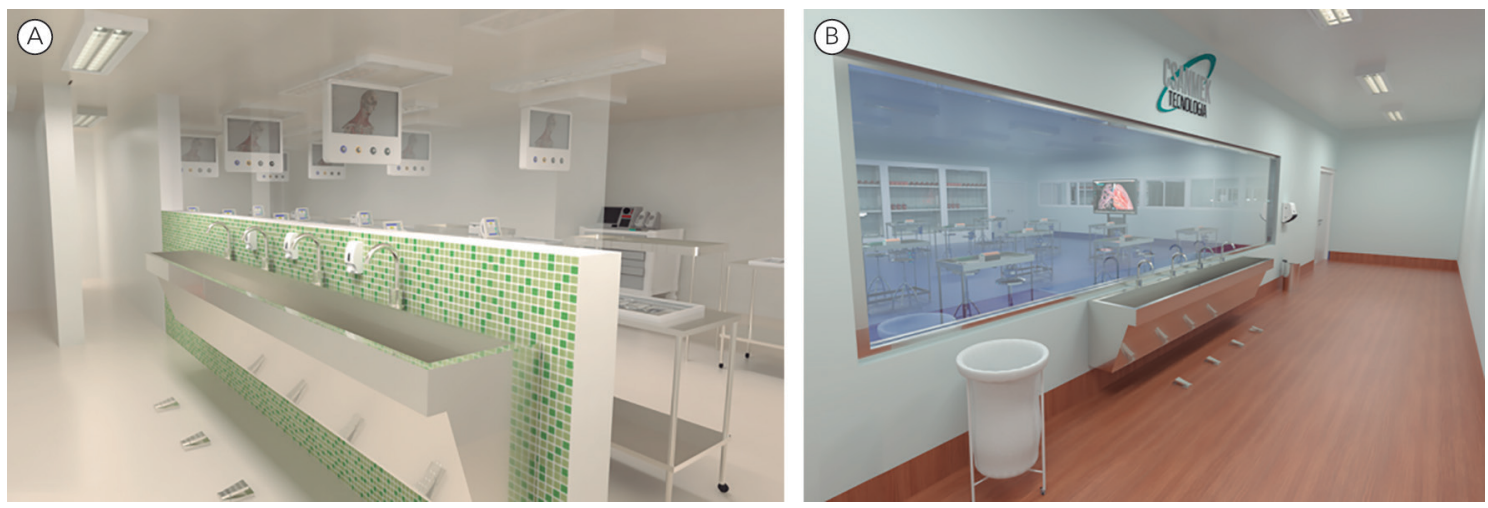

Figura 6 - Visão duas opções (A e B) de bancada de lavagem das mãos para procedimentos cirúrgicos.

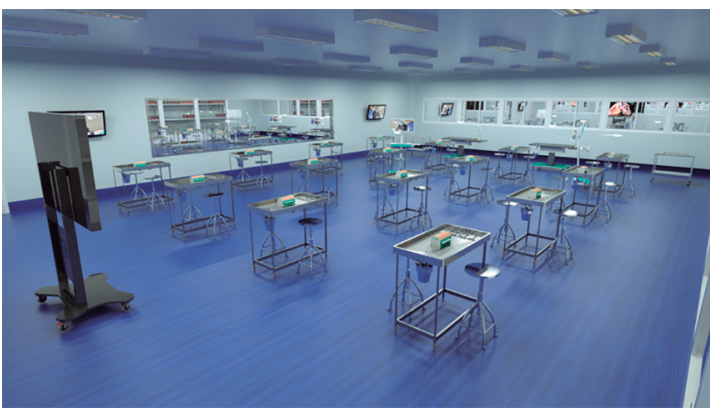

Figura 7 - Opção de sala de treinamento de habilidades cirúrgicas básicas.

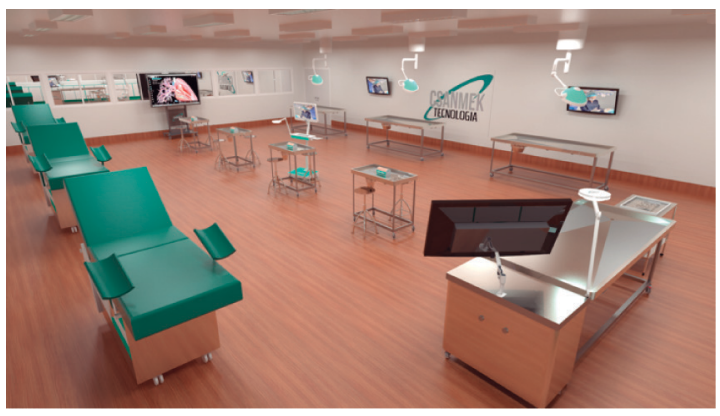

Figura 8 - Opção de sala de treinamento de habilidades cirúrgicas avançadas. 


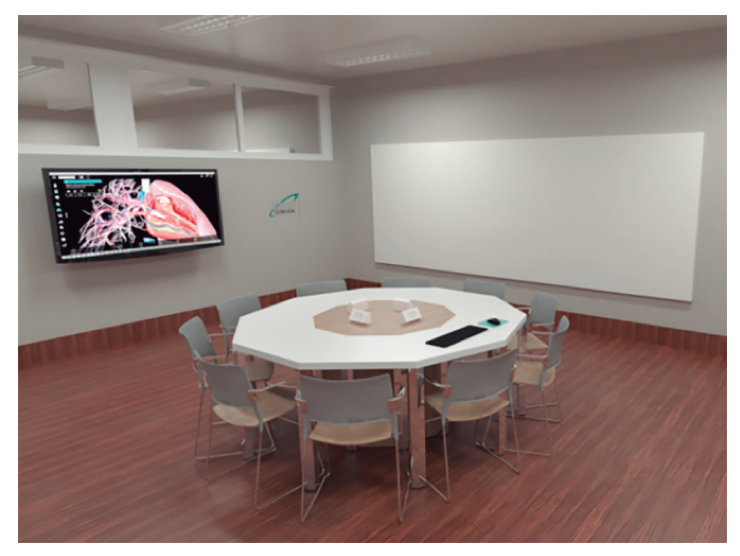

Figura 9 - Opção de sala de treinamento de habilidades cirúrgicas avançadas.

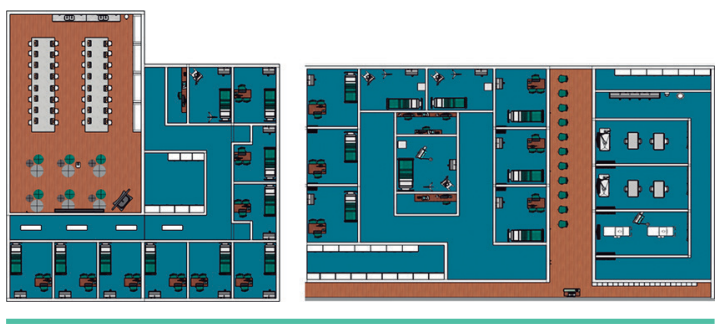

Figura 10 - Modelos de projetos de layout que podem ser elaborados após a avaliação das áreas físicas dos Centros de Simulação de cada instituição ou curso.

O principal objetivo desse projeto arquitetônico é a otimização dos espaços e do fluxo de pessoas, garantindo o melhor desempenho possível das atividades a serem realizadas nos ambientes que serão reformados ou construídos. Isso garante a certeza da elaboração de um ambiente que seja funcional e que traga conforto aos usuários.

Dessa forma, ao final da avaliação dos espaços destinados ao Centro de Simulação, o projeto de layout deve mostrar a planta do espaço a ser readequado com toda a previsão de espaços e medidas, móveis, pontos de tomadas, pontos de Internet, pontos hidráulicos (cubas, pias, torneiras e ralos) e equipamentos, como pode ser visto no exemplo da Figura 10.

\section{DETALHES TÉCNICOS DOS ESPAÇOS FÍSICOS E DA INFRAESTRUTURA DO CENTRO DE SIMULAÇÃO}

Visando ao pleno aproveitamento da infraestrutura e ao melhor aprendizado dos estudantes, os Centros de Simulação devem ser elaborados para emular o mais fidedignamente, tanto a aparência física quanto o fluxo interno dos ambientes dos serviços de saúde, particularmente os hospitalares. Também devem ser levados em consideração a quantidade de estudantes e os rodízios das turmas, para dimensionar a capacidade de atender a demanda de aulas e estudantes no centro de simulação, de acordo com a particularidade de cada instituição de ensino (entrada semestral ou anual, número de estudantes, relação docente/estudantes, tipo de divisão dos estudantes em grupo para rodízio das atividades, presença concomitante de outros cursos etc.). Para tanto, devem seguir as orientações abaixo.

\subsection{DIMENSIONAMENTOS DOS AMBIENTES SIMULADOS DE SAÚDE}

Seguindo a Resolução RDC n ${ }^{\circ}$ 50, DE 21 de fevereiro de 2002 (Agência Nacional de Vigilância Sanitária, 2002), que determina como os ambientes de saúde devem ser elaborados, seguem abaixo as dimensões mínimas indicadas (Quadro 1):

\subsection{DIMENSÕES MÍNIMAS DOS CORREDORES}

Os corredores destinados à circulação de pacientes devem ter corrimãos em ao menos uma parede lateral, a uma altura de $80 \mathrm{~cm}$ a $92 \mathrm{~cm}$ do piso, e com finalização curva. Os bate-macas podem ter também a função de corrimão.

Os corredores de circulação de pacientes ambulantes ou em cadeiras de rodas, macas ou camas, devem ter a largura mínima de 2,00 m para os maiores de 11,0 m e 1,20 m para os demais, não podendo ser utilizados como áreas de espera.

Os corredores de circulação de tráfego intenso de material e pessoal devem ter largura mínima de 2,00 m, não podendo ser utilizados como área de estacionamento de carrinhos.

Nas áreas de circulação, só podem ser instalados telefones de uso público, bebedouros, extintores de incêndio, carrinhos e lavatórios, de tal forma que não reduzam a largura mínima estabelecida e não obstruam o tráfego, a não ser que a largura exceda a $2,00 \mathrm{~m}$;

Os corredores destinados apenas à circulação de pessoal e de cargas não volumosas devem ter largura mínima de $1,20 \mathrm{~m}$.

No caso de desníveis de piso superiores a $1,5 \mathrm{~cm}$, deve ser adotada solução de rampa unindo os dois níveis.

Circulações das unidades de emergência e urgência, centro cirúrgico e obstétrico, devem sempre possuir largura mínima de 2,00 m. 
Quadro 1 - Dimensões mínimas dos ambientes de saúde.

\begin{tabular}{|c|c|}
\hline AMBIENTE & DIMENSÃO MÍNIMA \\
\hline Sala de demonstração e educação em saúde & $1 \mathrm{~m}^{2}$ por ouvinte \\
\hline Consultórios & $6,0 \mathrm{~m}^{2}$ \\
\hline Salas coletivas de observação & $8,5 \mathrm{~m}^{2}$ por leito \\
\hline \multirow[b]{2}{*}{ Sala de emergência/UTI } & $12 \mathrm{~m}^{2}$ por leito \\
\hline & $\begin{array}{l}\text { Com distância de } 1 \mathrm{~m} \text { entre os leitos e paredes, exceto } \\
\text { cabeceira, e com espaço suficiente para manobra da maca } \\
\text { junto ao pé dessa. Pé-direito mínimo }=2,7 \mathrm{~m}\end{array}$ \\
\hline \multirow{4}{*}{ Enfermaria (01 Leito) } & $12 \mathrm{~m}^{2}$ \\
\hline & Distância entre leito e paredes: $1 \mathrm{~m}$ cabeceira = inexistente; \\
\hline & Pé do leito =1,2 m; \\
\hline & Lateral $=0,5 \mathrm{~m}$ \\
\hline \multirow{5}{*}{ Enfermaria (02 leitos) } & Quarto de 2 leitos $=7,0 \mathrm{~m}^{2}$ por leito \\
\hline & Distância entre leitos paralelos $=1 \mathrm{~m}$ \\
\hline & Distância entre leito e paredes: cabeceira = inexistente; \\
\hline & Pé do leito =1,2 m; \\
\hline & Lateral $=0,5 \mathrm{~m}$ \\
\hline \multirow{5}{*}{ Enfermaria (03 a 06 leitos) } & Quarto de 3 a 6 leitos $=6,0 \mathrm{~m}^{2}$ por leito \\
\hline & Distância entre leitos paralelos $=1 \mathrm{~m}$ \\
\hline & Distância entre leito e paredes: cabeceira = inexistente; \\
\hline & Pé do leito =1,2 m; \\
\hline & Lateral $=0,5 \mathrm{~m}$ \\
\hline Sala de aula & $0,8 \mathrm{~m}^{2}$ por aluno \\
\hline
\end{tabular}

\subsection{PISOS E RODAPÉS}

Os pisos indicados para esses ambientes são o vinílico e o epóxi, pois não podem ter índice de absorção de água superior a $4 \%$. E, para as áreas críticas, utilizar materiais de acabamento que tornem as superfícies monolíticas, com o menor número possível de ranhuras ou frestas, mesmo após o uso e limpeza frequente. Esses tipos de piso são indicados também em ambientes de Instituições onde houver a opção de utilização de cadáveres, pois, por serem hospitalares, eles estão de acordo com as normas técnicas de biossegurança preconizadas pela ANVISA (RDC 50/2002).

A execução da junção entre o rodapé e o piso deve ser com cantos em formatos arredondados em 45 graus, permitindo a completa limpeza do ambiente.
Especial atenção deve ser dada à união do rodapé com a parede de modo que os dois estejam alinhados, evitando-se o tradicional ressalto do rodapé que permite o acúmulo de pó e é de difícil limpeza.

Fica estabelecida a utilização de piso condutivo somente quando houver uso de misturas anestésicas inflamáveis com oxigênio ou óxido nitroso, bem como quando houver agentes de desinfecção, incluindo-se aqui a Zona de Risco.

\subsection{ACABAMENTOS DE PAREDES, TETOS, BANCADAS E DIVISÓRIAS}

Como esses locais devem mimetizar ambientes hospitalares e, em alguns casos, utilizar ou ter de contar com a circulação de materiais biológicos, é necessário cumprir alguns requisitos. 
A limpeza e a sanitização de pisos, paredes, tetos, pias e bancadas devem seguir as normas contidas no manual Processamento de Artigos e Superfícies em Estabelecimentos de Saúde $2^{\mathrm{a}}$ edição, Ministério da Saúde/Coordenação de Controle de Infecção Hospitalar. Brasília-DF, 1994 ou o que vier a substituí-lo.

Os materiais adequados para o revestimento de paredes, pisos e tetos dos ambientes devem ser resistentes à lavagem e ao uso de desinfetantes, conforme preconizado no manual supracitado.

Os materiais, cerâmicos ou não, quando usados nas áreas críticas, não podem possuir índice de absorção de água superior a $4 \%$ individualmente ou depois de instalados no ambiente, além de se observar que o rejunte de suas peças, quando existir, também deve ter esse mesmo índice de absorção.

As tintas elaboradas à base de epóxi, PVC, poliuretano ou outras destinadas a áreas molhadas podem ser utilizadas nas áreas críticas tanto nas paredes e tetos quanto nos pisos, desde que sejam resistentes à lavagem, ao uso de desinfetantes e não sejam aplicadas com pincel. Quando utilizadas no piso, devem resistir também a abrasão e impactos a que serão submetidas.

O uso de divisórias removíveis nas áreas críticas não é permitido, entretanto paredes pré-fabricadas podem ser usadas, desde que, quando instaladas, tenham acabamento monolítico, ou seja, não possuam ranhuras ou perfis estruturais aparentes, e sejam resistentes à lavagem e ao uso de desinfetantes, conforme preconizado no manual citado no primeiro parágrafo deste item. Nas áreas semicríticas, as divisórias só podem ser utilizadas se forem, também, resistentes ao uso de desinfetantes e à lavagem com água e sabão, conforme preconizado no manual ora citado.

Nas áreas críticas e semicríticas, não deve haver tubulações aparentes nas paredes e tetos. Quando estas não forem embutidas, devem ser protegidas em toda sua extensão por um material resistente a impactos, lavagem e uso de desinfetantes.

\subsection{FORROS}

Os tetos em áreas críticas (especialmente nas salas destinadas à realização de procedimentos cirúrgicos ou similares) devem ser contínuos, sendo proibido o uso de forros falsos removíveis, do tipo que interfira na assepsia dos ambientes. Nas demais, pode-se utilizar forro removível, inclusive por razões ligadas à manutenção, desde que, nas áreas semicríticas, esses sejam resistentes aos processos de limpeza, descontaminação e desinfecção.
Nos demais casos em que houver apenas simulação sem materiais biológicos, o uso de forros contínuos pode ser utilizado normalmente.

\subsection{ACESSÓRIOS (BATE-MACAS, PROTETORES DE PAREDE)}

O sistema de proteção de paredes, portas e cantos, também conhecido como bate-macas, é imprescindível para a segurança em ambientes hospitalares. O bate maca hospitalar tem como função absorver os impactos dos processos cotidianos, para assim oferecer máxima proteção e conservação do ambiente. No mercado, há fabricantes especializados em cortinas divisórias para leitos e sistemas de proteção que oferecem soluções adequadas às mais exigentes normas técnicas arquitetônicas para execução em projetos hospitalares.

\subsection{PORTAS}

Todas as portas de acesso a pacientes devem ter dimensões mínimas de 0,80 (vão livre) $\times 2,1 \mathrm{~m}$, inclusive nos sanitários.

Todas as portas de acesso aos ambientes onde forem instalados equipamentos de grande porte têm de possuir folhas ou painéis removíveis, com largura compatível com o tamanho do equipamento, permitindo assim sua saída.

Todas as portas utilizadas para a passagem de camas/macas e de laboratórios devem ter dimensões mínimas de 1,10 (vão livre) × 2,10 m, exceto as portas de acesso para as unidades de diagnóstico e terapia, que necessitam acesso de maca. As salas de exame ou terapias devem ter dimensões mínimas de $1,20 \times 2,10 \mathrm{~m}$.

As portas de banheiros e sanitários de pacientes devem abrir para fora do ambiente ou permitir a retirada da folha pelo lado de fora, a fim de que sejam abertas sem necessidade de empurrar o paciente eventualmente caído atrás da porta. As portas devem ser dotadas de fechaduras que permitam facilidade de abertura em caso de emergência e barra horizontal a $90 \mathrm{~cm}$ do piso.

\subsection{INSTALAÇÕES ELÉTRICAS}

\subsubsection{ILUMINAÇÃO}

Nos ambientes onde não acontecerão simulações com pacientes simulados, não serão necessárias condições especiais de iluminação. Também não necessitam de incidência de luz de fonte natural direta nem de iluminação artificial especial.

Nos ambientes em que houver simulações com pacientes simulados, deve ser adotada iluminação 
que não altere a cor do paciente, como focos auxiliares e similares.

\subsubsection{TOMADAS ELÉTRICAS}

O número de pontos de tomadas elétricas deve ser determinado após avaliação da sala/laboratório, levando em conta as funções de destinação do local e os equipamentos elétricos que podem ser utilizados no ambiente.

\subsection{INSTALAÇÕES HIDRÁULICAS}

Deverá ser desenvolvido um projeto básico das instalações hidráulicas e especiais do estabelecimento, destinado a compatibilizar o projeto arquitetônico com as diretrizes básicas a serem adotadas no desenvolvimento do projeto, contendo quando aplicáveis:

- Descrição básica do sistema de abastecimento de água: entrada;

- Previsões do consumo de água;

- Descrição básica do sistema de proteção e combate a incêndio;

- Localização da rede pública de esgoto e/ou, quando necessária, a indicação de sistema de tratamento (fossa séptica, câmaras de decantação para esgoto radioativo, outros), e

- Descrição básica do sistema de fornecimento de gases medicinais (oxigênio, óxido nitroso, ar comprimido medicinal e outros) quando for o caso.

\subsection{ACÚSTICA}

Para a realização de simulação dentro dos ambientes destinados para tal função, é necessário controle de ruídos para que o áudio de um local não atrapalhe os demais. Para isso, existe uma série de princípios arquitetônicos gerais para controle acústico nos ambientes, em que todos agem no sentido de isolar as pessoas da fonte de ruído, a partir de limites de seus níveis estabelecidos por normas brasileiras e internacionais.

A Norma Brasileira NBR 10152 estabelece os níveis de ruídos aceitáveis para diferentes ambientes.

\subsection{CLIMATIZAÇÃO}

Visando ao conforto dos alunos e professores, deve ser desenvolvido um programa básico das instalações de ar-condicionado e ventilação mecânica, destinado a compatibilizar o projeto arquitetônico com as diretrizes básicas a serem adotadas no desenvolvimento do projeto.

\subsection{GASES}

Os projetos de ambientes simulados, em sua maioria, não utilizarão instalações de gases convencionais. Em determinados projetos, somente haverá a instalação da régua de gases para simulação e, em alguns destes projetos, haverá instalação de ar comprimido por meio de compressores que devem ser instalados externamente ao ambiente de simulação para evitar problemas com ruídos.

Quando necessário, realizar a instalação de gases medicinais por meio de tubulações, sendo que os projetos devem atender a NBR 12188 e suas especificações.

\subsection{SEGURANÇA}

\subsubsection{SINALIZAÇÃO DE SEGURANÇA}

Todas as saídas de pavimento e setores de incêndio têm de estar sinalizadas. As circulações contarão com sinais indicativos de direção desde os pontos de origem de evacuação até os pontos de saída. A sinalização perfeitamente visível deve confirmar a utilização, por exemplo, de escadas de incêndio. Toda porta que não seja saída e que não tenha indicação relativa à função do recinto a que dá acesso pode induzir a erro. Dessa forma, deve ser sinalizada com o rótulo "SEM SAÍDA".

Os sistemas de detecção são constituídos pelos seguintes elementos:

- Dispositivos de entrada - Detectores automáticos, acionadores automáticos e acionadores manuais;

- Centrais de alarme - Painéis de controle individualizados, no mínimo, por setor de incêndio;

- Dispositivos de saída - Indicadores sonoros, indicadores visuais, painéis repetidores, discagem telefônica automática, desativadores de instalações, válvulas de disparo de agentes extintores, fechamento de portas CORTA-FOGO e monitores, e

- Rede de interligação - Conjunto de circuitos que interligam a central com os dispositivos de entrada, saída e as fontes de energia do sistema.

\subsubsection{GUARDA DE PERTENCES DE ESTUDANTES, FUNCIONÁRIOS, PROFESSORES E CONVIDADOS}

Em um local externo ao Centro de Simulação, devem ser destinados armários com dispositivo de fechamento individual para a guarda de pertences das diversas pessoas que podem adentrá-lo. De acordo com as regras definidas pela instituição ou curso, estes armários podem ter dispositivos de fechamento individual, com cadeados e chaves que são retirados na recepção, mediante a entrega de 
documentos com fotos, ou permitir que cada estudante tenha seu armário.

\subsubsection{CONTROLE DE ACESSO}

Uma das melhores opções é o uso de catracas eletrônicas com um sistema de controle de acesso biométrico ou cartões de acesso (proximidade ou código de barras). Porém, a biometria oferece mais segurança e comodidade, pois evita empréstimos de cartões e/ou senhas de acesso, assim como perda ou extravio dos mesmos, além de custos adicionais com emissão dos cartões.

Para os frequentadores da faculdade, sua identificação se dá quando coloca-se o dedo no leitor biométrico da catraca. $\mathrm{O}$ sistema de controle de acesso, ao reconhecer a impressão digital do usuário cadastrada no banco de dados, libera então sua entrada ou saída. Pessoas que não estão com sua digital cadastrada no sistema não poderão ter acesso livre às dependências do recinto, garantindo, assim, a segurança de todos.

As principais vantagens, ao controlar o Fluxo de Acesso de pessoas, são:

- Tranquilidade e segurança para alunos, professores e demais funcionários;

- Bloqueio da entrada de pessoas não autorizadas e/ou mal intencionadas, etc.;

- Segurança patrimonial dos equipamentos;

- Controle de frequência dos estudantes;

- Relatório dos registros da entrada de alunos, professores e terceiros, e

- Controle de presença por turno, por turmas, etc.

\subsection{RECOMENDAÇÕES DE HUMANIZAÇÃO}

A humanização dos estabelecimentos de saúde tem uma diretriz transversal e constitui-se num conjunto de ações sobre diversas práticas e condições na prestação dos serviços de saúde, assim como em diferentes níveis do Sistema, formando uma construção coletiva de todos os atores envolvidos. Para o Ministério da Saúde, trata-se de uma das estratégias para alcançar a qualificação da atenção e da gestão em saúde no SUS. Trata-se de uma forma de tornar parceiros, tanto usuários como profissionais de saúde, na busca da qualidade dos serviços, um projeto de corresponsabilidade e qualificação dos vínculos interprofissionais e entre estes e os usuários na produção de saúde. Essa humanização hospitalar, ao mesmo tempo em que colabora com o processo terapêutico do paciente, contribui para a qualidade dos serviços de saúde prestados pelos profissionais envolvidos (MARTINS, 2004).

\subsection{RECOMENDAÇÕES DE RECURSOS HUMANOS}

Os profissionais técnicos em um centro de simulação são de suma importância e têm as seguintes funções:

- É peça-chave para apoio direto ao docente na construção da prática simulada solicitada;

- Acompanha diretamente os docentes e estudantes durante a simulação;

- Faz cumprir as normas estabelecidas para adentrar ao centro de simulação;

- Executa as manutenções necessárias nos simuladores e demais equipamentos, bem como a limpeza dos materiais e simuladores, e

- Gerencia estoque dos materiais.

Em geral, esses profissionais são da área de enfermagem, pois já conhecem todos os materiais utilizados nas atividades práticas.

\subsection{ACESSIBILIDADE}

Todos os ambientes devem ser desenvolvidos norteados pelas Leis 10.048 e 10.098 (BRASIL, 2000), as quais regulam a acessibilidade nos ambientes educacionais.

\section{DETALHES TÉCNICOS DA UTILIZAÇÃO E CONVERGÊNCIA DE RECURSOS TECNOLÓGICOS E DO MOBILIÁRIO DOS DIVERSOS SETORES DO CENTRO DE SIMULAÇÃO}

O uso das tecnologias de informação e comunicação (TICs) nos cursos da área da saúde, particularmente na medicina, favorece a institucionalização de métodos e práticas de ensino/ aprendizagem, incentiva o uso das tecnologias da comunicação e informação, e visa criar uma cultura acadêmica que considere tais recursos como instrumentos motivadores da aprendizagem individual e em grupo. Eles devem estar alinhados com os objetivos de aprendizagem e o projeto pedagógico, permitindo a melhor utilização dos mesmos e otimizando a integração entre a rede de saúde, a atenção e a universidade.

Desta forma, objetiva a formação de qualidade, em que profissionais médicos sejam capazes de reconhecer, nas aplicações das tecnologias de informação e comunicação, amplas possibilidades de aprender a ensinar, desenvolvendo a habilidade de manusear os recursos tecnológicos existentes, em favor de sua formação e atualização, bem como a sua competência para conceber ações em direção à saúde e ao bem-estar social.

Os conteúdos educacionais e materiais didáticos serão desenvolvidos através da utilização de re- 
cursos tecnológicos, tais como ambientes virtuais de aprendizagem, programas de indexação e busca de conteúdo, objetos educacionais e outros, que devem ser acessíveis em versão mobile, por computadores pessoais e tablets.

Para melhor uso das metodologias ativas, as instituições podem usar os elementos tecnológicos que as apoiem, como utilização de câmeras e sistema de vídeo para gravar as atividades e enviar aos estudantes para reflexão pós-debriefing ou uso em sala de aula invertida, de elementos de multimídia, como computadores, projetores, telas grandes de TV, entre outros, para apoio em ambientes de reflexão de casos, que podem ser também utilizados como pré-briefing e sala de TBL ou PBL, tornando esses locais multiuso e multifuncionais (Quadro 2).
O uso de elementos interativos como realidade virtual podem ser utilizados, tanto para simulação clínica como para apoio à anatomia, tornando o aprendizado mais interessante ao aluno, pois esse tipo de recurso se faz presente no cotidiano deles.

O sistema de rede de dados e voz deve ser bem estruturado, contendo banda larga suficiente para atender aos discentes e docentes com qualidade, de modo que sejam utilizados os diversos portais de pesquisa via internet e também os aplicativos e recursos de ambientes virtuais proporcionados pela própria instituição, facilitando a acessibilidade aos aprendizes.

A seguir, em cada quadro (Quadros 3 a 11), serão apresentados os mobiliários e recursos tecnológicos sugeridos para cada setor descrito do Centro de Simulação.

Quadro 2 - Hall central (vide Figura 1)

\section{Sugestões de equipamentos e mobiliários}

\begin{tabular}{|l|l|}
\hline Puffs e mochos confortáveis & $\begin{array}{l}\text { Para que os alunos fiquem à vontade e interajam com } \\
\text { as tecnologias disponíveis e tenham maior rendimento } \\
\text { e interação em grupos, de acordo com a metodologia } \\
\text { utilizada. }\end{array}$ \\
\hline $\begin{array}{l}\text { Plataforma multidisciplinar 3D ou mesa } \\
\text { anatômica }\end{array}$ & $\begin{array}{l}\text { Permite interação nos conteúdos, como anatomia, fisiologia, } \\
\text { histologia, patologia, entre outras possibilidades, auxiliando } \\
\text { na discussão pós-prática dos alunos e no uso do currículo } \\
\text { integrado dentro desse ambiente. }\end{array}$ \\
\hline Projetor e tela de projeção retrátil & $\begin{array}{l}\text { É utilizado como apoio à discussão em grupo, reflexão } \\
\text { pós-prática, sala de aula invertida, briefing e debriefing, } \\
\text { entre outras aplicações. }\end{array}$ \\
\hline Câmeras de alta definição & $\begin{array}{l}\text { Utilizadas para filmar os ambientes, atividades e avaliações } \\
\text { de simulação. }\end{array}$ \\
\hline Lousa fixa ou móvel & Lousa para apoio às discussões de casos, reflexão de casos. \\
\hline
\end{tabular}

Quadro 3 - Consultórios (vide Figuras 2 e 3)

\section{Sugestões de equipamentos, softwares e mobiliários}

\section{A. Equipamentos}

\begin{tabular}{|l|l|}
\hline Item & Descrição \\
\hline $\begin{array}{l}\text { Câmeras de alta definição com } \\
\text { sistema de captura de áudio e } \\
\text { vídeo }\end{array}$ & $\begin{array}{l}\text { Utilizadas para filmar os ambientes, atividades e avaliações de } \\
\text { simulação. }\end{array}$ \\
\hline $\begin{array}{l}\text { Infraestrutura de captura de } \\
\text { vídeos e áudios }\end{array}$ & $\begin{array}{l}\text { Cabeamento e sala de controle para gerenciar a gravação, } \\
\text { armazenamento e agendamento das atividades de multimídia } \\
\text { envolvendo os equipamentos. }\end{array}$ \\
\hline Laptop ou desktop & $\begin{array}{l}\text { Para uso durante simulação na qual serão utilizados softwares para } \\
\text { emular prontuário eletrônico com telemedicina. }\end{array}$ \\
\hline
\end{tabular}


Quadro 3 - Continuação...

\section{Sugestões de equipamentos, softwares e mobiliários}

\section{A. Equipamentos}

\begin{tabular}{|l|l|}
\hline Item & Descrição \\
\hline Balança & Balança Antropométrica. \\
\hline Ar condicionado & $\begin{array}{l}\text { Para manter a temperatura equilibrada e a integridade dos } \\
\text { equipamentos e simuladores. }\end{array}$ \\
\hline B. Softwares & $\begin{array}{l}\text { Sistema de telerradiologia com casos reais de diversas patologias para } \\
\text { uso remoto e presencial nas simulações. }\end{array}$ \\
\hline Sistema de telerradiologia & $\begin{array}{l}\text { Software para gerenciar gravação, armazenamento e agendamento } \\
\text { das atividades de multimídia envolvendo os equipamentos. }\end{array}$ \\
\hline Software para gravação & \multicolumn{2}{|l|}{} \\
\hline C. Mobiliários & Maca hospitalar com armário. \\
\hline Maca & Mesa para uso durante a simulação pelos alunos e professores. \\
\hline Mesa para atendimento & Lavatório em inox para assepsia com acionamento por pedal. \\
\hline Lavatório em inox para assepsia & $\begin{array}{l}\text { Cadeiras confortáveis para uso durante a simulação pelos alunos e } \\
\text { professores. }\end{array}$ \\
\hline Cadeiras & \multicolumn{2}{|l|}{} \\
\hline D. Outros & Lixeira branca com pedal. \\
\hline Lixeira branca & Dispenser de sabonete líquido próximo ao lavatório. \\
\hline Dispenser de sabonete líquido & Dispenser de álcool gel próximo à entrada do consultório. \\
\hline Dispenser de álcool gel & Dispenser de papel próximo ao lavatório. \\
\hline Dispenser de papel & Coletor perfurocortante (3 litros) com suporte de parede \\
\hline Coletor perfurocortante & \multicolumn{2}{|l|}{}
\end{tabular}

Quadro 4 - Salas de simulação e controle (para 1, 2 e 4 salas contíguas) (vide Figura 4)

\begin{tabular}{|l|l|}
\hline \multicolumn{2}{|c|}{ Sugestões de equipamentos, softwares e mobiliários } \\
\hline Cadeiras & $\begin{array}{l}\text { Cadeiras confortáveis para uso dos técnicos de multimídia } \\
\text { que farão a operação dos sistemas de gestão de imagens. }\end{array}$ \\
\hline Mesas & $\begin{array}{l}\text { Para uso durante a gravação e controle dos simuladores e } \\
\text { sistemas. }\end{array}$ \\
\hline Mesa de som & $\begin{array}{l}\text { Equipamento para gestão do áudio e vídeo das salas de } \\
\text { simulação. }\end{array}$ \\
\hline $\begin{array}{l}\text { Câmeras de alta definição com sistema de } \\
\text { captura de áudio e vídeo }\end{array}$ & $\begin{array}{l}\text { Utilizadas para filmar ambientes, atividades e avaliações de } \\
\text { simulação. }\end{array}$ \\
\hline $\begin{array}{l}\text { Infraestrutura de captura de vídeos e } \\
\text { áudios }\end{array}$ & $\begin{array}{l}\text { Cabeamento e sala de controle para gerenciar gravação, } \\
\text { armazenamento e agendamento das atividades de } \\
\text { multimídia envolvendo os equipamentos. }\end{array}$ \\
\hline $\begin{array}{l}\text { TV 40 polegadas (utilizada na sala de } \\
\text { debriefing) }\end{array}$ & $\begin{array}{l}\text { Serão utilizadas como monitores externos para reprodução } \\
\text { do conteúdo gravado nos consultórios. }\end{array}$ \\
\hline Servidor de Vídeo & $\begin{array}{l}\text { Em caso de a instituição optar por armazenamento local dos } \\
\text { conteúdos gerados. }\end{array}$ \\
\hline
\end{tabular}


Quadro 5 - Enfermarias (vide Figura 5)

\section{Sugestões de equipamentos, softwares, mobiliários e materiais}

\begin{tabular}{|c|c|}
\hline \multicolumn{2}{|l|}{ A. Equipamentos } \\
\hline Item & Descrição \\
\hline $\begin{array}{l}\text { Câmeras de alta definição com } \\
\text { sistema de captura de áudio e vídeo }\end{array}$ & $\begin{array}{l}\text { Utilizadas para filmar ambientes, atividades e avaliações de } \\
\text { simulação. }\end{array}$ \\
\hline $\begin{array}{l}\text { Infraestrutura de captura de vídeos } \\
\text { e áudios }\end{array}$ & $\begin{array}{l}\text { Cabeamento e sala de controle para gerenciar gravação, } \\
\text { armazenamento e agendamento das atividades de multimídia } \\
\text { envolvendo os equipamentos. }\end{array}$ \\
\hline Monitor multiparamétrico & Monitor multiparamétrico simulado ou simples. \\
\hline $\begin{array}{l}\text { TV } 40 \text { polegadas (utilizada na sala } \\
\text { de debriefing) }\end{array}$ & $\begin{array}{l}\text { Serão utilizadas como monitores externos para reprodução do } \\
\text { conteúdo gravado nos consultórios (colocaria somente na sala de } \\
\text { debriefing). }\end{array}$ \\
\hline Ar condicionado & $\begin{array}{l}\text { Para manter a temperatura equilibrada e a integridade dos } \\
\text { equipamentos e simuladores. }\end{array}$ \\
\hline Régua de gases & Régua de gases para uso em simulação. \\
\hline \multicolumn{2}{|l|}{ B. Softwares } \\
\hline Software para gravação & $\begin{array}{l}\text { Software para gerenciar gravação, armazenamento e agendamento } \\
\text { das atividades de multimídia envolvendo os equipamentos. }\end{array}$ \\
\hline \multicolumn{2}{|l|}{ C. Mobiliários } \\
\hline Cama Hospitalar & $\begin{array}{l}\text { Cama hospitalar com elevação manual ou mecânica para uso em } \\
\text { simulação. }\end{array}$ \\
\hline Mesa Mayo & Mesa auxiliar \\
\hline Lavatório em inox para assepsia & Lavatório em inox para assepsia com acionamento por pedal. \\
\hline \multicolumn{2}{|l|}{ D. Outros } \\
\hline Lixeira branca & Lixeira branca com pedal. \\
\hline Dispenser de sabonete líquido & Dispenser de sabonete líquido próximo ao lavatório. \\
\hline Dispenser de álcool gel & Dispenser de álcool gel próximo à entrada do consultório. \\
\hline Dispenser de papel & Dispenser de papel próximo ao lavatório. \\
\hline Coletor perfurocortante & Coletor perfurocortante (3 litros) com suporte de parede \\
\hline
\end{tabular}

Quadro 6 - UTI adulto (vide Figura 5)

Sugestões de equipamentos, softwares, mobiliários

\section{A. Equipamentos}

\section{Item}

Câmeras de alta definição com sistema de captura de áudio e vídeo

Infraestrutura de captura de vídeos e áudios

\section{Descrição}

Utilizadas para filmar ambientes, atividades e avaliações de simulação.

Cabeamento e sala de controle para gerenciar gravação, armazenamento e agendamento das atividades de multimídia envolvendo os equipamentos. 
Quadro 6 - Continuação...

Sugestões de equipamentos, softwares, mobiliários

\section{A. Equipamentos}

\begin{tabular}{|c|c|}
\hline Item & Descrição \\
\hline Ventilador mecânico & Ventilador simples ou simulado. \\
\hline Monitor multiparamétrico & Monitor multiparamétrico (simulado ou não) \\
\hline $\begin{array}{l}\text { TV } 40 \text { polegadas (utilizada na sala } \\
\text { de debriefing) }\end{array}$ & $\begin{array}{l}\text { Serão utilizadas como monitores externos para reprodução do } \\
\text { conteúdo gravado nos consultórios (colocaria somente na sala de } \\
\text { debriefing). }\end{array}$ \\
\hline Ar Condicionado & $\begin{array}{l}\text { Para manter a temperatura equilibrada e a integridade dos } \\
\text { equipamentos e simuladores. }\end{array}$ \\
\hline Régua de gases & Régua de gases para uso em simulação. \\
\hline \multicolumn{2}{|l|}{ B. Softwares } \\
\hline Software para gravação & $\begin{array}{l}\text { Software para gerenciar gravação, armazenamento e agendamento } \\
\text { das atividades de multimídia envolvendo os equipamentos }\end{array}$ \\
\hline \multicolumn{2}{|l|}{ C. Mobiliários } \\
\hline Suporte de soro & Suporte simples de soro \\
\hline Cama hospitalar & Cama hospitalar com elevação mecânica para uso em simulação \\
\hline Carrinho de parada & Simulado ou simples \\
\hline Mesa Mayo & Mesa auxiliar \\
\hline Lavatório em inox para assepsia & Lavatório em inox para assepsia com acionamento por pedal \\
\hline \multicolumn{2}{|l|}{ D. Outros } \\
\hline Lixeira branca & Lixeira branca com pedal \\
\hline Dispenser de sabonete líquido & Dispenser de sabonete líquido próximo ao lavatório \\
\hline Dispenser de álcool gel & Dispenser de álcool gel próximo à entrada do consultório \\
\hline Dispenser de papel & Dispenser de papel próximo ao Lavatório \\
\hline Coletor perfurocortante & Coletor perfurocortante (3 litros) com suporte de parede \\
\hline
\end{tabular}

Quadro 7 - Treinamento de técnicas cirúrgicas básicas e avançadas (vide Figuras 6, 7 e 8)

\section{Sugestões de equipamentos, softwares e mobiliários}

\section{A. Equipamentos}

\section{Item}

Câmeras de alta definição com sistema de captura de áudio e vídeo

Infraestrutura de captura de vídeos e áudios

Foco de teto

\section{Descrição}

Utilizadas para filmar ambientes, atividades e avaliações de simulação.

Cabeamento e sala de controle para gerenciar gravação, armazenamento e agendamento das atividades de multimídia envolvendo os equipamentos.

Para simulação em ambiente cirúrgico com as mesmas características do original. 
Quadro 7 - Continuação...

\section{Sugestões de equipamentos, softwares e mobiliários}

\section{A. Equipamentos}

\begin{tabular}{|c|c|}
\hline Item & Descrição \\
\hline Mesa de inox inteligente & $\begin{array}{l}\text { Mesa com sistema de filmagem, transmissão e gravação de imagens } \\
\text { de procedimentos, que pode ser utilizada para envio de vídeos em } \\
\text { tempo real para os alunos dentro ou fora do ambiente, evitando } \\
\text { aglomerações em redor do professor e permitindo o uso para } \\
\text { acompanhamento remoto. }\end{array}$ \\
\hline TV 40 polegadas & $\begin{array}{l}\text { Serão utilizadas como monitores externos para reprodução do } \\
\text { conteúdo ministrado das mesas de inox inteligentes. }\end{array}$ \\
\hline Infraestrutura de assepsia & $\begin{array}{l}\text { Instalação de ambiente de assepsia contendo vestiários, área de } \\
\text { paramentação e cubas para lavagem de mãos e antebraços, com } \\
\text { sistema de acionamento por pedal ou similar. }\end{array}$ \\
\hline Ar condicionado & $\begin{array}{l}\text { Para manter a temperatura equilibrada e a integridade dos } \\
\text { equipamentos e simuladores. }\end{array}$ \\
\hline \multicolumn{2}{|l|}{ B. Softwares } \\
\hline Software para gravação & $\begin{array}{l}\text { Software para gerenciar gravação, armazenamento e agendamento } \\
\text { das atividades de multimídia envolvendo os equipamentos. }\end{array}$ \\
\hline \multicolumn{2}{|l|}{ C. Mobiliários } \\
\hline Banquetas em inox & $\begin{array}{l}\text { Com regulagem de altura para uso durante os treinamentos e } \\
\text { simulações. Deve ser em inox para evitar riscos biológicos. (Se o } \\
\text { objetivo do local for lidar somente com peças sintéticas, não há } \\
\text { necessidade de ser totalmente em inox, pois o custo é alto). }\end{array}$ \\
\hline Mesas de inox de 50 centímetros & Para treinamento em suturas e demais habilidades cirúrgicas. \\
\hline Lavatório em inox para assepsia & Lavatório em inox para assepsia com acionamento por pedal. \\
\hline Mesas de inox & Para treinamentos em habilidades cirúrgicas e simulação. \\
\hline \multicolumn{2}{|l|}{ D. Outros } \\
\hline Lixeira branca & Lixeira branca com pedal. \\
\hline Dispenser de sabonete líquido & Dispenser de sabonete líquido próximo ao lavatório. \\
\hline Dispenser de álcool gel & Dispenser de álcool gel próximo à entrada do consultório. \\
\hline Dispenser de papel & Dispenser de papel próximo ao lavatório \\
\hline Coletor perfurocortante & Coletor perfurocortante (3 litros) com suporte de parede \\
\hline
\end{tabular}

Quadro 8 - Salas de debriefing (vide Figura 9)

\begin{tabular}{|l|l|}
\hline \multicolumn{2}{|c|}{ Sugestões de equipamentos, softwares e mobiliários } \\
\hline Puffs e mochos confortáveis & $\begin{array}{l}\text { Para que os alunos fiquem à vontade e interajam com } \\
\text { as tecnologias disponíveis e tenham maior rendimento } \\
\text { e interação em grupos, de acordo com a metodologia } \\
\text { utilizada. }\end{array}$ \\
\hline Mesas sextavadas modulares & $\begin{array}{l}\text { Mesa estratégica modular que se divide em seis lugares } \\
\text { permitindo ao docente dividir a turma em grupos de acordo } \\
\text { com a metodologia ou a estratégia educacional utilizada. }\end{array}$ \\
\hline
\end{tabular}


Quadro 8 - Continuação...

Sugestões de equipamentos, softwares e mobiliários

\begin{tabular}{|l|l|}
\hline \multicolumn{2}{|c|}{ Sugestões de equipamentos, softwares e mobiliários } \\
\hline TV 55' polegadas com minisservidor & $\begin{array}{l}\text { Esse recurso acompanha teclado e mouse sem fio para que } \\
\text { os alunos o utilizem nas bancadas e mesas para discussões } \\
\text { avançadas com acesso à base de dados e bibliotecas virtuais } \\
\text { do curso. }\end{array}$ \\
\hline Lousas laterais ou móveis & Para apoio às discussões entre discentes e professores. \\
\hline $\begin{array}{l}\text { Câmeras de alta definição com sistema de } \\
\text { captura de áudio e vídeo }\end{array}$ & $\begin{array}{l}\text { Utilizadas para filmar ambientes, atividades e avaliações de } \\
\text { simulação. }\end{array}$ \\
\hline Sistema de checklist informatizado & $\begin{array}{l}\text { Utilizado nos ambientes de debriefing, permitindo aos } \\
\text { alunos interagir nas simulações. }\end{array}$ \\
\hline $\begin{array}{l}\text { Infraestrutura de captura de vídeos e } \\
\text { áudios }\end{array}$ & $\begin{array}{l}\text { Cabeamento e sala de controle para gerenciar gravação, } \\
\text { armazenamento e agendamento das atividades de } \\
\text { multimídia envolvendo os equipamentos. }\end{array}$ \\
\hline
\end{tabular}

Quadro 9 - Salas de treinamento de habilidades (vide Figuras 7 e 8)

\begin{tabular}{|l|l|}
\hline \multicolumn{2}{|c|}{ Sugestões de equipamentos, softwares e mobiliários } \\
\hline A. Equipamentos & Descrição \\
\hline Item & $\begin{array}{l}\text { Utilizadas para filmar ambientes, atividades e avaliações de } \\
\text { sistema de captura de áudio e vídeo } \\
\text { simulação. }\end{array}$ \\
\hline $\begin{array}{l}\text { Infraestrutura de captura de vídeos } \\
\text { e áudios }\end{array}$ & $\begin{array}{l}\text { Cabeamento e sala de controle para gerenciar gravação, } \\
\text { armazenamento e agendamento das atividades de multimídia } \\
\text { envolvendo os equipamentos. }\end{array}$ \\
\hline Console TM para orientação virtual & $\begin{array}{l}\text { Console soft para telemedicina com braço articulado com câmera } \\
\text { permitindo ao aluno transmitir os procedimentos em tempo real, } \\
\text { compartilhando experiências, inclusive sendo utilizado como } \\
\text { recurso para sala de aula invertida }\end{array}$ \\
\hline Foco de teto & $\begin{array}{l}\text { Para simulação em ambiente cirúrgico com as mesmas } \\
\text { características do original. }\end{array}$ \\
\hline Mesa de inox inteligente & $\begin{array}{l}\text { Mesa com sistema de filmagem, transmissão e gravação de imagens } \\
\text { de procedimentos, que pode ser utilizada para envio de vídeos em } \\
\text { tempo real para os alunos dentro ou fora do ambiente, evitando } \\
\text { aglomerações em redor do professor e permitindo o uso para } \\
\text { acompanhamento remoto. }\end{array}$ \\
\hline Infraestrutura de assepsia condicionado & $\begin{array}{l}\text { Serão utilizadas como monitores externos para reprodução do } \\
\text { conteúdo ministrado das mesas de inox inteligentes. }\end{array}$ \\
\hline TV 50 polegadas & $\begin{array}{l}\text { Instalação de ambiente de assepsia contendo vestiários, área de } \\
\text { paramentação e cubas para lavagem de mãos e antebraços, com } \\
\text { sistema de acionamento por pedal ou similar. }\end{array}$ \\
\hline $\begin{array}{l}\text { Para manter a temperatura equilibrada e a integridade dos } \\
\text { equipamentos e simuladores. }\end{array}$ \\
\hline and
\end{tabular}


Quadro 9 - Continuação...

\section{Sugestões de equipamentos, softwares e mobiliários}

\section{B. Softwares}

Sistema de checklist informatizado

Software para gravação
Utilizado nos ambientes de debriefing, permitindo aos estudantes interagir nas simulações.

Software para gerenciar gravação, armazenamento e agendamento das atividades de multimídia envolvendo os equipamentos.

\section{Mobiliários}

\begin{tabular}{|l|l|}
\hline Banquetas em inox & $\begin{array}{l}\text { Com regulagem de altura para uso durante os treinamentos e } \\
\text { simulações. Deve ser em inox para evitar riscos biológicos (se o } \\
\text { objetivo do local for lidar somente com peças sintéticas, não há } \\
\text { necessidade de ser totalmente em inox, pois o custo é alto). }\end{array}$ \\
\hline Mesas de inox de 50 centímetros & Para treinamento em suturas e demais habilidades cirúrgicas. \\
\hline Maca ginecológica & Para simulação de procedimentos. \\
\hline Lavatório para assepsia em inox & Lavatório para assepsia em inox com acionamento por pedal. \\
\hline Lousas laterais ou móveis & Para apoio às discussões entre discentes e professores. \\
\hline Mesas de Inox & Para treinamentos em habilidades cirúrgicas e simulação. \\
\hline D. Outros & \multicolumn{2}{|l}{ Lixeira branca com pedal. } \\
\hline Lixeira branca & Lixisen sabonete líquido próximo ao lavatório. \\
\hline Dispenser de sabonete líquido & Dispenser de sário. \\
\hline Dispenser de álcool gel & Dispenser de álcool gel próximo à entrada do consultório \\
\hline Dispenser de papel & Dispenser de papel próximo ao lavatório. \\
\hline Coletor perfurocortante & Coletor perfurocortante (3 litros) com suporte de parede \\
\hline
\end{tabular}

Quadro 10 - Centro Obstétrico (Admissão, pré-parto e sala de parto)

\section{Sugestões de equipamentos, softwares e mobiliários}

\section{A. Equipamentos}

\section{Item}

Câmeras de alta definição com sistema de captura de áudio e vídeo

Infraestrutura de captura de vídeos e áudios

Console TM para orientação virtual

Berço aquecido simulado

Foco de teto

\section{Descrição}

Utilizadas para filmar ambientes, atividades e avaliações de simulação,

Cabeamento e sala de controle para gerenciar gravação, armazenamento e agendamento das atividades de multimídia envolvendo os equipamentos.

Console soft para telemedicina com braço articulado com câmera, permitindo ao aluno transmitir os procedimentos em tempo real, compartilhando experiências, inclusive sendo utilizado como recurso para sala de aula invertida.

Para configuração do cenário obstétrico.

Para simulação em ambiente cirúrgico com as mesmas características do original. 


\section{Sugestões de equipamentos, softwares e mobiliários}

\section{A. Equipamentos}

\begin{tabular}{|l|l|}
\hline Item & Descrição \\
\hline Mesa de inox inteligente & $\begin{array}{l}\text { Mesa com sistema de filmagem, transmissão e gravação de imagens } \\
\text { de procedimentos, que pode ser utilizada para envio de vídeos em } \\
\text { tempo real para os alunos dentro ou fora do ambiente, evitando } \\
\text { aglomerações em redor do professor e permitindo o uso para } \\
\text { acompanhamento remoto. }\end{array}$ \\
\hline TV 50 polegadas & $\begin{array}{l}\text { Serão utilizados como monitores externos para reprodução do } \\
\text { conteúdo ministrado nas mesas de inox inteligentes. }\end{array}$ \\
\hline Infraestrutura de assepsia & $\begin{array}{l}\text { Instalação de ambiente de assepsia contendo vestiários, área de } \\
\text { paramentação e cubas para lavagem de mãos e antebraços, com } \\
\text { sistema de acionamento por pedal ou similar. }\end{array}$ \\
\hline Ar condicionado & $\begin{array}{l}\text { Para manter a temperatura equilibrada e a integridade dos } \\
\text { equipamentos e simuladores. }\end{array}$ \\
\hline B. Softwares & \multicolumn{2}{|l}{ Utilizado nos ambientes de debriefing, permitindo aos estudantes } \\
\hline Sistema de checklist informatizado & $\begin{array}{l}\text { Software para gerenciar gravação, armazenamento e agendamento } \\
\text { das atividades de multimídia envolvendo os equipamentos. }\end{array}$ \\
\hline Software para gravação &
\end{tabular}

\section{Mobiliários}

\begin{tabular}{|l|l|}
\hline Banquetas em inox & $\begin{array}{l}\text { Com regulagem de altura para uso durante os treinamentos e } \\
\text { simulações. Deve ser em inox para evitar riscos biológicos (se o } \\
\text { objetivo do local for lidar somente com peças sintéticas, não há } \\
\text { necessidade de ser totalmente em inox, pois o custo é alto). }\end{array}$ \\
\hline Mesas de inox de 50 centímetros & Para treinamento em suturas e demais habilidades cirúrgicas. \\
\hline Maca ginecológica & Para simulação de procedimentos. \\
\hline Lavatório em inox para assepsia & Lavatório em inox para assepsia com acionamento por pedal. \\
\hline Mesas de inox & Para treinamentos em habilidades cirúrgicas e simulação. \\
\hline D. Outros & Lixeira branca com pedal. \\
\hline Lixeira branca & Dispenser de sabonete líquido próximo ao lavatório. \\
\hline Dispenser de sabonete líquido & Dispenser de álcool gel próximo à entrada do consultório. \\
\hline Dispenser de álcool gel & Dispenser de papel próximo ao lavatório. \\
\hline Dispenser de papel & Coletor perfurocortante (3 litros) com suporte de parede \\
\hline Coletor perfurocortante &
\end{tabular}

Quadro 11 - Sala de controle e gravação de áudio e vídeo (vide Figura 4)

\section{Sugestões de equipamentos, softwares e mobiliários}

\section{Cadeiras}


Quadro 11 - Continuação...

\begin{tabular}{|l|l|}
\hline \multicolumn{2}{|c|}{ Sugestões de equipamentos, softwares e mobiliários } \\
\hline Mesas & $\begin{array}{l}\text { Para uso durante gravação e controle dos simuladores e } \\
\text { sistemas. }\end{array}$ \\
\hline Mesa de som & $\begin{array}{l}\text { Equipamento para gestão do áudio e vídeo das salas de } \\
\text { simulação. }\end{array}$ \\
\hline Microfones de ambiente & $\begin{array}{l}\text { Microfones para captação de áudio do ambiente, } \\
\text { permitindo gravação das simulações com qualidade. }\end{array}$ \\
\hline $\begin{array}{l}\text { Câmeras de alta definição com sistema de } \\
\text { captura de áudio e vídeo }\end{array}$ & $\begin{array}{l}\text { Utilizadas para filmar ambientes, atividades e avaliações de } \\
\text { simulação. }\end{array}$ \\
\hline $\begin{array}{l}\text { Infraestrutura de captura de vídeos e } \\
\text { áudios }\end{array}$ & $\begin{array}{l}\text { Cabeamento e sala de controle para gerenciar gravação, } \\
\text { armazenamento e agendamento das atividades de } \\
\text { multimídia envolvendo os equipamentos. }\end{array}$ \\
\hline
\end{tabular}

\section{CONSIDERAÇÕES FINAIS}

Este capítulo mostrou a necessidade contínua de as instituições de ensino superior, com foco nos cursos da área da saúde, manterem seus projetos pedagógicos atualizados, com a introdução de diversas metodologias ativas de aprendizagem com integração horizontal e vertical dos conteúdos didáticos, ao longo das matrizes curriculares, visando à introdução precoce de atividades práticas e vivência nos serviços, para obterem o melhor desempenho possível na formação de seus profissionais e para que eles entendam e tenham engajamento no seu processo de educação permanente.

Essa atualização do projeto pedagógico prevê um redesenho e uma reorganização dos ambientes físicos de aprendizagem, desde as salas de aula até os vários laboratórios do curso, inclusive do mobiliário, para torná-los mais acolhedores às novas gerações de estudantes e para a incorporação de diversos re- cursos tecnológicos que permitirão o ensino híbrido (blended learning), combinando, numa aprendizagem polissíncrona, uma mistura de canais com momentos presenciais, assíncronos e síncronos de comunicação online. A participação dos estudantes em diversos locais é o principal benefício, o que exige que as salas de aula físicas sejam projetadas para permitir que os estudantes se comuniquem perfeitamente com outras pessoas de forma presencial e virtual.

A convergência tecnológica de diferentes recursos existentes - e, agora, mais acessíveis - exige mudanças muito mais profundas, que afetam os cursos em todas as suas dimensões: infraestrutura, projeto pedagógico, formação docente e mobilidade. Os ambientes devem estar cada vez mais adaptados para o uso de tecnologias móveis.

Dessa forma, o objetivo do capítulo foi mostrar essas necessidades para os diversos níveis da gestão acadêmica - reitores, coordenadores, supervisores, entre outros - e para os professores e estudantes.

\section{REFERÊNCIAS}

ALMEIDA, M. E. B.; VALENTE, J. A. Integração currículo e tecnologias e a produção de narrativas digitais. Currículo sem Fronteiras, v. 12, n. 3, p. 57-82, 2012.

ALMEIDA, N. M. P. Educação a distância na formação de trabalhadores: registro, documentação e acompanhamento. In: TRINDADE, M. A. B. (Org.). As tecnologias da informação e comunicação (TIC) no desenvolvimento profissional de trabalhadores do SUS. São Paulo: Instituto de Saúde, 2011.

AGÊNCIA NACIONAL DE VIGILÂNCIA SANITÁRIA. $\mathrm{RDC} \mathrm{n}^{\circ} 50,2002$. Dispõe sobre o Regulamento Técnico para planejamento, programação, elaboração e avaliação de projetos físicos de estabelecimentos assistenciais de saúde. Diário Oficial da República Federativa do Brasil, Brasília, 
DF, 21 fev. 2002. Disponível em: <http://bvsms.saude.gov. br/bvs/saudelegis/anvisa/2002/rdc0050_21_02_2002. html>. Acesso em: 13 mar. 2021.

BACICH, L.; TANZI NETO, A.; TREVISANI, F. M. Ensino Híbrido: personalização e tecnologia na educação. Porto Alegre: Penso, 2015.

BATTISTA, A.; NESTEL, D. Simulation in medical education. In: SWANWICK, T.; FORREST, K.; O’BRIEN, B. C. (Eds.). Understanding Medical Education: Evidence, theory, and practice. 3rd ed. Wiley Online Library, 2018. p. 151-162.

BERBEL, N. A. N.; GAMBOA, S. A. S. A metodologia da problematização com o Arco de Maguerez: uma perspectiva teórica e epistemológica. Revista Filosofia e Educação., v. 3, n. 2, p. 264-287, 2012.

BRASIL. Lei $\mathrm{n}^{\circ}$ 10.098, de 19 de dezembro de 2000. Estabelece normas gerais e critérios básicos para a promoção da acessibilidade das pessoas portadoras de deficiência ou com mobilidade reduzida, e dá outras providências. Diário Oficial da República Federativa do Brasil, Brasília, DF, 20 dez. 2000. Disponível em: < https://www2. camara.leg.br/legin/fed/lei/2000/lei-10098-19-dezembro-2000-377651-publicacaooriginal-1-pl.html>. Acesso em: 13 mar. 2021.

BURGESS, A. et al. Team-based learning (TBL) in the medical curriculum: Better than PBL? BMC Medical Education, v. 17, p. 243, 2017.

COOREY, J. Active learning methods and technology: strategies for design education. International Journal of Art \& Design Education, v. 35, n. 3, p. 337-347, 2016.

DAVIS, M. H.; HARDEN, R. M. AMEE Medical Education Guide No. 15: Problem-based learning: A practical guide. Medical Teacher, v. 21, n. 2, p. 130-140, 1999.

DERUISSEAU, L. R. The flipped classroom allows for more class time devoted to critical thinking. Advances in Physiology Education, v. 40, n. 4, p. 522-528, 2016.

DILEKLI, Y. Project-Based Learning. In: Ş. ORAKCI. (Ed.). Paradigm Shifts in 21st Century Teaching and Learning. IGI Global, 2020. p. 53-68.

DOLMANS, D. H. J. M. et al. Problem-based learning: future challenges for educational practice and research. Medical Education, v. 39, p. 732-741, 2005.

WONG, W. Colleges Transform Off-Campus Sites into High-Tech Spaces, Ed Tech, 2016. Disponível em: $<$ https://edtechmagazine.com/higher/article/2016/08/ colleges-transform-campus-sites-high-tech-spaces $>$. Acesso em: 13 mar. 2021.

GIMENO SACRISTÁN, J. Currículo: os conteúdos do ensino ou uma análise da prática? In: GIMENO SACRISTAN, J; PÉREZ GOMES, A. I. Compreender e transformar o ensino. 4. ed. Porto Alegre: Artmed, 1998. p. 119-148.

HEMMING, T. R. Simulation methodology education and adult learning theory adult learning. Adult Learning, v. 23, n. 3, p. 129-37, 2012.
HIGHER ED IQ. Everything you need to know about designing polysynchronous learning spaces, 2015 Disponível em: <https://higherediq.wordpress.com/2015/01/28/ev erything-you-need-to-know-about-designing-polysynchronous-learning-spaces/>. Acesso em: 13 mar. 2021.

HORN, M. B.; STAKER, H. Blended: usando a inovação disruptiva para aprimorar a educação. Porto Alegre: Penso, 2015.

HURTUBISE, L. et al. The flipped classroom in medical education: engaging students to build competency. Journal of Medical Education and Curricular Development, v. 2, p. 35-43, 2015.

INSTRUCTIONAL \& INFORMATION TECHNOLOGY SERVICES. Classrooms \& Labs, 2020. Disponível em: <https://www.csusm.edu/iits/services/classrooms/>. acesso em 13 de março de 2021.

IS. Designing for High-Impact Learning Spaces, 2017. Disponível em: <https://iands.design/articles/34443/ designing-high-impact-learning-spaces $>$. Acesso em: 13 mar. 2021.

KEEGAN, D. (Org.). Mobile Learning: A practical guide. Ericsson: Leonardo da Vinci Programme of the European Commission, 2007.

KRISHNAN, D. G.; KELOTH, A. V.; UBEDULLA, S. Pros and cons of simulation in medical education: A review. International Journal of Medical and Health Research, v. 3 , n. 6 , p. $84-87,2017$.

LAMBERT, C. Twilight of the Lecture. Harvard Magazine, 2012. Disponível em: <https://harvardmagazine. com/2012/03/twilight-of-the-lecture>. Acesso em: 13 mar. 2021.

MARTINS, V. P. A humanização e o ambiente físico hospitalar. In: CONGRESSO NACIONAL DA ABDEH IV SEMINÁRIO DE ENGENHARIA CLÍNICA, 1., 2004, Anais... 2004. Disponível em: <http://bvsms.saude.gov. $\mathrm{br} / \mathrm{bvs} /$ publicacoes/humanizacao_ambiente_fisico.pdf $>$. Acesso em 13 de março de 2021.

MCLEAN, S. F. Case-Based Learning and its Application in Medical and Health-Care Fields: A Review of Worldwide Literature. Journal of Medical Education and Curricular Development, v. 3, p. 39-49, 2016.

MORAN, J.M. Mudando a educação com metodologias ativas. In: SOUZA, C. A.; MORALES, O. E. T. (Orgs.). Convergências Midiáticas, Educação e Cidadania: aproximações jovens. Ponta Grossa: UEPG/PROEX, 2015. Coleção Mídias Contemporâneas, Vol. 2.

MORAN, J. M. Novos modelos de sala de aula. Revista Educatrix, n. 7, p. 33-37, 2013.

NEW ENGLAND BOARD OF HIGHER EDUCATION. The New Role of Librarians and Libraries: Removing the Silence Signs, 2015. Disponível em: <https://nebhe.org/ journal/the-new-role-of-librarians-and-libraries-removing-the-silence-signs/>. Acesso em: 13 mar. 2021.

OLIVEIRA, B. L. C. A. et al. Team-Based learning como forma de aprendizagem colaborativa e sala de aula 
invertida com centralidade nos estudantes no processo ensino-aprendizagem. Revista Brasileira de Educação Médica, v. 42, n. 4, p. 86-95, 2018.

PACHECO, J. A. Estudos Curriculares: Coleção Currículo, Políticas e Práticas. Porto: Porto, 2005.

QUEENSLAND UNIVERSITY. Learning Spaces, 2019. Disponível em: <https://www.eait.uq.edu.au/ learning-spaces>. Acesso em: 13 mar. 2021.

SI, J. Course-based research experience of undergraduate medical students through project-based learning. Korean Journal of Medical Education, v. 32, n. 1, p. 47-57, 2020.
VALENTE, J. A. Tecnologias e Currículo: trajetórias convergentes ou divergentes? São Paulo: Paulus, 2011.

VALENTI, M. Beyond Active Learning: Transformation of the Learning Space, 2015. Disponível em: <https:// er.educause.edu/-/media/files/article-downloads / erm1542.pdf>. Acesso em: 13 mar. 2021.

VIEIRA, M. N. C. M.; PANÚNCIO-PINTO, M. P. A Metodologia da Problematização (MP) como estratégia de integração ensino-serviço em cursos de graduação na área da saúde. Medicina, Ribeirão Preto, v. 48, n. 3, p. 241-248, 2015. 


\section{Hermila Tavares Vilar Guedes}

\section{é médica, com residência médica em Pediatria,}

Mestrado e Doutorado pela UFBA. É professora adjunta do Curso de Medicina do Departamento de Ciências da Vida - Universidade do Estado da Bahia - UNEB (disciplina: Pediatria); e professora adjunta da Escola Bahiana de Medicina e Saúde Pública (disciplina: Metodologia da Pesquisa Científica). Foi Coordenadora Técnica do Curso de Formadores de Multiplicadores em Simulação Clínica (ABEM/EBSERH/OPAS), quando ocupou o cargo de Diretora Executiva da Associação Brasileira de Educação Médica (ABEM).

\section{Gerson Alves Pereira Júnior}

é médico, com residências médicas em Cirurgia Geral, de Urgência e do Trauma, e Terapia Intensiva, Mestrado e Doutorado pela FMRP/USP. É docente do Curso de Medicina de Bauru/USP. É especialista em Cirurgia Geral pelo Colégio Brasileiro de Cirurgiões (CBC), Cirurgia Digestiva pelo Colégio Brasileiro de Cirurgia Digestiva (CBCD), Terapia Intensiva pela Associação de Medicina Intensiva Brasileira (AMIB) e em Medicina de Emergência pela Associação Brasileira de Medicina de Emergência (ABRAMEDE). Foi Coordenador Pedagógico do Curso de Formadores de Multiplicadores em Simulação Clínica (ABEM/EBSERH/OPAS). É Coordenador do Programa de Simulação Clínica da Associação Brasileira de Educação Médica (ABEM).
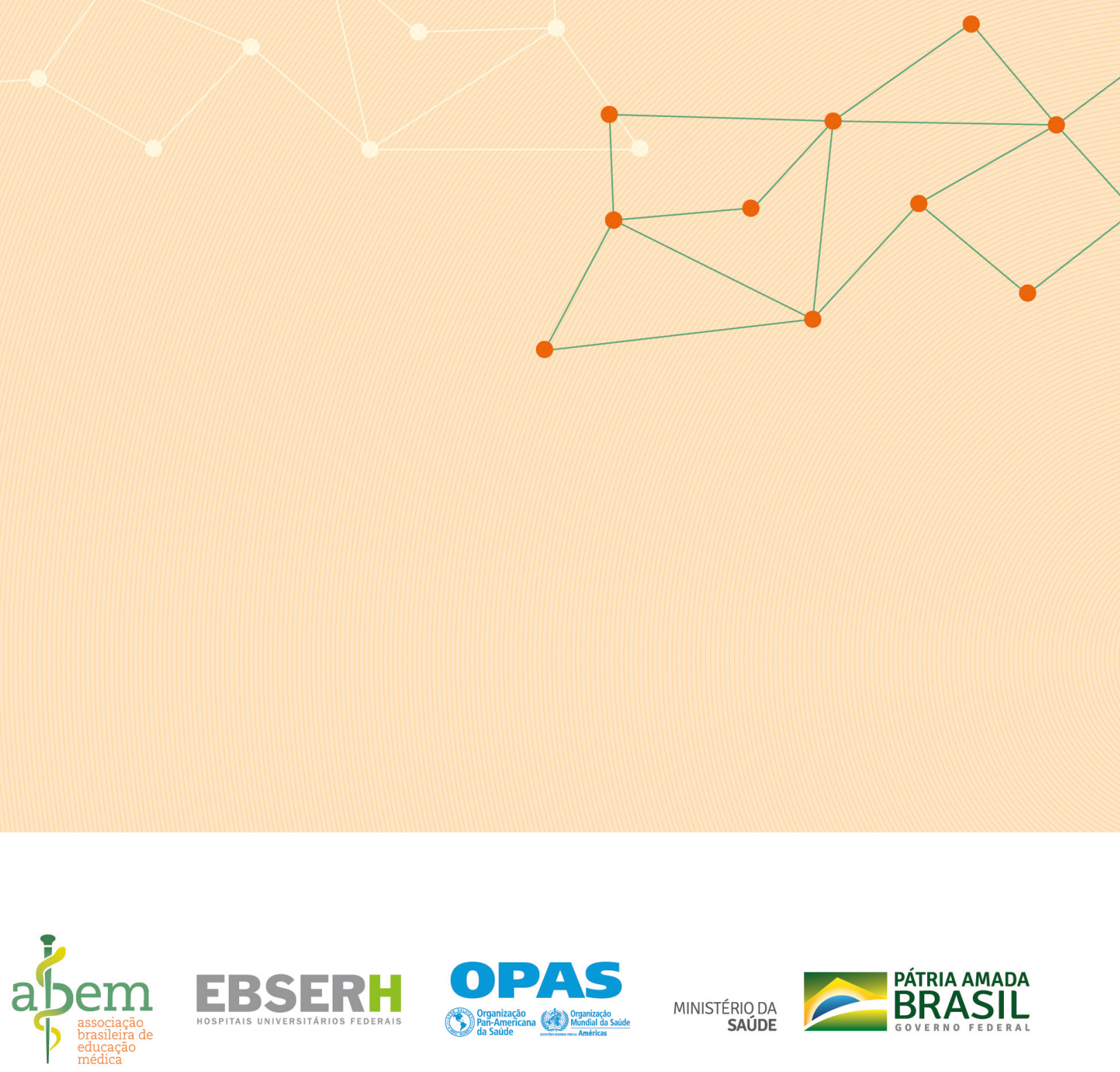